\title{
THE COMPOSER'S HAND: AN ANALYSIS OF SELECTED STRING ORCHESTRAL WORKS BY ARVO PÄRT
}

by

Mark Kenneth Johnson

A thesis submitted to the Victoria University of Wellington in fulfilment of the requirements for the degree of

Doctor of Philosophy

Victoria University of Wellington

New Zealand School of Music 


\begin{abstract}
Arvo Pärt's music has received little attention from theoretical scholars, in part, because it is often labelled as minimalist or process music. This is due primarily to his use of limited sets of musical materials and predetermined repetitive melodic and rhythmic procedures. In this sense, it is implied that authorial decisions play little role in the compositional process of his music. In addition, the confluences of multiple M-voice/T-voice pairings, which create a rich array of harmonically non-functional chord progressions, do not lend themselves to traditional approaches to musical analysis, thus acting as a further deterrent to analysts and theorists.
\end{abstract}

This investigation postulates that the presence of the 'composer's hand' is much more significant in Pärt's music than has been previously realised by those who label his music as minimalist or process music; and by engaging in a multimodal methodology, this thesis demonstrates that Pärt's music does, in fact, respond to post-tonal analytical approaches. It also shows that a non-traditional application of post-tonal analytical techniques can yield valuable and productive insights into Pärt's compositional system, and that there is actually much for theorists and analysts to discover in his music.

The approach to the investigation is based on drawing from and combining several post-tonal analytical methods, any one of which would be insufficient on its own, given the uniqueness of Pärt's sound world and the fact that such approaches have been developed to enlighten very different repertoires. The methodology incorporates the following post-tonal analytical methods: 
descriptions of the 'musical fabric' of each work; a detailed analysis of how each composition appears to have been constructed; new approaches to visualising the relationships between the pitch classes of particular works; and mappings of each work's pitch-class and interval-vector content.

This investigation demonstrates, through multimodal analysis of six selected string orchestral works by the composer, that hidden beneath the seemingly 'minimal' surface layers of Pärt's music are carefully crafted musical constructions that result from intersecting procedures and multifaceted rules, as well as what appear to be intentional exceptions to those rules - thus revealing the composer's hand. An awareness of these hidden constructions and the careful craftsmanship that went into their creation can provide the informed listener with the critical foundation from which the aesthetic value of Pärt's music can be assessed and appreciated. 


\section{Table of Contents}

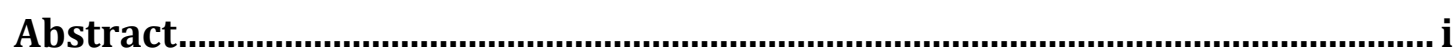

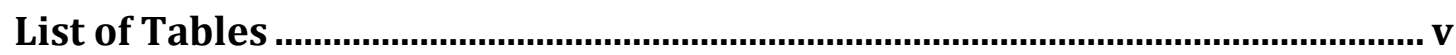

List of Figures................................................................................................. vii

Introduction ..............................................................................................

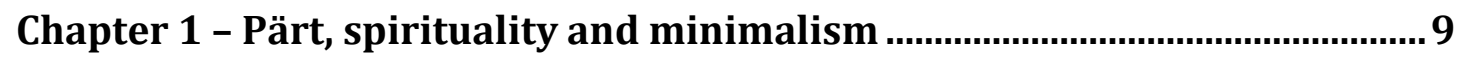

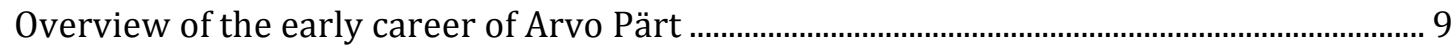

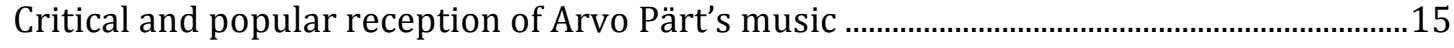

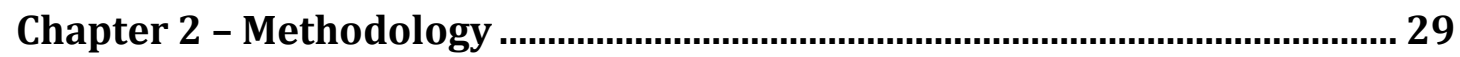

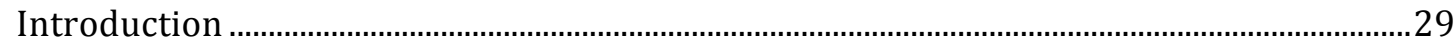

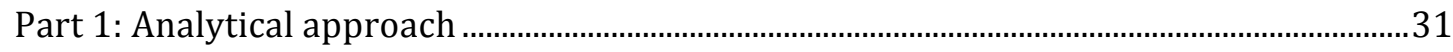

Style analysis .................................................................................................................................32

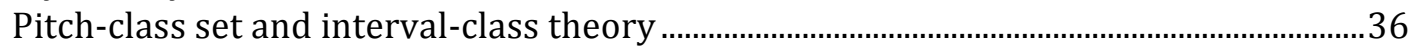

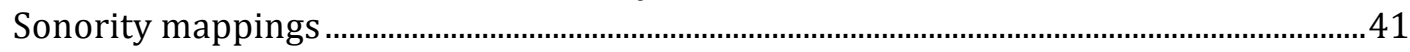

Part 2: Basic operations of Pärt's tintinnabuli …………………………………………………....50

Tintinnabuli ....................................................................................................................................51

A taxonomy of the ordering of intervallic content and sonorities created by different

M-voice/T-voice pairings.....................................................................................................................68

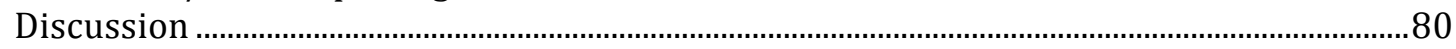

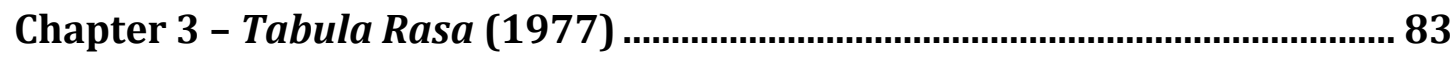

Introduction ............................................................................................................................................

Tabula Rasa: Ludus ....................................................................................................................

Style analysis of Ludus.........................................................................................................

Interval class analysis and sonority mappings of Ludus ......................................................108

Ludus - Cadenza ..................................................................................................................................

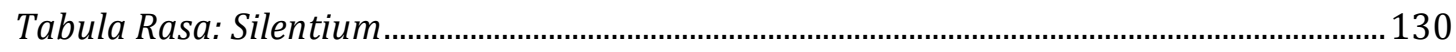

Style analysis of Silentium .............................................................................................................130

Interval class analysis and sonority mappings of Silentium ..................................................141

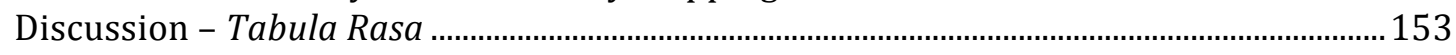

Chapter 4 - Cantus (1977) and Festina Lente (1988 rev. 1990) ...................155

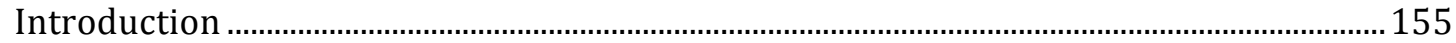

Cantus in memoriam Benjamin Britten ……………………….......................................................157

Style analysis of Cantus ...................................................................................................................158

Interval class analysis and sonority mappings of Cantus.......................................................177

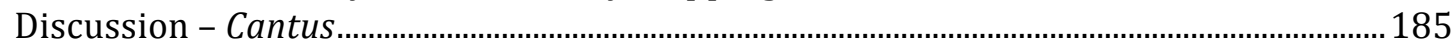

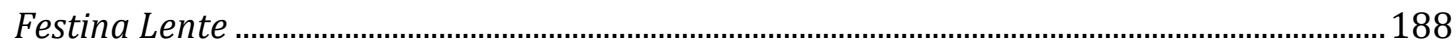

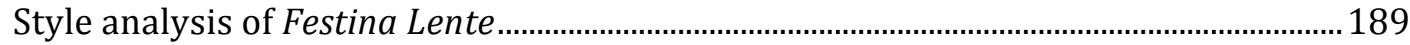

Interval class analysis and sonority mappings of Festina Lente ……………………….....2.217

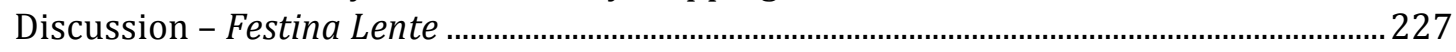

Chapter 5 - Psalom (1985 rev. 1997) and Silouan's Song (1991).................229

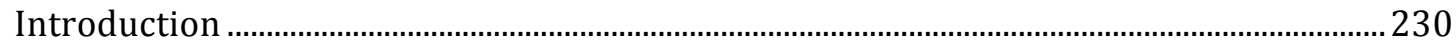

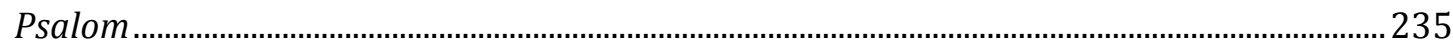

Style analysis of Psalom ....................................................................................................237

Interval class analysis and sonority mappings of Psalom ..................................................225

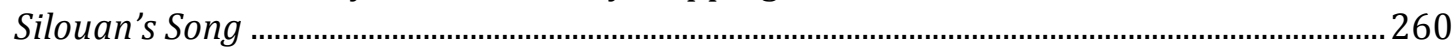

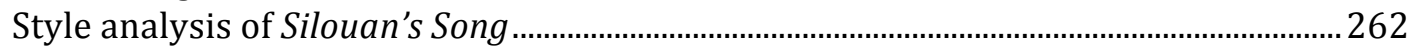

Interval class analysis and sonority mappings of Silouan's Song .......................................283 
Discussion - Psalom and Silouan's Song.

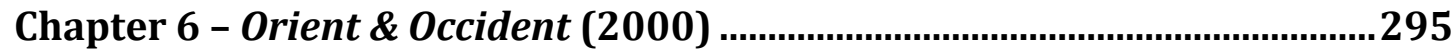

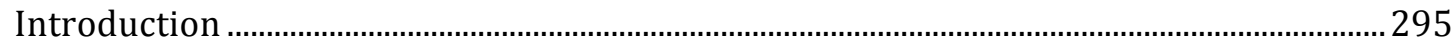

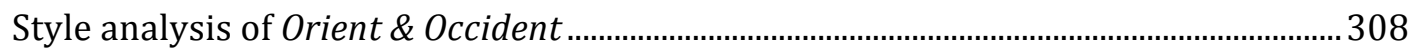

Interval class analysis and sonority mappings of Orient \& Occident .................................349

Discussion - Orient \& Occident .............................................................................................. 359

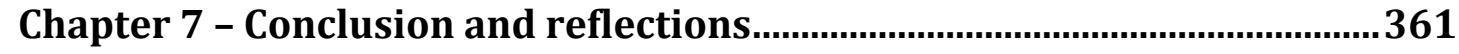

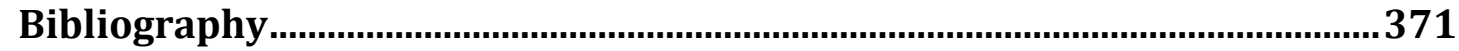

Appendix A: Interval class ordering in Pärt's tintinnabuli system - diatonic

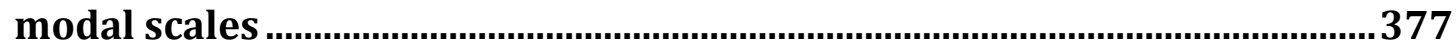




\section{List of Tables}

Table 2.1: LaRue's basic components for style analysis .............................................. 35

Table 2.2: Integer names associated with pitch-class content................................... 37

Table 2.3: Integer names associated with traditional names and numbers of

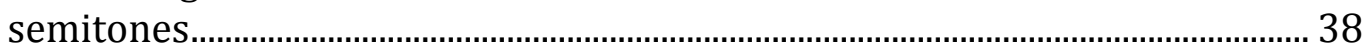

Table 2.4: Interval classes associated with pitch interval content ........................... 39

Table 2.5 Matrix of vectors occurring on beats 1, 2, 3, and 4 of Ludus bars 141145.

Table 2.6: Summary of interval class vectors arising from an A Aeolian scale paired with different modally related triads and T-voice positions................ 76

Table 3.1: Ludus - number of bars and variance of dynamics in each section...... 96

Table 3.2: Ludus - M-voice and T-voice placement - cellos and contrabasses...... 97

Table 3.3: Interval vectors, Ludus - bars 3 and 6....................................................111

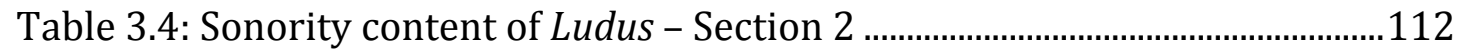

Table 3.5: Matrix of vectors occurring in Ludus on beats 1, 2, 3 and 4-Sections 1 through 8 (continues overleaf).

Table 3.6: Matrix of vectors occurring in Ludus on beats 1, 2, 3 \& 4 Section G bars 141-145

Table 3.7: Pitch class vectors and chord progressions in the cadenza of Ludus Bars 192-230..

Table 3.8: Matrix of vectors and their frequency of occurrence in Silentium Sects. 1 and 2 .

Table 3.9: Matrix of vectors and their frequency of occurrence in Silentium Sects. 3 and 4

Table 3.10: Matrix of vectors and their frequency of occurrence in Silentium Sects. 5 and 6 .

Table 3.11: Matrix of vectors and their frequency of occurrence in Silentium Sects. 7 and 8

Table 3.12: Matrix of vectors and their frequency of occurrence in Silentium ...150

Table 4.1: Cantus - starting and ending pitch classes of each instrumental section

Table 4.2: Cantus - campana in la dynamic markings ..............................................169

Table 4.3: Interval vectors, Cantus - bars 7 through 12 ..........................................180

Table 4.4: Interval vectors, Cantus - order of first occurrence.................................181

Table 4.5: Cantus chords represented by interval vectors ......................................183

Table 4.6: Progressions of chordal families occurring in Cantus - bars 7.1 through 41.2 .

Table 4.7: Summary of deployment of theme a, Variations 1 through 4 and their respective sub-variations in Festina Lente.

Table 4.8: Interval vectors and chords, Festina Lente - bars 7 through 12 .........219

Table 4.9: Interval vectors, Festina Lente - order of first occurrence ......

Table 4.10: Festina Lente - chords represented by interval vectors (and frequency of occurrence as number of beats)

Table 5.1: Church Slavonic and Russian Cyrillic Alphabets......................................234

Table 5.2: Psalom metrical structure.........................................................................242

Table 5.3: Psalom melodic line dynamics as indicated in the score........................243

Table 5.4: Interval class vectors and chords generated by the process in Psalom 
Table 5.5: Interval class vectors and chords in the nine different sections of Psalom (frequency of occurrence as number of beats) .....................................257

Table 5.6: Silouan's Song - metrical structure...............................................................267

Table 5.7: Silouan's Song - dynamics as indicated in the score ................................269

Table 5.8: Silouan's Song - metrical structure with silent bars denoted in grey 270

Table 5.9: Interval class vectors and chords generated by the processes in Silouan's Song

Table 5.10: Interval class vectors and chords in the 16 different statements of Silouan's Song (frequency of occurrence as number of beats) ..........................286

Table 6.1 Orient \& Occident - dynamics as indicated in the score..............................317

Table 6.2 Orient \& Occident - metrical structure ..........................................................318

Table 6.3 Orient \& Occident - T-voice variances..........................................................319

Table 6.4: Pitch class centres of monophonic material and M-voice 1 and associated T-voice during homophonic subsections

Table 6.5 Illustration of Orient \& Occident's shifting interval class vectors ..........352 Table 6.6: Interval class vectors and chords generated by the processes in Orient $\&$ Occident - frequency of occurrence as number of beats . 354

Table 6.7: Interval vectors and chords, Orient \& Occident - bars 26 through 40

Table 6.8: Interval vectors and chords, Orient \& Occident - bars 230 through 234 358

Table A.0.1: Interval class sets arising from a C Ionian scale paired with different triads and T-voice positions

Table A.0.2: Interval class sets arising from a D Dorian scale paired with different triads and T-voice positions

Table A.0.3: Interval class sets arising from an E Phrygian scale paired with different triads and T-voice positions.

Table A.0.4: Interval class sets arising from an F Lydian scale paired with different triads and T-voice positions

Table A.0.5: Interval class sets arising from a G Mixolydian scale paired with different triads and T-voice positions

Table A.0.6: Interval class sets arising from an A Aeolian scale paired with different triads and T-voice positions

Table A.0.7: Interval class sets arising from a B Locrian scale paired with different triads and T-voice positions 


\section{List of Figures}

Figure 2.1: Illustration from Excel-based interval-class identification tool Cantus bar 12

Figure 2.2: Pärtian Tonnetz - visual model of the pitch class relationships on an A

Aeolian scale.

Figure 2.3: Visual multiple stepwise operations in an A Aeolian based M-voice. 47

Figure 2.4: Sonority map - Cantus in memoriam Benjamin Britten .......................... 49

Figure 2.5: Basic M-voice/T-voice positions*............................................................. 52

Figure 2.6: Berliner Mass: Gloria - bars 1-4 ……................................................... 54

Figure 2.7: M-voice modes (pitch centre = A Aeolian) ................................................ 55

Figure 2.8: Berliner Mass: Gloria - alto line (bars 1-18)............................................ 56

Figure 2.9: Berliner Mass: Gloria - bars 1-4 ................................................................. 58

Figure 2.10: M-voice operations used in In spe - Operations 1 and 2 ..................... 61

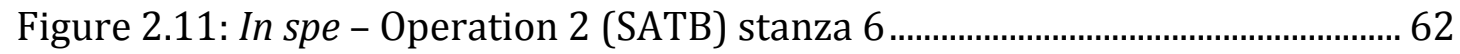

Figure 2.12: M-voice operations used in In spe - Operations 3, 4 and 5.................. 63

Figure 2.13: In spe - Operation 4 (SATB) stanza 11 ….............................................. 64

Figure 2.14: M-voice operations used in In spe - Operations 6 and 7 .......................6 65

Figure 2.15: M-voice operations used in In spe - Operations 1 through 7 ............ 67

Figure 2.16: Intervals arising from an A Aeolian scale and A minor triad pairing

Figure 2.17: Interval ordering and class content of an A minor triad 1st position, superior to seven modal scales .............................................................................. 71

Figure 2.18: Interval ordering and class content of an A minor triad 1st position, inferior to seven modal scales.

Figure 2.19: Interval ordering and class content of an A minor triad 2nd position, superior of seven modal scales.

Figure 2.20: Interval ordering and class content of an A minor triad 2nd position, inferior to seven modal scales.

Figure 2.21: Interval ordering and class content of an A Aeolian scale paired with different triads in 1st position, superior................................................................. 77

Figure 2.22: Interval ordering and class content of an A Aeolian scale paired with different triads in 1st position, inferior............................................................. 78

Figure 2.23: Interval ordering and class content of an A Aeolian scale paired with different triads in 2 nd position, superior...

Figure 2.24: Interval ordering and class content of an A Aeolian scale paired with different triads in 2nd position, inferior ............................................................. 80

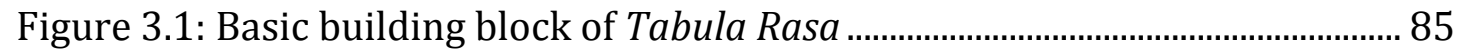

Figure 3.2: Ludus - MIDI-recreation (with contrabasses shown in their sounding register) 88

Figure 3.3: Ludus - MIDI-recreation (first and second violins and contrabasses)

Figure 3.4: Interval classes generated by an A minor triad and an A Aeolian

(natural minor) scale, first position, superior and first position, inferior .... 90

Figure 3.5: Registral spans of string sections - Ludus ............................................. 91

Figure 3.6: Ludus - opening bars ………….......................................................... 92

Figure 3.7: Ludus - general musical scheme ............................................................... 93

Figure 3.8: Solo violins Ludus - figures and variations Section 1 (bars 3 through

11) 
Figure 3.9: Solo violin lines, Ludus - Sections 1 \& 2 ...............................................100

Figure 3.10: Solo violin lines, Ludus - Section 3 (bars 26 through 43) ..................101

Figure 3.11: Solo violin lines, Ludus - Sections 2 \& 3................................................102

Figure 3.12: Solo violins Ludus - Section 4 figurations (i) .........................................103

Figure 3.13: Solo violins Ludus - Section 5 figurations (i) and (ii).........................104

Figure 3.14: Solo violins Ludus - Section 5 figuration (iii) ......................................104

Figure 3.15: Solo violins Ludus - Sections 6 through 8, figuration (i) and its

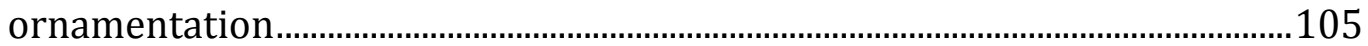

Figure 3.16: Solo violins Ludus - Sections 6-8, figuration (ii) .................................106

Figure 3.17: Solo violins Ludus - Sections 6-8, figuration (iii) .................................107

Figure 3.18: Pärtian Tonnetz of T-voice/M-voice pitch class relationships in

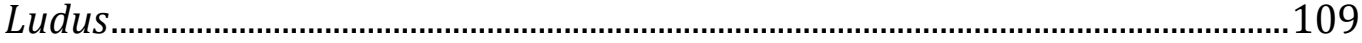

Figure 3.19: Ludus - opening bars.........................................................................110

Figure 3.20: Ludus - sonority map Sections 1-8.....................................................114

Figure 3.21: Ludus - sonority map Sections 1-5 ........................................................115

Figure 3.22: Ludus - sonority map Sections 6-8......................................................116

Figure 3.23: Ludus - sonority map Section 8 ….........................................................117

Figure 3.24: Interactions of prevalent pitch classes with interval vectors - Ludus

(bars 141-145) ................................................................................................123

Figure 3.25: Ludus cadenza - solo violins bars 192 to 197 .....................................124

Figure 3.26: Ludus cadenza - solo violins bars 208 to 213 ........................................125

Figure 3.27: Ludus cadenza - orchestral strings bars 192 to 197 ...........................126

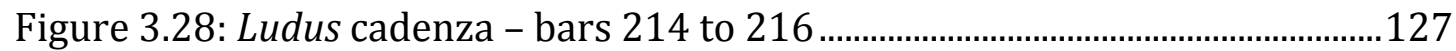

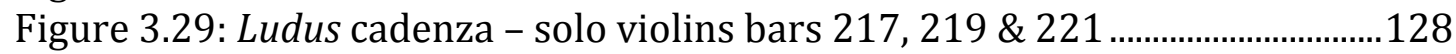

Figure 3.30: Basic building block of Tabula Rasa ....................................................130

Figure 3.31: Potential interval class content generated by a D Aeolian scale and D minor triad M-voice/T-voice pairing................................................................131

Figure 3.32: Silentium - opening bars..........................................................................132

Figure 3.33: Silentium - MIDI recreation (with contrabasses shown in their

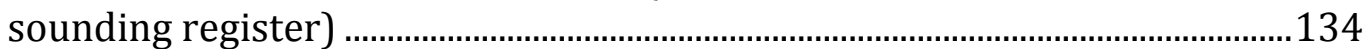

Figure 3.34: Silentium - M-voice and T-voice patterns .............................................135

Figure 3.35: Silentium - bars 19-21 …….................................................................137

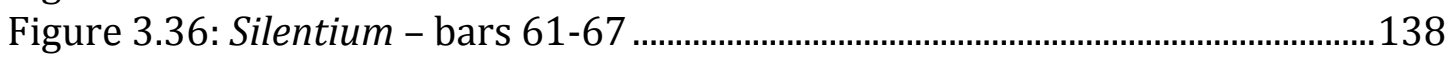

Figure 3.37: Silentium - bars 103-108......................................................................139

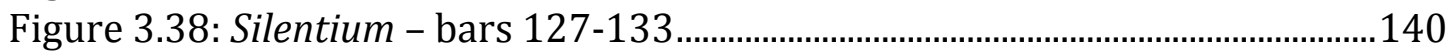

Figure 3.39: Silentium - bars 34-38 ..................................................................141

Figure 3.40: Pärtian Tonnetz of Silentium's M-voice/T-voice pitch class

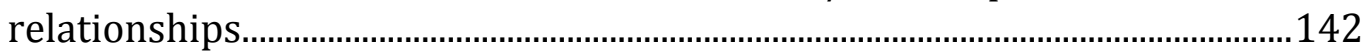

Figure 3.41: Silentium - sonority map Sections 1 through 8 ....................................151

Figure 3.42: Silentium - sonority map Sections 7 and 8 ...........................................152

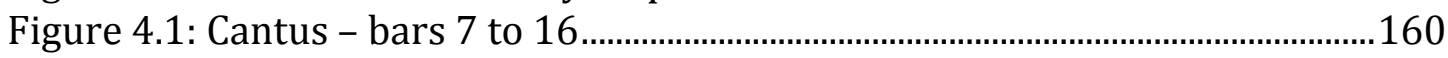

Figure 4.2: Cantus - MIDI-recreation all strings (with contrabasses shown in

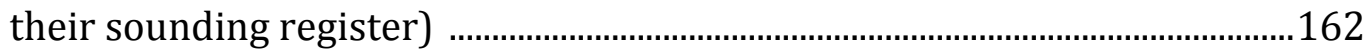

Figure 4.3: Interval classes generated by an A minor triad and an A Aeolian (natural minor) scale, $1^{\text {st }}$ position, inferior ......................................................163

Figure 4.4: MIDI-recreation of the $1^{\text {st }}$ violins' part in Cantus ...................................164

Figure 4.5: Registral spans of string sections - Cantus ...............................................166

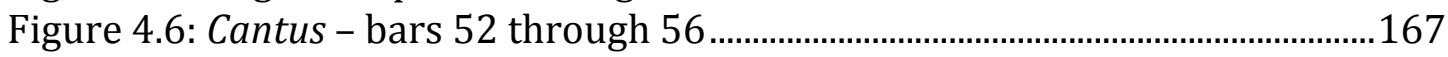

Figure 4.7: Cantus - bars 52 through 56 ……..............................................................168 
Figure 4.8: Cantus - first violins' dynamic marking changes.

Figure 4.9: Cantus - second violins' dynamic markings changes.............................172

Figure 4.10: Cantus - violas' dynamic marking changes ............................................173

Figure 4.11: Cantus - violoncellos' dynamic marking changes................................174

Figure 4.12: Cantus - contrabasses' dynamic marking changes ..............................175

Figure 4.13: Interval classes generated by an A minor triad and an A Aeolian

(natural minor) scale, $1^{\text {st }}$ position, inferior

Figure 4.14: Cantus - string orchestra rhythmic patterns .......................................176

Figure 4.15: Pärtian Tonnetz - M-voice/T-voice pitch class interrelationships in

Cantus.

Figure 4.16: Cantus - sonority map

Figure 4.17: Festina Lente - bars 1 through 8

Figure 4.18: Festina Lente - violins I and II bars 1 through 9..................................192

Figure 4.19: Festina Lente - violins II, bars 1 through 49

Figure 4.20: Festina Lente - MIDI-recreation all strings (with contrabasses shown

in their sounding register)

Figure 4.21: Festina Lente - violins II, bars 1 through 49

Figure 4.22: Festina Lente - violins II, theme and Variation 1

Figure 4.23: Festina Lente - violins II, theme and Variation 2

Figure 4.24: Festina Lente - violins II, theme and Variation 3

Figure 4.25: Festina Lente - violins II, theme and Variation 4

Figure 4.26: Festina Lente - violins II, theme and sub-variations ...........................198

Figure 4.27: Festina Lente - violins II, Variation 1 and sub-variations ..................199

Figure 4.28: Festina Lente - violins II, Variation 2 and sub-variations ..................199

Figure 4.29: Festina Lente - violins II, Variation 3 and sub-variations ..................200

Figure 4.30: Festina Lente - violins II, Variation 4 (fragment) and sub-variations

200

Figure 4.31: Festina Lente - violins II, Variation 1 and sub-variations ..................203

Figure 4.32: Festina Lente - bars 120 and 121 (with alternative possible voicing shown as b)

204

Figure 4.33: Festina Lente - Variation 1 and sub-variations iv (violas transposed and mensurally transformed) and $\mathrm{v}$ (violoncellos and contrabasses transposed and mensurally transformed). 206

Figure 4.34: Festina Lente - Variation 3 sub-variations ii, phrase ii - violoncellos and contrabasses (bars 161-174) 206

Figure 4.35: Festina Lente - primary rhythmic scheme (and secondary rhythmic motive).

Figure 4.36: Interval classes generated by an A minor triad and an A Aeolian (natural minor) scale, 1 st and $2^{\text {nd }}$ position, superior and $1^{\text {st }}$ position, inferior

Figure 4.37: Festina Lente - violins I and II (bars 41-64)

Figure 4.38: Festina Lente - violins I and II (bars 81-96).......................................211

Figure 4.39: Festina Lente - violins I and II (bars 105-112) ...................................212

Figure 4.40: Festina Lente - violins IV, violoncellos and contrabasses (bars 41$55)$

Figure 4.41: Festina Lente - violins IV, violoncellos and contrabasses (bars 8996)

Figure 4.42: Festina Lente - violins III and violas (bars 45-52)...............................214

Figure 4.43: Festina Lente - violins III and violas (bars 93-100) ............................215 
Figure 4.44: Festina Lente - violins III and violas (bars 104-112) ..........................215

Figure 4.45: Festina Lente - violoncellos, contrabasses and harp (bars 1-8)......216

Figure 4.46: Pärtian Tonnetz - M-voice/T-voice pitch class interrelationships in

Festina Lente.

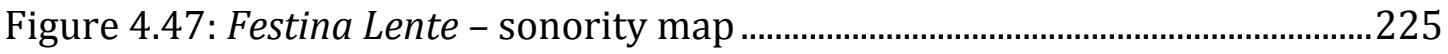

Figure 4.48: Festina Lente Section A - sonority map..................................................226

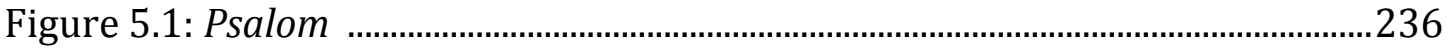

Figure 5.2: Psalom - registral ranges of instrumental sections..............................238

Figure 5.3: Psalom - MIDI-recreation all strings (with contrabasses shown in

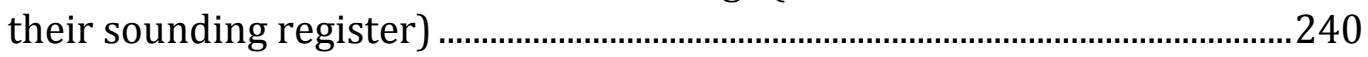

Figure 5.4: Psalom - arch of the melodic material....................................................241

Figure 5.5: Psalom - first six bars violins ..................................................................241

Figure 5.6: Psalom - dynamics and articulations of the M-voice lines ...................245

Figure 5.7: Psalom - melodic voice leading …….......................................................246

Figure 5.8: Psalom - nine rhythmic schema...........................................................247

Figure 5.9: Psalom - M-voice lines of Sections i and ii with the Church Slavonic

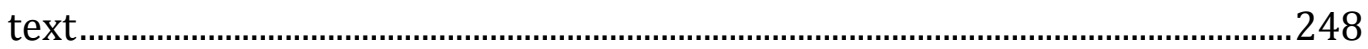

Figure 5.10: Psalom - melodic lines with the Church Slavonic text........................250

Figure 5.11: Pärtian Tonnetz - pitch class relationships of Psalom .......................254

Figure 5.12: Psalom - sonority map......................................................................256

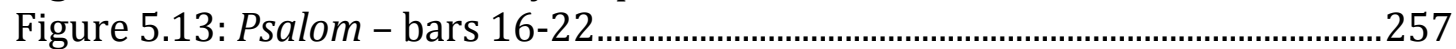

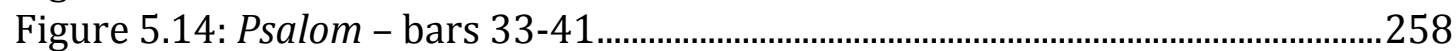

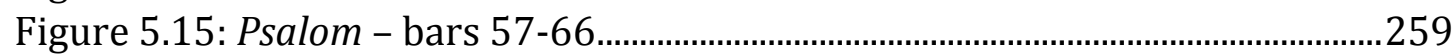

Figure 5.16: Text of Silouan's Song in Russian ...........................................................260

Figure 5.17: Silouan's Song - bars 1-5........................................................................262

Figure 5.18: Silouan's Song - registral ranges of instrumental sections................264

Figure 5.19: Silouan's Song - MIDI-recreation all strings (with contrabasses shown in their sounding register) .....................................................................265

Figure 5.20: Silouan's Song melodic movement above and below a central pitch.

268

Figure 5.21: Silouan's Song - opening statement......................................................269

Figure 5.22: Silouan's Song - Statements 8, 13 and 14 (first violins).....................270

Figure 5.23: Silouan's Song - text as distributed across 16 musical statements 271

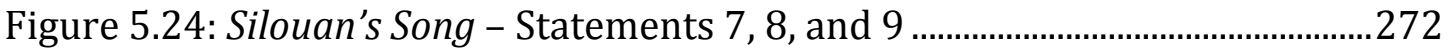

Figure 5.25: Silouan's Song - Statement 14 .............................................................273

Figure 5.26: Silouan's Song - upper M-voice line Statement 1................................276

Figure 5.27: Silouan's Song - upper M-voice line Statements 1 through 4 ...........278

Figure 5.28: Silouan's Song - upper M-voice line Statement 5................................279

Figure 5.29: Silouan's Song - upper M-voice line Statement 6................................280

Figure 5.30: Silouan's Song - upper M-voice line Statements 10 and 16...............281

Figure 5.31: Silouan's Song - upper M-voice line all 16 statements .......................282

Figure 5.32: Pärtian Tonnetz - pitch class relationships of Silouan's Song ..........284

Figure 5.33: Silouan's Song - Statement 14 …..........................................................287

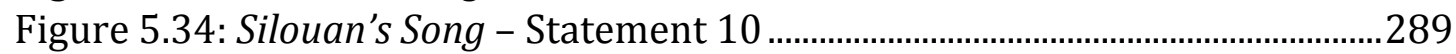

Figure 5.35: Silouan's Song - sonority mapping .........................................................290

Figure 6.1: Orient \& Occident Section A - opening bars ..............................................309

Figure 6.2: Orient \& Occident - MIDI recreation (with contrabasses shown in

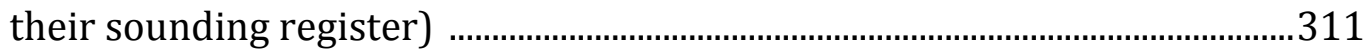

Figure 6.3: Orient \& Occident - registral ranges of instrumental sections.............313 
Figure 6.4: Orient \& Occident - first violins bars 26-33.

Figure 6.5: Text of the Nicene Constantinopolitan Creed as distributed across the

12 sections of Orient \& Occident .............................................................................316

Figure 6.6: Orient \& Occident - Section C bars 89-96 …….........................................320

Figure 6.7: Orient \& Occident - Section B bars 26-41 ...................................................323

Figure 6.8: Orient \& Occident - violoncello line Section B bars 26-76 ....................326

Figure 6.9: Orient \& Occident - violoncello line Section A bars 1-25 .....................327

Figure 6.10: Orient \& Occident - first violins and violoncello lines Sections A bars 1-25

Figure 6.11: Orient \& Occident - movement between monophonic and M-voice 1 pitch class centres.

Figure 6.12: Orient \& Occident - first violin and violoncello lines Sections B bars 26-76

Figure 6.13: Orient \& Occident - first violin and violoncello lines Section C bars 77-103

Figure 6.14: Orient \& Occident - first violin, second violin and violoncello lines

Sections D and E bars 104-125

Figure 6.15: Orient \& Occident - first violin and violoncello lines Sections E, F and $\mathrm{G}$ bars $118-157$.

Figure 6.16: Orient \& Occident - violoncello line Section H bars 158-192 ...........335

Figure 6.17: Orient \& Occident - violoncello line Sections I through L bars 193234.

Figure 6.18: Orient \& Occident - M-voices Section A bars 1-14 ...............................341

Figure 6.19: Orient \& Occident - M-voices Section B bars 26-75 ..............................344

Figure 6.20: Orient \& Occident - Section D bars 104-110 ..........................................345

Figure 6.21: Orient \& Occident - Section I bars 193-205 ..........................................346

Figure 6.22: Orient \& Occident - Section B bars 50-63 ...........................................347

Figure 6.23: Orient \& Occident - Section B bars 50-63 …..........................................348

Figure 6.24: Orient \& Occident - Section F bars 126-138 .........................................348

Figure 6.25: Orient \& Occident - Section E bars 118-125 ….......................................349

Figure 6.26: Visual model of the potential pitch class relationships of Orient \& Occident's three M-voice/T-voice sets .

Figure 6.27: Orient \& Occident - sonority mapping .....................................................355

Figure A.1: Interval ordering and class content of a C Ionian scale paired with different triads in 1 st position, superior.

Figure A.2: Interval ordering and class content of a C Ionian scale paired with different triads in 1st position, inferior.

Figure A.3: Interval ordering and class content of a C Ionian scale paired with different triads in 2 nd position, superior

Figure A.4: Interval ordering and class content of a C Ionian scale paired with different triads in 2 nd position, inferior

Figure A.5: Interval ordering and class content of a D Dorian scale paired with different triads in 1 st position, superior.

Figure A.6: Interval ordering and class content of a D Dorian scale paired with different triads in 1st position, inferior

Figure A.7: Interval ordering and class content of a D Dorian scale paired with different triads in 2 nd position, superior

Figure A.8: Interval ordering and class content of a D Dorian scale paired with different triads in 2 nd position, inferior 
Figure A.9: Interval ordering and class content of an E Phrygian paired scale paired with different triads in 1st position, superior.

Figure A.10: Interval ordering and class content of a E Phrygian scale paired with different triads in 1st position, inferior.

Figure A.11: Interval ordering and class content of an E Phrygian scale paired with different triads in 2 nd position, superior

Figure A.12: Interval ordering and class content of a E Phrygian scale paired with different triads in 2 nd position, inferior

Figure A.13: Interval ordering and class content of a F Lydian scale paired with different triads in 1st position, superior

Figure A.14: Interval ordering and class content of a F Lydian scale paired with different triads in 1st position, inferior

Figure A.15: Interval ordering and class content of a F Lydian scale paired with different triads in 2 nd position, superior

Figure A.16: Interval ordering and class content of a F Lydian scale paired with different triads in 2 nd position, inferior

Figure A.17: Interval ordering and class content of a G Mixolydian scale paired with different triads in 1st position, superior

Figure A.18: Interval ordering and class content of a G Mixolydian scale paired with different triads in 1st position, inferior

Figure A.19: Interval ordering and class content of a G Mixolydian scale paired with different triads in 2 nd position, superior

Figure A.20: Interval ordering and class content of a G Mixolydian scale paired with different triads in 2 nd position, inferior

Figure A.21: Interval ordering and class content of an A Aeolian scale paired with different triads in 1st position, superior...

Figure A.22: Interval ordering and class content of an A Aeolian scale paired with different triads in 1st position, inferior.

Figure A.23: Interval ordering and class content of an A Aeolian scale paired with different triads in 2 nd position, superior

Figure A.24: Interval ordering and class content of an A Aeolian scale paired with different triads in 2 nd position, inferior

Figure A.25: Interval ordering and class content of a B Locrian scale paired with different triads in 1st position, superior.

Figure A.26: Interval ordering and class content of a B Locrian scale paired with different triads in 1st position, inferior.

Figure A.27: Interval ordering and class content of a B Locrian scale paired with different triads in 2 nd position, superior

Figure A.28: Interval ordering and class content of a B Locrian scale paired with different triads in 2 nd position, inferior 


\section{Introduction}

Arvo Pärt developed his tintinnabuli composition system in the 1970s, following a seven-year period of self-imposed reflection and relative compositional silence. ${ }^{1}$ The system is based upon the seemingly simple premise of a two-part, note against note texture consisting of: 1) the M-voice, a diatonic melody that moves towards and away from a single central pitch, and 2) the T-voice, which is restricted to using only the notes of a single major or minor triad, set out in relation to the notes of the M-voice in a predetermined pattern. ${ }^{2}$ Pärt has likened the three notes of the T-voice's triad to the sounding of bells - hence, the term 'tintinnabuli'. ${ }^{3}$

Many critics and commentators view Pärt's compositions as 'minimalist'.4 5 This is due, in part, to his use of predetermined rules to guide the development of his compositions, the relatively spare sound world of many of his works, as well as the manner in which the recording company ECM has marketed his music. ${ }^{6}$ Thomas Robinson has taken the position that one of the reasons Pärt's music has received little attention from theoretical scholars is the categorisation of his

\footnotetext{
${ }^{1}$ Andrew Shenton, "Introduction: The Essential and Phenomenal Arvo Pärt," in The Cambridge Companion to Arvo Pärt (Cambridge: Cambridge University Press, 2012), 1.

${ }^{2}$ The terms 'M-voice' and 'T-voice', as coined by Hillier, are abbreviations for 'melodic voice' and 'tintinnabuli voice'. See Paul Hillier, Arvo Pärt (New York: Oxford University Press, 1997), 92-93.

3 Ibid., 86.

${ }^{4}$ See Clarke, 1993; Fisk, 1994; Hillier, 1997; Smith, 1999; Brauneiss, 2005; Cizmic, 2008; Taruskin, 2010; Dolp, 2012; Robinson, 2012.

5 I should acknowledge at this point that the terms 'minimalistic' and 'minimal', as they apply to music, are problematic. Timothy Johnson notes "minimalism in music has been defined as an aesthetic, a style, and a technique, each of which has been a suitable description of the term at certain points in the development of minimal music", as it relates to certain musical works of a select number of American composers during the late 1950's through the 1970s: Steve Reich, Terry Riley, Phillip Glass, and La Monte Young. Ian Quinn defines minimal music (including Pärt's music) as being process music, which is a product of the use of minimalist compositional techniques. See Ian Quinn, "Minimal Challenges: Process Music and the Uses of Formalist Analysis," Contemporary Music Review 25, no. 3 (June 2006): 283-94.

${ }^{6}$ Laura Dolp, "Arvo Pärt in the Marketplace," in The Cambridge Companion to Arvo Pärt, 2012th ed. (Cambridge: Cambridge University Press, n.d.), 178-82.
} 
music as being minimalist, noting that the label acts as "a deterrent to [many] theorists and analysts who find minimalist music of little value regardless of composer, regardless of technique."7

At the beginning of this investigation in 2011, only a small number of scholars had written about technical aspects of Arvo Pärt's tintinnabuli system to any degree. Paul Hillier and Leopold Brauneiss have catalogued and documented the basic Mvoice and T-voice operations of tintinnabuli and described the manner in which Pärt constructs his melodies through outwards and inwards stepwise progressions. ${ }^{8}{ }^{9}$ Both have noted that Pärt's melodies are often based on structural characteristics of liturgical texts, but neither has gone on to illustrate in any detail aspects of how this applies to any of the composer's instrumental compositions.

Despite the relatively minimal nature of Pärt's tintinnabuli sound world, in many of his compositions, the confluence of multiple M-voice/T-voice pairings creates a rich array of harmonically non-functional chord progressions that do not lend themselves to traditional approaches to musical analysis. Robinson makes the argument that to analyse Pärt's music, "analysts must devise new techniques and, in equal measure, engage existing theories in completely new ways". ${ }^{10}$ In his article in the Cambridge Companion to Arvo Pärt, "Analyzing Pärt", he has suggested several post-tonal approaches to analysing Pärt's music, including set

\footnotetext{
7 Thomas Robinson, "Analyzing Pärt," in The Cambridge Companion to Arvo Pärt (Cambridge: Cambridge University Press, 2012), 76.

8 Hillier, Arvo Pärt.

${ }^{9}$ Leopold Brauneiss, "Musical Archetypes: The Basic Elements of Tintinnabuli Style," in The Cambridge Companion to Arvo Pärt (Cambridge: Cambridge University Press, 2012), 49-75.

10 Robinson, "Analyzing Pärt," 78.
} 
theory, triadic transformation, style analysis, Schenkerian analysis, and musical hermeneutics. ${ }^{11}$

Using some of these suggestions, which are integrated into the analytical framework of this study, this thesis will demonstrate that Pärt's music does, in fact, respond to post-tonal analytical approaches. It will also show that through a non-traditional application of such techniques, these can yield valuable and productive insights into Pärt's compositional system, and that there is actually much for theorists and analysts to discover in his music.

Importantly, I will demonstrate through analyses of three process-based and three text-based string orchestral works by the composer that hidden beneath the seemingly simple surface layers of his music are carefully crafted musical constructions that result from intersecting processes and multifaceted rules, as well as what appear to be intentional exceptions to those rules - thus revealing the 'composer's hand' as being actively engaged in shaping these works. An awareness of these hidden constructions and the careful craftsmanship that went into their creation can provide the informed listener with the theoreticalanalytical foundation from which the aesthetic value of Pärt's music can be assessed and appreciated.

\section{Methodology}

In this thesis, I have taken a multimodal approach to analysing Pärt's music, which I describe in detail in Chapter 2. This approach is based on selectively drawing from and combining several post-tonal approaches, any one of which

\footnotetext{
11 Ibid., 78-93.
} 
would be insufficient on its own, given the uniqueness of Pärt's sound world and the fact that such approaches have been developed to enlighten very different repertoires. Specifically, the methodology incorporates: a combination of descriptions of the 'musical fabric' of each work; a detailed examination of how each composition appears to have been constructed; new approaches to visualising the relationships between the pitch classes of particular works; and mappings of each work's pitch-class and interval-vector content. In the case of the three text-based string compositions covered in Chapters 5 and 6, I show how the

musical parameters of these works are also derived from structural aspects of specific liturgical texts that Pärt used to develop additional compositional parameters that shaped how each instrumental work was composed.

Using these approaches, this thesis documents the unique combinations of tintinnabuli processes and non-tintinnabuli procedures that Pärt employs in the six selected string works to achieve the distinctive textures, timbres, harmonic structure and progressions that define the individual identity of each.

\section{Scope of the investigation}

While the primary focus is on six of the composer's string orchestral works composed since 1976, Chapter 2 includes excerpts from two works not composed for strings to illustrate the basic rules and operations of Pärt's systems. Chapter 2 includes an analysis of an excerpt from the Gloria of Pärt's Berliner Mass to provide the reader with insights into how Pärt composes the melodic material for his M-voices in vocal works, based upon structural characteristics of a written 
text. Also discussed in Chapter 2 is $I n s p e^{12}$, a work that originally was composed for wind quintet and a quartet of strings and later arranged for voices and organ; its analysis provides insight into how Pärt is able to generate a wealth of varied melodic material through the development of a number of systematic musical variations.

The six string orchestral works covered by this thesis include the following:

1. The three works Tabula Rasa (1976), Cantus in memoriam Benjamin Britten (1976), and Festina Lente (1990) represent the seminal early style of Pärt's tintinnabuli music. All three works are process-based and illustrate different realisations of Pärt's tintinnabuli compositional system. While the first two works that are examined strictly adhere to the rules of tintinnabuli, the third work illustrates a greater mutability in the composer's method of constructing melodies as well as the manner in which T-voices are deployed.

2. The three later works Psalom (1985), Silouan's Song (1992), and Orient \& Occident (2000) evidence how Pärt's compositional practice has developed into a freer application of the rules of his early tintinnabuli system, particularly when combined with more complex sets of additional rules derived from various structural aspects of particular liturgical texts.

The string orchestral works not covered by this thesis are: 1) string orchestral works originally composed for other genres: Summa (1976), which was originally composed as a choral piece and does not stray from the early principles of tintinnabuli, and Mein Weg (1989/1999), which was originally composed for solo

\footnotetext{
12 In spe (1976) was originally scored for wind quintet and a quartet of strings (with a double bass instead of a second violin). Pärt subsequently rescored it for voices and organ and retitled the work An den Wassern zu Babel sassen wir and weinten (1984). Hillier, Arvo Pärt, 98-99.
} 
organ; 2) string orchestral works that rely heavily on other orchestral forces such as percussion and/or brass: La Sindone (2006), Symphony Nr. 4 "Los Angeles" (2008), and Silhouette (2009); and 3) two works that appear to have been based upon very similar sets of compositional parameters as those used by the composer in Silouan's Song (1992): Trisagion (1992) and Für Lennart in memoriam (2006).

\section{Thesis structure}

The thesis is structured as follows:

- Chapter 1 provides an overview of Arvo Pärt's early compositional career as a student at the Tallin Conservatory through to the development of his tintinnabuli system (1958 to 1976), followed by a summary of the popular and critical reception of his tintinnabuli music.

- Chapter 2 provides a detailed explanation of the multimodal approach I have used to analyse Pärt's string orchestral works. This is followed by an introduction to the basic rules and operations of Arvo Pärt's tintinnabuli composition system, as initially detailed by Paul Hillier in his monograph on Pärt. ${ }^{13}$ The chapter concludes with my identification of a number of distinct aspects of Pärt's tintinnabuli system that have not previously been noted.

- Chapter 3 provides a detailed analysis of the process-based string orchestral piece Tabula Rasa (1976) to illustrate the procedures of Pärt's tintinnabuli system in action and the resulting complex intervallic content.

\footnotetext{
13 Hillier, Arvo Pärt.
} 
- Chapter 4 examines two other string orchestral process-based pieces, Cantus in memoriam Benjamin Britten (1976) and Festina Lente for 4, 8 or 12 violoncellos (1990), as two examples of Pärt's application of mensural canon procedures. The chapter explicitly examines the processes that Pärt used in composing these two particular works, and how his application of such processes appears to have evolved between 1976 and 1990. Importantly, the analyses call into question whether Pärt merely constructs a series of predetermined processes that, once designed, are left to play out to their own devices - thus abnegating any further composerly responsibility - and instead shows how Pärt remains actively engaged in shaping the composition process throughout the creation of each work.

- Chapter 5 focuses on two of Pärt's later seminal works that show developments in his applications of text-based parameters for structure, melodic, rhythmic, and dynamic components of the music: Psalom (1985) and Silouan's Song (1991). Importantly, it provides the first detailed analyses of the text-based rules that Pärt used to derive the musical parameters for each work.

- Chapter 6 provides the first detailed analysis of the relationship between the text of the Nicene Constantinopolitan Creed and one of Pärt's most complexly constructed musical works, Orient \& Occident (2000). In this chapter, Orient \& Occident is also examined within the context of its historic reception as an expression of a clash between the musical cultures of the East and West, while proposing an additional interpretation of the 
work, e.g. as a commentary on the schism between the Eastern and Western traditions of Christianity.

- Chapter 7 discusses the conclusions of this study and reflects on their implications for future research. 


\section{Chapter 1 - Pärt, spirituality and minimalism}

This section of the thesis provides an overview of the early career of Arvo Pärt and what led to the development of his tintinnabuli system of composition. This is followed by a brief summary of the critical reception of Pärt's tintinnabuli music in the late 1980s and early 1990s, during which the terms 'spiritual' and 'minimalism' became dominant tropes associated with his tintinnabuli music.

\section{Overview of the early career of Arvo Pärt}

In his early career, Pärt followed a compositional path of development that took him through a range of styles. ${ }^{14}$ He wrote his earliest published compositions while still a student at the Tallin Conservatory (1957-1963), producing the neo-classicist piano works Sonatine Op.1 No.1 (1958), Partita Op. 2, (1958), and Sonatine Op.1 No. 2 (1959) (showing the influence of Shostakovich, Prokofiev, and Bartók). ${ }^{15}$ During his student years, he also composed the Soviet-realist-style cantata for children's choir and orchestra Meie Eide (1959). ${ }^{16}$

Between 1960 and 1963, Pärt embraced the dodecaphonic, or 12-tone, style of composition and produced a number of serialist works for orchestra in quick succession: Nekrolog Op. 5 (1960), Perpetuum Mobile Op. 10 (1963), and Symphony No. 1 'Polyphonic' (1963). In doing so, he became the first Estonian composer and one of the first Soviet-bloc composers to actively engage with serialism - a move that was to garner Pärt a considerable amount of criticism from the Soviet musical establishment, as the composer himself has noted:

\footnotetext{
14 Ibid., xi.

15 Throughout this thesis I have only referred to works that Pärt recognises as part of his canon.

${ }^{16}$ Meie Eide, or Our Garden, garnered Pärt his first official recognition in the Soviet music establishment, winning The All-Union Survey of the Creative Work of Young Composers prize in 1962. See Hillier, Arvo Pärt, 32.
} 
In the course of my life there have been several upsets. It started as far back as 1961, when I composed Nekrolog, which was my first orchestral piece. I was a student at the conservatory of music in Tallin, and I had written a piece in 12-tone technique, which was at the time and place extraordinary. As a result there was strong criticism from the highest circles. Nothing was considered more hostile than so-called influences from the West, to which 12 -tone music belonged. ${ }^{17}$

Until 1958, the music of Schoenberg and Webern was banned in the Soviet Union. While the ban was lifted shortly after the 1957 Second All-Union Congress of Composers in Moscow, Pärt's early adoption of serialism and subsequent use of other avant-garde techniques such as 'collage' composition were viewed as a rejection of Soviet ideology, which espoused "forced optimism and artificially inseminated international benevolence". ${ }^{18}$ Despite such criticism, Pärt continued to follow his own distinctive path and developed an ever more rigorously abstract serialist style that culminated in a prolific outpouring of published works during 1964: Diagrames Op. 11 for piano, Musica Sillabica Op. 12 - a chamber work for 12 instruments, including piano, vibraphone, and electric guitar, Quintettino for flute, oboe, clarinet, horn, and bassoon, and Solfegio for SATB choir.

By 1964, however, Pärt had already begun to tire of serialism, and in response to this he turned to collage composition. Collage sur $B-A-C-H$ (1964), which is based on the famous musical motif B-A-C-H (Bb, A, C, B 七), is a three-movement work for strings, oboe, piano, and harpsichord. Collage is the first example where Pärt explicitly quotes the music of Bach. As one the first unabashed presentations of tonal material in Pärt's official cannon, through its use of tonal quotations of another composer, Collage hints at the growing

\footnotetext{
17 Martin Elste, "An Interview with Arvo Pärt," Fanfare, November 1988, 338. See also Hillier, Arvo Pärt, 35. ${ }^{18}$ Hillier, p. 30.
} 
musical crisis that Hillier notes Pärt had begun to experience in the early 1960 s. $^{19}$ Collage uses both the musical translation of Bach's name and quotations from the Saraband of the English Suite in D Minor. This interest in the music of Bach was to become a prominent feature of Pärt's collage phase, which includes the works Pro et Contra (1966), Symphony No. 2 (1966), and his pivotal work for solo piano, chorus, and orchestra Credo (1968), the last of his collage period works. ${ }^{20}$

In these pieces, serial and aleatoric writing is juxtaposed with tonality, with an increasing tendency by Pärt to present his atonal and aleatoric writing in a negative light. ${ }^{21}$ During a 2010 interview with American journalist Arthur Lubow, he explained, "[with Credo] I wanted to put together the two worlds of love and hate. I knew what kind of music I would write for hate, and I did it. But for love, I was not able to do it."22 It was this desire to express the sound world of 'love and forgiveness' that led Pärt to incorporate Bach's material in Credo, selecting the main motif from Bach's Prelude in $C$ major from Book 1 of the Well-Tempered Clavier. The quoted material from Bach's compositions was juxtaposed against the atonal sound world of hate, which Pärt portrayed through his own original serialist and aleatoric music. Notably, Credo also marks the last of his major attempts to reconcile the use of serialist and aleatoric techniques, which had been his media for almost ten years, with music based on the Western tonal tradition.

Neeme Järvi, who is a long-time collaborator and supporter of Pärt, conducted the 1968 premier of Credo. The audience greeted the work with enthusiasm and called for an

\footnotetext{
19 Hillier, Arvo Pärt, 30.

20 Pärt's Wenn Bach Bienen Gezüchtet Hättet for piano, string orchestra, and wind quintet (1976/2001), which is neither a serial nor tintinnabuli work, is another example of Pärt's referencing Bach, in both the title, the use of the B-A-C-H motif throughout, as well as musical quotation in the final bars (158-163) of Bach's B minor prelude, The Well-Tempered Clavier, Book 1. Ibid., 100.

21 Jamie McCarthy, “An Interview with Arvo Pärt,” Contemporary Music Review 12:22 (1995): 58.

${ }^{22}$ Arthur Lubow, "The Sound of Spirit," The New York Times, October 15, 2010.
} 
immediate encore. ${ }^{23}$ The local Communist Party authorities, however, interpreted the work's religious title as being intentionally provocative and ultimately questioned Pärt's political aims. Subsequently the work was banned from being performed in the Soviet Union or any of its satellite states for a decade. ${ }^{24}$ In relation to this, Neeme Järvi told the journalist Lubow:

The law was that you first had to show the score to the composers' union. I didn't. I thought they wouldn't let us [perform it]. The Estonian Philharmonic organization said, "Let's do it." Next morning it was a big scandal in the Politburo of Estonia. Then the pressure starts. Some people were sacked from the Philharmonic organization. ${ }^{25}$

Järvi told Lubow he ultimately retained his position because there was no one to replace him at the Estonian Philharmonic, but that the scandal "dried up Pärt's official commissions". ${ }^{26}$ Shortly after the banning of Credo, Pärt seems to have come to an impasse with atonal music and found that he no longer had any interest to continue with music in that vein. Expressing his views on serialism to Lubow, Pärt stated:

I think if the human has conflict in his soul and with everything, then this system of 12-tone music is exactly good for this. But if you have no more conflict with people, with the world, with God, then it is not necessary. You have no need to have a Browning in your pocket, or a dagger. ${ }^{27}$

Hillier notes that Pärt felt he "had written himself into a cul-de-sac: he had reached a position of complete despair, in which the composition of music appeared to be the most futile of gestures, and he lacked the musical faith and will-power [sic] to write even a

\footnotetext{
${ }^{23}$ Hillier, Arvo Pärt, 58. authority.

${ }^{25}$ Lubow, "The Sound of Spirit."

${ }^{26}$ Ibid.

${ }^{27}$ Ibid., XX.
}

${ }^{24}$ Hillier notes that, while Pärt's use of serialism was no longer viewed as a serious problem by the Soviet musical establishment by 1968, Pärt's paraphrasing of the liturgical credo 'Credo in Jesum Christum' (the text in the Catholic liturgy begins 'Credo in unum Deum' and the subsequent text from the Gospel of St Mathew [5: 38-9], which in English translates into 'You have heard it said: an eye for an eye and a tooth for a tooth. But I say unto you: do not resist injury') was seen as a direct challenge to Soviet dogma and 
single note." ${ }^{28}$ In terms of his musical output, Pärt lapsed into relative silence for seven years, during which time he produced only two major works Symphony No. 3 and the symphonic cantata Laul Armastatule, the latter of which the composer subsequently withdrew from public performance and publication. Despite Pärt's apparent lack of 'official' creative output between 1968 and 1974, he was anything but unproductive. During this period, he wrote pages of stylistic and technical studies based on his study of Gregorian chant and music of the Notre Dame School. He also supported himself and his family by writing film music and music for children's television shows. ${ }^{29}$

It was during this period of musical reflection and study that Pärt and his wife Nora also converted to the Russian Orthodox faith in 1972. Hillier observes that it was through the hesychastic tenants of Eastern Orthodoxy, with their emphasis on silent religious reflection,,$^{30}$ that Pärt found what was to be the guiding spirit in the new music that he would begin to write. ${ }^{31}$ In relation to this Pärt notes:

And maybe there was one point when I said, "Stop with this old music as a composer." Now in this place must be born something of mine - from everything that I have learned in old music, in religion, in life, and how much I was able to see my own sins and imperfections, and to repent it. To say, "Yes". ... But it is a good thing. Begin from zero, from nothing. It's like if there is a fresh snow and nobody has walked, and you take the first steps on this snow. And this is the beginning of new life. ${ }^{32}$

Ultimately, it was through his studies of plainchant and monophonic early music that Pärt found a map to guide himself out of the musical cul-de-sac into which he had

\footnotetext{
${ }^{28}$ Hillier, Arvo Pärt, 64.

29 Ibid., 66.

${ }^{30}$ In monastic life in Eastern Christianity, practitioners seek quietness (Greek "hesychia") of mind and spirit through the contemplation of God in continual prayer. Source: http://www.patheos.com/Library/Glossary/Hesychasm.html. Accessed 19 February 2012.

${ }^{31}$ Hillier, Arvo Pärt, 7-10. See also Lewis Owens, "Arvo Pärt : Miserere : Miserere and Minimalism," Spike Magazine, accessed September 4, 2011, http://www.spikemagazine.com/0600arvopart.php.

32 Lubow, "The Sound of Spirit," XX.
} 
written himself during his experiments with serialism, collage, and aleatoric composition. On this, Pärt noted in a 1999 interview:

In our century, we have somehow forgotten that two times two make four. Old music was a bit like a breath of fresh air for me. At that stage, I was missing something natural like that. I began to realise through old music that there are hidden worlds behind two notes. Monophony has its own language in no need of mediation by harmony. I also began to understand at that time that harmony relates to melody in a very direct way. The vertical and horizontal aspects are inseparable. They are not abstract entities. There is a reason for relating both together. ${ }^{33}$

Pärt developed his tintinnabuli composition system as a result of both his early music and religious studies in the early 1970s. ${ }^{34}$ The system is based upon the seemingly simple premise of a two-part, note against note, texture consisting of: 1) the M-voice, a diatonic melody that moves towards and away from a single central pitch, and 2) the Tvoice, which is restricted to using only the notes of a single major or minor triad, set out in relation to the notes of the M-voice in a predetermined pattern. During an interview conducted in 1978 by fellow Estonian composer Ivalo Randalu, Pärt described his early development of tintinnabuli within the context of combining two notes of different colours to create new sonorities that allow the listener to embrace the beauty of the individual notes one pairing at a time..$^{35}$

When asked what he was trying to achieve with tintinnabuli, he responded that the keynote, or tonic-based M-voice, represents 'infinity', while the triad T-voice represents 'chastity'. When further questioned as to what he meant by chastity, he replied that it is

\footnotetext{
${ }^{33}$ Geoff Smith, "An Interview with Arvo Pärt: Sources of Invention," The Musical Times 140, no. 1868 (October 1, 1999): 23.

${ }^{34}$ Hillier, Arvo Pärt, 68.

35 Randalu's interview of Pärt was included in Andres Sööt's film-portrait of the composer. See Andreas Sööt, "Arvo Pärt in November 1978," trans. Andreas Didrik (Teater, Muusika, Kino, 1988). Trans. Andres Didrik with Doug Maskew, 1997, from David Pinkerton, "David Pinkerton's Arvo Pärt Information Archive," n.d., http://www.arvopart.org/.
} 
something that he always searches for while composing and knows what it is only once he has found it. In his interview with Randalu it is not clear, however, whether Pärt is specifically couching this idea of searching for chastity in the compositional process as an expression of the spiritual, or within the context of a search for purity or restraint and simplicity in the design of the composition itself. In his discussions with Paul Hillier, Pärt was clearer in relation to his views of the M-voice/T-voice pairing as an expression of his spiritual sensitivities.

The M-voice always signifies the subjective world, the daily egoistic life of sin and suffering; the T-voice meanwhile is the objective realm of forgiveness. The M-voice may appear to wander, but is always held firmly by the T-voice. This can be likened to the eternal dualism of body and spirit, earth and heaven; but the two voices are in reality one voice, a twofold single entity. ${ }^{36}$

\section{Critical and popular reception of Arvo Pärt's music}

Arvo Pärt has enjoyed one of the most commercially successful careers of any living Western art music composer. ${ }^{37}$ Despite this commercial success, the early critical reception of Pärt's music was polarised across a range of different musical communities and the music's commercial success did not translate into universal critical acclaim by the musical establishment, particularly during the late 1980s and 1990s. Within the contexts of the modernist/postmodernist debate during this period, some critics praised his music, while others attacked it as being overtly simplistic, monochromatic and fundamentalist. It was during this period that the tropes 'spiritual' and 'minimalism' also came to be associated with Pärt and his tintinnabuli music.

\footnotetext{
36 Hillier, Arvo Pärt, 96.

37 See Dolp, “Arvo Pärt in the Marketplace,” 181.
} 
In his 1994 article The New Simplicity: The Music of Górecki, Tavener and Pärt, Josiah Fisk takes Pärt and other composers such as John Tavener and Henryk Górecki to task for 'abandoning' modernism and adopting a minimalist style he refers to as "The New Simplicity". Fisk accuses all three composers of breaking with the Western musical tradition that seeks to:

... extend and transform itself, to amend, to shade, to counterbalance, to reassert, to contradict. That's why we listen: so our ears can make sense out of what we're hearing. That note - did it signal the end of a phrase or the beginning of a new one? Is this theme fully formed the first time it appears, or does it achieve its real identity only after metamorphosis? Is that triad the tonic or is it the dominant of the subdominant? ${ }^{38}$

In Fisk's views, true musical works present the listener with questions, ambiguities and 'meaning' that we can perceive, even if we cannot resolve that meaning. He argues that since its first inception, Western music has drawn its strength from such ambiguity, and that well composed musical works, whether written during the Renaissance or the twentieth century, "carry meanings within themselves, presenting them to us in all their cross-grained complexity as stories that unfold. They do that most human of things: they approach you, greet you, and proceed to engage you in [a musical] dialogue."39 Fisk proceeds to take a historicist position that even the musical modernist revolutionists of the twentieth century such as Stravinsky, Schoenberg, Bartók, and Ives - regardless of how dramatic their perceived break with earlier styles, principles and practices of their predecessors - never lost sight of the past, nor challenged the inherent principle of musical dialogue. ${ }^{40}$ Rather, Fisk feels Pärt's music withdraws "from the here and now through a self-styled form of monkish transcendence". ${ }^{41} \mathrm{He}$ asserts that Pärt, Tavener,

\footnotetext{
38 Josiah Fisk, "The New Simplicity: The Music of Górecki, Tavener and Pärt," The Hudson Review 47, no. 3 (Autumn 1994): 394.

39 Ibid.

40 Ibid., 395.

${ }^{41}$ Ibid., 403.
} 
and Górecki break with the tradition of musical dialogue, and as such their music has neither inner life nor substance. ${ }^{42}$ He further excoriates the three composers' return to tonality (in Pärt's case modal diatonicism), arguing that all three attempt to wrap modern listeners in a 'populist fairy tale', in which music has become stifled by 'ivory tower' academic complexity, and that the only way out is for a return to the music of kinder, simpler times. ${ }^{43}$ In the process, while their music may sound pretty to the listener upon first hearing it, it is also lacking in any substance, as it is not imbued with a musical dialogue and the requisite ambiguities of meaning that, Fisk argues, are the hallmark of all great classical music:

And so we have a music that, for the listener who seeks more than the token artefacts of classical music, offers no dialogue, no ambiguity and no inner life. What we are left with is a surface that speaks of depth, and a depth that speaks of nothing. The sounds that at first blush tell us this is classical music give way to a center that is classical music's opposite more completely so than any other type of music. What we gain in this bargain is a way of asserting faith in simplicity. What we give up is faith in music as an art. ${ }^{44}$

J. Peter Burkholder characterises historicist views such as those of Fisk, i.e. that composers of Western art music and their products should be evaluated within the context of contemporary ideas of 'tradition', as a 'hold over' of Hegelian philosophy, which has come down to us through the mostly Germanic tradition of music criticism during the nineteenth century. He argues that this idea, as promulgated by music critics and musicologists in the twentieth century, has resulted in a 'museum-like' concert hall system that places emphasis on the works of the 'great masters' of the (German) musical past. Before the postmodern period, this situation put many modernist composers in the uncomfortable position of having to position themselves not only relative to a tradition

\footnotetext{
42 Ibid., 402.

43 Fisk, p. 406.

${ }^{44}$ Ibid., 411-12.
} 
that may have no relevance to their own musical roots and cultural heritage, but also to differentiate themselves somehow from that tradition to prove themselves as being worthy of wearing its mantle. ${ }^{45}$

Another early critic who took strong issue with the diatonic modal nature of Pärt's music and its perceived simplicity is David Clarke. In his 1993 article "Parting Glances: David Clarke Reappraises the Music and the Aesthetics of Arvo Pärt”, Clarke accuses Pärt of exercising a type of dualistic compositional rhetoric that tries to simultaneously meet modernism on its own terms, yet deny modernism's aesthetic possibilities by emphasising the primacy of the music's spiritual nature over the concerns of modernity. While applauding Pärt for re-opening channels of communication between modern music and a general public that has been alienated by the "atonal complex structural abstraction" of modernist music, ${ }^{46}$ Clarke questions whether Pärt's turn to tonal materials and adoption of 'simplicity' in musical design is actually a valid postmodernist response to the values of modernism. Drawing heavily on Adorno, Clarke argues that while Pärt's tintinnabuli music is a break with the modernist progress narrative towards ever-greater musical complexity that has defined value in Western art music, the 'Holy Minimalist' composer needs to "convince his critics of the validity of his postmodern agenda." 4748 He writes:

\footnotetext{
45 J. Peter Burkholder, "Museum Pieces: The Historicist Mainstream in Music in the Last Hundred Years", The Journal of Musicology, 2 (1983), 115-34 (p. 121). See also J. Peter Burkholder, "Musical Time and Continuity as a Reflection of the Historical Situation of Modern Composers", The Journal of Musicology, 9 (1991), 411-29; and Lydia Goehr, The Imaginary Museum of Musical Works (New York: Oxford University Press, 1992), 205-42.

46 David Clarke, "Parting Glances: David Clarke Reappraises the Music and the Aesthetics of Arvo Pärt," The Musical Times 134, no. 1810 (December 1, 1993): 680.

47 Ibid.

${ }^{48}$ Adorno argued that the characteristic state of contemporary subjectivity is one of alienation and rationalism, and this in turn determines the authenticity and mimetic value system of modern art. "The modernity of art lies in its mimetic relation to a petrified and alienated reality. This, and not the denial of that mute reality, is what makes art speak. One consequence of this is that modern art does not tolerate anything that smacks of innocuous compromise." (See Theodoro Adorno, Aesthetic Theory, tran. C.
} 
Pärt attempts to legitimise his use of pure diatonic tonality in a period of our culture which has seen the breakdown not only of the diatonic system, but also of its associated syntax of rhythm, phrase structure and developmental processes - a consequence of modernism's restless critique of established modes of meaning. He strives to inoculate the tintinnabuli style against such critique by paradoxically introducing an analogous critical stance into the treatment of its own historically retrieved materials. Classical tonal elements are made to resist participation in their associated systems of meaning - such as functional harmony or unfolding musical argument - through a number of devices, among them mensuration canon, isorhythm, quasi-serial manipulation or permutation of note sequences, and principles of symmetry. ... These examples demonstrate the perilously fine line Pärt treads between simplicity and vacuity. ${ }^{49}$

What is not completely clear in Clarke's argument is whether he interprets Pärt's 'remortgaging' of musical materials from the past, while refusing to engage tonality in a traditional manner, as merely a rhetorical break with the 'progress narrative' of Western music, or a modernist act as defined by Adorno, i.e. a rejection of those aspects of musical modernism from which Clarke believes Pärt has become alienated. If the latter is the case, Clarke's Adorno-esque assessment of Pärt's music appears to assume that tintinnabuli music is a postmodern response to modernism within the context of the Western classical tradition, as it has come down to us through the 'German masters' of the eighteenth and nineteenth centuries. However, this position neglects the fact that contextually, Pärt received all of his musical training in Soviet-occupied Estonia; as such his musical training and early compositional career were based on the objective political

\footnotetext{
Lenhardt, London: Rouglede \& Kegan Paul, 1984, p. 31.) Therefore Adorno contends that true art must mime the alienation of the modern subject from the objective world by constantly moving towards evergreater degrees of abstraction through "purging itself of the not new, which amounts to purging itself of the objective in the form of conventions (conditions laid down by the other, that is society)." (Christopher Dennis, Adorno's Philosophy of Modern Music, New York: Edwin Meelen Press, 1998, p. 35) Adorno argued that some of the victims of this purging of the 'not new' were the conventions of the 'illusion of tonality' and the 'illusion of organicism', which while relevant to the mimetic processes of the great music of the 18th and early 19th centuries - during and post The Enlightenment - are no longer authentic within the context of contemporary art music, and the state of total alienation from the objective of the contemporary modern subject (Max Paddison, "Adorno's Aesthetics of Modernism" in Adorno, Modernism and Mass Culture: essays on critical theory and music, London: Kahn \& Averill, 2004, pp. 43-80.)

${ }^{49}$ Clarke, "Parting Glances: David Clarke Reappraises the Music and the Aesthetics of Arvo Pärt," 682-83.
} 
realities and artistic conventions of the Soviet Union during the 1950s through early 1970s, and not necessarily solely on the foundation of the 'German masters'.

In relation to this, Maria Cizmic notes that when Pärt converted to the Russian Orthodox faith, this occurred "at a time when [Soviet oppression] spawned an unofficial religious subculture that attracted people searching for alternative ways to create meaning in their life." ${ }^{50}$ Therefore, it is possible that Pärt's rejection of Soviet-promulgated atheism and subsequent conversion to Orthodoxy during the same period when he turned his back on the 'ideals' of modernist aesthetics (in his disavowal of modernist compositional models) was a symptom of his own alienation from the objective realities of political and artistic conventions in the Soviet Union in the 1970s, rather than an Adorno-esque response to Western musical modernist conventions. If this is the case, then it is just as possible to conclude that Pärt's tintinnabuli music is in effect a purging of certain aspects of both Soviet cultural conventions and modernist compositional models that had seeped into the Soviet avant-garde from the West in the late 1950s and early 1960s - making it a type of modernist gesture, as defined by Adorno - just not one that Adorno (or critics such as Fisk or Clarke) anticipated or can appreciate within the context of the Western musical tradition.

The British musical scholar Robert Sholl points out that Pärt was not the first twentieth century composer to eschew the historic model of 'organic musical development' (itself a modernist gesture), citing examples such as Stravinsky, Messiaen, Cage, and Ligeti (the early mid-1960s' works) as a few composers who have developed their own approaches in composing music that creates new forms of musical narrative by juxtaposing blocks of material in new and unique ways. He argues that Pärt's tintinnabuli music uses

50 Maria Cizmic, "Transcending the Icon: Spirituality and Post Modernism in Arvo Pärt's Tabula Rasa and Spiegel Im Spiegel," Twentieth-Century Music 5, no. 1 (2008): 55. 
consonance and dissonance to create a developmental musical narrative that is dependent on the creation of short-term (localised) and long-term (structural) senses of tension and release". ${ }^{51}$ As such, rather than developing his musical works through more traditional methods such as the manipulation of motivic material through embellishment, augmentation, diminution or inversion, Pärt instead creates these tensions and releases through the accretion of multiple voices and careful methods of construction. These result in the creation of cohesive musical structures in each work that are "generally characterized by a certain repertoire of dissonances and consonances, and a selection of textures and sounds that provide a stable identity to that particular work."52

Spirituality is another frequent trope in both the public and critical reception of Pärt's music, and often is imbricated with the tropes of simplicity and minimalism. Advocates such as Paul Hillier, Maria Cizmic, and Wilfrid Mellers insist it is the simplicity of his music, with its emphasis on silence, single notes, and relatively static sound elements reminiscent of chant and early monophony, which is integral to many listeners embracing it as 'spiritual'. 53

There are a number of other factors, besides the perceived 'simplicity' of his music, that have contributed to associations of Pärt's music with spirituality. Both Pärt and his wife are publicly known as devout adherents to the Russian Orthodox faith, and both have openly discussed in interviews the importance of religion in their lives. Both have also emphasised that Pärt expresses his faith through his music, as evidenced by the titles of

\footnotetext{
${ }^{51}$ Robert Sholl, "Arvo Pärt and Spirituality," in The Cambridge Companion to Arvo Pärt (Cambridge: Cambridge University Press, 2012), 143.

52 Ibid.

53 See Paul Hillier, "Arvo Pärt: Magister Ludi", The Musical Times, 130 (1989), 134-37. Cizmic, "Transcending the Icon: Spirituality and Post Modernism in Arvo Pärt's Tabula Rasa and Spiegel Im Spiegel." Wilfrid Mellers, "Arvo Pärt, God and Gospel: Passio Domini Nostri Jesu Christi Secudum Johannem", Contemporary Music Review, 12 Part 2 (1995), 35-48.
} 
many of his early works: De Profundis and Te Deum, Sarah was Ninety Years Old, Passio, and the Berlin Mass.

Another factor that has led to associations of Pärt's music with spirituality, by both critics such as Fisk and Clarke and supporters such as Hillier, is the strong resemblance of many of his melodies to monophony and the sound world of Gregorian chant and early discant and organum. ${ }^{54}$ German musical scholar Leopold Brauneiss, who is also an advocate of Pärt, has examined the similarities of Pärt's melodies and tintinnabuli-based counterpoint to the organa of the Notre Dame School. However, Brauneiss concludes that despite a number of similarities to aspects of what we as Western listeners believe medieval music 'sounds like', in the end Pärt's application of the rules in tintinnabuli to dictate the placement of the T-voice; and the manner in which Pärt constructs his Mvoice melodies is in fact a translation of the models of early polyphony into a new system of rules of his own making. This makes tintinnabuli not a return to the music of the Middle Ages, but rather something new and postmodern that is a combination of both medieval and modern elements. ${ }^{55}$

Whereas critics such as Fisk and Clarke disparaged the supposed rhetorical positioning of Pärt's music as a postmodernist denial of music's historical contingencies through an affiliation with the spiritual, Robert Sholl sees Pärt's music as an active engagement with the modernist spirit. He notes that "as much as it espouses a unity with God, [it] is symptomatic of humanity's search for God, and as such it is a self-conscious and modernist form of political vangardism that relies on a productive engagement (rather

\footnotetext{
${ }^{54}$ The terms discant and organum refer to two different styles of vocal writing in early polyphony. Discant denotes a note against note counterpoint that is not unlike the note against note relationship between the $\mathrm{M}$-voice and the T-voice in tintinnabuli. Organum refers to vocal writing that is more melismatic in nature. See Jeremy Yudkin, Music in Medieval Europe, Prentice Hall History of Music Series (Upper Saddle River, New Jersey: Prentice Hall, 1989), 344.

${ }^{55}$ Leopold Brauneiss, "Arvo Pärt's Tintinnabuli Style: Contemporary Music Toward a New Middle Ages?," in Postmodern Medievalisms, vol. XIII, Studies in Medievalism (Cambridge: D. S. Brewer, 2005), 33.
} 
than any antipathy) with modernity." ${ }^{56}$ Sholl posits that far from escapism from modernism, contemporary Western spirituality "is a consciousness that has absorbed and even reconfigured the problems of modernity through alternative and sometimes equally rational discourses". 5758 Sholl argues that, to be understood and appreciated, Pärt's music requires a stance of listening that relies on other traditions of musical structure, rather than that of traditional Western art music. He notes that the music's seemingly static nature, in contrast to the dynamism of common practice Western musical narrative, alludes to the devotional icons of Pärt's Russian Orthodox faith, likening it to:

... a musical and ideological construction that configures the meaning of the music as a panacea to the sense of dynamism, drama and progress associated with modernity. This perceived staticism of the music has led to a description by Paul Hillier of the music as a "sounding icon". The music has therefore been inextricably linked to the devotional art associated with the composer's own Russian Orthodox faith. ${ }^{59}$

However, this may be a misreading of Hillier. In his monograph on Pärt, Hillier writes about the history of icons in the Russian Orthodox Church and their role in the contemplative, self-reflecting nature of hesychastic practice in Eastern Christian spirituality, suggesting that this model of contemplative listening might be an entrance into appreciating Pärt's tintinnabuli music. However, he also is explicit in stating that such art should not be taken "as an 'explanation' of Pärt's music, but as a potentially useful corollary of it." 60 This appears to be in reference to Hillier's later attempt to reconcile the labels 'minimalistic' and 'repetitive' that critics like Fisk and Clarke have associated with Pärt and the composer's devotion to the Russian Orthodox faith, noting:

\footnotetext{
56 Sholl, “Arvo Pärt and Spirituality," 141.

57 Ibid.

58 See also Richard Taruskin, Music in the Late Twentieth, vol. 5, The Oxford History of Western Music (Oxford: Oxford University Press, 2010), 526.

59 Sholl, "Arvo Pärt and Spirituality," 144.

${ }^{60}$ Hillier, Arvo Pärt, 3.
} 
The music may seem 'ritualistic', but culturally there is no pre-ordained pattern to which it conforms, no inherited iconography - even so, minimalist music does articulate the possibility at least of a bona fide existential ritual, if only quite literally for the time being.

With Pärt we are taken one step further, though we are obliged to accept or at least take on trust, the framework of Christianity within which he works ... The ritual aspect of his music derives both aesthetically and spiritually from its function as a sounding icon. The music ushers us into the presence of a recurring process. ${ }^{61}$

\section{The modernist versus postmodernist debate}

While the argument as to whether Pärt's tintinnabuli music is a modernist or postmodernist gesture is outside the scope and focus of this thesis, I should acknowledge that the argument as to what defines these gestures was largely a historical debate among musical critics during the last two decades of the twentieth century, and does not necessarily hold sway any longer. However, it must be borne in mind that much of the modernist/postmodernist debate regarding Pärt's music in the 1980s and 1990s was within the context of the Western classical tradition as it has come down to us through the 'German masters'. Tillman notes that within the context of the German debate on postmodernism and music, Pärt's tintinnabuli music was not seen as postmodernist. Rather, Pärt's pre-tintinnabuli collage and aleatoric compositions were viewed as being a specific type of Soviet postmodernism, due to their complexity and poly-stylism. However, his later tintinnabuli music was not perceived as postmodernist, due to its unity and 'purified' nature. ${ }^{62}$ Similarly, under the terms of reference as used by Clendinning, which are couched in comparisons with postmodernism in architecture, despite a degree of 'co-opting from past materials and practices' Pärt's tintinnabuli music would technically not qualify as being postmodernist. She takes the position that "postmodern compositions

\footnotetext{
61 Ibid., 17.

62 Joakim Tillman, "Postmodernism and Art Music in the German Debate," in Postmodern Music/Postmodern Thought, vol. 4, Studies in Contemporary Music and Culture (New York and London: Routledge, 2002), 83-84.
} 
are purposefully disunified" and that postmodernism in music is defined in terms of “complexity and contradiction, messy vitality, richness over clarity, many levels of meaning, a combination of forms, decoration and ornament for its own sake, mixed media, symbolism, representationalism and starting with the listener's value system ...".63

Alternative views of some scholars, however, might point to the issue of modernity/postmodernity being outside of the realm of the musical text and the composer's intentions, placing it in the domain of the consumption and reception of Pärt's music by its listeners. In relation to this, Kramer notes that postmodernism and modernism are imprecise concepts that raise many issues about unity, intertextuality, and eclecticism in compositional and musical consumption practices. ${ }^{64} \mathrm{He}$ takes the position that 'postmodernism' is more of an attitude, which is dependent upon the "placement of meaning in the listener". ${ }^{65}$ Perhaps expanding on the views of Kramer, Taylor takes the position that many definitions of postmodernism and postmodernity, for the most part, overlook social and economical realities, noting that:

Most discussions of postmodernism and music talk about sounds only, and there is less attention to what music (as form and practice) in postmodernity might be. If we view postmodernity as a historical moment and postmodernism as ways of cultural production linked to political and economical realities, ... then we can't just look at musical texts to understand what postmodernity might be; we need also to look at the circumstances surrounding the production and receptions of those texts. ${ }^{66}$

63 Jane Piper Clendinning, "Postmodern Architecture/Postmodern Music," in Postmodern Music/Postmodern Thought, vol. 4, Studies in Contemporary Music and Culture (New York and London: Routledge, 2002), 135.

64 Jonathan D. Kramer, "The Nature and Origins of Musical Postmodernism," in Postmodern Music/Postmodern Thought, vol. 4, Studies in Contemporary Music and Culture (New York and London: Routledge, 2002), 13-26.

65 Ibid., 19.

66 Timothy D. Taylor, "Music and Musical Practices in Postmodernity," in Postmodern Music/Postmodern Thought, vol. 4, Studies in Contemporary Music and Culture (New York and London: Routledge, 2002), 102. 
Importantly, the preceding summary of the critical reception of Pärt's music during the 1980s and 1990s is not intended to imply that all listeners or critical scholars necessarily approach Pärt's music as an engagement, or an attempt to engage, with 'the spiritual' or as an example of a postmodern response to the alienation of the modern condition. However, much of the early critical reception tended to focus on issues of modernity and postmodernity and attempts to classify Pärt's music as 'minimalist' and/or a return to 'spirituality' by embracing simplicity. ${ }^{67}$

In relation to the former term, the usage of terms 'minimalism' and 'minimalist' in relation to music can be problematic for some readers. In relation to 'minimalism', Timothy Johnson has noted that: "minimalism in music has been defined as an aesthetic, a style, and a technique, each of which has been a suitable term at certain points in the development of minimal music". ${ }^{68}$ But in terms of both musical aesthetics - which implies a certain stance of listening and reception - and stylistic considerations, Johnson defines 'minimalist' music as encompassing some or all of the following concerns or characteristics: "a continuous formal structure, an even rhythmic texture and bright tone, a simple harmonic palette, a lack of extended melodic lines and repetitive rhythmic patterns". ${ }^{69}$ While arguably certain aspects of Pärt's tintinnabuli music can be deemed as meeting some of these criteria - in terms of style and certain listeners' aesthetic listening positions - the focus of this thesis is on: perceptions of Pärt's compositional techniques as being minimalist in terms of his use of repetitive rhythmic and melodic processes and

\footnotetext{
67 Writers such as Maria Cizmic have also written extensively on the composer's biographical background and his place within the context of the Soviet avant-garde. In addition, writers such as Hillier, Sholl, and Cizmic have also attempted to explain what it is about Pärt's music that leads to its broader appeal to diverse musical audiences.

68 Timothy A. Johnson, “Minimalism: Aesthetic, Style or Technique?," The Musical Quarterly 78, no. 4 (Winter 1994): 742.

${ }^{69}$ Ibid., 751.
} 
pre-compositionally determined procedures; and how this has translated into his music receiving little critical attention from musical analysts and theorists to date.

While both Hillier and Brauneiss have described the basic principles of tintinnabuli, ${ }^{70}$ few critics have delved at length into how Pärt's music actually 'works' by identifying the different procedures and rules that Pärt applies when composing each work. Three doctoral studies by Ivan Jimanez, Mark Vuoinen, and Thomas Robinson are notable exceptions. Ivan Jimenez's 2005 doctoral dissertation examines the similarities and differences between Górecki and Pärt's use of canons and pandiatonicism to generate harmonic patterns through manipulation of triadic content in a modal environment.71 Mark Vuorinen's 2014 doctoral dissertation attempts to make an "explicit link" between the methods Pärt used in his early serial works and the application of similar methods and processes in Pärt's tintinnabuli music - arguing that Pärt's primary method of controlled pre-compositional design in his tintinnabuli procedures is in effect an extension of his serialist approach to writing, and therefore is part of a "continuum of [serialistic] compositional method". ${ }^{72}$ As part of his 2009 doctoral study on pitch-class theory and pitch-class multisets, Thomas Robinson uses Pärt's Psalom as a case study of "transformational growth" based upon a single pitch-class set.73

In his contributing chapter to the Arvo Pärt Companion, Robinson posits that there are three reasons why Pärt's music has received little analytical attention as yet. ${ }^{74}$ The first is that because Pärt is still living, there has been insufficient time for his music to become

\footnotetext{
70 These are described in detail in Chapter 2 of this thesis.

71 Jimenez, "Textural Depth, Structural Depth, Expressive Depth: Ladders from Line to Sonority in Arvo Pärt and Henryk Mikolaj Górecki and Burning the Deep Red Sea (an Original Composition for Chamber Ensemble)".

72 Mark Vuorinen, "Arvo Pärt's Serial and Tintinnabuli Works: A Continuum of Process." (Doctor of Musical Arts, Faculty of Music, University of Toronto, 2014), ii, ProQuest Dissertations \& Theses Global.

73 Thomas Robinson, "Pitch-Class Multisets" (Doctoral of Philosophy, City University of New York, 2009).

${ }^{74}$ Robinson, “Analyzing Pärt," 76.
} 
an object of interest. The second reason is the characterisation of Pärt's music as minimalist. Robinson notes: "As labels go ... it is a deterrent to theorists and analysts who find minimalist music of little value regardless of composer, regardless of technique."75 The third potential hindrance according to Robinson is that the composer's commercial success, combined with his "austere and reclusive persona, arouses suspicion in some casual observers." 76 In relation to this, Robinson seems to imply that there is a perception among some academics that, because Pärt's music has a significant appeal to a broad audience of listeners who are not normally seen as the primary audience for 'classical' music, it therefore is not perceived as meriting a significant amount of scholarly attention. ${ }^{77} 78$

In relation to this dearth of scholarly attention, in an interview with Enzo Restagno, Pärt laments, "Some beginnings have been made regarding my tintinnabuli style, and these shed a little light in the general fog, but one must bear in mind that while my music has already found a place with the audience, the theoretical side that should go hand in hand with this has not yet been fully worked out."79 This thesis seeks to help address this paucity of theoretical literature on Pärt's tintinnabuli compositional system, as well as to challenge the positions held by some theorists and analysts that little new knowledge can be gained from detailed analyses of music such as Pärt's minimalist tintinnabuli music.

\footnotetext{
75 Ibid.

76 Ibid.

77 See also Dolp, “Arvo Pärt in the Marketplace.”

${ }^{78}$ Susan McClary has also noted the problematic position among music scholars that musical works and musical genres that lack complexity and/or attain broad popularity outside of the 'musical elite' are of little value and thus do not merit 'serious' scholarly attention. See Susan McClary, 'Terminal Prestige: The Case of Avant-Garde Music Composition', Cultural Critique, 1989, 57-81.

${ }^{79}$ Enzo Restagno et al., Arvo Pärt in Conversation, trans. Robert Crow (Champaign, Illinois: Dalkey Archive Press, 2011), 63.
} 


\section{Chapter 2 - Methodology}

The purpose of Chapter 2 is to set out the analytical framework that I will use in my analyses of six selected string orchestral tintinnabuli works in the chapters that follow. Chapter 2 is divided into two parts, providing the reader with a description of the multimodal approach used in the analyses in Chapters 3 through 6, as well as an introduction into the processes and procedures that Arvo Pärt uses to create his tintinnabuli world. This chapter also concludes with my identification of a number of distinct aspects of Pärt's tintinnabuli system that have not previously been noted.

\section{Introduction}

Part 1 of Chapter 2 sets out the analytical framework that I will use in my analyses of six selected string orchestral tintinnabuli works in the chapters that follow. Specifically, this multimodal methodology incorporates: 1) style analysis (descriptions of the 'musical fabric' of each work) based on Jan LaRue's 1970 Guidelines for Style Analysis; 2) detailed examination of how each composition appears to have been constructed, based on pitchclass set and interval-class theory; and 3) sonority mappings, new approaches to visualising the relationships between the pitch classes of particular works and mappings of each work's pitch-class and interval-vector content.

While LaRue's approach to style analysis can provide important insights into Pärt's music, it also has distinct limitations. Four or five of the six basic components in LaRue's analytical framework are applicable when undertaking a style analysis of Pärt's string orchestral works, and style analysis can, to a limited degree, also provide some insight into the growth (or form) of Pärt's work and the nature of the latent harmonic potential of the musical materials used in each work. As such, style analysis also provides a consistent rubric against which to compare the different works. However, because of 
the post-tonal nature of Pärt's tintinnabuli system, LaRue's approach to style analysis is lacking somewhat in its ability to describe in detail the harmonies and chord progressions that result when more than one M-voice/T-voice operation is operating at the same time in a particular work. To address this shortcoming, I will use a multimodal approach by also incorporating two post-tonal analytical methods: pitch-class set and interval-class theory, and graphical structural analyses, or what I term 'sonority mappings' ${ }^{\prime} 80$

Part 2 of the chapter provides insights into the basic operations and procedures (as documented by Hillier) that are hallmarks of Pärt's tintinnabuli system, which are relevant to the analyses in Chapters 3 through 6 . Part 2 also extends beyond Hillier's discussions to provide original analysis of the nature of sounds that these processes and procedures generate. Importantly, Part 2 also identifies a number of distinct aspects of Pärt's tintinnabuli system that have not previously been noted.

80 For the purposes of the proceeding analyses, the term 'sonority' implies the sounding of one or multiple pitches at any given moment in the music. 


\section{Part 1: Analytical approach}

In order to unpack and better understand what is happening in Pärt's tintinnabuli music, I have selectively drawn on the following post-tonal analytical methods in my analyses of the six orchestral works covered in Chapters 3 through 6:

- Style analysis: An examination of the distinct stylistic aspects of each work, based in part on Jan LaRue's analytical framework, as detailed in his 1970 Guidelines for Style Analysis. ${ }^{81}$ LaRue's framework is used to describe the 'musical fabric' and sound aspects of each work (e.g. timbre, range, tessitura, special effects, dynamics and rhythm) and how these contribute to the sense of movement, shape and growth of the overall work. ${ }^{82}$ The style analysis of each work is supplemented by graphic representation in the form of a MIDI-recreation of the work's musical lines to provide a visual overview of the entire work.

- Pitch-class set and interval-class theory: Analysis and descriptions of the specific tintinnabuli operations and non-tintinnabuli procedures and graphic representations of the operations that Pärt deploys in each work. This is done to provide insight into the rules and processes that Pärt used to create the carefully crafted symmetrical constructions and cyclical patterns that occur in each work. The analysis of each work's pitch class and intervallic content is supplemented by graphic representation in the form of a Pärtian Tonnetz, to demonstrate the

\footnotetext{
81 Jan LaRue, Guidelines for Style Analysis.

${ }^{82}$ As noted by Robinson, LaRue's style analysis approach has a number of advantages over certain other formalist analytical approaches that concentrate on harmonic progressions, intervals, or hierarchies of rhythm. While the latter approaches can yield insights into specific musical domains, this comes at the expense of the analyst overlooking other elements that might further illuminate how a particular musical work functions. LaRue's approach, in contrast, provides a comprehensive, albeit non-explanatory, descriptive technique, requiring the systematic observation of each of the musical elements of particular work across multiple dimensions of scale. The resulting description can then serve as a contextual backdrop for further detailed analysis of specific musical elements. Robinson, "Analyzing Pärt," 78-79. See also LaRue, Guidelines for Style Analysis, 2-6.
} 
interrelations between the different M-voice and T-voice pitch classes and the resulting intervallic content when any two pitches occur at the same time.

- Graphical analysis: A detailed graphic structural analysis of the resulting sonic phenomena, based on pitch-class set and interval class theory, and graphical structural analyses (sonority mappings). These mappings detail the rich nonfunctional harmonic content that defines the unique identity of each work, as well as serve as graphical visual aides illustrating how each work functions in general.

\section{Style analysis}

The style analyses in Chapters 3 through 6, based in part on Jan LaRue's analytical framework as described in his 1970 Guidelines for Style Analysis, provide insights into the general nature of the sound (e.g. timbre, range, texture, and dynamics) of the selected string orchestral works examined in this thesis. ${ }^{83}$ They will also describe aspects of the melodies and rhythmic schemes and serve as an entrée into how Pärt develops rules for musical parameters and constructions based upon characteristics of particular texts in the works analysed in Chapter 5 and Chapter 6. Only then is it possible to examine the resulting sonic phenomena, and appreciate how Pärt has created such a seemingly simple, and at times spare, sound world through a series of complex rules, musical procedures and, what appear to be, aesthetically-based decisions/interventions by the composer that are not necessarily evident to the listener.

\footnotetext{
83 These style analyses have been undertaken, based upon a combination of close listenings to recordings of each piece and detailed analysis of the scores. As part of this process, each work was also digitally recreated in Sibelius, based upon the score, for the purpose of creating visual diagrams of salient aspects of each work.
} 
LaRue's seminal text sets out a general method for approaching the stylistic analysis of musical works via a system of observations of different musical elements - sound, harmony, melody, rhythm, growth (LaRue's term for form) and where relevant, textual influence - across the three "standard dimensions of analysis": large, middle, and small. ${ }^{84}$ In LaRue's system, the concept of a large dimension pertains to 'musical wholes' such as entire movements or series of related works. He notes: "At the largest, a musical whole might consist of a giant cycle of complete multimovement [sic] works, such as a series of descriptive symphonies". ${ }^{85}$ In the large dimension, the analysis should give consideration to instrumentation (sound), the relationships between tonalities of different movements (harmony), meter and tempo (rhythm), and the 'varieties of form employed' (growth). At the single movement level and when dealing with works that only have one movement, the large dimension analysis should shift its concerns to dynamic climaxes (sound), those keys that are prominent apart from the tonic (harmony), metrical and directional aspects of melodic movement, and the complexity of rhythm. Depending upon the work, where relevant there should be an examination of contrasts between periods of relative stability among the four elements of sound, harmony, melody, and rhythm, as compared with periods of greater variety of musical activity. ${ }^{86}$

At the other extreme, in the small dimension, focus should be placed on the smallest distinct units that define the individual work, such as dynamic contrasts, phrasing and shapes of melody, homophonic versus polyphonic and monophonic writing, motivic rhythms, etc. Within the middle dimension - which LaRue notes is sometimes harder to define, given the overlapping boundaries between the middle dimension and the large and small dimensions that frame it - musical analysts should concern themselves with the

\footnotetext{
84 LaRue, Guidelines for Style Analysis, 3.

85 Ibid., 6.

86 Ibid., 6-7.
} 
individual characteristics of parts of the piece and how they manage their own hierarchies, rather than their contribution to the work as a whole. As such, an analysis of the middle dimension can include an examination of the deployment of different orchestral forces for certain sections, harmonic modulations and cadences, thematic development of melodic and rhythmic structures, etc. ${ }^{87}$

The above approaches to style analysis have focused on sound, harmony, melody, and rhythm - aspects of a musical work that the listener can easily hear - but not necessarily on form. On this LaRue writes that the 'growth' or movement and shape of the work (i.e. its form) is a "complex extension of rhythm that results from changes of all sorts... [that] depends upon the frequency of change" between stability and relative activity, the structuring of harmonic change, changes in rhythmic stress, and changes in directional motion. ${ }^{88}$ LaRue also notes that in some cases there is a sixth element that may need to be taken into account, and this is particularly pertinent to many of Pärt's compositions, namely textual influence - the relationship between text and music - given that Pärt frequently relies on structural aspects of a written text in determining the operations of an M-voice for a number of his works.

Table 2.1 overleaf presents the elements LaRue believes should be considered when analysing the six basic components (sound, harmony, melody, rhythm, growth, and textual influence) and when undertaking a style analysis of a musical work across its different dimensions (large, middle, small). In Chapters 3 through 6 of the thesis, it will be seen that four or five of the six basic components in LaRue's analytical framework are applicable when undertaking a style analysis of Pärt's string orchestral works. However, when those components are analysed using LaRue's multidimensional approach (i.e. large, middle,

\footnotetext{
87 Ibid., 7-9.
}

88 Ibid., 13. 
small), some dimensions are not stylistically relevant for particular basic components - for

example, harmonic function in the large dimension, given that many of the sonorities in

Pärt's works result from the interaction of multiple processes and are not the result of an over-arching structural harmonic scheme (e.g. I - V - I). While this might suggest that LaRue's approach to style analysis may not be an appropriate method for gaining insights into Pärt's music, LaRue notes that the inability to identify considerations for a particular component within one or two dimensions is common. The absence of a dimension or basic component merely indicates that it is not stylistically relevant to that particular work, or at times a particular composer's oeuvre. ${ }^{89}$

Table 2.1: LaRue's basic components for style analysis ${ }^{90}$ (continues overleaf)

\begin{tabular}{|c|c|}
\hline Component & Considerations \\
\hline Sound & $\begin{array}{l}\text { - } \quad \text { Timbre: selection, combination degree of contrast of instruments and voices. } \\
\text { - } \quad \text { Texture and fabric: doubling, overlap, contrast of components; homophonic, cantus firmus, } \\
\text { contrapuntal, polarised (polychoric; melody / figured base or } 2+1 \text {, etc.; } \\
\text { melody/accompaniment; solo/ripieno). } \\
\text { - Dynamics: terraced, graduated, implied by instrumentation or range; types and frequencies. }\end{array}$ \\
\hline Harmony & 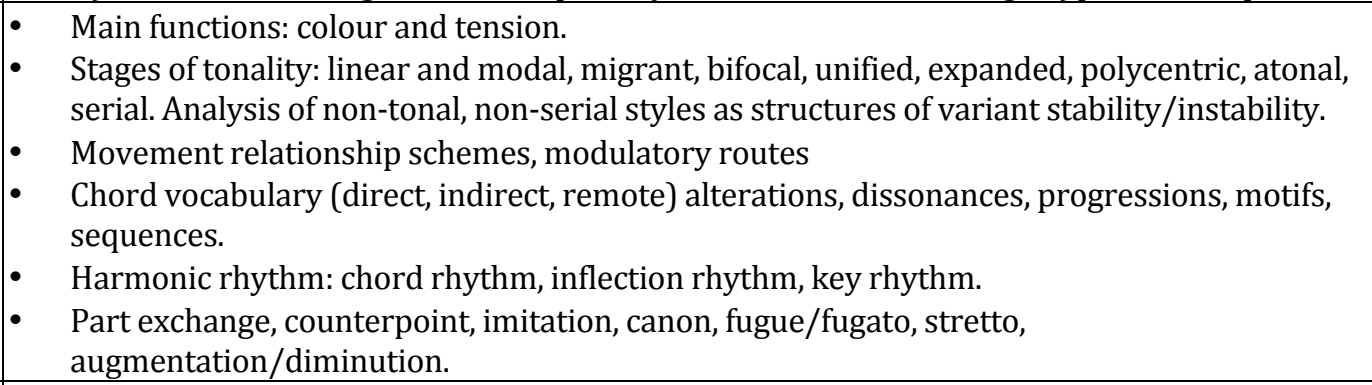 \\
\hline Melody & $\begin{array}{l}\text { - } \quad \text { Range: mode, tessitura, vocal/instrumental } \\
\text { - } \text { Motion: stepwise, skipping, leaping, chromatic; active/stable, articulated/continuous } \\
\text { - } \quad \text { Patterns: rising, falling, level, wave, undulating, saw tooth. } \\
\text { - } \quad \text { New or derived: function as primary (thematic) or secondary (cantus firmus, ostinato). } \\
\text { Middle and large dimensions: peaks and lows. }\end{array}$ \\
\hline Rhythm & 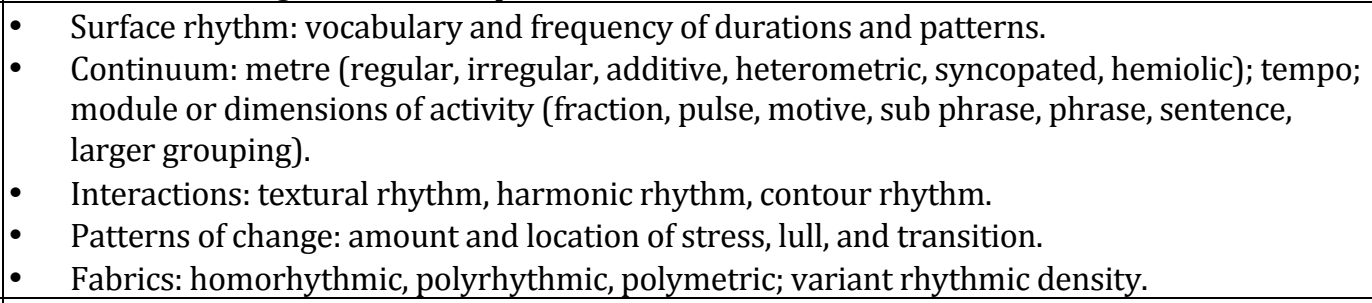 \\
\hline Growth & $\begin{array}{l}\text { Large dimension considerations: balance and relationship between movements in } \\
\text { dimensions, tempos, tonalities, textures, meters, dynamics. }\end{array}$ \\
\hline
\end{tabular}

89 Ibid., 233.

90 Ibid., 230-31. 


\begin{tabular}{|c|c|}
\hline Component & Considerations \\
\hline & 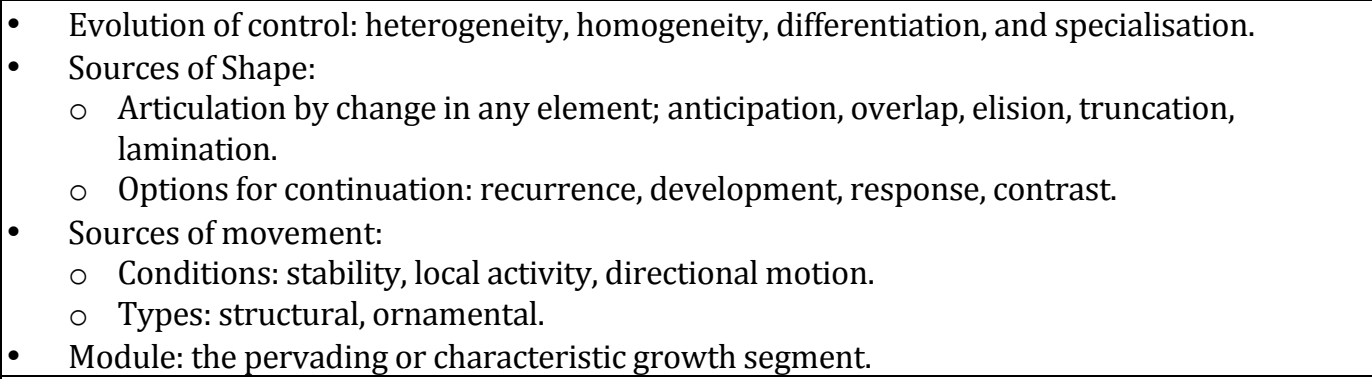 \\
\hline $\begin{array}{l}\text { Text } \\
\text { Influence }\end{array}$ & $\begin{array}{l}\text { - Choice of timbre; exploitation of word-sound for mood and texture; word evocation of chord } \\
\text { and key change; clarification of contrapuntal lines by forceful keywords; influences of word } \\
\text { and sentence intonation on musical line; limitation by awkward vocables; influence of word } \\
\text { rhythms on surface rhythms and poetic meter on musical meter; degree of adherence to text } \\
\text { form (line, stanza, refrain, da capo, etc.) in articulations and options for continuation; } \\
\text { concinnity or conflict in mood changes, fluctuations of intensity, location of climax, degree of } \\
\text { movement. }\end{array}$ \\
\hline
\end{tabular}

As demonstrated in the following chapters, style analysis can, to a limited degree, also provide some insight into the growth (or form) of Pärt's work and the nature of the latent harmonic potential of the musical materials used in each work. As such style analysis also provides a consistent rubric against which to compare the different works. However, because of the post-tonal nature of Pärt's tintinnabuli system, LaRue's approach to style analysis is lacking somewhat in its ability to describe in detail the harmonies and chord progressions that result when more than one M-voice/T-voice operation is operating at the same time in a particular work. To address this shortcoming, I will also incorporate two post-tonal analytical methods: 1) pitch-class set and interval-class theory, and 2) graphical structural analyses, or what I term 'sonority mappings' ${ }^{91}$

\section{Pitch-class set and interval-class theory}

Pitch-class set theory and interval-class theory, as applied in this thesis, rely on certain key assumptions about musical content in Western music: 9293

\footnotetext{
${ }^{91}$ For the purposes of the proceeding analyses, the term 'sonority' implies the sounding of one or multiple pitches at any given moment in the music.

92 Pitch-class set theory and interval-class theory are based on basic concepts in the writing and teaching of Milton Babbitt, which were subsequently elaborated on by Allen Forte. Joseph Nathan Straus,
} 
- Octave equivalence, i.e. the assumption that two or more pitches separated by one or more octaves are 'equivalent' in manner.

- This allows for the grouping of pitches with different frequencies with the same name, e.g. C2, C5, C6, etc. to belong to a 'pitch class' e.g. "C".

- Because the traditional musical system of Western music is 'tempered', meaning that pitches such as $\mathrm{A \#}$ and $\mathrm{Bb}$ are enharmonic, this results in there being 12 pitch classes - or 'Mod 12'.

- This allows for the assigning of integer notation to each pitch class, assuming one uses a 'fixed do' approach and arbitrarily assigns the pitch class " $\mathrm{C}$ " to " 0 " (as shown in Table 2.2).

Table 2.2: Integer names associated with pitch-class content ${ }^{94}$

\begin{tabular}{|c|c|}
\hline Integer name & pitch-class content \\
\hline 0 & $\mathrm{~B} \#, \mathrm{C}, \mathrm{Dbb}$ \\
\hline 1 & $\mathrm{C \#}, \mathrm{Db}$ \\
\hline 2 & $\mathrm{Cx}, \mathrm{D}, \mathrm{Ebb}$ \\
\hline 3 & $\mathrm{D} \#, \mathrm{~Eb}$ \\
\hline 4 & $\mathrm{Dx}, \mathrm{E}, \mathrm{Fb}$ \\
\hline 5 & $\mathrm{E} \#, \mathrm{~F}, \mathrm{Gbb}$ \\
\hline 6 & $\mathrm{~F} \#, \mathrm{~Gb}$ \\
\hline 7 & $\mathrm{Fx}, \mathrm{G}, \mathrm{Abb}$ \\
\hline 8 & $\mathrm{G} \#, \mathrm{Ab}$ \\
\hline 9 & $\mathrm{Gx}, \mathrm{A}, \mathrm{Bb}$ \\
\hline 10 & $\mathrm{~A} \#, \mathrm{Bb}$ \\
\hline 11 & $\mathrm{Ax}, \mathrm{B}, \mathrm{Cb}$ \\
\hline
\end{tabular}

- When more than one pitch occurs in a sequence of notes, chord or other grouping of notes, it is called a 'pitch-class set'.

Introduction to Post-Tonal Theory, Third Edition (Pearson Prentice Hall, 2005), 61. See also Allen Forte, The Structure of Atonal Music (New Haven: Yale University Press, 1973).

93 Definitions of the following terms are paraphrased from: Straus, Introduction to Post-Tonal Theory, 115.

94 Ibid., 5. 
- The relationships between the different pitches in a pitch class set can be examined by identifying the intervallic content - the spaces between any two given pitches or pitch classes - they create.

- Similar intervals are defined by the number of semitones between the first pitch and the second pitch.

- Regardless of the pitches, intervals with the same number of semitones can also be grouped into 'interval classes", which in turn can also be assigned integer names (Table 2.3).

Table 2.3: Integer names associated with traditional names and numbers of semitones 95

\begin{tabular}{|c|c|c|c|}
\hline traditional name & $\begin{array}{l}\text { number of } \\
\text { semi-tones }\end{array}$ & traditional name & $\begin{array}{l}\text { number of } \\
\text { semi-tones }\end{array}$ \\
\hline unison & 0 & major $6^{\text {th }}$, diminished $7^{\text {th }}$ & 9 \\
\hline $\operatorname{minor} 2^{\text {nd }}$ & 1 & augmented $6^{\text {th }}$, minor $7^{\text {th }}$ & 10 \\
\hline minor $2^{\text {nd }}$, diminished $3^{\text {rd }}$ & 2 & major $7^{\text {th }}$ & 11 \\
\hline minor $3^{\text {rd }}$, augmented $2^{\text {nd }}$ & 3 & Octave & 12 \\
\hline major $3^{\text {rd }}$, diminished $4^{\text {th }}$ & 4 & minor $9^{\text {th }}$ & 13 \\
\hline augmented $3^{\text {rd }}$, perfect $4^{\text {th }}$ & 5 & major 9th & 14 \\
\hline augmented $4^{\text {th }}$, diminished $5^{\text {th }}$ & 6 & $\operatorname{minor} 10^{\text {th }}$ & 15 \\
\hline perfect $5^{\text {th }}$, diminished $6^{\text {th }}$ & 7 & major $10^{\text {th }}$ & 16 \\
\hline augmented $5^{\text {th }}$, minor $6^{\text {th }}$ & 8 & & \\
\hline
\end{tabular}

- Like pitches, intervals - the spaces between any two given pitches or pitch classes - are also enharmonic, e.g. a major $6^{\text {th }}$ and minor third are inversions of the same two pitches or pitch classes " $\mathrm{C}$ " and "A".

- Intervals can be studied based on their ordered pitch-class content or unordered pitch-class content.

- With unordered pitch-class intervals, direction (i.e. counting upwards or counting downward) no longer applies 96 Therefore, for the purposes of interval 
identification, one would generally identify the interval by opting for the one that contains the smallest number of semi-tones, e.g. in the case of our previous example of a major $6^{\text {th }}$ and minor third, the shortest distance between " $C$ " and " $\mathrm{A}$ " is a minor third, which contains three semitones, while a major $6^{\text {th }}$ comprises nine semitones.

- This allows for the grouping of intervals into seven interval classes (Table 2.4) ${ }^{97}$

Table 2.4: Interval classes associated with pitch interval content 98

\begin{tabular}{|c|c|}
\hline interval class & pitch intervals \\
\hline 0 & $0,12,24$ \\
\hline 1 & $1,11,13$ \\
\hline 2 & $2,10,14$ \\
\hline 3 & $3,9,15$ \\
\hline 4 & $4,8,16$ \\
\hline 5 & $5,7,17$ \\
\hline 6 & 6,18 \\
\hline
\end{tabular}

- Finally, interval classes allow the musical analyst to classify the intervallic content of sonorities (chords, melodic passages and harmonies, etc.) into interval class vectors - strings of six numbers that provide insight into the numbers of different types of interval classes that occur in particular sonorities. ${ }^{99}$

The first number in an interval class vector provides the number of occurrences of interval class 1 (i.e. the number of minor seconds); the second gives the number of occurrences of interval class 2 (the number of major seconds), etc. For example, a C

\footnotetext{
${ }^{96}$ It is acknowledged that the use of unordered pitch-class intervals, in relation to Pärt's music, does have certain limitations, as it removes details as to the composer's vertical ordering of pitch materials. However, this loss of detail is dealt with, in part, by including relevant score excerpts as part of the style analyses, as well as some of the graphical illustrations of the musical operations.

${ }^{97}$ As noted by Joseph Strauss, in his Introduction to Post-Tonal Theory, under common mod 12 practice, pitch-class intervals larger than 6, the equivalent of a tritone, are considered equivalent to their complements $\bmod 12$, e.g. $0=12,1=11,2=10,3=9,4=8,5=7$, and $6=6$. Straus, Introduction to Post-Tonal Theory, 10-11.

98 Ibid., 11.

${ }^{99}$ Because of octave equivalence, generally interval class " 0 " is not included in interval class vectors.
} 
major 7 chord is comprised of four pitch classes 0 (C), 4 (E), 7 (G), 11 (B). A chord with four distinct pitch classes contains six intervallic relationships as represented by the interval class vector $<101220>$ comprising: one minor second (the unordered interval between pitch classes 0 and 11); one minor third (the interval between pitch classes 4 and 7); two major thirds (the intervals between pitch classes 0 and 4, and pitch classes 7 and 11); and two perfect fourths (the intervals between pitch classes 0 and 7 and pitch classes 4 and 11).

In addition to being identified through the use of interval class vectors, sonorities and pitch-class sets can also be represented by a number of different labelling systems, depending upon how the analyst wishes to examine a particular sonority. As noted by Straus, in post-tonal theory, there are two standard methods of naming the specific pitch-class sets that can be derived from a particular set of intervals. 100

The first method is to examine all similar members of a set class and select the one that is the 'most normal' of the set - normal being defined as the collection of pitches that begins with pitch class 0 , or $\mathrm{C}$, and is most packed to the left, i.e. has the smallest number of steps between the different pitch classes in that set. In the case of Interval Class Vector $<001110>$, the vector that contains an interval of a minor third, a major third, and a perfect $5^{\text {th }}$ (enharmonically interchangeable with the perfect fourth) represents all minor triad chords, e.g. A minor, D minor, C minor etc. (as well as all major triad chords, which also contain the same frequency of intervallic content.). The most normal of the set is the $C$ minor triad, which comprises C (pitch class 0), E flat (pitch class 3), and G (pitch class 7).

100 See Straus, Introduction to Post-Tonal Theory, 57-59. 
Allan Forte developed the second common method for classifying and naming pitch class sets that can be derived from a particular interval-class vector. ${ }^{101}$ In Forte's system, each pitch class set is composed of three or more pitches and identified by a pair of numbers separated by a dash (e.g. 3-11).102 The first number tells the reader the number of pitch classes in that particular set, while the second number denotes the position of the set on Forte's list for all sets of intervals having the same number of pitches.

\section{Sonority mappings}

As noted previously, in the following chapters I use an adaptation of LaRue's analytical framework to describe the general nature of the sound of the selected string orchestral works by Pärt (e.g. timbre, range, texture, and dynamics); aspects of the melodies and how Pärt has constructed them, including the influence of text; and rhythmical aspects of each work. However, to provide visual representations and insight into the sonorities that arise in Pärt's music as a result of the manner in which he deploys different musical processes in combination with his tintinnabuli system, I have devised my own method of graphical structural analysis to identify and collate the harmonic content of each work, the specifics of which are described in the following pages.

In addition to providing details of the interval-class vectors that arise as a result of Pärt's tintinnabuli operations (which are one of my primary tools in Chapters 3-6 for analysing, identifying and classifying the sonorities that arise as a result of Pärt's tintinnabuli system), I also provide the relevant Forte Codes and the prime form associated with each of those codes. This is done primarily through the use of tables.

\footnotetext{
101 Ibid., 57.

102 Meaning that pitch-class sets and intervals comprised of only one or two pitches do not map back to a Forte Code, whereas one can still construct an interval class vector to represent the pitch classes in question.
} 
To assist in the process of identifying and analysing the interval-class vectors, I annotated the various parts in each score studied, and converted the pitch class of each note into its respective integer value (0 through 11 ). I then developed a spread-sheeting programme that allowed me to input and collate the numeric pitch-class content into a single worksheet, identify the frequency of each pitch class during any given moment of the music, and reduce those pitch classes into single interval-class vectors. I wrote a series of formulas within the worksheets, which identify the prime form and Forte Code associated with each vector. An illustration of the tool can be found below in Figure 2.1.

Figure 2.1: Illustration from Excel-based interval-class identification tool - Cantus bar 12

\begin{tabular}{|c|c|c|c|c|c|c|}
\hline Bar and beat & 12.1 & 12.2 & 12.3 & 12.4 & 12.5 & 12.6 \\
\hline \multicolumn{7}{|l|}{ Bell } \\
\hline Violin 1 (M1) & 4 & 4 & 2 & 0 & 0 & 9 \\
\hline Violin 2 (T2) & 0 & 0 & 0 & 9 & 9 & 4 \\
\hline Violin 3 (M2) & 5 & 5 & 5 & 5 & 4 & 4 \\
\hline Violin 4 (T2) & 4 & 4 & 4 & 4 & 0 & 0 \\
\hline Viola (M3) & 7 & 7 & 9 & 9 & 9 & 9 \\
\hline Cello 1 (M4) & 9 & 9 & 9 & 9 & 9 & 9 \\
\hline Cello 2 (T4) & 4 & 4 & 4 & 4 & 4 & 4 \\
\hline \multicolumn{7}{|l|}{ Contrabasso 1 (M5) } \\
\hline \multicolumn{7}{|l|}{ Contrabasso 2 (T5) } \\
\hline \multicolumn{7}{|l|}{ Pitch Class Frequency } \\
\hline (B) 11 & 0 & $0^{*}$ & $0^{2}$ & 0 & $0^{*}$ & 0 \\
\hline$(\mathrm{A \# /Bb}) 10$ & $0^{\prime}$ & $0^{2}$ & $0^{F}$ & 0 & $0^{F}$ & 0 \\
\hline (A) 9 & 1 & $1^{*}$ & $2^{r}$ & 3 & $3^{*}$ & 3 \\
\hline$(\mathrm{G \# /Ab)} 8$ & $F$ & $0^{7}$ & $0^{2}$ & 0 & $0^{F}$ & 0 \\
\hline (G) 7 & 1 & $1^{r}$ & $0^{2}$ & 0 & $0^{*}$ & 0 \\
\hline (F\#/Gb) 6 & 0 & $0^{*}$ & $0^{2}$ & 0 & $0^{*}$ & 0 \\
\hline (F) 5 & 1 & $1^{r}$ & $1^{F}$ & 1 & $0 \%$ & 0 \\
\hline (E) 4 & 3 & $3^{r}$ & $2^{r}$ & 2 & $2^{F}$ & 3 \\
\hline (D\#/Eb) 3 & 0 & $0 \%$ & $0 \%$ & 0 & $0 \%$ & 0 \\
\hline (D) 2 & 0 & $0^{2}$ & $1 \%$ & 0 & $0^{*}$ & 0 \\
\hline (C\#/Db)1 & 0 & $0^{2}$ & $0^{2}$ & 0 & $0^{*}$ & 0 \\
\hline (C) 0 & $F$ & $1^{r}$ & $1^{r}$ & 1 & $2^{F}$ & 1 \\
\hline Interval Class Vector & $<122230>$ & $<122230>$ & $<122230>$ & $<101220>$ & $<001110>r_{<}$ & $<001110>$ \\
\hline Forte Code & 5-27: & F 5-27: F & 5-27: & 4-20: & F 3-11: F & $3-11:$ \\
\hline Prime Form & $(0,1,3,5,8)$ & $(0,1,3,5,8)$ & $(0,1,3,5,8)$ & $(0,1,5,8)$ & $(0,3,7) \quad F$ & $(0,3,7)$ \\
\hline
\end{tabular}

Where relevant, I have provided more traditional chord identifiers (e.g. D minor 7) in my taxonomies of intervallic and harmonic content. This was done because, while most readers are familiar with the more traditional chord names used in Western harmony, 
many are not as familiar with the use of Forte Codes and prime form identifiers. Also, a particular Forte Code and prime identifier can represent a number of chord equivalents. For example and as noted previously, the interval-class vector $<001110>$, Forte Code: 311 prime form $(0,3,7)$, represents all major and minor triads as they pertain to any chord containing a single interval of a minor third, a single interval of a major third, and one interval of a perfect fourth/fifth. Providing only the interval-class vectors, Forte Codes, and prime forms fails to communicate much of the richness of detail that can be found when analysing Pärt's music, particularly given that, at times, more traditional chord names can provide a reader with a better understanding of the nature of a particular work and what it sounds like based upon a written description.

The arrangements of a specific set of pitches in any particular vertical construction can be labelled as a number of different chords, depending upon their harmonic function in relation to the cadences of the musical work in question, or when looking at their unordered pitch-class content. However, Pärt's tintinnabuli system, being modal in nature, does not follow any particular harmonically functional hierarchy; the order in which different chords occur is purely predetermined by the specific rules and operations of each different work. Thus in determining the chord labels as listed throughout this thesis, where more than one identifier could be used to classify a chord, (e.g. whether to classify an Fsus4 chord as a $\mathrm{Bb}^{\text {sus2 }}$, or $\mathrm{C}^{7 \text { sus4 no5 }}$ chord), I have used those identifiers that represent the most simple chord possible within the context of the modality of the piece and the triad of the T-voice.

In some cases, where more than one chord identifier is equally valid based on those parameters, I have identified the most likely chord based upon the prominence of specific pitches occurring at the time (i.e. pitches occurring with the greatest frequency 
in the chord). In instances where this has not been possible, I have attempted always to make a choice between two options in a consistent manner. ${ }^{103}$

In addition to annotated score excerpts, descriptions of the processes Pärt employs in each piece, and tables of intervallic and pitch-class content, I provide visual models of the intervallic relationships between the pitch classes of specific works. These are intended to provide insights into the underlying harmonic structure of each work, the controlled pre-compositional design(s) Pärt has applied in manipulating the tintinnabuli procedures he has used for that work, and the resulting sonorities, which are outcomes of both.

Given that much of Pärt's music is based on modal scales, in many of the works the pitch class content can be reduced to seven or eight distinct pitch classes that can be arranged visually to display the intervallic relationships between the different pitch classes in question. To illustrate this, Figure 2.2 provides a new visual model, which I have termed a Pärtian Tonnetz. I developed the model to illustrate the interrelationships between the three pitch classes that comprise an A minor T-voice and the remaining four pitch classes of the diatonic A Aeolian scale (denoted by both their pitch name as well as the standard numeric value typically used for each in post-tonal analysis). The figure also shows the interval classes that occur when different pitch classes are sounded simultaneously.

In this model, I have arranged the pitch classes that would comprise a hypothetical T-voice that uses the same pitch centre as that of the M-voice (in this case an A minor triad) vertically on the left hand side. On the right side of the tonnetz are the remaining non-T-

\footnotetext{
${ }^{103}$ For instance, with my example of the $\mathrm{Fsus}^{\text {s }}$ chord as a $\mathrm{Bb}^{\text {sus2 }}$, at times either one of them could be a valid choice, particularly as frequently no true 'suspension' has occurred as a result of carrying over a specific pitch from a previous chord in Pärt's tintinnabuli system. Similarly, at times the voice leadings to the next chord does not result in a resolution of the suspension to a triad. In such cases, I have made the decision to always choose the sus4 option over the sus2.
} 
voice pitch classes, also arranged vertically. From bottom to top, the pitches are arranged in the order they would occur on a musical staff, i.e. ascending major and minor thirds. Starting from the bottom left cell (A or pitch class 9) the red lines denote the relationships of the root pitch of the triad with the four non-T-voice pitches and the subsequent interval that would occur should both pitch classes be played simultaneously. Similarly, the green and blue lines denote the relationships between the third (C; pitch class 0 ) and fifth (E; pitch class 4) pitches of the triad, respectively, and the same four non-T-voice pitches. The black curved lines on the left of the diagram illustrate the intervallic relationships between the three voices of the T-voice, while the black curved lines on the right denote the intervallic relationships between the non-T-voice pitch classes.

The intervallic potentiality of the pitches that occur in an Aeolian scale (or any white key diatonic scale for that matter) includes two minor and five major seconds, four minor and three major thirds, and as many as six occurrences of perfect fourths and one tritone. ${ }^{104}$ These relationships are summarised in the top right of the corner of Figure 2.2 using the interval-class vector $<254361>$, where the first number in the vector (2) denotes the frequency of minor seconds that can occur, the second number the frequency of major seconds, etc. Below the interval-class vector, I have also included the equivalent Forte Code: 7-35 and prime form.

104 See previous footnote on the enharmonic nature of intervals, such as perfect fourths and fifths, minor thirds, and major sixths, etc. 


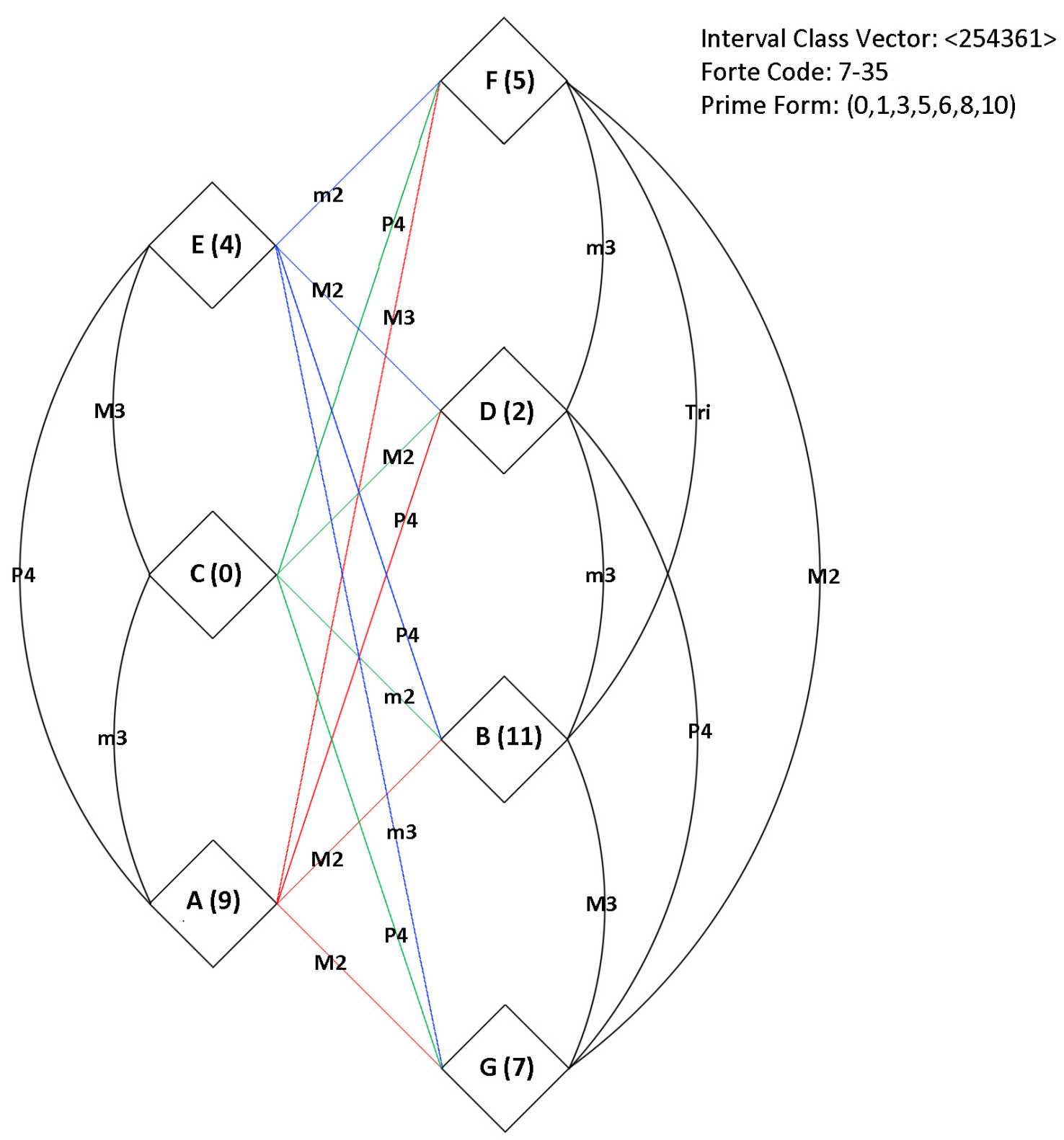

This new approach to visualising the relationships between the pitch classes of a particular work can also be used to graphically illustrate the motions from one pitch class to another when more than one stepwise based M-voice occurs in a particular work. ${ }^{105}$ Figure 2.3 illustrates a hypothetical scenario of four different M-voices, based on an A Aeolian scale, occurring concurrently or otherwise in the same tintinnabuli composition.

105 While most of Pärt's early tintinnabuli works use M-voices that are generated from a precompositionally decided process, this is not always the case for some of his later works. 
M-voice 1 and M-voice 2 operate by progressing outwards from the scale's pitch-class centre of "A", while M-voices 3 and 4 both proceed inwards towards the scale's pitch-class centre, but from different pitch-class centres (i.e. C and F, respectively).

Figure 2.3: Visual multiple stepwise operations in an A Aeolian based M-voice

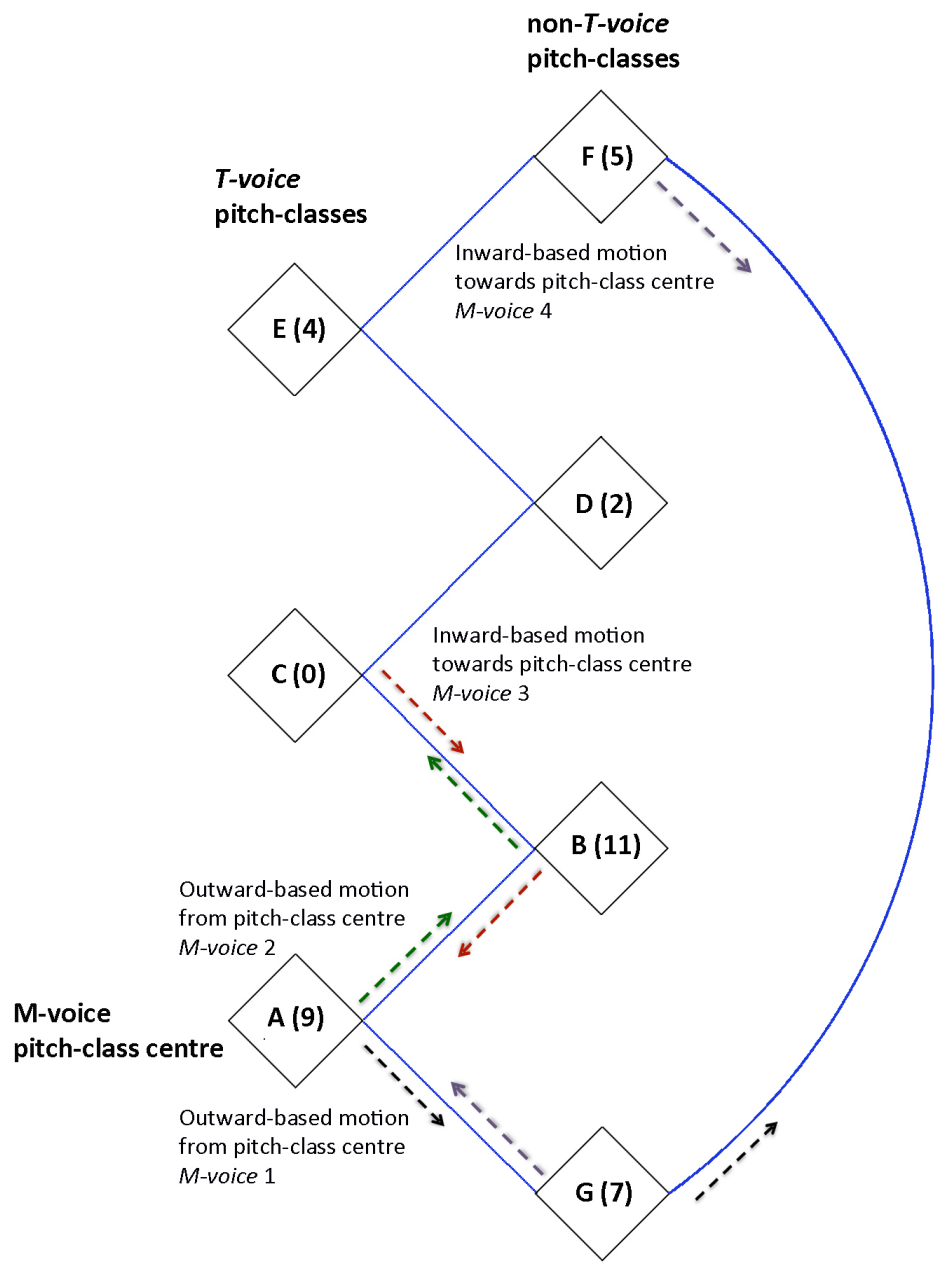

Finally the third approach I have used to provide insight into the sonorities that occur in the different works covered by this thesis is to provide sonority mappings of the various interval-class vectors that are present in each. These sonority mappings summarise my analysis of the intervallic and harmonic content of each work and are illustrated in both graphic form (Figure 2.4, which provides an illustration of the sonorities in Cantus in 
memoriam Benjamin Britten) and tabular form (Table 2.5, which summarises the content of bars 141-145 in Ludus). They also allow for the identification of the various sonorities that predominate the work as a whole or a particular section of the work. For example, Figure 2.4 illustrates the sum content of different interval classes at any one point of time in Cantus. At the beginning of the work, the only sounds presented to a listener are periods of silence broken by the tolling of a funereal bell on a single pitch (bars 1-6). Starting in bar 7 the divisi first violins sound pitches E and A (an interval of a perfect fourth); as the work proceeds, other interval classes are introduced. Where multiple interval classes occur (e.g. interval vector $<143250>$ ), those interval classes that occur more frequently occupy a greater proportion of the vertical dimension of the figure at a specific point.

Table 2.5 Matrix of vectors occurring on beats 1, 2, 3, and 4 of Ludus bars 141-145

\begin{tabular}{|l|l|l|l|c|}
\hline & & & & \\
Vectors & Forte Codes & Prime Forms & Chord equivalent & $\begin{array}{c}\text { Frequency } \\
\text { of } \\
\text { occurrence }\end{array}$ \\
\hline$<111000>$ & $3-2:$ & $(0,1,3)$ & Am add 9/no 5 & 1 \\
\hline$<001110>$ & $3-11:$ & $(0,3,7)$ & Am & 6 \\
\hline$<111120>$ & $4-14:$ & $(0,2,3,7)$ & Am add 9 & 2 \\
\hline$<101220>$ & $4-20:$ & $(0,1,5,8)$ & Fmaj7 & 1 \\
\hline$<021120>$ & $4-22:$ & $(0,2,4,7)$ & Amin add & 1 \\
\hline$<012120>$ & $4-26:$ & $(0,3,5,8)$ & Amin7 & 1 \\
\hline$<132130>$ & $5-23:$ & $(0,2,3,5,7)$ & Amin add2/4 & 1 \\
\hline$<122230>$ & $5-27:$ & $(0,1,3,5,8)$ & Fmaj9 & 3 \\
\hline$<323430>$ & $5-35:$ & $(0,24,7,9)$ & C6/9 & 1 \\
\hline$<143250>$ & $6-32:$ & $(0,2,4,5,7,9)$ & Dmin11 & 1 \\
\hline$<233241>$ & $6-Z 25:$ & $(0,1,3,5,6,8)$ & Dmin13 chord & 2 \\
\hline
\end{tabular}


Figure 2.4: Sonority map - Cantus in memoriam Benjamin Britten

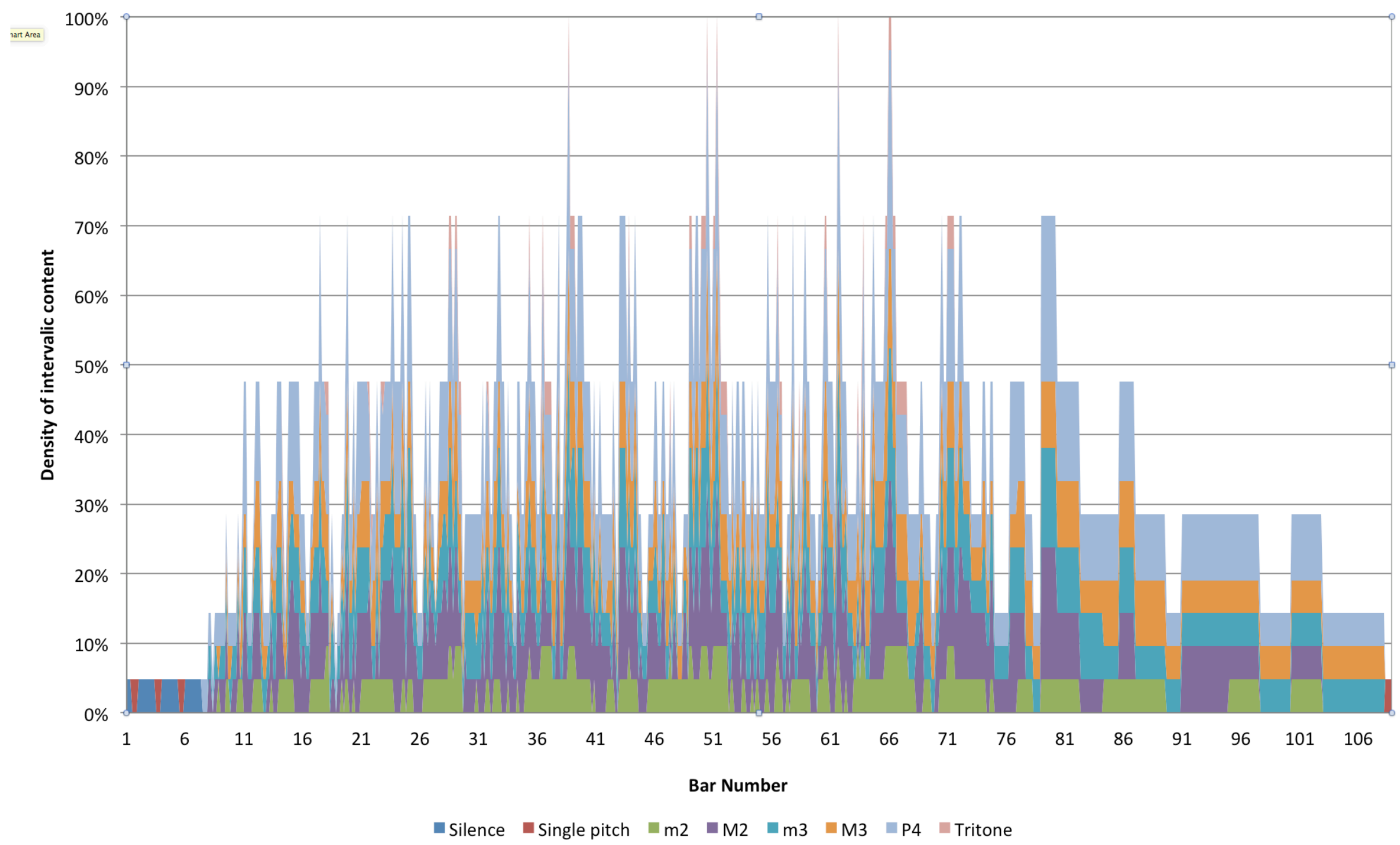




\section{Part 2: Basic operations of Pärt's tintinnabuli}

In addition to providing insights into the basic operations and procedures that are hallmarks of Pärt's tintinnabuli system (as documented by Hillier), Part 2 extends beyond Hillier and other theorists' analyses to explore the nature of sounds that these processes and procedures generate. In Part 2, I also identify a number of distinct aspects of Pärt's tintinnabuli system that have not previously been noted. In addition, Part 2 provides a taxonomy of the ordering of intervallic content and sonorities that results from different diatonic M-voice/T-voice pairings, when different modal scales and triads are combined together in the pan-diatonic sound world that Pärt frequently uses.

The following section uses examples from my analyses of two of Pärt's non-string orchestral works, the Gloria from the Berlin Mass (1990) and In spe (1976), which are outside of the stated scope of this thesis. I have selected these examples intentionally for two specific reasons. 1) Excerpts from the Gloria are used to introduce the reader to some relatively simple text-based rules that Pärt commonly uses, in preparation for the significantly more complex schemes of text-derived rules that he deploys in works such as Psalom, Silouan's Song and Orient \& Occident. These excerpts from the Gloria illustrate how Pärt uses structural aspects of written, and usually religious, texts to generate the melodic material for his M-voices, as well as to dictate other structural aspects of a work, such as barring, metre changes, and periods of silence. 2) The analysis of In spe, the first of the composer's tintinnabuli works that "unites tintinnabuli principles with a systematic melodic process"106, provides insight into how Pärt is able to take a simple musical procedure, such as an ascending and descending stepwise scale, and generate a wealth of varied melodic material through the application of common compositional

\footnotetext{
106 Hillier, Arvo Pärt, 98.
} 
procedures such as additive scalic expansion, parallel voicing, and retrograde and inversion operations.

\section{Tintinnabuli}

As noted in the introductory chapter, tintinnabuli is based upon the simple premise of a two-voiced contrapuntal pairing consisting of: 1) a diatonic melody, termed the Mvoice, which generally moves in melodic patterns towards and away from a single central pitch, and 2) the T-voice, which is restricted to using only the three pitches of a single triad. The T-voice moves in a predetermined pattern, as dictated by the scale position of the M-voice at any particular point in time. Once a pattern has been established for an M-voice/T-voice pairing, Pärt generally adheres to it throughout the duration of the piece, particularly in his early tintinnabuli works.

Hillier notes there are four basic positions that the T-voice can take in relation to an Mvoice. ${ }^{107}$ In all four examples in Figure 2.5 (overleaf), the M-voice is a simple diatonic A Aeolian scale (or A minor natural scale), with the T-voice comprising the pitches of an A minor triad, which is also the tonic triad of the scale. In the first example, which Hillier calls first position, superior, the T-voice always takes the position in the triad that is above and closest to the position of the M-voice. In second position the T-voice always takes the position in the triad of the 'next plus one'. The same rules apply for the inferior positions, except that the pitches of the T-voice occur below the M-voice. In combining scalic and triadic textures in the tonally non-functional manner that he does, Pärt creates bell-like sonorities in his music, hence the term tintinnabuli, which means many bells.

107 Hillier, Arvo Pärt, 94. 
Figure 2.5: Basic M-voice/T-voice positions*
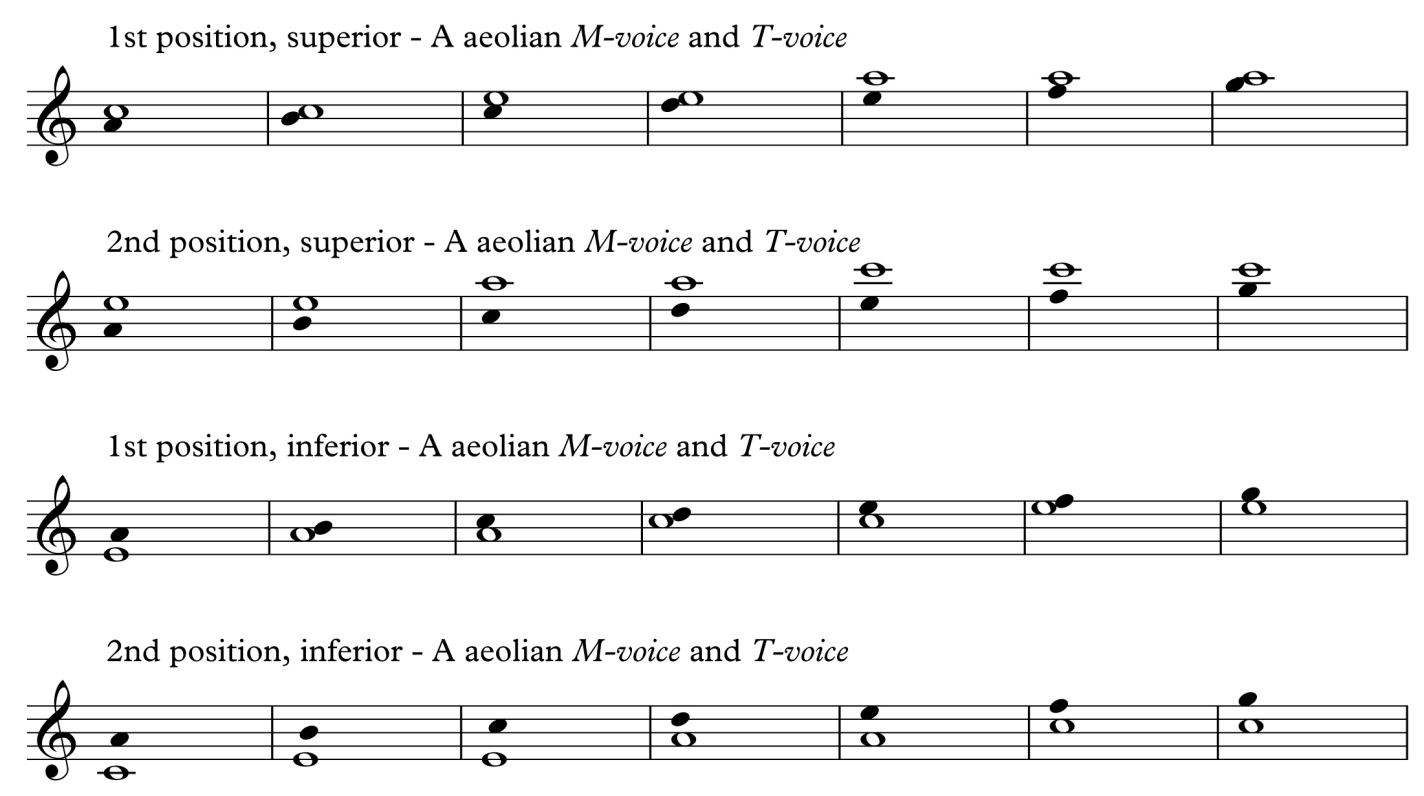

* White notes equal T-voice and black notes equal M-voice

\section{Gloria}

Often in actual operation the T-voice alternates above and below the M-voice, though usually in either first position only or second position only. Pärt rarely uses both first and second positions in a single M-voice/T-voice pairing; however, it is not uncommon for different T-voices in a single piece to operate under different positioning rules in relation to their M-voice. An example of this can be found in my analysis of an excerpt from the Gloria of Pärt's Berliner Mass (1990). As detailed in Figure 2.6 overleaf, the Gloria has five M-voices, four of which (the alto, baritone, first violin, and lower divisi cello line ${ }^{108}$ ) are paired with a T-voice. The fifth M-voice is played by violas, but is not paired with a T-voice. The T-voices in the soprano and tenor lines are in first position, superior (alternating) to their respective M-voices, while the T-voice line played by the second violins is first position, inferior (alternating).

108 Doubled an octave below by the contrabasses. 
As Hillier notes, any T-voice can also be translated upwards or downwards by one or more octaves. When a first position, inferior T-voice is transposed upwards by an octave so that it is in effect above its M-voice (as is the T-voice in the upper divisi cello line in Figure 2.6), or a first position, superior T-voice is transposed downwards by an octave so that it is below its M-voice, to the listener this results in the illusion of a third and more distant pairing position. However, from an analytical perspective this does not actually result in a true third T-voice position, due to octave equivalence. ${ }^{109}$ An example of this can be seen in the upper divisi line of the cellos (T-voice 4), which is paired with the doubled M-voice of the contrabasses and lower divisi cello lines (denoted by the green box). Commencing on the second pitch (G4) ${ }^{110}$ T-voice 4 is a first position, (inferior) alternating T-voice that has been transposed upwards by two octaves from G2 below the lower divisi cello's line.

109 Hillier, Arvo Pärt, 94.

110 The first pitch of E4 is a 'false' T-voice pitch, as the pitch class E is not part of the G minor triad (comprising G, Bb, and D) used by all four T-voices in Gloria. 
Figure 2.6: Berliner Mass: Gloria - bars 1-4
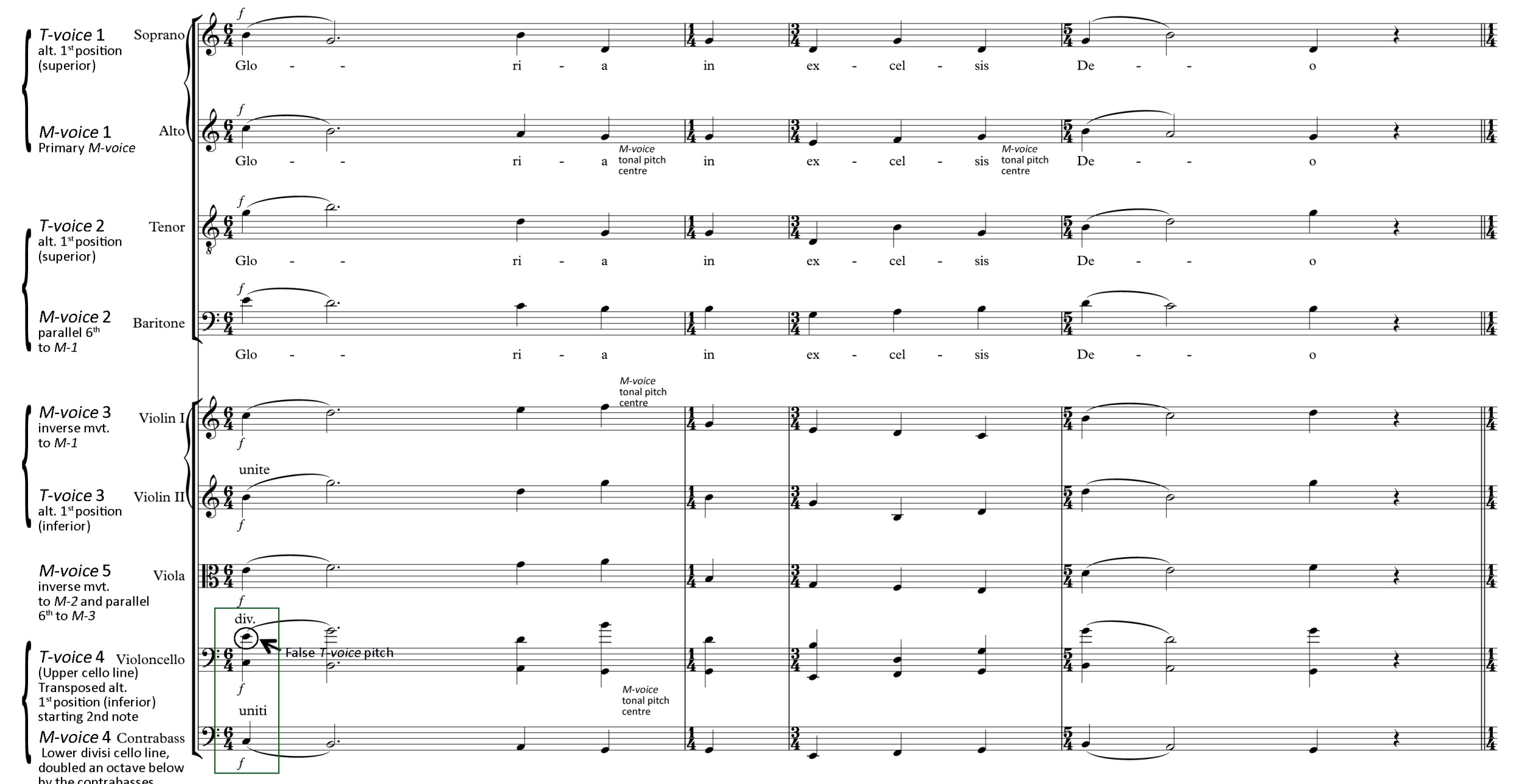

by the contrabasses 
Another key characteristic of Pärt's tintinnabuli system is the manner in which he constructs M-voices. As described above, a 'typical' M-voice proceeds towards or away from a central sounding pitch, which is frequently the 'tonic' of a diatonic major, minor or modal scale. In many of Pärt's early works, M-voice motion frequently proceeds in one of four stepwise manners that Hillier termed 'modes': upwards (first mode) or downwards (second mode) away from the pitch centre, or downwards (third mode) or upwards (fourth mode) towards the central pitch (Figure 2.7). ${ }^{111}$

Figure 2.7: M-voice modes ( $p$ itch centre $=$ A Aeolian)

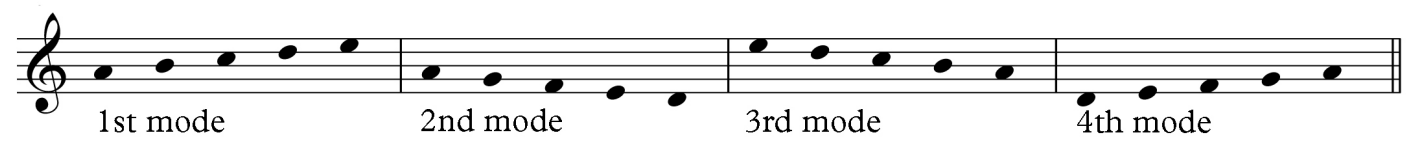

In some works Pärt alternates between two modes within a single M-voice. As illustrated in Figure 2.8, the first bar of the alto line of the Gloria from his Berliner Mass commences with a stepwise descent for the word Gloria from C to G, the M-voice's pitch centre, then ascends from $\mathrm{E}$ to $\mathrm{G}$ for the word excelsis (bar 3), and descends again from $\mathrm{D}$ to $\mathrm{G}$ for the word Deo (bar 4) etc.

Figure 2.8 illustrates another of Pärt's compositional practices, whereby structural aspects of the texts determine the development of melodic material for the M-voice. This generally involves creating predetermined melodic patterns as dictated by the number of syllables in each word of the text, as well as the syllable upon which the accent or stress falls in particular key words. Note that the length and occurrence and duration of rests are frequently determined by rules associated with specific punctuation marks.

111 Hillier, Arvo Pärt, 95. 
In the Gloria example below, Pärt has taken the basic principle of stepwise motion towards and away from the M-voice's tonal centre, and assigned each word to its own bar and each syllable of each word to a pitch in the stepwise progression towards or away from pitch class G. The resulting number of beats per word determines the metre for each bar, with the final word of each phrase having an extra beat that is always assigned a crochet (quarter note) rest (e.g. Deo in bar four). In addition, the first and last multisyllabic words in each phrase are augmented by assigning two pitches to the accented or stressed syllable in the word, with the second pitch being two beats in duration at the beginning of a phrase. ${ }^{112}$

Figure 2.8: Berliner Mass: Gloria - alto line (bars 1-18)

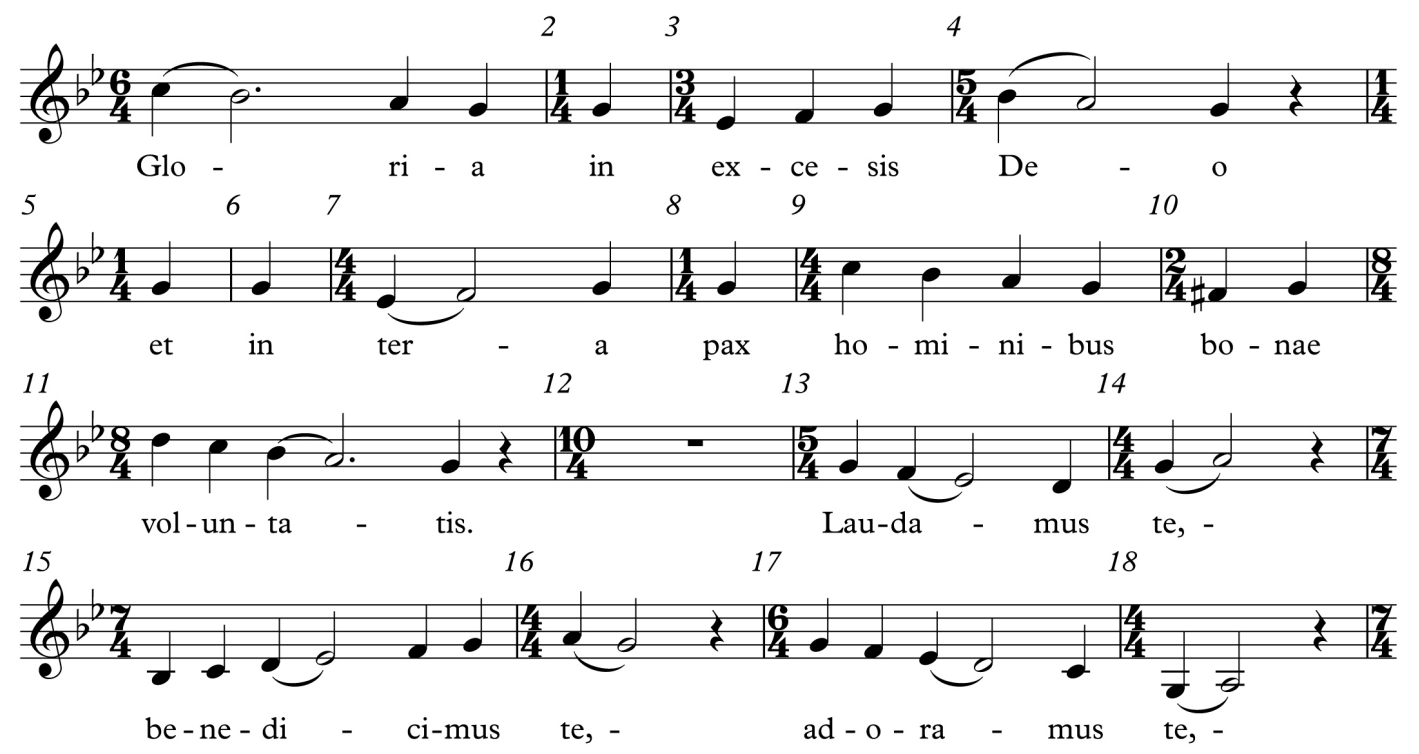

At the end of phrases throughout the Gloria, the second pitch of the stressed syllable will be either two or three beats in duration, depending upon whether the phrase ends in a full stop or another punctuation mark. For example, in bar 11 of Figure 2.8, "ta" is the stressed syllable in the multisyllabic word voluntatis. It is therefore assigned two pitches

${ }^{112}$ As the first word of the movement, Gloria is the one exception to this rule. For the word Gloria Pärt has assigned three beats to the second pitch, rather than two. 
(G4 and A4). As the phrase also ends with a full stop, the second pitch is allotted a duration of three beats. In contrast, the phrases in bars 14,16, and 18 are punctuated with commas. As such the second pitch assigned to the stressed syllable in each bar is allotted two beats. Similarly, bar 4 has no punctuation at all, but as Pärt treats it as the end of a phrase the second pitch in the word Deo is also allotted two beats.

Another aspect of how Pärt translates punctuation into a musical parameter can be observed in the Gloria. Textual phrases ending in a full stop are always followed by a full bar of rest, the length of which is determined by the number of beats in the preceding measure - ten beats when preceded by an eight beat bar, six beats when preceded by a six beat bar, and four beats when preceded by a ten beat bar.

In works such as the Gloria that have multiple M-voices, at times there can be a primary M-voice that dictates how the other M-voices operate. Figure 2.9 overleaf illustrates that the alto line's M-voice 1 is the primary M-voice of the Gloria, with the movement of Mvoices 2, 3, and 5 being determined by it. M-voice 1 descends from C5 to G4 (G being the M-voice pitch-class centre for the entire movement) in bar one, repeats G4 in bar two, and then ascends towards G4 from E4 in bar three. The second M-voice mirrors the ascending and descending patterns of M-voice 1 , but starting one parallel $6^{\text {th }}$ below. The first violins' M-voice 3 operates in inverse motion to M-voice 1, ascending from C5 to F5 in bar one, mirroring it at G4 in bar two and then descending from E4 to C4 in bar three. The viola line's M-voice 5 operates both in inverse to M-voice 2 in the baritone line, as well as in parallel motion to the first violins' M-voice 3 - starting on E4 one $6^{\text {th }}$ below the first violins at C5. The lower divisi cello line's M-voice 4, which is doubled an octave lower by the contrabasses, mirrors M-voice 1 exactly but sounds at registers of two and three octaves below it, respectively. 
Figure 2.9: Berliner Mass: Gloria - bars 1-4

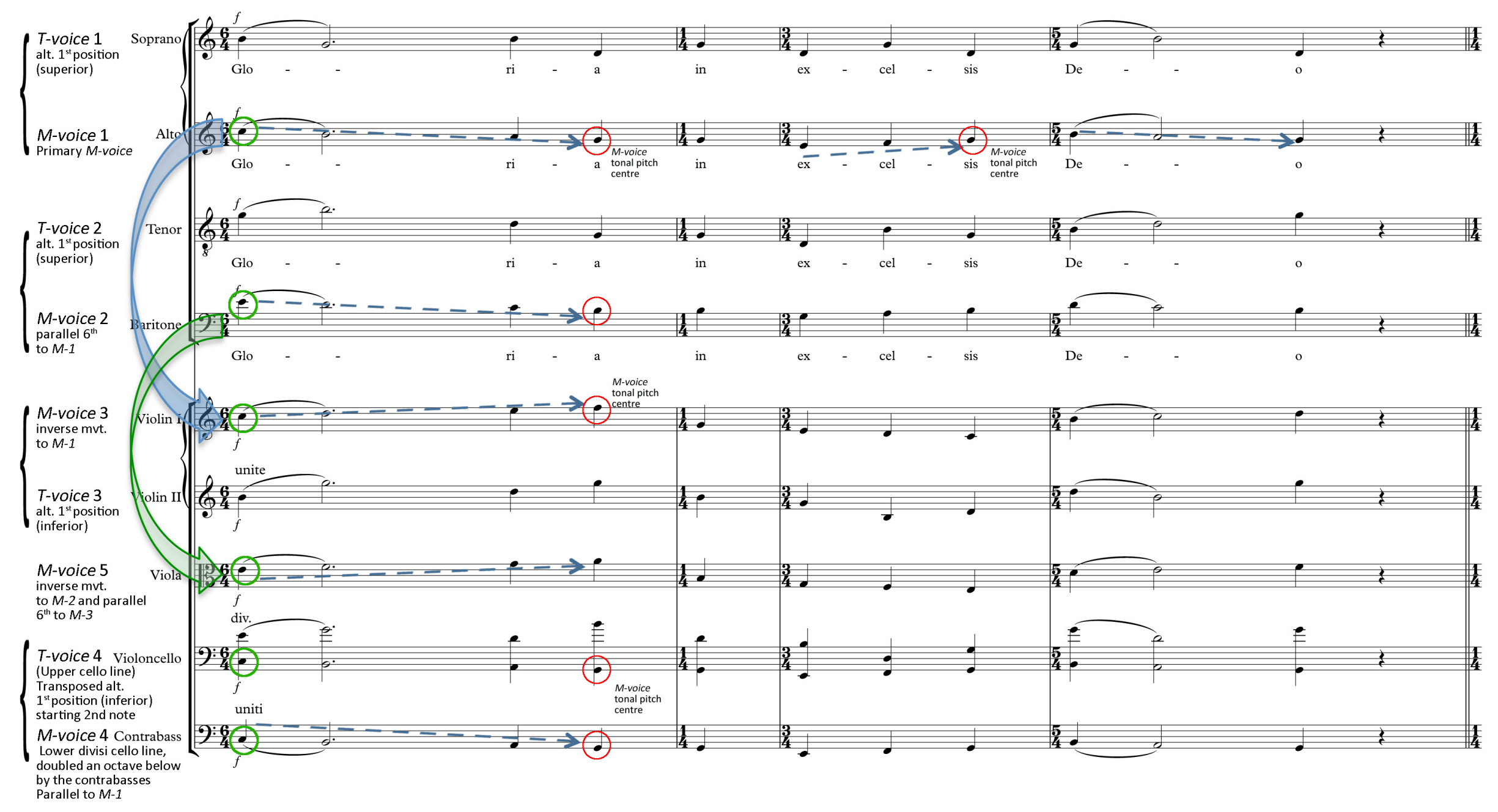




\section{In spe}

In other works the M-voice can include reiterated pitches, modified scale patterns with small leaps of a few intervals, or melodic turns. Often this latter effect is the result of Pärt working through a number of different melodic manipulations or procedures with the same basic melodic material. An early example of this can be found in his 1976 work In spe for wind quintet and quartet of strings (with a contrabass and no second violin), which Pärt later arranged for voices and organ, retitling it An den Wassern zu Babel sassen wir und weinten (Psalm 137: By the waters of Babylon we sat and wept). ${ }^{113}$ As noted by Hillier, the structure of the work is based upon the tripartite Kyrie-Christe-Kyrie structure of the Kyrie of the Mass, using only the vowels of the text to determine how the M-voices function. ${ }^{114}$

The M-voices in In spe are based on a stepwise 'white-key' scalic progression, spanning a fifth above and below a specific pitch class, subjected to a series of seven different M-voice operations and their inversions. These are illustrated in Figure 2.10 through Figure 2.14 overleaf (and summarised in Figure 2.15).

In my analysis below, I have described the different operations' functions in relation to the vocal lines of An den Wassern. This has been done because An den Wassern ultimately became the better-known arrangement of the work, and because there is a direct linkage between the text of the Kyrie to Pärt's construction of the melodic operations of the M-voices. However, to make clear the lineage of the work, I continue to refer to the original version as In spe in the footnotes and figure labels.

\footnotetext{
113 Hillier, Arvo Pärt, 98.
}

114 Ibid. 
Figure 2.10: M-voice operations used in In spe - Operations 1 and 2

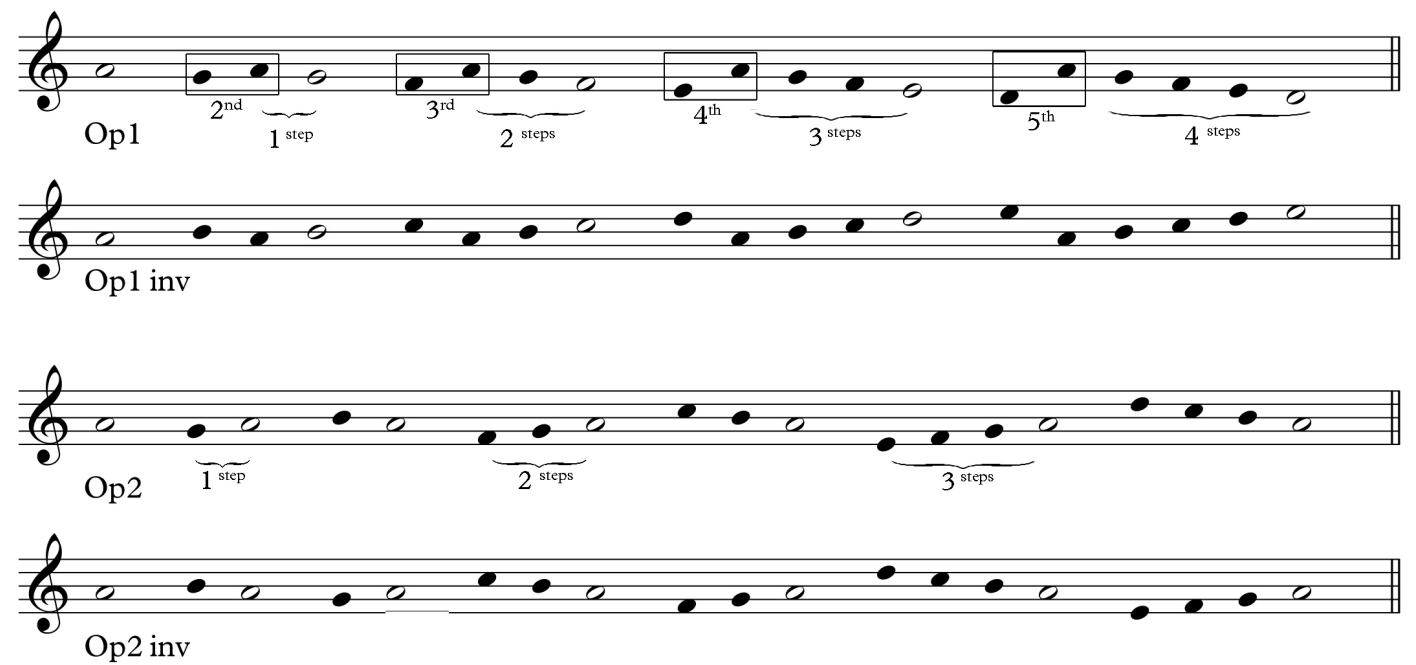

Pärt assigns Operation 2 to the word eleison. The operation is a common early tintinnabuli operation: alternating between modes 1 and 3, it is an expanding, additive stepwise progression towards the pitch centre of the M-voice. After an initial sounding of the central pitch, the pattern commences a single step away from it ( $G$ proceeding to $A$, mode 1 ; followed by B descending to $A$, mode 3 ). The second iteration starts two steps away from the pitch centre on $\mathrm{F}$ and $\mathrm{C}$ respectively, and the third iteration starts three steps away, first on E ascending towards $\mathrm{A}$ and then $\mathrm{D}$ descending towards $\mathrm{A}$. In its first presentation by the sopranos, the operation is not paired with the T-voice.

The operation is then inverted with the basses taking the M-voice and the tenors taking an alternating first position, superior/inferior T-voice. Both Operation 2 and its inversion are then repeated simultaneously in stanza 6 , with the basses singing the un-inverted version, the sopranos singing the inverted material, and the tenors and altos providing T-voices, again in alternating first position, inferior/superior positions (Figure 2.11). 
Figure 2.11: In spe - Operation 2 (SATB) stanza 6

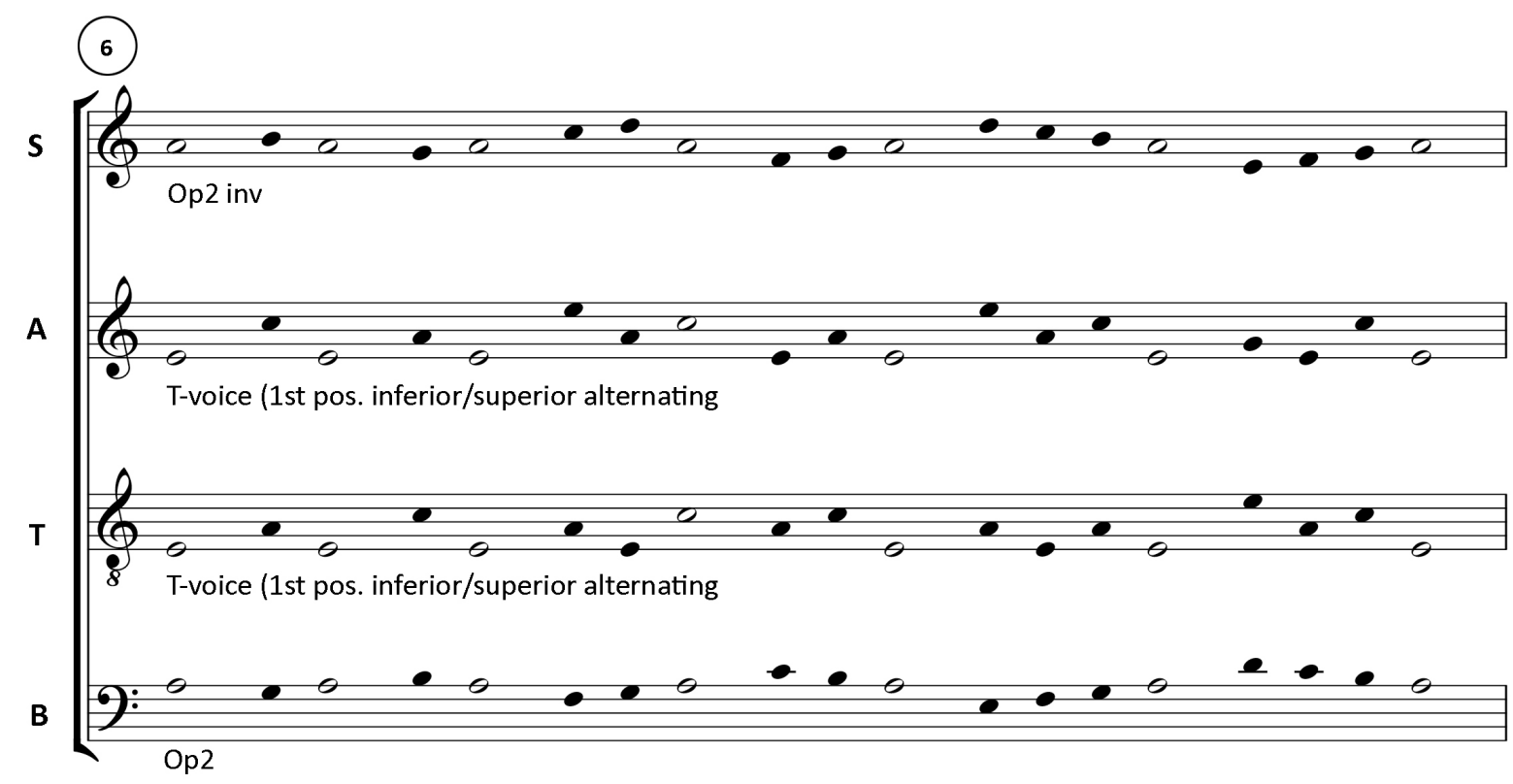

Operation 3, assigned to the vowels of Christe, is the only operation that does not have an inverted version (Figure 2.12). Sung first by the tenors and then the basses, without any T-voice pairings, the operation is another additive stepwise process, but this time the melodic movement is away from the M-voice's pitch centre, using mode 2 and then mode 1 in alternation. After the initial sounding of the central pitch, the scale expands outwards in stepwise manner, first by one step (A to $G$, followed by A to B), then two steps (A-G-F, followed by A-B-C), three steps, and four steps, until the span of a fifth in each direction has been attained. 
Figure 2.12: M-voice operations used in In spe - Operations 3, 4 and 5

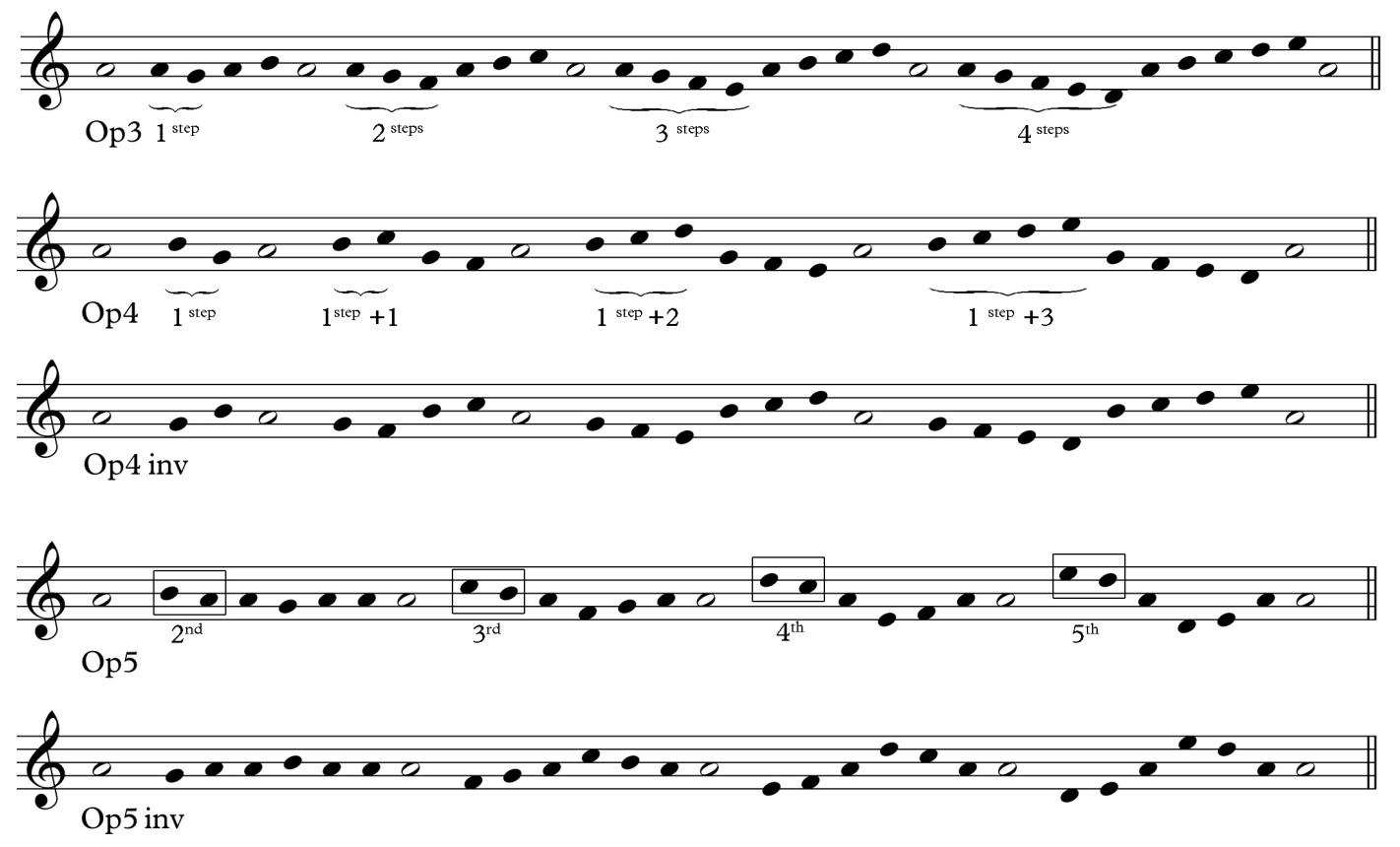

Operation 4 is an additive, stepwise progression proceeding in alternating paired four-note patterns using modes 1 and 2, respectively, first by one step (A to G followed by A to B), then two steps (A-G-F followed by A-B-C), then three and four steps away from the tonal centre until the M-voice has covered a span of a fifth in both directions. Like Operation 2, Operation 4 corresponds with the vowels of the word eleison, with the sopranos presenting the operation first, followed by the basses singing the inverted patterns of the operation and paired again with the tenors, who execute an alternating first position, superior/inferior T-voice. Both versions of the operation are then sung simultaneously with the sopranos singing the inverted material (in stanza 11), the basses singing the un-inverted version of the operation and the altos and tenors respectively singing the T-voices which alternate between first position, superior and first position, inferior (Figure 2.13). 
Figure 2.13: In spe - Operation 4 (SATB) stanza 11

\section{(11)}

$\mathbf{S}$

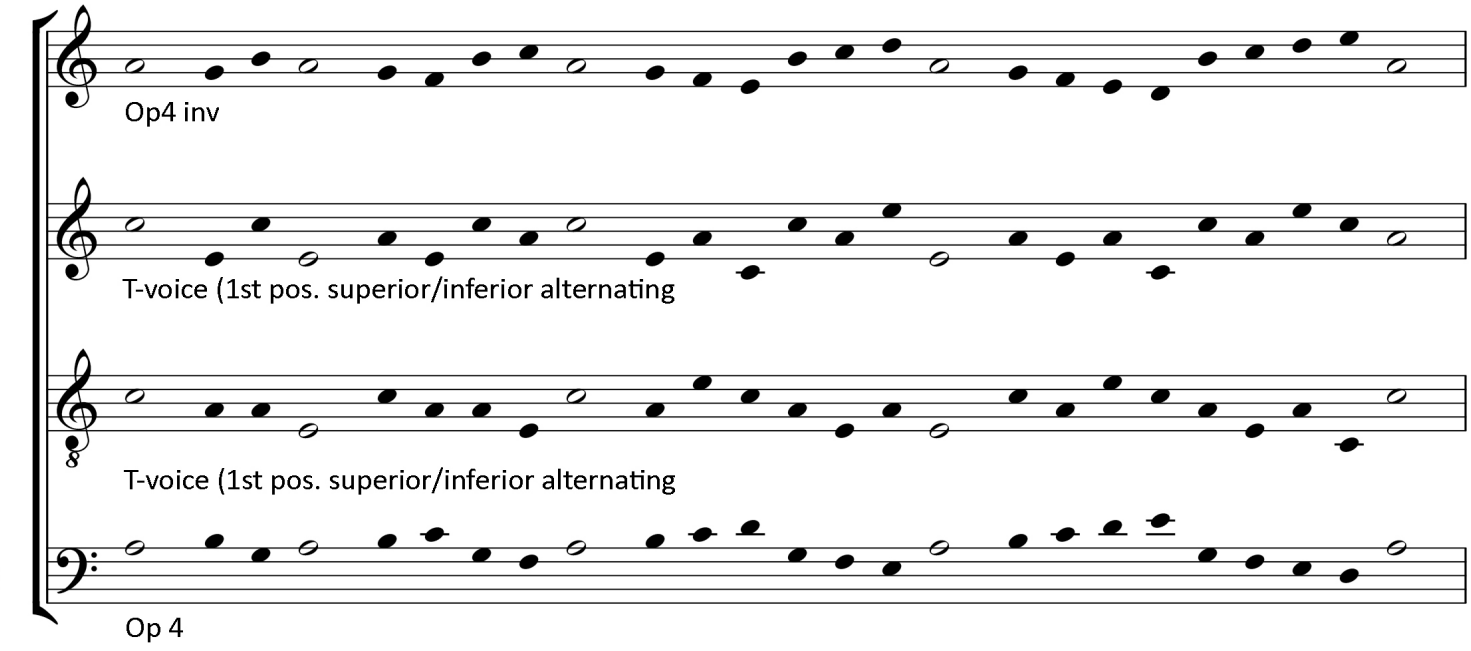

Operation 5 and its inversion, again assigned to the vowels of the word eleison, follow the same voicing and presentation patterns described for Operations 2 and 4. However, it is a further variant on the stepwise patterns discussed above. Initially the operation commences using Modes 4 and 3 respectively, but in retrograde and using an alternating, unfolding three-note pattern that starts one scale step further from the tonal centre each time it occurs. After the sounding of its pitch centre, the M-voice starts one step of the scale above on B, before returning to A which it then repeats (B-A-A). The second half of the pattern then starts one step of the scale below on $\mathrm{G}$, before returning to A, which it then again repeats (G-A-A). The central pitch (A) sounds again and then both patterns shift further out on the scale by one scale step in either direction (i.e. C-B-A, followed by F-G-A). This pattern then occurs two more times, with each iteration starting one scale step further away from the tonal centre in either direction (D-C-A descending followed by E-F-A ascending, and finally E-D-A followed by D-E-A).

Unlike Operations 1 through 5, Operation 6 is unique in its restriction of the use of semibreves to denote the pitch centre to only the first and last notes of the 
operation. Rather in both operations, Pärt opts to assign each remaining occurrence of the pitch-class centre the duration of one un-stemmed crochet (Figure 2.14). Operation 6 also signals the commencement of the closing of the piece by starting at the outset with all four voices singing concurrently, but eschewing any M-voice/T-voice pairings. The pattern of Operation 6 is an unfolding descending and ascending melismatic line, which moves away from and back towards the pitch centre (modes 2 and 4, respectively), first by one scale step (G-A), then by two scale steps (G-F-G), three steps (G-F-E), and so on, until the scale covers the span of a fifth. In its inverted form the scale unfolds in an ascending-descending pattern using modes 1 and 3 respectively. In Operations 6 and 7 (described below), all four voices operate concurrently as M-voices with the altos and the sopranos singing the un-inverted version of the operation in parallel fifths to each other (pitch centres A and E, respectively), and the basses and tenors singing the inverted operation, again in parallel fifths to each other, using $\mathrm{A}$ and $\mathrm{E}$ as the respective tonal centres for their vocal lines.

Figure 2.14: M-voice operations used in In spe - Operations 6 and 7
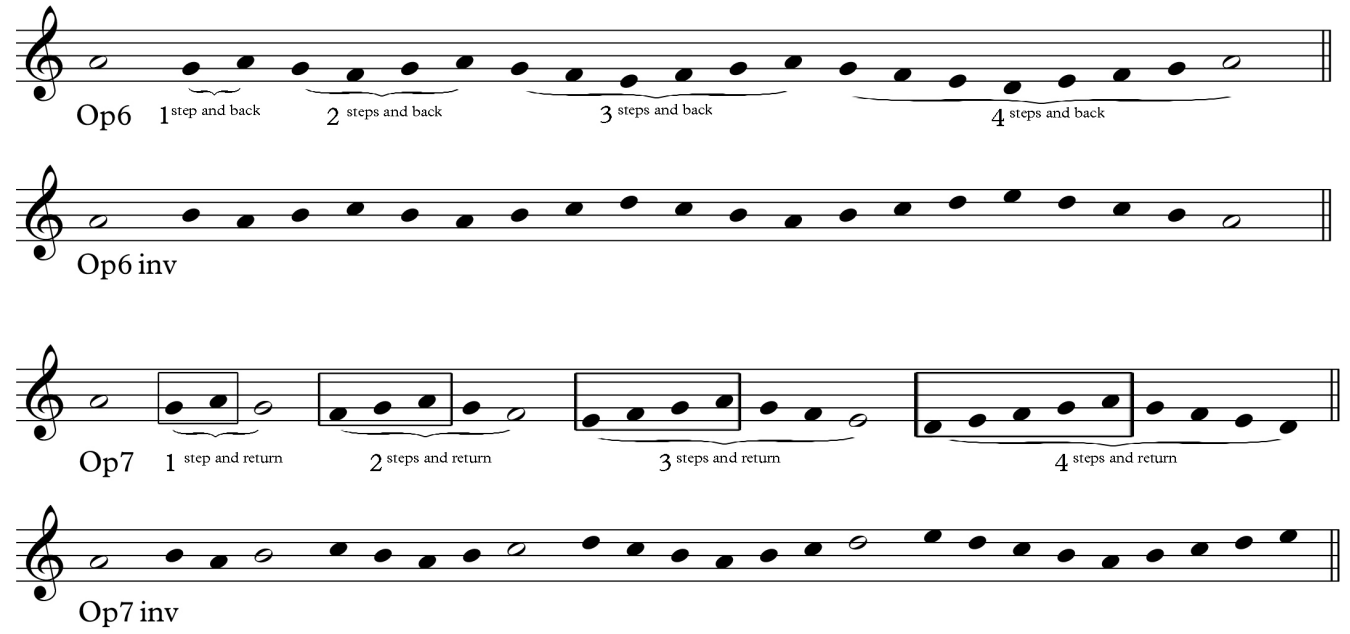

Operation 7 closes the piece in a manner that is reminiscent of how the work began - a stepwise expansion of a scale descending the span of a fifth from A to E, 
using the retrograde versions of first mode 4 and then mode 2 in the un-inverted version of the operation with the soprano line taking A as its central pitch and the altos singing in parallel fourths taking $\mathrm{E}$ as their centre. In the inverted version of the operation, the scales ascend and descend away from their tonal centre using the retrograde versions of modes 1 and 3 in respective order, with the tenors singing a parallel fifth above the bass line.

Figure 2.15 overleaf provides a visual summary of all seven operations and their respective inversions (where applicable).

While the above discussion and summary analyses have focused on identifying and illustrating the basic operations and procedures that are hallmarks of Pärt's tintinnabuli system (as documented by Hillier), what Hillier's work does not touch on is the nature of sounds that are generated as a result. The next section of this chapter provides original analysis of the intervallic content that can be generated by such procedures and the resulting sonorities that arise as a result of multiple procedures happening concurrently. 
Figure 2.15: M-voice operations used in In spe - Operations 1 through 7
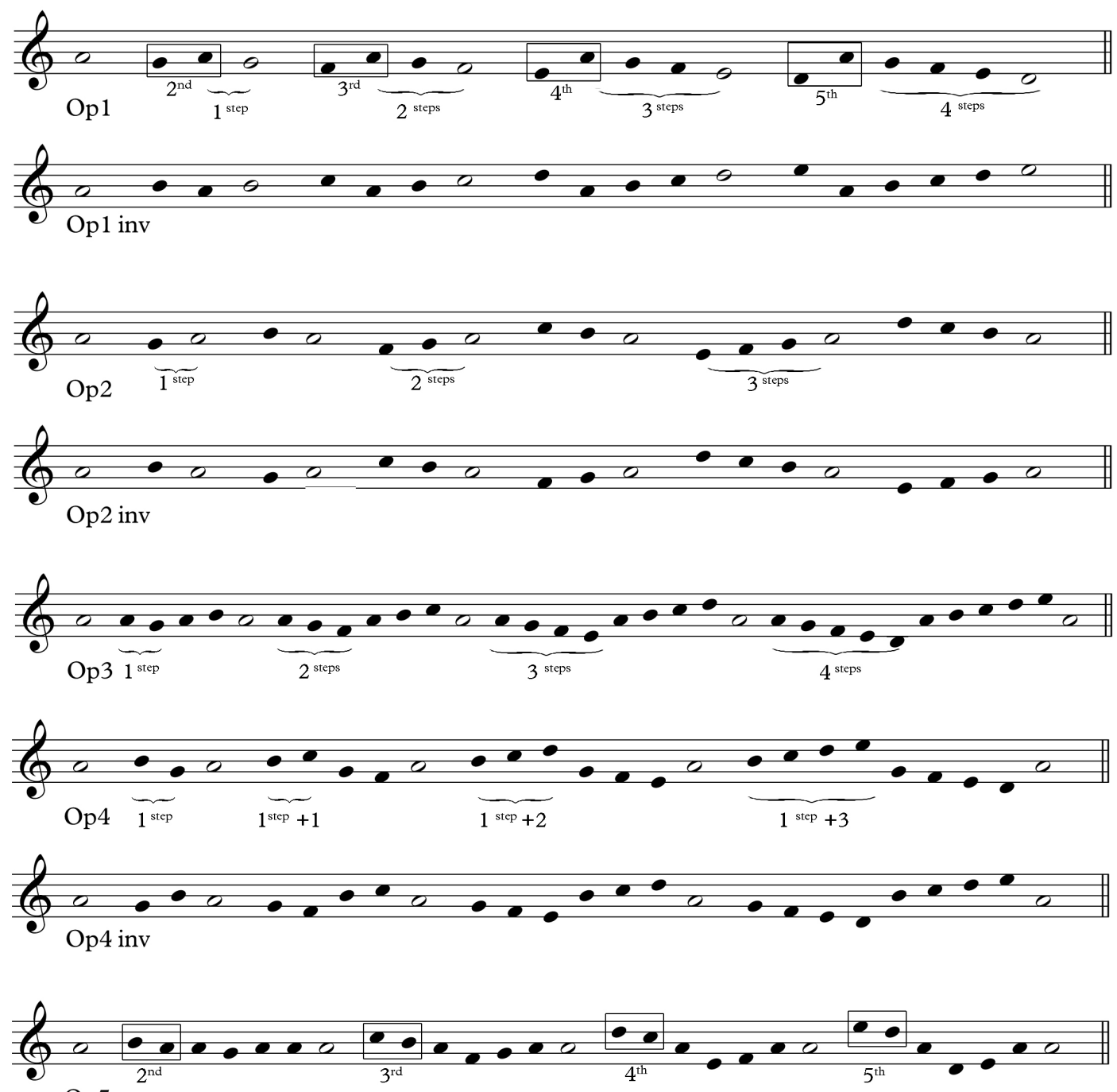
Op5

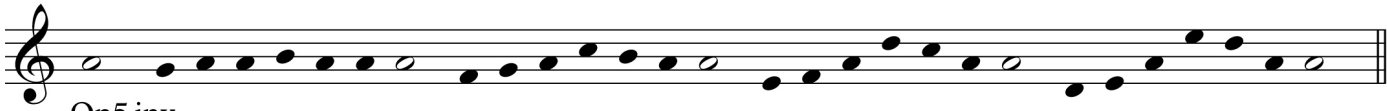

Op5 inv
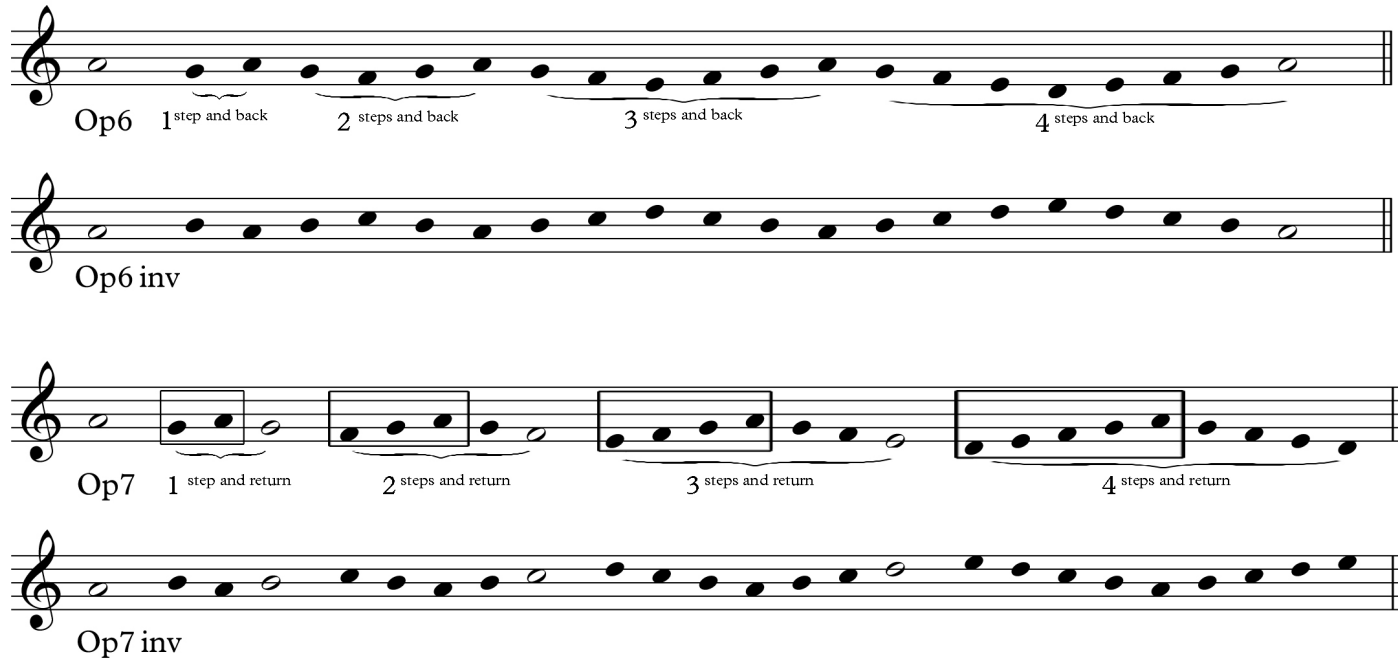


\section{A taxonomy of the ordering of intervallic content and sonorities created by different M-voice/T-voice pairings}

\section{Implications of fixed T-voices and resulting sonorities in Pärt's tintinnabuli system}

The intervallic content that is created by the different M-voice/T-voice pairings in Pärt's tintinnabuli system results in a limited number of sonorities when one looks at a single pairing only, and there are few differences in possible intervallic content between a first position and second position M-voice/T-voice pairing. Using an A Aeolian modal scale, combined with the pitches of an A minor triad (Figure 2.16), the following intervals result from a first position, superior Mvoice/T-voice pairing: a minor second, two major seconds, a minor third, two major thirds, and a perfect fourth. A first position, inferior pairing creates the following intervals: one minor second, two major seconds, two minor thirds, one major third, and a lone perfect fourth. The only difference in intervallic content between the two pairings is that a first position, superior pairing results in one minor third and two major thirds, while a first position, inferior pairing results in two minor thirds and only one major third. Both the second position, superior and second position, inferior pairings result in two intervals of one perfect fourth, three perfect fifths, one minor sixth, and one major sixth. 
Figure 2.16: Intervals arising from an A Aeolian scale and A minor triad pairing

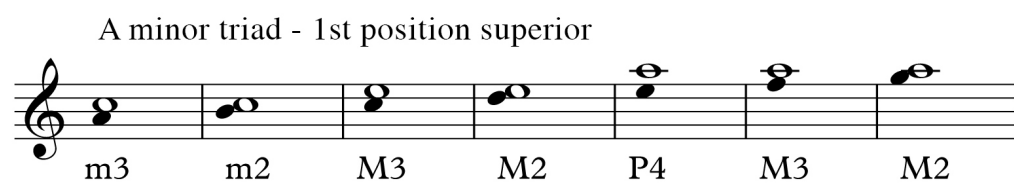

\begin{tabular}{l|l|l|l|l|l|l|}
\multirow{2}{*}{ interval class } & 1 & 2 & 3 & 4 & 5 & 6 \\
\cline { 2 - 7 } occurrences & $\mathbf{1}$ & $\mathbf{2}$ & $\mathbf{1}$ & $\mathbf{2}$ & $\mathbf{1}$ & $\mathbf{0}$ \\
\cline { 2 - 7 } & & & & &
\end{tabular}

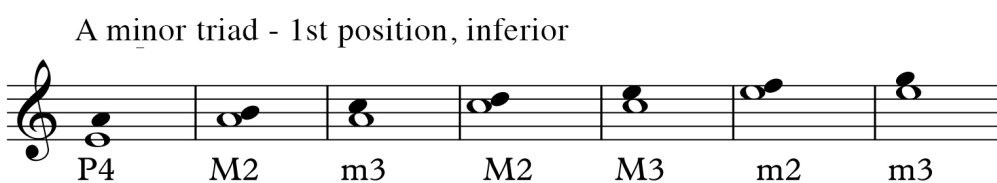

\begin{tabular}{l|l|l|l|l|l|l|} 
interval class & 1 & 2 & 3 & 4 & 5 & 6 \\
\cline { 2 - 7 } occurrences & $\mathbf{1}$ & $\mathbf{2}$ & $\mathbf{2}$ & $\mathbf{1}$ & $\mathbf{1}$ & $\mathbf{0}$ \\
\cline { 2 - 6 } & & & & &
\end{tabular}

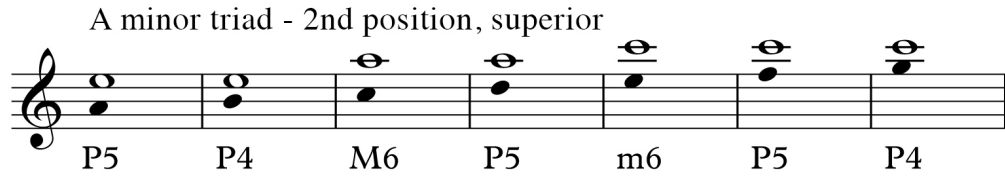

\begin{tabular}{l|l|l|l|l|l|l|} 
interval class & 1 & 2 & 3 & 4 & 5 & 6 \\
\cline { 2 - 7 } occurrences & $\mathbf{0}$ & $\mathbf{0}$ & $\mathbf{1}$ & $\mathbf{1}$ & $\mathbf{5}$ & $\mathbf{0}$ \\
\cline { 2 - 6 } & & & &
\end{tabular}

A minor triad (2nd position, inferior)

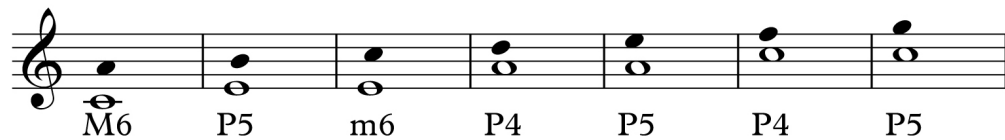

\begin{tabular}{l|l|l|l|l|l|l|}
\cline { 2 - 5 } interval class & 1 & 2 & 3 & 4 & 5 & 6 \\
\cline { 2 - 6 } occurrences & $\mathbf{0}$ & $\mathbf{0}$ & $\mathbf{1}$ & $\mathbf{1}$ & $\mathbf{5}$ & $\mathbf{0}$ \\
\cline { 2 - 5 } & & \multicolumn{3}{|c|}{} &
\end{tabular}

Differences in intervallic content arising from the use of superior and inferior second position M-voice/T-voice pairings

Compared to the intervallic content of the first position, superior and inferior Mvoice/T-voice pairings, the intervallic content of the superior and inferior second position M-voice/T-voice pairings is relatively consonant. In both of the second position pairings, there are three intervals of one perfect fifth, two perfect fourth intervals (in effect five occurrences of interval class 5), one minor and one major sixth (interval classes 3 and 4, respectively). In contrast, both the superior and inferior first position M-voice/T-voice pairings result in one minor second (interval class 1), two major seconds (interval class 2), and only one perfect fourth.

Pärt uses an A Aeolian-based M-voice with an A minor triad-based T-voice as the tonal basis in several of his early tintinnabuli works, such as the first movement of Tabula rasa (Ludus), and Cantus in Memory of Benjamin Britten. In many of his 
other string orchestral works, however, he does not restrict himself to using the same sounding pitch or tonal centre in an M-voice/T-voice pairing as the tonic of the T-voice triad. As his tintinnabuli system evolved, he began to assign the pitch class centre of the M-voice to a pitch other than the root pitch of the T-voice triad (e.g. assigning the pitch class centre of the M-voice to C or E when paired with an A minor triad T-voice).

\section{Implications of pandiatonicism and Pärt's tintinnabuli system}

Though it is infrequent in his early tintinnabuli compositions, Pärt has also at times used a pitch centre for the M-voice that does not align with one of the pitches in the T-voice's triad at all, for example a D Dorian M-voice paired with an A minor triad for the T-voice (one such case is his work Fratres). However, because of the 'white-key' modal manner in which Pärt constructs most Mvoice/T-voice pairings for his early tintinnabuli works, the general sonority of the interval-class content of specific pairings is not affected by shifting the tonal centre of the M-voice to a different pitch class in the same scale, only the order by which intervals are presented to a listener as the M-voice proceeds towards or away from its pitch centre.

As illustrated in Figure 2.17 through Figure 2.20 overleaf, and still using an Aminor triad T-voice as the example, shifting the tonal centre of the M-voice to a different white key mode scale than A Aeolian (e.g. D Dorian, E Phrygian, F Lydian, etc.) results in the following intervals, as long as the T-voice is in first position, superior: one minor second, two major seconds, one minor third, two major thirds, and a perfect fourth. A first position, inferior T-voice results in the same 
intervallic content, but with two minor thirds and only one major third, while both second position, superior and second position, inferior result in two perfect fourths, three perfect fifths, one minor sixth, and one major sixth, regardless of the position of the pitch centre of the mode being used.

Figure 2.17: Interval ordering and class content of an A minor triad 1st position, superior to seven modal scales

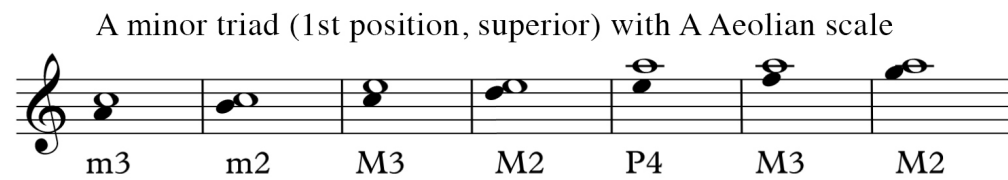

\begin{tabular}{l|l|l|l|l|l|l|}
\cline { 2 - 5 } interval class & 1 & 2 & 3 & 4 & 5 & 6 \\
\cline { 2 - 6 } occurrences & $\mathbf{1}$ & $\mathbf{2}$ & $\mathbf{1}$ & $\mathbf{2}$ & $\mathbf{1}$ & $\mathbf{0}$ \\
\cline { 2 - 5 }
\end{tabular}

A minor triad (1st position, superior) with $\mathrm{C}$ Ionian scale

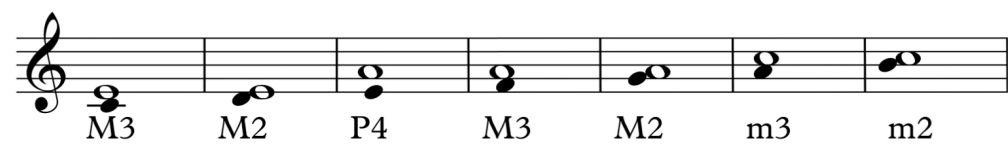

\begin{tabular}{l|l|l|l|l|l|l|}
\cline { 2 - 6 } interval class & 1 & 2 & 3 & 4 & 5 & 6 \\
\cline { 2 - 6 } occurrences & $\mathbf{1}$ & $\mathbf{2}$ & $\mathbf{1}$ & $\mathbf{2}$ & $\mathbf{1}$ & $\mathbf{0}$ \\
\cline { 2 - 4 }
\end{tabular}

A minor triad (1st position, superior) with E Phrygian scale

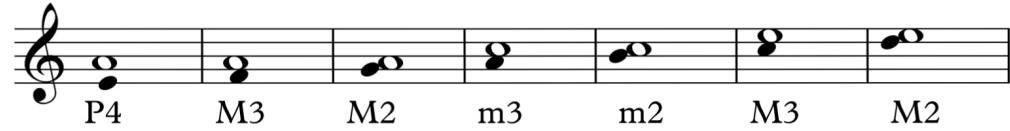

\begin{tabular}{l|l|l|l|l|l|l|}
\cline { 2 - 5 } interval class & 1 & 2 & 3 & 4 & 5 & 6 \\
\cline { 2 - 5 } occurrences & $\mathbf{1}$ & $\mathbf{2}$ & $\mathbf{1}$ & $\mathbf{2}$ & $\mathbf{1}$ & $\mathbf{0}$ \\
\cline { 2 - 5 }
\end{tabular}

A minor triad (1st position, superior) with D Dorian scale

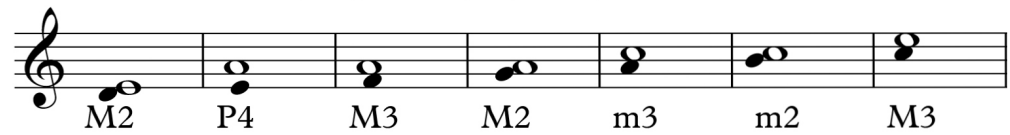

\begin{tabular}{l|l|l|l|l|l|l|}
\cline { 2 - 5 } interval class & 1 & 2 & 3 & 4 & 5 & 6 \\
\cline { 2 - 6 } occurrences & $\mathbf{1}$ & $\mathbf{2}$ & $\mathbf{1}$ & $\mathbf{2}$ & $\mathbf{1}$ & $\mathbf{0}$ \\
\hline
\end{tabular}

A minor triad (1st position, superior) with F Lydian scale

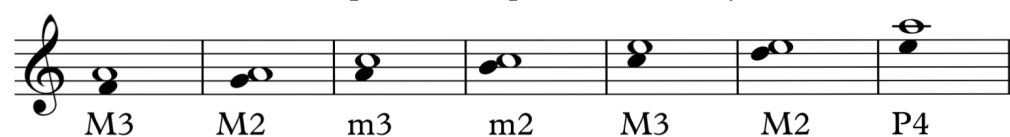

interval class \begin{tabular}{l|l|l|l|l|l|l|}
\cline { 2 - 5 } & 1 & 2 & 3 & 4 & 5 & 6 \\
\cline { 2 - 5 } & 1 & $\mathbf{2}$ & $\mathbf{1}$ & $\mathbf{2}$ & 1 & 0 \\
\cline { 2 - 5 }
\end{tabular}

M3

$\mathrm{M} 2 \mathrm{~m} 3$

$\mathrm{m} 2$

M3

2

P4

A minor triad (1st position, superior) with G Mixolydian scale

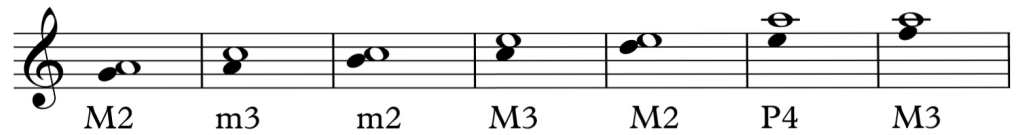

\begin{tabular}{l|l|l|l|l|l|l|}
\cline { 2 - 5 } interval class & 1 & 2 & 3 & 4 & 5 & 6 \\
\cline { 2 - 6 } occurrences & $\mathbf{1}$ & $\mathbf{2}$ & $\mathbf{1}$ & $\mathbf{2}$ & $\mathbf{1}$ & $\mathbf{0}$ \\
\cline { 2 - 6 } & & & &
\end{tabular}

A minor triad (1st position, superior) with B Locrian scale

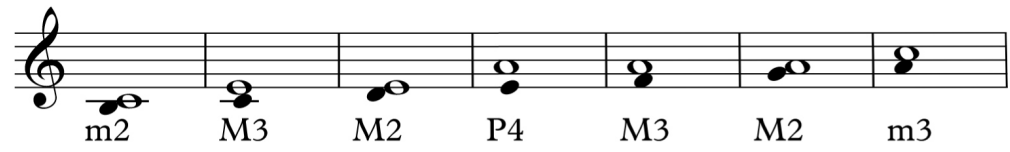

\begin{tabular}{l|l|l|l|l|l|l|}
\cline { 2 - 6 } interval class & 1 & 2 & 3 & 4 & 5 & 6 \\
\cline { 2 - 6 } occurrences & $\mathbf{1}$ & $\mathbf{2}$ & $\mathbf{1}$ & $\mathbf{2}$ & $\mathbf{1}$ & $\mathbf{0}$ \\
\cline { 2 - 5 }
\end{tabular} 
Figure 2.18: Interval ordering and class content of an A minor triad 1st position, inferior to seven modal scales

A minor triad (1st position, inferior) with A Aeolian scale

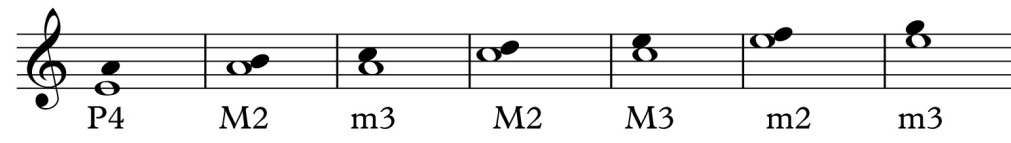

\begin{tabular}{l|l|l|l|l|l|l|}
\cline { 2 - 5 } interval class & 1 & 2 & 3 & 4 & 5 & 6 \\
\cline { 2 - 6 } occurrences & $\mathbf{1}$ & $\mathbf{2}$ & $\mathbf{2}$ & $\mathbf{1}$ & $\mathbf{1}$ & $\mathbf{0}$ \\
\cline { 2 - 5 }
\end{tabular}

A minor triad (1st position, inferior) with C Ionian scale

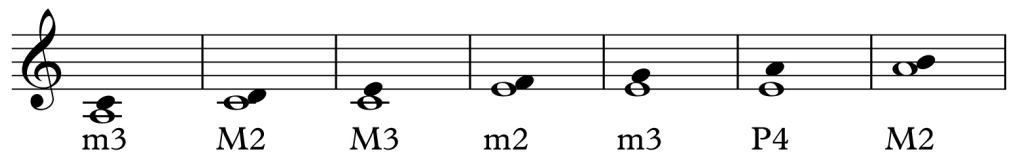

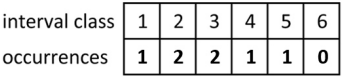

A minor triad (1st position, inferior) with E Phrygian scale

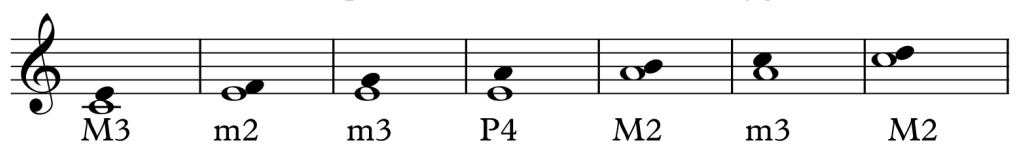

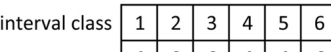
\begin{tabular}{llllllll|}
\multirow{2}{*}{ occurrences } & 1 & 2 & 2 & 1 & 1 & 0 \\
\cline { 2 - 7 } \\
\cline { 2 - 6 }
\end{tabular}

A minor triad (1st position, inferior) with D Dorian scale

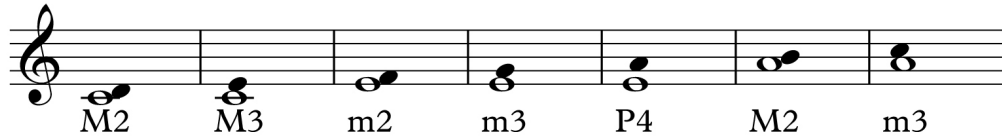

\begin{tabular}{l|l|l|l|l|l|l|}
\cline { 2 - 5 } interval class & 1 & 2 & 3 & 4 & 5 & 6 \\
\cline { 2 - 6 } occurrences & $\mathbf{1}$ & $\mathbf{2}$ & $\mathbf{2}$ & $\mathbf{1}$ & $\mathbf{1}$ & $\mathbf{0}$ \\
\cline { 2 - 6 } & & &
\end{tabular}

A minor triad (1st position, inferior) with F Lydian scale

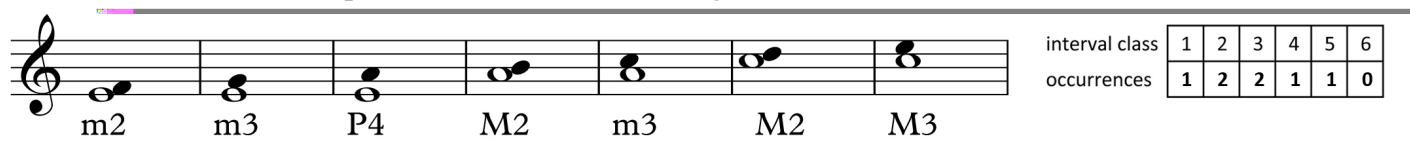

A minor triad (1st position, inferior) with G Mixolydian scale)

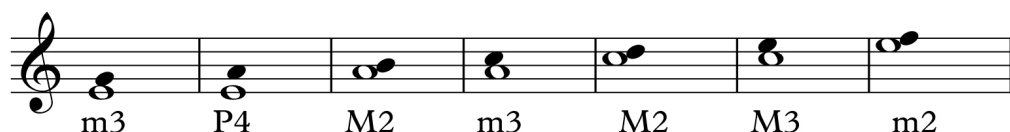

interval class \begin{tabular}{l|l|l|l|l|l|l|}
\cline { 2 - 6 } & 1 & 2 & 3 & 4 & 5 & 6 \\
\cline { 2 - 6 } & 1 & $\mathbf{2}$ & $\mathbf{2}$ & $\mathbf{1}$ & $\mathbf{1}$ & $\mathbf{0}$ \\
\hline
\end{tabular}

$\begin{array}{lllllll}\mathrm{m} 3 & \mathrm{P} 4 & \mathrm{M} 2 & \mathrm{~m} 3 & \mathrm{M} 2 & \mathrm{M} 3 & \mathrm{~m} 2\end{array}$

A minor triad (1st position, inferior) with B Locrian scale

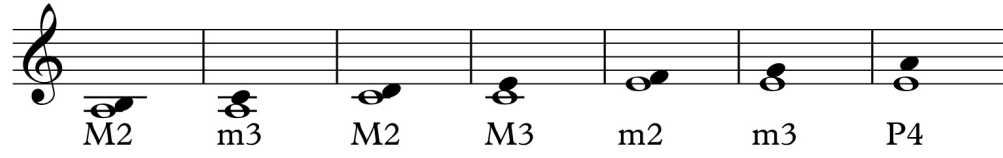

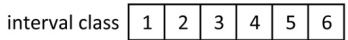

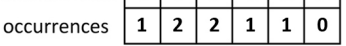


Figure 2.19: Interval ordering and class content of an A minor triad 2nd position, superior of seven modal scales

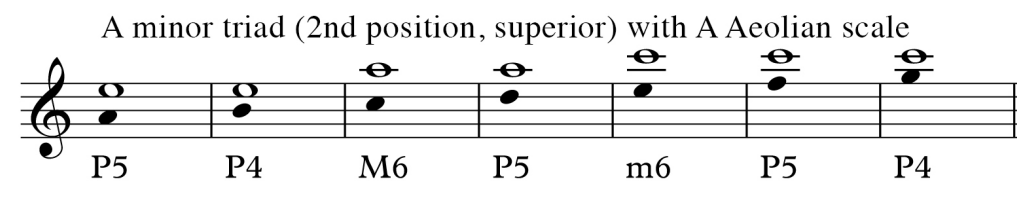

\begin{tabular}{l|l|l|l|l|l|l|} 
& & \\
interval class & 1 & 2 & 3 & 4 & 5 & 6 \\
\cline { 2 - 6 } occurrences & $\mathbf{0}$ & $\mathbf{0}$ & $\mathbf{1}$ & $\mathbf{1}$ & $\mathbf{5}$ & $\mathbf{0}$ \\
\cline { 2 - 6 } & & & & &
\end{tabular}

A minor triad (2nd position, superior) with C Ionian scale

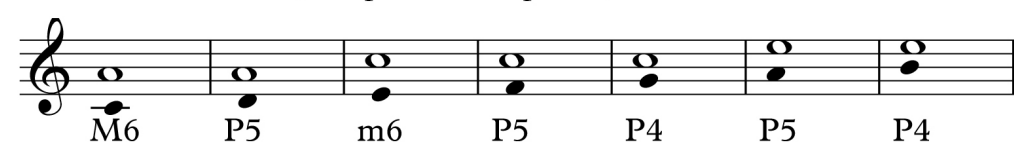

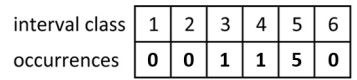

A minor triad (2nd position, superior) with E Phrygian scale

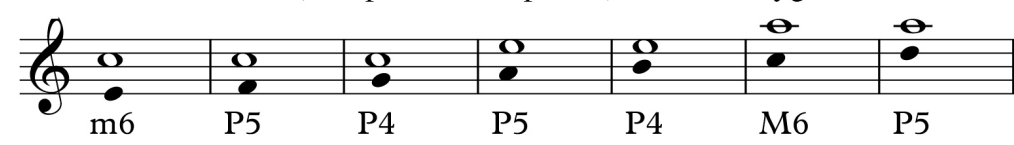

\begin{tabular}{l|l|l|l|l|l|l|}
\cline { 2 - 6 } interval class & 1 & 2 & 3 & 4 & 5 & 6 \\
\cline { 2 - 6 } & 0 & $\mathbf{0}$ & $\mathbf{1}$ & $\mathbf{1}$ & $\mathbf{5}$ & 0 \\
\hline
\end{tabular}

A minor triad (2nd position, superior) with D Dorian scale

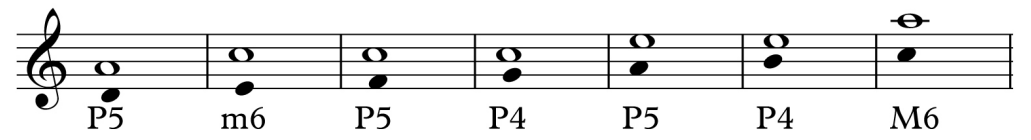

\begin{tabular}{l|l|l|l|l|l|l|} 
& & & \\
interval class & 1 & 2 & 3 & 4 & 5 & 6 \\
\cline { 2 - 7 } occurrences & $\mathbf{0}$ & $\mathbf{0}$ & $\mathbf{1}$ & $\mathbf{1}$ & $\mathbf{5}$ & $\mathbf{0}$ \\
\cline { 2 - 6 } & & & & &
\end{tabular}

A minor triad (2nd position, superior) with F Lydian scale

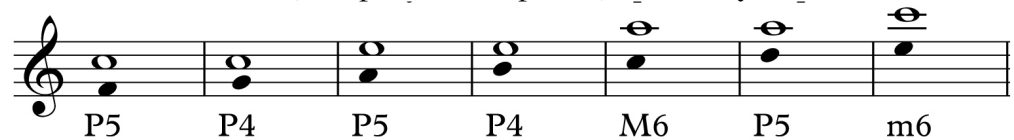

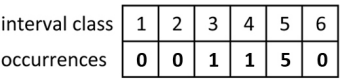

A minor triad (2nd position, superior) with G Mixolydian scale

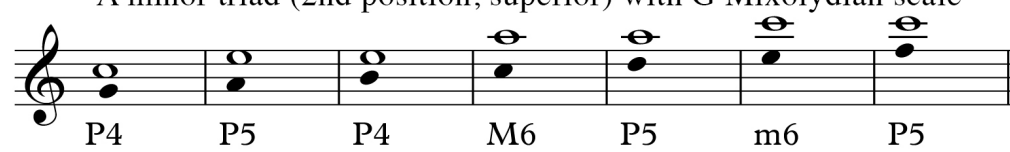

\begin{tabular}{l|l|l|l|l|l|l|} 
interval class & 1 & 2 & 3 & 4 & 5 & 6 \\
\cline { 2 - 7 } occurrences & $\mathbf{0}$ & $\mathbf{0}$ & $\mathbf{1}$ & $\mathbf{1}$ & $\mathbf{5}$ & $\mathbf{0}$ \\
\cline { 2 - 6 } & & & & &
\end{tabular}

A minor triad (2nd position, superior) with B Locrian scale

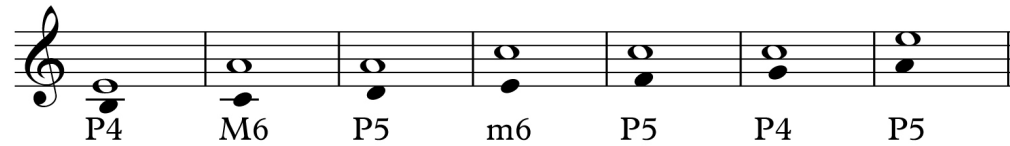

\begin{tabular}{l|l|l|l|l|l|l|}
\cline { 2 - 5 } interval class & 1 & 2 & 3 & 4 & 5 & 6 \\
\cline { 2 - 6 } occurrences & $\mathbf{0}$ & $\mathbf{0}$ & $\mathbf{1}$ & $\mathbf{1}$ & $\mathbf{5}$ & $\mathbf{0}$ \\
\cline { 2 - 6 } & & &
\end{tabular} 
Figure 2.20: Interval ordering and class content of an A minor triad 2nd position, inferior to seven modal scales

A minor triad (2nd position, inferior) with A Aeolian scale

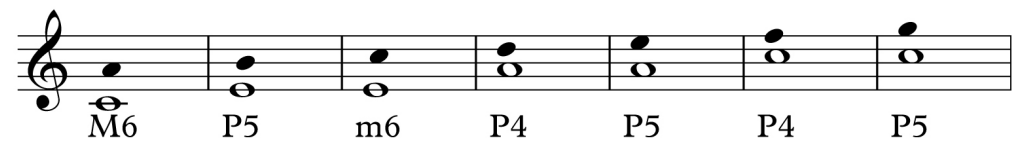

\begin{tabular}{l|l|l|l|l|l|l|}
\cline { 2 - 5 } interval class & 1 & 2 & 3 & 4 & 5 & 6 \\
\cline { 2 - 5 } occurrences & 0 & 0 & 1 & 1 & 5 & 0 \\
\cline { 2 - 5 }
\end{tabular}

A minor triad (2nd position, inferior) with C Ionian scale

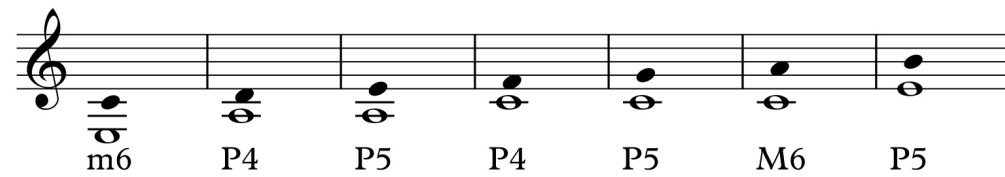

\begin{tabular}{l|l|l|l|l|l|l|}
\cline { 2 - 5 } interval class & 1 & 2 & 3 & 4 & 5 & 6 \\
\cline { 2 - 5 } occurrences & $\mathbf{0}$ & $\mathbf{0}$ & $\mathbf{1}$ & $\mathbf{1}$ & $\mathbf{5}$ & $\mathbf{0}$ \\
\cline { 2 - 5 }
\end{tabular}

A minor triad (2nd position, inferior) with E Phrygian scale

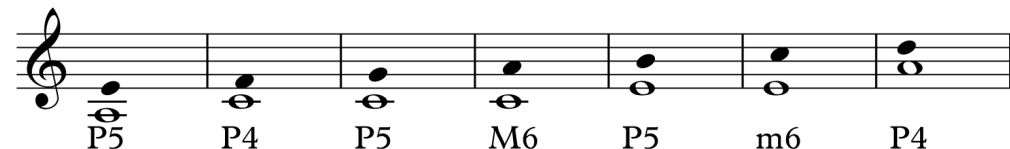

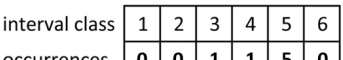

$\overline{\mathrm{P} 5}$

P4

P5 M6

P5

P4

A minor triad (2nd position, inferior) with D Dorian scale

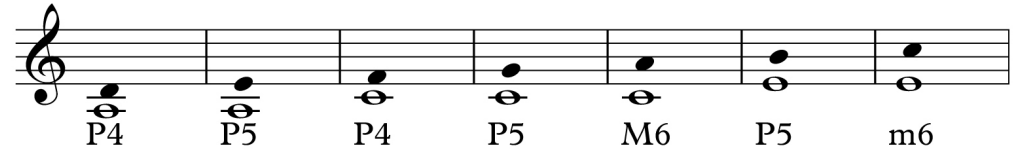

\begin{tabular}{l|l|l|l|l|l|l|}
\cline { 2 - 5 } interval class & 1 & 2 & 3 & 4 & 5 & 6 \\
\cline { 2 - 6 } occurrences & $\mathbf{0}$ & $\mathbf{0}$ & $\mathbf{1}$ & $\mathbf{1}$ & $\mathbf{5}$ & $\mathbf{0}$ \\
\cline { 2 - 6 } & & &
\end{tabular}

A minor triad (2nd position, inferior) with F Lydian scale

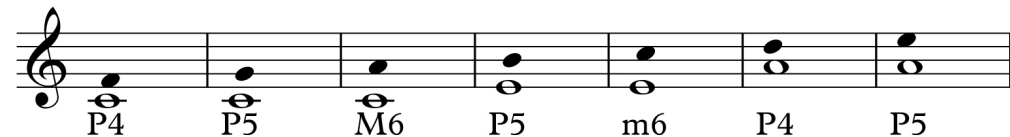

\begin{tabular}{l|l|l|l|l|l|l|}
\cline { 2 - 5 } interval class & 1 & 2 & 3 & 4 & 5 & 6 \\
\cline { 2 - 6 } occurrences & $\mathbf{0}$ & $\mathbf{0}$ & $\mathbf{1}$ & $\mathbf{1}$ & $\mathbf{5}$ & $\mathbf{0}$ \\
\cline { 2 - 6 } & & &
\end{tabular}

A minor triad (2nd position, inferior) with G Mixolydian scale

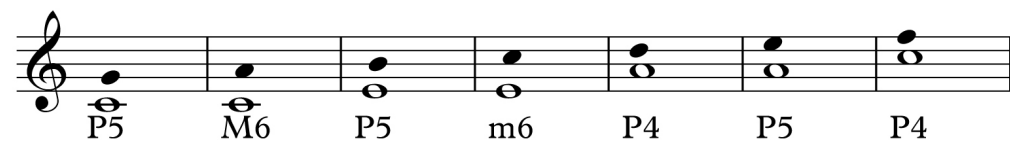

interval class \begin{tabular}{c|c|c|c|c|c|c|}
\cline { 2 - 6 } & 1 & 2 & 3 & 4 & 5 & 6 \\
\cline { 2 - 6 } & 0 & 0 & 1 & 1 & 5 & 0 \\
\hline
\end{tabular}

A minor triad (2nd position, inferior) with B Locrian scale

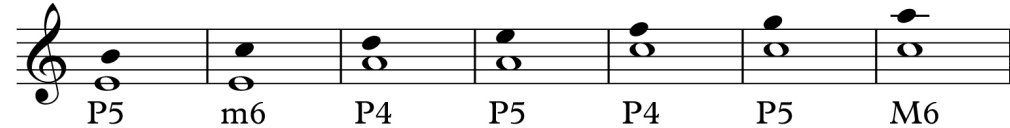

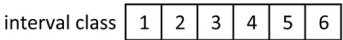

\begin{tabular}{l|l|l|l|l|l|l|l|}
\multirow{3}{*}{ occurrences } & 0 & 0 & 1 & 1 & 5 & 0 \\
\cline { 2 - 6 } \\
\cline { 2 - 6 } & & &
\end{tabular} 
As can be seen from each of the above figures, a fixed T-voice in its different positions results in only three sets of interval class content, i.e. <121210>, $<122110>$, and $<001150>$, regardless of which modally-related scale is paired with it for the M-voice. Shifting the pitch centre that a particular M-voice uses, however, will result in the intervallic content of a specific work being presented in a markedly different order to the listener. This particular aspect of Pärt's tintinnabuli system is reinforced and further enhanced by the additive stepwise approach and other operations that Pärt frequently uses in constructing his Mvoice melodies.

The phenomenon of identical interval class sets arising from the use of a particular fixed T-voice position (e.g. first position, superior), regardless of the modally-related scale with which it is paired, does not apply when the inverse situation is applied. As detailed in Figure 2.21 through Figure 2.24 overleaf and summarised in Table 2.6, a fixed diatonic scale paired with its different 'possible' related triads results in nine unique interval class vectors $(<001141>,<001150>$, $<002041\rangle, \quad<031210\rangle, \quad<032110>, \quad<121210\rangle, \quad<122101>, \quad<122110>$, $<212110>)^{117}$

117 In Appendix A, I have provided a full set of figures for M-voice based scales for all seven 'white-key' modes (e.g. Dorian, Phrygian, etc.) and the interval ordering and interval class content that arrives from using different triads in first position, superior; first position, inferior; second position, superior; and second position, inferior. However, in most of his early tintinnabuli works Pärt restricted himself to closely related pairings, wherein the M-voice uses one of the triadic notes of the $\mathrm{T}$-voice as its tonal centre. Using the A minor T-voice as an example, this would generally preclude pairing it with a G Mixolydian or B Locrian M-voice. In later works Pärt is less restrictive in his M-voice/T-voice pairings. One example of this is Orient \& Occident, which is the focus of Chapter 6. 
Table 2.6: Summary of interval class vectors arising from an A Aeolian scale paired with different modally related triads and $\mathrm{T}$-voice positions

\begin{tabular}{|l|l|l|l|l|}
\hline $\begin{array}{l}\text { Interval } \\
\text { class set }\end{array}$ & $\begin{array}{l}\mathbf{1}^{\text {st }} \text { position, } \\
\text { superior }\end{array}$ & $\begin{array}{l}\mathbf{1}^{\text {st }} \text { position, } \\
\text { inferior }\end{array}$ & $\begin{array}{l}\mathbf{2}^{\text {nd }} \text { position, } \\
\text { superior }\end{array}$ & $\begin{array}{l}\mathbf{2}^{\text {nd }} \text { position, } \\
\text { inferior }\end{array}$ \\
\hline 001141 & & & $\begin{array}{l}\text { D minor } \\
\text { E minor } \\
\text { F major } \\
\text { G major }\end{array}$ & $\begin{array}{l}\text { D minor } \\
\text { E minor } \\
\text { F major } \\
\text { G major }\end{array}$ \\
\hline 001150 & & & $\begin{array}{l}\text { C major } \\
\text { A minor }\end{array}$ & $\begin{array}{l}\text { C major } \\
\text { A minor }\end{array}$ \\
\hline 002041 & & B diminished & B diminished \\
\hline 031210 & E minor & F major & & \\
\hline 032110 & G major & D minor & & \\
\hline 121210 & A minor & C major & & \\
\hline 122101 & B diminished & B diminished & & \\
\hline 122110 & C major & G major & & \\
\hline 212110 & F minor & E minor & & \\
\hline
\end{tabular}

As mapped in Table 2.6, because of the close relationships of certain triads in a modally based system, several triads will share the same interval class content in certain T-voice positionings when combined with the same modal scale. For example D minor, E minor, F major, and G major triads paired with an A Aeolian scale in second position, superior or inferior, all share the interval class set 001140. However, as Figure 2.21 through Figure 2.24 illustrate, under the rules of Pärt's tintinnabuli system, the order in which their respective intervals are presented will differ markedly. 
Figure 2.21: Interval ordering and class content of an A Aeolian scale paired with different triads in 1st position, superior
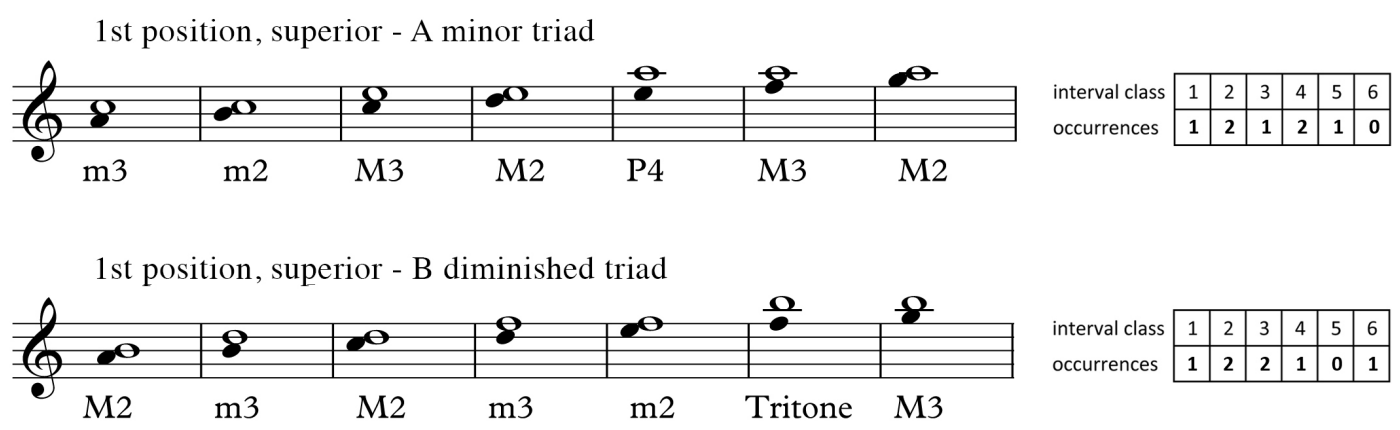

\begin{tabular}{l|l|l|l|l|l|l|} 
interval class & $\mathbf{1}$ & $\mathbf{2}$ & $\mathbf{3}$ & 4 & $\mathbf{5}$ & 6 \\
\cline { 2 - 7 } occurrences & $\mathbf{1}$ & $\mathbf{2}$ & $\mathbf{2}$ & $\mathbf{1}$ & $\mathbf{0}$ & $\mathbf{1}$ \\
\cline { 2 - 7 } & & & & &
\end{tabular}

st position, superior - C major triad

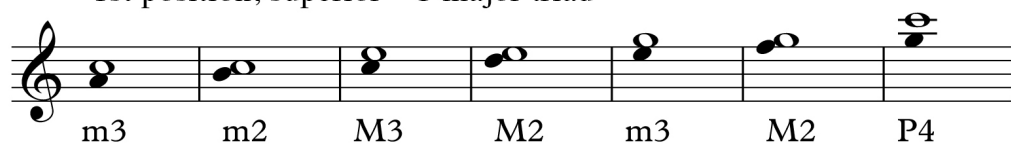

\begin{tabular}{l|l|l|l|l|l|l|} 
interval class & 1 & 2 & 3 & 4 & 5 & 6 \\
\cline { 2 - 7 } occurrences & $\mathbf{1}$ & $\mathbf{2}$ & $\mathbf{2}$ & $\mathbf{1}$ & $\mathbf{1}$ & $\mathbf{0}$ \\
\cline { 2 - 6 } & & & &
\end{tabular}

$\begin{array}{llllll}\mathrm{m} 3 & \mathrm{~m} 2 & \mathrm{M} 3 & \mathrm{M} 2 & \mathrm{~m} 3 & \mathrm{M} 2\end{array}$

1st position, superior - D minor triad

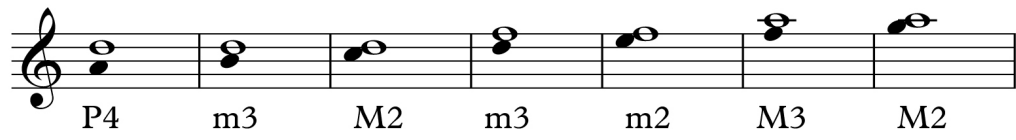

\begin{tabular}{l|l|l|l|l|l|l|}
\cline { 2 - 6 } interval class & 1 & 2 & 3 & 4 & 5 & 6 \\
\cline { 2 - 7 } occurrences & $\mathbf{1}$ & $\mathbf{2}$ & $\mathbf{2}$ & $\mathbf{1}$ & $\mathbf{1}$ & $\mathbf{0}$ \\
\cline { 2 - 5 } & \multicolumn{3}{|c|}{} & \multicolumn{3}{|c}{}
\end{tabular}

1st position, superior - E minor triad

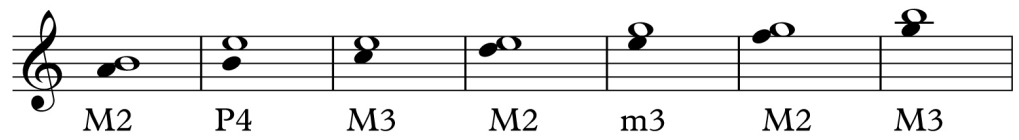

\begin{tabular}{l|l|l|l|l|l|l|}
\cline { 2 - 5 } interval class & 1 & 2 & 3 & 4 & 5 & 6 \\
\cline { 2 - 5 } occurrences & $\mathbf{0}$ & $\mathbf{3}$ & $\mathbf{1}$ & $\mathbf{2}$ & $\mathbf{1}$ & $\mathbf{0}$ \\
\cline { 2 - 5 }
\end{tabular}

\section{1st position, superior - F major triad}

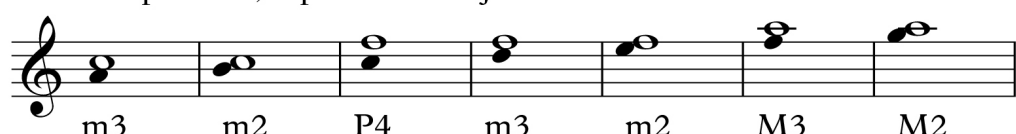

\begin{tabular}{c|c|c|c|c|c|c|} 
interval class & 1 & 2 & 3 & 4 & 5 & 6 \\
\cline { 2 - 6 } & 2 & 1 & 2 & 1 & 1 & 0 \\
\hline
\end{tabular}

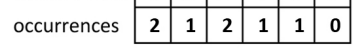

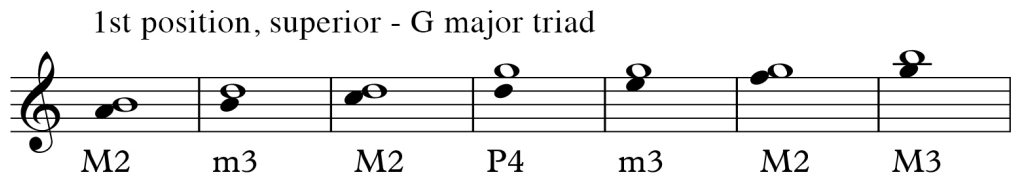

\begin{tabular}{c|c|c|c|c|c|c|}
\cline { 2 - 6 } interval class & 1 & 2 & 3 & 4 & 5 & 6 \\
\cline { 2 - 7 } occurrences & $\mathbf{0}$ & $\mathbf{3}$ & $\mathbf{2}$ & $\mathbf{1}$ & $\mathbf{1}$ & $\mathbf{0}$ \\
\cline { 2 - 6 } & & & & &
\end{tabular} 
Figure 2.22: Interval ordering and class content of an A Aeolian scale paired with different triads in 1st position, inferior

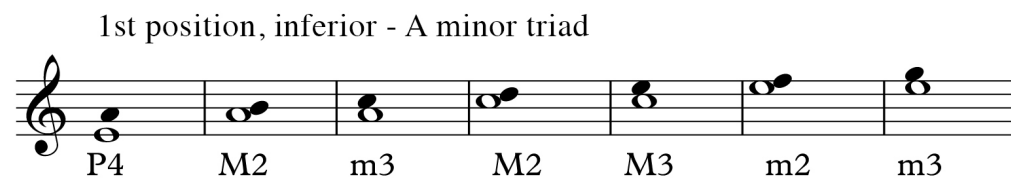

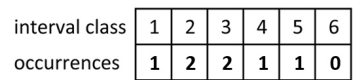

1st position, inferior - B diminished triad

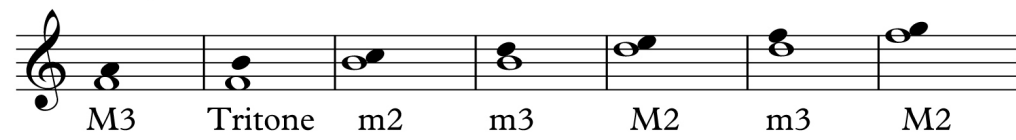

\begin{tabular}{l|l|l|l|l|l|l|}
\cline { 2 - 6 } interval class & 1 & 2 & 3 & 4 & 5 & 6 \\
\cline { 2 - 7 } occurrences & $\mathbf{1}$ & $\mathbf{2}$ & $\mathbf{2}$ & $\mathbf{1}$ & $\mathbf{0}$ & $\mathbf{1}$ \\
\cline { 2 - 6 } & & & & &
\end{tabular}

1st position, inferior - C major triad

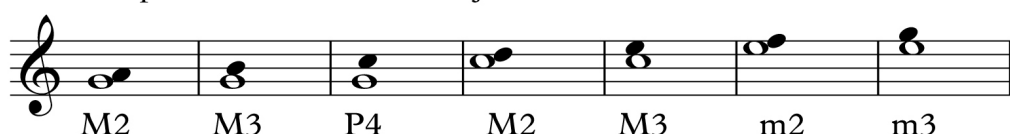

\begin{tabular}{l|l|l|l|l|l|l|}
\cline { 2 - 5 } interval class & 1 & 2 & 3 & 4 & 5 & 6 \\
\cline { 2 - 6 } occurrences & $\mathbf{1}$ & $\mathbf{2}$ & $\mathbf{1}$ & $\mathbf{2}$ & $\mathbf{1}$ & $\mathbf{0}$ \\
\cline { 2 - 5 } & & & &
\end{tabular}

M2

M3

P4 M2

M3

m3

1st position, inferior - D minor triad

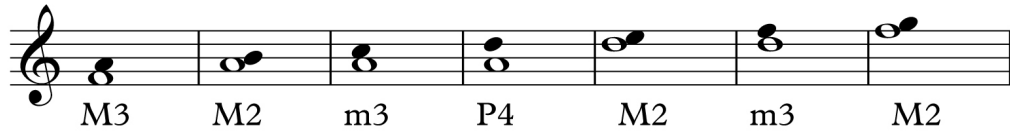

\begin{tabular}{l|l|l|l|l|l|l|}
\cline { 2 - 5 } interval class & 1 & 2 & 3 & 4 & 5 & 6 \\
\cline { 2 - 6 } occurrences & $\mathbf{0}$ & $\mathbf{3}$ & $\mathbf{2}$ & $\mathbf{1}$ & $\mathbf{1}$ & $\mathbf{0}$ \\
\cline { 2 - 6 } & & &
\end{tabular}

1st position, inferior - E minor triad

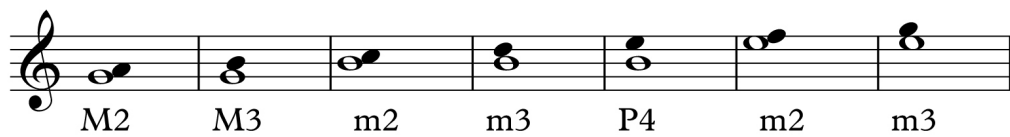

\begin{tabular}{l|l|l|l|l|l|l|}
\cline { 2 - 5 } interval class & 1 & 2 & 3 & 4 & 5 & 6 \\
\cline { 2 - 6 } occurrences & $\mathbf{2}$ & $\mathbf{1}$ & $\mathbf{2}$ & $\mathbf{1}$ & $\mathbf{1}$ & $\mathbf{0}$ \\
\cline { 2 - 6 }
\end{tabular}

1st position, inferior - F major triad

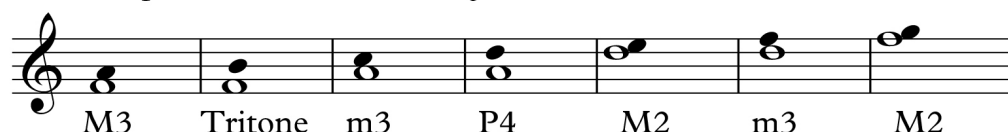

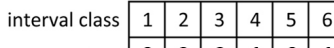

M3 Tritone $\mathrm{m3} \quad \mathrm{P} 4 \quad \mathrm{M} 2 \quad \mathrm{~m} 3 \quad$ M2

\begin{tabular}{ll|l|l|l|l|l|}
\multirow{3}{*}{ occurrences } & 0 & 2 & 2 & 1 & 0 & 1 \\
\cline { 2 - 6 } \\
\cline { 2 - 5 }
\end{tabular}

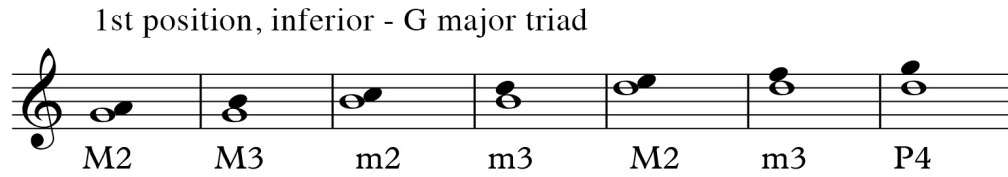

\begin{tabular}{l|l|l|l|l|l|l|}
\cline { 2 - 6 } interval class & 1 & 2 & 3 & 4 & 5 & 6 \\
\cline { 2 - 6 } occurrences & $\mathbf{1}$ & $\mathbf{2}$ & $\mathbf{2}$ & $\mathbf{1}$ & $\mathbf{1}$ & $\mathbf{0}$ \\
\hline
\end{tabular} 
Figure 2.23: Interval ordering and class content of an A Aeolian scale paired with different triads in 2nd position, superior

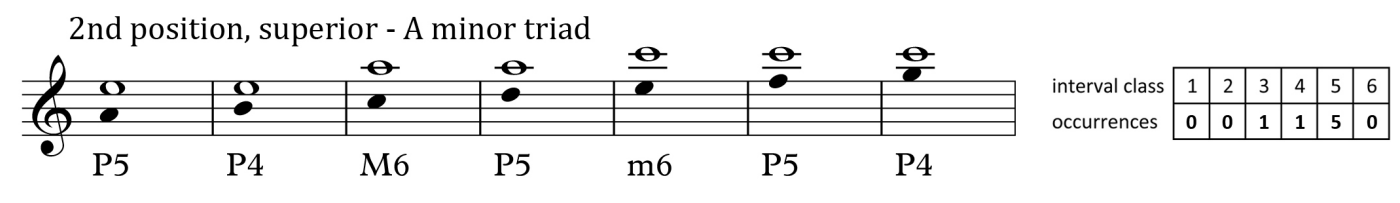

2nd position, superior - B diminished triad

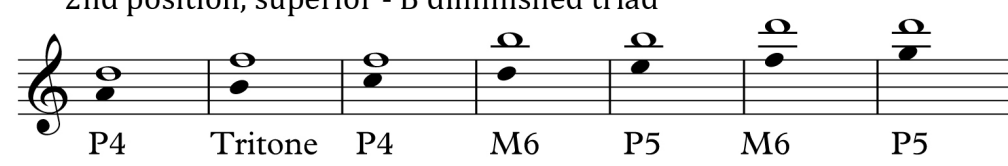

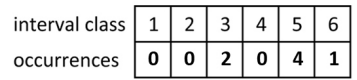

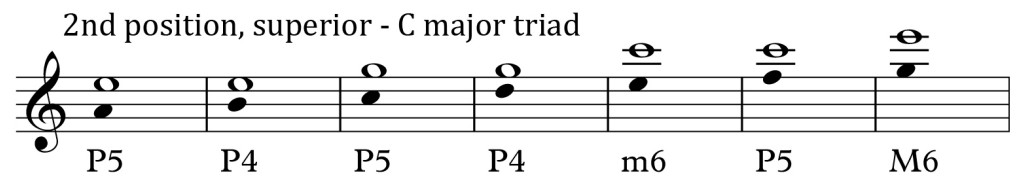

\begin{tabular}{l|l|l|l|l|l|l|} 
interval class & 1 & 2 & 3 & 4 & 5 & 6 \\
\cline { 2 - 7 } occurrences & $\mathbf{0}$ & $\mathbf{0}$ & $\mathbf{1}$ & $\mathbf{1}$ & $\mathbf{5}$ & $\mathbf{0}$ \\
\cline { 2 - 6 } & \multicolumn{3}{|c|}{} & \multicolumn{3}{|c}{} \\
\hline
\end{tabular}

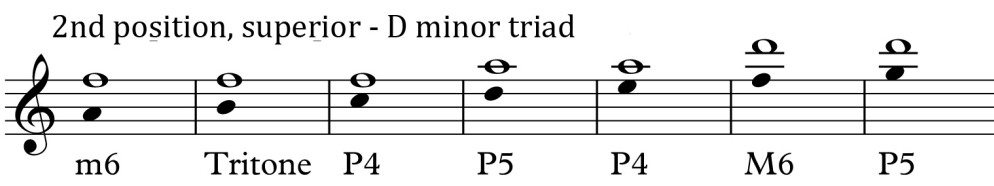

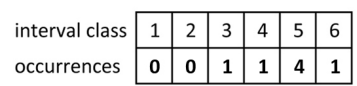

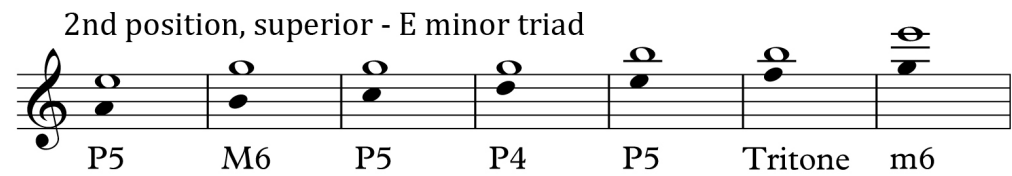

\begin{tabular}{l|l|l|l|l|l|l|}
\cline { 2 - 5 } interval class & 1 & 2 & 3 & 4 & 5 & 6 \\
\cline { 2 - 6 } occurrences & $\mathbf{0}$ & $\mathbf{0}$ & $\mathbf{1}$ & $\mathbf{1}$ & $\mathbf{4}$ & $\mathbf{1}$ \\
\cline { 2 - 5 }
\end{tabular}

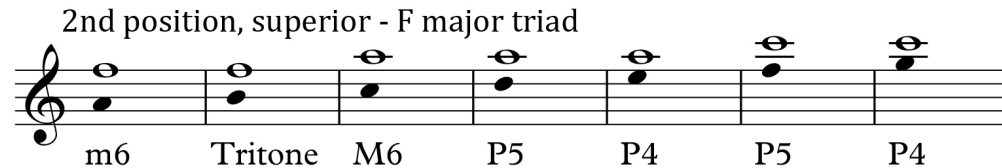

\begin{tabular}{l|l|l|l|l|l|l|} 
& & \\
interval class & 1 & 2 & 3 & 4 & 5 & 6 \\
\cline { 2 - 6 } occurrences & $\mathbf{0}$ & $\mathbf{0}$ & $\mathbf{1}$ & $\mathbf{1}$ & $\mathbf{4}$ & $\mathbf{1}$ \\
\cline { 2 - 6 } & & & &
\end{tabular}

2nd position, superior - F major triad

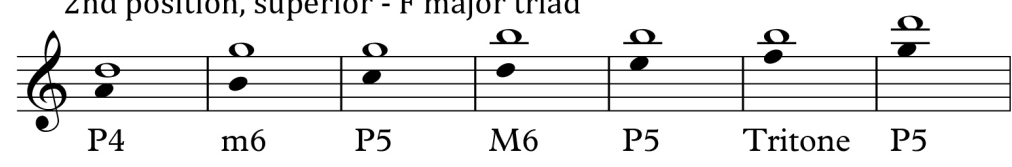

\begin{tabular}{l|l|l|l|l|l|l|}
\cline { 2 - 5 } interval class & 1 & 2 & 3 & 4 & 5 & 6 \\
\cline { 2 - 5 } occurrences & $\mathbf{0}$ & $\mathbf{0}$ & $\mathbf{1}$ & $\mathbf{1}$ & $\mathbf{4}$ & $\mathbf{1}$ \\
\cline { 2 - 5 }
\end{tabular} 
Figure 2.24: Interval ordering and class content of an A Aeolian scale paired with different triads in 2nd position, inferior

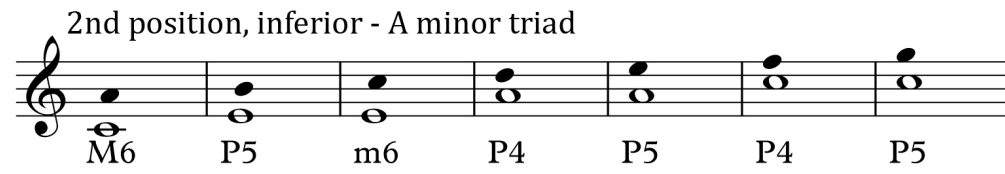

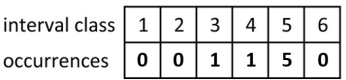

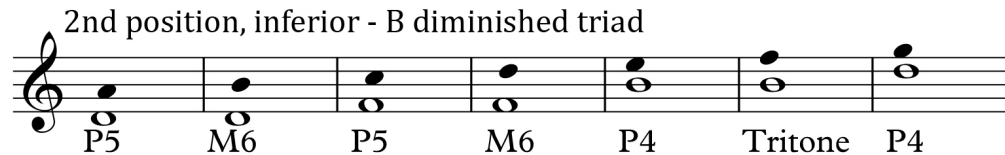

\begin{tabular}{l|l|l|l|l|l|l|}
\cline { 2 - 5 } interval class & 1 & 2 & 3 & 4 & 5 & 6 \\
\cline { 2 - 5 } occurrences & $\mathbf{0}$ & $\mathbf{0}$ & $\mathbf{2}$ & $\mathbf{0}$ & $\mathbf{4}$ & $\mathbf{1}$ \\
\cline { 2 - 5 }
\end{tabular}

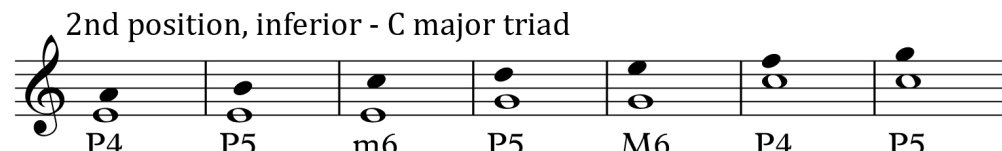

\begin{tabular}{l|l|l|l|l|l|l|}
\hline \multirow{3}{*}{ interval class } & 1 & 2 & 3 & 4 & 5 & 6 \\
\cline { 2 - 5 } occurrences & $\mathbf{0}$ & $\mathbf{0}$ & $\mathbf{1}$ & $\mathbf{1}$ & $\mathbf{5}$ & $\mathbf{0}$ \\
\cline { 2 - 5 } & & & &
\end{tabular}

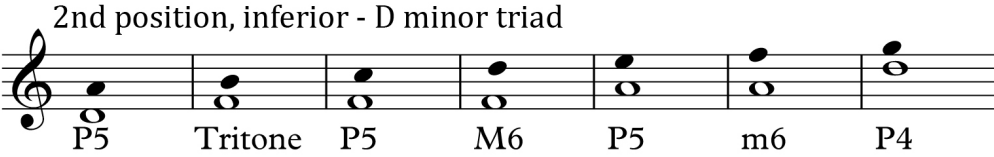

\begin{tabular}{l|l|l|l|l|l|l|}
\cline { 2 - 6 } interval class & 1 & 2 & 3 & 4 & 5 & 6 \\
\cline { 2 - 7 } occurrences & $\mathbf{0}$ & $\mathbf{0}$ & $\mathbf{1}$ & $\mathbf{1}$ & $\mathbf{4}$ & $\mathbf{1}$ \\
\cline { 2 - 6 } & & & &
\end{tabular}

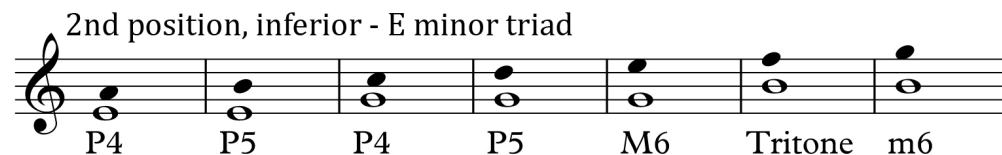

\begin{tabular}{l|l|l|l|l|l|l|}
\cline { 2 - 5 } interval class & 1 & 2 & 3 & 4 & 5 & 6 \\
\cline { 2 - 5 } occurrences & $\mathbf{0}$ & $\mathbf{0}$ & $\mathbf{1}$ & $\mathbf{1}$ & $\mathbf{4}$ & $\mathbf{1}$ \\
\cline { 2 - 5 } & & &
\end{tabular}

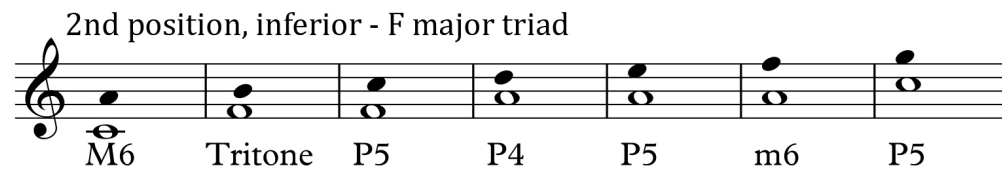

interval class \begin{tabular}{l|l|l|l|l|l|l|}
\cline { 2 - 5 } & 1 & 2 & 3 & 4 & 5 & 6 \\
\cline { 2 - 6 } & 0 & 0 & 1 & 1 & 4 & 1 \\
\hline
\end{tabular} \begin{tabular}{l|llllll|} 
occurrences & 0 & 0 & 1 & 1 & 4 & 1 \\
\cline { 2 - 6 } \\
\cline { 2 - 5 } & & & &
\end{tabular}

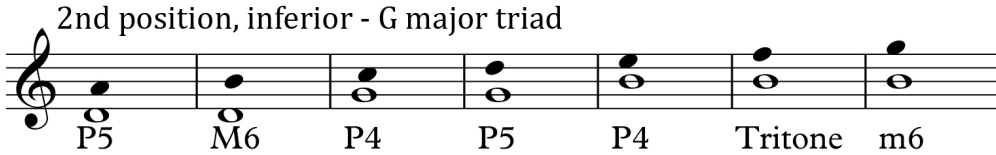

\begin{tabular}{l|l|l|l|l|l|l|}
\cline { 2 - 6 } interval class & 1 & 2 & 3 & 4 & 5 & 6 \\
\cline { 2 - 7 } occurrences & $\mathbf{0}$ & $\mathbf{0}$ & $\mathbf{1}$ & $\mathbf{1}$ & $\mathbf{4}$ & $\mathbf{1}$ \\
\cline { 2 - 6 } & & & &
\end{tabular}

\section{Discussion}

This chapter has laid the groundwork for the analyses of the six selected string orchestral works by Arvo Pärt in the chapters that follow. In addition to providing insights into the basic operations and procedures that are hallmarks of Pärt's 
tintinnabuli system (as documented by Hillier), it has provided original analysis of the nature of sounds that these processes and procedures generate. It has also identified a number of distinct aspects of Pärt's tintinnabuli system that have not previously been noted:

- A fixed T-voice in its different positions results in only three possible sets of interval class content, i.e. <121210> and <122110> and <001150>, regardless of which modally-related M-voice scale that is paired with it.

- Superior and inferior second position M-voice/T-voice pairings result in relatively consonant interval class content (i.e. <0011500>), when compared with both the superior and inferior first position M-voice/T-voice pairings $<121210>$ and $<122110>$ respectively.

- The pandiatonic manner in which Pärt constructed most of the M-voice/Tvoice pairings for his early tintinnabuli works creates a phenomenon in which the general sonority of the interval-class content of specific pairings is not affected when the M-voice is shifted to a different scalic mode; the only aspect affected is the order by which intervals are presented to the listener as the M-voice proceeds towards or away from its pitch centre.

- In contrast to a fixed T-voice when paired with different modally related M-voice scales, a fixed diatonic scale paired with its different 'possible' related triads results in nine distinct interval class vectors: <001141>, $<001150\rangle, \quad<002041\rangle,<031210\rangle,<032110\rangle,<121210\rangle,<122101>$, $<122110>$, and $<212110>$.

Furthermore at the end of Part 1 one of this chapter (Figure 2.2) I have put forward a model (which I have termed a 'Pärtian Tonnetz') for visualising the 
interrelationships between the three pitch classes that comprise a tintinnabuli work's T-voice and the remaining pitch classes of the M-voice, as well as produced a taxonomy of the ordering of intervallic content and sonorities that results from different diatonic M-voice/T-voice pairings, when different modal scales and triads are combined together in the pan-diatonic sound world that Pärt frequently uses (the full taxonomy is provided in Appendix A).

The preceding discussion on the relatively sparse intervallic content and sonorities created by potential M-voice/T-voice pairings on their own (e.g. only two voices occurring at any one time such as in In spe) frequently applies to sections of many of Pärt's compositions. However, his music often involves more than one M-voice/T-voice pairing occurring simultaneously, such as the earlier noted example in the Gloria of Pärt's Berliner Mass.

In addition, in many cases a work will have different T-voice positionings in relation to different $\mathrm{M}$-voices (i.e. first or second position, inferior, superior, or alternating) with different M-voices operating under multiple musical procedures, such as his ascending and descending stepwise based modes, additive scalic expansion, parallel voicing and retrograde and inversion procedures. The analyses in Chapters 3-6 will demonstrate that when more than one M-voice/T-voice occurs at the same time in Pärt's work, harmonically the work becomes increasingly more rich and complex. The resulting intervallic content results in unusual and non-functional harmonic progressions that do not lend themselves to traditional approaches to musical analysis. 


\section{Chapter 3 - Tabula Rasa (1977)}

Pärt does not sound like anyone we are likely to meet. There is a great deal that something - What? - has forbidden [the music] to say. Much that we know to be possible has been revoked, which places it in a very different category from music which may sound in some ways similar, .... Pärt's music, however, simple in substance, is complex in that it stands before us inexplicably tongue-tied. We may feel that we have nothing to say in return.

- Paul Griffiths ${ }^{118}$

The objective of this chapter is to provide insight into how Pärt combined the same simple melodic generative procedure with the basic contrapuntal processes of his tintinnabuli system and two other common musical processes (melodic and mensural variation) to create the two movements of his seminal work Tabula Rasa. It will also demonstrate how, with only a small number of Mvoice/T-voice pairings and melodic and mensural variations, Pärt is able to deploy his seemingly simple tintinnabuli principles to construct multiple cyclical patterns that move from lesser to greater complexity on multiple levels, creating myriad arrays of different sonorities.

For the most part, Tabula Rasa follows set rules and procedures for tintinnabuli. In comparison to Tabula Rasa, it will be seen in Chapters 4 through 6 that Pärt's later string works begin to evidence a more 'fluid interpretation' of his application of the 'rules' of tintinnabuli and a much greater degree of composerly intervention to shape the aesthetic results of these works.

\footnotetext{
118 Paul Griffiths, Modern Music and After - Directions since 1945 (New York: Oxford University
} Press, 1995), 312-13. 


\section{Introduction}

During 1977, Pärt composed three process-based instrumental works: Fratres, Cantus in memoriam Benjamin Britten, and Tabula Rasa meaning 'blank slate'. These three works would ultimately comprise the album Tabula Rasa, the first commercial release of his music, in 1984 by ECM Records. ${ }^{119}$ Tabula Rasa was also the inaugural release of New Line, ECM's new classical music division, ${ }^{120}$ and marked the beginning of a successful and enduring professional collaboration between Pärt and ECM founder Manfred Eicher. Eicher has been instrumental in distributing Pärt's music to a broader range of listening audiences than one might normally expect would be interested in music by a twentieth-century Western art music composer. ${ }^{121} 122$ Two of the works on the album, Tabula Rasa and Cantus in memoriam Benjamin Britten, were specifically composed for string orchestra. Fratres was originally composed for seven early or modern instruments and percussion and was first performed by Hortus Musicus, the Estonian early music ensemble. Pärt has subsequently produced multiple arrangements of Fratres for a wide array of different musical forces, including an arrangement for the 12 cellists of the Berlin Philharmonic in 1980, which appears on the album Tabula Rasa, as well as the better known 1980 solo violin and piano arrangement. ${ }^{123}$

\footnotetext{
${ }^{119}$ Hillier, Arvo Pärt, pp. 208-209.

${ }^{120}$ ECM Records / Universal Edition AG, ed., Arvo Pärt - Tabula Rasa, ECM New Series 1275 (Wien: Universal Edition, 2010).

${ }^{121}$ Paul Griffiths, "Now, and Then," in Arvo Pärt - Tabula Rasa, ECM New Series 1275 (Wien: Universal Edition, 2010), 5-7.

122 While all three of the string orchestral works, along with a violin and piano arrangement of Fratres, introduced Pärt to a broad Western audience, each work had also been performed in public concerts to both Eastern and Western European audiences prior to the release of the album Tabula Rasa.

${ }^{123}$ ECM Records/ Universal Edition AG, ed., Arvo Pärt - Tabula Rasa, CD, Issue, Special edition (Munich: ECM in collaboration with Universal Edition, 2010), 31.
} 
Compared to his other early tintinnabuli works, Tabula Rasa is a relatively lengthy composition at 25 minutes in duration. The work is a double concerto for two solo violins, string orchestra, and prepared piano ${ }^{124}$ comprising two movements: Ludus, the Latin word for 'play' or 'game', and Silentium, meaning 'silence', 'stillness', or 'repose'. Bridging Ludus and Silentium is a 38 bar cadenza.

The basic melodic building block of both Ludus and Silentium is a stepwise upwards and downwards progression from a single pitch class centre that expands outwards in alternating arcs one pitch at a time until a predetermined span has been achieved (Figure 3.1).

Figure 3.1: Basic building block of Tabula Rasa

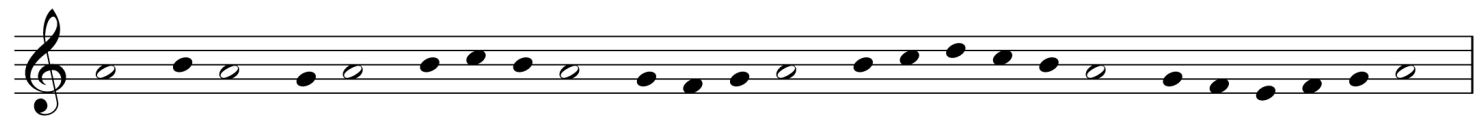

The 'game-like' aspect of Ludus plays out in the manner that Pärt manipulates this basic concept, via a series of varied procedures to create a frenetic shimmering tapestry of sound that is punctuated with searing fortissimos and moments of silence. In contrast, Silentium, while based on the same outward expanding melodic material, develops in a purposeful slow-motion manner, wherein the music is revealed through a triple-metre canon that Pärt notes should be played senza moto (without motion).

\footnotetext{
124 To prepare the piano, metallic threaded screws, each five to six millimetres in diameter, are placed behind the damper for each note, between two of the three strings. This is so that the two piano strings separated by the screw will produce a 'distorted timbral' effect, while the third string is allowed to ring freely. The resulting sound is that of a muted bell-like gong, that must be amplified, so as to be heard over the orchestra, by placing a microphone inside the piano 20 to 30 centimetres above the middle register strings.
} 


\section{Tabula Rasa: Ludus}

The following style analysis is supplemented by graphic representation in the form of a MIDI-recreation of the work's musical lines to provide a visual overview of the entire work.

\section{Style analysis of Ludus}

\section{Large dimension}

All melodic and harmonic movement in Ludus is based upon the stepwise process illustrated above in Figure 3.1, which plays out using A natural minor scale (A Aeolian) M-voices, paired with A minor triad first position alternating T-voices. Rhythmically, the central process expands outwards from its tonal centre using a duple-metre scheme of varying bar lengths and pulsing crotchets that Pärt indicates should be executed con moto (played with motion), quarter note $=c .120$ (120 beats to the minute). Figure 3.2 overleaf provides a MIDI-recreation of Ludus (without its cadenza), which illustrates the outward expansion of the string orchestral voices from their pitch class centres, while Figure 3.3 details just the first violins, second violins, and contrabasses' lines.

As can clearly be seen in Figure 3.3, both the violins and contrabasses' musical material comprises eight pairings of pitch class content separated by periods when the string sections of the orchestra fall silent. Each pairing initially expands upwards then downwards and then upwards again from a central pitch (a), and the inverse operation occurs in the second half of each pairing. While not shown in Figure 3.3, the violas and violoncellos execute the same musical patterns as the violins and contrabasses, though in a slightly staggered fashion to the violins 
(discussed below). A drone tone on A0 in the contrabasses acts as a bridge between the first and second half of each pairing (c). During periods when the main string sections are silent, one or both of the solo violins repeat the second part of each pairing's musical material (b) in a higher register (Figure 3.2). 
Figure 3.2: Ludus - MIDI-recreation (with contrabasses shown in their sounding register) ${ }^{125}$

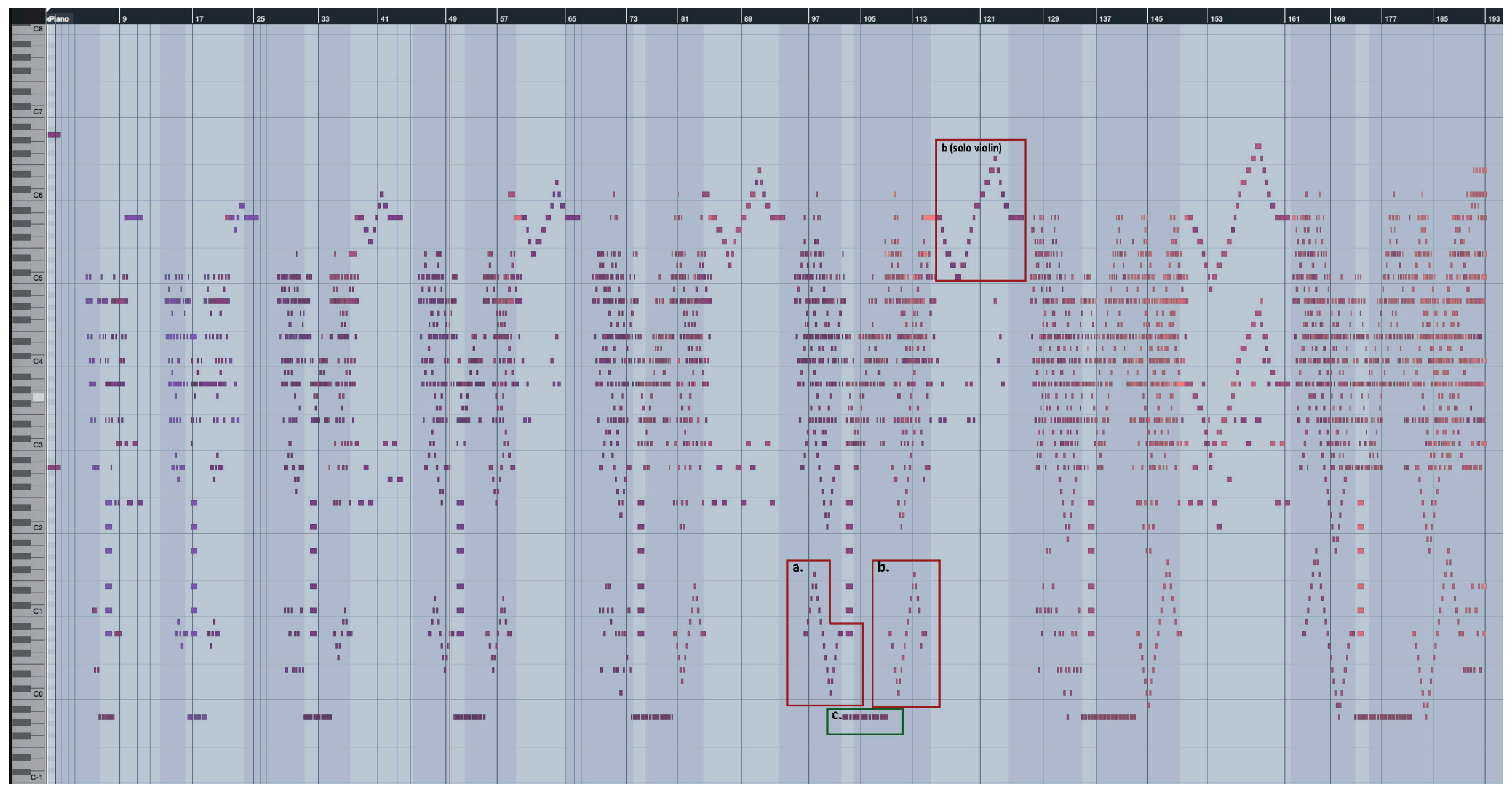

125 Midi-recreation created using Cubase ${ }^{\mathrm{TM}} 7.5$. 
Figure 3.3: Ludus - MIDI-recreation (first and second violins and contrabasses) ${ }^{126}$

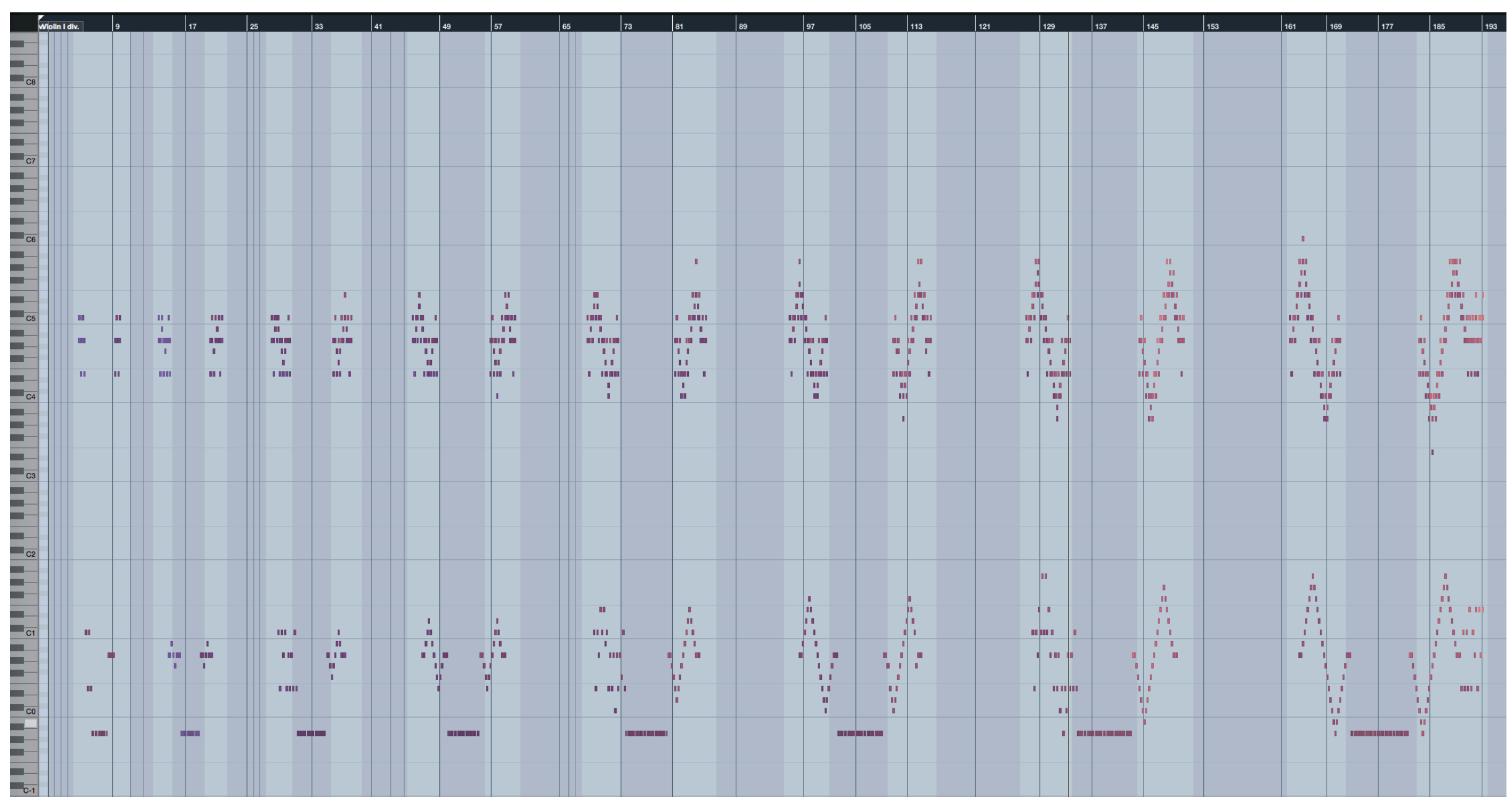

126 Midi-recreation created using Cubase ${ }^{\mathrm{TM}}$ 7.5. 
The A Aeolian M-voice and first position alternating T-voice operations in Ludus generate two interval class vectors (Figure 3.4), from which all harmonic content ultimately arises. When the T-voice is in first position, superior to the M-voice, the following intervals are generated: one minor second, two major seconds, one minor third, two minor thirds, and one perfect fourth. When the T-voice is in first position, inferior to the M-voice, the following intervals occur: one minor second, two major seconds, two minor thirds, one major third, and a perfect fourth.

Figure 3.4: Interval classes generated by an A minor triad and an A Aeolian (natural minor) scale, first position, superior and first position, inferior

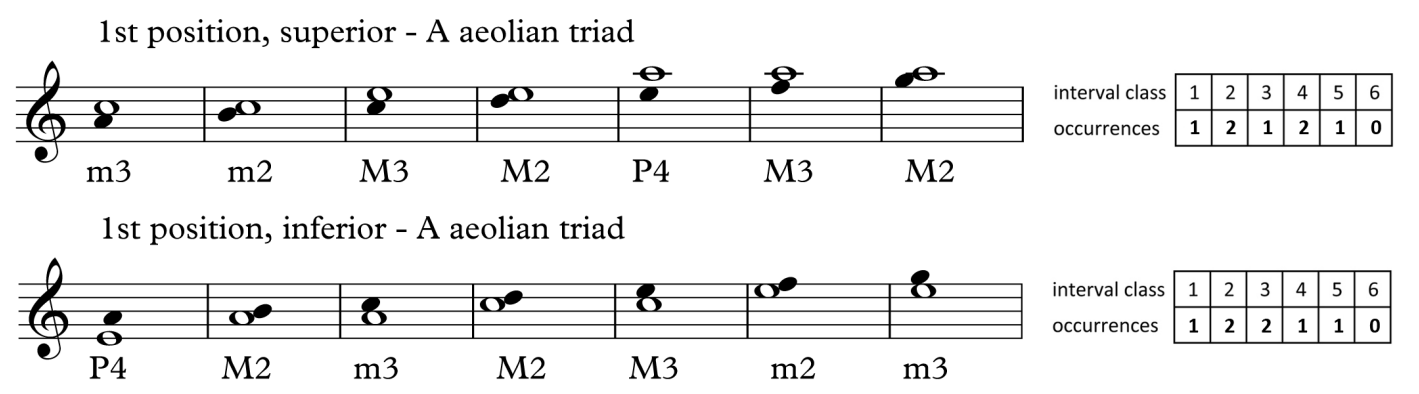

As can be seen in Figure 3.4, the interval class content of both vectors is very similar. The difference between the two is that an A Aeolian M-voice paired with an A minor triad first position, superior T-voice results in one minor third and two major thirds, while an A Aeolian M-voice paired with an A minor triad first position, inferior T-voice results in two minor thirds and one major third.

Except for the violas, which have a range of an octave plus a minor third, all of the string sections of the orchestra play within a two-octave range in Ludus (Figure 3.5). The solo violin 2 plays within a 3 octave range (A3 to A6), while the upper range of the solo violin 1exceeds that by a fourth (E4 to A7). 
Figure 3.5: Registral spans of string sections - Ludus

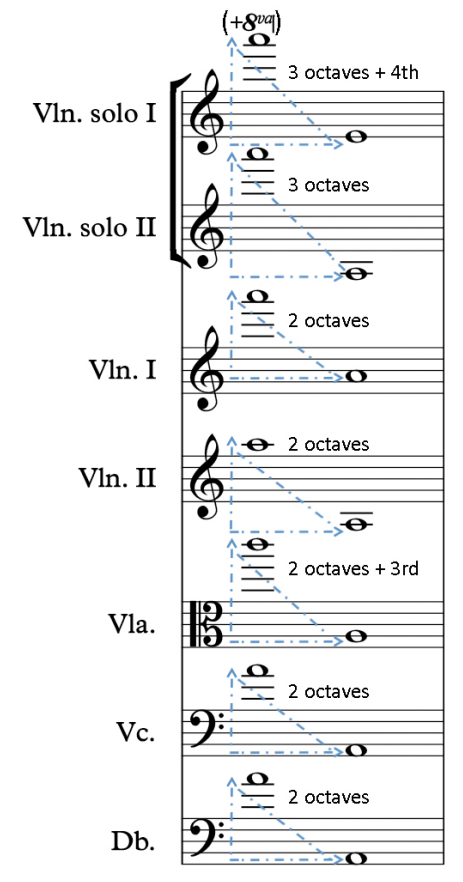

Ludus commences with the two solo violins playing a single fortissimo A four octaves apart at A3-A7, which is roughly the full playable span of a violin, followed by eight beats (approximately four seconds) of silence (Figure 3.6). ${ }^{127}$ The silence is broken by staggered pianissimo entrances of different sections of the string orchestra, starting with the first violins playing divisi. The upper violin line initially executes four pulsing crochets, played détaché on A5, thus reinforcing A as the pitch centre of the movement. Simultaneously the lower of the divisi first violin lines plays détaché crochets, alternating between C5 and E4 above and below the upper first violin line.

127 While not specifically noted in the score, in performance and recordings the opening fortissimo A four octaves apart at A3-A7 is usually played with extremely heavy vibrato. 
Figure 3.6: Ludus - opening bars

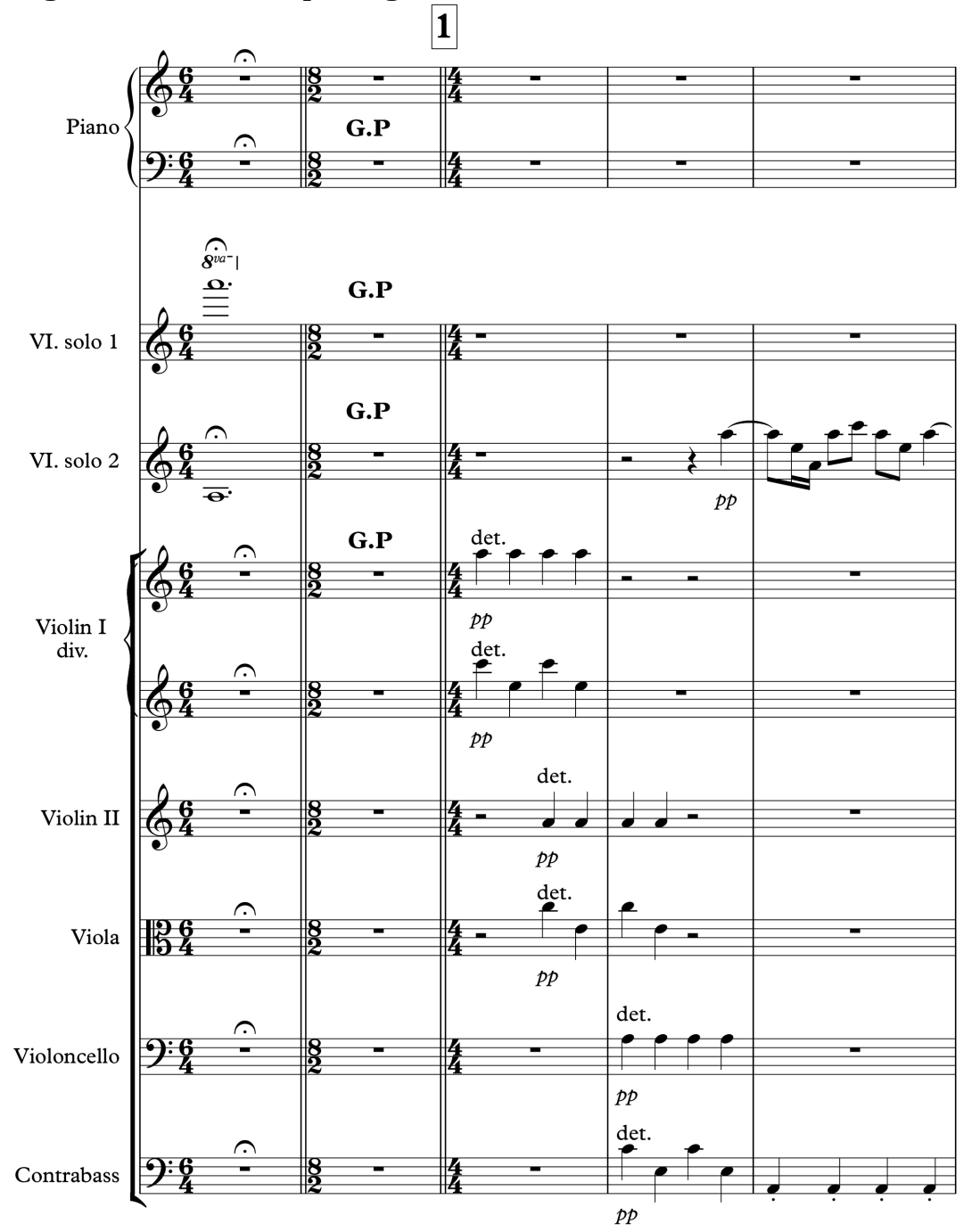

The combination of détaché bowing and the lower first violins alternately sounding C5 and E4 above and below the upper first violins' A5 creates a singsong-like mechanical pattern, which becomes a sonic bookend announcing the beginning and end of each of Ludus's eight main sections.

\section{Middle dimension}

The basic musical premise of Ludus, which plays out in each of the movement's eight sections, is the manifestation of the contrasting textures of a homophonic string orchestra and two virtuosic solo violins that are engaged in a complex 
game of 'call and response' as the M-voice lines unfurl and expand outwards from their central pitch, pitch class A. An illustration of this can be seen in Figure 3.7.

Figure 3.7: Ludus - general musical scheme
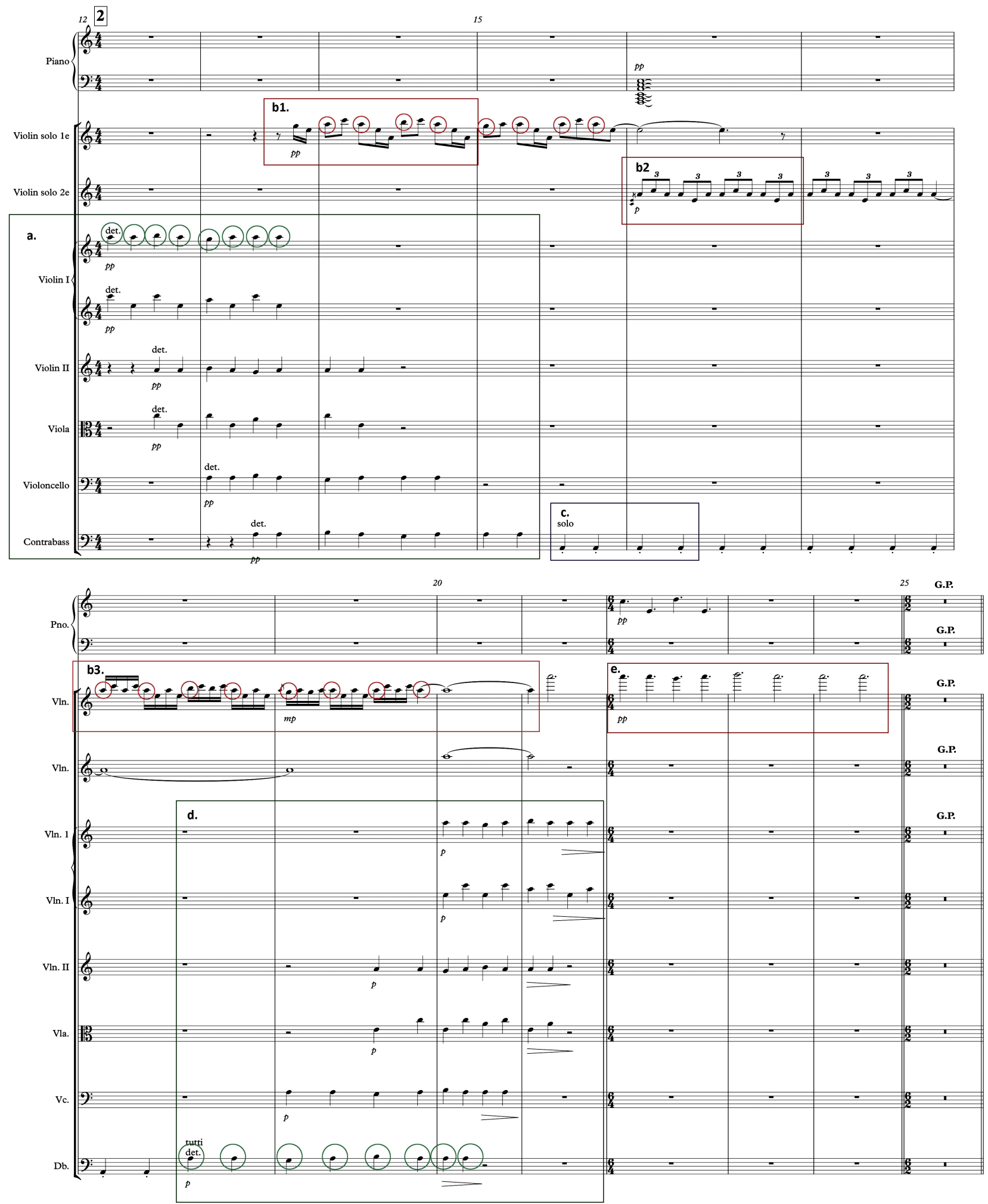
In Section 2 bar 12, the divisi first violins enter, followed by the other sections of the string orchestra in staggered fashion. After the upper line of the first violins has finished presenting the musical germ of A-A-B-A-G-A-A-A as crotchets (see a, in Figure 3.7) accompanied by the lower first violins T-voice, the solo violin 1 enters at the end of bar 13 playing the same musical fragment (see b1), but at twice the speed (i.e. as quavers) while ornamenting each pitch of the 'melody' with additional pitches from the triad of the T-voice (C-E-A). After the solo violin 1 has completed its first statement in Section 2, the solo violin 2 enters at bar 16 (see b2) as an unaccompanied T-voice. While the solo violins engage in their game of 'call and response', the contrabasses drone staccato crotchets on A2 (sounding at A1) (see c).

Solo violin 1 returns in bar 18, restating the melodic fragment as semiquavers, again ornamenting the melody with pitches from the T-voice triad (see b3). Two beats later the contrabasses commence playing the melodic fragment (see d) followed by the violoncellos, second violins and the upper divisi line of the first violins - but with the pitches $\mathrm{G}$ and $\mathrm{B}$ presented in reverse order to that of the original melodic germ (i.e. A-A-G-A-B-A-A-A). After the upper divisi line of first violins has completed this melodic fragment, the metre changes from $4 / 4$ to $6 / 4$, and the solo violin 1 restates the melodic germ one last time as dotted crotchets (see e). The section ends with a Grande Pause bar of silence in bar 25.

Each of the remaining sections of Ludus are dictated by this same general 'call and response' scheme between the two solo violins and the string orchestra, with the melodic material in each subsequent section expanding upwards and downwards by one additional pitch in each direction of the scale from the central pitch A. 
The staggered entrances of the strings across their different registers create shifting layers of sound across roughly a four-octave range of the orchestra. This creates the aural illusion that the music is seemingly starting from a distance at the beginning of each section with the initial entrance of the first and second violins, approaching the listener, ever closer, when the violas followed by the violoncellos and contrabasses make their entrances - only to recede again as first the violoncellos and contrabasses drop out, then the violas followed by the violins. At the end of each section, only the two solo violins and prepared piano remain, until they too fall silent.

As the A Aeolian scales of each M-voice in Ludus expand upwards and downwards from their pitch centre, each subsequent section of Ludus is longer than its predecessor, except for Section $8,{ }^{128}$ which does not follow this trend (Table 3.1). Including the solo violins' entrance, which is followed by a bar of silence, Section 1 is 11 bars in duration including a 7/2 bar of silence at the end of the section. Section 2 is 14 bars in duration, including a $6 / 2$ bar of silence at its end. By the time the movement gets to Section 7, wherein the M-voice lines have almost achieved their maximum span of two octaves, the section is 36 bars in duration. These temporal expansions are the natural result of the increasing scalar spans of the M-voices, which reach their furthest span by finally unfolding across a two octave diatonic span of the A minor scale - one octave in each direction (e.g. A2 to A4 in the case of the cellos). When the full two-octave span is achieved in Section 8, this involves 30 bars. Section 8 is also shorter than Section 6 or 7 due to the 'omission' of 10 bars at the end of the section, wherein

${ }^{128}$ In Section 8, the solo violins commence concurrently with the entrance of the first string section of the orchestra, rather than entering in a staggered manner as is the case for the other seven sections. 
one of the two solo violins would have executed the full melodic pattern one final time. In lieu of this happening, the orchestra commences the movement's cadenza instead.

Table 3.1: Ludus - number of bars and variance of dynamics in each section

\begin{tabular}{|l|l|l|l|}
\hline Section & Bars & $\begin{array}{l}\text { Number } \\
\text { of bars }\end{array}$ & $\begin{array}{l}\text { String orchestra } \\
\text { dynamics (bars) }\end{array}$ \\
\hline Section 1 & $1-11$ & 11 & $p p(3-7), p(7-10)$ \\
\hline Section 2 & $12-25$ & 14 & $p p(12-19), p(19-21)$ \\
\hline Section 3 & $26-43$ & 18 & $p(25-34), m p(42)$ \\
\hline Section 4 & $44-66$ & 23 & $p(44-54), m p(54-59)$ \\
\hline Section 5 & $67-93$ & 27 & $m p(67-79), m f(79-84)$ \\
\hline Section 6 & $94-125$ & 32 & $m p(94-108), m f(108-115)$ \\
\hline Section 7 & $126-161$ & 36 & $m f(126-142), f(142-150)$ \\
\hline Section 8 & $162-191$ & 30 & $m f(162-180), f(180-191)$ \\
\hline
\end{tabular}

In contrast to the expanding operation in the M-voices that results in temporally longer successive sections, Pärt introduces a process of temporal diminution in each bar of silence in Ludus, whereby with each reoccurrence of a bar of silence, the number of beats per bar contracts by an increment of a crotchet. As noted previously, after the initial entrance of the solo violins in bar 1 of Ludus, an 8/2 bar of silence follows before Section 1 commences. The bar of silence at the end of Section 1 reduces to seven minims; the bar at the end of Section 2 reduces to six minims, etc. This process of subtraction continues to the end of Section 7 , which has a $1 / 2$ bar of silence, one minim in duration. ${ }^{129}$ By the end of Section 8 , there is no silence left.

Another middle dimension aspect of Ludus is its dynamic scheme. After the fortissimo entrance of the two solo violins at the beginning of Ludus, the dynamics drop to pianissimo with the string orchestra's first entrance. The dynamics of the orchestra build slowly as the work progresses, and within each section, the

\footnotetext{
${ }^{129}$ See also Hillier, Arvo Pärt, 115.
} 
orchestra's second entrance is always one dynamic marking louder than that of its initial entrance (see Table 3.1 above).

Generally, the two solo violins follow suit, initially matching the string orchestra's starting dynamic marking, increasing by one or two dynamic increments as the section progresses, and then retreating back to each section's initial dynamic marking at its end when one of the solo violins restates the section's M-voice melodic germ (e.g. bars 22 through 24 in Figure 3.7 above). The exception to this is Section 8, wherein the solo violins enter playing forte in contrast to the string orchestra's mezzo forte entrance.

A further middle dimension aspect of Ludus relates to the movement's T-voices. As a further reflection of its title Ludus (play or game), Section 2 also establishes the precedent of Pärt 'playing' with the placement of T-voices in the cellos and contrabass lines, with the two parts swapping M-voice/T-voice roles in the second half of Sections 1, 3, 5, and 7, while both lines take an M-voice role in both the first and second halves of Sections 2, 4, 6, and 8 (Table 3.2).

Table 3.2: Ludus - M-voice and T-voice placement - cellos and contrabasses

\begin{tabular}{|l|l|l|l|l|l|l|l|l|l|l|l|l|l|l|l|l|l|l|}
\hline & \multicolumn{3}{|l|}{ Sec. 1 } & \multicolumn{3}{l}{ Sec. 2 } & \multicolumn{3}{l|}{ Sec. 3 } & \multicolumn{2}{l|}{ Sec. 4 } & \multicolumn{2}{l|}{ Sec. 5 } & \multicolumn{2}{l|}{ Sec. 6 } & \multicolumn{2}{l|}{ Sec. 7 } & \multicolumn{2}{l|}{ Sec. 8 } \\
& $1^{\text {st }}$ & $2^{\text {nd }}$ & $1^{\text {st }}$ & $2^{\text {nd }}$ & $1^{\text {st }}$ & $2^{\text {nd }}$ & $1^{\text {st }}$ & $2^{\text {nd }}$ & $1^{\text {st }}$ & $2^{\text {nd }}$ & $1^{\text {st }}$ & $2^{\text {nd }}$ & $1^{\text {st }}$ & $2^{\text {nd }}$ & $1^{\text {st }}$ & $2^{\text {nd }}$ \\
\hline Cellos & $M$ & $T$ & $M$ & $M$ & $M$ & $T$ & $M$ & $M$ & $M$ & $T$ & $M$ & $M$ & $M$ & $T$ & $M$ & $M$ \\
\hline Contrabasses & $T$ & $M$ & $M$ & $M$ & $T$ & $M$ & $M$ & $M$ & $T$ & $M$ & $M$ & $M$ & $T$ & $M$ & $M$ & $M$ \\
\hline
\end{tabular}




\section{Small dimension}

The small dimension of Ludus is dominated by Pärt's treatment of the three different arpeggiation figurations that are executed by the solo violins in each section. These figurations initially occur in Section 1 bars 3 through 11 (Figure 3.8)

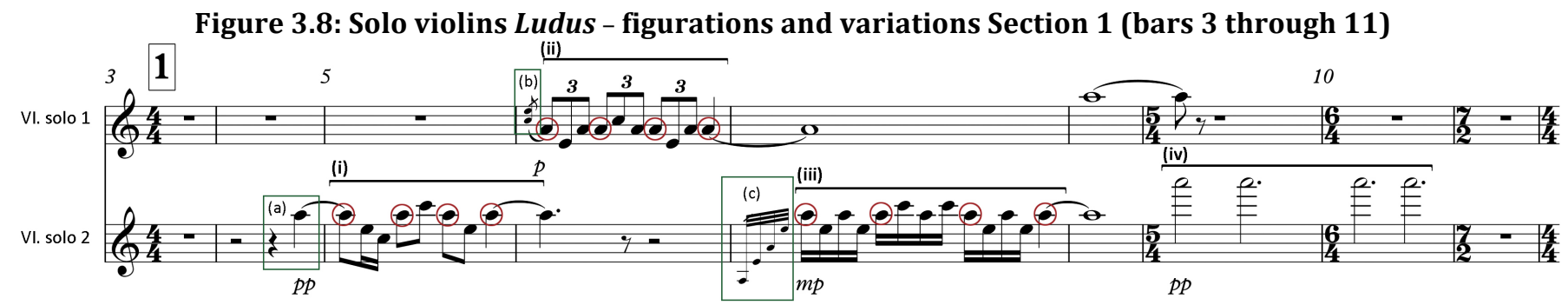

The solo violin 2 line presents the first of these patterns (i) as a quaver on the downbeat of bar 5 followed by two semiquavers and then four quavers; the four iterations of A5 on each crotchet beat of the measure recall the M-voice material that is being played by different sections of the string orchestra below, while the notes occurring off the beat can be considered to be the figuration's T-voice. As the second violin reaches the end of its figuration, the first violin enters playing triplet quavers (ii) wherein the M-voice sounds on the first and third note of the tuplet, and the T-voice alternates above and below on the second note of each triplet. The second violin enters again (iii), but with the tuplet figuration expanded to four semiquavers with the M-voice sounding on the first and third semiquaver in each four note grouping, and the T-voice sounding on the second and fourth semiquavers. Above this figure the first solo violin plays a sustained A for four beats an octave below at A4.

Each of these figurations by the solo violins commences with a different ornamentation. The ornamentation for figuration (i) is a crotchet on A (a), tied 
over from the last beat of the preceding bar to the first note of figuration (i). The ornamentation for figuration (ii) is pseudo acciaccatura (b) simultaneously sounding the upper two pitches of the A minor triad (E and $\mathrm{C}$ above the A), while ornamentation for figuration (iii) is a rising four note arpeggio (c) from below (A-E-A-E). Section 1 ends with the restatement of the four As of the M-voice (at A6) by solo violin 2 (see iv, Figure 3.8), but as a minim followed by three dotted minims, which are in effect 'ornamented' by violin solo 1 playing a sustained A6 for four and one-half beats commencing in the prior bar.

These four figurations and their associated ornamentations define the primary set of rhythmic patterns and ornamentations for the solo violin lines in Ludus, as well as the order in which they will be played in the seven subsequent sections of Ludus until the work's cadenza. In contrast, the ensemble string sections are rhythmically restricted to playing only the pulsing détaché and staccato crotchets throughout the movement.

While it might seem that these rhythmic patterns and their associated ornamentations would restrict the diversity of the solo violin lines in each of the subsequent sections, Pärt finds a way to work around this by playing with the way the two solo violin parts are staggered in relation to each other, by omitting one or more of the ornamentations in favour of repeating another one instead - displacing the ornamentations from the beginning to a later part of a particular solo violin line, or by having one of the solo violins execute just part of an ornamentation.

For example, in Figure 3.9 overleaf, while the main rhythmic patterns of the figurations and their usage in relation to the two solo lines in Section 2 are 
identical to that found in Section 1, Pärt truncates the first ornamentation (a) for figuration (i) in bar 13, leaving out the crotchet suspension to the first quaver, and keeping only the two semiquaver notes. The second ornamentation (b) to figuration (ii) in Section 2 is an acciaccatura simultaneously sounding the upper two pitches of the A minor triad ( $\mathrm{C}$ and $\mathrm{E}$ ) but from below on A3 and C4 in bar 16, rather than above as was the case in Section 1. Where one would expect to find ornamentation (c) just before figuration (iii) at bar 18, this has been omitted from the beginning of the re-entrance of the solo violin 1 line, and instead ornament (c) occurs as an acciaccatura at the beginning of bar 19 , as a single grace note (A above G). The red-circled notes in Figure 3.9 indicate the progression of the Mvoice material in the solo voice arpeggiations as it expands outwards from its pitch class centre. In Section 2 figurations (b) and (d), Pärt also reorders the sequence of the M-voice notes from A-A-B-A-G-A-A-A to A-A-G-A-B-A-A-A (see bars 16-17 and 22-23 in Figure 3.9).

Figure 3.9: Solo violin lines, Ludus - Sections 1 \& 2
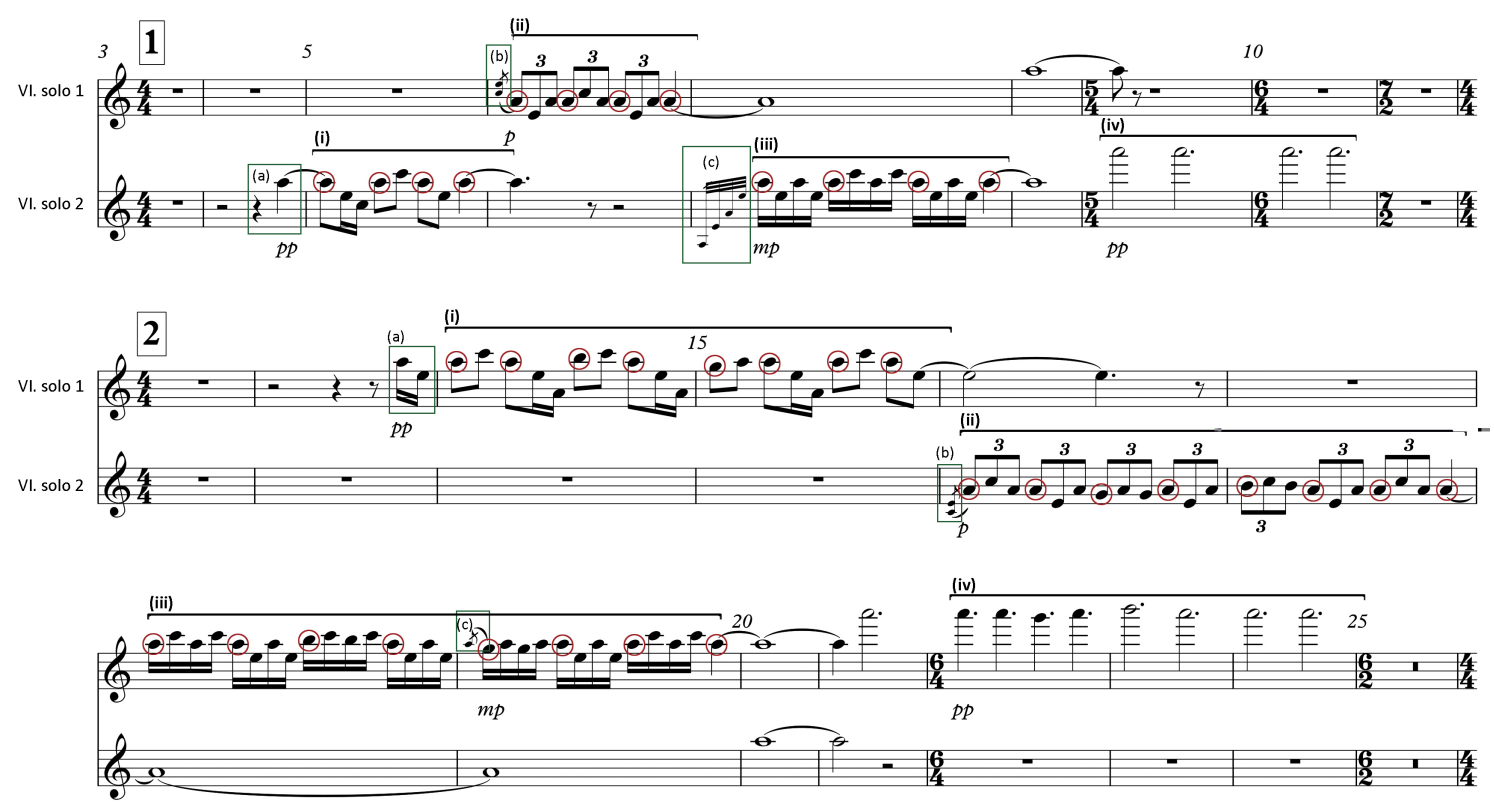
In the solo violin variations in Section 3 (Figure 3.10), Pärt reinstates the ornaments in their original form and placements as those used in Section 1, but he also introduces a new T-voice operation in bars 28 through 36 by having the solo violins alternate between playing the M-voice material ornamented by first position alternating T-voice arpeggiations, and including an additional crotchetbased T-voice (as indicated in Figure 3.10 by red boxes) in first position, alternating above and below the M-voice notes in the arpeggiations in the opposing solo violin line.

Figure 3.10: Solo violin lines, Ludus - Section 3 (bars 26 through 43)
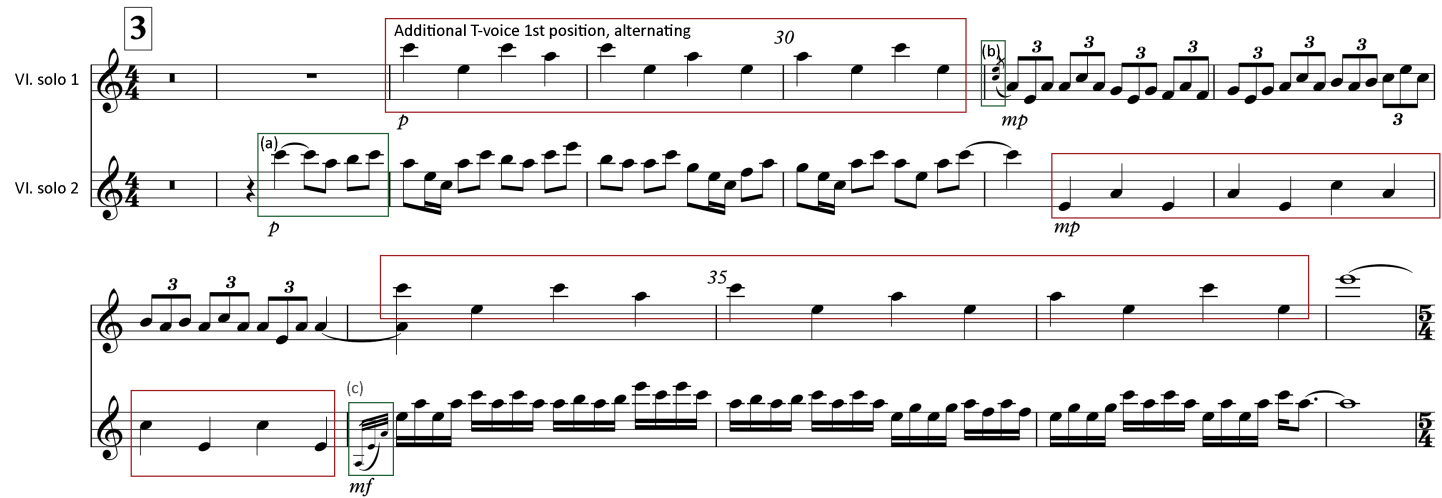

Pärt also changes the positional relationships of the T-voice arpeggiations and their respective M-voices. For example in figurations ii and iii in Section 2 (see bars 14 and 16 in Figure 3.11 overleaf), the M-voice component of the tuplet figurations both commence with the M-voice material occurring on the first and third quavers of the triplet (figuration ii), and the quadruple semiquaver (figuration 3) figures, with the alternating T-voice arpeggiations commencing in the superior position to the M-voice material in operation ii and below the Mvoice material in operation iii.

In Section 3, Pärt reverses these arrangements with the T-voice material in both the triplet quaver and quadruplet semiquaver arpeggiations starting in the 
inferior position to the initial M-voice pitches in figurations (ii) and (iii) in bars 28 and 31, while also shifting the M-voice material in figuration (iii) to the second and fourth notes of each quadruplet sixteenth note figure (c), as opposed to the first and third notes as is the case in operation iii of Section 2.

Figure 3.11: Solo violin lines, Ludus - Sections 2 \& 3
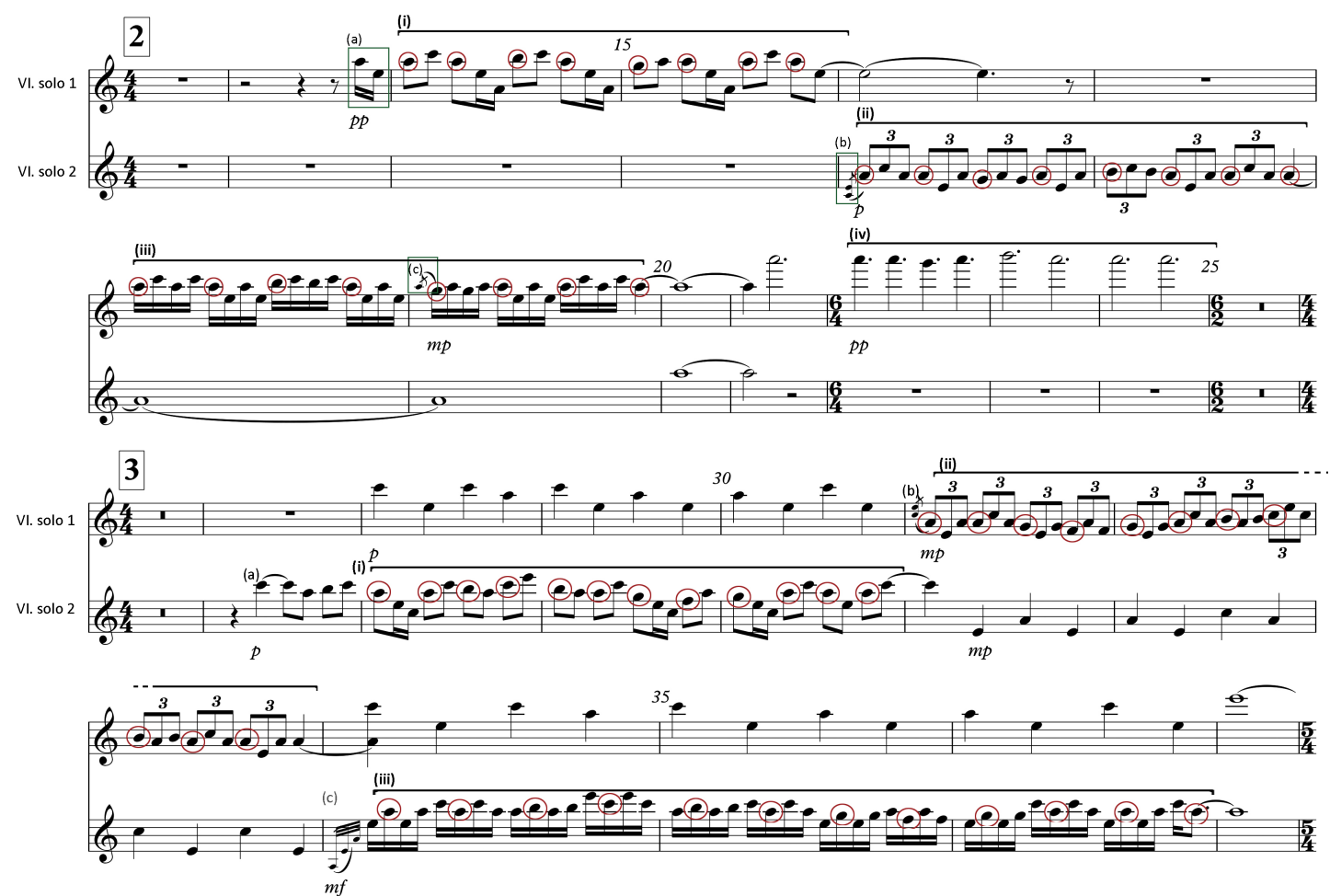

In each subsequent section, Pärt continues to subtly introduce further degrees of complexity to figurations (i), (ii), and (iii), as well as the relationship between the two solo violin lines. In Section 4, the placement of the T-voice and M-voice materials and their relative positions within their respective operations are almost identical to that found in Section 2. However, the solo violins now alternate between playing M-voice material and providing additional T-voice lines concurrently to each M-voice operation (see bars 46 and 47, Figure 3.12 overleaf), as in Section 3. At first glance the ornamentation to operation (i) 
would appear to be an expanded version of that found in the equivalent operation in Section 1; however, Pärt has also introduced the inclusion of neighbouring pitches $\mathrm{F}$ and $\mathrm{G}$ in the ornamentation in bar 45 , both pitches of which are foreign to the T-voice triad.

Figure 3.12: Solo violins Ludus - Section 4 figurations (i)

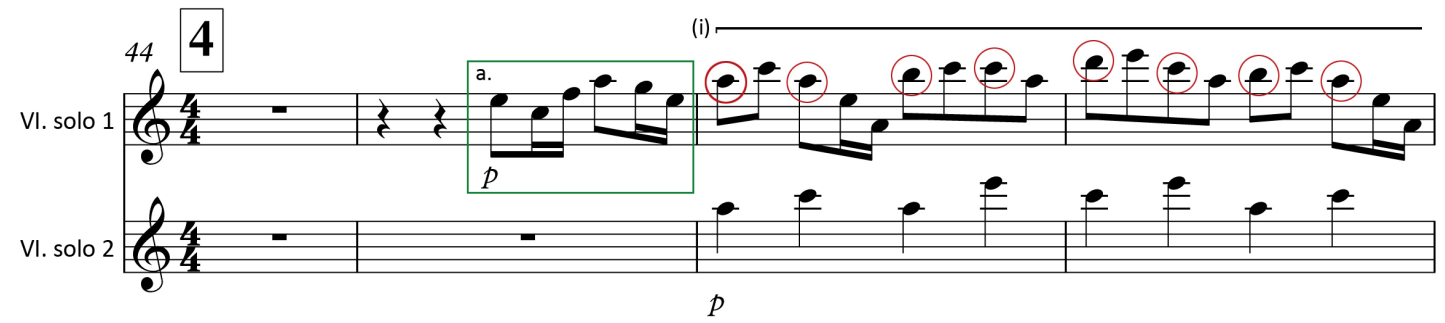

Starting in bar 70 in Section 5 (Figure 3.13), both solo violin lines in figuration (i) function as a single more complex M-voice/T-voice operation. The M-voice material in the solo violin 1 line echoes that of the solo violin 2 in hocket fashion (see bar 70), while the T-voice materials of each solo violin line expand and contract towards and away from each other as they alternate between superior and inferior positions in relation to the M-voice material in their respective lines. In figuration (ii) the M-voice material now only occurs on the first note of the triplet with the other two notes of the triplet taking a first position, alternating $\mathrm{T}$ voice function. As illustrated in the last bar of Figure 3.13, in the solo violin 2 line the third note of the triplet echoes the M-voice material of solo violin 1 doublestopped by repeated T-voice material from beats $1,2,3$, and 4 in the lower line (indicated by the green boxes in bar 75). 
Figure 3.13: Solo violins Ludus - Section 5 figurations (i) and (ii)

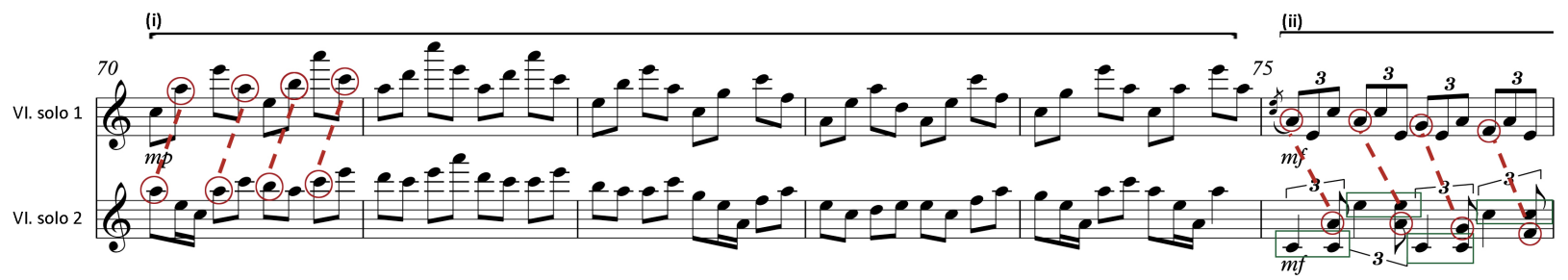

In figuration (iii) there is a break with the previous pattern of dual M-voice/Tvoice pairings in both solo voices, with the solo violin 1 functioning solely as an additional T-voice line, working its way upwards and downwards along the pitches of the T-voice triad in alternating first and second position, superior and inferior patterns, in relation to the M-voice material in the solo violin 2 line (as denoted by the green and blue circles in bar 80 in Figure 3.14).

Figure 3.14: Solo violins Ludus - Section 5 figuration (iii)

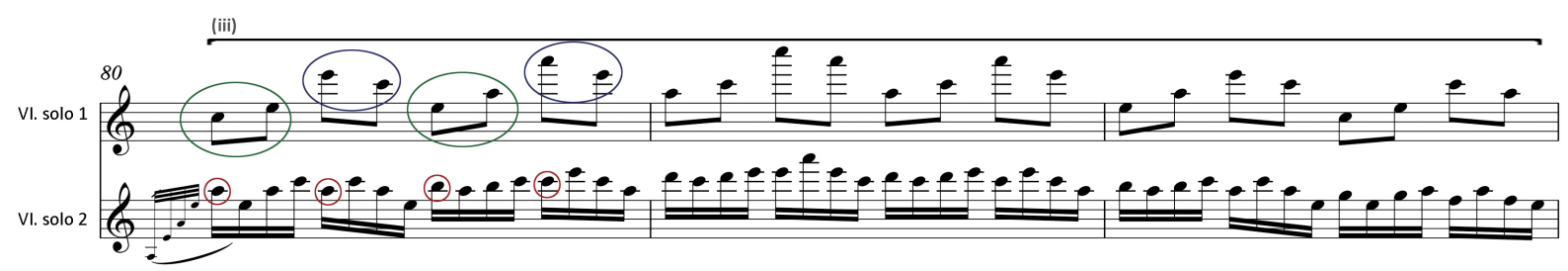

From Section 5 onwards, the solo violin lines in Sections 6 through 8 continue to operate as compound M-voice/T-voice operations. While Pärt continues to introduce additional subtle variations to figurations (i) through (iii) in each section (e.g. staggered entrances, double stopped notes, and repeating M-voice pitches), to the listener the differences between each begin to blur into a kaleidoscope of motion dominated by the pitch classes of the A minor triad. Figure 3.15 through Figure 3.17 overleaf provide visual summaries of the three different figurations and their respective ornaments as they continue to subtly evolve in Sections 6 through 8 of Ludus. 
Figure 3.15: Solo violins Ludus - Sections 6 through 8, figuration (i) and its ornamentation
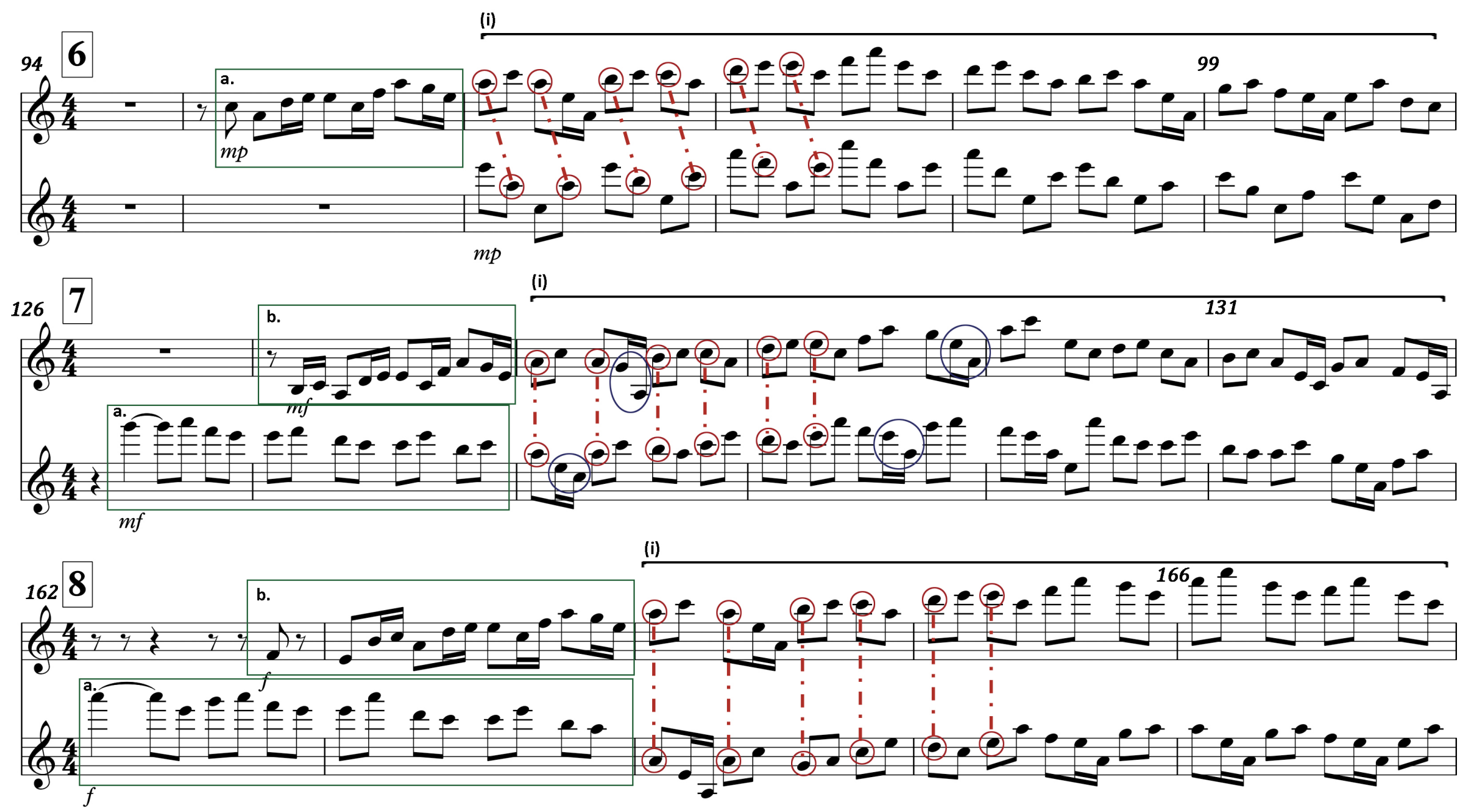
Figure 3.16: Solo violins Kudus - Sections 6-8, figuration (ii)

6

(ii)

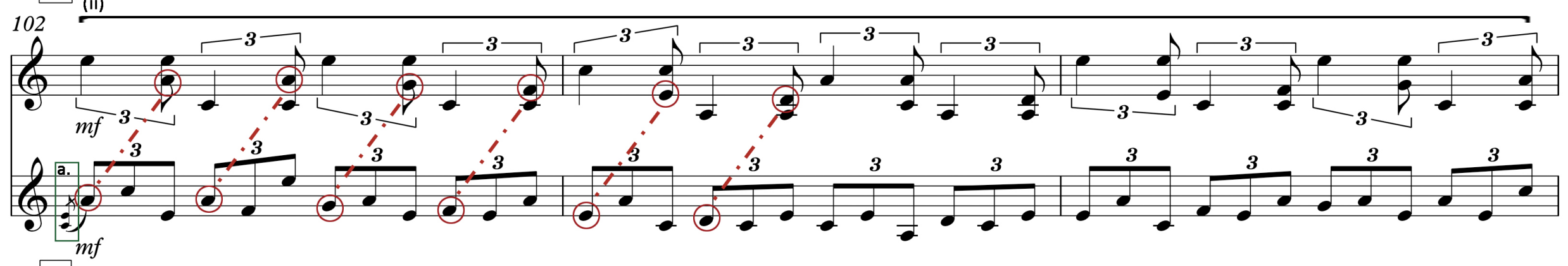

7

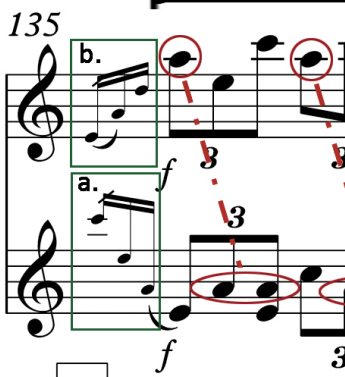

8

(ii)
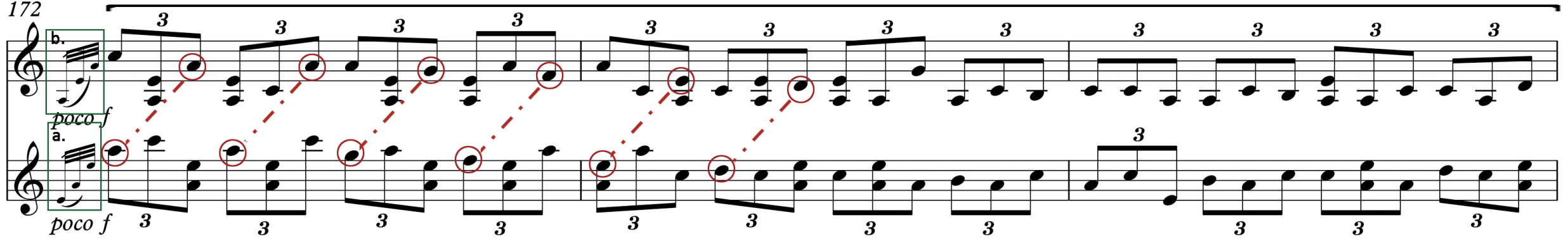

106 
Figure 3.17: Solo violins Ludus - Sections 6-8, figuration (iii)

6 a. (iii)

(6)

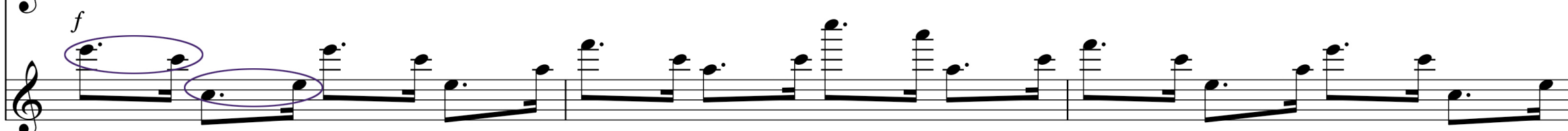

e $f$

7

7 (iii)

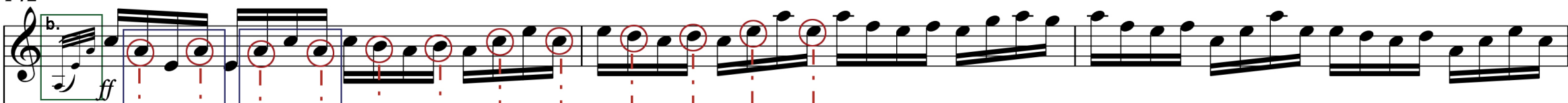

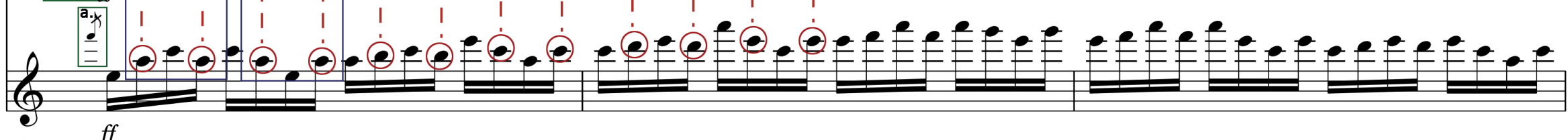

(2) 


\section{Interval class analysis and sonority mappings of Ludus}

The following section builds on the preceding style analysis and examines: 1) the intervallic content that arises from the combination of mensural cannon with tintinnabuli operations in Ludus and 2) sonority mapping of this content, detailing the shifting musical sonorities throughout the work. This content analysis is supplemented by graphic representation in the form of a Pärtian Tonnetz, to demonstrate the interrelations between the different M-voice and T-voice pitch classes and the resulting intervallic content when any two pitches occur at the same time.

The intervallic content potential of the pitch classes of an A Aeolian, or A natural minor, scale includes two minor seconds, five major seconds, four minor thirds, three major thirds, six perfect fourths and one tritone, i.e. Interval Class Vector <254361> (Forte Code: 7-35). The Pärtian Tonnetz in Figure 3.18 overleaf details the various intervallic relationships between the pitch classes of Ludus. 
Figure 3.18: Pärtian Tonnetz of T-voice/M-voice pitch class relationships in Ludus $^{130}$

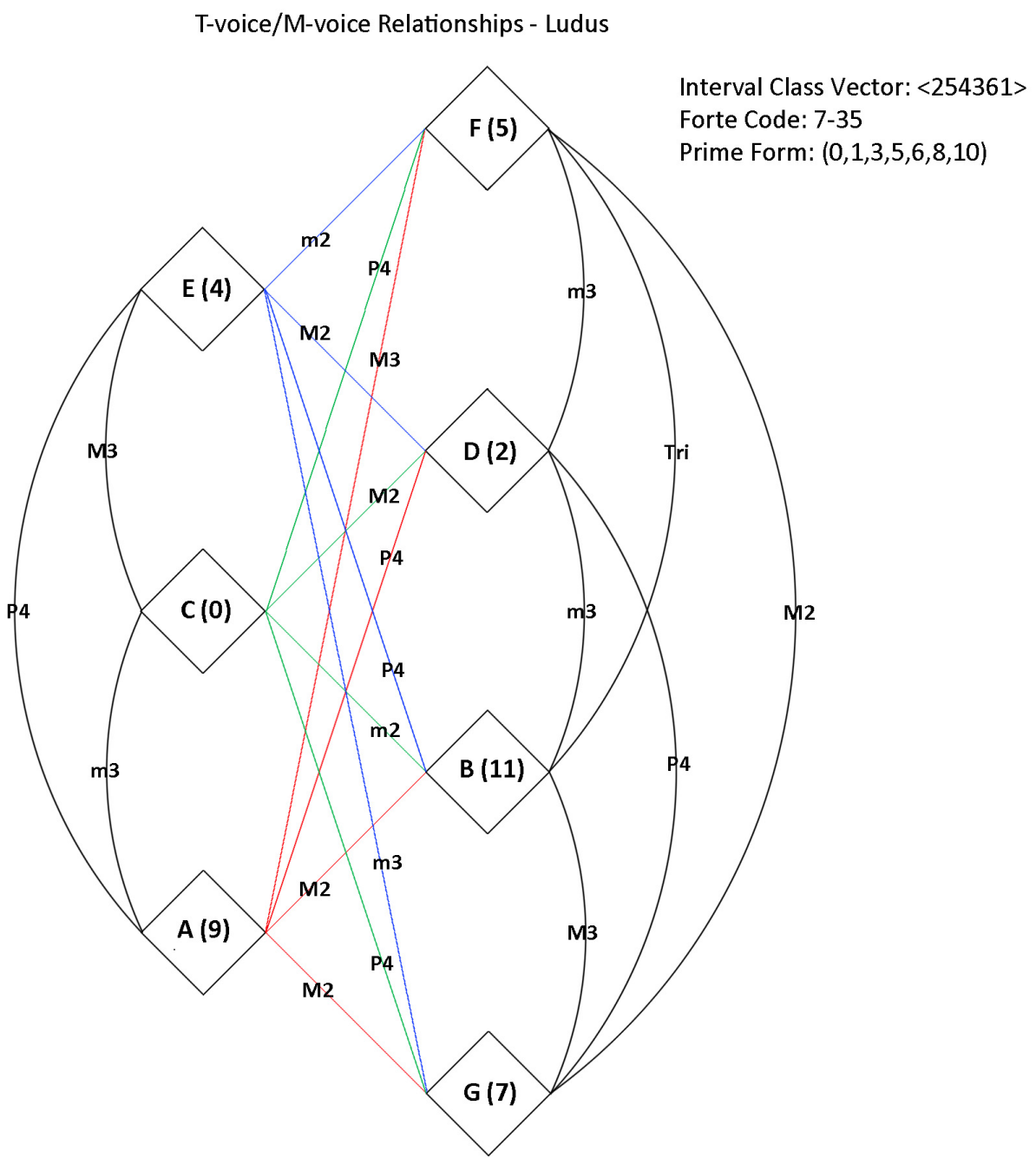

From a listener's perspective, Ludus unfolds from its pitch centre of A. As the first and second violins of the string orchestra commence in Section 1, alternating in quarter notes between a minor $3^{\text {rd }}$ above a perfect $4^{\text {th }}$ below the M-voice's tonal centre, they aurally sketch the pitches of a series of A minor triads, distributed across three and onehalf octaves of the orchestra for two bars. At a con moto pace of quarter note = ca 120 (120 beats to the minute), the music alternates between occurrences of interval class 3 , a minor third, falling on beats 1 and 3 of the bar and interval class 5 , and a perfect fourth/fifth on beats 2 and 4 - but not a full occurrence of the A minor triad (see Figure 3.19).

130 The coloured lines denote the relationships of the pitches of the T-voice triad with the four non-T-voice pitches and the subsequent interval that would occur should both pitch classes be played simultaneously. 
Figure 3.19: Ludus - opening bars

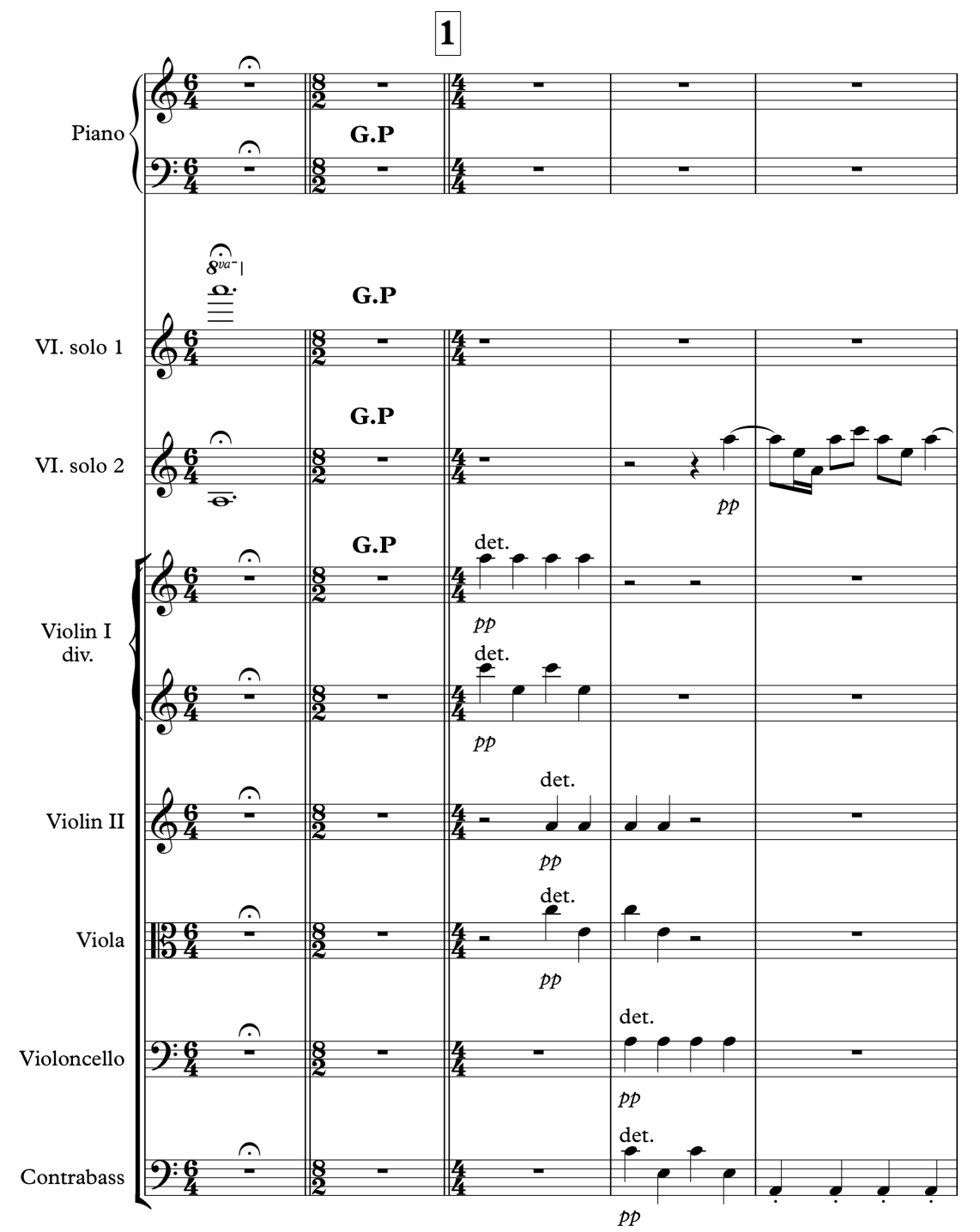

When solo violin 2 commences at the end of bar 4, all three notes of the triad are delineated in its arpeggios, but not concurrently. Technically, all three notes of the A minor T-voice triad do not sound simultaneously as a chord until 15 seconds into the work in bar 6, when the prepared piano sounds two A minor triads for four beats. On the first beat of bar six, the solo violin 2 line also sounds all three pitches simultaneously (E and $\mathrm{C}$ above the $\mathrm{A}$ ), as in the previously noted pseudo acciaccatura-like ornamentation to its second entrance. This results for the first time in four beats (approximately two seconds to the listener), when an actual stacked chord is present, interval class vector $<001110>$, which can also be represented in its prime form as $(0,3,7)$. Table 3.3 details the interval vectors of the opening bars (3 through 6) of Ludus. 
Table 3.3: Interval vectors, Ludus - bars 3 and 6

\begin{tabular}{|c|c|c|c|c|c|c|c|c|}
\hline Bar & 3 & & & & 4. & & & \\
\hline Beat & 1 & 2 & 3 & 4 & 1 & 2 & 3 & 4 \\
\hline Interval Class Vector & $\begin{array}{l}<001000 \\
>\end{array}$ & $\begin{array}{l}<000010 \\
>\end{array}$ & $\begin{array}{l}<001000 \\
>\end{array}$ & $\begin{array}{l}<000010 \\
>\end{array}$ & $\begin{array}{l}<001000 \\
>\end{array}$ & $\begin{array}{l}<000010 \\
>\end{array}$ & $\begin{array}{l}<001000 \\
>\end{array}$ & $\begin{array}{l}<000010 \\
>\end{array}$ \\
\hline Forte Code & $\mathrm{N} / \mathrm{A}$ & $\mathrm{N} / \mathrm{A}$ & $\mathrm{N} / \mathrm{A}$ & $\mathrm{N} / \mathrm{A}$ & $\mathrm{N} / \mathrm{A}$ & $\mathrm{N} / \mathrm{A}$ & $\mathrm{N} / \mathrm{A}$ & $\mathrm{N} / \mathrm{A}$ \\
\hline Prime Form & $(0,3)$ & $(0,5)$ & $(0,3)$ & $(0,5)$ & $(0,3)$ & $(0,5)$ & $(0,3)$ & $(0,5)$ \\
\hline Chord name(s) & $A m^{\text {no5 }}$ & A5 & $\mathrm{Am}^{\mathrm{no5}}$ & A5 & $A m^{\text {no5 }}$ & A5 & $\mathrm{Am}^{\mathrm{no5}}$ & A5 \\
\hline Bar & 5 & & & & 6 & & & \\
\hline Beat & 1 & 2 & 3 & 4 & 1 & 2 & 3 & 4 \\
\hline Interval Class Vector & $\begin{array}{l}<001110 \\
>\end{array}$ & $\begin{array}{l}<001000 \\
>\end{array}$ & $\begin{array}{l}<000010 \\
>\end{array}$ & $\begin{array}{l}<000000 \\
>\end{array}$ & $\begin{array}{l}<001110 \\
>\end{array}$ & $\begin{array}{l}<001110 \\
>\end{array}$ & $\begin{array}{l}<001110 \\
>\end{array}$ & $\begin{array}{l}<001110 \\
>\end{array}$ \\
\hline Forte Code & $3-11$ & $\mathrm{~N} / \mathrm{A}$ & $\mathrm{N} / \mathrm{A}$ & $\mathrm{N} / \mathrm{A}$ & $3-11$ & $3-11$ & $3-11$ & $3-11$ \\
\hline Prime Form & $(0,3,7)$ & $(0,3)$ & $(0,5)$ & single note & $(0,3,7)$ & $(0,3,7)$ & $(0,3,7)$ & $(0,3,7)$ \\
\hline Chord name(s) & $\mathrm{Am}^{* *}$ & $\mathrm{Am}^{\text {no5 }}$ & A5 & $($ pitch A) & $\mathrm{Am}$ & $\mathrm{Am}$ & $\mathrm{Am}$ & Am \\
\hline
\end{tabular}

${ }^{* *}$ A minor chord sketched out in arpeggiations in solo violin 2 line.

In Section 2, when pitch classes B and G are introduced to the M-voice line, the variety of pitch class sets that arise becomes more varied and begins to evolve more frequently. This is as a result of the interactions between the different operations in the string orchestra, the solo violin lines and the periodic entrance of the prepared piano. As shown in Table 3.4 overleaf, a total of 13 different interval vectors can be identified in Section 2 of Ludus, as opposed to the four that occur in Section 1. 
Table 3.4: Sonority content of Ludus - Section 2

\begin{tabular}{|c|c|c|c|c|c|c|c|c|}
\hline Bar & 12 & & & & 13 & & & \\
\hline Beat & 1 & 2 & 3 & 4 & 1 & 2 & 3 & 4 \\
\hline Interval Class Vector & $\begin{array}{l}<001000 \\
>\end{array}$ & $\begin{array}{l}<000010 \\
>\end{array}$ & $\begin{array}{l}<111000 \\
>\end{array}$ & $\begin{array}{l}<000010 \\
>\end{array}$ & $\begin{array}{l}<121110 \\
>\end{array}$ & $\begin{array}{l}<000010 \\
>\end{array}$ & $\begin{array}{l}<121110 \\
>\end{array}$ & $\begin{array}{l}<011010 \\
>\end{array}$ \\
\hline Forte Code & $\mathrm{N} / \mathrm{A}$ & $\mathrm{N} / \mathrm{A}$ & 3-2: & $\mathrm{N} / \mathrm{A}$ & $4-11$ & $\mathrm{~N} / \mathrm{A}$ & $4-11$ & $3-7$ \\
\hline Prime Form & $(0,3)$ & $(0,5)$ & $(0,1,3)$ & $(0,5)$ & $(0,1,3,5)$ & $(0,5)$ & $(0,1,3,5)$ & $(0,2,5)$ \\
\hline Chord name(s) & Am no5 & A5 & Fsus4 & A5 & Fadd 9 & A5 & Fadd9 & Fadd9 no5 \\
\hline Bar & 14 & & & & 15 & & & \\
\hline Beat & 1 & 2 & 3 & 4 & 1 & 2 & 3 & 4 \\
\hline Interval Class Vector & $\begin{array}{l}<121110 \\
>\end{array}$ & $\begin{array}{l}<000010 \\
>\end{array}$ & $\begin{array}{l}<121110 \\
>\end{array}$ & $\begin{array}{l}<000010 \\
>\end{array}$ & $\begin{array}{l}<010000 \\
>\end{array}$ & $\begin{array}{l}<000010 \\
>\end{array}$ & $\begin{array}{l}<001000 \\
>\end{array}$ & $\begin{array}{l}<000010 \\
>\end{array}$ \\
\hline Forte Code & $4-11$ & $\mathrm{~N} / \mathrm{A}$ & $4-11$ & $\mathrm{~N} / \mathrm{A}$ & $\mathrm{N} / \mathrm{A}$ & $\mathrm{N} / \mathrm{A}$ & $\mathrm{N} / \mathrm{A}$ & $\mathrm{N} / \mathrm{A}$ \\
\hline Prime Form & $(0,1,3,5)$ & $(0,5)$ & $(0,1,3,5)$ & $(0,5)$ & $(0,2)$ & $(0,5)$ & $(0,3)$ & $(0,5)$ \\
\hline Chord name(s) & Fadd 9 & A5 & Fadd 9 & A5 & A7no3 no5 & A5 & $\mathrm{Am}^{\mathrm{no5}}$ & A5 \\
\hline Bar & 16 & & & & 17 & & & \\
\hline Beat & 1 & 2 & 3 & 4 & 1 & 2 & 3 & 4 \\
\hline Interval Class Vector & $\begin{array}{l}<001110 \\
>\end{array}$ & $\begin{array}{l}<001110 \\
>\end{array}$ & $\begin{array}{l}<012120 \\
>\end{array}$ & $\begin{array}{l}<001110 \\
>\end{array}$ & $\begin{array}{l}<010000 \\
>\end{array}$ & $\begin{array}{l}<000010 \\
>\end{array}$ & $\begin{array}{l}<001000 \\
>\end{array}$ & $\begin{array}{l}<000000 \\
>\end{array}$ \\
\hline Forte Code & $3-11$ & $3-11$ & $4-26$ & $3-11$ & $\mathrm{~N} / \mathrm{A}$ & $\mathrm{N} / \mathrm{A}$ & $\mathrm{N} / \mathrm{A}$ & $\mathrm{N} / \mathrm{A}$ \\
\hline Prime Form & $(0,3,7)$ & $(0,3,7)$ & $(0,3,5,8)$ & $(0,3,7)$ & $(0,2)$ & $(0,5)$ & $(0,3)$ & single note \\
\hline Chord name(s) & Am & Am & $\mathrm{Am}^{7}$ & Am & A7no3 no5 & A5 & A5 & (A) \\
\hline Bar & 18 & & & & 19 & & & \\
\hline Beat & 1 & 2 & 3 & 4 & 1 & 2 & 3 & 4 \\
\hline Interval Class Vector & $\begin{array}{l}<001000 \\
>\end{array}$ & $\begin{array}{l}<000010 \\
>\end{array}$ & $\begin{array}{l}<111000 \\
>\end{array}$ & $\begin{array}{l}<000010 \\
>\end{array}$ & $\begin{array}{l}<020100 \\
>\end{array}$ & $\begin{array}{l}<000010 \\
>\end{array}$ & $\begin{array}{l}<122230 \\
>\end{array}$ & $\begin{array}{l}<001000 \\
>\end{array}$ \\
\hline Forte Code & $\mathrm{N} / \mathrm{A}$ & $\mathrm{N} / \mathrm{A}$ & $3-2$ & $\mathrm{~N} / \mathrm{A}$ & $3-6$ & $\mathrm{~N} / \mathrm{A}$ & $5-27$ & $\mathrm{~N} / \mathrm{A}$ \\
\hline Prime Form & $(0,3)$ & $(0,5)$ & $(0,1,3)$ & $(0,5)$ & $(0,2,4)$ & & $\begin{array}{l}(0,1,3,5,8 \\
)\end{array}$ & $(0,3)$ \\
\hline Chord name(s) & Am no5 & A5 & Cmaj13 no3 no5 & A5 & $\mathrm{G}^{\text {add9 }}$ no5 & A5 & $\mathrm{Am}^{9}$ & Amno5 \\
\hline Bar & 20 & & & & 21 & & & \\
\hline Beat & 1 & 2 & 3 & 4 & 1 & 2 & 3 & 4 \\
\hline Interval Class Vector & $\begin{array}{l}<021120 \\
>\end{array}$ & $\begin{array}{l}<001000 \\
>\end{array}$ & $\begin{array}{l}<021120 \\
>\end{array}$ & $\begin{array}{l}<001000 \\
>\end{array}$ & $\begin{array}{l}<010020 \\
>\end{array}$ & $\begin{array}{l}<001000 \\
>\end{array}$ & $\begin{array}{l}<000010 \\
>\end{array}$ & $\begin{array}{l}<001000 \\
>\end{array}$ \\
\hline Forte Code & $4-22$ & $\mathrm{~N} / \mathrm{A}$ & $4-22$ & $\mathrm{~N} / \mathrm{A}$ & $3-9$ & $\mathrm{~N} / \mathrm{A}$ & $\mathrm{N} / \mathrm{A}$ & $\mathrm{N} / \mathrm{A}$ \\
\hline Prime Form & $(0,2,4,7)$ & $(0,3)$ & $(0,2,4,7)$ & $(0,3)$ & $(0,2,7)$ & $(0,3)$ & $(0,5)$ & $(0,3)$ \\
\hline Chord name(s) & Emadd4 & $\mathrm{Am}^{\text {no5 }}$ & Emadd4 & Amno5 & A7no3 & Amno5 & A5 & $\mathrm{Am}^{\text {no5 }}$ \\
\hline Bar & 22 & & & & 23 & & & \\
\hline Beat & 1 & 2 & 3 & 4 & 2 & 3 & 4 & 6 \\
\hline Interval Class Vector & $\begin{array}{l}<001000 \\
>\end{array}$ & $\begin{array}{l}<000010 \\
>\end{array}$ & $\begin{array}{l}<010000 \\
>\end{array}$ & $\begin{array}{l}<000010 \\
>\end{array}$ & $<000000>$ & & $<000000>$ & \\
\hline Forte Code & $\mathrm{N} / \mathrm{A}$ & $\mathrm{N} / \mathrm{A}$ & $\mathrm{N} / \mathrm{A}$ & $\mathrm{N} / \mathrm{A}$ & $\mathrm{N} / \mathrm{A}$ & & $\mathrm{N} / \mathrm{A}$ & \\
\hline Prime Form & $(0,3)$ & $(0,5)$ & $(0,2)$ & $(0,5)$ & single note & & single note & \\
\hline Chord name(s) & Am no5 & A5 & A7no3 no5 & A5 & (A) & & & \\
\hline Bar & 24 & & & & 25 & & & \\
\hline Beat & 1 & 3 & 5 & 6 & 1 & 3 & 4 & 6 \\
\hline $\begin{array}{l}\text { Interval Class Vector } \\
\text { Forte Code } \\
\text { Prime Form } \\
\text { Chord name(s) }\end{array}$ & $\begin{array}{l}<000000> \\
\text { N/A } \\
\text { single note } \\
\text { (A) }\end{array}$ & & $\begin{array}{l}<000000> \\
\text { N/A } \\
\text { single note } \\
\text { (A) }\end{array}$ & & $\begin{array}{l}<000000> \\
\text { N/A } \\
\text { Silence }\end{array}$ & & & \\
\hline
\end{tabular}


The sonorities that occur in Section 2 range from the constant oscillation between the intervals of a minor third or perfect fourth/fifth, to a relatively more complex major $9^{\text {th }}$ chord $<122230>$, prime form $(0,1,3,5,8)$, where the listener is confronted simultaneously with 10 different intervallic relationships: one minor second, two major seconds, two minor thirds, two major thirds, and four perfect fourths - only to diminish to a progression of single notes and then silence. At this stage the only interval class that has not occurred yet in Ludus is interval class 6, or the tritone.

Figure 3.20 overleaf provides a sonority mapping of the intervallic content (e.g. minor seconds, major seconds, perfect fourths, etc.) that occurs in Ludus. Figure 3.21 (Ludus Sections 1-5) and 3.22 (Sections 6-8) provide more detailed views of Sections 1 through 5 and 6 through 8, respectively. The vertical dimension (Axis Y) in each figure details the relative density of the total intervallic content occurring at any given moment in the work (the horizontal axis which denotes bar numbers), in relation to the work's maximum number of intervallic relationships. The various sonorities in the work are stacked vertically, bottom to top, from a single pitch through to the tritone. The relative depth of a particular sonority, in relation to all vertical content at a given moment, is proportional to the total occurrences of a specific interval class (e.g. a major 3), relative to all other intervals occurring at that time. For example, in Figure 3.22, only one interval class (or a single pitch) occurs at any one time in Ludus during bars 114 through 126. This is in contrast to bars 127 through 150, wherein multiple intervals occur simultaneously, and there is a significant fluctuation between the total number of minor second (m2), major second (M2) and minor 3 (M3) intervals. This effect is even more evident in Figure 3.33, which provides a telescoped view of the intervallic content of Section 8. In bars 182 through 187 in the figure, hints of the presence of tritones (see pink shadings) during moments of greater dissonance can be observed in the uppermost part of the sonority map. 
Figure 3.20: Ludus - sonority map Sections 1-8

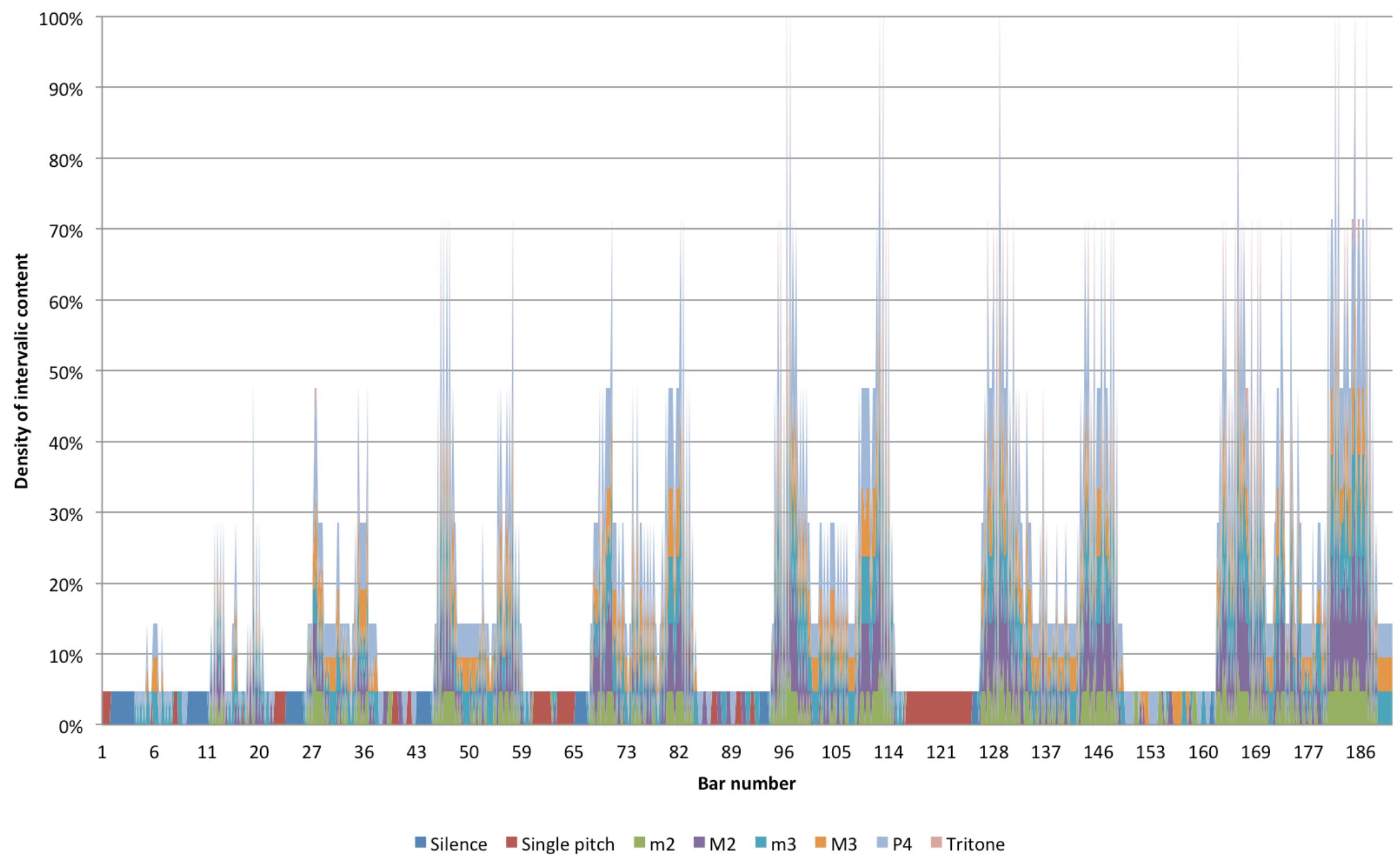


Figure 3.21: Ludus - sonority map Sections 1-5

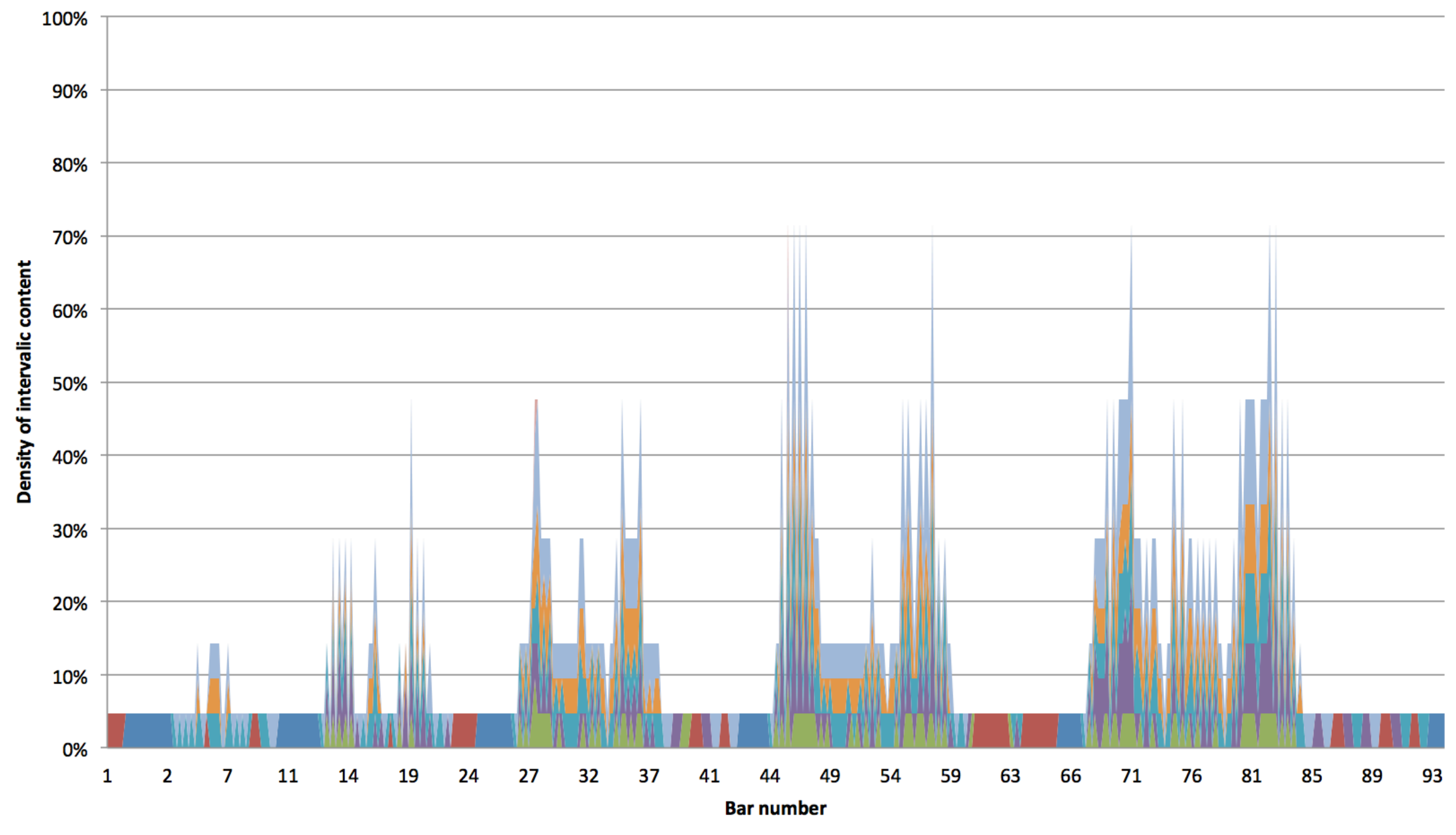

Silence $\quad$ Single pitch $\square \mathrm{m} 2 \quad \square \mathrm{M} 2 \quad \square \mathrm{m} 3 \quad \square \mathrm{M} 3 \quad \square \mathrm{P} 4 \quad$ Tritone 
Figure 3.22: Ludus - sonority map Sections 6-8

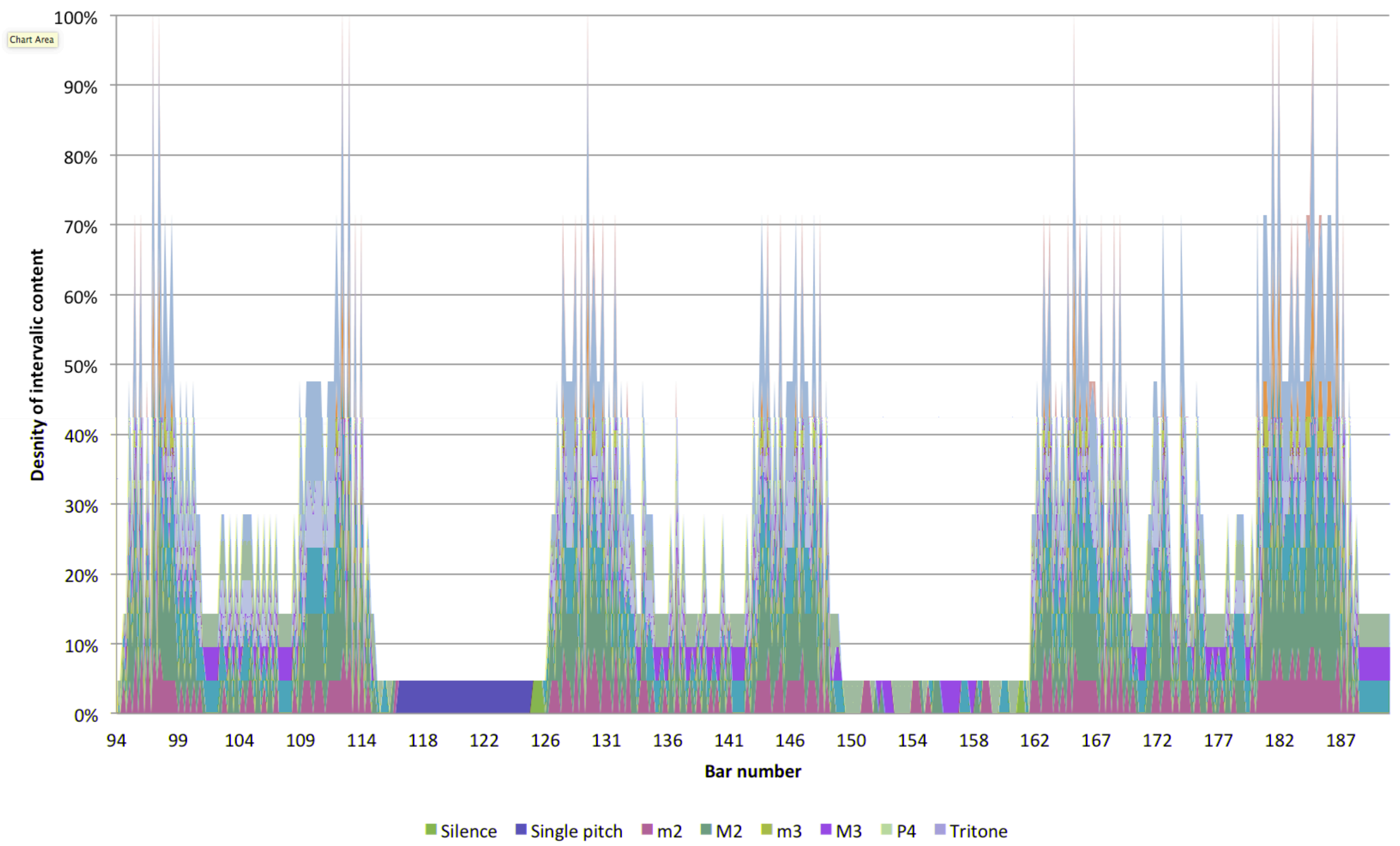


Figure 3.23: Ludus - sonority map Section 8

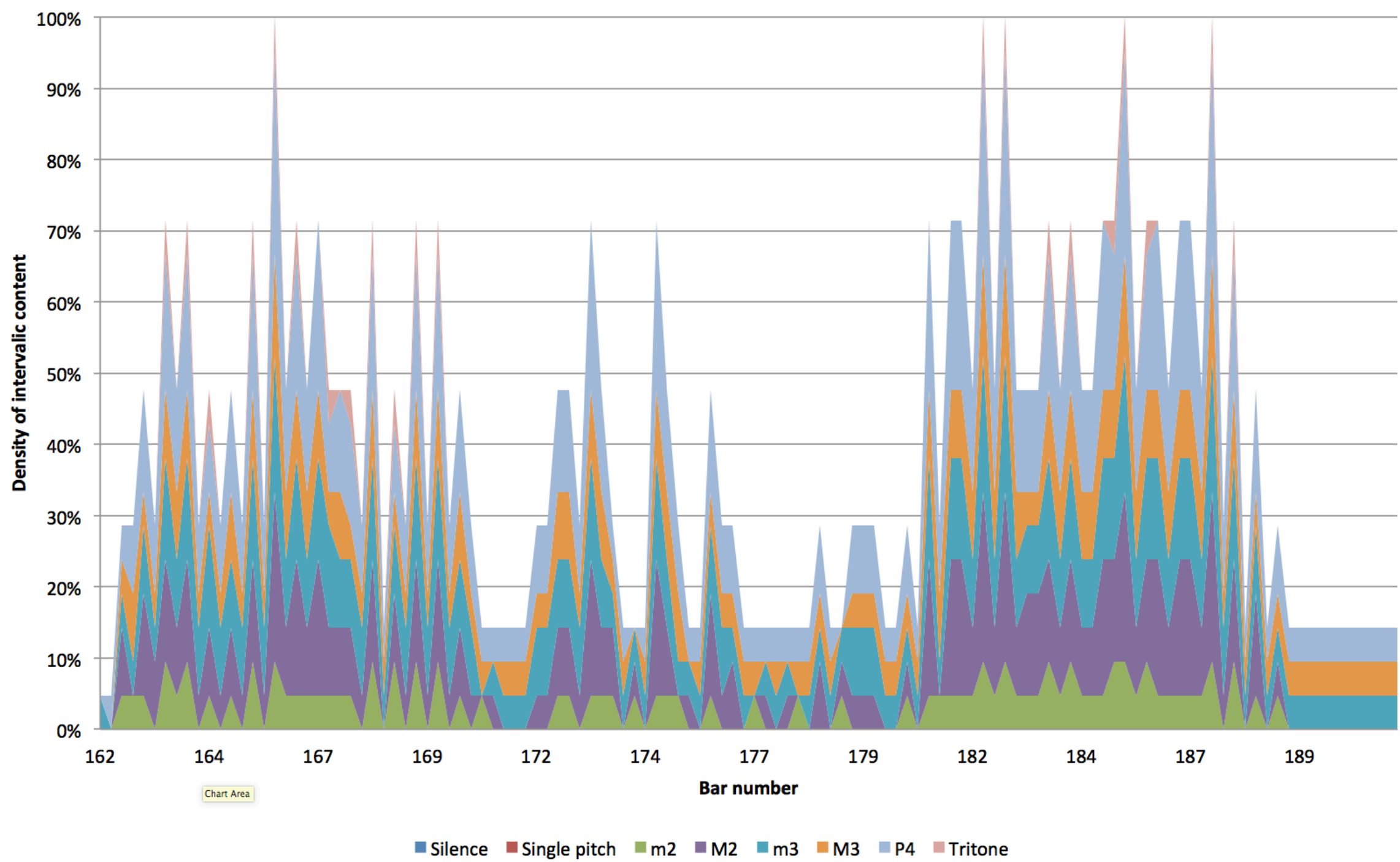


As detailed in Table 3.5 overleaf, a total of thirty-one different sonority vectors arise during the eight sections of Ludus. With each new section, new vectors are introduced, and certain prevalent vectors begin to dominate the soundscape. An example of this is no. 7 in the table, $<001110>$ Forte Code: 3-11 (which comprises a minor third, major third, and perfect fourth/fifth); however, in Ludus, Pärt manages to avoid the use of any triads other than A minor. In Ludus, the A minor triad occurs just six times in Section 1 and only three times in Section 2; whereas, as the work progresses and the sonorities of Ludus become more varied, <001110> occurs even more frequently, e.g. twenty-seven of Section 8's 120 beats.

The relatively dissonant vector $<122230>$ (identified as the $23^{\text {rd }}$ vector in Table 3.5 overleaf), comprising primarily A min 9th and D min 9th chords) increases in frequency from a single occurrence in Section 2, to nineteen occurrences in Section 8. A vertical scan of the matrix reveals that specific sections are dominated by certain sonorities, i.e. those with occurrences of nine or more per section (denoted by shaded cells in the table). In the case of Sections 6, 7, and 8, the more dominant sonorities are frequently some of the most dissonant, such as no. $18<012120>$ comprising only A min 7 th chords, the previously noted no. $23<122230>$, and vectors no. $27<143250>$ and no. 29 $<233241>$. The increased frequency of these particular sonorities arises as a result of the expanded pitch class content occurring in Ludus as the outward expanding M-voices in Ludus extend to the full span of a diatonic A natural minor scale. 
Table 3.5: Matrix of vectors occurring in Ludus on beats 1, 2, 3, and 4- Sections 1 through 8 (continues overleaf)

\begin{tabular}{|c|c|c|c|c|c|c|c|c|c|c|c|c|}
\hline No. & Vectors & Forte Codes & Prime Forms & 1 & 2 & 3 & 4 & 5 & 6 & 7 & 8 & Chords \\
\hline 1 & $<000000>$ & $\mathrm{N} / \mathrm{A}$ & $\begin{array}{l}\text { single pitch } \\
\text { and silence }\end{array}$ & 40 & 21 & 17 & 32 & 17 & 8 & 2 & & $\mathrm{~N} / \mathrm{A}$ \\
\hline 2 & $<100000>$ & $\mathrm{N} / \mathrm{A}$ & $(0,1)$ & & & 3 & 2 & & 1 & 10 & & C7no3 no5, D7 no3 no5, F7no3 no5 \\
\hline 3 & $<010000>$ & $\mathrm{N} / \mathrm{A}$ & $(0,2)$ & & 3 & 6 & 2 & 9 & 1 & 7 & & A 7 th no3 no5, D7th ${ }^{\text {no3 no5 }}$, E7th ${ }^{\text {no3 no5 }}, A^{\text {add9 no3 no5 }}, D^{\text {add9 no3 no5 }}$, Fadd9 no3 no5, \\
\hline 4 & $<001000>$ & $\mathrm{N} / \mathrm{A}$ & $(0,3)$ & 12 & 10 & 2 & 8 & 12 & 4 & 10 & 1 & $\mathrm{Am}^{\mathrm{no5}}, \mathrm{Em}^{\mathrm{no5}}$ \\
\hline 5 & $<000100>$ & $\mathrm{N} / \mathrm{A}$ & $(0,4)$ & & & & & 3 & & 12 & & $\mathrm{~A}^{\text {aug5 no3 }}, \mathrm{C}^{\text {no5 }}$ \\
\hline 6 & $<000010>$ & $\mathrm{N} / \mathrm{A}$ & $(0,5)$ & 13 & 14 & 11 & 3 & 12 & 3 & 20 & 1 & $\mathrm{~A} 5, \mathrm{C} 5, \mathrm{~F} 5, \mathrm{~A}^{\text {sus } 4 \text { no5 }}$ \\
\hline 7 & $<001110>$ & $3-11$ & $(0,3,7)$ & 6 & 3 & 19 & 18 & 23 & 25 & 23 & 27 & $\mathrm{Am}$ \\
\hline 8 & $<111000>$ & $3-2$ & $(0,1,3)$ & & 2 & 4 & 4 & 1 & 1 & 2 & 2 & Am add9 no5 \\
\hline 9 & $<100110>$ & $3-4$ & $(0,1,5)$ & & & 1 & 4 & & & 5 & 3 & $A^{\text {aug5 w5 no3 }}$ \\
\hline 10 & \begin{tabular}{|c|c|}
$<0100>$ \\
\end{tabular} & $3-6$ & $(0,2,4)$ & & 1 & & & & & & & A 9thno3 no5 \\
\hline 11 & \begin{tabular}{|c|c|}
$<1010>$ \\
\end{tabular} & $3-7$ & $(0,2,5)$ & & 1 & 3 & 5 & & 1 & 4 & 4 & A 7th ${ }^{\text {no3}}$, A min 7 th $^{\text {no5 }}$ \\
\hline 12 & $<010020>$ & $3-9$ & $(0,2,7)$ & & 1 & 2 & 1 & & 1 & 1 & & A sus2 \\
\hline 13 & $<122010>$ & $4-10$ & $(0,2,3,5)$ & & & & 2 & & 1 & & & Am add9 sus4 no5 \\
\hline 14 & $<121110>$ & $4-11$ & $(0,1,3,5)$ & & 4 & 3 & & 1 & & 2 & 2 & Am 9th no5, A 7thaug5 w5 no3, Cadd9 maj7 no5 \\
\hline 15 & $<111120>$ & $4-14$ & $(0,2,3,7)$ & & & 1 & & 4 & 3 & 4 & 2 & Am ${ }^{\text {add } 9}$ \\
\hline 16 & $<101220>$ & $4-20$ & $(0,1,5,8)$ & & & 6 & 9 & 8 & 8 & 4 & 3 & Am aug5 w5 \\
\hline 17 & $<021120>$ & $4-22$ & $(0,2,4,7)$ & & 2 & 2 & 1 & 6 & 5 & 7 & 3 & Am ${ }^{\text {add } 4}$, A 7 th $^{\text {sus } 2 \text { no3 }}$, Am $^{\text {sus } 4 \text { no5 }}$ \\
\hline 18 & $<012120>$ & $4-26$ & $(0,3,5,8)$ & & 1 & 1 & 2 & 4 & 8 & 8 & 17 & Am 7th \\
\hline 19 & $<211231>$ & $5-20$ & $(0,1,5,6,8)$ & & & 1 & & & & 1 & & Am add9 aug5 w5 \\
\hline 20 & $<132130>$ & $5-23$ & $(0,2,3,5,7)$ & & & & 1 & 4 & 1 & 4 & 5 & Am ${ }^{\text {add2 } 2 \text { add } 4}$ \\
\hline 21 & $<131221>$ & $5-24$ & $(0,1,3,5,7)$ & & & & & & & 1 & & Fadd9 \\
\hline 22 & $<123121>$ & $5-25$ & $(0,2,3,5,8)$ & & & & & & & & 2 & Am ${ }^{\text {add9 } 9 \text { aug5 sus } 4}$ \\
\hline 23 & $<122230>$ & $5-27$ & $(0,1,3,5,8)$ & & 1 & 3 & 3 & 12 & 15 & 12 & 19 & Am 9th, Am 7thaug 5 w5, Am 9thaug 5 sus4 w5, D min 9th, F maj 9th \\
\hline 24 & $<122131>$ & $5-29$ & $(0,1,3,6,8)$ & & & & & & & & 1 & $A^{\text {add } 9 \text { aug } 5 \text { sus } 4 \text { w5 }}$ \\
\hline 25 & $<032140>$ & $5-35$ & $(0,2,4,7,9)$ & & & & 2 & 2 & 2 & 4 & & A 11th no3, Am 11th no 9 \\
\hline 26 & $<222121>$ & $5-\mathrm{Z} 12$ & $(0,1,3,5,6)$ & & & & & & 1 & & 1 & Dm 13th no5 \\
\hline
\end{tabular}




\begin{tabular}{|c|c|c|c|c|c|c|c|c|c|c|c|c|}
\hline No. & Vectors & Forte Codes & Prime Forms & 1 & 2 & 3 & 4 & 5 & 6 & 7 & 8 & Chords \\
\hline 27 & $<143250>$ & $6-32$ & $(0,2,4,5,7,9)$ & & & & 4 & 3 & 3 & 3 & 10 & Am 11th, A min 7thaug5 sus4 w5 \\
\hline 28 & $<143241>$ & $6-33$ & $(0,2,3,5,7,9)$ & & & & & & & & 1 & F maj 13 th $^{\text {flat } 5}$ \\
\hline 29 & $<233241>$ & $6-\mathrm{Z} 25$ & $(0,1,3,5,6,8)$ & & & & 1 & & 4 & 9 & 11 & C maj 13thn ${ }^{\text {no5}}$, Am add9 aug5 sus4 w5, Dm 13th \\
\hline 30 & $<232341>$ & 6-Z26 & $(0,1,3,5,7,8)$ & & & & & & & 1 & & Am 7 th add9 aug5 w5 \\
\hline 31 & $<254361>$ & $7-35$ & $(0,1,3,5,6,8,10)$ & & & & & & 4 & 1 & 5 & $\mathrm{C}$ maj 13th \\
\hline
\end{tabular}




\section{Pitch class frequency as a factor in Pärt's tintinnabuli system}

It is the prevalence of the pitch classes of a single triad, combined with the M-voice's tonal centre, in any particular tintinnabuli work, that creates the 'bell-like' sound world of tintinnabuli - a sound world dominated by 'pure' intervals and the prevalence of subtle overtones. An illustration of this can be seen in Figure 3.24 overleaf (Ludus bars 141-145), wherein the shifting frequencies of the pitch classes 9 (A), 0 (C), and 4 (E) emphasise different pitches of the A minor triad.

Another phenomenon that sometimes arises in Pärt's tintinnabuli system is the subtle masking of dissonant intervals that occurs as a result of the stepwise progression of multiple M-voice interactions occurring at once. As detailed in Table 3.6 overleaf, a total of eleven different interval class vectors of varying complexity can be observed on beats 1, 2, 3, and 4 in bars 141 through 145 of Ludus (Table 3.6 overleaf). A number of intervals in those vectors could be considered as being dissonant by many listeners, e.g., $<021120>$ (Forte Code: 4-22, which includes an added $4^{\text {th }}$ ) and <233241> (Forte Code: 6-Z25, which includes a tritone). However, as can be seen in Figure 3.24 when such 'dissonant' interval vectors occur, they frequently arise when a larger number of instrumental voices are interacting simultaneously.

When this is the case, the pitch classes of the T-voice triad also tend to occur at much greater frequencies across a wide range of the orchestra's overall register, e.g. beat three in bar 144 , wherein pitch class 0 ( $\mathrm{C}$ in the T-voice triad) occurs five times, while pitch class 4 (E in the T-voice triad) occurs three times. In such instances, the increased frequency of T-voice pitches tends to temper, if not overwhelm, the dissonant intervals when they occur, making them less prominent to the listener and more like subtle 
colours and intimations of the different overtones and tonal richness of the omnipresent A minor triad.

Table 3.6: Matrix of vectors occurring in Ludus on beats 1, 2, 3, \& 4 Section G bars 141-145

\begin{tabular}{|l|l|l|l|l|}
\hline Occurrences & Vectors & Forte Codes & Prime Forms & Chord \\
\hline 1 & $<111000>$ & $3-2$ & $(0,1,3)$ & Am add 9/no 5 \\
\hline 6 & $<001110>$ & $3-11$ & $(0,3,7)$ & Am \\
\hline 2 & $<111120>$ & $4-14$ & $(0,2,3,7)$ & Am add 9 \\
\hline 1 & $<101220>$ & $4-20$ & $(0,1,5,8)$ & Fmaj7 \\
\hline 1 & $<021120>$ & $4-22$ & $(0,2,4,7)$ & Am add \\
\hline 1 & $<012120>$ & $4-26$ & $(0,3,5,8)$ & Am 7 \\
\hline 1 & $<132130>$ & $5-23$ & $(0,2,3,5,7)$ & Am add2 add4 \\
\hline 3 & $<122230>$ & $5-27$ & $(0,1,3,5,8)$ & F 9 \\
\hline 1 & $<323430>$ & $5-35$ & $(0,24,7,9)$ & C6/9 \\
\hline 1 & $<143250>$ & $6-32$ & $(0,2,4,5,7,9)$ & Dm11 \\
\hline 2 & $<233241>$ & $6-Z 25$ & $(0,1,3,5,6,8)$ & Dm13 \\
\hline
\end{tabular}


Figure 3.24: Interactions of prevalent pitch classes with interval vectors - Ludus (bars 141-145) ${ }^{131}$
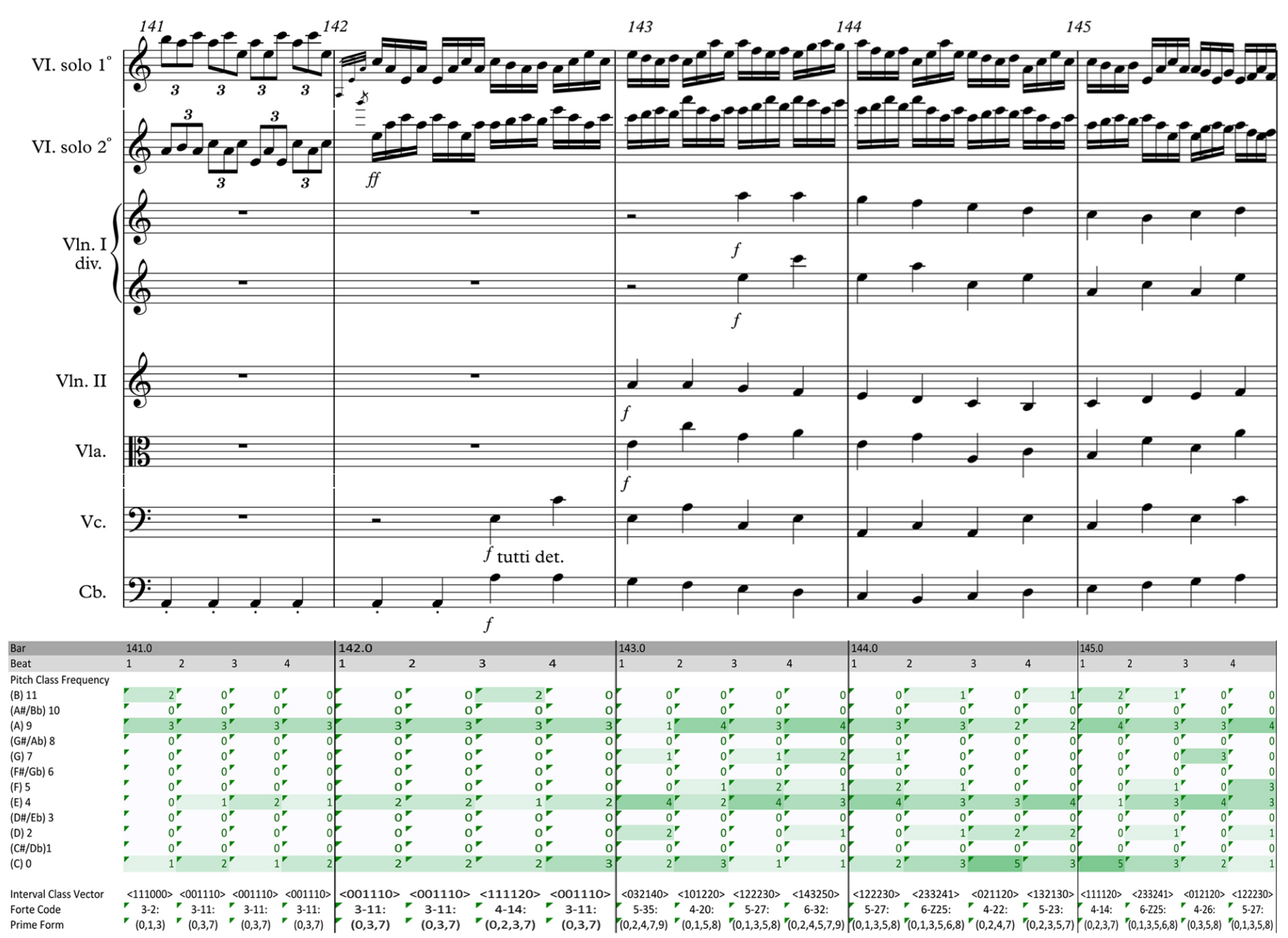

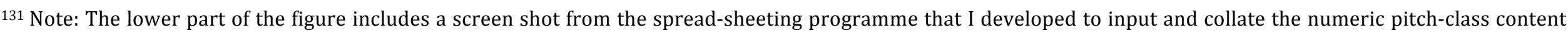
into a single worksheet, identify the frequency of each pitch class during any given moment of the music, and reduce those pitch classes into single interval-class vectors 


\section{Ludus - Cadenza}

The cadenza commences immediately after the completion of Section 8 of Ludus. Both solo violins and the prepared piano begin executing fortissimo arpeggios - marked in the score to be executed arpeggiato, presto possible e legato molto or "play as legato broken chords progressively faster until playing as fast as possible" - with each instrument's arpeggios containing both $\mathrm{M}$-voice and T-voice material, as a descending A natural minor scale, spanning two octaves, with alternate notes of the scale distributed between the two solo violins.

Starting first in the solo violin 2 line (Figure 3.25), the first figuration in bar 192 is played from bottom to top A4-E5-C6-A6, then top to bottom A6-C6-E5-A4, for eight beats as fast and as slurred as possible. Solo violin 1 enters three beats later on the downbeat of bar 193 playing from bottom to top G3-C5-C6-G6, then top to bottom G6-C6-C5-G3, for eight beats. This is then followed by the solo violin 2 playing F4-C5-C6-F6, etc.

Figure 3.25: Ludus cadenza - solo violins bars 192 to 197

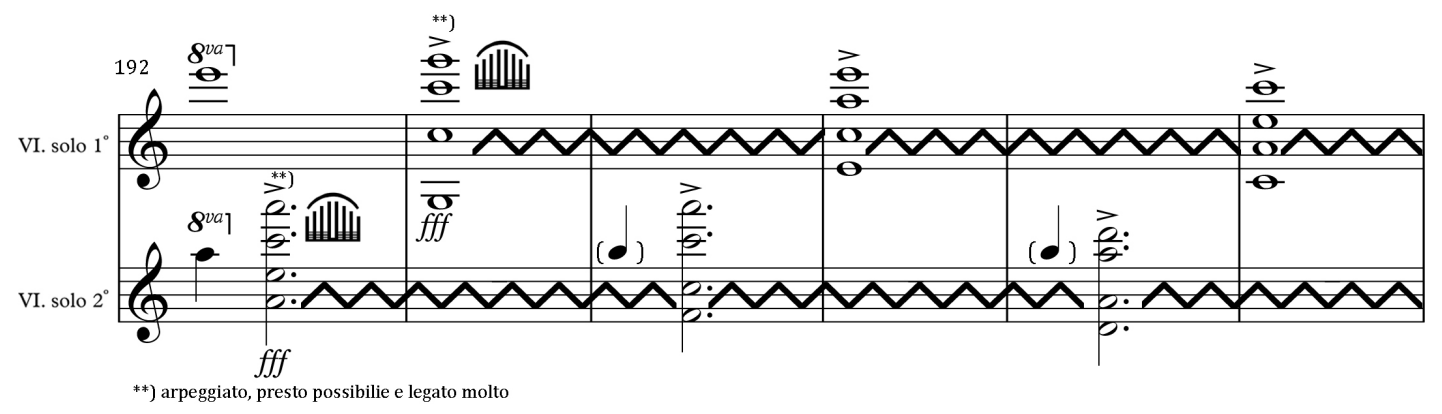

The alternating entrances of four-note arpeggiated figures between the two solo violin lines continue until bar 203, when the four-note arpeggiations are replaced by threenote arpeggiations - first in the solo violin 1 line, from bottom to top A3-D4-D5, then top to bottom D5-D4-A3 for eight beats. The solo violin 2 line also switches to three-note 
arpeggiations starting in bar 204 - playing the pattern from bottom to top B3-E4-B5, then top to bottom B4-E4-B3.

Starting on the second beat of bar 208, the solo violin 2 changes to playing a two-note figuration, alternating between the pitches of C4 and F4 (Figure 3.26), with the solo violin 1 shortly following suit on the downbeat of bar 209, alternating between A3 and E4 for eight beats - and then playing a sustained C4 for three bars commencing on the downbeat of bar 211. Just before this final change in the solo violin 1 line, the solo violin 2 line completes its descent through the A natural minor scale, with its final figuration being the pitches $\mathrm{A} 3$ and $\mathrm{D} 4$, before settling on a sustained $\mathrm{B} 4$.

Figure 3.26: Ludus cadenza - solo violins bars 208 to 213

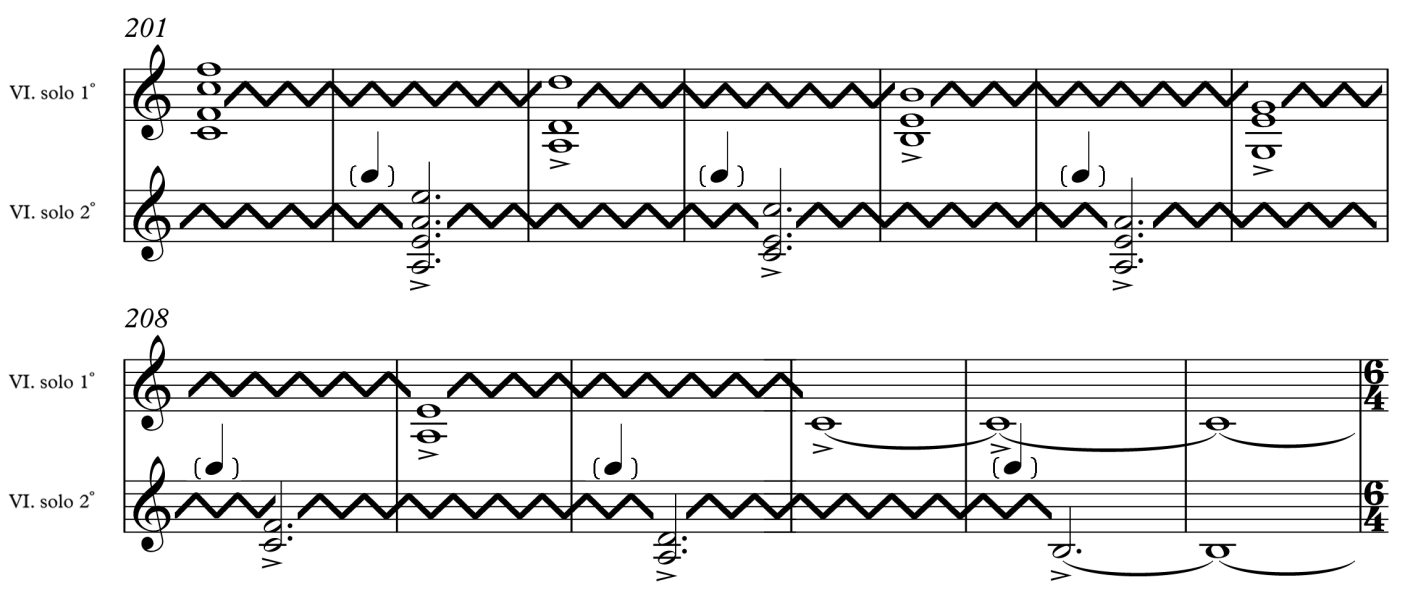

The prepared piano replicates the same musical material as the two solo violin lines concurrently, but playing three-note tremolos, and alternating the pitches of the descending A natural minor scale between the left and the right hand. Below the solo violins, the different sections of the string orchestra execute strongly accented sustained single pitches as the orchestra descends through the A natural minor scale in staggered fashion (Figure 3.27 overleaf). 


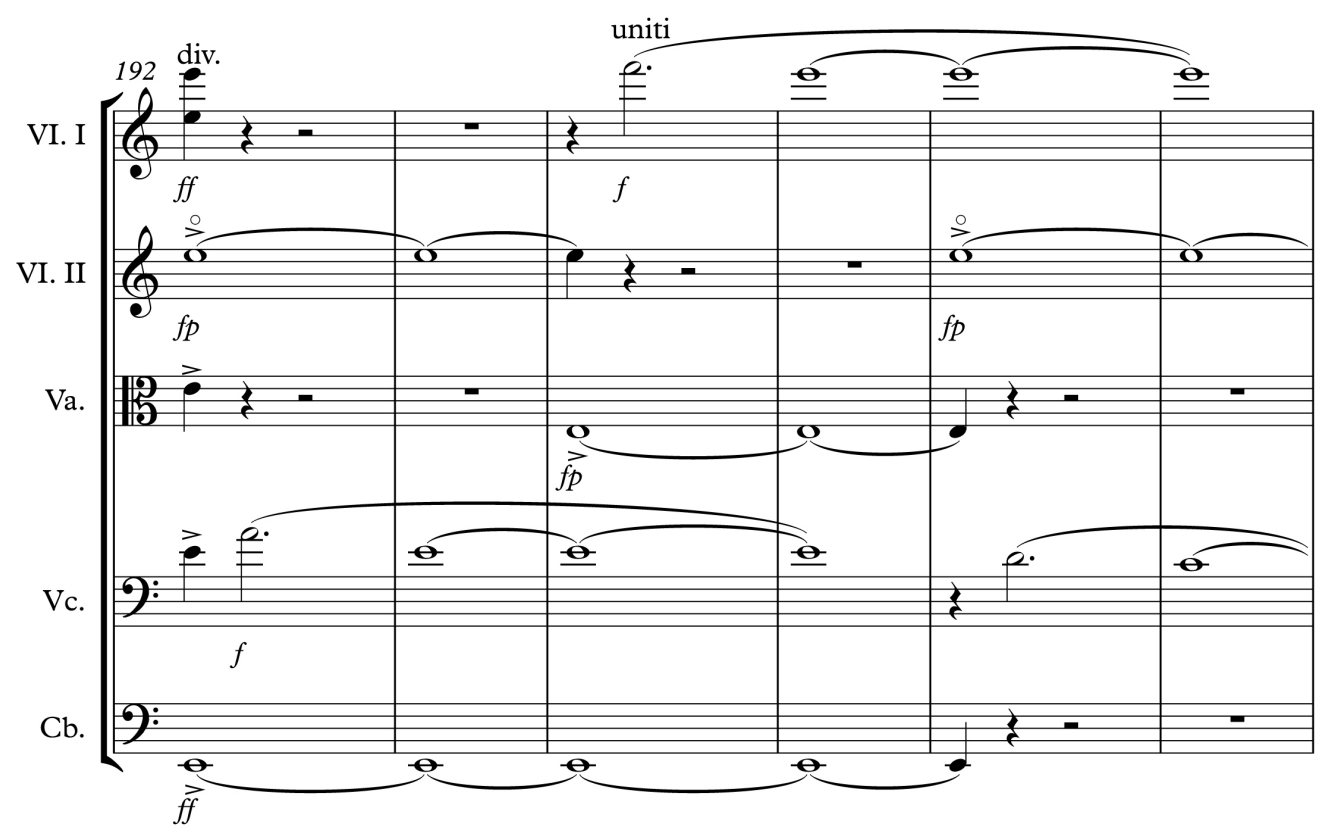

To the listener, the chord progressions of the first part of the cadenza are a journey through a diatonic world of layered sonorities of different durations that, with the exception of bar 206, all contain an A minor triad (see Table 3.7 later in this section, which details the interval class vector and chord progressions of the entire cadenza).

The second half of the cadenza starts at bar 214 and is unusual in that it breaks with the diatonicism of all that has preceded it so far, but it also deviates from the typical operations of Pärt's tintinnabuli system into a chromatic sound world as well (Figure 3.28 overleaf). It is as if this is a final gesture of acknowledgment by Pärt that he is creating a tabula rasa, 'wiping his musical slate clean'. This cleansing of the slate commences with the orchestral strings and prepared piano first striking a double forte ${ }_{\text {B7dim9 }}$ chord (pitch classes C-D\#-F\#-A-B, vector $<114112>$ Forte Code: $5-31$ ), a sonority that includes both minor and major seconds and thirds, as well as two tritones and a perfect fifth. This is followed by the strings pulsing for two beats on $\mathrm{F} \mathrm{m}^{\text {flat5}}$ /sus4 (pitch classes A-B-C-F\#, vector <112011>, Forte Code: 4-13), and then executing three beats of 
a diminished F\# chord (pitch classes C-F\#-A <vector 002001>, Forte Code: 3-10).

Figure 3.28: Ludus cadenza - bars 214 to 216
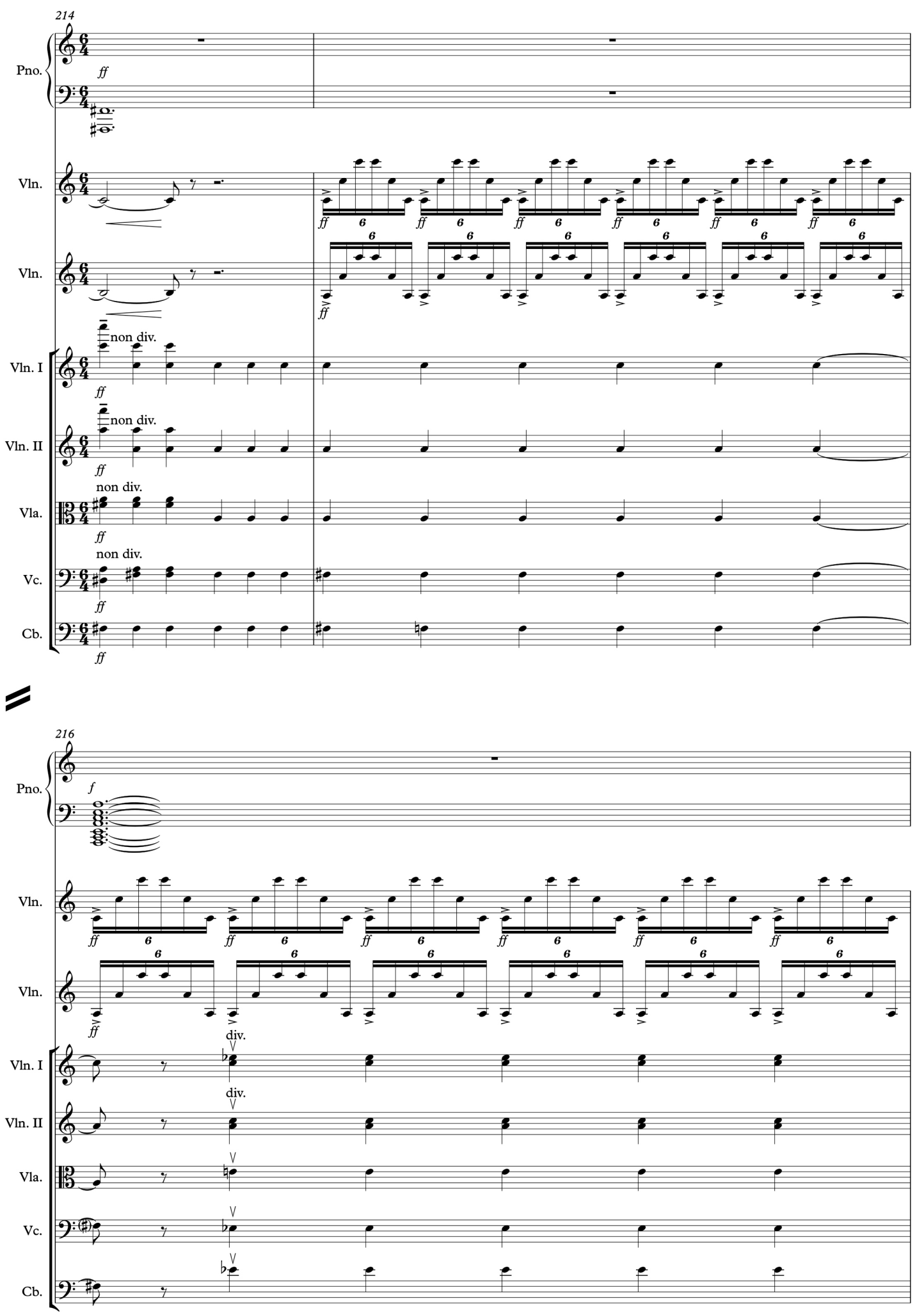
The two solo violins re-enter at bar 215 , each playing six-note arpeggiations of a single pitch class, one third apart: C4-C5-C6 in the case of solo violin 1 and A3-A4-A5 by solo violin 2 (Figure 3.28 above). Commencing at bar 217, the solo violin 1 figuration introduces pitch class $\mathrm{E} b$ (i.e., $\mathrm{C} 4-\mathrm{E} b 4-\mathrm{C} 5-\mathrm{E} b 5$, etc.), while the solo violin 2 line adds pitch class C to its arpeggiations. At bar 219, each of the solo violin lines adds further pitch class content to their figurations: $\mathrm{F \#}$ in the case of solo violin 1 line and $\mathrm{E}$ in the case of solo violin 2 (Figure 3.29).

In bar 221, the solo violin 1's figuration expands to four pitch classes, C, Eb, F\#, and A, while the solo violin 2 starts emphasising pitch class E, by repeating it once at each occurrence in both its ascending and descending figuration, changing from playing A3C4-E4-A4-C5-E5 etc. to A3-C4-E4-E4-A4-C5-E5-E5, etc.

Figure 3.29: Ludus cadenza - solo violins bars 217, 219 \& 221

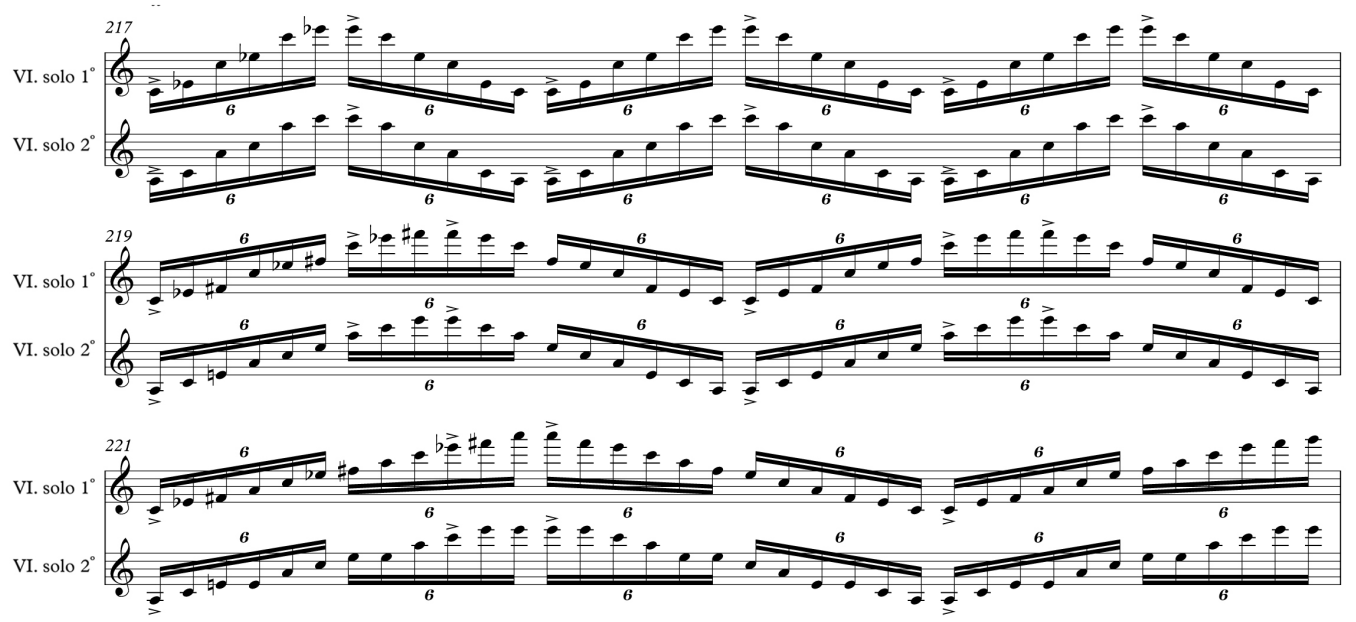

In the cadenza's closing bars (starting at bar 223), the orchestral strings change to playing only the pitches of the A minor triad, followed by solo violin 1 . Only the pitches of the A minor triad sound across the orchestra before it falls silent. In its frenzied 'game' of call and response, Ludus has seemingly explored and exhausted the harmonic 
possibilities of the key of A minor, while also bidding a final acknowledging farewell to the hallmark chromaticism of Pärt's pre-tintinnabuli compositional voice. The composer's musical slate has now been washed clean (i.e. Tabula Rasa), after almost eight years of self-imposed creative silence, and the stage is now set for him to lead his listeners into the quietude of Silentium.

Table 3.7: Pitch class vectors and chord progressions in the cadenza of Ludus - Bars 192-230

\begin{tabular}{|c|c|c|c|c|c|}
\hline Bar & $\begin{array}{l}\text { Interval } \\
\text { Class } \\
\text { Vector } \\
\end{array}$ & $\begin{array}{l}\text { Forte } \\
\text { Code }\end{array}$ & $\begin{array}{l}\text { Prime } \\
\text { Form }\end{array}$ & Duration & Chord \\
\hline 192.1 & $<101220>$ & $4-20$ & $(0,1,5,8)$ & 4 & A min ${ }^{\text {sus } 5}$ \\
\hline 193.1 & $<012120>$ & $4-26$ & $(0,3,5,8)$ & 4 & $A \min 7$ \\
\hline 194.1 & $<122230>$ & $5-27$ & $(0,1,3,5,8)$ & 4 & F maj $^{9}$ \\
\hline 195.1 & $<101220>$ & $4-20$ & $(0,1,5,8)$ & 4 & A min ${ }^{\text {sus } 5}$ \\
\hline 196.1 & $<122230>$ & $5-27$ & $(0,1,3,5,8)$ & 1 & $D \min ^{9}$ \\
\hline 196.2 & $<021120>$ & $4-22$ & $(0,2,4,7)$ & 7 & A min add4 \\
\hline 198.1 & $<132130>$ & $5-23$ & $(0,2,3,5,7)$ & 1 & A minadd2/add4 \\
\hline 198.2 & $<111120>$ & $4-14$ & $(0,2,3,7)$ & 7 & A min add 9 \\
\hline 200.1 & $<122230>$ & $5-27$ & $(0,1,3,5,8)$ & 1 & $A \min ^{9}$ \\
\hline 200.2 & $<012120>$ & $4-26$ & $(0,3,5,8)$ & 3 & $A \min 7$ \\
\hline 201.1 & $<122230>$ & $5-27$ & $(0,1,3,5,8)$ & 5 & F maj $^{9}$ \\
\hline 202.2 & $<101220>$ & $4-20$ & $(0,1,5,8)$ & 3 & A min aug 5 \\
\hline 203.1 & $<122230>$ & $5-27$ & $(0,1,3,5,8)$ & 4 & $\mathrm{D} \min ^{9}$ \\
\hline 204.1 & $<021120>$ & $4-22$ & $(0,2,4,7)$ & 4 & A min add4 \\
\hline 205.1 & $<132130>$ & $5-23$ & $(0,2,3,5,7)$ & 4 & A min add2/add4 \\
\hline 206.1 & $<111120>$ & $4-14$ & $(0,2,3,7)$ & 8 & A min add 9 \\
\hline 207.1 & $<021120>$ & $4-22$ & $(0,2,4,7)$ & 5 & E min add4 \\
\hline 208.1 & $<121110>$ & $4-11$ & $(0,1,3,5)$ & 1 & $E \min ^{9}$ sus4 (no 5) \\
\hline 208.2 & $<122230>$ & $5-27$ & $(0,1,3,5,8)$ & 8 & F maj $^{9}$ \\
\hline 211.2 & $<111120>$ & $4-14$ & $(0,2,3,7)$ & 8 & A min add 9 \\
\hline 213.2 & $<100000>$ & $\mathrm{N} / \mathrm{A}$ & $(0,1)$ & 3 & $\mathrm{~N} / \mathrm{A}$ \\
\hline 214.1 & $<114112>$ & $5-31$ & $(0,1,3,6,9)$ & 1 & B7dim9 \\
\hline 214.2 & $<112011>$ & $4-13$ & $(0,1,3,6)$ & 2 & F\# min flat5/sus4 \\
\hline 214.4 & $<002001>$ & $3-10$ & $(0,3,6)$ & 10 & F\#dim \\
\hline 216.2 & $<102111>$ & $4-18$ & $(0,1,4,7)$ & 12 & A min add\#11 \\
\hline 218.2 & $<114112>$ & $5-31$ & $(0,1,3,6,9)$ & 29 & B7dim9 \\
\hline 223.1 & $<001110>$ & $3-11$ & $(0,3,7)$ & 37 & $A \min$ \\
\hline 230.2 & $<000000>$ & $\mathrm{N} / \mathrm{A}$ & & 5 & Silence \\
\hline
\end{tabular}




\section{Tabula Rasa: Silentium}

The following style analysis is supplemented by graphic representation in the form of a MIDI-recreation of the work's musical lines to provide a visual overview of the entire work.

\section{Style analysis of Silentium}

What you can see now is a cool geometry: very particular and clear. ... The geometry is the point where everything starts. - Arvo Pärt ${ }^{132}$

Despite both movements of Tabula Rasa having the same basic generative process for their M-voices (Figure 3.30 below), in effect Ludus and Silentium could not be more dissimilar. Whereas Ludus is a relatively frenetic work, punctuated by fortissimos and periods of silence, Silentium is all hushed pianos and pianissimos throughout. In contrast to the relentless sense of motion imparted by Ludus, the rhythmic structure of Silentium is an unchanging triple-metre (long-short) motion that unfolds across a triple-metric canon that Pärt notes should be played senza moto (played without motion), quarter note $=$ ca 60.

Figure 3.30: Basic building block of Tabula Rasa

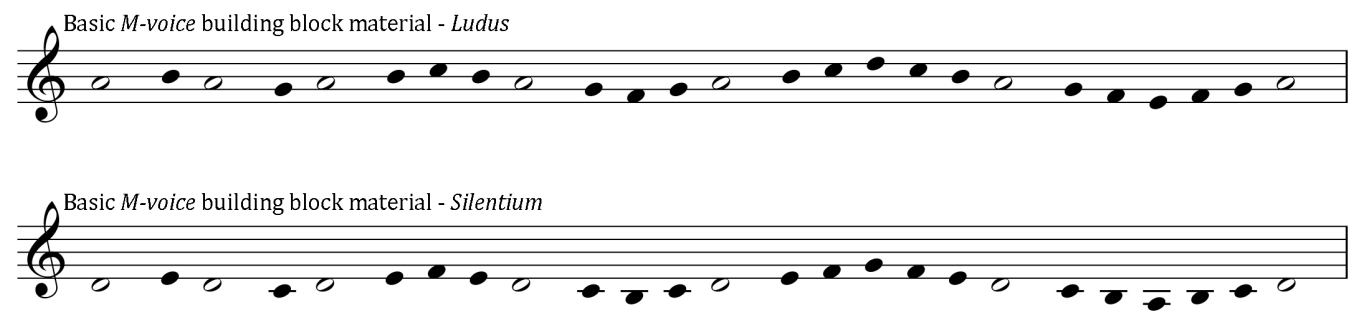

132 Smith, "An Interview with Arvo Pärt: Sources of Invention," 20. 


\section{Large dimension}

In Silentium the M-voices take D as their tonal centre ${ }^{133}$ - with the process expanding outwards in both directions across a D natural minor scale (D Aeolian) paired with D minor triad T-voices of varying positions (first position, alternating, second position, superior, and second position, inferior). This combination of M-voice/T-voice pairings covers all of the possible interval classes that can be generated from an Aeolian-based Mvoice paired with a T-voice that is based upon the tonic triad of the same scale (Figure 3.31. As was the case with Ludus, one might expect that this limited pallet of musical materials would not provide much promise in relation to a variety of different sonorities and creative expression. However, the following analysis will show that while Silentium's sound world is one of slow motion and quietude, it is anything but static or empty.

Figure 3.31: Potential interval class content generated by a D Aeolian scale and D minor triad Mvoice/T-voice pairing
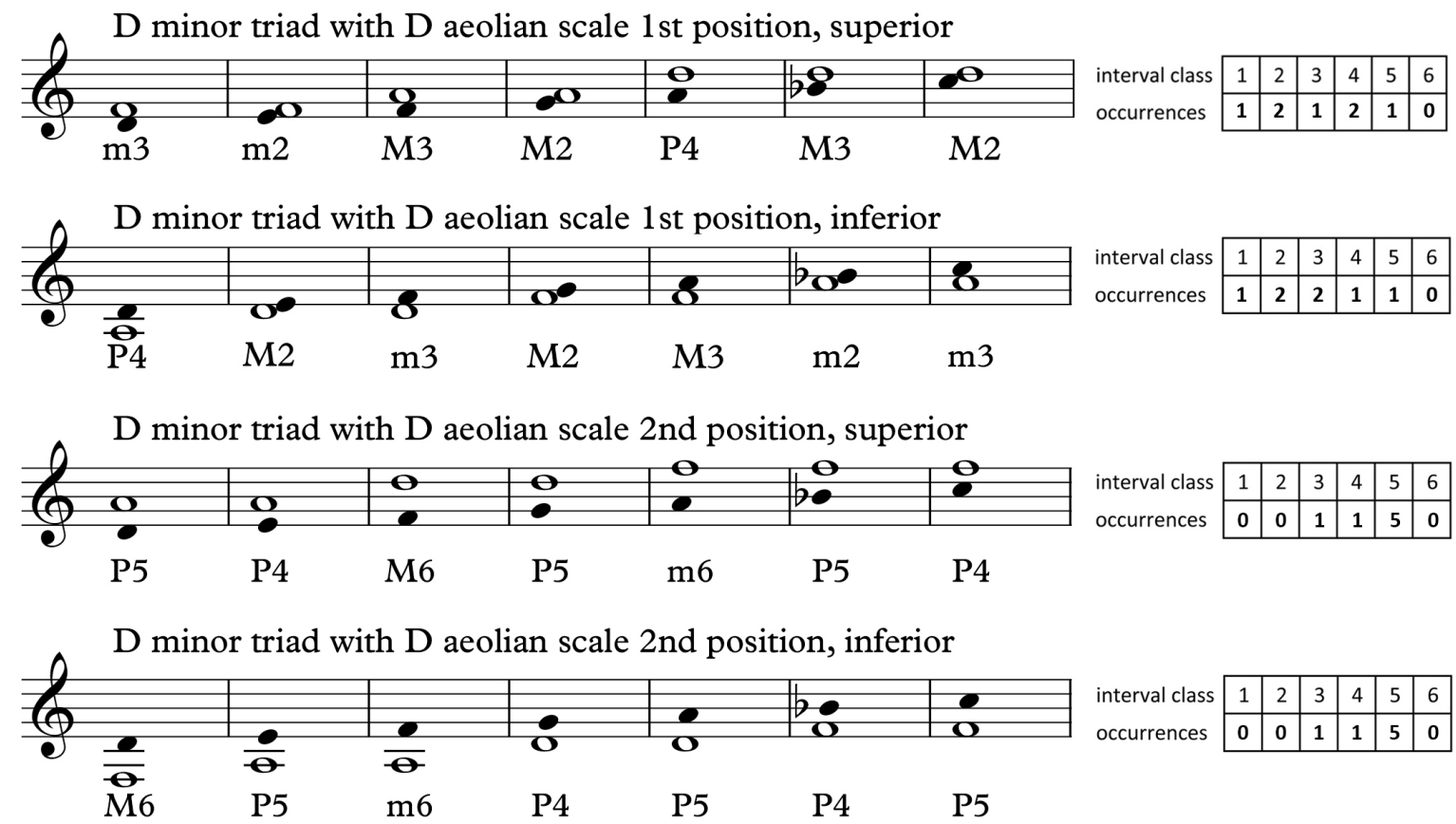

133 Silentium's tonal centre of D can also be interpreted as having a tonic relationship to Ludus's pitch class centre of A. 
Following the five bars of silence at the end of the cadenza in Ludus, Silentium commences with the prepared piano playing a pianissimo second inversion $\mathrm{D}$ minor chord as an ascending arpeggio. Spanning two octaves from A3 to F5, this occurs as an upbeat to the first bar of the movement (Figure 3.32). On beat one of the first bar, the prepared piano then sounds an open fifth chord at D2, D3, and A5, with the contrabasses doubling the piano by playing D1 and D2 (sounding pitches) non divisi pizzicato. This sounding of an arpeggiated D minor chord, followed by an open fifth chord at D and A by the prepared piano and contrabasses, continues periodically throughout the remainder of the movement, signalling those points when solo violin 1's M-voice arrives at its pitch centre of D6.

Figure 3.32: Silentium - opening bars

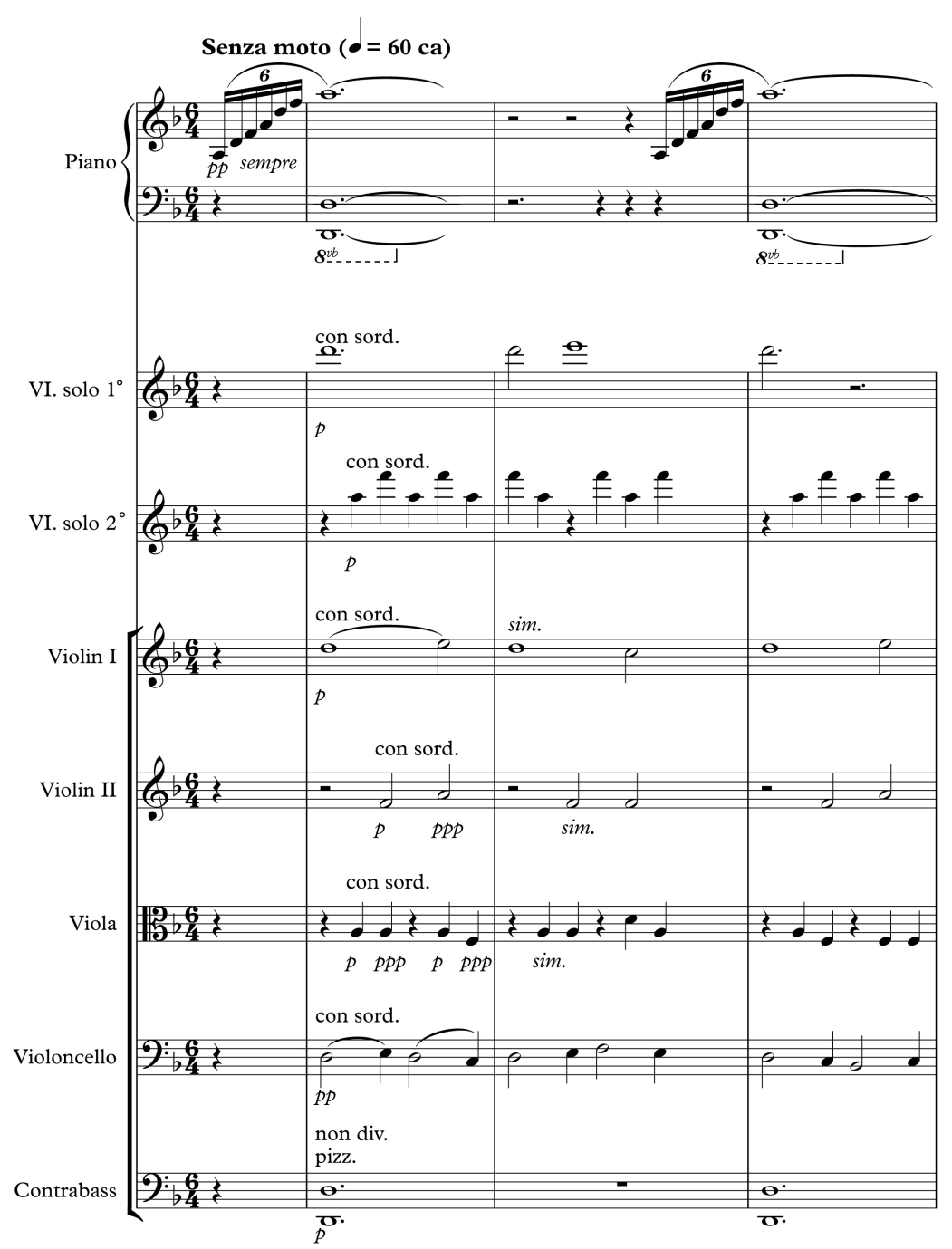


As the piece proceeds from its opening bars, the slow stepwise motion of the solo violin 1 line occupies the front of Silentium's sonic field, moving slowly away from and back towards its tonal centre of D6. Sitting much further back in the sonic field, almost as if they are playing in a different and distant room, the remaining sections of the string orchestra also play in a slow moving hushed fashion.

As the span of the solo violin 1's uppermost and lowest notes expands outwards from its tonal centre, solo violin 2 plays individual pitches of the D minor triad as crochets, executing an alternating first position, inferior/superior T-voice above and below the solo violin 1 line. As the violins proceed in this arrangement, the number of measures between each occurrence of the piano's arpeggiated D minor chord increases by two measures - occurring on the pickup and downbeat of bars 3 and 5, then on the pickup and downbeat of bars 9 and 14, bars 19 and 25, etc. - until the pattern culminates in bars 99 and 113 (a span of fourteen bars) and finishes at bar 129, sixteen bars after its penultimate occurrence in bar 113.

Figure 3.33 overleaf provides a MIDI-recreation of Silentium as an overview of the movement in its entirety. In it can be clearly seen the movement of the different string sections of the different M-voice lines, framed by their respective T-voices, as they trace their respective journeys away from and back towards their corresponding pitch-class centres throughout the registral range of the orchestra. Figure 3.33 also clearly illustrates Silentium's expanding eight-section 'architecture'. 
Figure 3.33: Silentium - MIDI recreation (with contrabasses shown in their sounding register) ${ }^{134}$

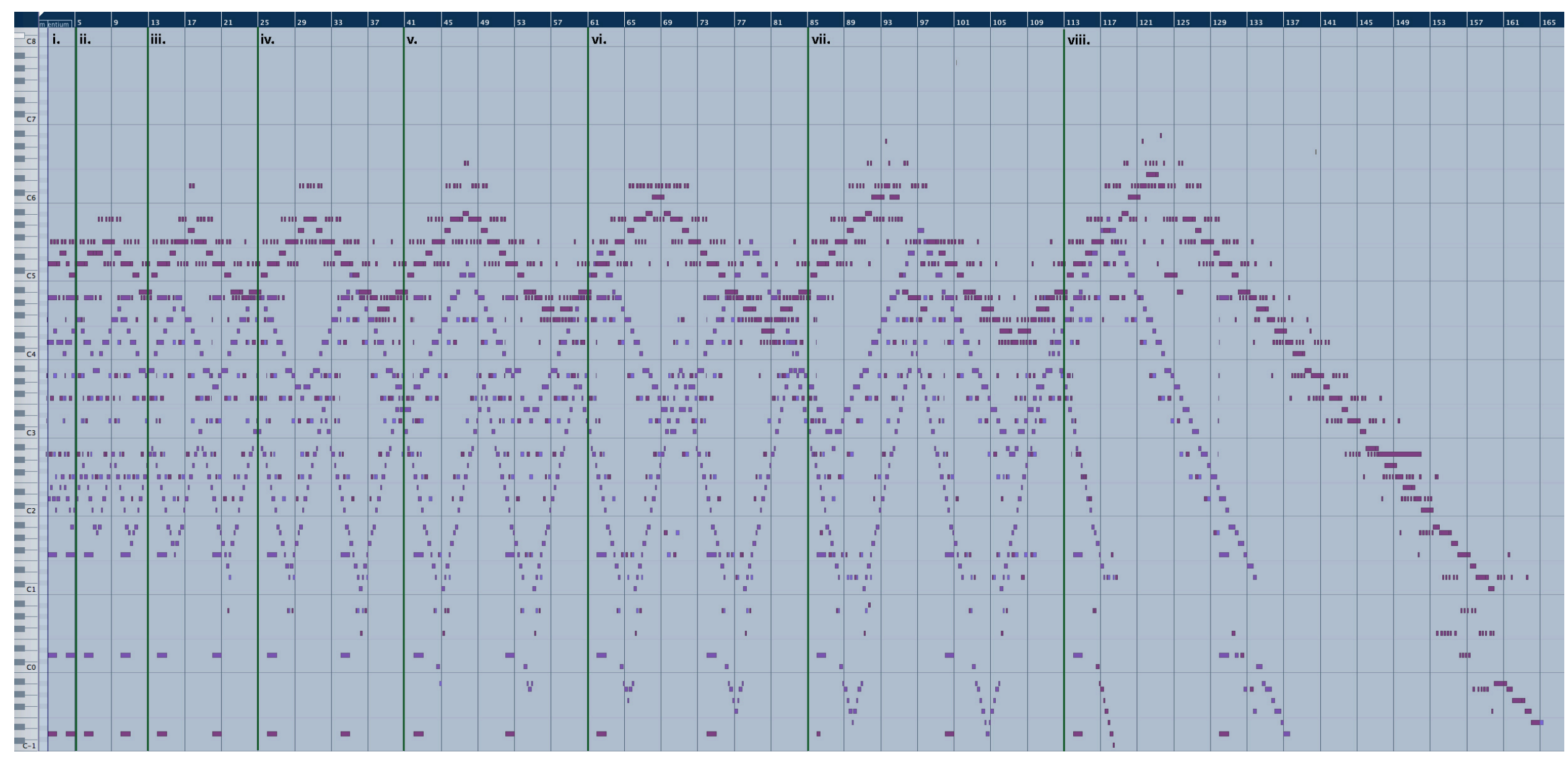

134 Midi-recreation created using Cubase ${ }^{\mathrm{TM}} 7.5$. 


\section{Middle dimension}

As illustrated in Figure 3.34 below, the solo violin 1, first violins, and the cellos each have their own outwardly expanding M-voice operation, occurring at three different paces with the solo violin 2, second violins, and violas, respectively, providing differently positioned T-voices, each using a different rhythmic pattern (discussed below). As detailed by the first four bars in Figure 3.34, the outwardly expanding process of the Mvoice solo violin 1 line is the slowest of the three M-voices. ${ }^{135}$ Its rhythmic pattern is based upon a two-bar schema, with the first bar comprising a dotted semibreve, followed by a minim and a semibreve, respectively, in the next bar. Melodically, the pattern expands upwards and downwards from its pitch centre of D6. Whenever the M-voice passes through the pitch centre, the half note in the following measure always repeats D6.

Figure 3.34: Silentium - M-voice and T-voice patterns

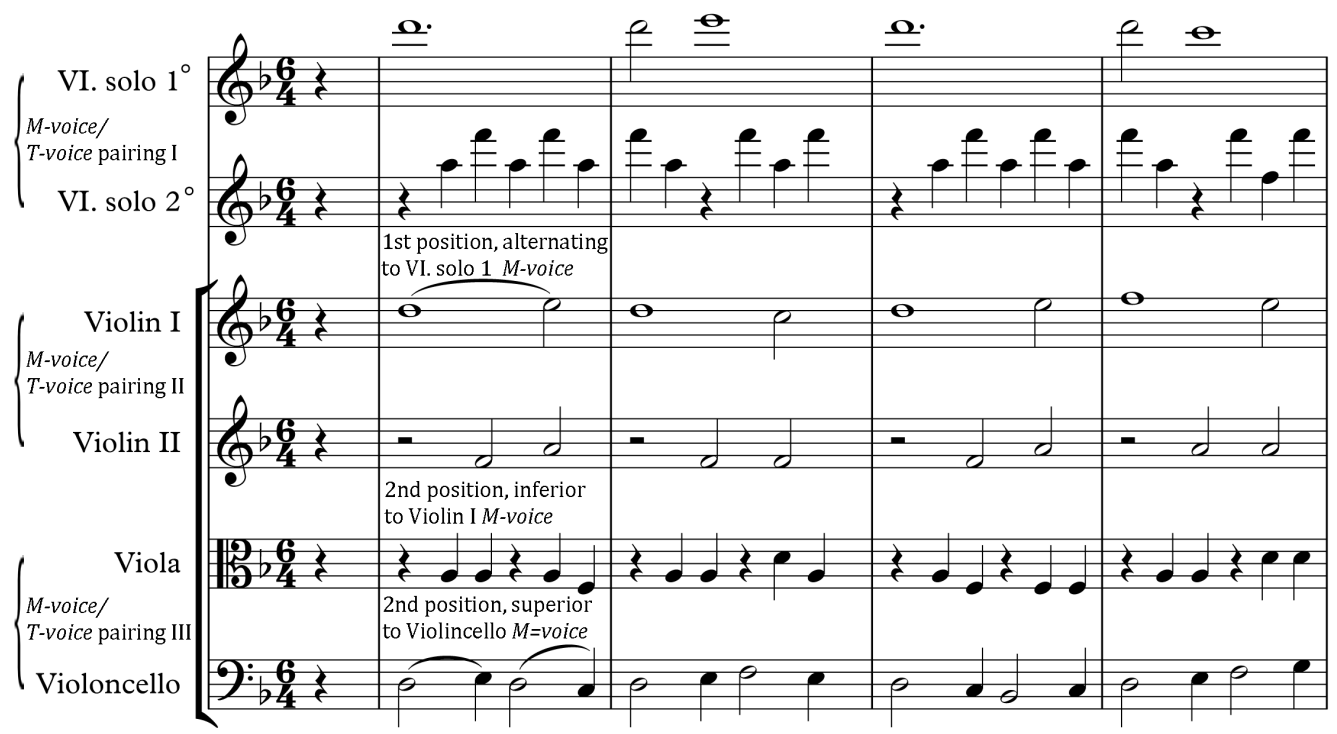

135 As will be seen in later pieces, assigning the slowest moving M-voice to the instrument playing in the highest register is unusual. In most of Pärt's string orchestral works, where he uses varying rhythmic paces in different M-voices, the pace of the uppermost M-voice has usually one of the fastest M-voice paces. 
The T-voice in the solo violin 2 line is in first position, alternating with the solo violin 1's M-voice. Its rhythmic pattern is also based on a two-bar schema. Comprising a series of crotchets, it is the fastest moving of all of the three T-voices, and it is slightly referential of the 'sing/song'-like pattern of the T-voices that bookended the beginning and end of each of Ludus's eight main sections. This T-voice starts on beat two of the first full bar, with beats $2,4,6$, and beat 1 of the next bar taking the first position, inferior pitch of the T-voice triad that is below the pitch played by solo violin 1 line. On the alternate beats $(3$, 5 , and beat 2 of bar two), the solo violin 2 T-voice plays the first position, superior triad pitch above the pitches played by the solo violin 1 . After a one beat rest, the solo violin 2's T-voice recommences on beat 3 of bar two, alternating in first position, superior and inferior above and below the solo violin 1 line for three more beats.

The first violins' M-voice is a modification of the solo violin $1 \mathrm{M}$-voice line, but with the duration of each note of the pattern shortened by two beats each. This is due to the omission of the half-note repetition of the tonal centre pitch, resulting in the first violins' M-voice pattern expanding outwards from the tonal centre at twice the speed of the solo violin $1 \mathrm{M}$-voice. The second position, inferior T-voice of the second violins enters in a staggered fashion playing minims on beats two and three of each measure. Depending upon the position in relation to the M-voice line, the paired T-voice notes are either the same pitch repeated twice, as in bars two and four, or two different pitches of the D minor triad, as in bars one and three. The violoncellos' M-voice is a temporal diminution of the pattern played by the first violins, consisting of a minim followed by a crotchet. The T-voice line of the violas is similar to that of the second violins, but in second position, superior, as opposed to second position, inferior, and with the note durations shortened to two crotchets alternating between $p$ and $p p p$ in their dynamics. 
As the three different M-voice/T-voice pairings slowly expand at different speeds over approximately a fourteen-minute period, they create Silentium's uniquely gentle and kaleidoscopic, slowly evolving soundscape. To the careful listener, the M-voice line of the solo violin divides the movement into eight musical sentences, with each section being four bars longer than the section preceding it. Some might argue that the work is divided into 16 sections, based upon the frequency of the piano arpeggiations, followed by an open fifth chord at D and A by the prepared piano and contrabasses. However, subdividing the movement into 16 sections does not align with Pärt's careful balancing of the stepwise-based M-voices that progress outwards in alternating directions from a single tonal centre (as illustrated above in the MIDI-recreation in Figure 3.33). ${ }^{136}$

\section{Small dimension}

The three M-voices, accompanied by their respective T-voices, each expand outwards from their tonal centre of $\mathrm{D}$, adding one additional pitch at the bottom and top of each cycle until they have reached a predetermined span. At bar 20, however, the violas encounter the bottom of their playable range, at which point the contrabasses begin taking up the violas' T-voice function whenever required (see bar 20, Figure 3.35).

Figure 3.35: Silentium - bars 19-21

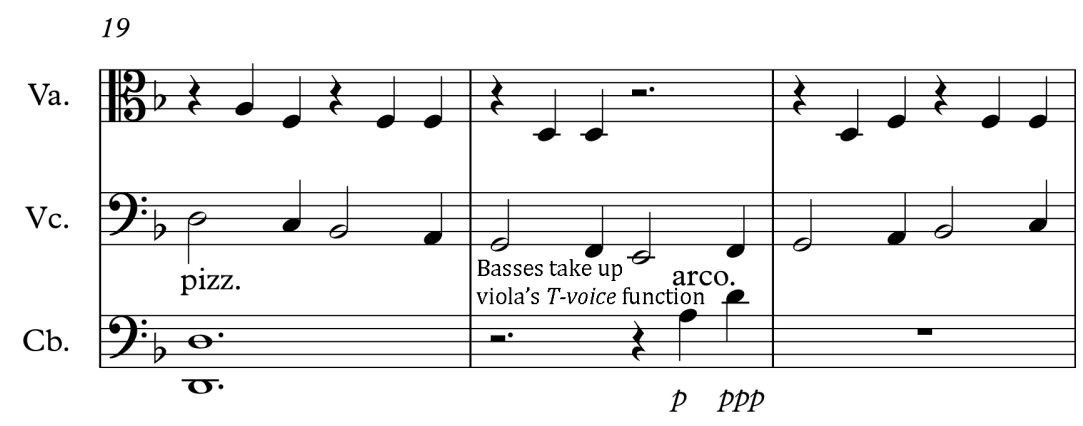

\footnotetext{
${ }^{136}$ As discussed in Chapter 2, the M-voices of most of the early tintinnabuli works are constructed based upon three approaches: a methodical stepwise outward expansion in alternating directions from a tonal centre; canons based upon a stepwise pattern, usually proceeding in only one direction; or melodic material developed and based upon the characteristics of religious text.
} 
This arrangement continues until bar 43, during which the cellos also encounter the lower end of their playing range. At this point, and for the remainder of the piece when this situation arises, the contrabasses take over the M-voice function and the cellos switch to playing the T-voice role. During such periods, the violas fall silent. During the 'hand-over' of voice parts from both the violas and the cellos to the contrabasses, in some measures the contrabasses contribute to both the M-voice and the T-voice lines of the pairing. ${ }^{137}$ Figure 3.36 provides an extended example of this role of swapping between the three lines of instruments in bars 61-66, with the red circles denoting the swapping of the T-voice between instruments and the blue circles the swapping of the M-voice.

\section{Figure 3.36: Silentium - bars 61-67}

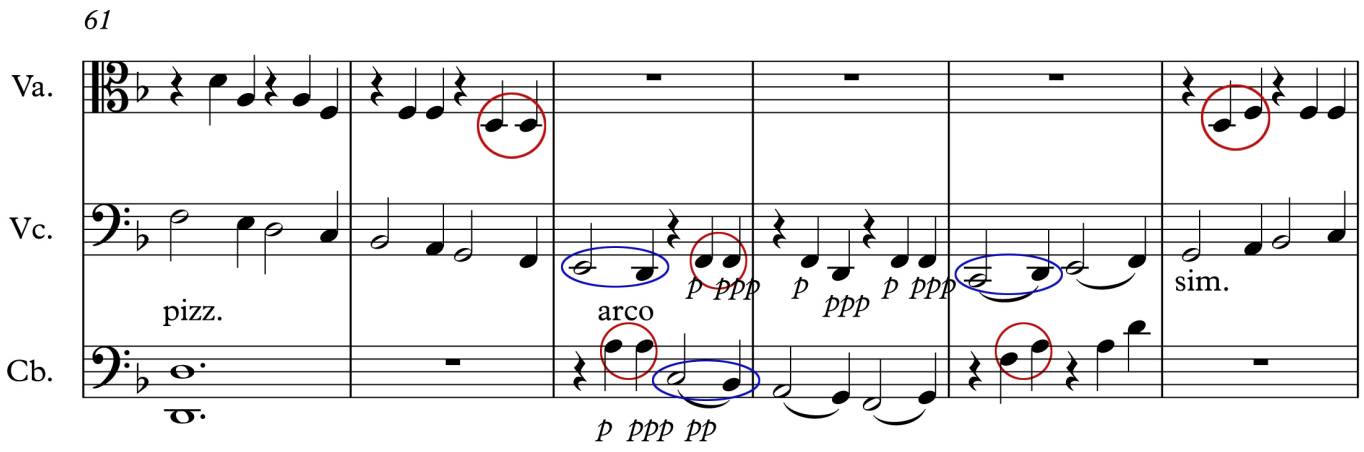

By bar 103, the T-voice in the second violin line also reaches the bottom of the instrument's range, only to be taken up briefly by the violas for one bar in bar 104 and then by the contrabasses in bar 105 (indicated with green circles in Figure 3.37 overleaf). In bar 105 the cellos pass the responsibility for the T-voice back to the violas at which point the cellos assume the role of playing the lowest M-voice line.

137 This swapping of roles between the cellos and the contrabasses has also been noted by Hillier (see Hillier, p. 118). 


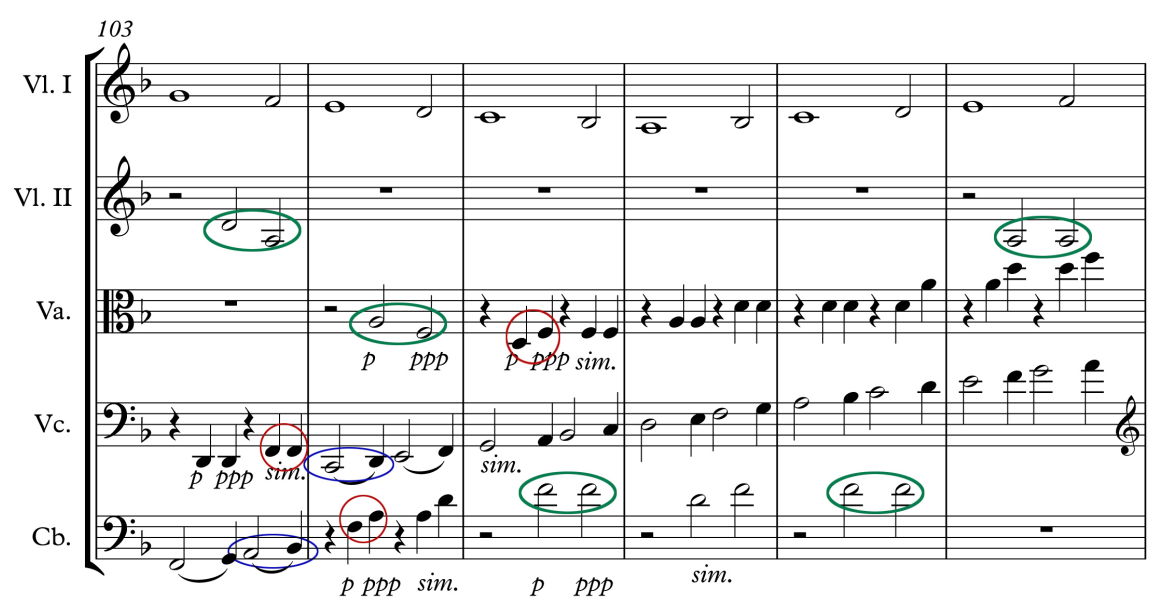

At the end of bar 109, the lowest and fastest moving M-voice has reached the uppermost span of its range (E5), and by the middle of bar 114 its lowest (D1 as played by the basses), after which the violas, cellos, and basses all fall silent for a period. By bar 124 the T-voice in the first and second violins' pairing reaches $\mathrm{A} 3$, the next to last note at the bottom of their playable range, after which the violas and then the cellos re-enter briefly to take up the role of the middle M-voice line for two and three bars, respectively, before passing it over to the contrabasses, which have been briefly providing the T-voice of the middle pairing since bar 125 . The middle M-voice line continues downwards for three more bars to the equivalent of $\mathrm{D} 1$ on the piano, ${ }^{138}$ though unaccompanied by its respective T-voice, as it winds down to silence (Figure 3.38 overleaf). This swapping of roles between the various instrumental sections arises out of the practicalities forced onto the composer by limits in the musical instruments' registers. However, as aurally it is imperceptible to the listener - and unlikely to be noticed unless one were to follow a live performance or broadcast of Silentium with a copy of the score - it seems unlikely that it is the outcome of Pärt attempting to achieve some specific aesthetic effect at this point in Silentium.

\footnotetext{
138 While this is noted as D2 on the score, as a transposing instrument the contrabass sounds one octave lower than its actual scoring.
} 
Figure 3.38: Silentium - bars 127-133

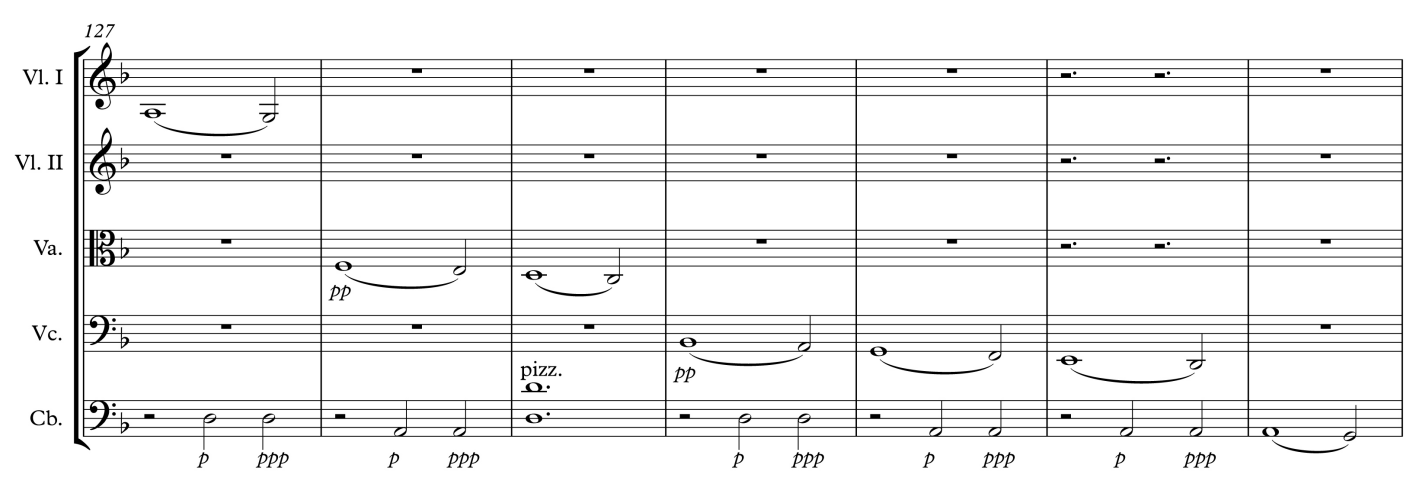

The uppermost M-voice line reaches its highest point (E7) at the beginning of bar 121 and progresses downwards as it begins its final descent. Passing from solo violin 1 to the violas and then cellos, it ultimately reaches the contrabasses where it proceeds down to E1 - though it never resolves to D1, the tonal centre of the M-voice. Throughout this final descent of the M-voice, its first position alternating T-voice has accompanied it, ending with the cellos on D2.

As can be seen from the preceding description of Silentium's operations, Pärt introduces very little variety in the way he treats the musical material in Silentium when compared with how he manipulates the musical material of Ludus. With the exception of periodic swapping of M-voice and T-voice lines to accommodate the range limitations of different members of the string family, and two other minor exceptions noted below, once the initial M-voice/T-voice patterns have been established and begin their outward expansions they remain relatively unchanged. The first of these exceptions occurs in Section 6, with the solo violin 1 and solo violin 2 switching M-voice/T-voice roles. ${ }^{139}$ The other exception also occurs in the solo violin 2's T-voice line, wherein the M-voice changes to second position, superior on beat four and then reinforces the entire D minor

\footnotetext{
139 However, as was the case with the passing of roles between the various string sections of the orchestra, the switching of roles by the solo violins is generally not perceptible to the listener on most recordings, unless they specifically listen for this change based on differences in the timbre of the two violins or are following the score.
} 
triad on the last beat of a bar by playing the two triadic notes not being played by the Mvoice as double stops (Figure 3.39). These double stops help to punctuate the presence of the T-voice's full triad and occur near the end of sections: bars 34, 36, and 38 in Section 4; bars 54, 56, and 58 in Section 5; bars 76, 78, and 80 in Section 6; bars 102, 104, 106, 108, and 109 in Section 7; and bars 120, 122, 134, and 136, and 148 and 150 in Section 8.

Figure 3.39: Silentium - bars 34-38

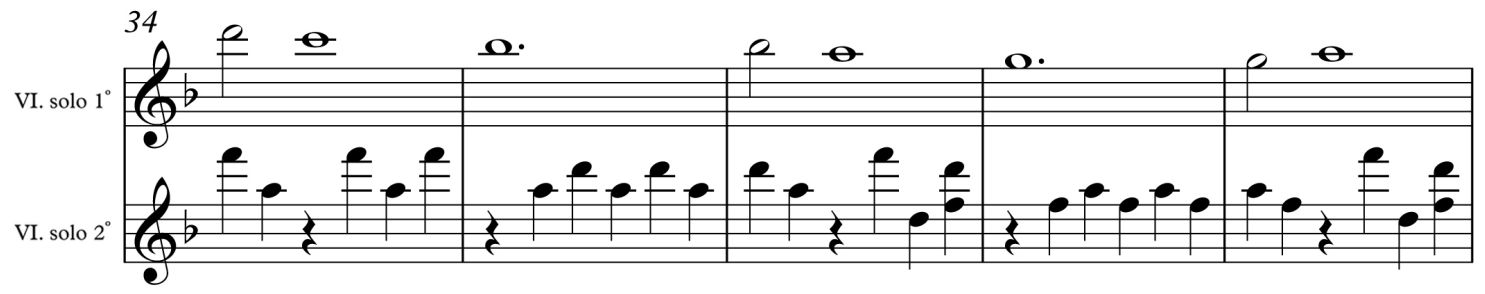

Interval class analysis and sonority mappings of Silentium

The following section builds on the preceding style analysis and examines: 1) the intervallic content that arises from the combination of mensural cannon with tintinnabuli operations in Silentium; 2) sonority mapping of this content, detailing the shifting musical sonorities throughout the work. This content analysis is supplemented by graphic representation in the form of a Pärtian Tonnetz, to demonstrate the interrelations between the different M-voice and T-voice pitch classes and the resulting intervallic content when any two pitches occur at the same time.

The Pärtian Tonnetz in Figure 3.40 overleaf shows the various intervallic relationships between the pitch classes of Silentium. While Silentium's pitch class content is slightly different to that of Ludus, due to Silentium's use of Bb (pitch class 10) rather than B (pitch class 11), its potential intervallic content is the same as that of Ludus, i.e. two minor seconds, five major seconds, four minor thirds, three major thirds, six perfect 
fourths and one tritone: Interval Class Vector $<254361>$ (Forte Code: $7-35$ ). This is due to both of Tabula Rasa's movements using an Aeolian scale paired with a T-voice triad based on the root note, third, and fifth of the scale.

Figure 3.40: Pärtian Tonnetz of Silentium's M-voice/T-voice pitch class relationships M-voice/T-voice Relationships - Silentium

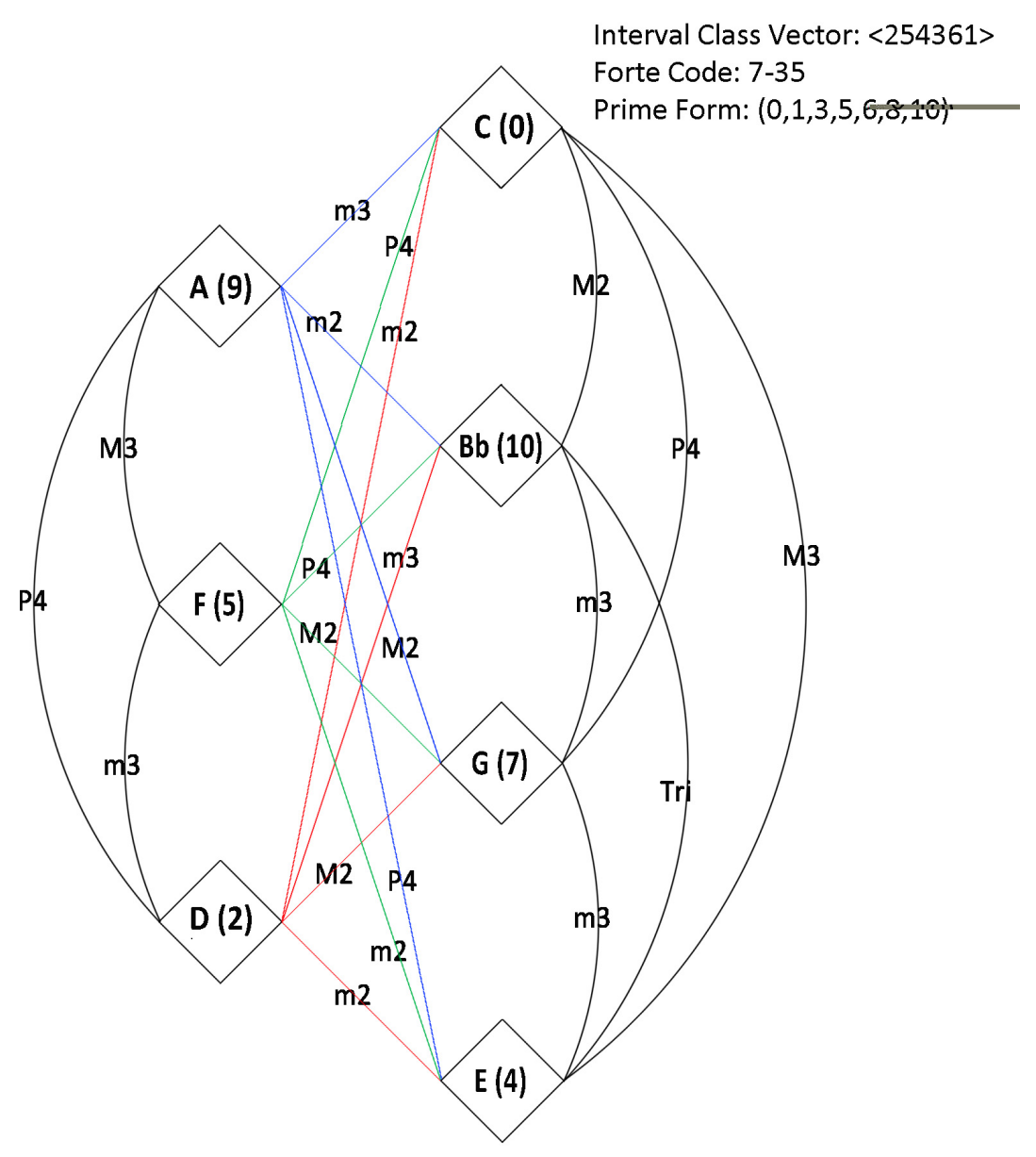

As was the case with Ludus, Silentium starts with a limited pallet of sonorities that slowly expands as the work progresses. Table 3.8 overleaf details the interval vectors that occur in Sections 1 and 2 of Silentium. Examination of the vectors and their frequencies of occurrence shows the dominant sonorities to be $<001110>$ (Forte Code: $3-11$, which in the first nine bars of Silentium always occurs as a D minor chord); $<111120>(4-14$, which in the first nine bars always occurs as a Dm ${ }^{\text {add9 }}$ chord); $<101220>(4-20$, which occurs as 
a B b maj7 or an F maj7 chord); and $<000010>$ (an open fifth chord occurring anchored to D5). Less frequently occurring vectors include $<012120>$ (Forte Code: 4-26, occurring as a Dmin7 chord), $<100110>$ (Forte Code: $3-4$ as F maj7 ${ }^{\text {no5}}$ ), and $<101220>$ (Forte Code: 527, occurring as either a Dmin9 or a Bb maj9 chord).

Table 3.8: Matrix of vectors and their frequency of occurrence in Silentium - Sects.1 and 2

\begin{tabular}{|c|c|c|c|c|c|c|c|c|}
\hline Vectors & $\begin{array}{l}\text { Forte } \\
\text { Codes }\end{array}$ & $\begin{array}{l}\text { Prime } \\
\text { Forms }\end{array}$ & $1 \mathrm{a}$ & $1 b$ & $2 a$ & $2 b$ & Total & $\begin{array}{l}\text { Chord } \\
\text { equivalent(s) }\end{array}$ \\
\hline$<000010>$ & $\mathrm{N} / \mathrm{A}$ & $(0,5)$ & 3 & 2 & & 1 & 6 & D5 \\
\hline$<000100>$ & $\mathrm{N} / \mathrm{A}$ & $(0,4)$ & & & 1 & 1 & 2 & F no 5 \\
\hline$<001000>$ & $\mathrm{N} / \mathrm{A}$ & $(0,3)$ & 1 & 1 & 1 & & 3 & Am no5 \\
\hline$<001110>$ & $3-11$ & $(0,3,7)$ & 2 & 2 & 6 & 3 & 13 & $\mathrm{Dm}$ \\
\hline$<010020>$ & $3-9$ & $(0,2,7)$ & & & & 1 & 1 & $\mathrm{D}$ suss 4 \\
\hline$<011010>$ & $3-7$ & $(0,2,5)$ & & & & 1 & 1 & Dm sus4 no5 \\
\hline$<012120>$ & $4-26$ & $(0,3,5,8)$ & & 1 & 2 & 2 & 5 & $\mathrm{Dm}^{7}$ \\
\hline$<021120>$ & $4-22$ & $(0,2,4,7)$ & & & & 1 & 1 & $\mathrm{Dm}$ add 4 \\
\hline$<032140>$ & $5-35$ & $(0,2,4,7,9)$ & & & & 1 & 1 & Dm ${ }^{11 \text { th }}$ \\
\hline$<100000>$ & $\mathrm{N} / \mathrm{A}$ & $(0,1)$ & & & & 1 & 1 & $A^{-9}$ no3 no5 \\
\hline$<100110>$ & $3-4$ & $(0,1,5)$ & & & 2 & 3 & 5 & F 7 no5 \\
\hline$<101220>$ & $4-20$ & $(0,1,5,8)$ & & 3 & 2 & 2 & 7 & $\mathrm{~B} b^{\text {maj }}, \mathrm{F}^{7}$ \\
\hline$<111000>$ & $3-2$ & $(0,1,3)$ & & & 1 & & 1 & Em -9 no5 \\
\hline$<111120>$ & $4-14$ & $(0,2,3,7)$ & 4 & & 2 & 5 & 11 & Dm add 9 \\
\hline$<122230>$ & $5-27$ & $(0,1,3,5,8)$ & 3 & 2 & & & 5 & $\begin{array}{l}\mathrm{Dm}^{9} \\
\mathrm{~B} b^{9}\end{array}$ \\
\hline$<132130>$ & $5-23$ & $(0,2,3,5,7)$ & & & 4 & & 4 & Dm add2 add4 \\
\hline$<143250>$ & $6-32$ & $(0,2,4,5,7,9)$ & & 1 & & & 1 & $\mathrm{~B} b^{13}$ \\
\hline$<200121>$ & $4-8$ & $(0,1,5,6)$ & & & 2 & & 2 & E-9 flat5 sus 4 \\
\hline$<211231>$ & $5-20$ & $(0,1,5,6,8)$ & & & 1 & 2 & 3 & Dmadd9 aug5 w5 \\
\hline \multicolumn{3}{|c|}{ Number of distinct vectors } & 5 & 7 & 11 & 13 & 19 & \\
\hline
\end{tabular}

As was found with Ludus, Table 3.8 also shows that the number of vectors occurring in the different subsections of Silentium increases, with there being five distinct vectors in Section 1a, seven vectors in Section $1 \mathrm{~b}$, eleven vectors in Section $2 \mathrm{a}$ and thirteen different vectors in Section $2 b$. Further examination shows that in each of the different subsections, one or more different vectors occur more frequently than the others: $1 \mathrm{a}$ and $2 \mathrm{~b}(<111120>), 1 \mathrm{~b}$ $(<101220>)$, and $2 \mathrm{a}(<001110>$, and to a lesser degree $<132130>)$. 
Table 3.9 overleaf details the interval vectors that occur in Sections 3 and 4 . The vector $<001110>$ (Forte Code: 3-11, representing the chords G minor, D minor, F, and B $b$ that occur throughout the Sections) is a dominant vector in both subsections $3 \mathrm{a}$ and $4 \mathrm{a}$ - occurring twenty-three times across the four subsections. Vector <101220> (Forte Code: 4-20, representing the chords $G$ minor 7 and $F$ major 7 ) is the most prominent vector in subsection $3 \mathrm{~b}$, and also is the second most frequently occurring vector across the four subsections, occurring eighteen times. Three other vectors occur twelve or more times across the four subsections as well: $<111120>$ (Forte Code: 4-14, occurring fifteen times and representing various inversions of a D minor chord); <021120> (Forte Code: 4-22, occurring twelve times, always as different inversions of a D7 with a suspended 4 chord); and $<100110>$ (Forte Code: 3-14, also occurring twelve times and representing various permutations of an $\mathrm{F}$ major 7 or $\mathrm{B} b$ major 7 chord, but always missing either the third or the fifth of the chord in question). 
Table 3.9: Matrix of vectors and their frequency of occurrence in Silentium - Sects. 3 and $4^{140}$

\begin{tabular}{|c|c|c|c|c|c|c|c|c|}
\hline Vectors & $\begin{array}{l}\text { Forte } \\
\text { Codes }\end{array}$ & $\begin{array}{l}\text { Prime } \\
\text { Forms } \\
\end{array}$ & $3 \mathbf{a}$ & $\mathbf{3 b}$ & $4 a$ & $4 b$ & Total & Chord equivalent(s) \\
\hline$<000010>$ & $\mathrm{N} / \mathrm{A}$ & $(0,5)$ & 1 & & & 3 & 4 & $\mathrm{D}^{5}, \mathrm{G}^{5}$ \\
\hline$<000100>$ & $\mathrm{N} / \mathrm{A}$ & $(0,4)$ & & 1 & 1 & 1 & 3 & $\mathrm{~F}$ no5 \\
\hline$<001110>$ & $3-11$ & $(0,3,7)$ & 9 & 3 & 9 & 2 & 23 & $\mathrm{Dm}, \mathrm{Gm}, \mathrm{B} b, \mathrm{~F}$ \\
\hline$<002001>$ & $3-10$ & $(0,3,6)$ & & & & 1 & 1 & E dim \\
\hline$<010020>$ & $3-9$ & $(0,2,7)$ & & 2 & 1 & & 3 & $\mathrm{D}$ sus4 \\
\hline$<011010>$ & $3-7$ & $(0,2,5)$ & 1 & 1 & 3 & 2 & 7 & $\mathrm{~F}^{6 \text { th no3 }}, \mathrm{Gm}^{7}$ no $3, \mathrm{Gm}^{7}$ no 5 \\
\hline$<012111>$ & $4-27$ & $(0,2,5,8)$ & & & & 1 & 1 & $\mathrm{G}^{7}$ \\
\hline$<012120>$ & $4-26$ & $(0,3,5,8)$ & & 2 & & 3 & 5 & $\mathrm{Gm}^{7}, \mathrm{Dm}^{7}$ \\
\hline$<020100>$ & $3-6$ & $(0,2,4)$ & 1 & & 1 & & 2 & $\mathrm{~F}$ and 9 no5 \\
\hline$<021030>$ & $4-23$ & $(0,2,5,7)$ & 3 & & 2 & 3 & 8 & 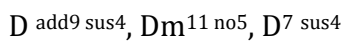 \\
\hline$<021120>$ & $4-22$ & $(0,2,4,7)$ & 3 & 4 & 4 & 1 & 12 & $\mathrm{D}^{7}$ sus 4 \\
\hline$<030201>$ & $4-21$ & $(0,2,4,6)$ & & & & 1 & 1 & $B$ badd9 sus4 \\
\hline$<032140>$ & $5-35$ & $(0,2,4,7,9)$ & & 3 & 3 & 2 & 7 & $\begin{array}{l}\mathrm{Dm}^{11} \\
\mathrm{Gm}^{7 / C}\end{array}$ \\
\hline$<032221>$ & $5-34$ & $(0,2,4,6,9)$ & & & & & 1 & $\mathrm{G}^{9}$ \\
\hline$<100000>$ & $\mathrm{N} / \mathrm{A}$ & $(0,1)$ & & 1 & & & 1 & $A^{-9}$ no3 no5 \\
\hline$<100011>$ & $3-5$ & $(0,1,6)$ & & & 1 & & 1 & Fmaj7 sus4 no5 \\
\hline$<100110>$ & $3-4$ & $(0,1,5)$ & 2 & 2 & 3 & 5 & 12 & 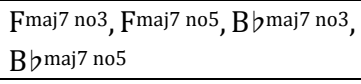 \\
\hline$<101220>$ & $4-20$ & $(0,1,5,8)$ & 4 & 7 & 3 & 4 & 18 & $\mathrm{Gm}^{7}$, Fmaj7 \\
\hline$<110121>$ & $4-16$ & $(0,1,5,7)$ & & 1 & & 1 & 2 & Fmaj7 sus4, $\mathrm{B} b^{\text {flat5 } 5 \text { maj7 }}$ \\
\hline$<111000>$ & $3-2$ & $(0,1,3)$ & & & 1 & 2 & 3 & $\mathrm{Dm}^{9}$ no5, $\mathrm{Am}^{-9}$ no5 \\
\hline$<111111>$ & $4-Z 15$ & $(0,1,4,6)$ & & & 1 & 1 & 2 & Dm $^{9}$ aug5, \\
\hline$<111120>$ & $4-14$ & $(0,2,3,7)$ & 4 & 4 & 5 & 2 & 15 & $\begin{array}{l}\text { Dm }^{9} \text { aug5, } \\
\text { Dm }^{11} \text { no5, }\end{array}$ \\
\hline$<112011>$ & $4-13$ & $(0,1,3,6)$ & & & & 1 & 1 & $A^{7-9 \text { no3 }}$ \\
\hline$<121110>$ & $4-11$ & $(0,1,3,5)$ & 2 & 2 & & 1 & 5 & $\begin{array}{l}\text { Fmaj7 add9 no5, } \\
\text { C13 no3 no5 }\end{array}$ \\
\hline$<122131>$ & $5-29$ & $(0,1,3,6,8)$ & & & & 2 & 2 & Em$^{11}$ flat5 \\
\hline$<122230>$ & $5-27$ & $(0,1,3,5,8)$ & 2 & 1 & 3 & 3 & 9 & $\mathrm{Dm}^{9}, \mathrm{~B} b^{\text {maj }}{ }^{9}, \mathrm{Gm}^{9}$ \\
\hline$<123121>$ & $5-25$ & $(0,2,3,5,8)$ & 1 & & & & 1 & $\mathrm{Gm}^{13}$ \\
\hline$<132130>$ & $5-23$ & $(0,2,3,5,7)$ & 2 & & 3 & 1 & 6 & $\mathrm{Gm}^{13}$ no 3 \\
\hline$<143250>$ & $6-32$ & $(0,2,4,5,7,9)$ & & & 1 & & 1 & $\mathrm{Dm}^{11}$ \\
\hline$<200121>$ & $4-8$ & $(0,1,5,6)$ & 1 & & & 1 & 2 & Fmaj11w3 no5 \\
\hline$<211231>$ & $5-20$ & $(0,1,5,6,8)$ & & 2 & 2 & 4 & 8 & Dmadd2 add 4 \\
\hline$<233241>$ & $6-Z 25$ & $(0,1,3,5,6)$, & & & 1 & & 1 & $\mathrm{Gm}^{13}$ no 5 \\
\hline \multicolumn{3}{|c|}{ Number of distinct vectors } & 14 & 15 & 19 & 24 & 32 & \\
\hline
\end{tabular}

140 Where an interval vector covers more than one chord equivalent, the different chords are usually listed in the frequency of their first occurrence, with the odd exception being an arbitrarily decided order to minimise the number of lines in a particular table row. 
The number of distinct interval vectors occurring in Sections 5 and 6 of Silentium are consistent throughout the different subsections, each containing twenty-two different vectors (Table 3.10 overleaf), although the total number of vectors across both Sections 5 and 6 is thirty-five, compared with thirty-two vectors across Sections 3 and 4 and just nineteen vectors across Sections 1 and 2.

Throughout Sections 5 and 6, there are quite a number of different vectors that occur with a fair degree of frequency. The most frequent vector (occurring thirty-one times) is <021120> (Forte Code: 4-22, which includes the following frequently occurring chords: D minoradd4, $B b^{\text {add9 }}$, D minor 7 , and Fadd9 in a number of different inversions through the four subsections). This same vector is also the most frequently occurring sonority in subsection 6 a (occurring thirteen times). The second most frequently occurring vector is $<001110>$ (Forte Code: 3-11, representing the triadic chords D minor, B b, F, C, and A minor). It occurs a total of twenty-nine times across Sections 5 and 6 , and is also the most frequently occurring vector in subsection 5 a (ten times).

There are also a number of second-tier vectors (as far as frequency of occurrence is concerned) that occur between twenty-one and twenty-four times in Sections 5 and 6: $<101220>$ (Forte Code: 4-20, which occurs twenty-four times as various inversions of B b and F major 7 chords); $<012120>$ (Forte Code: 4-26, which occurs twenty-three times as either a D minor 7 or G minor 7 chord, again in various inversions); and $<111120>$ (Forte Code: 4-14, which occurs twenty-one times as either a D minor add9 or G minoradd9 chord, or Fadd4 or Cadd4 chord). 
Table 3.10: Matrix of vectors and their frequency of occurrence in Silentium - Sects. 5 and 6

\begin{tabular}{|c|c|c|c|c|c|c|c|c|}
\hline Vectors & $\begin{array}{l}\text { Forte } \\
\text { Codes }\end{array}$ & $\begin{array}{l}\text { Prime } \\
\text { Forms }\end{array}$ & $\mathbf{5 a}$ & $5 b$ & $6 a$ & $6 b$ & Total & $\begin{array}{l}\text { Chord } \\
\text { equivalent(s) }\end{array}$ \\
\hline$<000000>$ & $\mathrm{N} / \mathrm{A}$ & $\begin{array}{l}\text { \{silence or } \\
\text { single note }\end{array}$ & & 1 & & & 1 & $\begin{array}{l}\text { Individual pitch } \\
\text { (G) }\end{array}$ \\
\hline$<000001>$ & $\mathrm{N} / \mathrm{A}$ & $(0,6)$ & & & 1 & & 1 & Eflat5 no 3 \\
\hline$<000010>$ & $\mathrm{N} / \mathrm{A}$ & $(0,5)$ & 4 & & 1 & 2 & 7 & $\mathrm{~F}^{5}, \mathrm{~A}^{5}, \mathrm{~B} \mathrm{~b}^{5}, \mathrm{D}^{5}$ \\
\hline$<000100>$ & $\mathrm{N} / \mathrm{A}$ & $(0,4)$ & & & 1 & & 1 & Fno5 \\
\hline$<001000>$ & $\mathrm{N} / \mathrm{A}$ & $(0,3)$ & 1 & & & 1 & 2 & $\mathrm{Am}^{\text {no5}}, \mathrm{Gm}^{\text {no5 }}$ \\
\hline$<001110>$ & $3-11$ & $(0,3,7)$ & 10 & 5 & 8 & 6 & 29 & $\mathrm{Dm}, \mathrm{B} b, \mathrm{~F}, \mathrm{Am}, \mathrm{C}$ \\
\hline$<010000>$ & $\mathrm{N} / \mathrm{A}$ & $(0,2)$ & 1 & & & & 1 & Gadd9 no 3 no5 \\
\hline$<010020>$ & $3-9$ & $(0,2,7)$ & 3 & 5 & 2 & & 10 & $\begin{array}{l}\mathrm{D}^{\text {sus } 4,}, \mathrm{~B} b^{\text {sus } 2} \\
\mathrm{~A}^{\text {flat5} 5 \text { sus4 }}, \mathrm{D}^{7 \text { sus4 } 4 \text { no5 }}\end{array}$ \\
\hline$<010101>$ & $3-8$ & $(0,2,6)$ & & 1 & & & 1 & $\mathrm{~B} b^{\text {flat } 5}$ \\
\hline$<011010>$ & 3-7 & $(0,2,5)$ & 3 & 2 & 1 & 2 & 8 & $\begin{array}{l}\mathrm{Dm}^{7} \text { no5, } \\
\mathrm{D}^{7} \text { no3, } \\
\mathrm{A}^{7 \text { no3 }}\end{array}$ \\
\hline$<012120>$ & $4-26$ & $(0,3,5,8)$ & 3 & 4 & 8 & 8 & 23 & $\mathrm{Dm}^{7}, \mathrm{Gm}^{7}$ \\
\hline$<020100>$ & $3-6$ & $(0,2,4)$ & & 2 & & 2 & 4 & 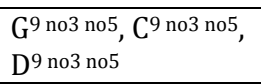 \\
\hline$<021030>$ & $4-23$ & $(0,2,5,7)$ & 1 & 2 & 3 & 2 & 8 & $\begin{array}{l}A^{7} \text { sus4 }, D^{7} \text { sus } 4, \\
D^{11} \text { no5 }\end{array}$ \\
\hline$<021120>$ & $4-22$ & $(0,2,4,7)$ & 8 & 3 & 13 & 7 & 31 & $\begin{array}{l}\mathrm{Dm}^{\text {add } 4}, \mathrm{~B}^{\text {add } 9}, \\
\mathrm{Dm}^{7}, \mathrm{~F} \text { Fadd } 9\end{array}$ \\
\hline$<030201>$ & $4-21$ & $(0,2,4,6)$ & & 1 & & & 1 & $C^{9}$ no5 \\
\hline$<032140>$ & $5-35$ & $(0,2,4,7,9)$ & & 3 & 1 & 7 & 11 & $\mathrm{~F} 6 / 9, \mathrm{C} 6 / 9, \mathrm{~B} b 6 / 9$ \\
\hline$<100000>$ & $\mathrm{N} / \mathrm{A}$ & $(0,1)$ & 1 & 1 & & & 2 & $\begin{array}{l}\text { Fmaj7 no } 3 \text { no5, } \\
\text { B } b^{\text {maj7 } 7 \text { no } 3 \text { no5 }} \\
\end{array}$ \\
\hline$<100011>$ & $3-5$ & $(0,1,6)$ & & 1 & & & 1 & A -9 no 3 \\
\hline$<100110>$ & $3-4$ & $(0,1,5)$ & 2 & 4 & 3 & 4 & 13 & $\begin{array}{l}\mathrm{B} b^{\text {maj7 no5 }}, \mathrm{B} b^{\text {maj7 }} \text { no3 } \\
\text { Fmaj7 no5 }\end{array}$ \\
\hline$<101220>$ & $4-20$ & $(0,1,5,8)$ & 4 & 7 & 5 & 8 & 24 & Bbmaj7, Fmaj7 \\
\hline$<110121>$ & $4-16$ & $(0,1,5,7)$ & & 1 & 2 & 1 & 4 & B b flat5 maj7, Fmaj7 sus 4 \\
\hline$<111000>$ & $3-2$ & $(0,1,3)$ & 1 & & 1 & 2 & 4 & $\mathrm{Dm}^{\text {add } 9 \text { no5 }}, \mathrm{Em}^{-9}$ no5 \\
\hline$<111111>$ & $4-Z 15$ & $(0,1,4,6)$ & & & & 1 & 1 & Dm add9 aug5 \\
\hline$<111120>$ & $4-14$ & $(0,2,3,7)$ & 6 & 3 & 6 & 6 & 21 & $\begin{array}{l}\text { Dm }{ }^{\text {add } 9}, \text { Fadd4 } \\
\text { Gm } \\
\text { add9, Cadd4 }\end{array}$ \\
\hline$<121110>$ & $4-11$ & $(0,1,3,5)$ & & 2 & 2 & 5 & 9 & $\begin{array}{l}\text { Em }^{-9} \text { sus4 no5, } \\
\mathrm{Gm}^{9} \text { no5, } \mathrm{Dm}^{9} \text { no5 }\end{array}$ \\
\hline$<122010>$ & $4-10$ & $(0,2,3,5)$ & 2 & & & 1 & 3 & Dmadd9 sus4 no5 \\
\hline$<122230>$ & $5-27$ & $(0,1,3,5,8)$ & 3 & 5 & 6 & 1 & 15 & $\begin{array}{l}\mathrm{Dm}^{9}, \mathrm{~B}^{\text {maj9 }}, \mathrm{Gm}^{9} \\
\mathrm{~F}^{9} \text { maj7 }\end{array}$ \\
\hline$<123121>$ & $5-25$ & $(0,2,3,5,8)$ & & & 1 & 1 & 2 & $\mathrm{Gm}^{7}$ \\
\hline$<132130>$ & $5-23$ & $(0,2,3,5,7)$ & 1 & 2 & 2 & 2 & 7 & $\begin{array}{l}\text { Dmadd2 add4, } \\
\text { Fadd2 add4 }\end{array}$ \\
\hline$<143250>$ & $6-32$ & $(0,2,4,5,7,9)$ & 1 & & & & 1 & $\mathrm{Dm}^{11}$ \\
\hline$<200121>$ & $4-8$ & $(0,1,5,6)$ & 1 & 1 & 2 & 1 & 5 & F11 maj7 no5 \\
\hline$<211231>$ & $5-20$ & $(0,1,5,6,8)$ & 2 & 4 & 1 & 2 & 9 & $\mathrm{~A}^{-9}$ sus 4 \\
\hline$<222121>$ & $5-Z 12$ & $(0,1,3,5,6)$ & 1 & & & & 1 & $\mathrm{Gm}^{13}$ no5 \\
\hline$<232341>$ & $6-\mathrm{Z} 26$ & $(0,1,3,5,7,8)$ & 1 & & & & 1 & $\mathrm{Dm}^{11 \text { aug5 }}$ \\
\hline$<233241>$ & $6-\mathrm{Z} 25$ & $(0,1,3,5,6,8)$ & & & 2 & & 2 & Fmaj13 w3 no5 \\
\hline \multicolumn{3}{|c|}{ Number of distinct vectors } & 22 & 22 & 22 & 22 & 35 & \\
\hline
\end{tabular}


Table 3.11 overleaf also reveals a particularly unique aspect of subsection $8 \mathrm{~b}$ : it contains more than seventy distinct occurrences of a single pitch, covering the range of all pitches in a D natural minor (Aeolian) scale (D, E, F, G, A, Bb, and C). Subsection $8 b$ has several other distinct aspects, as Silentium winds down to its conclusion. The first of these is the high frequency of 'open 5 ' chords that occur (G5, D5, A5, C5, Bb5, F5), as well as the number of simple triadic chords represented by <001110> (Forte Code: $3-11$ ). In total, there are forty-six occurrences of the following chords: D minor, B b , F, C, A minor, and G minor, and twenty-seven occurrences of 'no 5' chords, vector $<000100>$ representing the major third intervals formed by $\mathrm{F}$ and $\mathrm{A}($ or $\mathrm{Fno5})$ and $\mathrm{B} b$ and $\mathrm{D}\left(\mathrm{B} b^{\mathrm{n} 05}\right)$. This makes section $8 \mathrm{~b}$ the most varied subsection in Silentium, in terms of the number of distinct chordal and single pitch sonorities.

While occurring less frequently, the 'second' tier of vectors occurring across the last two sections of Silentium is more familiar to the listener as these vectors are 'carry-overs' from vectors which tended to be dominant in previous sections, including: <111120> (Forte Code: 4-14, twenty-nine occurrences of various inversions of Dm ${ }^{\text {add } 9}$, Fm $^{\text {add }}, \mathrm{Gm}^{\text {add9 }}$,); $<010020>$ (Forte Code: 3-9, with twenty-five different occurrences of the chords $D^{\text {sus4 }}$, Gus4, $\mathrm{A}^{\text {sus4 }}, \mathrm{F}^{\text {sus4 }}, \mathrm{C}^{\text {sus4}}$ ); and $<021120>$ (Forte Code: 4-22, twenty-four occurrences in total of $\mathrm{B}^{\text {add9 }}$, Dm $^{\text {add4}}$, and $C^{\text {add9 }}$ ). Table 3.12 overleaf provides a full taxonomy of the interval vectors occurring in Silentium and in each of its sixteen subsections. What is notable upon examining the table is that the majority of the vectors listed represent more than just one chord. The interactions of the different M-voice/T-voice pairings, each progressing at a different pace, usually result in each chord occurring in root form and various inversions in each section. It is this phenomenon that creates the subtle kaleidoscopic soundscape of Silentium, as illustrated by the sonority map of its intervallic content in Figure 3.41. The sonority map in 
Figure 3.42 provides a telescoped view of Sections 7 and 8 only, wherein Silentium's winding down into a series of single intervals (bars 152 through 156), single pitches, and ultimately silence can be readily observed (bars 161 through 165).

Table 3.11: Matrix of vectors and their frequency of occurrence in Silentium - Sects. 7 and 8

\begin{tabular}{|c|c|c|c|c|c|c|c|c|}
\hline Vectors & $\begin{array}{l}\text { Forte } \\
\text { Codes }\end{array}$ & $\begin{array}{l}\text { Prime } \\
\text { Forms }\end{array}$ & $7 a$ & $7 \mathbf{b}$ & $\mathbf{8 a}$ & $8 b$ & Total & Chord equivalent \\
\hline$<000000>$ & $\mathrm{N} / \mathrm{A}$ & $\begin{array}{l}\text { \{silence or } \\
\text { single note }\end{array}$ & & & 1 & 73 & 74 & $\begin{array}{l}\text { Individual pitches } \\
\text { D minor (Aeolian) }\end{array}$ \\
\hline$<000010>$ & $\mathrm{N} / \mathrm{A}$ & $(0,5)$ & 1 & 3 & 5 & 47 & 56 & $G^{5}, D^{5}, A^{5}, C^{5}, B b^{5}, F^{5}$ \\
\hline$<000100>$ & $\mathrm{N} / \mathrm{A}$ & $(0,4)$ & & & 3 & 24 & 27 & $\mathrm{Fno5}, \mathrm{B} b^{\text {no5 }}$ \\
\hline$<001000>$ & $\mathrm{N} / \mathrm{A}$ & $(0,3)$ & 1 & 1 & 4 & 24 & 30 & $\mathrm{Am}^{\mathrm{no5}}, \mathrm{Gm}^{\mathrm{n} 05}, \mathrm{Dm}^{\mathrm{no5}}$ \\
\hline$<001110>$ & $3-11$ & $(0,3,7)$ & 9 & 10 & 15 & 12 & 46 & $\mathrm{Dm}, \mathrm{B} b, \mathrm{~F}, \mathrm{C} \mathrm{Am}, \mathrm{Gm}$ \\
\hline$<010000>$ & $\mathrm{N} / \mathrm{A}$ & $(0,2)$ & & 1 & 3 & 15 & 19 & $\begin{array}{l}\text { Fadd9 no } 3 \text { no5, Dadd9 no } 3 \\
\text { no5, B badd9 no } 3 \text { no5, Gadd9 } \\
\text { no } 3 \text { no5, C Cadd9 no } 3 \text { no5 }\end{array}$ \\
\hline$<010020>$ & $3-9$ & $(0,2,7)$ & 4 & 6 & 7 & 8 & 25 & $\begin{array}{l}D^{\text {sus4 }}, G^{\text {sus } 4}, A^{\text {sus } 4}, F^{\text {sus } 4} \\
\text { Csus } 4\end{array}$ \\
\hline$<010101>$ & $3-8$ & $(0,2,6)$ & & & & 1 & 1 & $\mathrm{Em}^{7}$ flat5 no3 \\
\hline$<011010>$ & $3-7$ & $(0,2,5)$ & 5 & 4 & 9 & 3 & 21 & $\begin{array}{l}\mathrm{Dm}^{7} \text { no5, } A^{7} \text { no3 }, D^{7} \text { no3, } \\
\mathrm{Am}^{7} \text { no5, } G^{7} \text { no3 }, \mathrm{Gm}^{7} \text { no5 }\end{array}$ \\
\hline$<012120>$ & $4-26$ & $(0,3,5,8)$ & 7 & 4 & 5 & 3 & 19 & $\mathrm{Dm}^{7}, \mathrm{Am}^{7}, \mathrm{Gm}^{7}$ \\
\hline$<020100>$ & $3-6$ & $(0,2,4)$ & & 2 & 1 & 6 & 9 & B badd9 no5, Fadd9 no5 \\
\hline$<021030>$ & $4-23$ & $(0,2,5,7)$ & 3 & & 3 & & 6 & $\begin{array}{l}D_{m}^{\text {add } 4}, C^{7} \text { sus } 4, D^{7} \text { sus } 4, \\
G^{7} \text { sus } 4,\end{array}$ \\
\hline$<021120>$ & $4-22$ & $(0,2,4,7)$ & 10 & 6 & 7 & 1 & 24 & B badd9, Dmadd4, Cadd 9 \\
\hline$<032140>$ & $5-35$ & $(0,2,4,7,9)$ & & 3 & & & 3 & $\mathrm{Dm}^{11}$ \\
\hline$<100000>$ & $\mathrm{N} / \mathrm{A}$ & $(0,1)$ & 1 & 1 & 2 & 9 & 13 & $\mathrm{Dm}^{7}$ \\
\hline$<100011>$ & $3-5$ & $(0,1,6)$ & 2 & 1 & 2 & 1 & 6 & $\begin{array}{l}\text { Cmaj7 sus4, } \\
\mathrm{B} \text { bmaj7 flat } 5 \text { no3 }\end{array}$ \\
\hline$<100110>$ & $3-4$ & $(0,1,5)$ & 2 & 2 & 11 & 6 & 21 & $\begin{array}{l}\text { Fmaj7 no3, Fmaj7 no5, } B \text { bmaj7 } \\
\text { no5, } B b^{\text {maj7 no3 }}\end{array}$ \\
\hline$<101220>$ & $4-20$ & $(0,1,5,8)$ & 6 & 6 & 4 & 1 & 17 & Fmaj7, B bmaj7 \\
\hline$<110121>$ & $4-16$ & $(0,1,5,7)$ & & 3 & & & 3 & 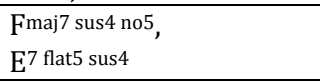 \\
\hline$<111000>$ & $3-2$ & $(0,1,3)$ & & 1 & 3 & 5 & 9 & $\begin{array}{l}\text { Dm } m^{\text {add9 no5, }}, \mathrm{Am}^{-9} \text { no5, } \\
\text { Gmadd9 no5 }\end{array}$ \\
\hline$<111120>$ & 4-14 & $(0,2,3,7)$ & 11 & 11 & 6 & 1 & 29 & Dmadd9, Fmadd4, Gmadd9, \\
\hline$<121110>$ & $4-11$ & $(0,1,3,5)$ & 2 & 3 & & & 5 & $\begin{array}{l}\text { Am-9 sus4 no5, Em }{ }^{\text {flat5 sus4 }}, \\
\text { Dm9 9o5 }\end{array}$ \\
\hline$<122230>$ & $5-27$ & $(0,1,3,5,8)$ & 9 & 9 & 3 & & 21 & $\begin{array}{l}\mathrm{B} b^{9} \text { maj7 }^{7}, F^{9} \text { maj7 }, \mathrm{Dm}^{9}, \\
\mathrm{Gm}^{9}\end{array}$ \\
\hline$<131221>$ & $5-24$ & $(0,1,3,5,7)$ & & 2 & & & 2 & $\operatorname{Dm}^{9}$ aug5 \\
\hline$<132130>$ & $5-23$ & $(0,2,3,5,7)$ & 4 & 2 & 1 & & 7 & $\begin{array}{l}\text { Dmadd2 add4, } \\
\text { Cadd2 add4 }\end{array}$ \\
\hline$<143250>$ & $6-32$ & $(0,2,4,5,7,9)$ & & 1 & & & 1 & $\mathrm{C} 13$ \\
\hline$<200121>$ & $4-8$ & $(0,1,5,6)$ & 1 & 1 & & & 2 & $\mathrm{~B} b$ maj7 flat5 w5 no3 \\
\hline$<211231>$ & $5-20$ & $(0,1,5,6,8)$ & 4 & 1 & 1 & & 6 & $\mathrm{C}^{11}$ w3 no5, Fmaj11 w3 \\
\hline$<232341>$ & $6-\mathrm{Z} 26$ & $(0,1,3,5,7,8)$ & 1 & & & & 1 & Fmaj13 w3 \\
\hline$<233241>$ & $6-\mathrm{Z} 25$ & $(0,1,3,5,6,8)$ & 1 & & & & 1 & Fmaj13 w3 no5 \\
\hline \multicolumn{3}{|c|}{ Number of distinct vectors } & 20 & 24 & 21 & 18 & 30 & \\
\hline
\end{tabular}


Table 3.12: Matrix of vectors and their frequency of occurrence in Silentium

\begin{tabular}{|c|c|c|c|c|c|c|c|c|c|c|c|c|c|c|c|c|c|}
\hline Vector & $1 a$ & $1 \mathrm{~b}$ & $2 a$ & $2 b$ & $3 a$ & $3 \mathbf{b}$ & $4 a$ & $4 b$ & $5 a$ & $5 b$ & $6 a$ & $6 b$ & $7 a$ & $7 \mathbf{b}$ & $8 a$ & $8 b$ & Total \\
\hline$<000000>$ & & & & & & & & & & 1 & & & & & 1 & 73 & 75 \\
\hline$<000001>$ & & & & & & & & & & & 1 & & & & & & 1 \\
\hline$<000010>$ & 3 & 2 & & 1 & 1 & & & 3 & 4 & & 1 & 2 & 1 & 3 & 5 & 47 & 73 \\
\hline$<000100>$ & & & 1 & 1 & & 1 & 1 & 1 & & & 1 & & & & 3 & 24 & 33 \\
\hline$<001000>$ & 1 & 1 & 1 & & & & & & 1 & & & 1 & 1 & 1 & 4 & 24 & 35 \\
\hline$<001110>$ & 2 & 2 & 6 & 3 & 9 & 3 & 9 & 2 & 10 & 5 & 8 & 6 & 9 & 10 & 15 & 12 & 111 \\
\hline$<002001>$ & & & & & & & & 1 & & & & & & & & & 1 \\
\hline$<010000>$ & & & & & & & & & 1 & & & & & 1 & 3 & 15 & 20 \\
\hline$<010020>$ & & & & 1 & & 2 & 1 & & 3 & 5 & 2 & & 4 & 6 & 7 & 8 & 39 \\
\hline$<010101>$ & & & & & & & & & & 1 & & & & & & 1 & 2 \\
\hline$<011010>$ & & & & 1 & 1 & 1 & 3 & 2 & 3 & 2 & 1 & 2 & 5 & 4 & 9 & 3 & 37 \\
\hline$<012120>$ & & 1 & 2 & 2 & & 2 & & 3 & 3 & 4 & 8 & 8 & 7 & 4 & 5 & 3 & 52 \\
\hline$<020100>$ & & & & & 1 & & 1 & & & 2 & & 2 & & 2 & 1 & 6 & 15 \\
\hline$<021030>$ & & & & & 3 & & 2 & 3 & 1 & 2 & 3 & 2 & 3 & & 3 & & 22 \\
\hline$<021120>$ & & & & 1 & 3 & 4 & 4 & 1 & 8 & 3 & 13 & 7 & 10 & 6 & 7 & 1 & 68 \\
\hline$<030201>$ & & & & & & & & 1 & & 1 & & & & & & & 2 \\
\hline$<032140>$ & & & & 1 & & 2 & 3 & 2 & & 3 & 1 & 7 & & 3 & & & 22 \\
\hline$<100000>$ & & & & 1 & & 1 & & & 1 & 1 & & & 1 & 1 & 2 & 9 & 17 \\
\hline$<100011>$ & & & & & & & 1 & & & 1 & & & 2 & 1 & 2 & 1 & 8 \\
\hline$<100110>$ & & & 2 & 3 & 2 & 2 & 3 & 5 & 2 & 4 & 3 & 4 & 2 & 2 & 11 & 6 & 51 \\
\hline$<101220>$ & & 3 & 2 & 2 & 4 & 7 & 3 & 4 & 4 & 7 & 5 & 8 & 6 & 6 & 4 & 1 & 66 \\
\hline$<110121>$ & & & & & & 1 & & 1 & & 1 & 2 & 1 & & 3 & & & 9 \\
\hline$<111000>$ & & & 1 & & & & 1 & 2 & 1 & & 1 & 2 & & 1 & 3 & 5 & 17 \\
\hline$<111111>$ & & & & & & & 1 & & & & & 1 & & & & & 2 \\
\hline$<111120>$ & 4 & & 2 & 5 & 4 & 4 & 5 & 2 & 6 & 3 & 6 & 6 & 11 & 11 & 6 & 1 & 76 \\
\hline$<112011>$ & & & & & & & & 1 & & & & & & & & & 1 \\
\hline$<121110>$ & & & & & 2 & 2 & & 1 & & 2 & 2 & 5 & 2 & 3 & & & 19 \\
\hline$<122010>$ & & & & & & & & & 2 & & & 1 & & & & & 3 \\
\hline$<122131>$ & & & & & & & & 2 & & & & & & & & & 2 \\
\hline$<122230>$ & 3 & 2 & & & 2 & 1 & 3 & 3 & 3 & 5 & 6 & 1 & 9 & 9 & 3 & & 50 \\
\hline$<123121>$ & & & & & 1 & & & & & & 1 & 1 & & & & & 3 \\
\hline$<131221>$ & & & & & & & & & & & & & & 2 & & & 2 \\
\hline$<132130>$ & & & 4 & & 2 & & 3 & 1 & 1 & 2 & 2 & 2 & 4 & 2 & 1 & & 24 \\
\hline$<143250>$ & & 1 & & & & & 1 & & 1 & & & & & 1 & & & 4 \\
\hline$<200121>$ & & & 2 & & 1 & & & 1 & 1 & 1 & 2 & 1 & 1 & 1 & & & 11 \\
\hline$<211231>$ & & & 1 & 2 & & 2 & 2 & 4 & 2 & 4 & 1 & 2 & 4 & 1 & 1 & & 26 \\
\hline$<222121>$ & & & & & & & & & 1 & & & & & & & & 1 \\
\hline$<232341>$ & & & & & & & & & 1 & & & & 1 & & & & 2 \\
\hline$<233241>$ & & & & & & 1 & 1 & & & & 2 & & 1 & & & & 5 \\
\hline$<012111>$ & & & & & & & & 1 & & & & & & & & & 1 \\
\hline$<032221>$ & & & & & & & & 1 & & & & & & & & & 1 \\
\hline $\begin{array}{l}\text { Total } \\
\text { sonorities }\end{array}$ & 13 & 12 & 24 & 24 & 36 & 36 & 48 & 48 & 60 & 60 & 72 & 72 & 84 & 84 & 96 & 240 & 1009 \\
\hline
\end{tabular}


Figure 3.41: Silentium - sonority map Sections 1 through 8

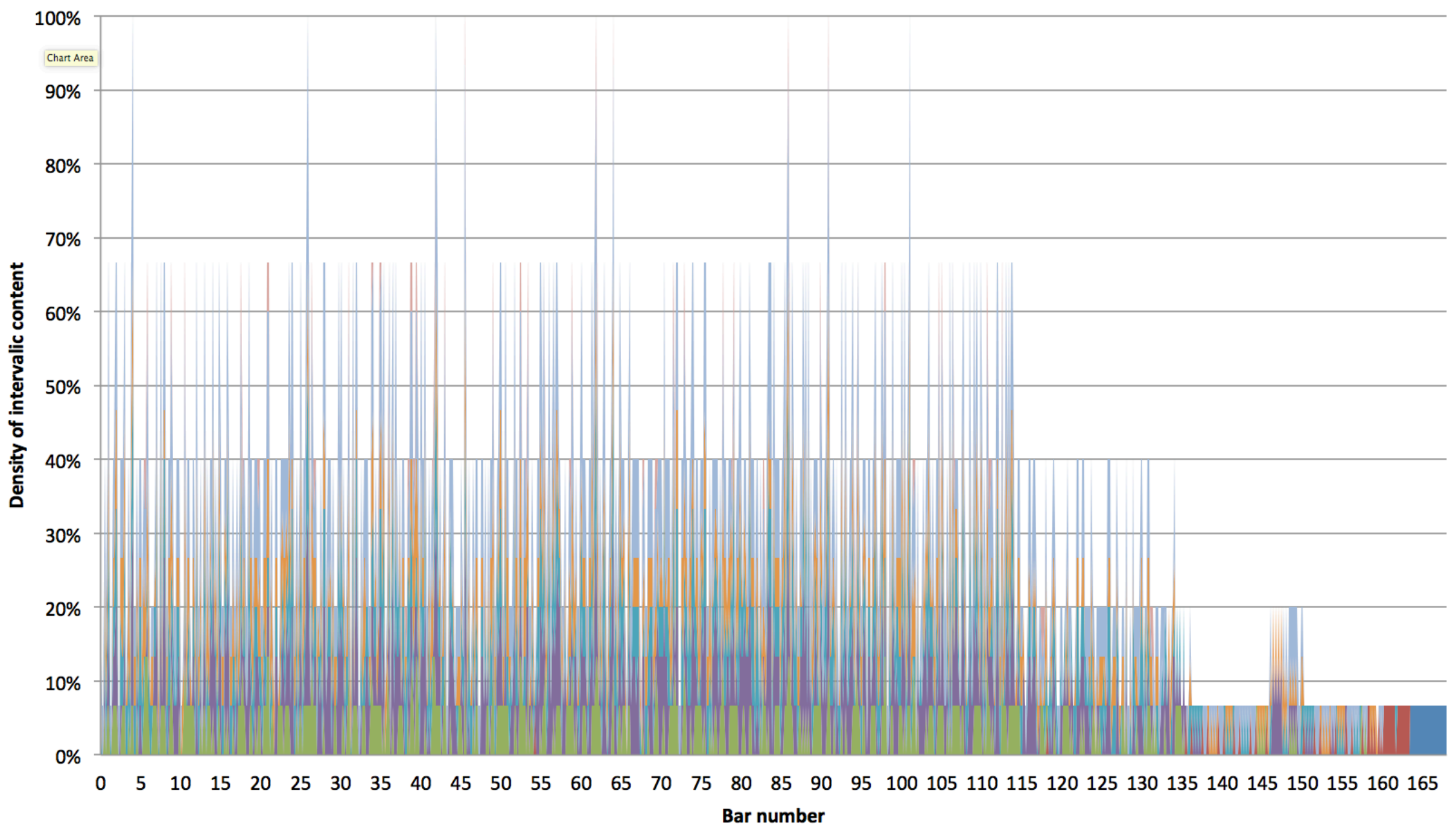

Silence $\quad$ Single pitch $\square \mathrm{m} 2 \quad \square \mathrm{M} 2 \quad \square \mathrm{m} 3 \quad$ M3 $\quad \mathrm{P} 4 \quad \square$ Tritone 
Figure 3.42: Silentium - sonority map Sections 7 and 8

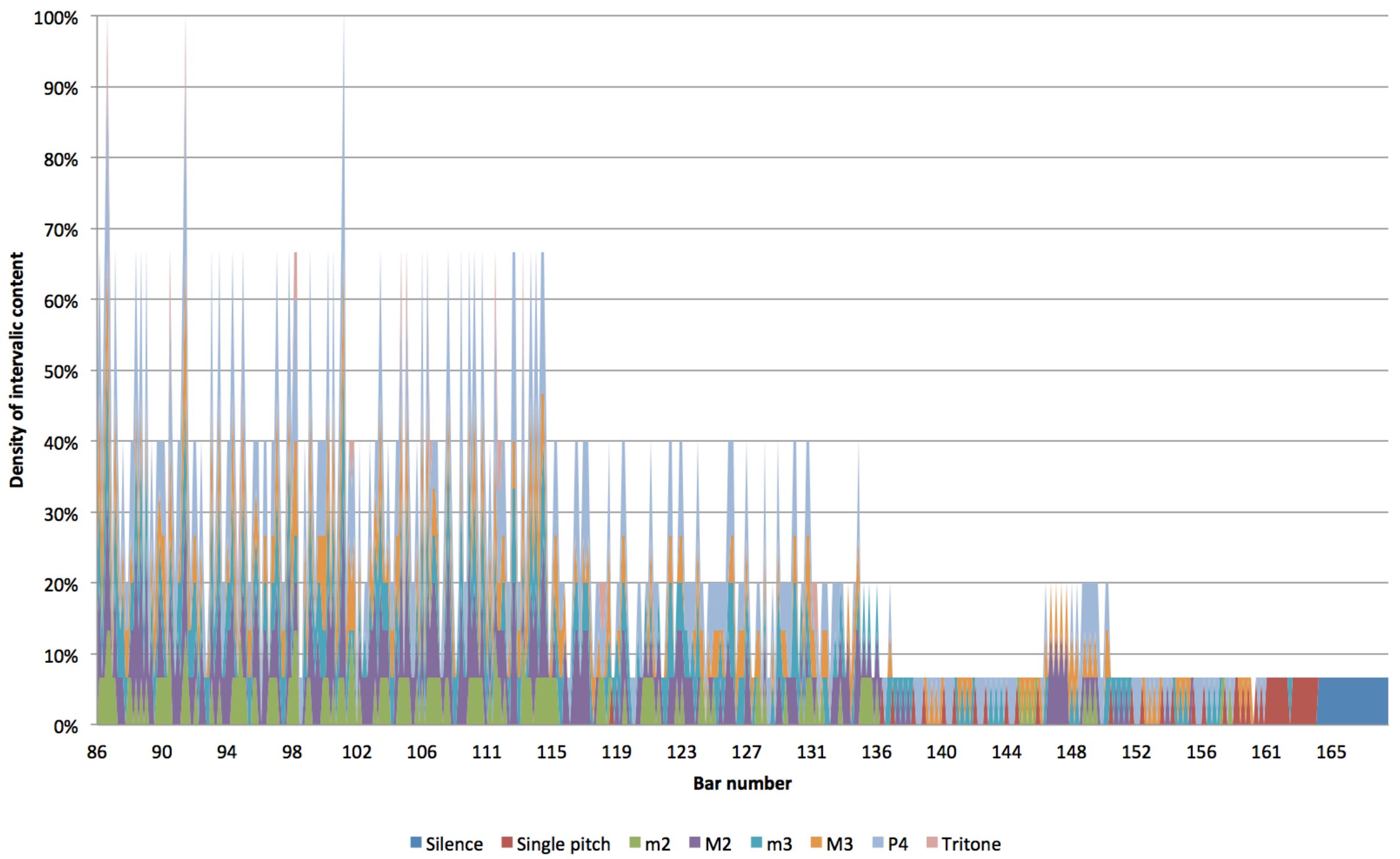




\section{Discussion - Tabula Rasa}

The preceding analyses of Tabula Rasa demonstrate how, with only a small number of M-voice/T-voice pairings and a basic melodic generative process combined with two other common musical processes (melodic and mensural variation), Arvo Pärt is able to deploy his seemingly simple tintinnabuli principles to construct multiple cyclical patterns that move from lesser to greater complexity on multiple levels. These patterns combine and build upon each other to generate a wide array of different 'consonant' and 'dissonant' sonorities.

This chapter also demonstrates that, as the sonorities in both Ludus and Silentium become more complex, and increasingly dissonant as a result of the stepwise progression of multiple M-voices occurring at once, the pitch classes of the T-voice triad tend to occur at much greater frequencies across a wide range of the orchestra's overall register. This results in a tempering of the dissonant sonorities and intervals such as minor seconds and tritones, making them less prominent to the listener and more like subtle colours and intimations of the different overtones and tonal richness of the omnipresent A minor triad.

Despite having the same melodic generative process and the use of Aeolian scales and T-voices based upon the root note triad of those scales, the sound worlds of Ludus and Silentium are starkly different - with each movement capable of standing alone as a distinct work in itself, or as two parts of a seamless unit, wherein the composer meticulously wipes his musical slate clean. 


\section{Chapter 4 - Cantus (1977) and Festina Lente (1988 rev. 1990)}

This chapter examines two other process-based tintinnabuli string compositions by Arvo Pärt: Cantus in memoriam Benjamin Britten and Festina Lente. Using these two works as examples, the chapter illustrates a number of key developments in Pärt's string orchestral process-based composition and the greater variety of sonorities that arise as a result of his approach to composing process-based works. In relation to Tabula Rasa, Cantus in memoriam Benjamin Britten, and particularly the later work Festina Lente, begin to evidence the importance of the 'composer's hand': a more 'fluid interpretation' of the 'rules' of tintinnabuli by Pärt. These works illustrate how Pärt's tintinnabuli system appears to have evolved between 1977 and the late 1980s, from a relatively stringent application of rules derived from the combination of rigid stepwise processes and vertical and horizontal relationships to a more fluid interpretation of what comprises a 'process' piece of music.

\section{Introduction}

Michael Nyman identifies five different types of processes that were commonly employed by twentieth century experimental composers. ${ }^{141}$ Galen Brown takes the position that there is a sixth type of process-based music, one based upon mathematical procedures, to manipulate musical pitches and rhythmic material. Mathematicalderived processes can include "addition, subtraction, multiplication of durations and

\footnotetext{
${ }^{141}$ Nyman's five different types of processes are: 1) Chance determination processes: based upon material randomly drawn from some other system or source (e.g. computer generated numbers, telephone books, or in John Cage's case, the I Ching); 2) People processes: wherein the performers are given leave to execute predetermined, or suggested, musical material in a manner of their choosing; 3) Contextual processes: based on actions that are "dependent on unpredictable conditions and on variables which arise from within the musical continuity" (Michael Nyman, Experimental Music: Cage and Beyond, Second Edition, Music in the 20th Century (New York: Cambridge University Press, 2009), 6.; 4) Repetition processes: where there is extended repetition of one or more musical processes used; and 5) Electronic processes: that are activated and manipulated by the performer, or participatory members of the audience. Ibid., 4-8. See also Galen H. Brown, "Process as Means and End in Minimalist and Postminimalist Music," Perspectives of New Music 48, no. 2 (2010): 185-86.
} 
changes in rate". ${ }^{142}$ In many of his early tintinnabuli compositions, Pärt has used a number of repetition and mathematical processes, including the works Arbos (1977), Fratres (1977), Tabula Rasa (1977), as well as Cantus in memoriam Benjamin Britten (1977) and Festina Lente (1988, rev. 1990).

This chapter explicitly examines the repetition and mathematical processes that Pärt used in composing Cantus in memoriam Benjamin Britten (1977) and Festina Lente (1988, rev. 1990), and how his application of such processes appears to have evolved between 1977 and 1990. It calls into question whether, like Steve Reich, Pärt merely constructs a series of predetermined processes that, once designed, are left to play out to their own devices - thus abnegating any further composerly responsibility - or rather, that Pärt is actively engaged in the composition process throughout the creation of each work. ${ }^{143}$

While the descriptions in the style analysis sections of both of these works are extremely detailed, the intention is to draw the reader's attention to the various processes - and variations to these processes - that Pärt deployed in composing Cantus and Festina Lente. This has been done: to gain a better understanding of how Pärt's approach to constructing process-based works has evolved; to determine if, like Reich, once Pärt has put a series of processes in place he leaves these unimpeded to run their course; and to gain an appreciation of how Pärt's approach to composing process-based

\footnotetext{
142 Brown, "Process as Means and End in Minimalist and Postminimalist Music," 186.

143 In his short essay "Music as a Gradual Process", Steve Reich describes the characteristics of processbased music as having pre-defined "all the note-to-note processes (sound-to-sound) details and overall form simultaneously", noting that as a composer, while he enjoyed "discovering musical processes and composing the musical material to run through them, once the process is set up and loaded it runs by itself". ${ }^{143}$ In Reich's essay, his use of the term 'process' as it relates to music was not in terms of the "process of composition but rather pieces of music that are, literally, processes". Reich is also strongly of the view that the processes, which he deploys in this music, should be simple and clearly audible to the listener; though this view is not held by all composers of process-based music. Steve Reich, "Music as a Gradual Process," in Writings on Music 1965-2000, ed. Paul Hillier (New York: Oxford University Press, 2002), 34.
} 
music seems to imply a more fluid interpretation of what defines a process piece. Importantly, many of the processes used in Cantus and Festina Lente are not readily audible to the ear and have not been previously commented upon in other analyses of these works. Describing and revealing these processes is intended to help the informed listener to appreciate the amount of careful craftsmanship that has gone into the creation of these works, and to help better inform critical and aesthetic judgements of each work's merit.

The style analyses of Cantus and Festina Lente are supplemented by graphic representations in the form of a MIDI-recreation of each work's musical lines to provide a visual overview of each entire work. The subsequent content analyses of both works are supplemented by graphic representations in the form of Pärtian Tonnetze, to demonstrate the interrelations between the different M-voice/T-voice pitch classes and the resulting intervallic content when any two pitches occur at the same time.

\section{Cantus in memoriam Benjamin Britten}

Cantus in memoriam Benjamin Britten was Arvo Pärt's musical response to the death of the British composer Benjamin Britten (1913-1976) to whom he dedicated the work, even though the two composers had never met one another. As described by Hillier:

... Cantus offers a peace and ineffable sadness. After an initial bell stroke has sounded three times, the violins enter with exquisite grace in their highest register, dancing slowly downward; an octave beneath the same pattern is unfolded in a slower tempo, while beneath that moves the same pattern at ever slower speeds and lower octaves. ${ }^{144}$ 
In relation to composing Cantus, Pärt said 1976 was a year of significant losses in the world of music, and that Britten's death had particularly struck him, given he had only recently discovered Britten's music, which Pärt likened to that of Guillaume de Machaut.

Just before his death I began to appreciate the unusual purity of his music - I had the impression of the same kind of purity in the ballads of Guillaume de Machaut. And besides, for a long time I had wanted to meet Britten personally - and now it would not come to that. ${ }^{145}$

\section{Style analysis of Cantus}

\section{Large dimension}

Cantus is a single movement work of 108 bars, for full string orchestra (violins I and II, violas, violoncellos, contrabasses) and a tubular bell. Metrically the work is in a compound duple meter of $6 / 4$, with each of the five string orchestral sections proceeding in different tempos (described below). The pitch classes used in Cantus (A, B, C, D, E, F, G) comprise the A Aeolian, or A natural minor scale. Pitch class A is the pitch centre for the work's five M-voices, as well as being the root pitch of the triad that applies to all of the work's various T-voices - an A minor triad. The funereal bell that sounds intermittently throughout the work, always tolls on A4 as well, thus firmly grounding the work further in the A Aeolian mode.

As described in Chapter 3, the primary melodic process for the M-voices of both movements of Tabula Rasa is a stepwise upwards and downward progression from a single tonal centre that expands outwards in alternating arcs one pitch at a time until a predetermined span has been achieved (see Figure 3.1 in Chapter 3). In Cantus the five M-voices use a variation of that same mathematical process to generate the musical material - a downward stepwise progression based on the A natural minor scale (e.g. 
A6 in the first violins, repeating again plus the next pitch, e.g. A6-G6, starting again from the pitch centre and then playing the next two lower pitches of the scale in succession, A6-G6-F6, starting again and playing the next three lower pitches, A6-G6-F6-E6, etc.) until each voice reaches a predetermined final resting pitch comprising one of the pitch classes of an A minor triad.

In Cantus, however, Pärt deploys an additional melodic/rhythmic process - a mensural or prolation canon, wherein each of the different string orchestra lines uses the same 2to-1 rhythmic scheme (e.g. minim, crotchet in the violin I line), but entering the work in a staggered manner, with each new string section's initial entrance starting one octave lower than its predecessor and at half the pace. ${ }^{146}$ This is illustrated in Figure 4.1, which shows the initial entrances of each of the five different string sections in bars 7 through 16 , as well as the relative mensural relationships between the five string orchestral lines. Except for the violas, which do not have a T-voice, each of the string sections in Cantus is split divisi for most of the piece - with half of the musicians in each section playing the M-voice material and the other half playing a first position, inferior T-voice, using one of the pitches of the A minor triad.

\footnotetext{
${ }^{146} \mathrm{~A}$ mensural (or prolation) canon is a canon in which the voices take the same musical material, but have different mensurations, as determined by some rhythmic proportion. Mensural cannons were particularly popular during the Renaissance. One of the most famous such compositions was Johannes Ockeghem's Missa prolationum, written in the fifteenth century, in which each section of the mass was written as a mensural cannon. See Alfred Mann, J. Kenneth Wilson, and Peter Urquhart, "Canon (i)," Grove Music Online, accessed May 10, 2014.
} 
Figure 4.1: Cantus - bars 7 to 16
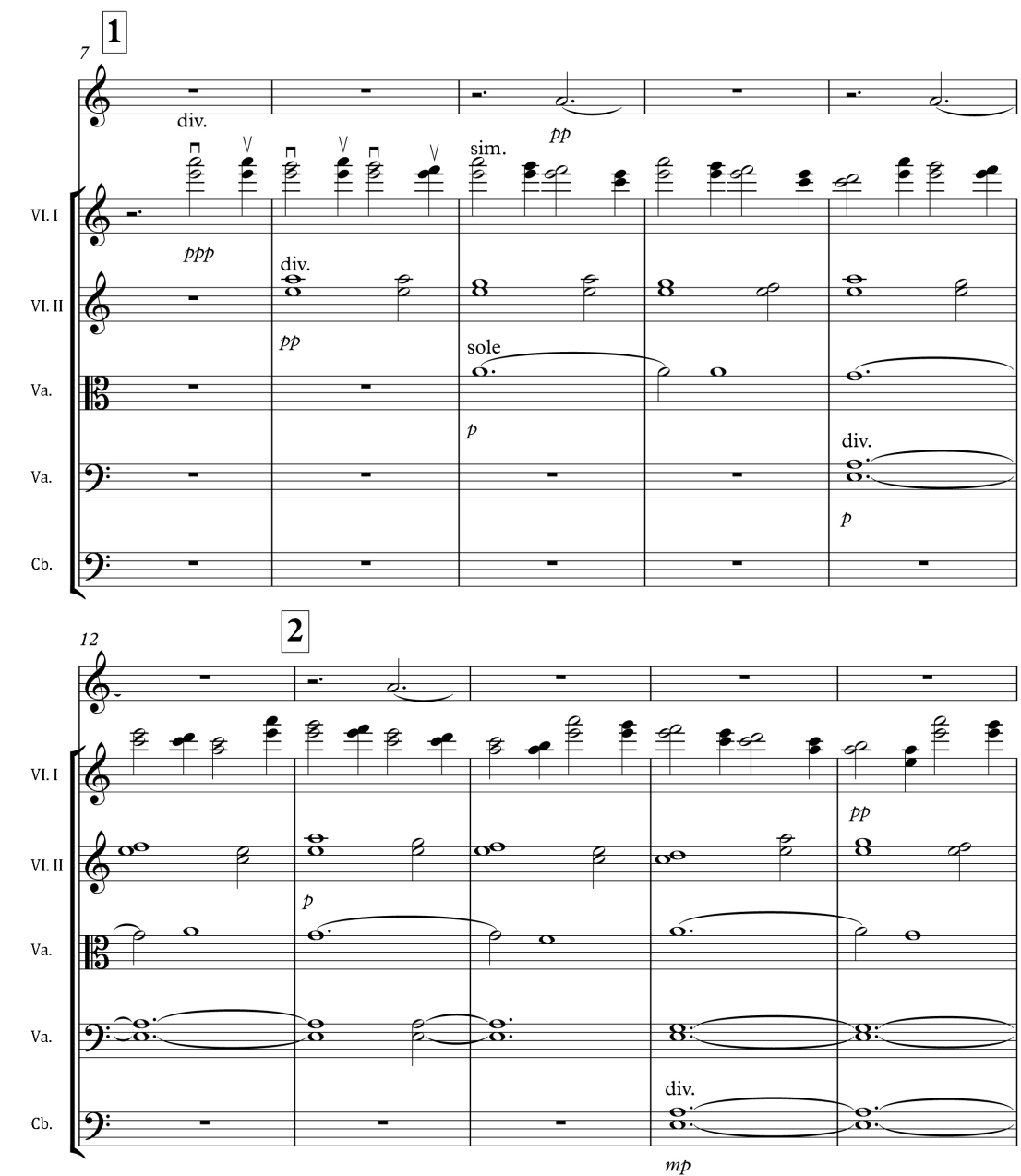

In the first violins, the 2-to- 1 rhythm is played out alternating between a minim and a crotchet, while Pärt doubles the durational value and uses a semibreve (four beats) and a minim (two beats) in the second violin line. The violas execute the same M-voice material as the violins, but at a tempo of a dotted semibreve that spans an entire bar plus the first two beats of the next (for a total of eight beats), followed by a semibreve; alternatively the pitches assigned the longer duration can be viewed notationally as a breve that breaks over two bars. In the violoncellos the durations of the notes in the 2to- 1 rhythm double again - two tied dotted semibreves tied to a semibreve (16 beats or the equivalent of longa) followed by a minim tied to a dotted semibreve (eight beats or the equivalent of one breve). The pattern as executed by the contrabass section spans five tied dotted semibreves tied to a minim ( 32 beats, or the equivalent of a maxima) 
followed by a semibreve tied to two dotted semibreves (16 beats, the equivalent of a longa).

This use of staggered entrances and mathematically expanded note durations that can span multiple bars obscures any sense of a downbeat. Pärt's deployment of the A, A-G, A-G, F, etc. descending pattern across all five of the string sections at different tempos also provides the work's main sense of motion, a descending series of registral expansions of the M-voices and T-voices across the entire string orchestra. With the staggered entrances of each section, and the expanding registral ranges as the piece progresses at different tempos, Cantus sounds like cascades of descending string lines, falling at different speeds and spanning almost the entire registral range of the orchestra - punctuated by ever louder soundings of the funereal bell on A4. Figure 4.2 overleaf provides a pictorial representation of these cascades, as detailed in a MIDIrecreation of the entire work. For the purposes of illustrating the full span of the music as heard by the listener, the contrabasses' MIDI-pitches are shown in their sounding octave in the figure, rather than as noted on the score. The colour gradations in the MIDI-notes as the piece progresses represent the increasing dynamic levels of the different string sections as they progress from pianississimo (represented by lilac) at the work's beginning to fortississimo starting in bar 63 (represented by hot pink). 
Figure 4.2: Cantus - MIDI-recreation all strings (with contrabasses shown in their sounding register) ${ }^{147}$

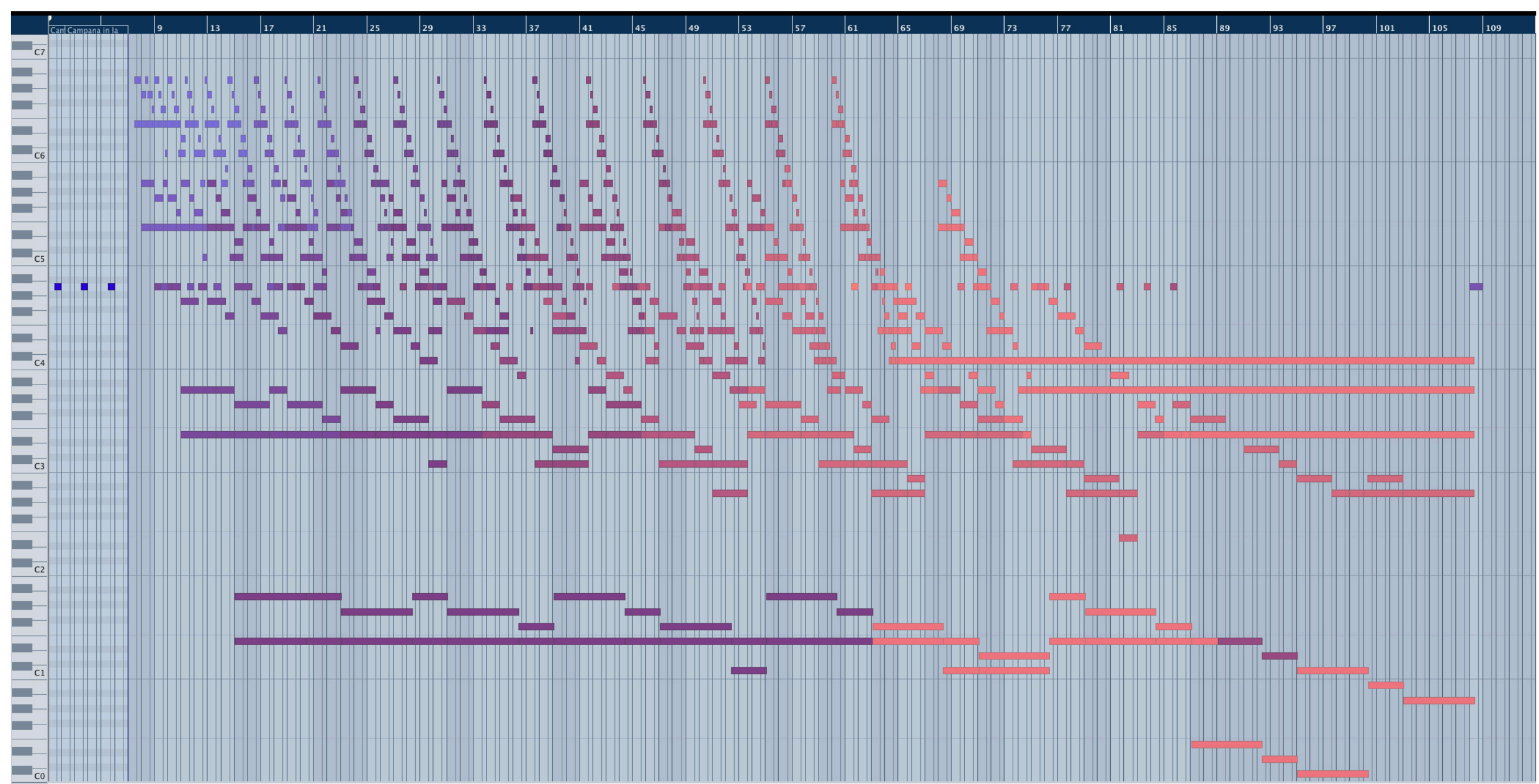

${ }^{147}$ Midi-recreation created using Cubase ${ }^{\mathrm{TM}} 7.5$ 
Due to the use of a first position, inferior T-voice and the same M-voice material in each M-voice/T-voice pairing, the interval classes generated between the divisi pairings in two violin sections, violoncello and contrabass sections are identical and limited to those shown in Figure 4.3: one minor second, two major seconds, two minor thirds, one major third, and a perfect fourth.

Figure 4.3: Interval classes generated by an A minor triad and an A Aeolian (natural minor) scale, $1^{\text {st }}$ position, inferior

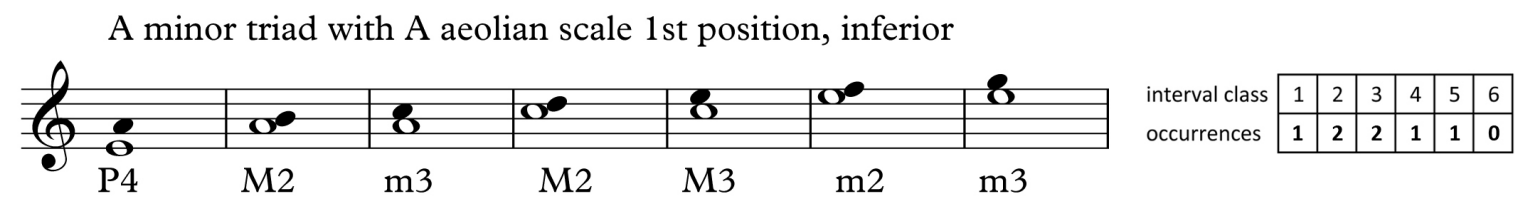

Despite this limited palette of interval classes, Pärt manages to produce a strikingly beautiful and varied soundscape with Cantus. He achieves this through an accretion of voices by staggering the entrances of the different string sections in relation to each other, and by the proportionally slower tempo of each section as it enters the work. This results in an elegiac tapestry of descending musical lines that slowly grow in volume to fill and ultimately overwhelm the soundscape.

\section{Middle dimension}

The manner in which Pärt constructed Cantus (i.e. a single mensural canonic process, played out over five different tempos) makes it more challenging to delineate the boundary between the large and middle dimensions of the work, particularly given that as a whole the work cannot be easily parsed into sections like the two movements of Tabula Rasa. ${ }^{148}$ However, it is possible to identify middle aspect dimensions of the work within the five different instrumental lines, as each descends a specified number of

\footnotetext{
${ }^{148}$ As indicated previously in Chapter 2, LaRue notes that sometimes it is harder to define middle dimensional aspects of certain works, given the overlapping boundaries between the middle dimension and the large and small dimensions that frame it. See LaRue, Guidelines for Style Analysis, 8.
} 
steps or half steps before returning to the starting pitch and commencing the process again a number of times. Because each section enters at a different pace and one octave lower than the string section preceding it, the number of individual returns to the starting pitch varies for different string sections.

For example, throughout the work, the first violins play A6 a total of 20 times then descend downwards in an incremental stepwise pattern through the pitches of the A Aeolian scale (e.g. A6-G6, A6-G6-F6, A6-G6-F6-E6, etc.) 19 times, until arriving at their final resting pitch of $\mathrm{C} 4$ in bar 65 . Ultimately, the first violins also descend to almost the bottom of their register twice (bars 55 through 59 and bars 60 through 64) before coming to rest on $\mathrm{C} 4$ in bar 65 . This can be observed visually in a MIDI-recreation of the first violin line in its entirety (Figure 4.4). The figuration details not only the expansion of the violins from an opening interval of an open fifth at E6 and A6 at their first entrance, but also their full registral span of two octaves plus a sixth and the increasing volume levels as the violins progress through the piece (as indicated by gradations of colour).

Figure 4.4: MIDI-recreation of the $1^{\text {st }}$ violins' part in Cantus ${ }^{149}$

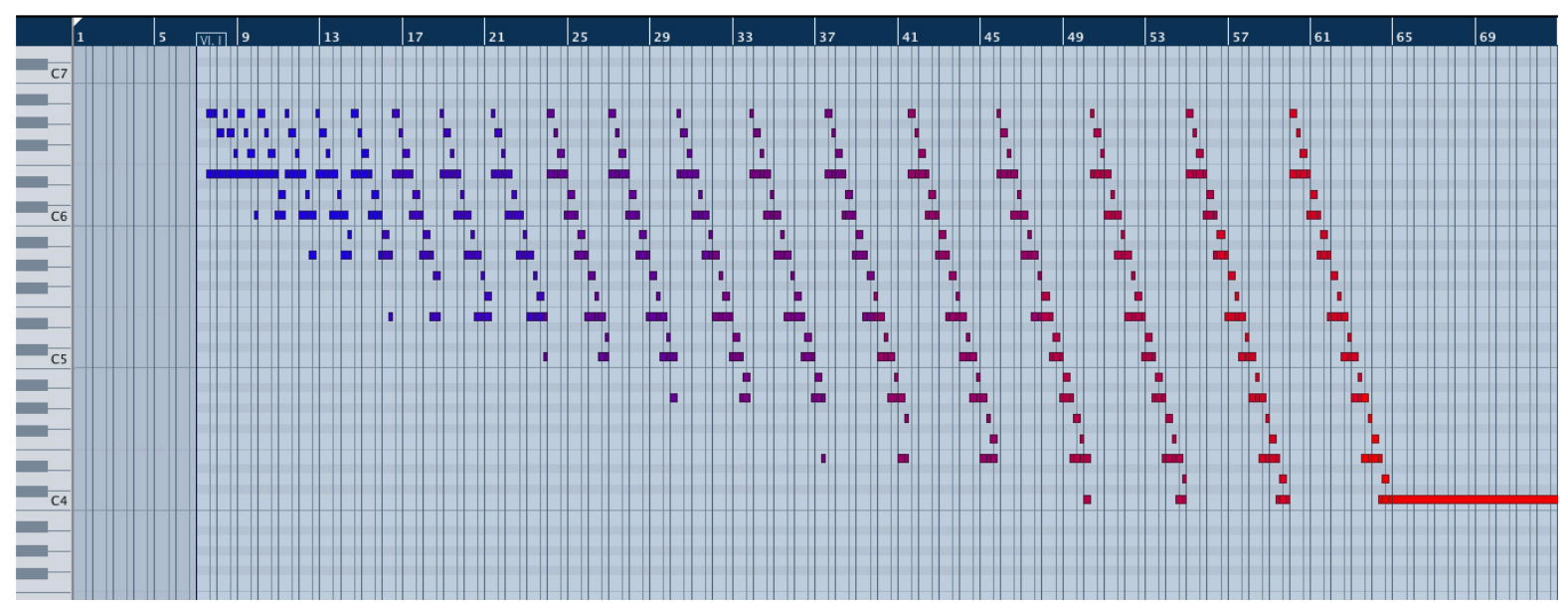

${ }^{149}$ Midi-recreation created using Cubase ${ }^{\mathrm{TM}}$ 7.5. 
Due to the prolongation of tempos, the pace of the violins is in sharp contrast to that of the contrabasses, which require 88 bars to complete a descent of just one octave from A1 to A0. Unlike the other sections, the contrabasses do not complete a full stepwise descent through all seven pitches of the scale (A-G-F-E-D-C-B) before restarting and descending the full octave (A-G-F-E-D-C-B-A) at the works end; rather the contrabasses progress through five degrees of the scale (A-G-F-E-D), return to the starting pitch and then descend the entire octave (A-G-F-E-D-C-B-A), skipping two cycles of their operation to arrive at a final resting pitch of A0. Table 4.1 details the starting and ending pitches of each string section, the number of times each section sounds and returns to its sounding pitch, the number of bars required for each to complete the full registral span of its line, and each section's final resting pitch.

Table 4.1: Cantus - starting and ending pitch classes of each instrumental section

\begin{tabular}{|c|c|c|c|c|c|c|}
\hline Instrument & $\begin{array}{c}\text { Starting } \\
\text { pitch }\end{array}$ & $\begin{array}{l}\text { Final } \\
\text { resting } \\
\text { pitch }\end{array}$ & $\begin{array}{l}\text { Registral } \\
\text { span of } \\
\text { primary } \\
\text { operation }\end{array}$ & $\begin{array}{c}\text { Number of times } \\
\text { starting pitch } \\
\text { sounded }\end{array}$ & $\begin{array}{c}\text { Number of } \\
\text { returns to } \\
\text { starting pitch }\end{array}$ & $\begin{array}{l}\text { Number of bars } \\
\text { to complete one } \\
\text { full M-voice } \\
\text { operation }\end{array}$ \\
\hline Violins I & A6 & $\mathrm{C} 4$ & $\begin{array}{l}2 \text { octaves } \\
\text { plus a } 6^{\text {th }}\end{array}$ & 20 & 19 & 52 \\
\hline Violins II & A5 & A3 & $\begin{array}{l}2 \text { octaves } \\
\text { plus a } 4 \text { th }\end{array}$ & 16 & 15 & 66 \\
\hline Violas & A4 & E3 & $\begin{array}{l}1 \text { octaves } \\
\text { plus a } 4^{\text {th }}\end{array}$ & 12 & 11 & 77 \\
\hline Violoncellos & A3 & A2 & 1 octave & 11 & 10 & 72 \\
\hline Contrabasses & A1 & A0 & 1 octave & 6 & 5 & 88 \\
\hline
\end{tabular}

Figure 4.5 illustrates the total registral span of each string section and shows how the primary spans, denoted by the large size notes, decrease from two octaves plus a sixth in the first violins line, to two octaves in the second violins line, an octave plus a fourth in the violas line, to just a single octave for both the violoncellos and contrabasses. 


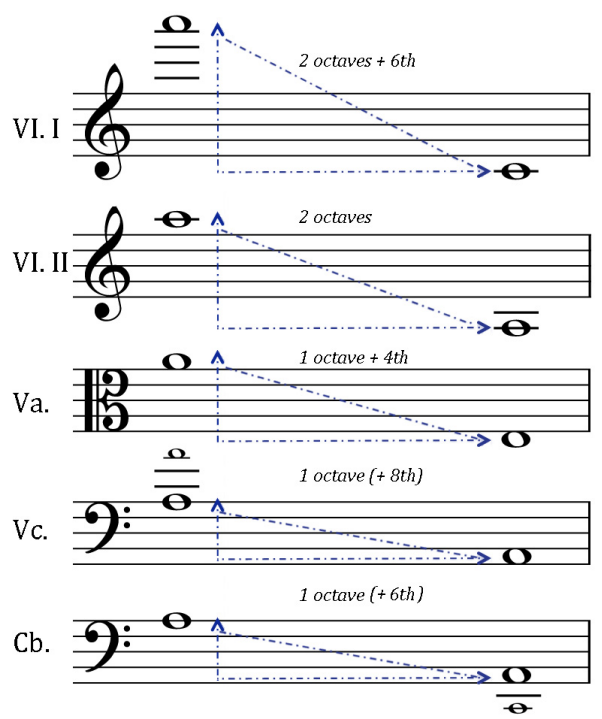

The small notes shown for the violoncellos and contrabasses denote the full registral range after taking into account two points in the Cantus wherein Pärt deviates from the established pattern of a single M-voice/T-voice pairing. For the contrabasses, the extended range occurs in bars 87 through the first two beats of bar 93, when the players sound E2 and E1 in divisi octaves, and bar 93 through bar 100, when three-quarters of the section sound D2 and C2 in succession, while the remaining players in the section sound D1 and C1 one octave below.

For the violoncellos, the registral extensions also occur at two different points in the work; the first point starts in bar 54 when one desk each from the upper and lower divisi sections begins to double the violas' M-voice line, while the remainder of the section continues with its paired M-voice/T-voice operation (Figure 4.6 overleaf). The manner in which Pärt redeploys four of the string section's players to the violas' material for 20 bars until the first two beats of bar 74, results in a thickening of sound of the viola section's M-voice line, while thinning the sound of the violoncellos' M-voice/Tvoice material. 
In bar 74, the two desks of players return to playing only the violoncellos' M-voice/Tvoice material until the fifth beat of bar 85 , when the violoncello section drops its Tvoice and plays only the descending M-voice material, until it reaches the violoncellos' resting pitch of A2 in bar 97. The second registral extension occurs at bar 100, when half of the violoncellos join the contrabasses, playing B2 above the contrabasses B1 before also returning to A2 in bar 102, which is sustained through to the end of the piece. The other half of the violoncello section remains on A2 throughout from bar 98 to bar 108.

Figure 4.6: Cantus - bars 52 through 56

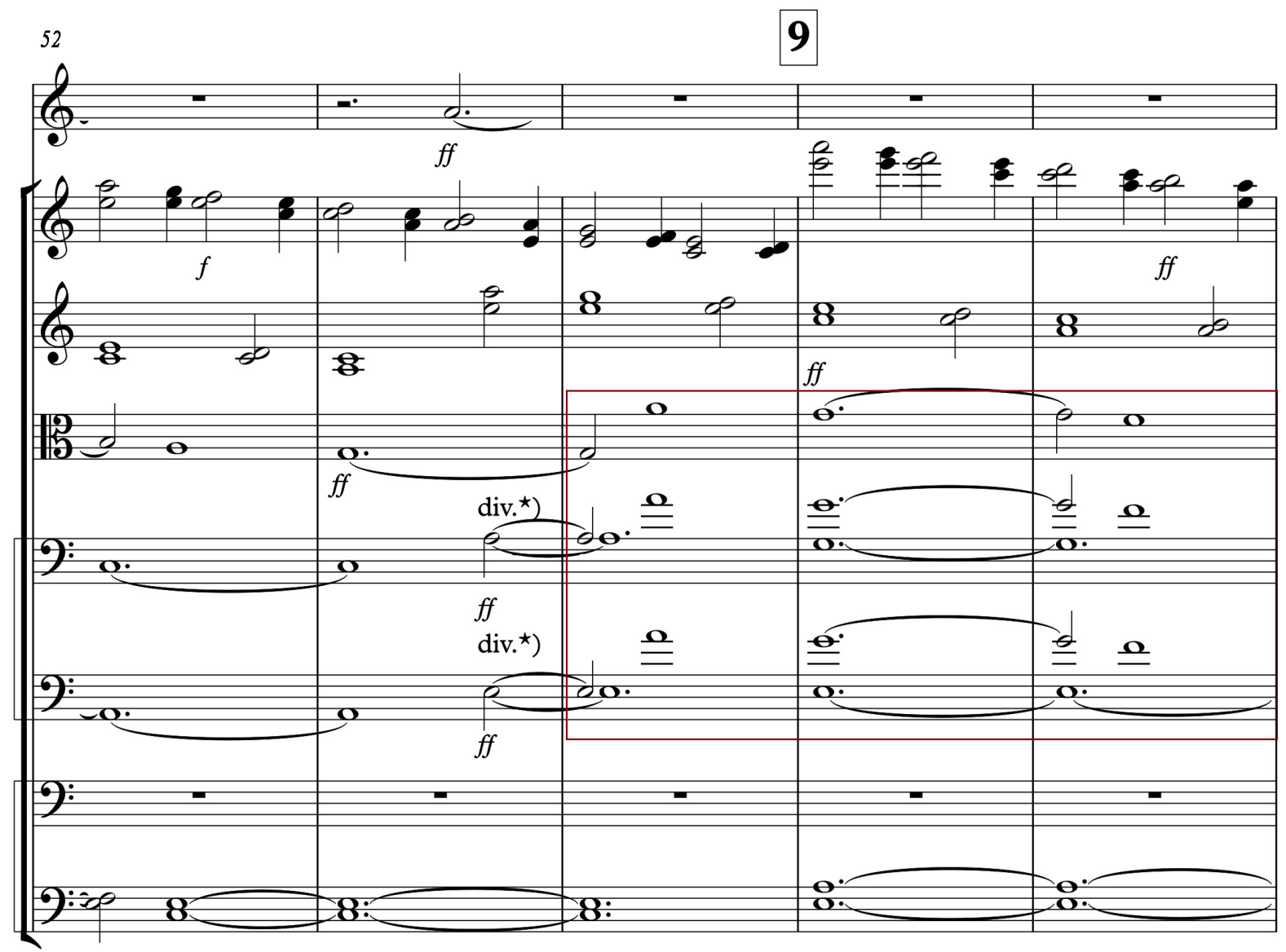

*) 2 soli $\left(1^{\circ}\right.$ leggio $)$

Another middle dimension aspect of Cantus relates to the tubular bell on A, or campana in la. Pärt deploys two operations in relation to the bell, with the first being the timing of its occurrence throughout the work, and the second being changes in dynamics. The 
bell opens the work, tolling three times for three beats each, with a rest of one and onehalf bars (nine beats) between first and second soundings, and second and third sounding (Figure 4.7). The bell then rests for three and one-half bars before the pattern recommences. This pattern occurs 11 times throughout the work up through bar 85, after which the bell falls silent until the final bar 108, when it tolls once to mark the end of the piece. Importantly, as discussed later in this chapter, the bell's tolling pattern has a relationship to when dynamic changes occur in different sections of the string orchestra. This is one of several processes in Cantus that are not readily evident to the ear, without a detailed examination of the musical score.

Figure 4.7: Cantus - bars 52 through 56

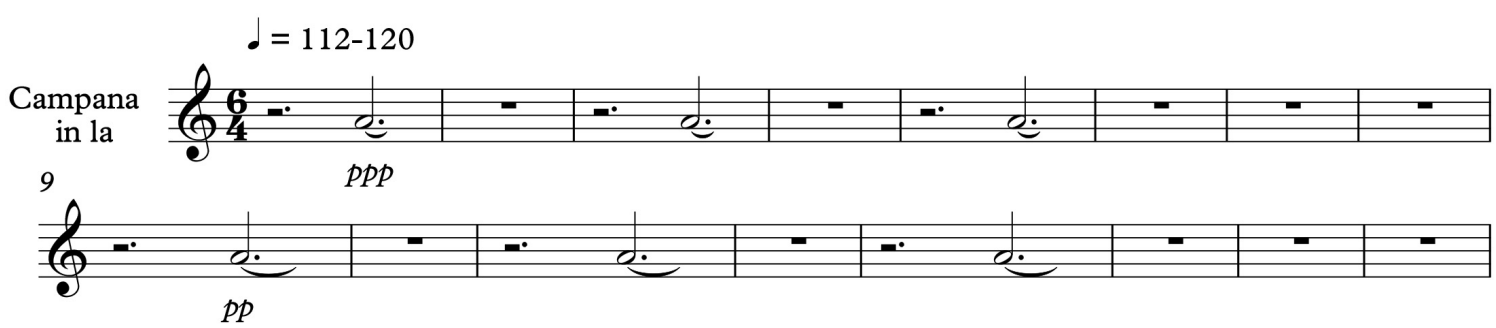

As noted, the second of the bell's operations relates to its changing dynamics. When the bell first tolls at the beginning of the work, the score is marked pianississimo. When the bell returns for a second time in the latter half of bar nine, its dynamic marking is pianissimo. With each reoccurrence of the three toll pattern, the dynamics increase until achieving fortississimo in bar 61, after which the dynamics decrease by one increment with each reoccurrence in bars 69 (fortissimo), 77 (forte), and 85 (mezzo forte). When the bell makes its final appearance in the last bar of the work, the dynamic marking is pianissimo, which would have been the applicable dynamic marking had Pärt opted to continue the three-toll pattern to the end of Cantus rather than suspend it after bar 85 . For the first two dynamic markings, $p p p$ and $p p$, Pärt assigns each to the first sounding in the three-toll pattern. He subsequently assigns the dynamic markings $p, m p$, and 
the first occurrences of $m f$ and $f$ to the second sounding of the bell in the pattern, while assigning the markings $f f$ and $f f f$ and the second occurrences of $m f$ and $f$ to the third sounding of the bell in each group of three tolls. This would suggest that the bell's player is meant to adjust (when dynamic changes occur accordingly), something that (if specifically listened for) can be heard occurring in the original ECM recording. Table 4.2 indicates the bars in which the bell's tolling patterns occur, the relevant dynamic markings, and which sounding of the bell in the three-toll pattern is assigned the dynamic marking.

Table 4.2: Cantus - campana in la dynamic markings

\begin{tabular}{|l|l|l|}
\hline Bars & $\begin{array}{c}\text { Pynamic marking } \\
\text { Placement of dynamic marking } \\
\text { in three-toll pattern }\end{array}$ \\
\hline $1-5$ & $\begin{array}{l}\text { first toll } \\
9-13 \& 108\end{array}$ & first toll \\
\hline $17-21$ & $p($ pianississimo $)$ & second toll \\
\hline $25-29$ & $m p($ mezzo piano $)$ & second toll \\
\hline $31-37$ & $m f($ mezzo forte $) 1^{\text {st }}$ occurrence & second toll \\
\hline $41-45$ & $f($ forte $) 1^{\text {st }}$ occurrence & second toll \\
\hline $49-51$ & $f f($ fortissimo $)$ & third toll \\
\hline $57-61$ & $f f f($ fortississimo $)$ & third toll \\
\hline $65-69$ & $f f($ fortissimo $)$ & third toll \\
\hline $73-77$ & $f($ forte $) 2^{\text {nd }}$ occurrence & third toll \\
\hline $81-85$ & $m f($ mezzo forte $) 2^{\text {nd }}$ occurrence & third toll \\
\hline
\end{tabular}

As the work proceeds, the increasing volume of the bell transforms its sound from plaintive reflective tolls to ones of greater urgency, sounding almost angry in bars 61 and 65 when it plays fortississimo, after which the bell's diminishing dynamics seem to move into the distance, sounding more resigned and finally melancholy when the final tolling occurs to mark Cantus's end.

As indicated above, another middle dimension function relates to when changes of the dynamics occur in the different string sections. On their initial entrance in the second half of bar 7, the first violins play pianississimo. Three beats later, the second violins 
enter playing pianissimo. One bar later on the downbeat of bar 9, the violas enter playing piano, as do the violoncellos on their entrance in bar 11 . When the contrabasses make their first entrance in bar 15 , the dynamic marking is mezzo piano.

As occurred in the tolling of the bell, the dynamics increase incrementally relative to the initial dynamic within each of the string orchestral sections until all five string sections peak at fortississimo in bar 63. However, the processes that determine when dynamic changes occur in each of the string sections are not as readily transparent as some of the other musical processes and operations discussed thus far. Rather, the changes in dynamics of different string lines have a relationship to soundings of the bell. For the first violins, dynamic changes occur between individual soundings of the bell, during one of the three and one-half bar periods when the bell is silent. Starting in bar 16, incremental increases in dynamics occur in alternation on the ninth beat (bar 16, 32 and 48) or tenth beat (bars 23 and 39) before the bell returns, tolls three times and falls silent again (Figure 4.8 overleaf). For the sixth and seventh dynamic changes for the first violins, Pärt opts to break with this pattern by displacing the dynamic change to fortissimo from the last beat of bar 55 to the fourth beat of bar 56 , and the change to fortississimo is brought forward from the first beat of bar 64 to the fourth beat of bar 63, twelve beats after the third sounding of the bell (Figure 4.8 overleaf). An examination of the score suggests that Pärt may have introduced the subtle displacement from bar 64 backwards to bar 63 to align the first violins' final dynamic change with the change to fff in the other four string sections. 
Figure 4.8: Cantus - first violins' dynamic marking changes
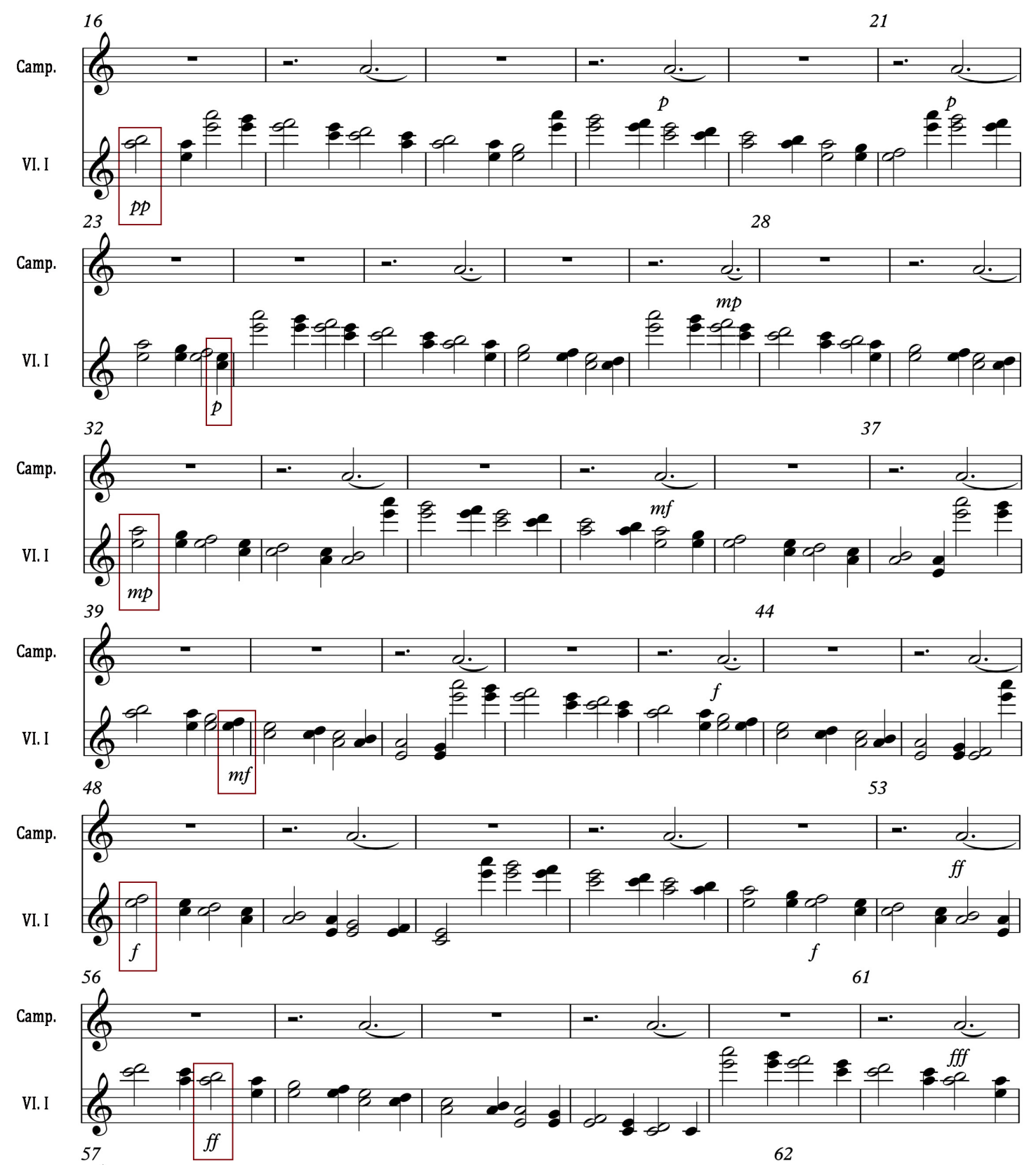

Camp.

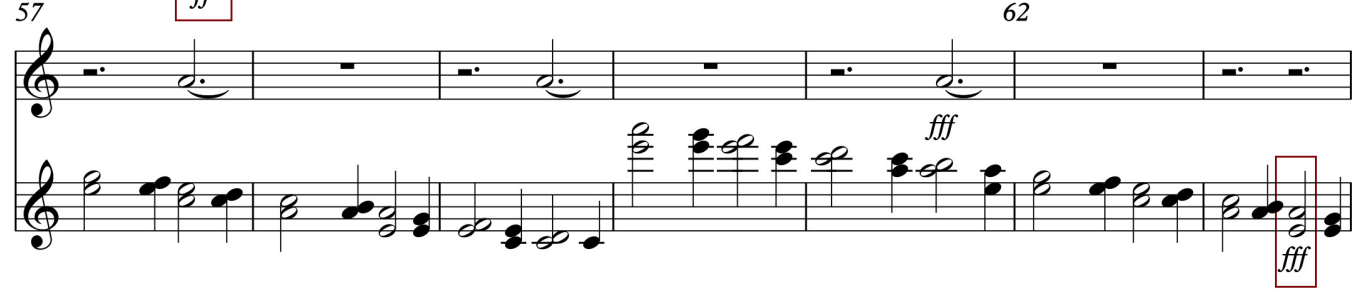


The relative positions of dynamic changes in the second violin section rotate in relation to the second and third soundings of the bell (Figure 4.9) when it reappears. The first occurrence is on the downbeat of bar 13 when the second violins' dynamics increase to piano, three beats before the third tolling of the bell during its first reappearance. The second dynamic change to mezzo piano occurs between the first and second soundings of the bell, beat five in bar 26 during the bell's fourth reappearance; while the change to mezzo forte falls on beat five during the bell's second tolling during its fifth reappearance (bar 35).

Figure 4.9: Cantus - second violins' dynamic markings changes

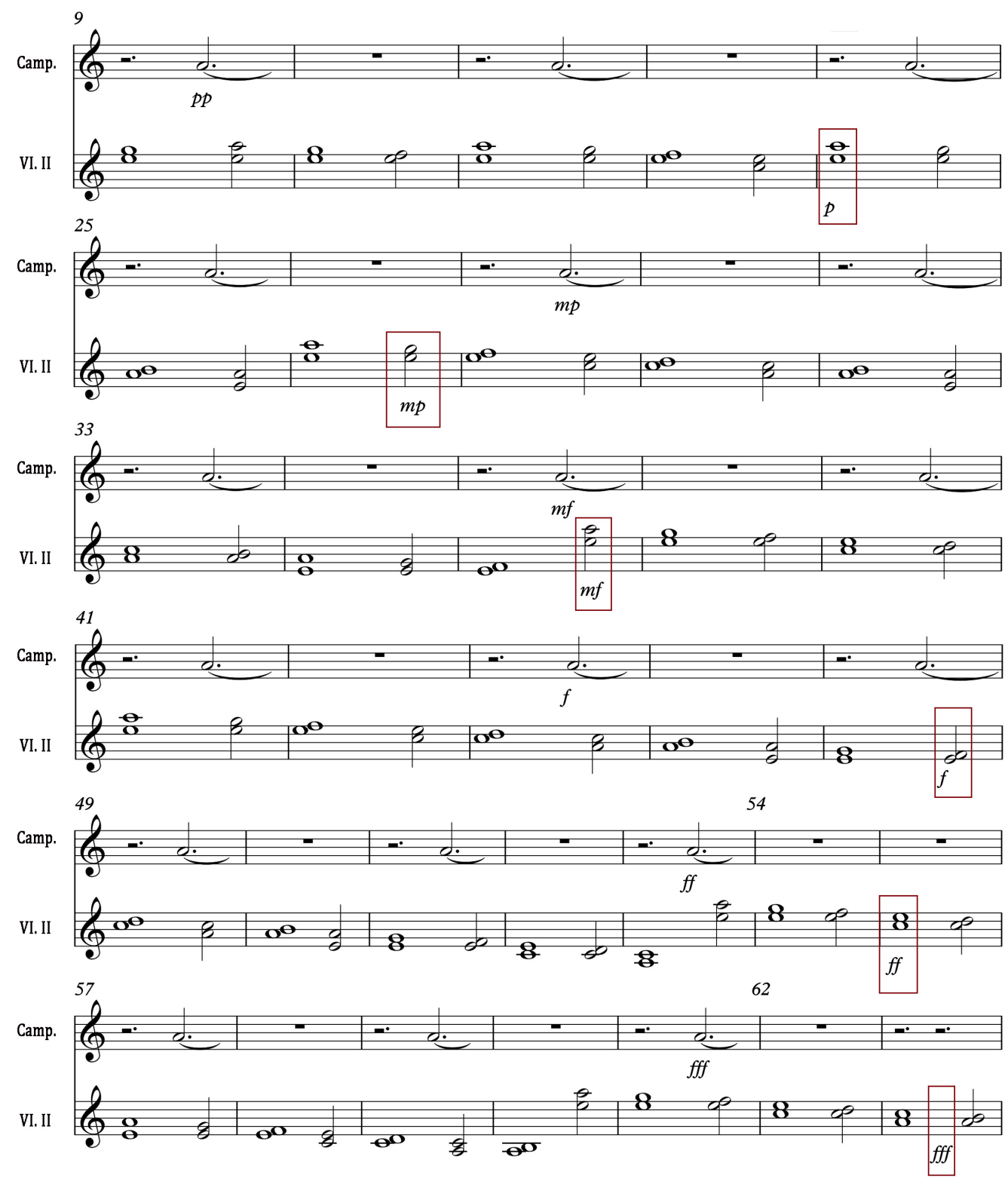


Subsequent changes occur on the third tolling of the bell's sixth reappearance in bar 45 (forte), bar 55 (fortissimo), and bar 63 (fortississimo), twelve beats after the third sounding of the bell during its eighth reappearance. The violas, which first enter Cantus playing piano have four dynamic changes with each change occurring before or after the third tolling of the bell during one of its reappearances (Figure 4.10). Whether a dynamic change occurs before or after the third tolling is dependent upon when the violas also execute a 'long' note (a dotted semibreve tied to a minim), e.g. bars 31 and 37.

Figure 4.10: Cantus - violas' dynamic marking changes
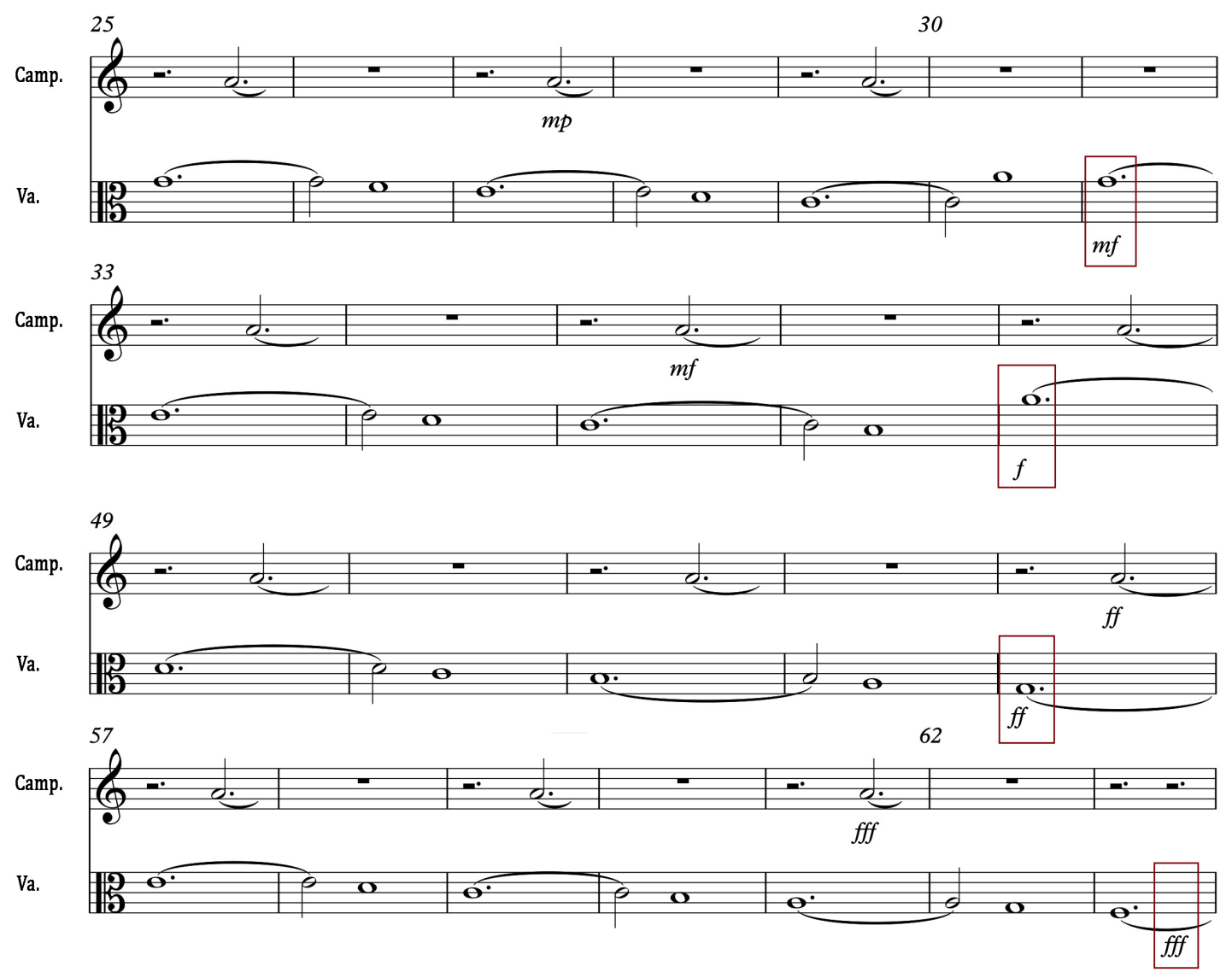
The relative positions of dynamic changes in the violoncellos also shift in relation to the different soundings of the bell (Figure 4.11). The first change from pianissimo to mezzo piano occurs on the downbeat of bar 22 , four beats after the third tolling of the bell in its second reappearance. The next change to mezzo forte occurs on the downbeat of bar 32, nine beats before the first sounding of the bell during its fifth reappearance. The changes to forte (bar 44) and fortissimo (bar 53) occur three beats after the second toll and one beat after the third toll of the bell. As with the above string sections, the final change to fortississimo in bar 64 occurs 12 beats after the bell's third toll in bar 61 .

Figure 4.11: Cantus - violoncellos' dynamic marking changes

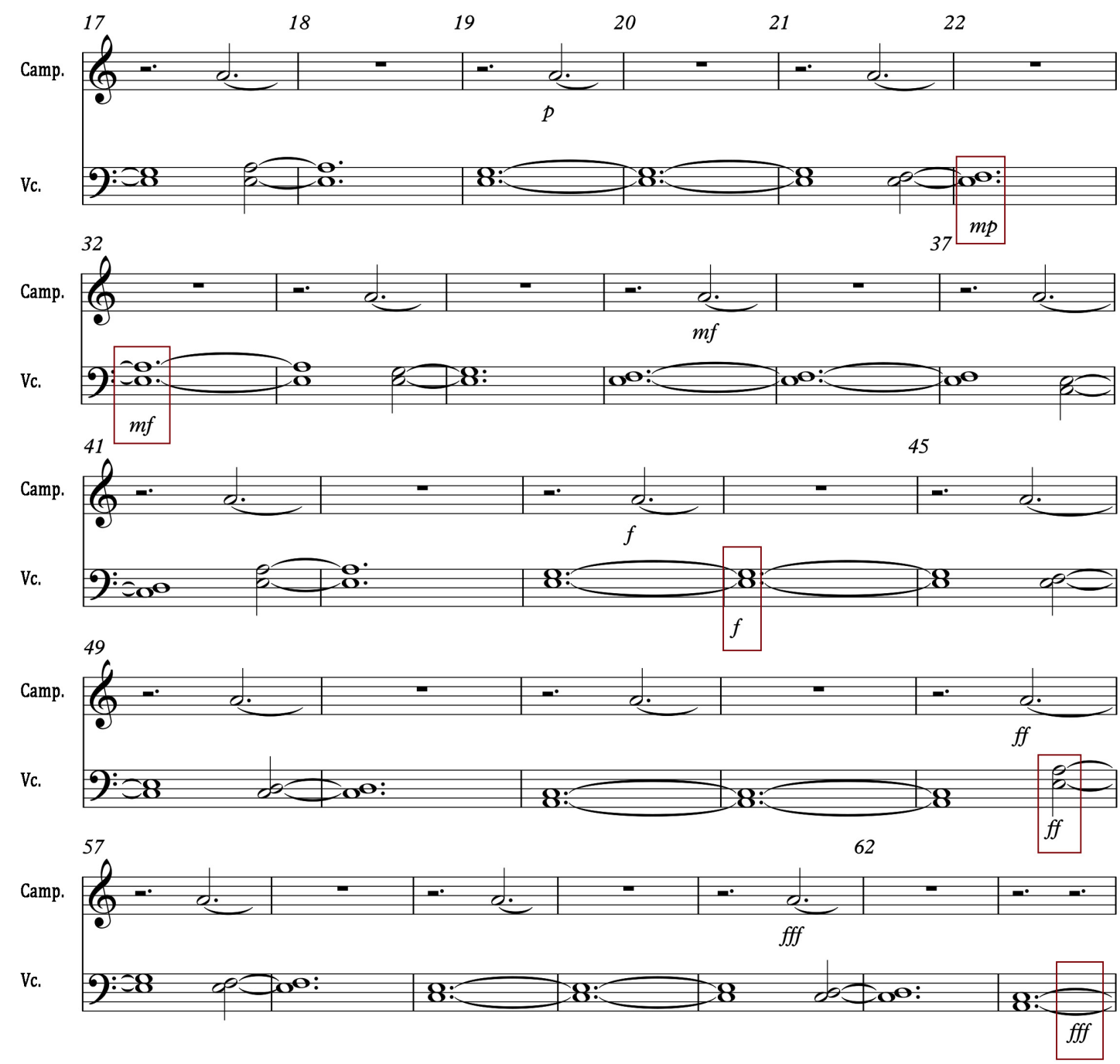


The dynamic changes in the contrabass section correspond to the second and third tolling of the bell when it makes its fourth, sixth, seventh, and eighth reappearances (Figure 4.12).

Figure 4.12: Cantus - contrabasses' dynamic marking changes

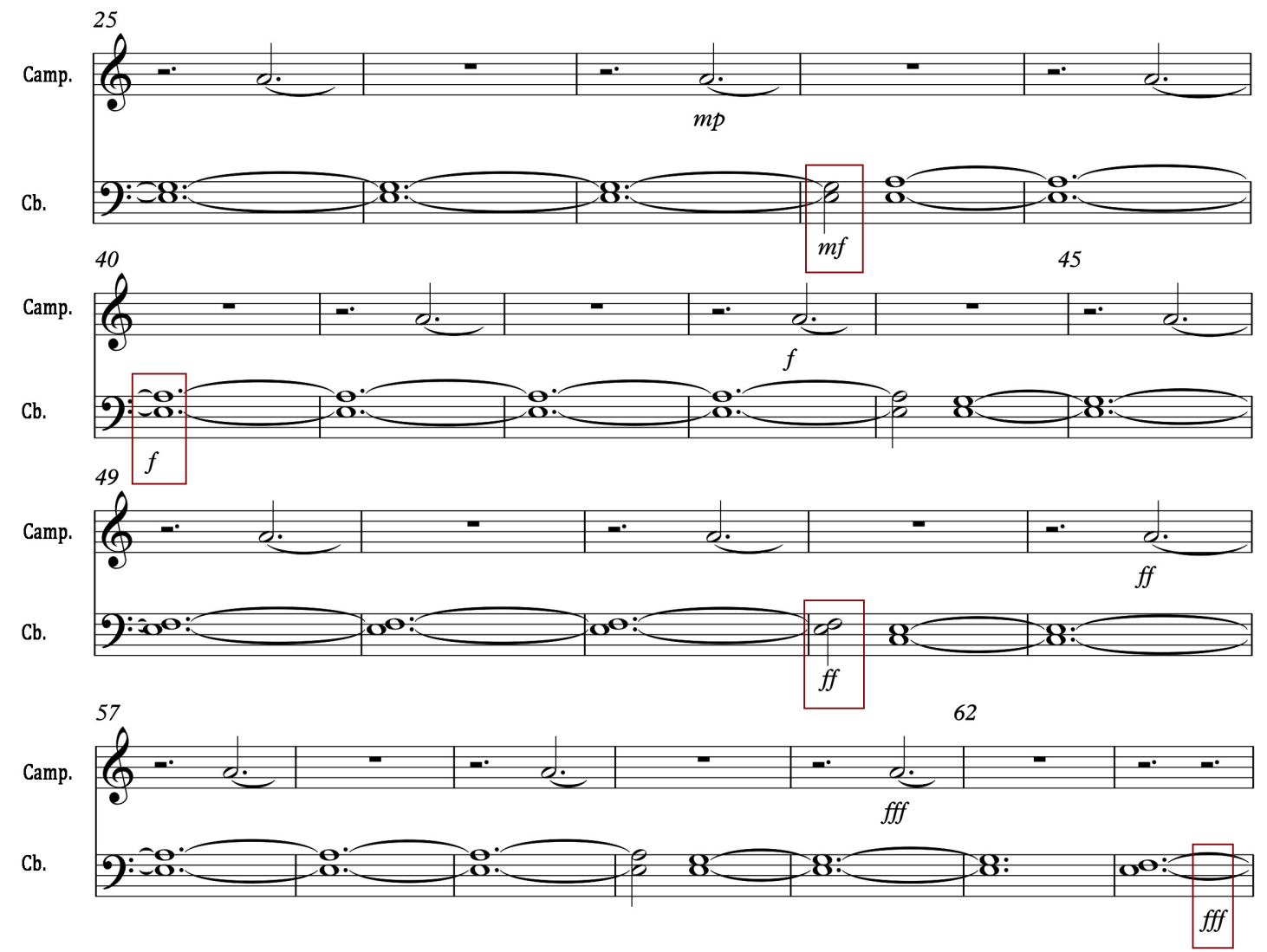

While the preceding discussion about the interrelationships between dynamic changes in the different string sections tolling of the bell in Cantus has been quite detailed, this has been to illustrate how the dynamic processes that Pärt used in composing Cantus are hidden within the works' musical fabric and cannot be readily identified without reference to the score. This suggests that even in his earliest process pieces Pärt did not intend to make all of the processes he used blatantly evident. 


\section{Small dimension}

As noted previously, due to the use of a first position, inferior relationship in each Mvoice/T-voice pairing, the interval classes generated between the divisi pairings in four string sections are limited to those shown in Figure 4.13.

Figure 4.13: Interval classes generated by an A minor triad and an A Aeolian (natural minor) scale, $1^{\text {st }}$ position, inferior

A minor triad with A aeolian scale 1st position, inferior

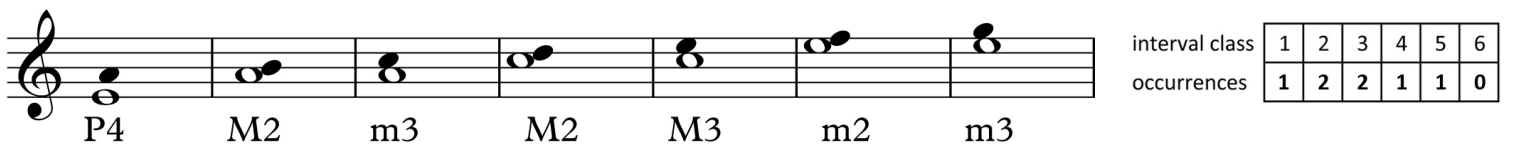

These intervals - one minor second (E-F), two major seconds (A-B and C-D), two minor thirds (A-C and E-G), one major third (C-E), and one perfect fourth (E-A) - comprise the smallest elements in the small dimension of Cantus. Other elements include: the shortlong rhythmic patterns (and their inversions) in each of the five sections (as described previously and summarised in Figure 4.14), which in interaction with each other also comprise an aspect of the large dimension of the work), the three-toll pattern of the bell on A, and the downward stepwise progression of the A Aeolian scale.

Figure 4.14: Cantus - string orchestra rhythmic patterns

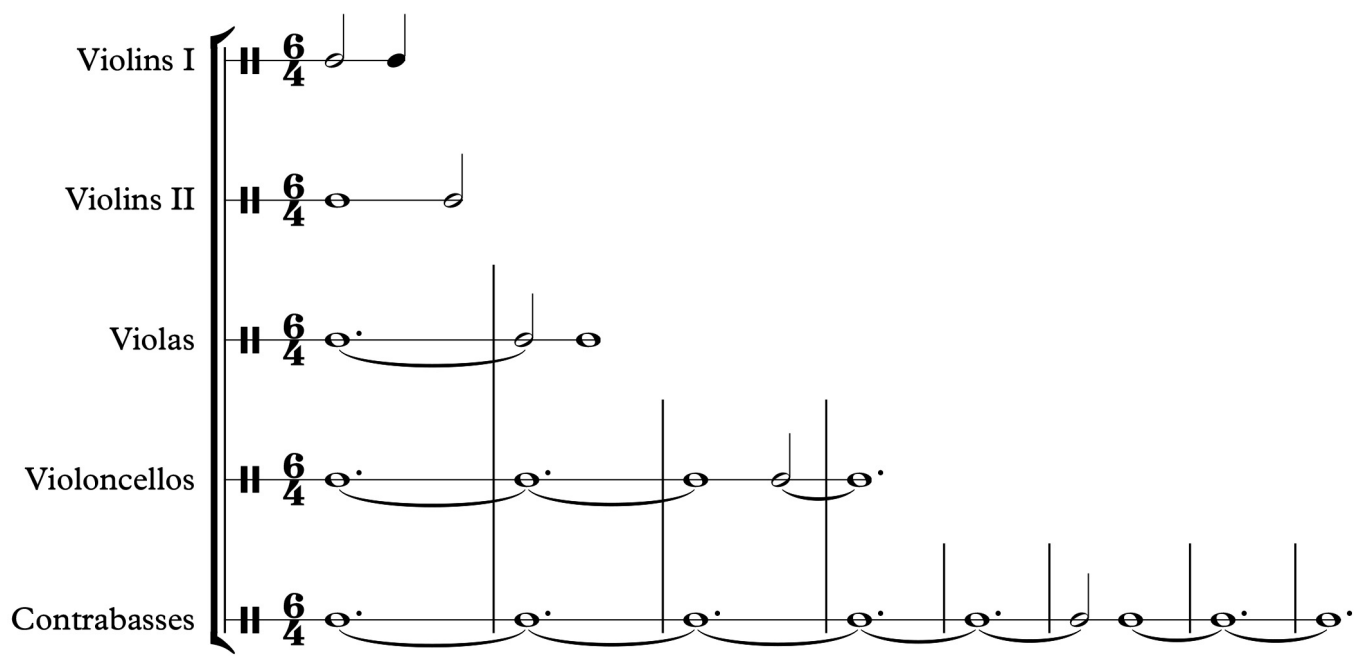


As individual elements, these small dimensional aspects of Cantus would appear to offer little opportunity for a great deal of sonic variety. However, as shown in the next section, when they are brought together in conjunction with the mensural and accretion processes described in the large and middle dimensions, the resulting sound world of Cantus is markedly varied and rich.

\section{Interval class analysis and sonority mappings of Cantus}

The following section of this chapter builds on the preceding style analysis and examines: 1) the intervallic content that arises from the use of a mensural cannon procedure combined with tintinnabuli operations in Cantus and 2) sonority mapping of this content, detailing the shifting musical sonorities throughout the work.

The intervallic content potential of the pitch classes of an A Aeolian, or A natural minor, scale includes two minor seconds, five major seconds, four minor thirds, three major thirds, six perfect fourths, and one tritone, i.e. Interval Class Vector <254361> (Forte Code: 7-35). This content is the same as that of Ludus in Tabula Rasa. The interrelationships between Cantus's different pitch classes are illustrated in Figure 4.15 overleaf. Insofar as the materials and methods deployed by Pärt are concerned, while both Cantus and Tabula Rasa have a number of similarities to one another (discussed later), in musical affect the two works are very different. 


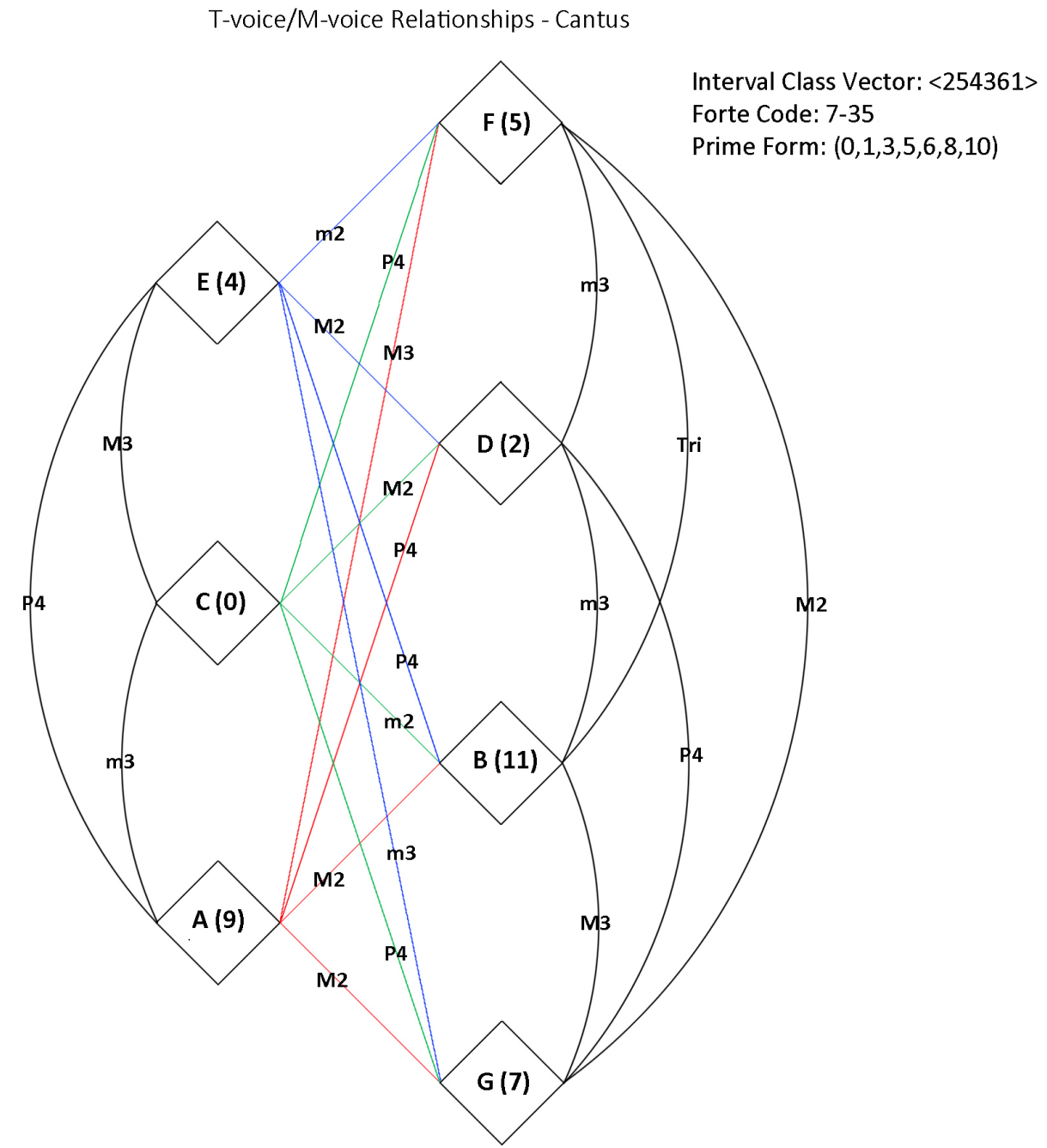

Table 4.3 overleaf details the interval vectors that occur in the first 13 bars of Cantus. Following the initial seven and one-half bars of relative silence, which is only broken by three tolls on A4 by the bell, the first violins enter playing divisi, an open fourth of A6 over E6 (<000100> or A5, with no third present), with pitch A6 establishing home pitch of the M-voice function and E6 functioning as a first position, inferior T-voice in the pairing. When the second violins enter divisi on the downbeat of bar 8, playing A5 over E5, the first violins have descended to G6 over E6, creating a brief moment of A7no3 $(<011010>$, Forte Code: 3-7). When the first violins recommence their descending pattern again from A6 paired with E6, a steady progression of new sonorities is 
introduced, starting in bar $8<100110>$ (Forte Code: 3-4, as an Fmaj7no5 chord); bar 9 $<121110>$ (Forte Code: 4-11, as an F7add9no5 chord); and <001110> (Forte Code: 3-11), which is the first full occurrence of the A minor triad that, along with various permutations of other A minor chords, is one of the dominant sonorities of Cantus. Additional sonorities follow in bar $10<100110>$ (Forte Code: 4-20 as a fully realised proper F7 chord); bar $11<032140>$ (Forte Code: $5-35$ as a C6/9 chord); and bar 12 $<122230>$ (Forte Code: 5-27 as a fully realised F9 chord). Further sonorities, generally of greater complexity, continue to arise in Cantus until bar 18 (Table 4.3 overleaf), after which additional new sonorities occur less frequently until bar 58 when the twentyfourth and final new sonority is introduced, $<112131>$ (Forte Code: 5-29), which is also the only occurrence of the chord Dm6/9. 
Table 4.3: Interval vectors, Cantus - bars 7 through 12

\begin{tabular}{|c|c|c|c|c|c|c|c|c|c|c|c|c|}
\hline Bar and beat & 7.1 & 7.2 & 7.3 & 7.4 & 7.5 & 7.6 & 8.1 & 8.2 & 8.3 & 8.4 & 8.5 & 8.6 \\
\hline Interval Class Vector & $<000000>$ & $<000000>$ & $<000000>$ & $<000010>$ & $<000010>$ & $<000010>$ & $<011010>$ & $<011010>$ & $<000010>$ & $<011010>$ & $<011010>$ & $<100110>$ \\
\hline Forte Code & $\mathrm{N} / \mathrm{A}$ & $\mathrm{N} / \mathrm{A}$ & $\mathrm{N} / \mathrm{A}$ & $\mathrm{N} / \mathrm{A}$ & $\mathrm{N} / \mathrm{A}$ & $\mathrm{N} / \mathrm{A}$ & $3-7$ & $3-7$ & $\mathrm{~N} / \mathrm{A}$ & $3-7$ & $3-7$ & $3-4$ \\
\hline Prime Form & $\mathrm{N} / \mathrm{A}$ & $\mathrm{N} / \mathrm{A}$ & $\mathrm{N} / \mathrm{A}$ & $(0,5)$ & $(0,5)$ & $(0,5)$ & $(0,2,5)$ & $(0,2,5)$ & $(0,5)$ & $(0,2,5)$ & $(0,2,5)$ & $(0,1,5)$ \\
\hline Chord/Pitch & Silence & Silence & Silence & A5 & A5 & A5 & A7no3 & A7no3 & A5 & A7no3 & A7no3 & Fmaj7no5 \\
\hline Bar and beat & 9.1 & 9.2 & 9.3 & 9.4 & 9.5 & 9.6 & 10.1 & 10.2 & 10.3 & 10.4 & 10.5 & 10.6 \\
\hline Interval Class Vector & $<011010>$ & $<011010>$ & $<011010>$ & $<121110>$ & $<100110>$ & $<001110>$ & $<011010>$ & $<011010>$ & $<011010>$ & $<121110>$ & $<100110>$ & $<101220>$ \\
\hline Forte Code & $3-7$ & $3-7$ & $3-7$ & $4-11$ & $3-4$ & $3-11$ & $3-7$ & $3-7$ & $3-7$ & $4-11$ & $3-4$ & $4-20$ \\
\hline Prime Form & $(0,2,5)$ & $(0,2,5)$ & $(0,2,5)$ & $(0,1,3,5)$ & $(0,1,5)$ & $(0,3,7)$ & $(0,2,5)$ & $(0,2,5)$ & $(0,2,5)$ & $(0,1,3,5)$ & $(0,1,5)$ & $(0,1,5,8)$ \\
\hline Chord/Pitch & A7no3 & A7no3 & A7no3 & F7add9no5 & Fmaj7no5 & $\mathrm{Am}$ & A7no3 & A7no3 & A7no3 & F7add9no5 & Fmaj7no5 & F7 \\
\hline Bar and beat & 11.1 & 11.2 & 11.3 & 11.4 & 11.5 & 11.6 & 12.1 & 12.2 & 12.3 & 12.4 & 12.5 & 12.6 \\
\hline Interval Class Vector & $<032140>$ & $<032140>$ & $<011010>$ & $<011010>$ & $<011010>$ & $<121110>$ & $<122230>$ & $<122230>$ & $<122230>$ & $<101220>$ & $<001110>$ & $<001110>$ \\
\hline Forte Code & $5-35$ & $5-35$ & $3-7$ & $3-7$ & $3-7$ & $4-11$ & $5-27$ & $5-27$ & $5-27$ & $4-20$ & $3-11$ & $3-11$ \\
\hline Prime Form & $(0,2,4,7,9)$ & $(0,2,4,7,9)$ & $(0,2,5)$ & $(0,2,5)$ & $(0,2,5)$ & $(0,1,3,5)$ & $(0,1,3,5,8)$ & $(0,1,3,5,8)$ & $(0,1,3,5,8)$ & $(0,1,5,8)$ & $(0,3,7)$ & $(0,3,7)$ \\
\hline Chord/Pitch & $\mathrm{C}^{6 / 9}$ & $\mathrm{C}^{6 / 9}$ & A7no3 & A7no3 & A7no3 & F7add9no5 & F9 & F9 & F9 & F7 & $\mathrm{Am}$ & $\mathrm{Am}$ \\
\hline
\end{tabular}


Table 4.4: Interval vectors, Cantus - order of first occurrence

\begin{tabular}{|c|c|c|c|c|}
\hline $\begin{array}{c}\text { Order 1st } \\
\text { occurrence }\end{array}$ & $\begin{array}{c}\text { Interval Class } \\
\text { Vector }\end{array}$ & $\begin{array}{l}\text { Forte } \\
\text { Code }\end{array}$ & Prime Form & $\begin{array}{c}\text { Bar 1st } \\
\text { occurrence }\end{array}$ \\
\hline 1 & $<000000>$ & $\mathrm{N} / \mathrm{A}$ & $\begin{array}{c}\text { silence or } \\
\text { single note }\end{array}$ & 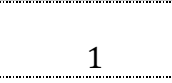 \\
\hline 2 & $<000010>$ & $\mathrm{N} / \mathrm{A}$ & $(0,5)$ & 7 \\
\hline 3 & $<011010>$ & $3-7$ & $(0,2,5)$ & 8 \\
\hline 4 & $<100110>$ & $3-4$ & $(0,1,5)$ & 8 \\
\hline 5 & $<121110>$ & $4-11$ & $(0,1,3,5)$ & 9 \\
\hline 6 & $<001110>$ & $3-11$ & $(0,3,7)$ & 9 \\
\hline 7 & $<101220>$ & $4-20$ & $(0,1,5,8)$ & 10 \\
\hline 8 & $<032140>$ & $5-35$ & $(0,2,4,7,9)$ & 11 \\
\hline 9 & $<122230>$ & $5-27$ & $(0,1,3,5,8)$ & 12 \\
\hline 10 & $<012120>$ & $4-26$ & $(0,3,5,8)$ & 13 \\
\hline 11 & $<110121>$ & $4-16$ & $(0,1,5,7)$ & 14 \\
\hline 12 & $<132130>$ & $5-23$ & $(0,2,3,5,7)$ & 15 \\
\hline 13 & $<021120>$ & $4-22$ & $(0,2,4,7)$ & 16 \\
\hline 14 & $<143250>$ & $6-32$ & $(0,2,4,5,7,9)$ & 17 \\
\hline 15 & $<211231>$ & $5-20$ & $(0,1,5,6,8)$ & 18 \\
\hline 16 & $<131221>$ & $5-24$ & $(0,1,3,5,7)$ & 21 \\
\hline 17 & $<111120>$ & $4-14$ & $(0,2,3,7)$ & 26 \\
\hline 18 & $<111000>$ & $3-2$ & $(0,1,3)$ & 27 \\
\hline 19 & $<233241>$ & $6-Z 25$ & $(0,1,3,5,6,8)$ & 28 \\
\hline 20 & $<232341>$ & $6-Z 26$ & $(0,1,3,5,7,8)$ & 29 \\
\hline 21 & $<222121>$ & $5-Z 12$ & $(0,1,3,5,6)$ & 36 \\
\hline 22 & $<254361>$ & $7-35$ & $(0,1,3,5,6,8,10)$ & 38 \\
\hline 23 & $<021030>$ & $4-23$ & $(0,2,5,7)$ & 41 \\
\hline 24 & $<122131>$ & $5-29$ & $(0,1,3,6,8)$ & 58 \\
\hline
\end{tabular}

As is frequently the case in Pärt's process-based music, the interval class vectors that occur in Cantus become more complex as the five orchestra sections progress through the work's various operations (described in the previous section): <211231> (Forte Code: 5-20); <131221> (Forte Code: 5-24); <233241> (Forte Code: 6-Z25); <232341> (Forte Code: 6Z26); <222121> (Forte Code: 5-Z12); <122131> (Forte Code: 5-29); and <254361> (Forte Code: 7-35). Notably, each of these vectors includes at least a minor second, major second, minor third, perfect fourth and a tritone.

As discussed earlier in relation to the analysis of Tabula Rasa, several of the interval vectors represent more than one chord in Table 4.5 overleaf (e.g. $<122230>$, Forte Code: 5-27, 
which includes all major and minor $9^{\text {th }}$ chords). The 24 different vectors that arise as a result of the mensural canon-based M-voice/T-voice operations and processes in Cantus comprise 42 distinct chords, plus the pitch class A by itself and silence. The most frequently occurring sonority, represented by interval class vector $<122230>$ (Forte Code: $5-27$, prime form $[0,1,3,5,8])$, occurs during 104 beats of the work, which is roughly ten per cent of Cantus's five minute duration. $<122230>$ represents the chords: Fmaj9 (40 occurrences), Dm9 (30 occurrences), Am9 (33 occurrences), and Cmaj9 (one occurrence). The second most frequently occurring sonority is $<001110>$ (Forte Code: $3-11$, prime form $[0,3,7]$ ), which occurs in 69 beats of Cantus, primarily as the A minor triad ( 67 beats) plus two beats when the $\mathrm{C}$ major triad occurs. The third most commonly occurring sonority is $<101220>$ (Forte Code: 4-20, prime form [0,1,5,8], comprising 62 beats and always occurring as an Fmaj7 chord). Other prominent sonorities include: <012120> (Forte Code: 4-26, [0,3,5,8], occurring as a total of 44 beats of the Am7 chord); 52 beats of $<021120>$ (Forte Code: 4-22 $[0,2,4,7]$, which includes the chords Em ${ }^{\text {add4 }} \mathrm{Dm}^{7 \text { th }}, \mathrm{C}^{\text {add9 }}, \mathrm{F} 6$, and Am ${ }^{\text {add4}}$ ); and $<111120>$ (Forte Code: 4-14 [0,2,3,7] with 43 occurrences representing the chords $C^{\text {add4 }}$, Dmadd9, Am add9).

Figure 4.16 overleaf provides a mapping of the intervallic content of Cantus from its beginning to its end. In the far left of the figure, the alternation between silence and the tolling of the funereal bell can be clearly seen in the alternating bands of blue (silence) and red (single pitch). As the work progresses the intervallic content becomes more complex and varied, as indicated by the various spikes in the figure. As illustrated in the far right of the figure, as Cantus draws to a close and the different string sections of the orchestra arrive at their final 'resting' pitches, the intervallic content diminishes to occurrences of only minor thirds, major thirds, and perfect fourths, i.e. $<001110>$ (Forte Code: $3-11$ ) as the orchestra sounds a final A minor triad for five and one half bars, before bell's final toll. 
Table 4.5: Cantus chords represented by interval vectors

\begin{tabular}{|c|c|c|c|c|}
\hline $\begin{array}{l}\text { Interval Class } \\
\text { Vector }\end{array}$ & Forte Code & Prime & $\begin{array}{l}\text { Frequency of Interval Class } \\
\text { occurrence (as number of beats) }\end{array}$ & $\begin{array}{l}\text { Frequency of chords occurrences } \\
\text { (as number of beats) }\end{array}$ \\
\hline$<122230>$ & 5-27: & $(0,1,3,5,8)$ & 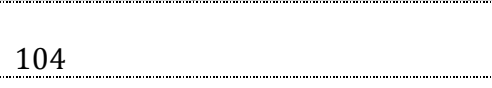 & $\begin{array}{l}\text { Fmaj9 (40), Dm9 (30), Am9 (33), } \\
\text { Cmaj9 (1) }\end{array}$ \\
\hline$<001110>$ & 3-11: & $(0,3,7)$ & 69 & $A m(67), C(2)$ \\
\hline$<101220>$ & 4-20: & $(0,1,5,8)$ & 62 & Fmaj7 (62) \\
\hline$<021120>$ & 4-22: & $(0,2,4,7)$ & 52 & $\begin{array}{l}\text { F6 (26), Amadd4 }(10), C^{\text {add } 9}(8), \text { Emadd4 } \\
(7), \operatorname{Dm}^{7 \text { th }}(1)\end{array}$ \\
\hline$<012120>$ & $4-26:$ & $(0,3,5,8)$ & 44 & $\mathrm{Am}^{7}(44)$ \\
\hline$<000000>$ & $\mathrm{N} / \mathrm{A}$ & silence or single note & 43 & Silence (30), or pitch class A (13) \\
\hline$<111120>$ & 4-14: & $(0,2,3,7)$ & 43 & $\operatorname{Am}^{\text {add } 9}(34), C^{\operatorname{add} 4}(6), \operatorname{Dm}^{\text {add } 9}(3)$ \\
\hline$<011010>$ & 3-7: & $(0,2,5)$ & 38 & A7no3 $(30), D 7$ no3 $(8)$ \\
\hline$<143250>$ & 6-32: & $(0,2,4,5,7,9)$ & 37 & $\mathrm{Dm}^{11 \text { th }}(21), \mathrm{G}^{11 \text { th }}(16)$ \\
\hline$<032140>$ & 5-35: & $(0,2,4,7,9)$ & 32 & $\mathrm{C}^{6 / 9}(32)$ \\
\hline
\end{tabular}


Figure 4.16: Cantus - sonority map

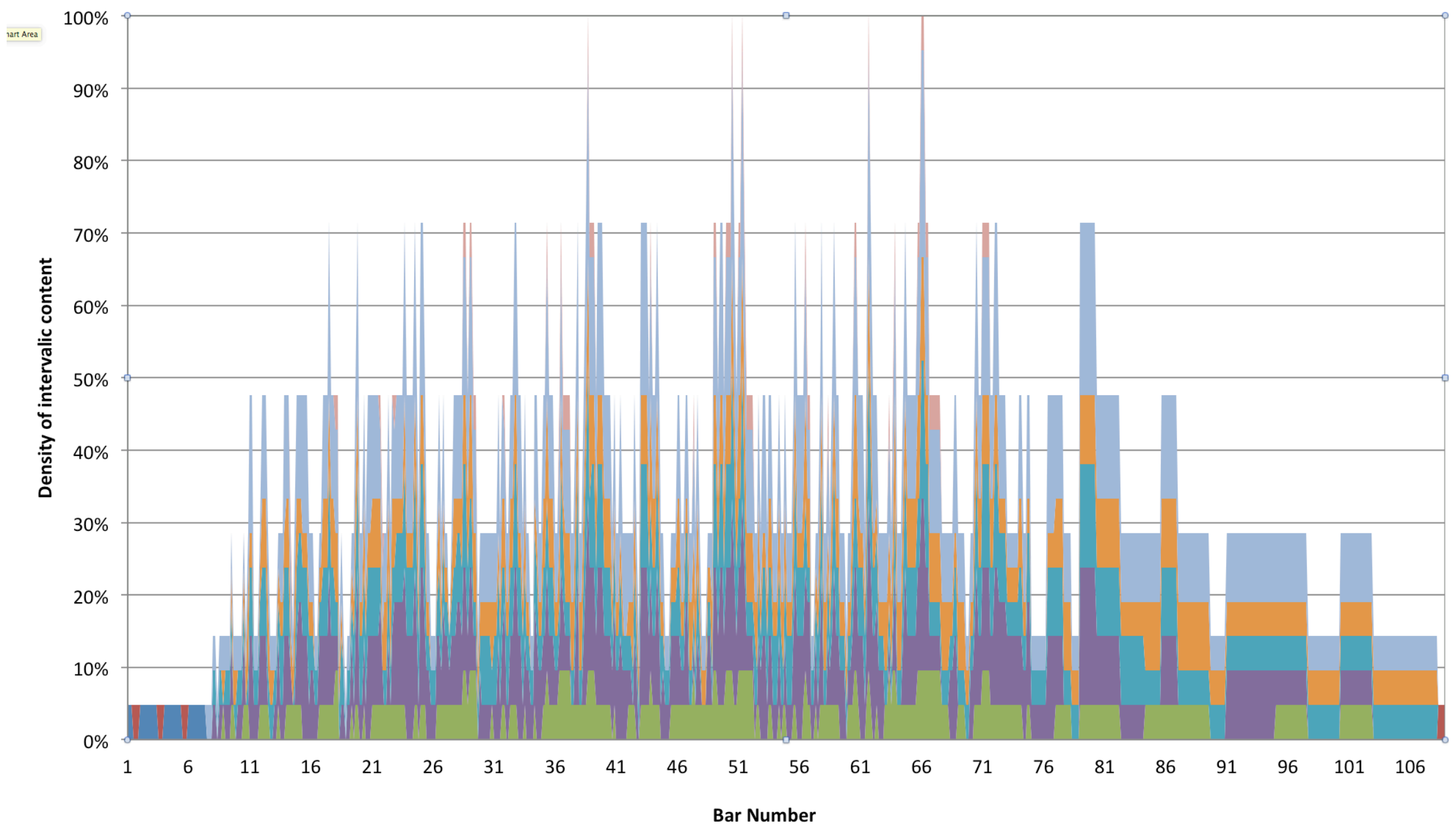

Silence $\quad$ Single pitch $\square \mathrm{m} 2 \quad \square \mathrm{M} 2 \quad \square \mathrm{m} 3 \quad \square \mathrm{M} 3 \quad \square \mathrm{P} 4 \quad$ Tritone 


\section{Discussion - Cantus}

As noted in Chapters 1 and 2, Pärt's tintinnabuli works do not follow the harmonic rules of common practice Western tonal music. However, it is possible to identify patterns of recurring chords and chordal progressions that constitute a specific work's organising 'harmonic' scheme. A scan of the chords detailed in Table 4.3 above shows that for the most part, they can be placed in six 'harmonic' categories: various permutations of A minor chords, C major chords, D minor chords, the occasional occurrence of E minor as an 'add 4' chord, F major chords, and G major chords. A mapping of these categories against the chords that arise as a result of Cantus's processes reveals that certain 'harmonic' tensions are operating - between $\mathrm{F}$ major and $\mathrm{A}$ minor, and $\mathrm{A}$ minor and $\mathrm{C}$ major - within the work (Table 4.6 overleaf), which ultimately resolve to the equivalent of a cadence on A minor.

In the absence of the harmonic tensions that one would find in a common practice tonal work, the primary harmonic progression (as illustrated in the shaded bars in Table 4.6) in Cantus suggests a pseudo-cadential relationship between various permutations of $\mathrm{F}$ major chords and permutations of A minor chords. While it can be argued that traditionally the progression from an $\mathrm{F}$ major chord to an A minor chord does not provide a satisfactory enough sense of repose to be defined as a true 'cadence', it can also be argued that by the arrival at Cantus's final chords, the listener has been so well conditioned to expect this progression that it does provide a satisfactory point of final repose and closure to the ear, and in the case of Cantus the progression serves as a type of 'functional harmony'. 
Table 4.6: Progressions of chordal families occurring in Cantus - bars 7.1 through 41.2

\begin{tabular}{|c|c|c|c|c|c|c|c|c|c|c|c|c|}
\hline Bars (and beat) & 7.1-8.5 & 8.6 & $9.1-9.3$ & 9.4-9.5 & $9.6-10.3$ & $10.4-10.6$ & $11.1-11.2$ & $11.3-11.5$ & $11.6-12.2$ & 12.3 & 12.4 & $12.5-13.2$ \\
\hline Chord family & A minor (implied) & F major & A minor & F major & A minor & F major & C major & A minor & F major & D minor & F major & A minor \\
\hline Bars (and beat) & 13.3 & $13.4-13.5$ & 13.6 & $14.1-14.6$ & $15.1-15.2$ & $15.3-15.6$ & $16.1-16.2$ & $16.3-16.4$ & $16.5-17.3$ & $17.4-17.6$ & $18.1-18.2$ & $18.3-19.2$ \\
\hline Chord family & F major & A minor & C major & F major & D minor & $\mathrm{C}$ major & E minor & A minor & F major & D minor & C major & A minor \\
\hline Bars (and beat) & 19.3 & 19.4 & 19.5 & 19.6 & $20.1-20.4$ & $20.5-20.6$ & 21.1-21.4 & 21.5 & $21.6-22.2$ & $22.3-22.4$ & 22.5 & $23.1-23.5$ \\
\hline Chord family & F major & A minor & F major & D minor & A minor & C major & F major & G major & F major & D minor & G major & D minor \\
\hline Bars (and beat) & $23.6-24.3$ & 24.4 & 24.5 & 24.6 & $25.1-25.2$ & 25.3 & $25.4-25.5$ & $25.6-26.2$ & $26.3-26.4$ & $26.5-26.6$ & 27.1-27.6 & 28.1-28.2 \\
\hline Chord family & $\mathrm{C}$ major & D minor & F major & A minor & G major & A minor & E minor & A minor & F major & C major & D minor & G major \\
\hline Bars (and beat) & $28.3-28.6$ & 29.1-29.2 & $29.3-29.4$ & 29.5 & 29.6 & $30.1-30.5$ & 30.6 & $31.1-31.2$ & 31.3 & 31.4 & 31.5 & 31.6 \\
\hline Chord family & D minor & G major & C major & A minor & D minor & A minor & F major & A minor & C major & A minor & F major & G major \\
\hline Bars (and beat) & $32.1-32.2$ & $32.3-32.4$ & $32.5-32.6$ & $33.1-33.2$ & 33.3-33.4 & $33.5-33.6$ & $34.1-34.2$ & 34.3 & $34.4-34.6$ & $35.1-35.2$ & 35.3 & $35.4-35.6$ \\
\hline Chord family & A minor & F major & D minor & C major & A minor & E minor & A minor & D minor & $\mathrm{C}$ major & F major & G major & F major \\
\hline Bars (and beat) & $36.1-36.3$ & 36.4 & $36.5-37.2$ & $37.3-37.4$ & $37.5-37.6$ & $38.1-38.3$ & 38.4 & 38.5 & 38.6 & $39.1-40.4$ & 40.5 & $40.6-41.2$ \\
\hline Chord family & $\mathrm{C}$ major & D minor & C major & F major & D minor & F major & D minor & $\mathrm{C}$ major & G major & D minor & C major & A minor \\
\hline
\end{tabular}


As observed previously, Cantus in memorium Benjamin Britten shares a number of similar characteristics to Ludus. While the title of Tabula Rasa implies either an empty space or clearing of space, it is in fact an exploration of the sonic potential of the Aeolian diatonic scale (A natural minor in the case of Ludus and D natural minor in Silentium). The content and boundaries of this scale in both movements of Tabula Rasa are rigorously explored by Pärt through his careful juxtaposition of cyclical stepwise additive patterns, which relentlessly expand outwards from, and inwards to, a single pitch centre at a single tempo - all the while harmonised by the arpeggiations of a single triad grounded in the tonic. Cantus, in turn, explores the same harmonic space - again an Aeolian diatonic scale - through an additive layering and accretion of staggered descending scales that expand downwards at different tempos in a long-short stepwise rhythmic manner by first one increment, then two increments, then three, etc., until the entire registral span of the orchestra has been exhausted.

In the case of both Tabula Rasa and Cantus, the triads of the T-voices have the same root as the pitch class centre of the scale in question. The contrapuntal T-voices' pitches in both works do not deviate in their positional relationship with their respective M-voices (e.g. first or second position, inferior or superior). Rhythmically the counterpoint between each Tvoice and its respective M-voice is one-to-one, i.e. sounding simultaneously as a single interval. Pärt also uses a mensural canonic procedure in Silentium.

Despite having a number of similarities, which is unsurprising given both works were composed in the same year, Cantus is a markedly different work when compared with Tabula Rasa, and in particular its first movement Ludus. From its outset, Ludus has a dynamic, almost violent energy, in contrast to Cantus's gentle elegiac soundscape. Ludus has eight clearly defined sections of varying length, separated by diminishing periods of 
silence; whereas, after the initial entrance of the first violins in bar 7, Cantus proceeds seamlessly from start to finish. Importantly, Cantus's soundscape is much more varied than that of Ludus. This is despite Ludus having a greater number of distinct interval class vectors (31) than does Cantus (24). Excluding periods of silence, approximately 85 per cent of Ludus's content comprises various permutations of A and A minor chords. In contrast and as illustrated above, the harmonic content of Cantus is more varied, in terms of the nature of chords that occur. While approximately 40 per cent of Cantus's content also comprises permutations of $\mathrm{A}$ and $\mathrm{A}$ minor chords, as illustrated above in Table 4.6, the work rarely lingers in A for more than a bar or two. Instead it cycles through a variety of A and A minor chords, C chords, D and D minor chords, F chords, as well as G chords. This is what imbues Cantus with a sense of having a schema of harmonic progressions, even though these progressions arise out of a series of repeating processes, rather than a framework of common practice harmony.

\section{Festina Lente}

The second process-based string composition examined in this chapter is Festina Lente. After 1977, Pärt's instrumental music output primarily comprises various the instrumental arrangements of Fratres, Summa, and Spiegel im Spiegel until 1985, when he composed the first versions of Psalom for various arrangements of string instruments (discussed in the next chapter). Festina Lente - Latin for "make haste slowly" - is a single movement mensural canon of 228 bars for string orchestra (violins I, II, III, and IV, violas, violoncellos, contrabasses) and a concert harp ad libitum. Composed in 1988 with revisions in 1990, it was Pärt's first new composition specifically for string orchestra since Cantus (1977). ${ }^{150}$

150 Universal Edition, "Paert Catalogue," 1991, 21-22, http://www.universaledition.com/ArvoPaert/composers-and-works/composer/534/worklist\#page=0. 
David Clarke posits that Festina Lente invites two different listening strategies, the first being analytical, wherein the listener attempts to trace the various canonical procedures throughout the work, although "the scale of the imitative treatment [within the canonic material] would seem to put this beyond the realms [sic] of what is cognitively possible"151. The second listening strategy, which Clarke believes is both more feasible and enjoyable from the perspective of the listener, is:

... allowing one's attention to migrate across the various layers, or savouring the resulting patterns of [Festina Lente's] total texture. The latter approach creates a strong image of freely floating presences, captured and cross-reflected in shifting mirrors. ${ }^{152}$

The following analysis of Festina Lente is intended to address and inform Clarke's first, and supposedly unfeasible, analytical listening strategy by tracing the various canonic and mensural processes that occur in the work. The analysis also evidences how these vary and ultimately fracture into a more fluid interpretation by Pärt of what comprises a 'process' piece of music.

\section{Style analysis of Festina Lente}

\section{Large dimension}

Festina Lente is in essence structured around a theme and series of variations that play out in five sections of $52,52,52,48$, and 24 bars, respectively. Metrically the work is in a simple triple meter of $3 / 4$, with each instrumental line adhering to a long-long-shortshort motive that frequently is prefaced by a short-note anacrusis. The tempo marking on the score is 52 dotted minims per minute or approximately 156 crotchets per minute

\footnotetext{
${ }^{151}$ David Clarke, "Summa for String Quartet; Festina Lente, for String Orchestra and Harp Ad Libitum; Fratres for String Quartet; Freatres for String Orchestra and Percussion; Fratres for Violonello and Piano; Fratres for Violin and Piano by Arvo Pärt. Review by David Clarke," Music \& Letters 75, no. 4 (November 1994): 655.

152 Ibid.
} 
or Allegro. However, the different instrumental lines in the work operate at three distinct tempos, with the lower-voiced instruments progressing quite slowly in relation to the upper voices - thus emphasising the 'hasten slowly' aspect of the work's title.

The first and second violins proceed at the fastest tempo, using primarily minims and crotchets (Figure 4.17). The violas progress at half the pace of the first and second violins, while the violoncellos, contrabasses and third and fourth violins proceed at a quarter of the pace of the first and second violins. This three-fold tempo, along with the long-long-shortshort rhythmic pattern, which is most readily discernable in the upper violin lines, obscures any sense of a universal 3/4 metre. Frequent ties across bar lines, which have the added effect of obscuring downbeats, further reinforce the lack of a clearly audible unifying metre.

\section{Figure 4.17: Festina Lente - bars 1 through 8}

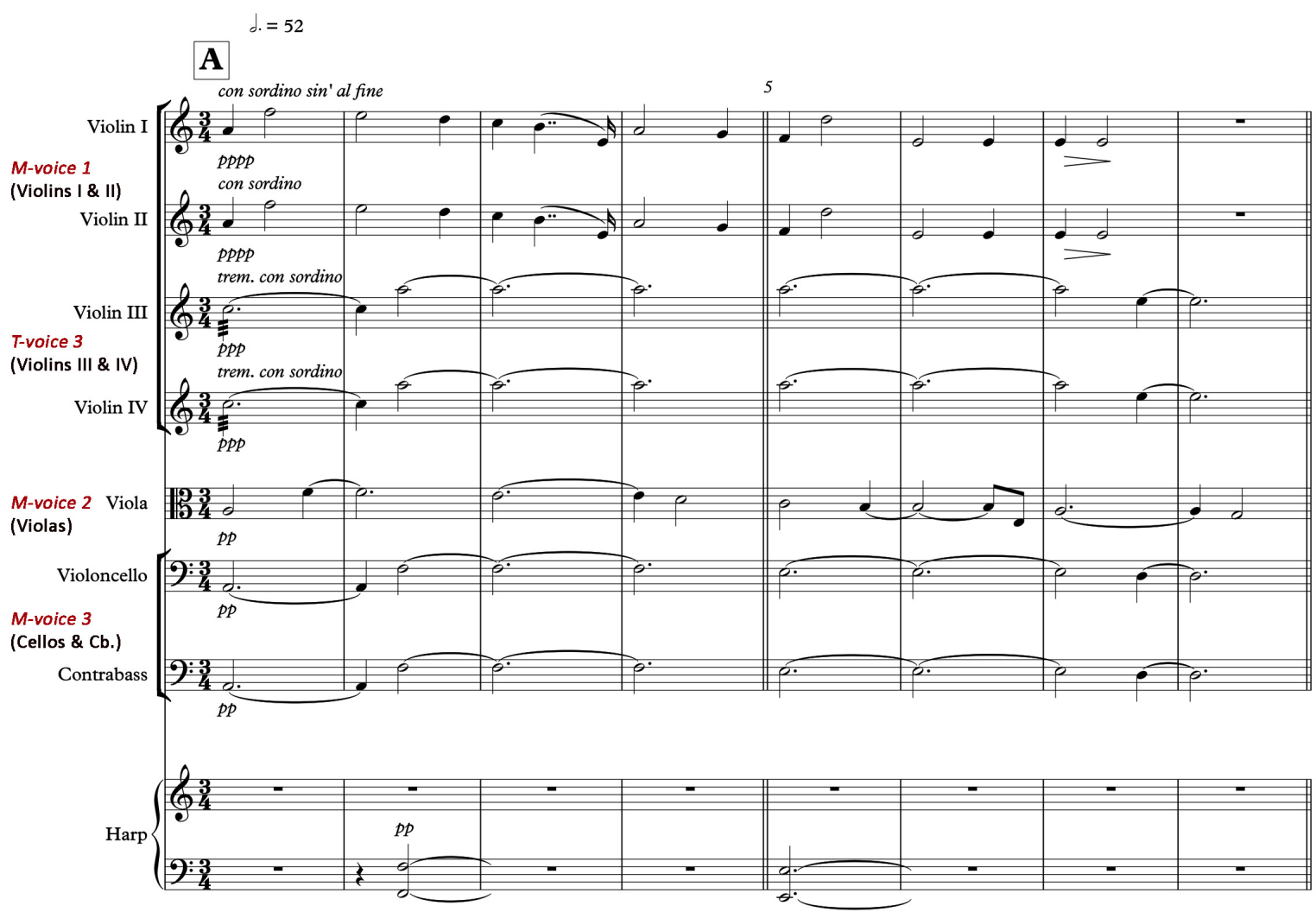


As illustrated in Figure 4.17 above, Festina Lente commences with three different M-voice lines, with the first and second violin lines functioning in unison as M-voice 1, the viola line as M-voice 2, and the violoncello and contrabass lines proceeding in unison as the third melodic line, or M-voice 3. At its outset, the work has only one true T-voice - violins III and IV in unison, paired with the M-voice 3 line of the cellos/contrabasses. ${ }^{153}$

The pitch classes used in Festina Lente (A, B, C, D, E, F, G) - the same as used in Cantus comprise the A Aeolian, or A natural minor scale. However, as David Clarke notes “...the strong emphasis on $\mathrm{F}$ at many points in the canonic melody, and its implied linear resolution to E, also posit a Phrygian interpretation" of the mode, rather than an Aeolian. ${ }^{154}$ The modal ambiguity of the work is further emphasised by its ending in bars 221 through 224 - a sustained D minor chord over a prolonged E pedal in the cellos and contrabasses (with the pedal commencing in bar 210).155

\section{Theme and variations}

Unlike Cantus, the melody of Festina Lente does not operate in a simple scale-wise manner, but rather is structured around a musical statement consisting of two phrases that are periodically punctuated with upward leaps of sixths and a fourth, and downward leaps of a fifth or seventh as the melody progresses. This is most readily illustrated in the opening bars of the first and second violins (Figure 4.18).

\footnotetext{
153 This is labelled as T-voice 3 in the diagram to align its numbering with that of its M-voice and to avoid confusion later in the work when additional T-voices come into play, starting in bar 45 .

154 David Clarke, 'Summa for String Quartet; Festina Lente, for String Orchestra and Harp Ad Libitum; Fratres for String Quartet; Fratres for String Orchestra and Percussion; Fratres for Violoncello and Piano; Fratres for Violin and Piano by Arvo Pärt. Review by David Clarke', Music \& Letters, 75.4 (1994), 652-58 (p. 655).

155 Though most of Pärt's tintinnabuli works do not 'modulate', this modal ambiguity is not unique to Festina Lente. Hillier notes Fratres, which has an octatonic pitch class set as opposed to diatonic, cycles through a chain of thirds, so that each pitch of the scale functions as a pitch centre for one full cycle. Hillier, Arvo Pärt, 104.
} 
Figure 4.18: Festina Lente - violins I and II bars 1 through 9

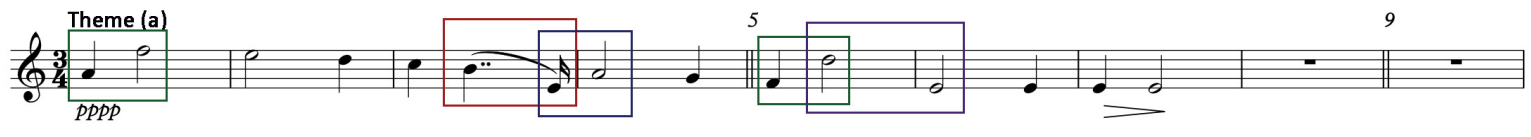

The first phrase of the statement in bars 1 through 5 sketches the primary melodic gestures of the work - an upward leap of a sixth from A4 to F5 in bar 1 followed by a stepwise descent to D5 and a downward leap of a fifth to E4 in bar 3, followed by an upward leap of a fourth back to A4. The melody then descends stepwise to F4 only to leap up a sixth to D5 in bar 5 and then drop down a seventh in bar 6 to E4 for the beginning of the second phrase. Starting in bar 6, the second phrase of the statement emphasises a single pitch, sounding it repeatedly, to further underscore the long-long-short-short rhythmic pattern that forms one of the two rhythmic motives of the entire work, followed by a period of silence. In the initial presentation of the theme this occurs as multiple soundings of E4.

In addition to the long-long-short-short rhythmic pattern (as highlighted in bars 6 and 7), the first phrase of the statement is further punctuated rhythmically by a double-dotted crochet/semi-quaver/minim motive in bars 3 and 4 . In the faster moving upper violin lines, the semi-quaver before the downbeat in bar 4 (and subsequent measures when it occurs) sounds as a brief acciaccatura. In the slower moving lower string lines, however, the rhythmic equivalent of this semi-quaver becomes a quaver in the viola line and a crotchet in the violoncello and contrabass lines, thus gaining greater prominence as a harmonic participant in determining chordal progressions. An example of this can be seen in Figure 4.19. The first violins' semi-quavers in bars 3 and 11 act as acciaccature, as well as being on pitch classes that already exist in one or more of the other instrumental lines. In contrast, the pitches E3 and E2 on the third beat of bar 12 in the violoncello and contrabass lines, which are equivalent within the context of those played by the first 
violins in bar 3, result in the realisation of all three pitches of the A minor triad.

Figure 4.19: Festina Lente - violins II, bars 1 through 49
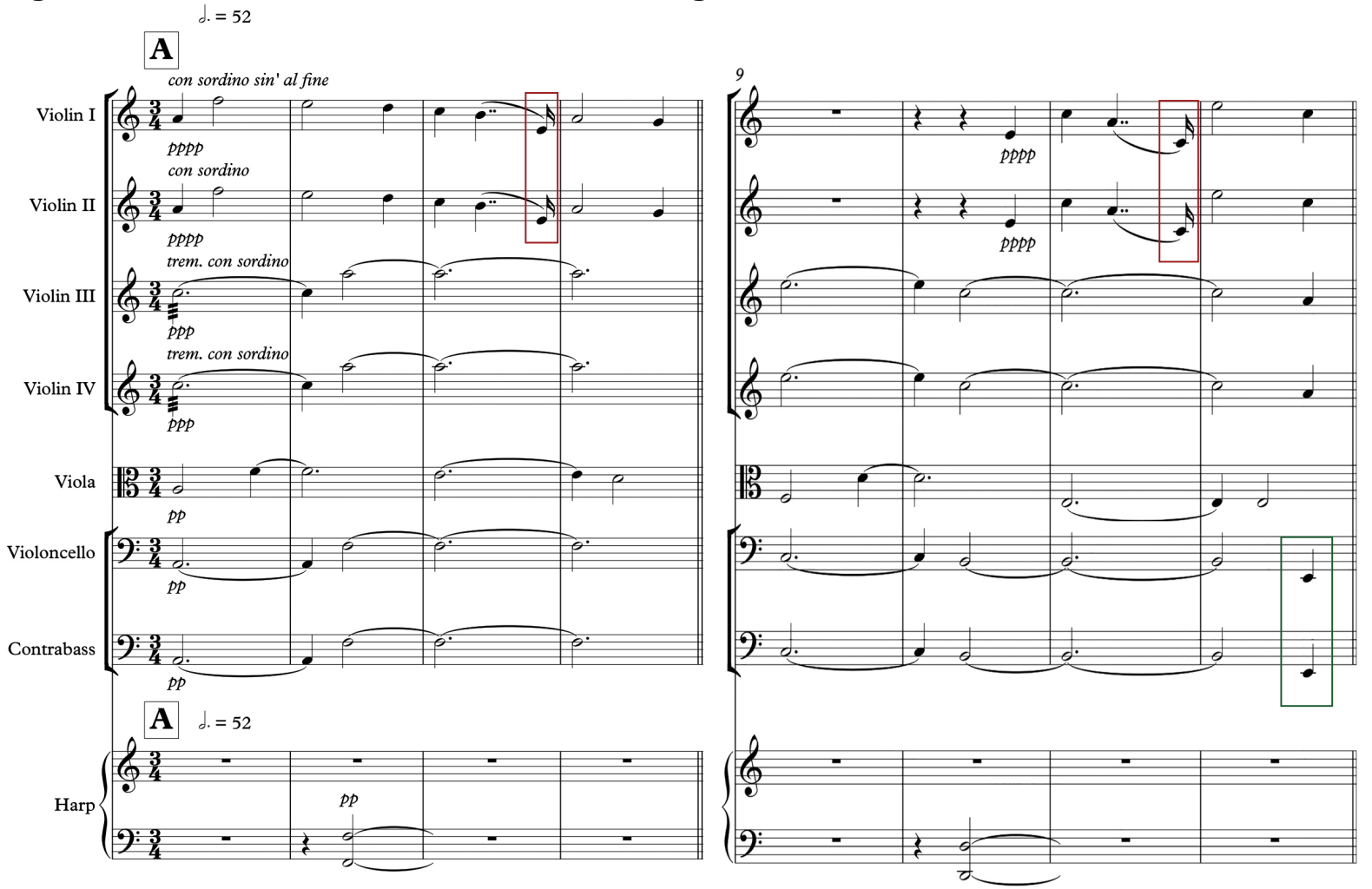

Figure 4.20 overleaf provides a MIDI-recreation of Festina Lente in its entirety. Despite the work being process-based piece, the patterns of Festina Lente are much less easy to discern visually then was previously observed for Ludus, Silentium and Cantus. This is due to the manner in which Pärt subsequently develops the initial two-part theme in Figure 4.18 above into a series of variations that are presented in succession by the different sections of the orchestra. ${ }^{156}$ Figure 4.21 overleaf demonstrates this theme and its subsequent variations as they appear in the second violin line.

156 The gradations in colour in Figure 4.20 illustrate changes in volume as the work progresses from pianississimo to fortissimo and back to pianississimo. 
Figure 4.20: Festina Lente - MIDI-recreation all strings (with contrabasses shown in their sounding register) 157

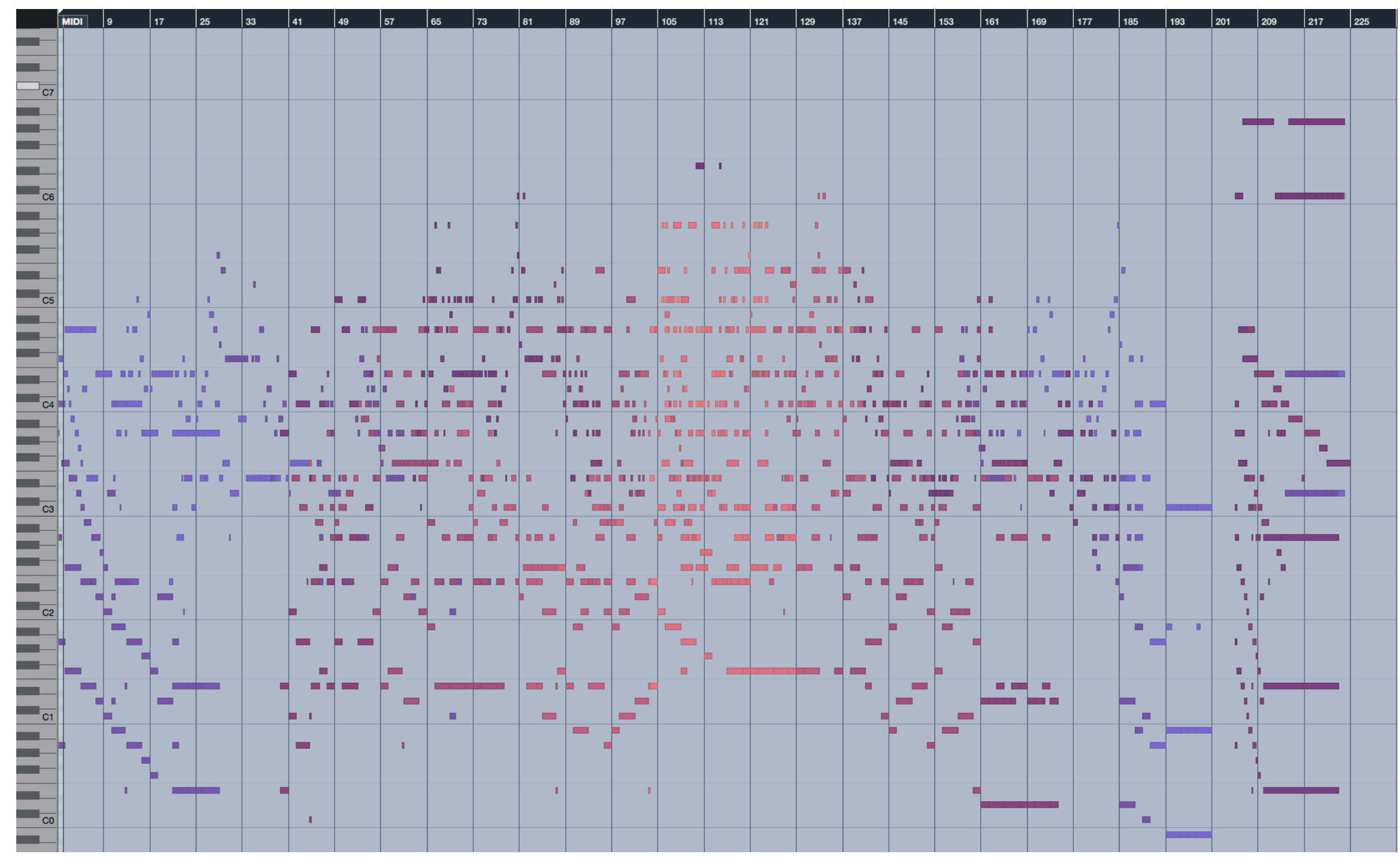

157 Midi-recreation created using Cubase ${ }^{\mathrm{TM}} 7.5$. 
Figure 4.21: Festina Lente - violins II, bars 1 through 49

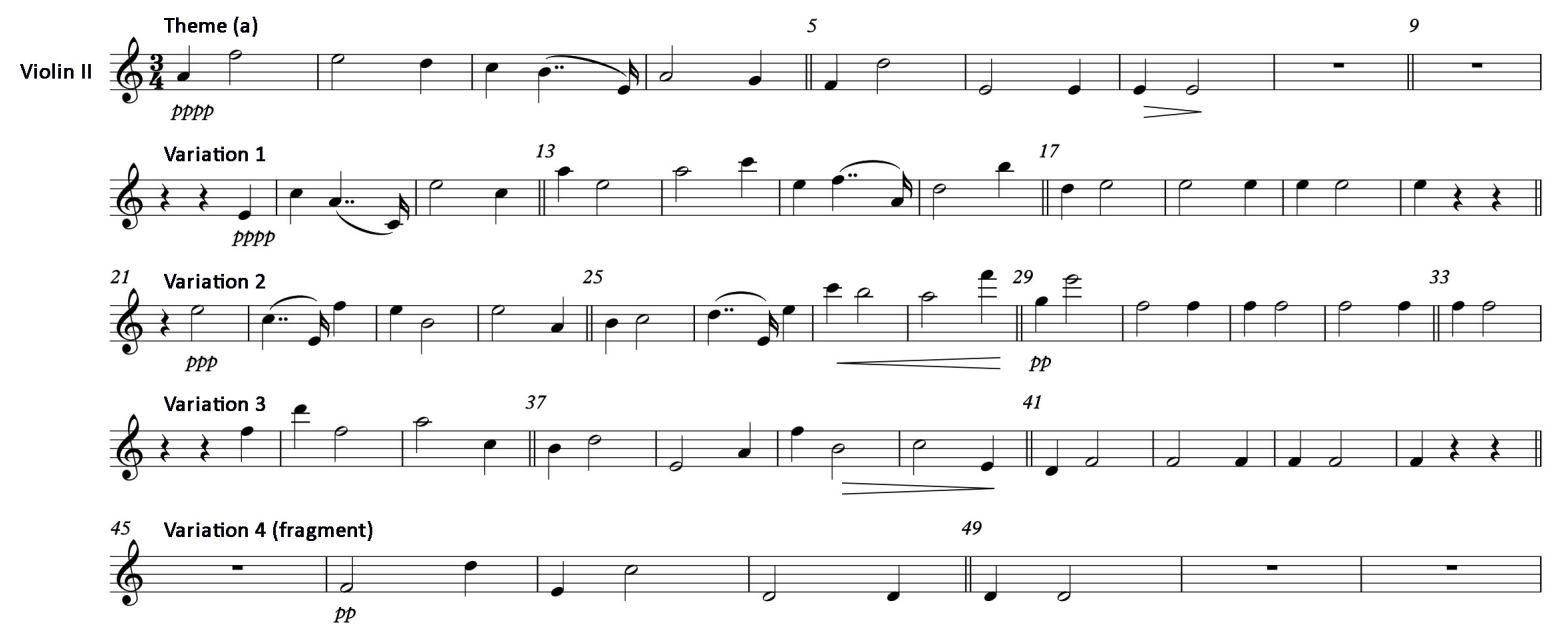

In the first variation shown in Figure 4.22, Pärt transposes the melody from its initial Aeolian/Phrygian-centred mode downwards by a fourth and extends the length of the first phrase of the statement, expanding it from roughly five bars to eight.

Figure 4.22: Festina Lente - violins II, theme and Variation 1

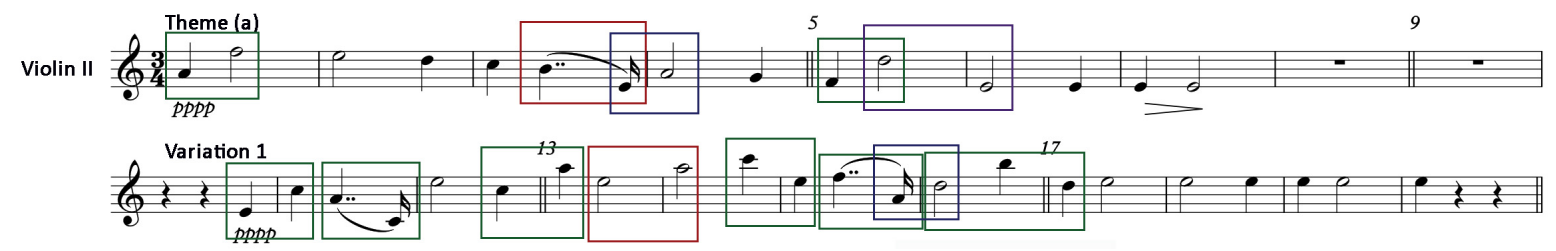

The first phrase of Variation 1 is dominated by leaps of a sixth, denoted by the green boxes, and generally eschews stepwise movement, except for the first two beats in bar 15. Like the initial theme in bars 1 through 7 , the variation has only a single interval of a fifth (red box, latter half of bar 13 and downbeat of bar 14) and a single interval of a seventh (purple box, last note of bar 15 and downbeat of bar 16). However, it introduces a second double-dotted crotchet/semi-quaver/minim figure in bars 15 and 16. In the second phrase of the statement, bars 17-20, the long-long-short-short pattern is also expanded by the repeated sounding of E5. For this variation Pärt also deviates slightly from the long-long-short-short pattern, substituting a crochet for the expected longer minim on the downbeat of bar 20. The eschewal of stepwise motion serves to 
fragment the melodic line, while the extension of the second half of the statement results in variation 1 being three bars longer in duration.

Figure 4.23: Festina Lente - violins II, theme and Variation 2

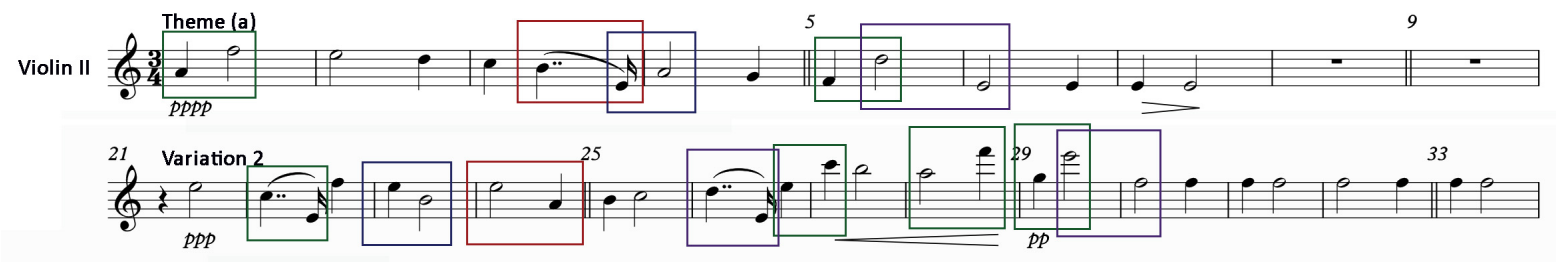

Variation 2 (Figure 4.23) has fewer intervals of a sixth, and again only one interval of a fifth (red box, bar 24). It also reintroduces an interval of a fourth in bar 23 (blue box), which was absent in Variation 1. While still retaining two double-dotted crotchet/semiquaver/minim figures (bars 22 and 26), the second occurrence of the figure leaps downwards by an interval of a seventh (purple box, bar 26), rather than the expected sixth. The variation also uses more stepwise motion: F4 to E4 in bars 22 and 23, A4-B4C4-D4 starting on the last beat of bar 24, and C5-B5-A5 in bars 27 and 28. This stepwise motion serves to obscure the pitch centre of the variation by emphasising $\mathrm{E}, \mathrm{B}$, and A before it finally settles on $\mathrm{F}$ in its last four bars (bars 30-33).

Figure 4.24: Festina Lente - violins II, theme and Variation 3

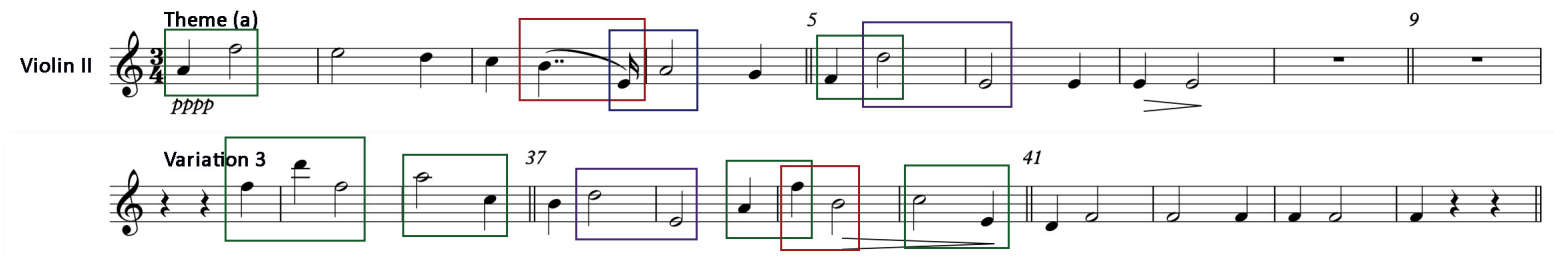

Variation 3 is more firmly grounded in F Lydian, emphasising pitch class $\mathrm{F}$ both at its beginning and its end (Figure 4.24). Variation 3 is also dominated by leaps of a sixth, and like the initial theme, demonstrates only one occurrence each of a fifth (bar 39) and a seventh (bars 37 and 38). Stepwise motion is also less prominent in Variation 3 than 
in Variation 2 (C4-B4 starting at the end of bar 36, and E3-D3 starting at the end of bar 40). In the second phrase of the variation, Pärt again truncates the repeated long-longshort-short pattern, substituting a crotchet in bar 43 rather than the expected minim.

Figure 4.25: Festina Lente - violins II, theme and Variation 4

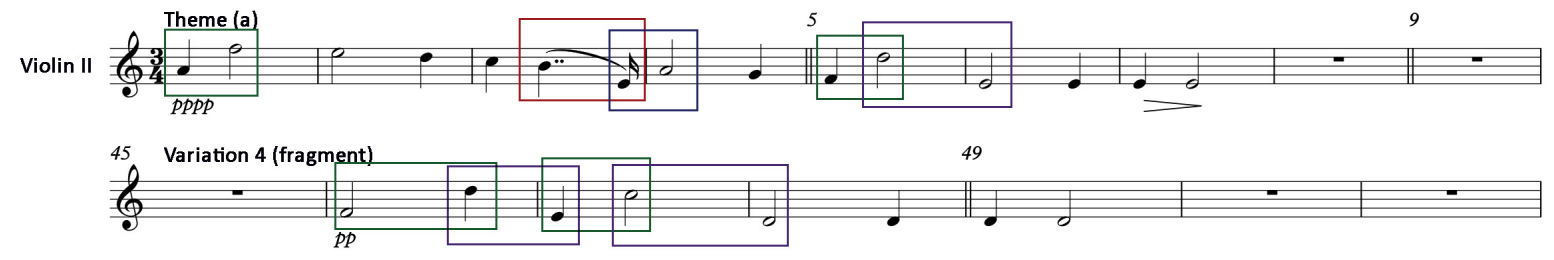

Compared to the original theme and Variations 1 through 3, Variation 4 (bars 46 through 49) is a mere fragment of the original melodic gesture, (Figure 4.25), comprising alternating upward leaps of a sixth (denoted by the two green boxes, bars 46 and 47) with downward leaps of a seventh (denoted by the two purple boxes, bars 46 and 47), and closing on repetitions of D3.

\section{Middle dimension}

Pärt subsequently repeats the above sequence of theme and variations three more times in the second violin line, though with each reoccurrence additional subtle modifications are introduced, which are labelled in the figures and table below as 'subvariations'. As illustrated in Figure 4.26, when the initial theme recurs in subsequent iterations, Pärt introduces an anacrusis on the third beat of the preceding measure. He also increases the length of the second phrase by adding an additional bar of repeated notes on E4 in sub-variation i (bars 58-60) and by two bars in sub-variation ii (bars 110-113). In bars 157-164, rather than presenting a third sub-variation, he repeats sub-variation i instead. 
Figure 4.26: Festina Lente - violins II, theme and sub-variations

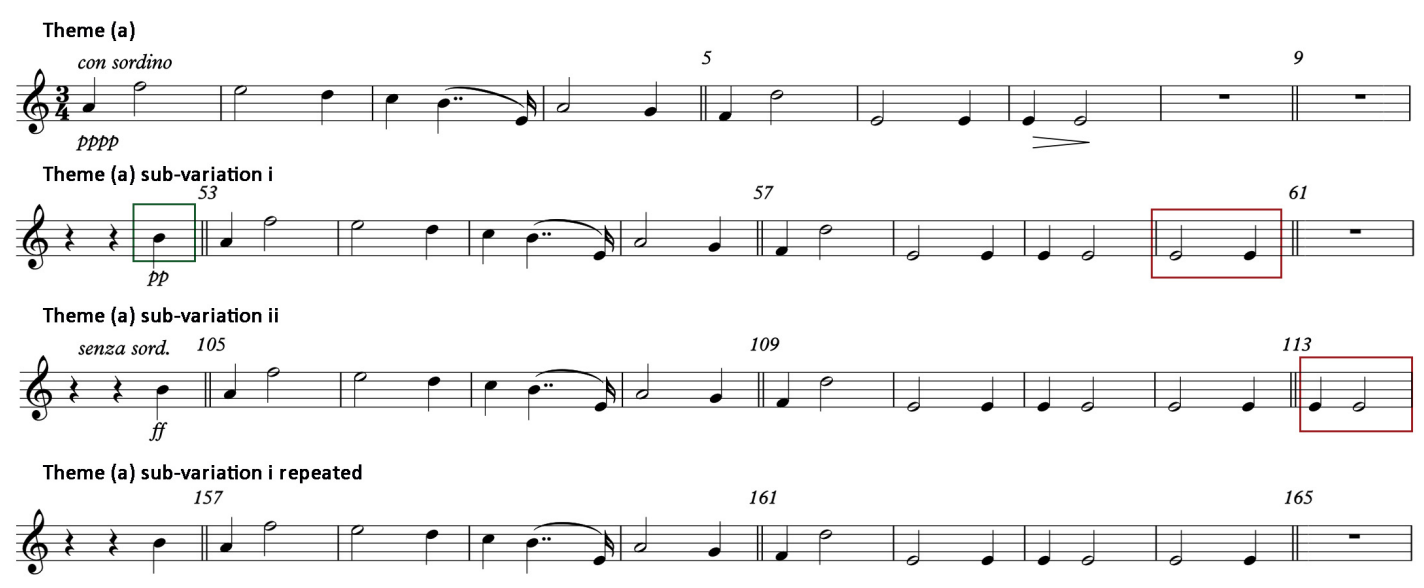

Similar subtle manipulations/sub-variations also take place when each of the initial variations recurs (e.g. 1 through 4, as described above and shown in Figure 4.18). In relation to Variation 1 sub-variation i (Figure 4.27 overleaf), Pärt reverses the pitch order in bar 66 from A5-C5 to C5-A5 (green box a). Instead of a leap of a sixth and back again, as seen in bars 16 and 17, the melody leaps by a seventh to $\mathrm{C} 5$ and then steps downwards to B5 (green box b bars 68-69). Pärt also 'corrects' his earlier modification of the end of long-long-short-short-long pattern on a reoccurring pitch in the second phrase by introducing the 'missing' minim at the beginning of bar 72 (red box c) Subvariation ii replicates sub-variation i until bar 120 when the melody leaps by a tenth to F5. The second statement of the sub-variation is also truncated ending on a crotchet rather than the expected minim. Sub-variation iii is in effect a repeat of sub-variation i, but with an even more truncated second statement. 

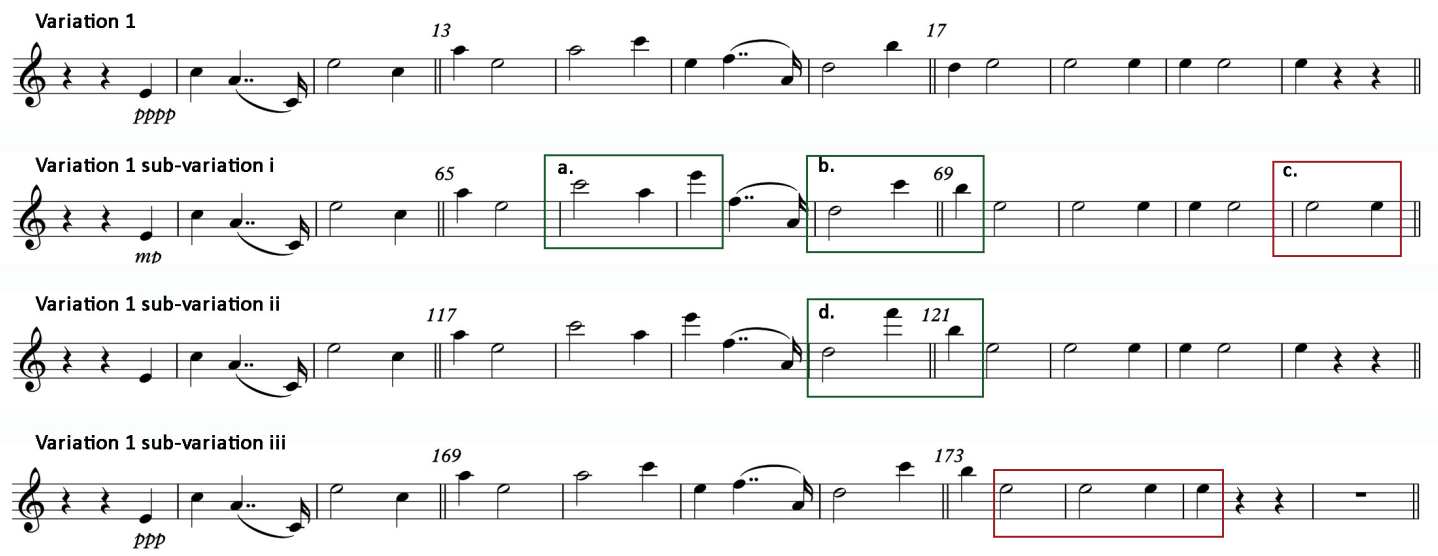

Similar subtle modifications of Variations 2, 3, and 4 are also deployed. In the second iteration of Variation 2 (Figure 4.28), Pärt reverses the expected pitch order from C4B4-A4 in bar 79 to A4-B4-C4 (green box a), while shortening the phrase of the statement (bars 81 through 84 ) by one bar. In its third iteration, the first phrase of subvariation ii is repeated verbatim, but the repetitions of F4 in the second phrase of the statement are truncated. In the variation's fourth and final iteration (sub-variation iii), rather than the expected leap of a fourth in bar 184, the melody leaps by a sixth to A6. In the second phrase of the sub-variation, the second violins alternate between repetitions of A4 and F4, rather than sounding F4 repeatedly as might be expected, based upon previous patterns.

Figure 4.28: Festina Lente - violins II, Variation 2 and sub-variations
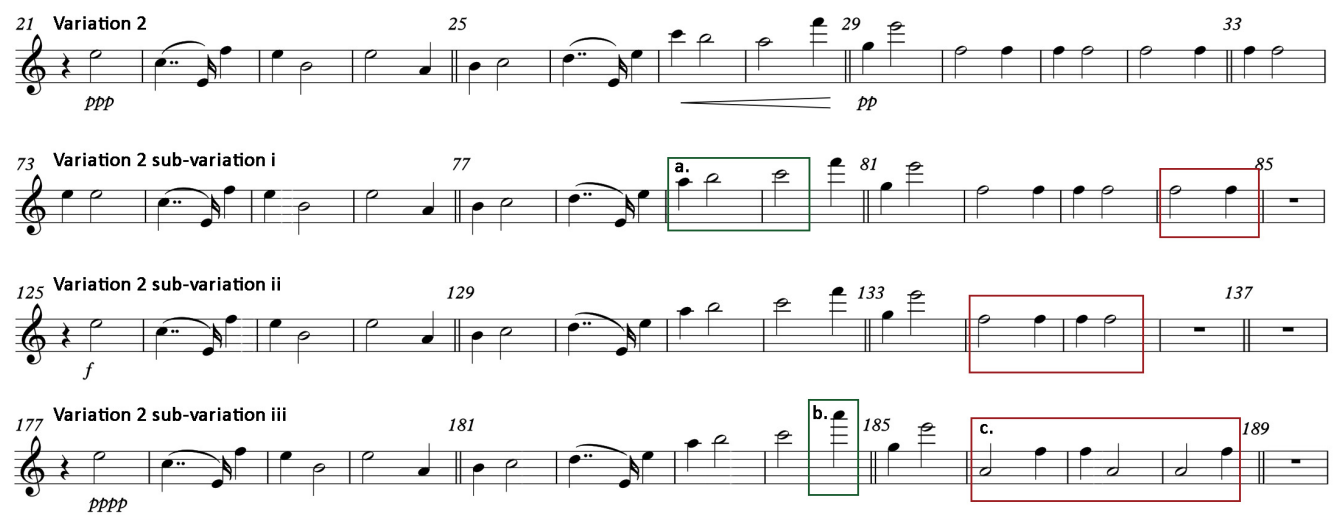
Both Variation 3 and Variation 4 (Figure 4.29 and Figure 4.30, respectively) occur only three times in the second violin line, rather than four times, as is the case for the original theme and Variations 1 and 2. Variation 3 and Variation 4 are also virtually unmodified in their sub-variations, other than the varying lengths of their respective second statements. For example, in the case of the sub-variation for Variation 3, only one pitch substitution/variation occurs. This is in bar 91, a downward leap of a third from F4 to D4, rather than the expected leap of a tritone to B4. In sub-variation i for Variation 4 (fragment) in Figure 4.30, the long-short-short-long pattern of the second phrase again alternates between two pitches (D3 and B4) in bars 100-102 (Figure 4.30), in a similar manner to that deployed in the second phrase of Variation 2 sub-variation iii as seen in Figure 4.28 above.

Figure 4.29: Festina Lente - violins II, Variation 3 and sub-variations

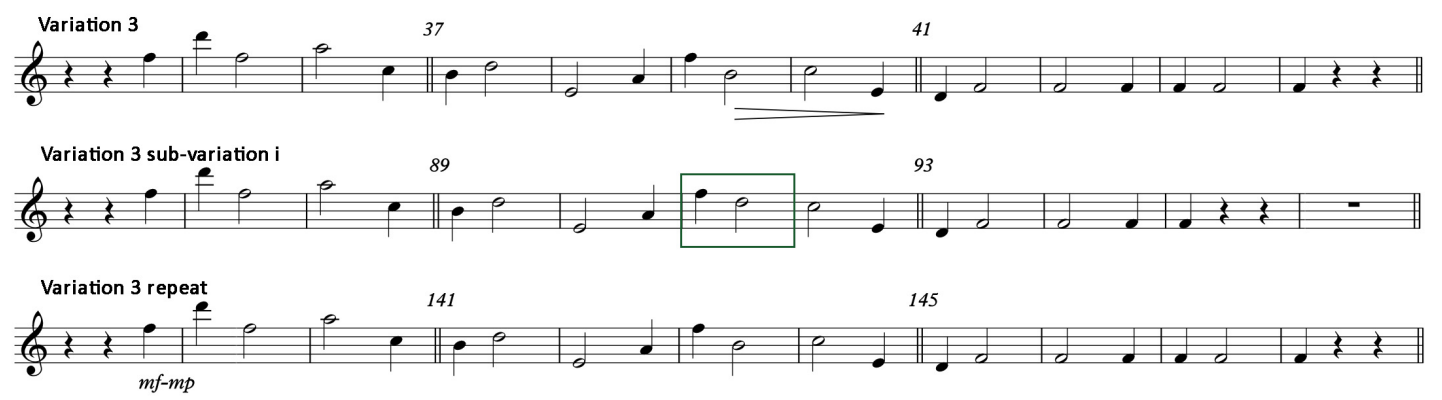

Figure 4.30: Festina Lente - violins II, Variation 4 (fragment) and sub-variations

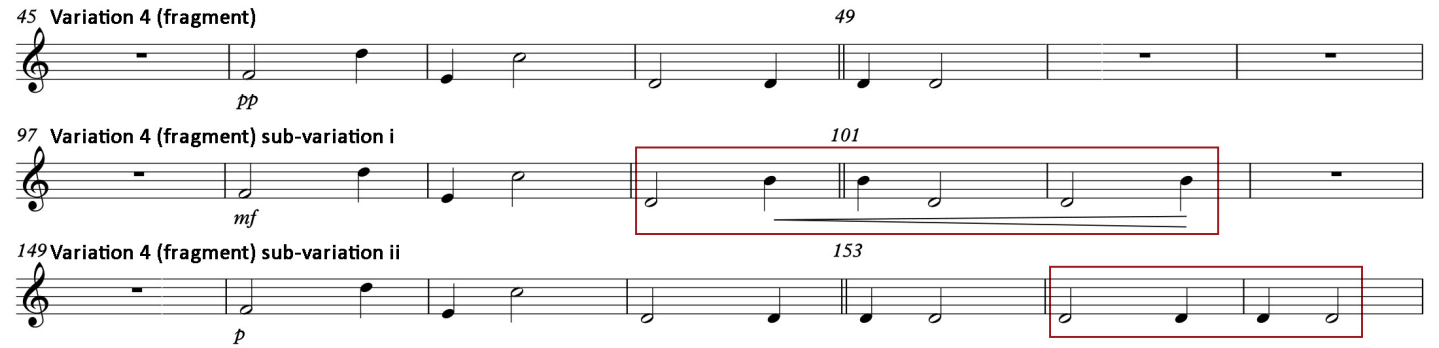


Table 4.7 provides an overview of the scheme of these variations and sub-variations as they apply to each of the different string sections in their entirety, with relevant bar numberings.

Table 4.7: Summary of deployment of theme a, Variations 1 through 4 and their respective sub-variations in Festina Lente

\begin{tabular}{|c|l|l|l|}
\hline & $\begin{array}{l}\text { 2nd violins (and 1st } \\
\text { violins periodically) }\end{array}$ & Violas & $\begin{array}{l}\text { Violoncellos and } \\
\text { Contrabasses }\end{array}$ \\
\hline Theme (a) & $\begin{array}{l}\text { Bars 1-7 } \\
\text { Bars 205-223 }\end{array}$ & $\begin{array}{l}\text { Bars 1-16 } \\
\text { Bars 205-223 }\end{array}$ & $\begin{array}{l}\text { Bars 1-28 } \\
\text { Bars 205-223 }\end{array}$ \\
\hline sub-variation i & $\begin{array}{l}\text { Bars 52-60 } \\
\text { Bars 56-164 }\end{array}$ & Bars 104-120 & \\
\hline sub-variation ii & Bars 104-113 & Bars 124-140 & \\
\hline Variation 1 & Bars 10-20 & & \\
\hline sub-variation i & Bars 62-72 & & Bars 39-78159 \\
\hline sub-variation ii & Bars 114-124 & & Bars 82-132 \\
\hline sub-variation iii & Bars 166-175 & Bars 20-39158 & \\
\hline sub-variation iv & & & Bars 41-66 \& \\
\hline sub-variation v & & Bars 145-168 & \\
\hline Variation 2 & Bars 21-33 & & \\
\hline sub-variation i & Bars 73-84 & Bars 91-98 & \\
\hline sub-variation ii & Bars 177-188 & & \\
\hline sub-variation iii & Bars 125-135 & & \\
\hline sub-variation iv & & & \\
\hline Variation 3 & Bars 34-44 & & \\
\hline sub-variation i & Bars 86-95 & & \\
\hline sub-variation ii & & Bars 46-49 & \\
\hline $\begin{array}{l}\text { Variation 4 } \\
\text { (fragment) }\end{array}$ & Bars 98-102 & & \\
\hline sub-variation i & Bars 150-155 & & \\
\hline sub-variation ii & & & \\
\hline
\end{tabular}

The above discussion illustrates the significant amount of retouching and modifications on Pärt's part to create Festina Lente's variations and sub-variations. ${ }^{161}$ Given this, it could be easily argued that, unlike Tabula Rasa, Festina Lente is not a mere playing out

\footnotetext{
158 Substitution of pitch class B for D in the viola line (bar 33), resulting in extension of an open tritone (B and F) for an additional two beats (Figure 4.33 overleaf), before resolving to an E7 no3 no5 chord.

159 Pitch alterations in both violoncello and contrabass lines (b1. and b2.), with additional alterations violoncello line only (shown as c and d).

${ }^{160}$ Second phrase of Variation3 sub-variation comprises repetitions of D0 in the contrabass line and alternations between and D1 and E1 in the violoncello line instead of repetitions of pitch class F as occurs in Variation 3 and its sub-variation i.

161 This 'retouching' has also been noted by Clarke in his previously cited review. Clarke, "Summa for String Quartet; Festina Lente, for String Orchestra and Harp Ad Libitum; Fratres for String Quartet; Freatres for String Orchestra and Percussion; Fratres for Violonello and Piano; Fratres for Violin and Piano by Arvo Pärt. Review by David Clarke."
} 
of a simple process that, once designed, is 'unleashed' by the composer and allowed to run its course as strictly constructed.

However, despite the many nuances introduced by Pärt in his modifications to the various sub-variations on the initial theme, it raises the question whether any of the above noted changes of pitch order, intervallic leaps, or modifications as to the number of bars of repeated pitches in the second phrase of each statement make any significant difference to what the listener actually discerns as the work progresses. Rather, are they merely artefacts of the compositional process, to be found only by a close examination of the score - artefacts, which in the end have little impact on the resulting sonic landscape of the work?

A further examination of the first phrase, as played out across the different variations and sub-variations, demonstrates that, in some cases, different sonorities and chordal progressions would have resulted had the composer not intervened in some manner. For example in bar 68 (Variation 1, sub-variation i) the substitution of C5 for B5 (Figure 4.31 below) results in the sonority $<101220>$ (Forte Code: 4-20, F maj ${ }^{7}$ ) and a chordal progression from an F6 chord on the second beat of the bar to $\mathrm{F} \mathrm{maj}{ }^{7}$ followed by Am $^{\text {add9 }}$ on the downbeat of bar 69.

Had the composer left the variation unmodified, the resulting sonority would have been $<211231>$ (Forte Code: 5-20, F maj7 w5 sharp11), with the pitches B in the second violins and $\mathrm{F}$ in the viola line forming a tritone. Pitches $\mathrm{B}$ and $\mathrm{C}$ in the second and first violins, respectively, would have introduced an additional minor second to the chord, and the interaction between B and A in the second violins and violoncellos, respectively, would have introduced a major second to the sonority (an interval that, like the tritone, is absent from the retouched sonority <101220>). This is not to say that Pärt regularly 
eschews the more 'dissonant' sonorities such as the tritone, minor seconds and major seconds in Festina Lente, as such dissonant intervals do occur in the piece. As evidenced later in the chapter when the various interval vectors that comprise the work are examined, when compared to Cantus, Festina Lente not only encompasses a greater number of interval vectors, but also a greater variety of vectors that include the more dissonant intervals of the tritone, minor seconds and major seconds.

Figure 4.31: Festina Lente - violins II, Variation 1 and sub-variations

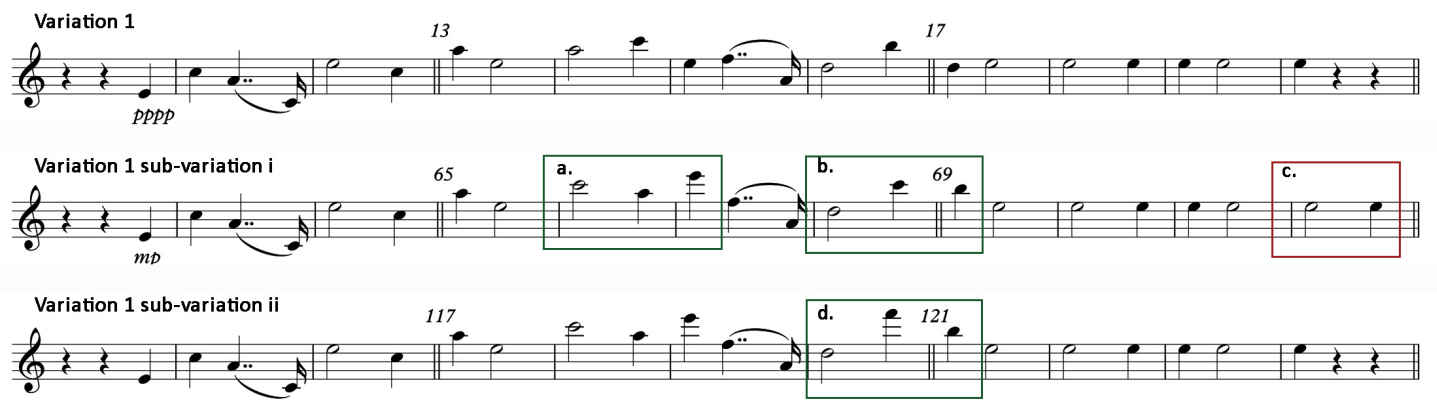

In contrast to the above interventions - to apparently avoid a particularly dissonant moment in passing, Pärt's choice of F5 over C5 in bar 120 (Variation 1 sub-variation ii) would appear at first glance to have no impact on the resulting sonority <122230> (Forte Code: 5-27, F maj ${ }^{13 t h}$ ) in that both pitch classes $\mathrm{F}$ and $\mathrm{C}$ are already present in one or more of the other orchestral lines at that moment in the music. However, had he opted in bar 120 to retain the B initially introduced in Variation 1 (bar 16) at the expense of dropping pitch class D (a pitch class that had been present in both beats 1 and 2 of the bar) (see b and a, respectively, Figure 4.32 overleaf), the sonority would have changed from $<122230>$ (Forte Code: 5-27, F maj13) ${ }^{162}$ to $<211231>$ (Forte Code: 5-20, F maj13\#11).

162 The resulting chord also could be harmonically interpreted as a $\mathrm{Dm}^{9 \text { th }}$ chord, had pitch class F not been so predominant among the other orchestral lines. 
While either of these chords could subsequently progress to $\mathrm{F}^{\mathrm{b} 5}$ (Forte Code: 3-8, $<010101>$ ) on the downbeat of bar 121 with relative aural success (Figure 4.32), the composer appears to have again opted to avoid introducing the tritone relationship between pitch classes $\mathrm{F}$ and $\mathrm{B}$ in the last beat of bar 120, as well as to avoid the addition of another minor second (between the pitch classes B and C) into the harmony, at the expense of the major second between pitch classes D and C.

Figure 4.32: Festina Lente - bars 120 and 121 (with alternative possible voicing shown as b)
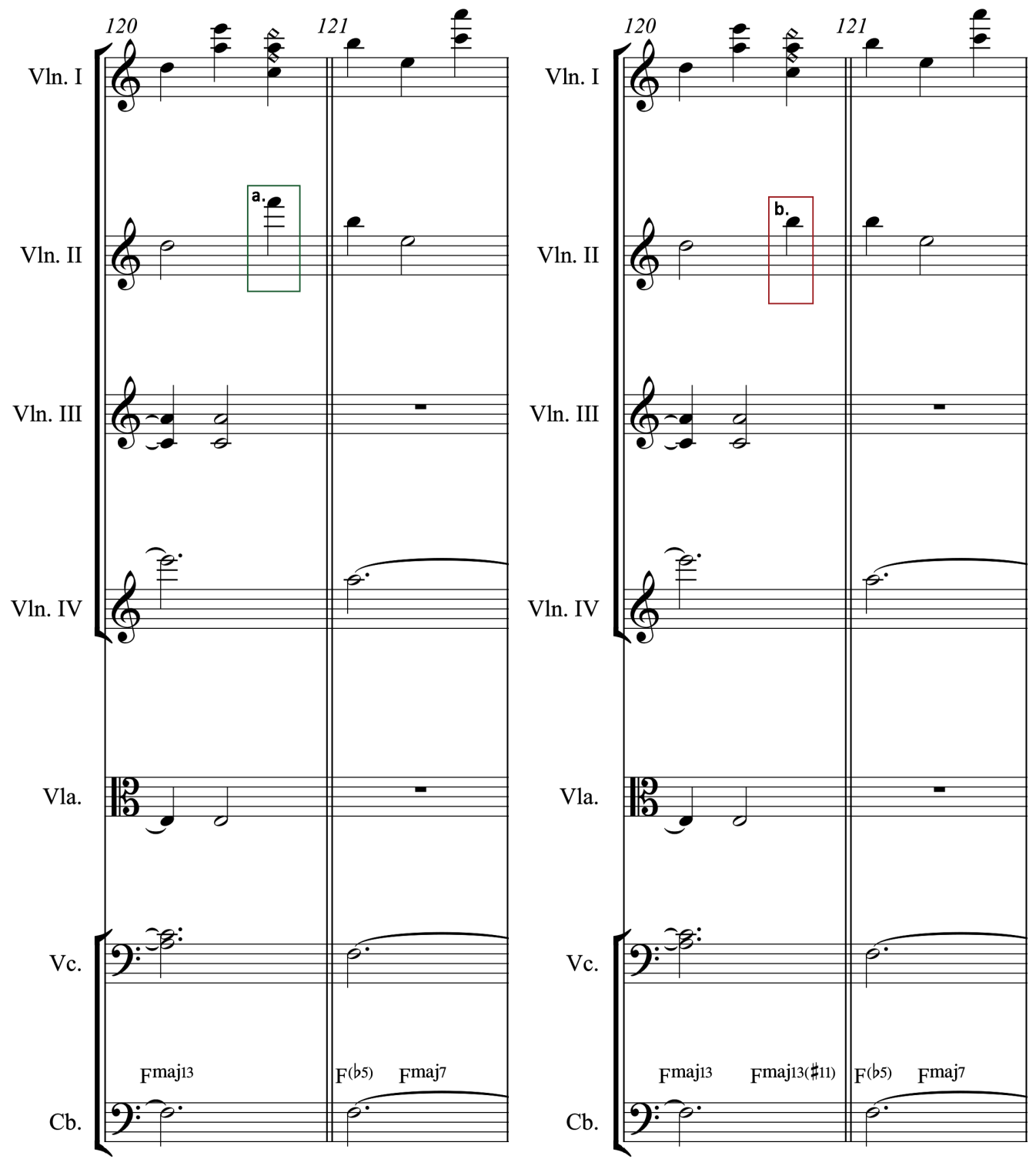
Figure 4.33 at the end of this section details the additional sub-variations that appear in the viola, violoncello, and contrabass lines in respect to Variation $1 .{ }^{163}$ In addition, a further modification to Variation 3 (sub-variation ii) occurs in the violoncellos and contrabass lines in the second phrase of the variation (see bars 161-174 in Figure 4.34), with the two contrabasses sounding repetitions of D0, while the violoncellos alternate between D1 and E1.

163 In order to facilitate comparison with the original variation, the additional sub-variations in the viola, violoncello, and contrabasses have been transposed to the treble clef and their mensuration has been reduced to the same temporal scale as that of the second violins. 
Figure 4.33: Festina Lente - Variation 1 and sub-variations iv (violas transposed and mensurally transformed) and $v$ (violoncellos and contrabasses transposed and mensurally transformed)
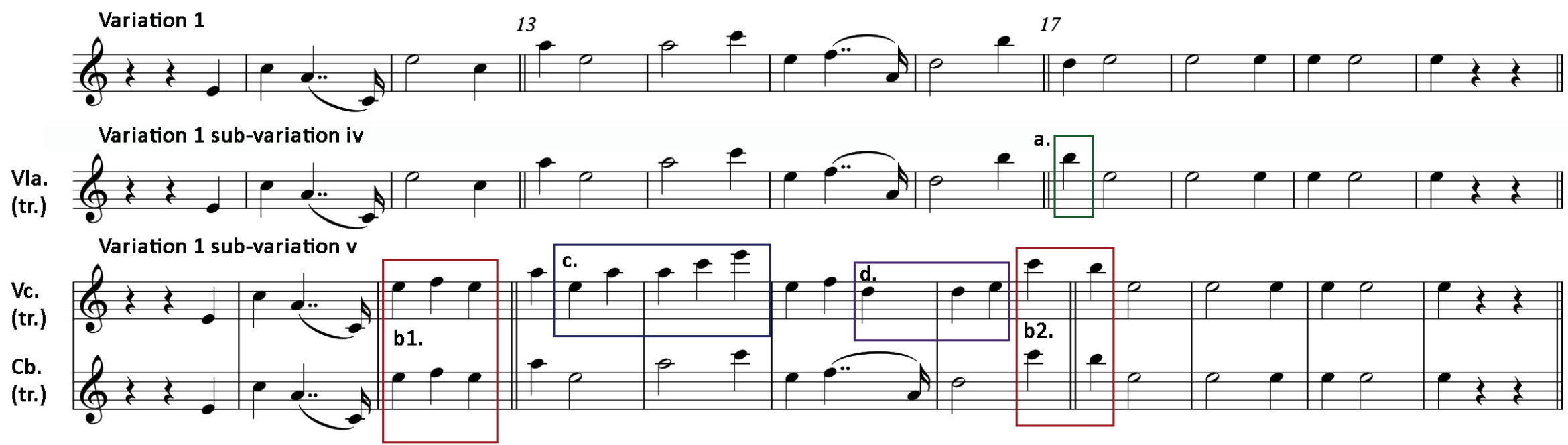

Figure 4.34: Festina Lente - Variation 3 sub-variations ii, phrase ii - violoncellos and contrabasses (bars 161-174)

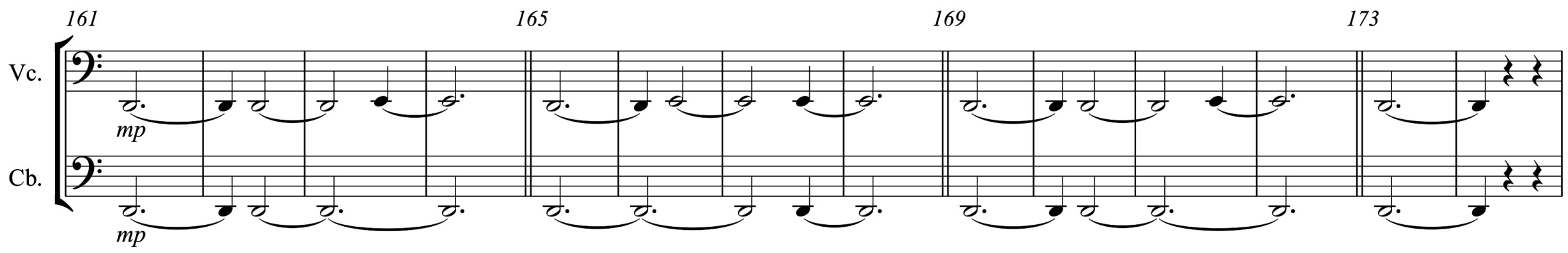




\section{Small dimension - T-voice functions}

As with Cantus, the main key features of the small dimension of Festina Lente relate to the work's primary rhythmic scheme and secondary rhythmic motive (noted earlier and shown again below in Figure 4.35 for reference) and the deployment of additional Tvoice functions throughout the different string instrumental lines.

Figure 4.35: Festina Lente - primary rhythmic scheme (and secondary rhythmic motive)

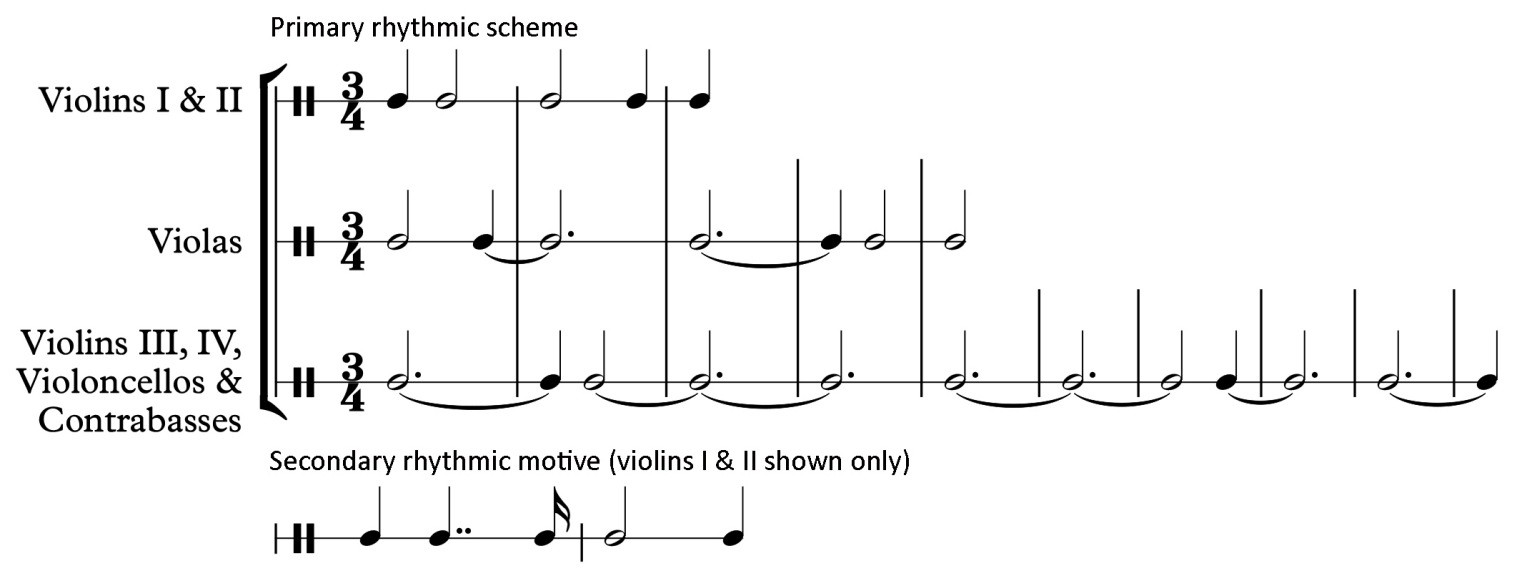

The third important small-dimensional aspect is how the composer has deployed these additional T-voice functions. Rather than relying on just one T-voice position (e.g. first position, inferior, as was the case in Cantus), for Festina Lente Pärt opted to use three of the four possible M-voice/T-voice positions that apply to an A Aeolian scale paired with a minor triad: first and second position, superior as well as first position, inferior (Figure 4.36 overleaf). 
Figure 4.36: Interval classes generated by an A minor triad and an A Aeolian (natural minor) scale, 1st and $2^{\text {nd }}$ position, superior and $1^{\text {st }}$ position, inferior

1st position, superior - A aeolian triad

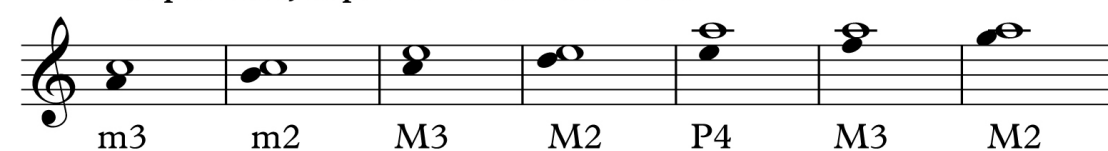

\begin{tabular}{l|l|l|l|l|l|l|}
\cline { 2 - 6 } interval class & 1 & 2 & 3 & 4 & 5 & 6 \\
\cline { 2 - 7 } occurrences & $\mathbf{1}$ & $\mathbf{2}$ & $\mathbf{1}$ & $\mathbf{2}$ & $\mathbf{1}$ & $\mathbf{0}$ \\
\cline { 2 - 6 } & & & &
\end{tabular}

2nd position, superior - A aeolian triad

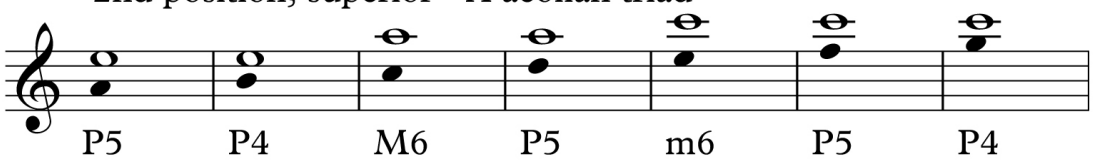

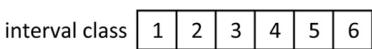

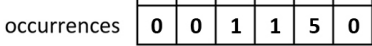

1st position, inferior - A aeolian triad

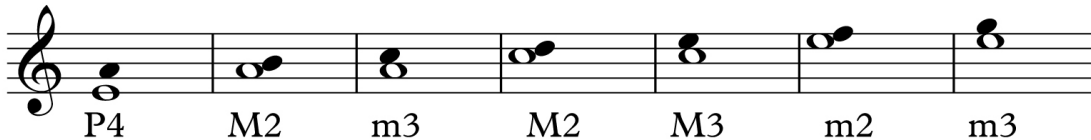

\begin{tabular}{l|l|l|l|l|l|l|}
\cline { 2 - 6 } interval class & 1 & 2 & 3 & 4 & 5 & 6 \\
\cline { 2 - 7 } occurrences & $\mathbf{1}$ & $\mathbf{2}$ & $\mathbf{2}$ & $\mathbf{1}$ & $\mathbf{1}$ & $\mathbf{0}$
\end{tabular}

The use of multiple T-voice positions introduces a greater degree of variety, in relation to the order that intervals occur, than would happen from the use of a single T-voice position. The manner in which Pärt deploys these different T-voice functions concurrently in the different instrumental lines of Festina Lente is discussed in detail below.

\section{First violins}

As noted previously, the first 45 bars of the work Festina Lente have only one true Tvoice, played by the third and fourth violin lines in first position, superior to M-voice 3 in the violoncello and contrabass lines. As the work proceeds, Pärt introduces additional T-voice functions, though these do not adhere to the strict application of the M-voice/Tvoice rules as codified by Hillier. ${ }^{164}$ Starting at bar 45 , after the first and second violins have presented the main theme and all four variations, the first violin line begins to 'fragment', alternating between playing the melody in unison with the second violins

\footnotetext{
${ }^{164}$ In his monograph Hillier notes, "the T-voice is fitted to [its M-voice] in a relationship that is never casual, but is ruled by a single principle which can function in various ways: the tintinnabuli note is always a note in the triad (other than a unison or octave) related in some specific and consistent way to the melodic note. Once a particular relationship has been chosen, it is adhered to consistently." Hillier, Arvo Pärt, 93-94. However, the manner in which Pärt deploys some of the T-voices in Festina Lente would appear to contradict Hillier's position.
} 
and executing a hybrid T-voice that floats between first and second position, superior, as well as first position, inferior.

For example, as shown in Figure 4.37 overleaf, the T-voice in the first violins is triggered in response to when either a minim or dotted crotchet occurs in the second violins' melody and the entrance of the T-voice is staggered by one beat in relation to the Mvoice's note. When the minim in the second violins' melody falls on the second beat of the measure, the first violins sound a crotchet-long single T-voice pitch one beat later (denoted in Figure 4.37 by the green ellipses labelled a - see bars 47,49 and). This is also the case when the second violins play a dotted crotchet, which always occurs on the second beat of the bar (denoted in Figure 4.37 by the blue ellipses labelled $\mathrm{c}$ in bars 55 and 67). As indicated in the figure, the first violins' T-voice pitches do not function in a prescribed position relative to the M-voice pitch. In bars 47,49 , and 53 , the T-voice pitches are in first position, superior to their respective M-voice pitches in the second violins. In bar 55, the T-voice pitch $\mathrm{C} 5$ occurs in first position, inferior to D5 in the second violins line. In bars 65, 69, and 71 the T-voice pitches occur in second position, superior to their respective M-voice pitches. 
Figure 4.37: Festina Lente - violins I and II (bars 41-64)

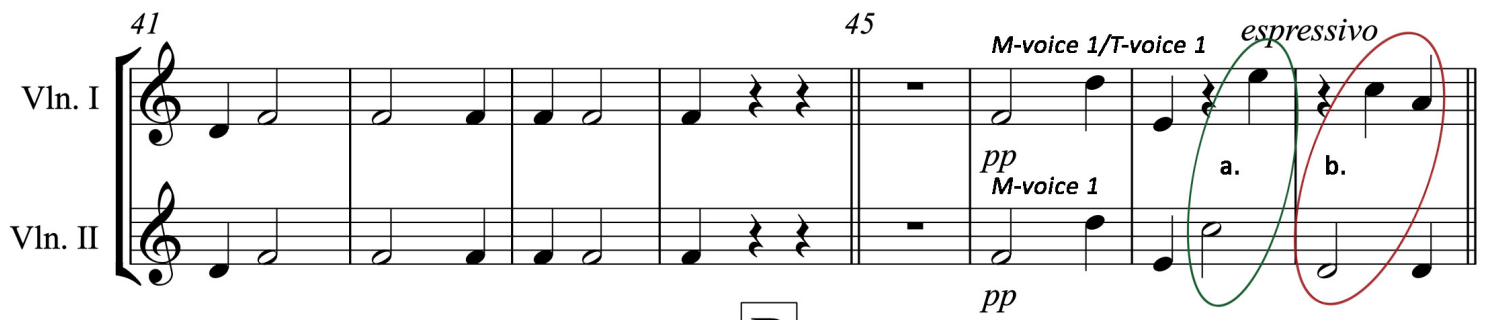

$\frac{B}{53}$
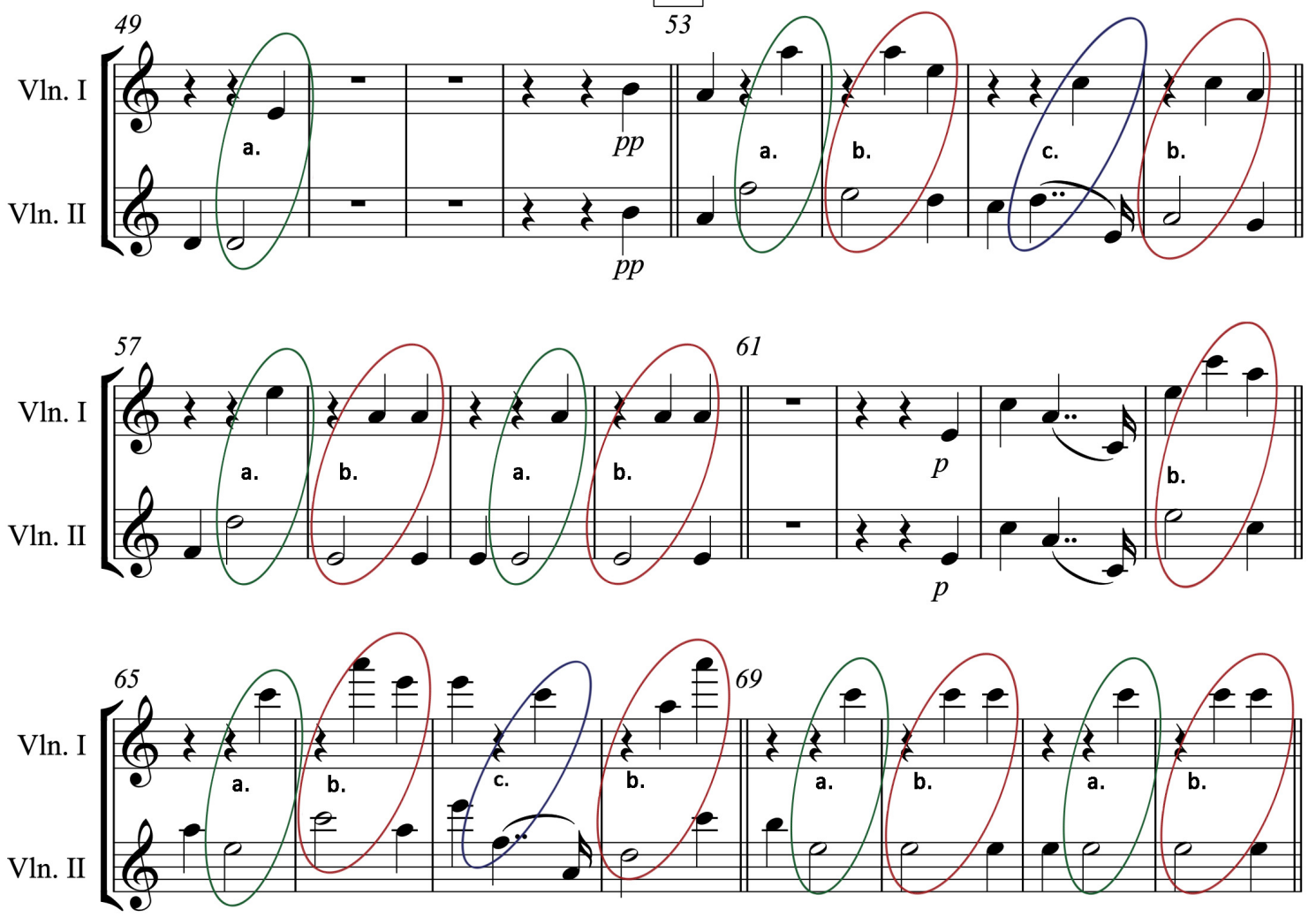

An additional T-voice function occurs in the first violins line as well, when the minim in the second violins falls on the first beat of the bar. When this is the case, the first violins sound two pitches of the T-voice triad on the second and third beat of the bar (denoted in the figure by the red circles labelled b, e.g. bar 49 , bar 54 , and bar 58). If the second violins are playing the first phrase of the main theme or one of its variations, as occurs in bars 47, 48, and 53-56, the second T-voice pitch of each b figuration will be on a different pitch of the triad from that preceding it - moving downwards (e.g. bars 48, 56, and 64) or upwards (e.g. bar 68) through the triad in the same direction as the melody in the second violins. If, however, the second violins are playing the second phrase of 
the theme or one of its variations, the first violins will continue to sound the same pitch of the T-voice triad until the end of the second phrase. ${ }^{165}$ This pattern continues until bar 87, when the T-voice function in the first violins expands to include two pitches of the triad (Figure 4.38), with the first violins alternating between playing in unison when playing the same pitches as the second violins M-voice, and playing divisi when functioning as T-voice 1.

Figure 4.38: Festina Lente - violins I and II (bars 81-96)
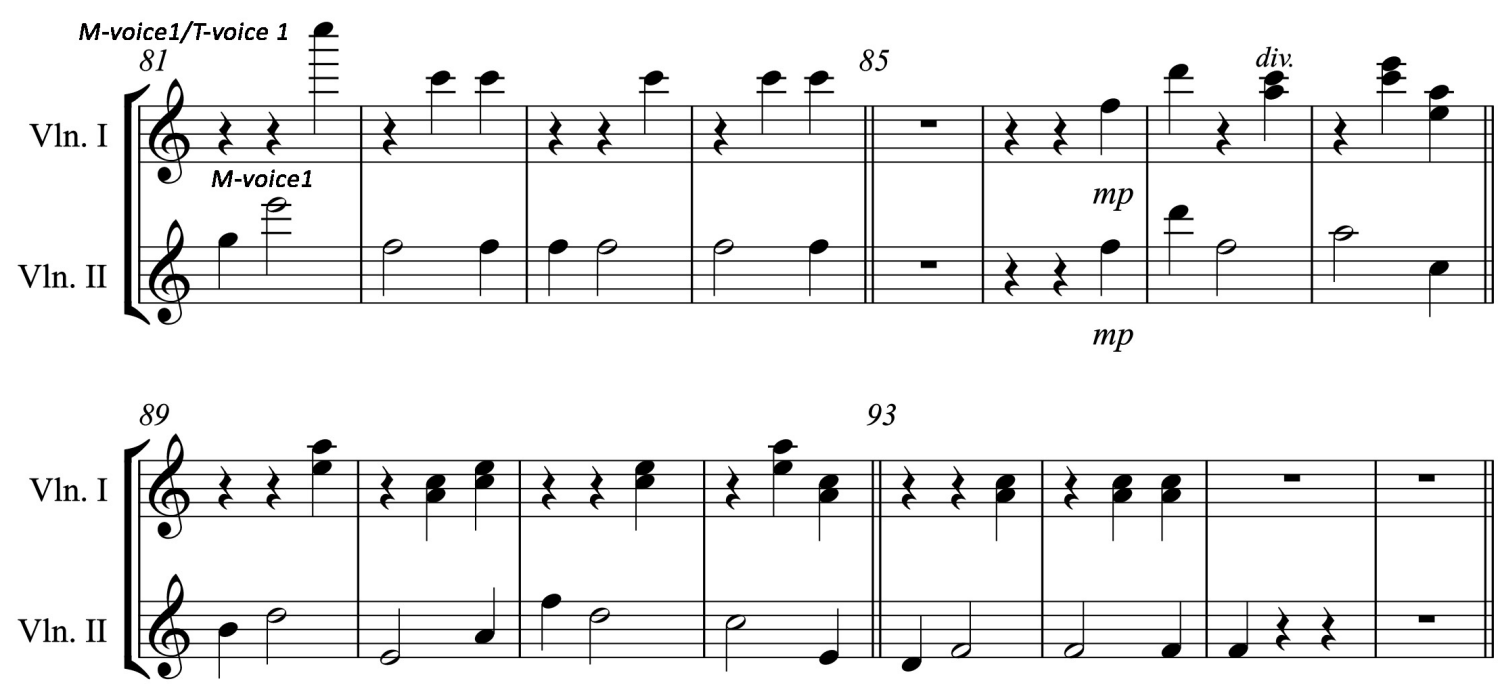

At the outset, the two T-voice pitches are either a third or a fourth apart (i.e. the upper pitch is in first position, superior to the lower T-voice pitch). However, starting in bar 105, Pärt shifts the upper T-voice pitch to second position, superior sounding a fifth or a sixth above the lower T-voice pitch. This is illustrated in Figure 4.39 overleaf. This practice continues through bar 123 , after which the first violins' T-voice function returns to playing a single $\mathrm{T}$-voice pitch in response to a minim or dotted crotchet in the second violin line.

165 Examples of this can be found in bars 58-60 and 69-72. 


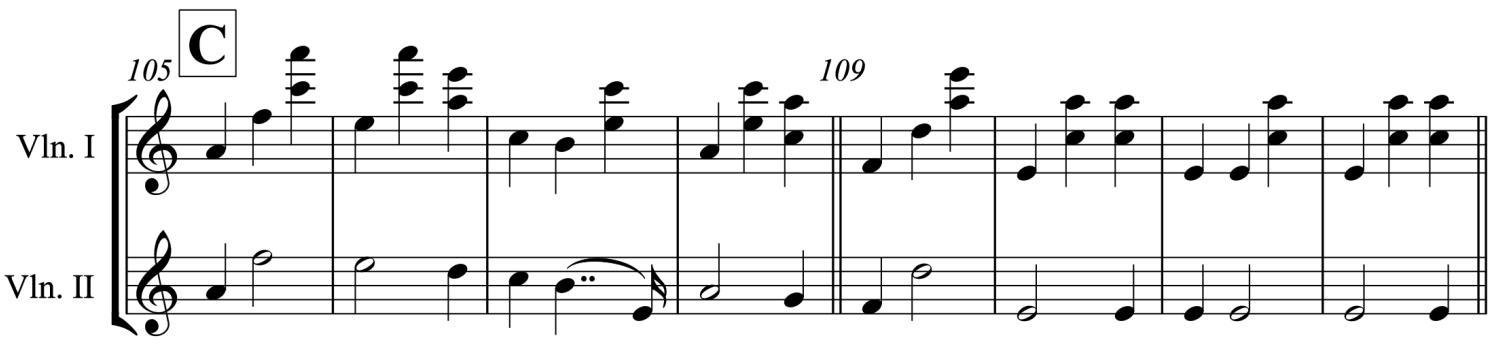

\section{Violoncellos and Violins IV}

Starting in bar 46, Pärt introduces a T-voice function in the violoncellos that, along the lines described above for the first violins, results in the violoncellos alternating between playing in unison with the contrabasses' M-voice and taking a first position, superior Tvoice to the contrabasses (Figure 4.40). As with the first violins, this occurs in a staggered manner, when the contrabass line plays a 'long' melodic note (i.e. two tied dotted minims tied to a third minim). When this happens, the violoncellos play in unison with the contrabasses for the first four beats of the long pitch, before shifting to a first position, superior T-voice relationship for four beats, as denoted by green bubbles labelled a (see bars 45-47, 49-51, and 53-55 in Figure 4.40). The violoncellos continue to function as a T-voice playing a note that is the same duration as that in the contrabass (as denoted by the red ellipses and labelled b, e.g. bars 47-48) until the next 'long' duration note in the contrabasses occurs. 
Figure 4.40: Festina Lente - violins IV, violoncellos and contrabasses (bars 41-55)
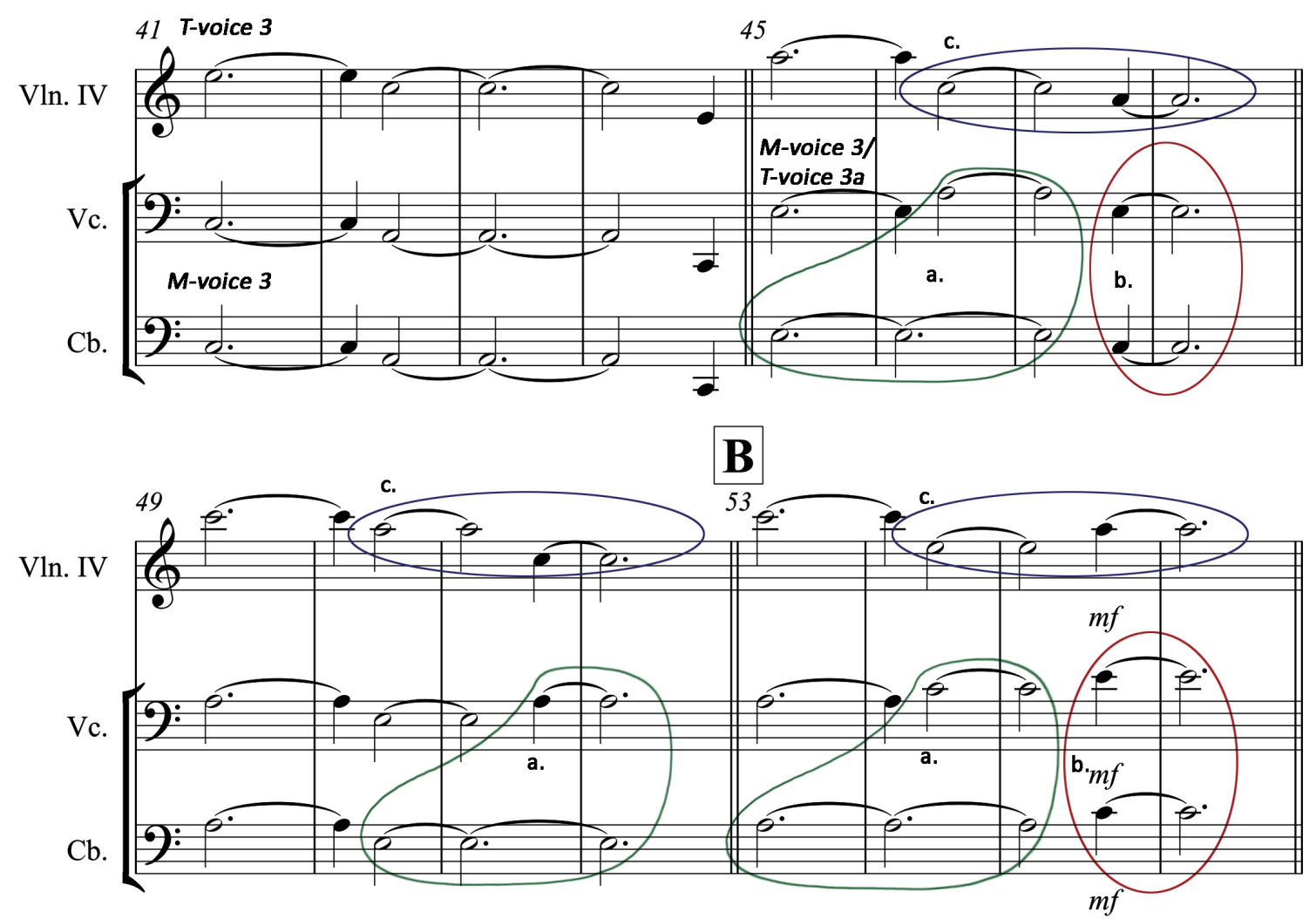

Starting in bar 46 another T-voice function is introduced in the fourth violin line (shown as T-voice 3a), alternating between second and first position, superior to the violoncellos, depending upon whether the violoncellos are functioning as part of Mvoice 3 or T-voice $3 \mathrm{a}$.

As was the case for the first violins, starting in bar 91, the violoncellos' T-voice starts to fracture and begins to play two pitches of the T-voice triad divisi in first and second position, superior to the contrabass line (Figure 4.41 overleaf). In order to avoid a 'doubling-up' with the T-voice function in the violoncellos, the fourth violins T-voice shifts up to the next superior pitch (see bars 91-92 and 95-96), resulting in the pitches of the A-minor triad being distributed across the violoncello and the fourth violins. 
Figure 4.41: Festina Lente - violins IV, violoncellos and contrabasses (bars 89-96)

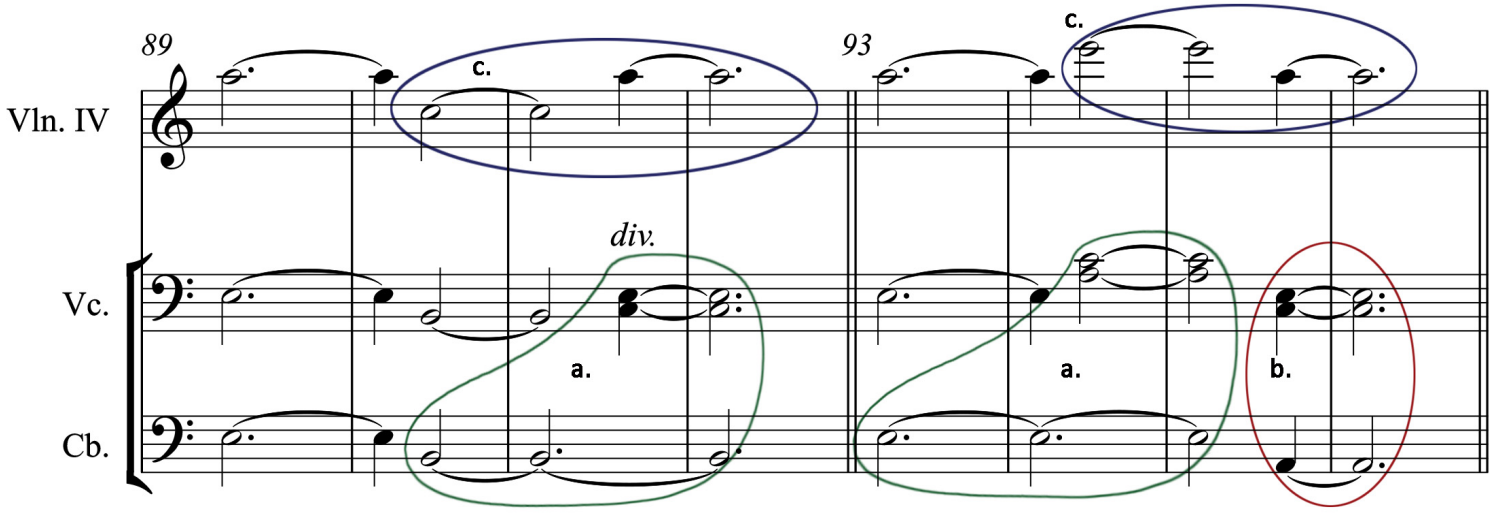

Violins III

Starting in bar 46, the third violin line, which started out playing T-voice 3 in unison with the fourth violin line (bars 1 through 28), takes on its own hybrid T-voice function (T-voice 2) in response to the violas' melody (M-voice 2). As was shown in relation to the other hybrid T-voices, the third violins' T-voice 3 reacts to the viola line's M-voice in a staggered fashion. In this case, the T-voice occurs in first position, superior, with the third violins sounding a minim, two beats after the viola line plays a 'long' pitch of four beats in duration (e.g. bar 46 and bars 47-48, Figure 4.42).

Figure 4.42: Festina Lente - violins III and violas (bars 45-52)

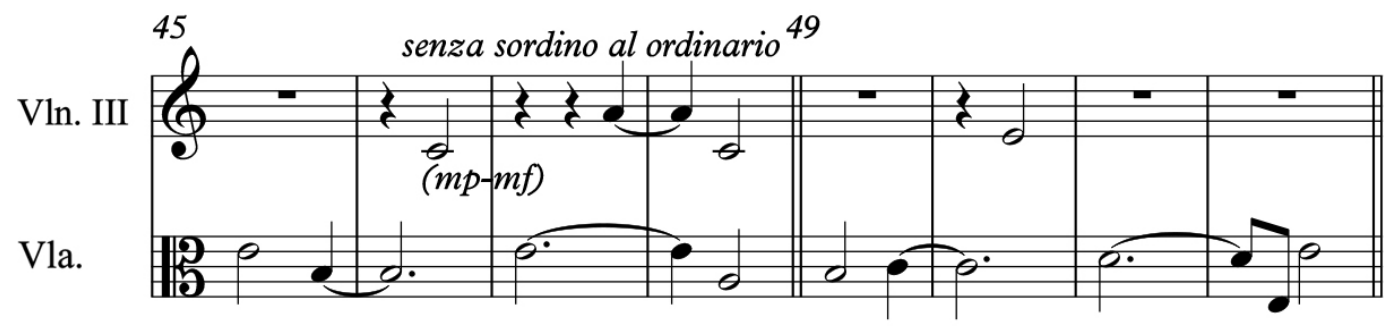

When the violas subsequently play a pitch of two beats in duration (i.e. a minim) following a long note of four beats in duration, the third violins sound a first position, superior T-voice concurrently as well (e.g. the latter part of bar 48 in Figure 4.42). This is then followed by one or more rests, until the violas play the next four-beat note of the 
melody. This arrangement continues until bar 94 (Figure 4.43), when the third violins' T-voice 3 function expands to include two pitches of the T-voice triad as well.

Figure 4.43: Festina Lente - violins III and violas (bars 93-100)

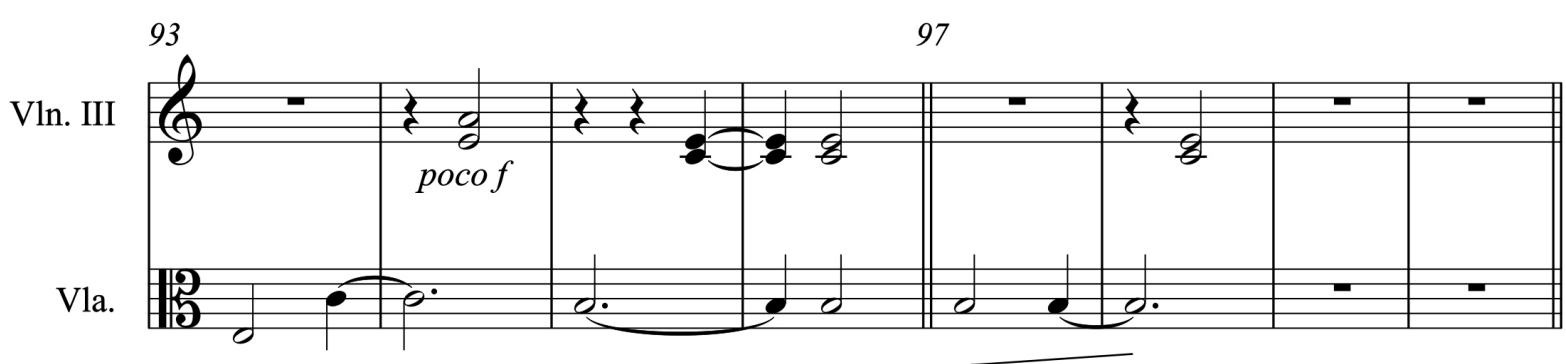

The third variation that Pärt introduces to the third violins' T-voice 3 function commences in bar 104 (Figure 4.44). After briefly playing in unison with the fourth violins in bars 102 through the downbeat of bar 104 (not shown), the third violins commence alternating between playing in unison with the violas' M-voice, (denoted by the green boxes labelled a1. through a4.) and sounding two pitches of the T-voice triad in first position, superior and first position, inferior to the pitch occurring in the violas' line.

Figure 4.44: Festina Lente - violins III and violas (bars 104-112)

Vln. III

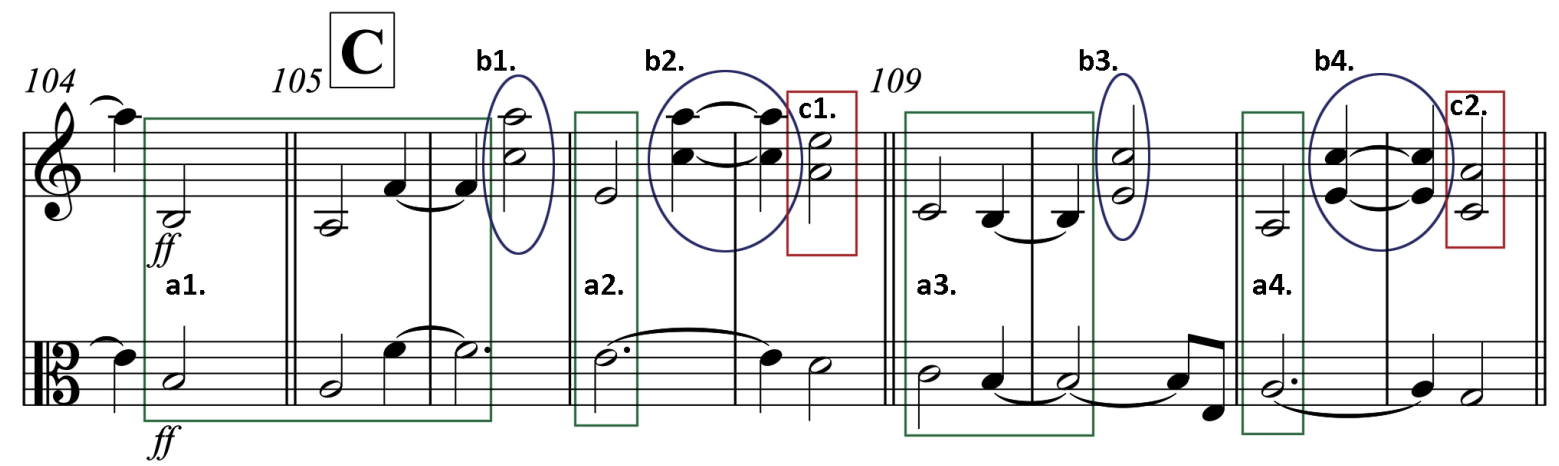

As before, the shift to a T-voice function occurs two beats after the violas play a full 'long' note of four beats in duration (e.g. bar 106), with the violins sounding T-voice pitches for a duration of a minim (denoted by the blue ovals, labelled b1. through b4). If the violas play a 'short' duration note (one minim) immediately after a long duration 
note, the third violins continue functioning as a T-voice (e.g. the end of bars 108 and 112 , as denoted by the red boxes labelled c1. and c2.). When the violas proceed to the second short note in the long-long-short-short pattern, the third violins play in unison with the violas until the next long duration pitch occurs in the viola line.

The preceding discussion has neglected the harp ad libitum. Throughout Festina Lente the harp periodically plays one or more pitches that occur above it in the string lines. Despite the score noting that the harp is to be played ad libitum, i.e. at the musician's discretion/pleasure, Pärt indicates in the score where this should occur (e.g. on the second beat of the second bar and the downbeat of the fifth bar of each eight-bar grouping) and what notes should be played. The only 'choice' that appears to be left to the discretion of the harpist is whether to repeat the same notes again in the latter part of the next measure (Figure 4.45). While for the most part the harp's pitches mirror those played directly above it in the violoncello and contrabass lines, as the work proceeds, additional pitches occurring in the viola or one or more of the violin lines are also played by the harp.

Figure 4.45: Festina Lente - violoncellos, contrabasses and harp (bars 1-8)

\section{$\mathbf{A}$}

ord.

5
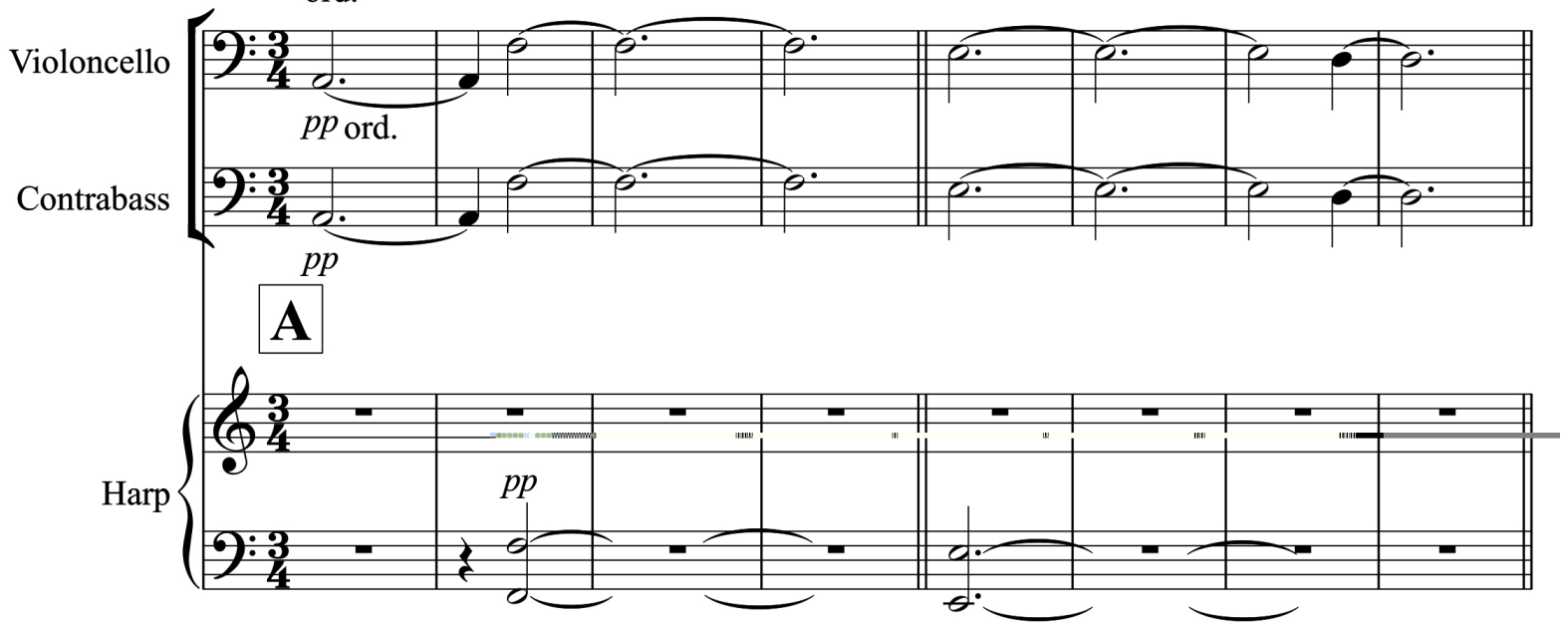


\section{Interval class analysis and sonority mappings of Festina Lente}

The following section of this chapter builds on the preceding style analysis of Festina Lente, by examining: 1) the intervallic content that arises as a result of the various processes and procedures occurring in the movement, and 2) sonority mappings of this content, which detail the relative density of musical sonorities throughout the work.

As noted previously, while the mode of the melodic lines of Festina Lente can be interpreted in a number of ways, the work uses the same pitch class set as that used in Cantus and Ludus, the first movement of Tabula Rasa - an A Aeolian scale (A, B, C, D, E, F, and $\mathrm{G}$ ), and $\mathrm{A}$ minor triad $\mathrm{T}$-voice functions. The resulting Interval Class Vector $<254361>$ (Forte Code: 7-35) contains two minor seconds, five major seconds, four minor thirds, three major thirds, six perfect fourths, and one tritone. These intervallic relationships are illustrated in the Pärtian Tonnetz in Figure 4.46. 
Figure 4.46: Pärtian Tonnetz - M-voice/T-voice pitch class interrelationships in Festina Lente

T-voice/M-voice Relationships Festina Lente

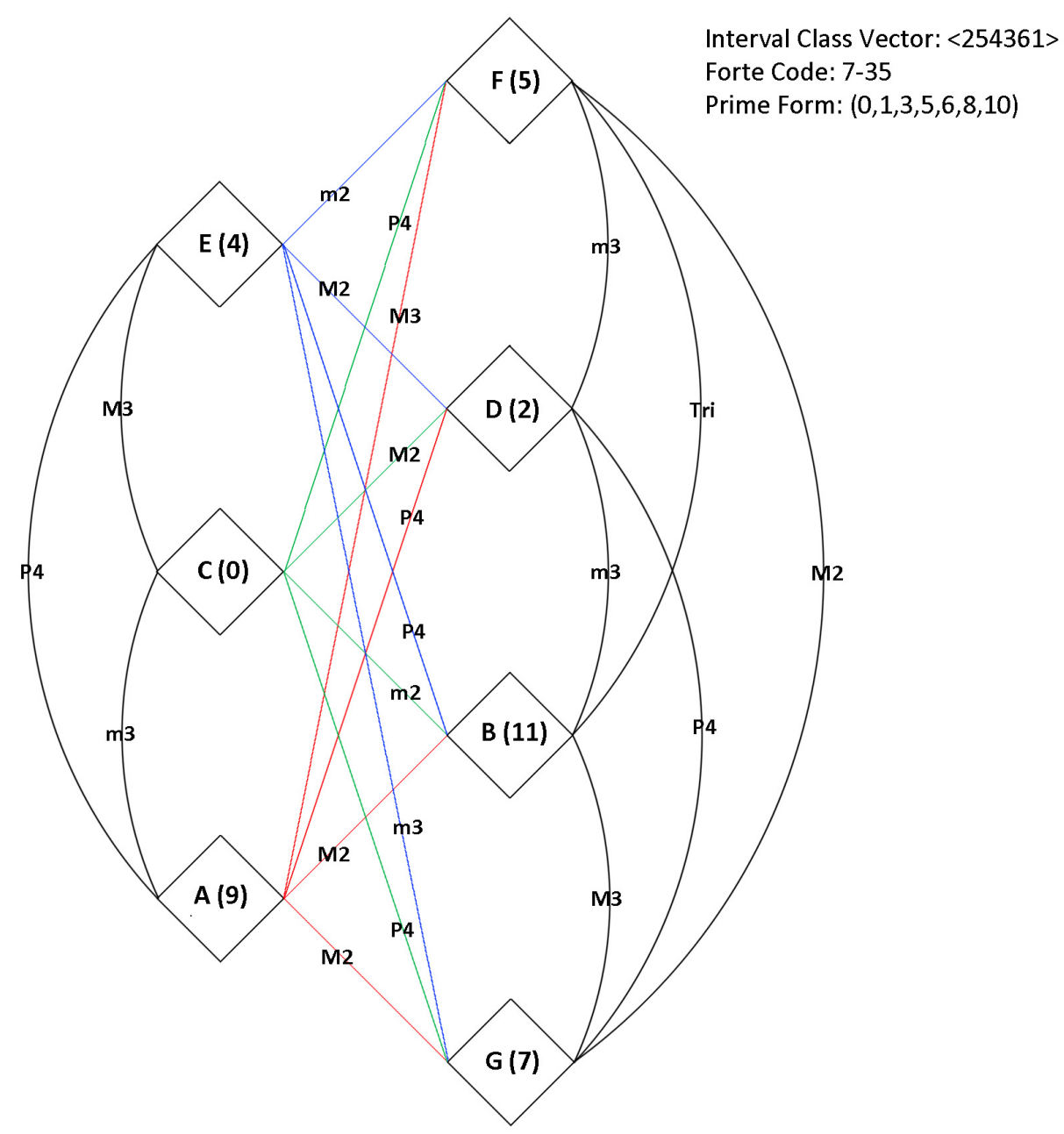

Table 4.8 overleaf details the interval vectors that occur in the first 16 bars of Festina Lente. While the downbeat of the work opens in A minor, the chordal sonorities immediately shift to various permutations of $\mathrm{F}$ major chords, starting on the second beat of bar 1 , and briefly slip in and out of D minor as pitch class $\mathrm{C}$ disappears, reappears and disappears again in subsequent bars. 
Table 4.8: Interval vectors and chords, Festina Lente - bars 7 through 12

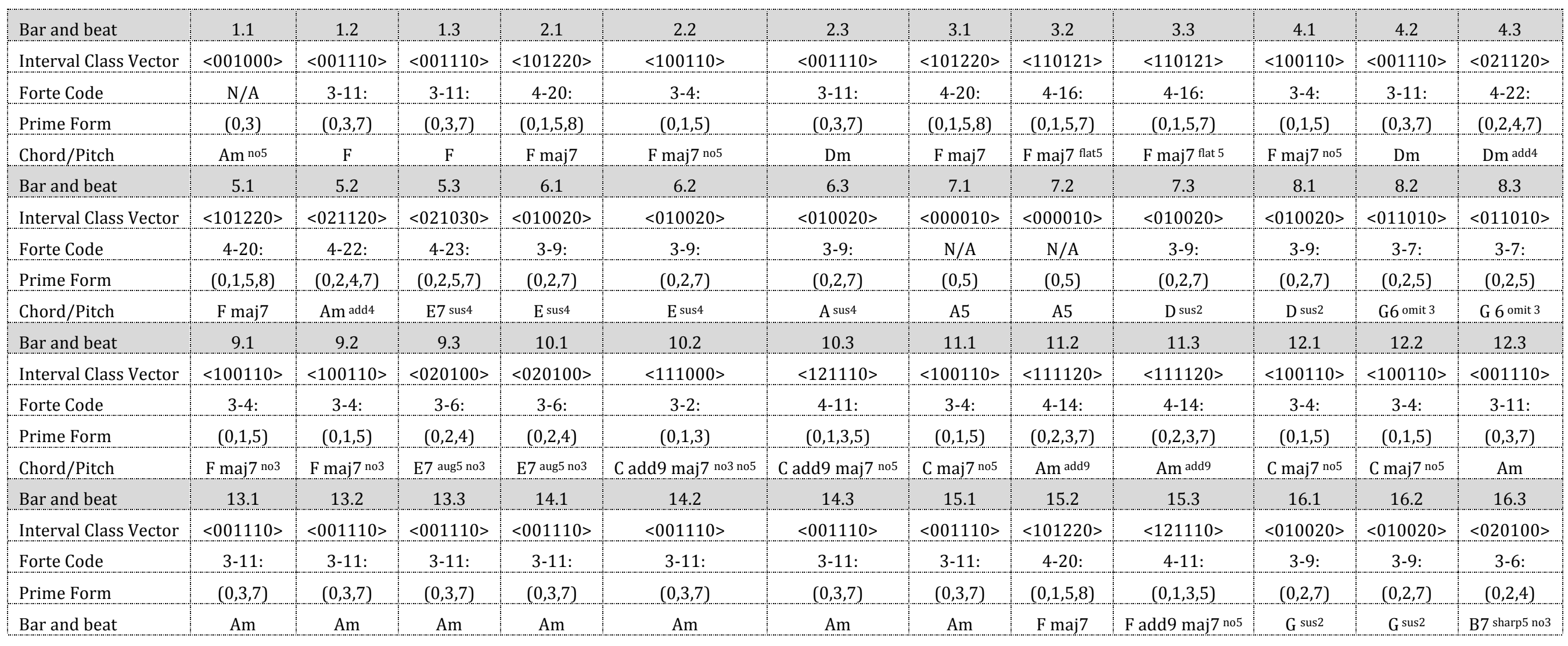


By the end of bar 8 , when the first and second violins have presented the main theme in its entirety, the listener has been presented no fewer than 14 different sonorities. As the work proceeds, a kaleidoscope of shifting sonorities occurs every one or two beats, predominantly presenting to the listener various pre-mutations of a particular set of related F chords (e.g. F, F maj7, F maj7 no 5, F maj7 flat 5), which define the sound world of Festina Lente. It is only at the end of bar 12, and continuing through the first beat of bar 15 , that the work comes to 'rest' briefly in its original sonority of A minor.

In total, the soundscape of Festina Lente comprises 33 different interval vectors and 84 distinct chords (plus the single pitch classes A, B, E, and F). This compares with the 24 interval vectors and 42 distinct chords of Cantus. Table 4.9 overleaf details the different interval class vectors of Festina Lente in their order of first occurrence. After the first eight bars the frequency with which new sonorities are introduced decreases. However, there are intermittent periods when a number of new sonorities are introduced within a relatively short span (e.g. bars 29-32, when four new interval class vectors make their first appearance in the work) as well as individual bars when a number of new and relatively complex sonorities make their first appearance: <211231> (Forte Code: 520), <233241> (Forte Code: 6-Z25), <122010> (Forte Code: 4-10), <111111> (Forte Code: 4-Z15), <132130> (Forte Code: 5-23), and <122230> (Forte Code: 5-27). 
Table 4.9: Interval vectors, Festina Lente - order of first occurrence

\begin{tabular}{|c|c|c|c|c|}
\hline $\begin{array}{c}\text { Order 1st } \\
\text { occurrence }\end{array}$ & $\begin{array}{c}\text { Interval Class } \\
\text { Vector }\end{array}$ & $\begin{array}{l}\text { Forte } \\
\text { Code }\end{array}$ & Prime Form & $\begin{array}{c}\text { Bar 1st } \\
\text { occurrence }\end{array}$ \\
\hline 1 & $<001000>$ & N/A & $(0,3)$ & 1 \\
\hline 2 & $<001110>$ & $3-11$ & $(0,3,7)$ & 1 \\
\hline 3 & $<101220>$ & $4-20$ & $(0,1,5,8)$ & 2 \\
\hline 4 & $<100110>$ & $3-4$ & $(0,1,5)$ & 2 \\
\hline 5 & $<110121>$ & $4-16$ & $(0,1,5,7)$ & 3 \\
\hline 6 & $<021120>$ & $4-22$ & $(0,2,4,7)$ & 4 \\
\hline 7 & $<021030>$ & $4-23$ & $(0,2,5,7)$ & 5 \\
\hline 8 & $<010020>$ & $3-9$ & $(0,2,7)$ & 6 \\
\hline 9 & $<000010>$ & $\mathrm{N} / \mathrm{A}$ & $(0,5)$ & 7 \\
\hline 10 & $<011010>$ & $3-7$ & $(0,2,5)$ & 8 \\
\hline 11 & $<020100>$ & $3-6$ & $(0,2,4)$ & 9 \\
\hline 12 & $<111000>$ & $3-2$ & $(0,1,3)$ & 10 \\
\hline 13 & $<121110>$ & $4-11$ & $(0,1,3,5)$ & 10 \\
\hline 14 & $<111120>$ & 4-14 & $(0,2,3,7)$ & 11 \\
\hline 15 & $<010000>$ & $\mathrm{N} / \mathrm{A}$ & $(0,2)$ & 18 \\
\hline 16 & $<000000>$ & $\mathrm{N} / \mathrm{A}$ & 0 \{silence or single note $\}$ & 29 \\
\hline 17 & $<100000>$ & $\mathrm{N} / \mathrm{A}$ & $(0,1)$ & 29 \\
\hline 18 & $<000100>$ & $\mathrm{N} / \mathrm{A}$ & $(0,4)$ & 30 \\
\hline 19 & $<000001>$ & $\mathrm{N} / \mathrm{A}$ & $(0,6)$ & 32 \\
\hline 20 & $<211231>$ & $5-20$ & $(0,1,5,6,8)$ & 46 \\
\hline 21 & $<233241>$ & $6-Z 25$ & $(0,1,3,5,6,8)$ & 46 \\
\hline 22 & $<122010>$ & $4-10$ & $(0,2,3,5)$ & 49 \\
\hline 23 & $<111111>$ & $4-Z 15$ & $(0,1,4,6)$ & 53 \\
\hline 24 & $<132130>$ & $5-23$ & $(0,2,3,5,7)$ & 54 \\
\hline 25 & $<122230>$ & $5-27$ & $(0,1,3,5,8)$ & 56 \\
\hline 26 & $<200121>$ & $4-8$ & $(0,1,5,6)$ & 65 \\
\hline 27 & $<100011>$ & $3-5$ & $(0,1,6)$ & 66 \\
\hline 28 & $<112011>$ & $4-13$ & $(0,1,3,6)$ & 91 \\
\hline 29 & $<143250>$ & $6-32$ & $(0,2,4,5,7,9)$ & 108 \\
\hline 30 & $<032140>$ & $5-35$ & $(0,2,4,7,9)$ & 113 \\
\hline 31 & $<010101>$ & 3-8 & $(0,2,6)$ & 121 \\
\hline 32 & $<012111>$ & $4-27$ & $(0,2,5,8)$ & 153 \\
\hline 33 & $<012120>$ & $4-26$ & $(0,3,5,8)$ & 154 \\
\hline
\end{tabular}


As shown in Table 4.10 overleaf, the two most prevalent sonorities in Festina Lente are <001110> (Forte Code: 3-11 presenting most frequently as an Am or F chord), and $<101220>$ (Forte Code: 4-20 presenting always as an Fmaj7 chord). Other prominent sonorities include: $<100110>$ (Forte Code: 3-4 occurring most frequently as the chords F maj7 no5, F maj7 $^{\text {no3 }}$, and C maj7 no5); <111120> (Forte Code: 4-14 mainly occurring as an Am add9 or Dm ${ }^{\text {add9 }}$ chord and $<010020>$ (Forte Code: 3-9 occurring as various permutations of sus2 and sus4 chords).

All of the above sonorities, which comprise almost half of the sonic content of Festina Lente (roughly 47 per cent of its duration), are relatively simple three and four pitch class sonorities. If taken alone and deployed in a more traditional fashion (e.g. a tonally-based harmonic structure dominated by the tonic, dominant and sub-dominant functions), one would not expect the result to be the evolving panoply of shifting chords that is Festina Lente. What gives the work its distinctive and mesmerising allure is the manner in which Pärt has deployed them as a matrix of fluctuating harmonies that evolve and devolve every one or two seconds into one of 28 other sonorities (comprising 68 different chords, plus the single pitch class sonorities of A, B, E, and F). This is illustrated in the sonority map in Figures 4.47 and 4.48 overleaf.

Festina Lente has multiple extended periods during which only one interval class or pitch class is present. Examples of this can be seen in Figure 4.48 (sonority map of Section A, detailing bars 1 through 52). Throughout Section A the density of the intervallic content periodically decreases to only a single sonority. Examples of this can be observed in bar 7 when only the interval class of a perfect fourth is present; bars 18 through 20 when only the interval class of a minor second occurs; and bars 29 through 39 when the work cycles through a series of single sonorities. 
Table 4.10: Festina Lente - chords represented by interval vectors (and frequency of occurrence as number of beats)

\begin{tabular}{|c|c|c|c|c|}
\hline Interval Class Vector & Forte Code & Prime & Frequency of Interval Class & Frequency of chord occurrence \\
\hline$<000000>$ & $\mathrm{N} / \mathrm{A}$ & $\begin{array}{c}0 \text { \{silence } \\
\text { or single note }\}\end{array}$ & 37 & $\begin{array}{l}\text { Silence }(24), \mathrm{A}^{\text {no3 no5 }}(1), \mathrm{B}^{\mathrm{n} 03} \text { no5 } \\
\text { (1), E no3 no5 (1), } \\
\text { F no3 no5 (1), }\end{array}$ \\
\hline$<000001>$ & $\mathrm{N} / \mathrm{A}$ & $(0,6)$ & 5 & F flat5 no3 $(5)$ \\
\hline$<000010>$ & $\mathrm{N} / \mathrm{A}$ & $(0,5)$ & 30 & $\begin{array}{l}\text { A5 (21), D5 (1), E5 (3), E sus4 no5 (3), F5 (1), } \\
\text { G5 (1) }\end{array}$ \\
\hline$<000100>$ & N/A & $(0,4)$ & 13 & $\mathrm{C}^{\mathrm{no5}}(7), \mathrm{F}$ no5 $(4), \mathrm{E}$ aug5 no3 $(1)$ \\
\hline$<001000>$ & N/A & $(0,3)$ & 22 & $A m^{\text {no5 }}(14), \mathrm{Dm}^{\text {no5 }}(5), \mathrm{Em}^{\text {no5 }}(2), \mathrm{Bm}^{\text {no5 }}(1)$ \\
\hline$<001110>$ & 3-11: & $(0,3,7)$ & 90 & Am (68), F (18), Dm (4), \\
\hline$<010000>$ & $\mathrm{N} / \mathrm{A}$ & $(0,2)$ & 27 & D add9 no3 no5 $(16)$, E7 no3 no5 $(10)$, D7 no3 no5 (1), \\
\hline$<010020>$ & 3-9: & $(0,2,7)$ & 44 & $\begin{array}{l}A \text { sus4 }(14), E \text { sus4 }(14), D \text { sus2 }(11), G \text { sus2 }(3), \text { E7 sus4 } \\
n o 5(2),\end{array}$ \\
\hline$<010101>$ & 3-8: & $(0,2,6)$ & 2 & $\mathrm{~F}$ flat5 $(2)$ \\
\hline$<011010>$ & 3-7: & $(0,2,5)$ & 12 & $\begin{array}{l}\text { E7 no3 (4), Am sus4 (3), Em7 no5 (2), G6 no3 (2), } \\
\text { Am7 no5 (1) }\end{array}$ \\
\hline$<012111>$ & 4-27: & $(0,2,5,8)$ & 2 & F6 flat5 (2) \\
\hline$<012120>$ & 4-26: & $(0,3,5,8)$ & 2 & Am7 (1), F6 (1) \\
\hline$<020100>$ & 3-6: & $(0,2,4)$ & 5 & $\begin{array}{l}\text { E7 aug5 no3 (2), B7 aug5 no3 (1), C add9 no5 (1), } \\
\text { D9 no3 no5 (1), }\end{array}$ \\
\hline$<021030>$ & 4-23: & $(0,2,5,7)$ & 7 & $A 7$ sus $4(2), E 7$ sus 4 (2) \\
\hline$<021120>$ & 4-22: & $(0,2,4,7)$ & 39 & $A m$ add $4(33), D 7$ sus2 $(5), D m$ add4 (1) \\
\hline$<032140>$ & 5-35: & $(0,2,4,7,9)$ & 1 & Am11 (1) \\
\hline$<100000>$ & $\mathrm{N} / \mathrm{A}$ & $(0,1)$ & 35 & $\begin{array}{l}\text { C maj7 no3 no5 (29), F maj7 no3 no5 (5), } \\
\text { E flat9 no3 no5 (1) }\end{array}$ \\
\hline$<100011>$ & 3-5: & $(0,1,6)$ & 5 & F sharp11 no3 (3), B dim (1), C maj7 sus4 no5 (1) \\
\hline$<100110>$ & 3-4: & $(0,1,5)$ & 52 & $\begin{array}{l}\text { F maj7 no5 (22), F maj7 no3 (16), C maj7 no5 (10), } \\
\text { A5 flat13 (4) }\end{array}$ \\
\hline$<101220>$ & 4-20: & $(0,1,5,8)$ & 83 & F maj7 (83) \\
\hline$<110121>$ & 4-16: & $(0,1,5,7)$ & 5 & F maj7 flat5 (5) \\
\hline$<111000>$ & 3-2: & $(0,1,3)$ & 20 & $\begin{array}{l}\text { Dm add9 no5 (14), D13 no3 no5 (3), Am add9 no5 (1), } \\
\text { C maj7 add9 no3 no5 (1), }\end{array}$ \\
\hline
\end{tabular}


Table 4.10 (cont.) Festina Lente - chords represented by interval vectors (and frequency of occurrence as number of beats)

\begin{tabular}{|c|c|c|c|c|}
\hline Interval Class Vector & Forte Code & Prime & Frequency of Interval Class & Frequency of chord occurrence \\
\hline$<111111>$ & 4-Z15: & $(0,1,4,6)$ & 6 & F sharp11 (6) \\
\hline$<111120>$ & 4-14: & $(0,2,3,7)$ & 51 & Am add9 (25), Dm add9 (25), Dm9 (1) \\
\hline$<112011>$ & 4-13: & $(0,1,3,6)$ & 1 & $\operatorname{Dm} 13$ no5 (1) \\
\hline$<121110>$ & 4-11: & $(0,1,3,5)$ & 14 & C maj9 no5 (5), Dm9 no5 (5), Fmaj9 no5 (4) \\
\hline$<122010>$ & 4-10: & $(0,2,3,5)$ & 3 & Am add9 sus 4 no5 (2), G13 no3 (1) \\
\hline$<122230>$ & 5-27: & $(0,2,3,5,8)$ & 31 & Dm9 (20), Fmaj13 (7), F maj9 (3), F add9 (1), \\
\hline$<132130>$ & 5-23: & $(0,2,3,5,7)$ & 20 & $\begin{array}{l}\text { D13 us } 2 \text { (13), Am add2 add4 (3), C maj13 no } 5 \text { (3), } \\
\text { G13 sus2 }(1)\end{array}$ \\
\hline$<143250>$ & 6-32: & $(0,2,4,5,7,9)$ & 1 & Am11 (1) \\
\hline$<200121>$ & 4-8: & $(0,1,5,6)$ & 5 & F maj7 sharp11 no3 (5) \\
\hline$<211231>$ & 5-20: & $(0,1,5,6,8)$ & 9 & F maj7 sharp 11 (9) \\
\hline$<233241>$ & $6-\mathrm{Z} 25$ & $(0,1,3,5,6,8)$ & 5 & Dm13 (5) \\
\hline
\end{tabular}


Figure 4.47: Festina Lente - sonority map

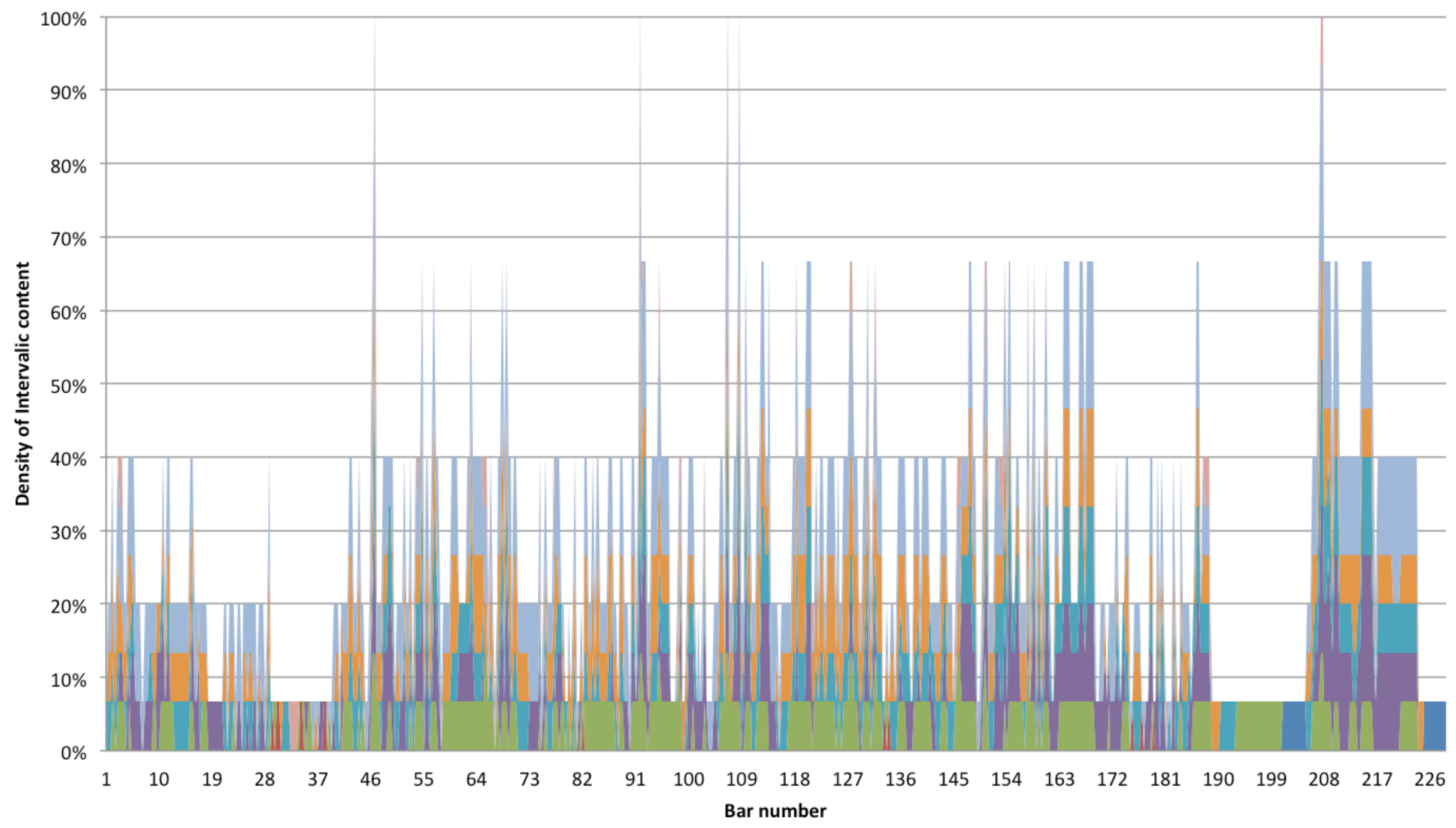

Silence $\quad$ Single pitch $\square \mathrm{m} 2 \quad \square \mathrm{M} 2 \quad \square \mathrm{m} 3 \quad \square \mathrm{M} 4 \quad \square \mathrm{P} 4 \quad$ Tritone 


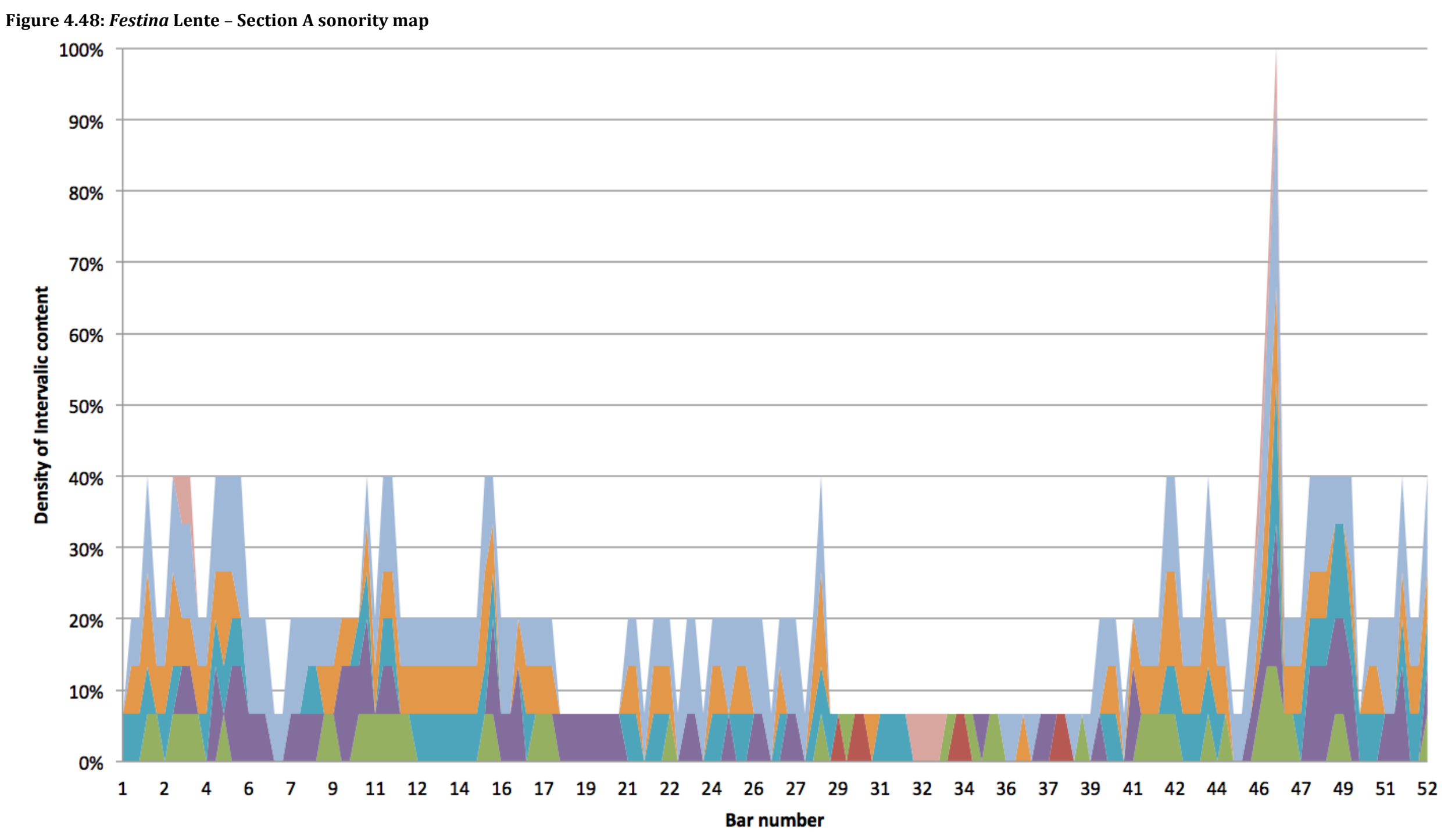

Silence $\quad$ Single pitch $\square \mathrm{m} 2 \quad \square \mathrm{M} 2 \quad \square \mathrm{m} 3 \quad$ M4 $\quad$ M4 $\quad$ Tritone 


\section{Discussion - Festina Lente}

The proceeding analysis illustrates developments in Pärt's deployment of his tintinnabuli system from a relatively stringent system of rules derived from the combination of stepwise processes and vertical and horizontal relationships (as exemplified by both Tabula Rasa and Cantus in memorium Benjamin Britten) to a more fluid interpretation of what comprises a 'process' piece of music, as exemplified by Festina Lente, illustrating in the latter work how the composers' hand is much more evident.

Festina Lente, while expanding on the mensural techniques introduced in Cantus, and still exploring the potentiality of a single diatonic scale (again A minor), breaks from its antecedents in a number of ways. Rather than having a clearly identifiable modal home, as was the case for the other two works, the melodic lines of Festina Lente are more nebulous, slipping from its primary home of F Lydian periodically to E Phrygian and even implying briefly D Dorian. Like Cantus and Ludus, the T-voices in Festina Lente are grounded in an A minor triad. However, the deployment of the T-voices in Festina Lente does not follow a single set of rules that are strictly adhered to once they have been established. Rather, the relationships between the T-voice's pitches and those of their respective M-voice become much more fluid as the work progresses, with some T-voices shifting between first and second superior positions, as well as first position, inferior. In addition, the contrapuntal writing of some T-voices is no longer operating in a strict note-on-note rhythmic manner in relation to their M-voices.

Finally the 'theme and variation' approach taken by Pärt in Festina Lente and the significant amount of retouching and modifications on Pärt's part demonstrate a greater mutability in the composer's approach to melody than was seen in the other two works. A number of the 
composer's melodic interventions also imply a desire on his part to exercise greater discretion in shaping the harmonic relationships of the work beyond merely setting up a series of rules and processes and then letting those processes run their course unimpeded something that would not necessarily be expected in a process-based piece of music.

This therefore raises the question: at what point do such interventions in a process-based piece mean that it is no longer a process piece of music at all? Alternatively, does this illustrate that, despite Reich's assertions (noted previously in footnote 143), that when creating process-based works the composer does not truly surrender control to shape the musical end result? In relation to this, Robinson asserts that process music "does not entail, as some believe, a relinquishing of control by the composer", noting that in fact the composer has:

... exclusive and complete control over the design of the process and, by extension, responsibility for the results as well. The difference is that at some point the composer, the listener, and the analyst all share the same role, somewhere between creator and listener. ${ }^{166}$

Robinson also notes that, to a degree, by default Pärt's tintinnabuli music can be construed as process music, but only to a certain degree. This is because Pärt's approach to composing process music, while governing all of the note-to-note relationships, has a greater degree of inventiveness in terms of form and shape of the work and moments of free form composing. What it does have in common with other process-based music, however, is its ability to generate such rich and varied results with so few inputs. ${ }^{167}$

166 Robinson, “Analyzing Pärt,” 108.

167 Ibid., 109. 


\section{Chapter 5 - Psalom (1985 rev. 1997) and Silouan's Song (1991)}

For me each language has, so to speak, its own world with its own history, character, intonation, and many other associations. When I choose a text all these aspects influence the compositional process, consciously or unconsciously.

- Arvo Pärtt 168

In early 2015, the Arvo Pärt Centre in Estonia published In Principio, a compendium of the texts Pärt has used to derive many of the parameters of his text-based compositions. Prior to this, it was not publicly known what texts the composer had used in composing a number of his instrumental works, nor the language of those texts. This chapter and the next provide the first detailed analyses of three such works: Psalom and Silouan's Song (both covered in this chapter), and Orient \& Occident (discussed in Chapter 6).

An appreciation of the careful craftsmanship that has gone into the construction of Pärt's text-based tintinnabuli work can be gleaned using the multimodal method that has been applied to the works covered in Chapters 3 and 4, including style analysis, pitch class and interval class analysis, and visual models of pitch class relationships and sonority mappings - supplemented by graphic representations in the form of a MIDI-recreations of the works' musical lines to provide a visual overview of each entire work and a Pärtian Tonnetz, to demonstrate the interrelations between the different M-voice and T-voice pitch classes and the resulting intervallic content when any two pitches occur at the same time. However, even when applying these methods to a text-based work, some of Pärt's procedures are not readily decipherable without access to the specific texts

\footnotetext{
168 Restagno et al., Arvo Pärt in Conversation, 85.
} 
involved. For example, it would not be possible to fully unpack, nor appreciate, the subtleties of how a work such as Psalom was constructed, without having access to the Eastern Orthodox text of Psalm $112(113)^{169}$ in Church Slavonic, and at least a rudimentary understanding of the pronunciation rules that apply to that liturgical language. The analyses that follow will show that Pärt's text-based compositions are carefully crafted works, and that evidence of the presence of the 'invisible' hand of the composer can be found within every aspect of the underpinning structures, at the more elaborate middle ground level, and even within surface aspects of these works.

\section{Introduction}

As discussed in Chapter 2, in addition to the use of predetermined contrapuntal rules to determine the vertical relationship of each M-voice/T-voice pairing in a tintinnabuli composition, another of Arvo Pärt's practices is to derive rules from structural aspects of a text to guide how a work is composed. This generally involves creating predetermined melodic patterns, as dictated by the number of syllables in each word of the text. Rhythmic aspects may be based upon which syllables of different words are stressed when spoken. Punctuation and diacritical marks (e.g. the accent grave ['], macrons, umlauts, etc.) that determine how a word is pronounced, as well as its meaning and/or grammatical function, can also come into play in relation to changes in melodic direction, note duration and the selection of instrumental articulations. Other aspects of a text, such as sentence length, may also be significant in informing rules governing the length and shape of a melodic statement, and the number of stanzas may also factor into a work's overall form.

169 Psalm 113 is the equivalent psalm in the Western Bible to Psalm 112 in the Eastern Orthodox Psalter. 
In most cases, the texts that Pärt selects as inspiration and source material for his compositions are liturgical in nature, such as a biblical passage, a psalm, an antiphon or a traditional prayer. However, despite the usually religious nature of these texts, the denotative meanings of the words themselves seldom play a significant role in determining musical parameters. For the most part, in his instrumental compositions Pärt does not treat texts as lyrics to be set in the manner that a songwriter or composer of a religious mass might do. As the Estonian musicologist Toomas Siitan observes:

[Pärt] is not a "construer" of the texts in his works; he does not highlight a personal aspect in them but rather presumes that the text comprises the entire message perfectly. The texts likewise possess their own music, which must merely be brought forth. As such, the composer does not have all that much to add to the texts on his own part - the music only services and carries out the text, giving it a sound-based existence. ${ }^{170}$

Siitan goes on to note that, in line with both the Eastern Orthodox and early Western Roman Catholic traditions, wherein liturgical texts are usually declaimed in a passionless manner that strictly follows the grammatical structure of the text being recited, Pärt follows similar principles in his own treatment of these texts. ${ }^{171}$ Pärt himself has explained:

The texts exist independently of us and are waiting for us: each of us has a time when he will find a way to them. This meeting happens when texts are not treated as literature or works of art, but as points of reference or as models. ${ }^{172}$

This is not to imply, however, that the liturgical nature of a text is not reflected in the general asceticism of Pärt's sound world or its associated musical work. It

170 Toomas Siitan, "Introduction," in In Principio: The Word in Arvo Pärt's Music (Harjumaa: The Arvo Pärt Centre, 2014), 11.

171 Ibid., 12.

172 Restagno et al., Arvo Pärt in Conversation, 55. See also Toomas Siitan, "Introduction," in In Principio: The Word In Arvo Pärt's Music (Harjumaa: The Arvo Pärt Centre, 2014), 9. 
seems unlikely that Pärt would use a solemn religious text as the basis for a 'vivacious' energetic M-voice in an Ionian or Mixolydian modal composition. As evidenced in the two compositions covered in this chapter, there also appear to be indications of Pärt engaging periodically in the occasional moment of word or text painting in relation to dynamics, tempo changes, and instrumental articulations.

While Pärt has used texts in nine different languages in 81 of his acknowledged compositions (English, Estonian, French, German, Italian, Latin, Russian, Spanish, and Church Slavonic), ${ }^{173}$ all but one of his text-based instrumental works written for string orchestra since 1985 are based on Church Slavonic texts. The exception is Silouan's Song, which is based on a Russian text by Staretz Silouan the Athenite (1866-1938), an Eastern Orthodox monk who was based at the Russian Monastery of St Panteleimon, Mount Athos northern Greece. ${ }^{174}$

\section{Church Slavonic and Russian language alphabets}

Church Slavonic and Russian are both part of the Slavic family of languages that use the Cyrillic alphabet.175 It is believed that Old Church Slavonic, the predecessor of contemporary Church Slavonic, developed through the missionary activities of Saint Cyril and Saint Methodius who led the first Byzantine mission among the

\footnotetext{
173 Hedi Rosma, Kristina Kõrver, and Kai Kurman, eds., In Principio: The Word In Arvo Pärt's Music (Harjumaa: The Arvo Pärt Centre, 2014), 18.

174 Anonymous, “St. Panteleimon's Monastery (Athos)," Orthodox Wiki, accessed March 5, 2015, http://orthodoxwiki.org/St._Panteleimon\%27s_Monastery_\%28Athos\%29.

175 The East Slavic group of languages (Russian, Ukrainian, and Belorussian) uses the Cyrillic alphabet, as do certain languages in the South Slavic Region (Bulgarian and Macedonian). The West Slavic group of languages (Czech, Kashubian, Polish, Slovak, Sorbian [Luatian]) uses an adaptation of the Latin alphabet, as does the South Slavic language of Slovenian. The SerboCroatian Slavic group of languages (which includes the sub-Slavic dialects Serbian, Bosnian, Croatian, and Montenegrin) use both the Cyrillic and Latin scripts. Alexander M. Schenker and Edward Stankiewicz, eds., The Slavic Literary Languages: Formation and Development, vol. Yale Russian and East European Publications, 1 of 3 vols. (New Haven: Yale Concilium on International and Area Studies, 1980).
} 
central Slavic peoples in the ninth century. ${ }^{176}$ While Saint Cyril (also known as Constantine) is credited with inventing the glagolica script, which is believed to be the predecessor of the Cyrillic alphabet, the Cyrillic writing system was most likely developed by Kliment (Saint Clement of Ohrid) by "adapting special signs to the letters of the Greek uncial" in the tenth century and given the name Cyrillic "to underline its orthodoxy and to honor the holy founder of [the Eastern Orthodox] church."177

In their contemporary forms, the Church Slavonic alphabet has 40 characters, while modern Russian uses 33 characters (two of which are silent). ${ }^{178}$ In addition, Church Slavonic makes significant use of 11 different diacritic markings to indicate pronunciation stress, changes in vowel inflection, and abbreviations, as well as to provide other grammatical information about a word's function in the context of a sentence (whether it is a singular or plural noun, for example). ${ }^{179}$ In contrast modern Russian uses only one true diacritic marking, the accent aigu [' ] to indicate a stressed syllable, while the markings above the letters "ё" and "й" are considered to be part of the letters' characters, distinguishing them from the letters "е" and "и", and so are not construed by Russian linguists to be true diacritics. ${ }^{180}$ Table 5.1 overleaf shows the two alphabets, along with their IPA equivalent pronunciation.

\footnotetext{
176 Vivian Pinto, "Church Slavonic," in The Slavic Literary Languages: Formation and Development, vol. Yale Russian and East European Publications (New Haven: Yale Concilium on International and Area Studies, 1980), 6-7.

177 Ibid., 13.

178 "Cyrillic Alphabet," Britannica Academic, accessed August 9, 2015, http://academic.eb.com.helicon.vuw.ac.nz/EBchecked/topic/148713/Cyrillic-alphabet.

179 Hanne Eckhoff, "Email Correspondence Re: Church Slavonic, Its Transliteration into the International Phonetic Alphabet and Pronunciation Traditions," April 14, 2015.

180 Terence Wade, Comprehensive Russian Grammar (Blackwell Reference Grammars), Second (Oxford: Wiley-Blackwell, 2000), 14-15.
} 
Table 5.1: Church Slavonic and Russian Cyrillic Alphabets

\begin{tabular}{|c|c|c|c|}
\hline Church Slavonic & $\begin{array}{c}\text { IPA } \\
\text { Equivalent }\end{array}$ & Russian & $\begin{array}{c}\text { IPA } \\
\text { Equivalent }\end{array}$ \\
\hline d & $/ \mathrm{a} /$ & A & $/ \mathrm{a} /$ \\
\hline Б & /b/ & Б & /b/ \\
\hline B & $/ \mathrm{v} /$ & B & $/ \mathrm{v} /$ \\
\hline$\Gamma$ & /g/ & $\Gamma$ & /g/ \\
\hline$A$ & /d/ & Д & /d/ \\
\hline \multirow[t]{2}{*}{$\mathrm{E}$} & $/ \mathrm{je}, \mathrm{e} /$ & E & $/ \mathrm{je}, \mathrm{e} /$ \\
\hline & & $\ddot{\mathrm{E}}$ & /jo/io/ \\
\hline XK & $/ 3 /$ & Ж & $\mid 3 /$ \\
\hline $\mathrm{S}$ & /Z/ & & \\
\hline Z (3) & $|z|$ & 3 & $/ z /$ \\
\hline \multirow[t]{2}{*}{$\mathrm{H}$} & /i/ & И & /i/ \\
\hline & & Й & $/ \mathrm{j} /$ \\
\hline I & /i/ & & \\
\hline $\mathrm{K}$ & $/ \mathrm{k} /$ & $\mathrm{K}$ & $/ \mathrm{k} /$ \\
\hline$\Lambda$ & $/ 1 /$ & Л & /1/ \\
\hline$M$ & $/ \mathrm{m} /$ & $M$ & $/ \mathrm{m} /$ \\
\hline $\mathrm{N}$ & $/ \mathrm{n} /$ & $\mathrm{H}$ & $/ \mathrm{n} /$ \\
\hline $\mathrm{O}$ & $10 /$ & 0 & /o/ \\
\hline$\Pi$ & $/ \mathrm{p} /$ & $\Pi$ & $/ \mathrm{p} /$ \\
\hline $\mathrm{P}$ & $/ \mathrm{r} /$ & $\mathrm{P}$ & $/ \mathrm{r} /$ \\
\hline $\mathrm{C}$ & $\mid \mathrm{s} /$ & C & $/ \mathrm{s} /$ \\
\hline $\mathrm{T}$ & $/ \mathrm{t} /$ & $\mathrm{T}$ & $/ \mathrm{t} /$ \\
\hline Oy (8) & $/ \mathrm{u} /$ & $\mathrm{y}$ & $/ \mathrm{u} /$ \\
\hline$\Phi$ & /f/ & $\Phi$ & /f/ \\
\hline $\bar{X}$ & $/ \mathrm{x} /$ & $\mathrm{X}$ & $/ \mathrm{x} /$ \\
\hline W & /o:/ & & \\
\hline Ц & $/ \mathrm{ts} /$ & Ц & $/ \mathrm{ts} /$ \\
\hline $\mathrm{Y}$ & $/ \mathrm{t}^{\mathrm{j} /}$ & 4 & $/ \mathrm{t}^{\mathrm{i} /}$ \\
\hline ШI & $/ S /$ & Ш & $/ \int /$ \\
\hline फ़ & $/ \mathrm{S}^{\mathrm{j}} \mathrm{t} / \mathrm{j} / \mathrm{j} \mathrm{j} /$ & Щ & $/ \int^{+j} t^{j} / \rho^{j} j^{j /}$ \\
\hline $\mathrm{b}$ & & $\mathrm{b}$ & - \\
\hline Ы & $/ y /$ & Ы & $/ \mathrm{y} /$ \\
\hline b & /ja/ & & \\
\hline \multirow[t]{2}{*}{$\mathrm{b}$} & & $\mathrm{b}$ & $/ \mathrm{j} /$ \\
\hline & $/ \mathrm{j} /$ & Э & /e/ \\
\hline Ю & /ju/ & Ю & $/ \mathrm{ju}, \mathrm{j} \mathrm{j} /$ \\
\hline Id & /ia/ & & \\
\hline A & $/ \tilde{\varepsilon} /$ & & \\
\hline $\bar{K}$ & $/ \tilde{\jmath} /$ & Я & $/ \mathrm{ja}, \mathrm{j} \mathrm{a} /$ \\
\hline ş & /ks/ & & \\
\hline$\Psi$ & $/ \mathrm{ps} /$ & & \\
\hline V & /I,y/ & & \\
\hline 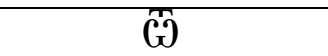 & /otŭ/ & & \\
\hline
\end{tabular}




\section{Psalom}

Originally conceived as a work for string quartet in 1985, Psalom was subsequently arranged for string orchestra in 1995 (with additional revisions in 1997 and 2010). ${ }^{181}$ The addition of contrabasses, doubling the violoncellos' part in the 1997 string orchestral arrangement (used in this analysis), results in the bass line of the work having a greater registral depth and sense of presence than is possible in the string quartet version. However, on a note-by-note basis, there are no significant differences between the score for the string quartet version of Psalom and that for string orchestra.

Pärt used the Church Slavonic text of Psalm 112 in the Eastern Orthodox Psalter as the basis to construct the two M-voices of the work. ${ }^{182}$ Figure 5.1 overleaf is a recreation of this text (in the stylised Cyrillic font Irmologian) as it appears in In Principio: The Word in Arvo Pärt's Music. ${ }^{183}$ However, prior to the publication of In Principio, the specific text and language used by Pärt to derive the parameters for Psalom were not generally known. ${ }^{184}$

\footnotetext{
${ }^{181}$ Hillier, Arvo Pärt, 175. While Pärt has created string quartet arrangements for a number of his other works, e.g. Fratres and Summa, Psalom is the only work in the official United Editions catalogue of Pärt's compositions that initially was written for string quartet. See: Universal Edition, "Paert Catalogue." Accessed 22 March

182 Kai Kutman, The Arvo Pärt Center, "Email Correspondence Re: Psalom," March 24, 2015. See also Rosma, Kõrver, and Kurman, In Principio: The Word In Arvo Pärt's Music, 97.

183 Rosma, Kõrver, and Kurman, In Principio: The Word In Arvo Pärt's Music.

184 This may explain why so little has been written on Psalom to date. In his monograph, Hillier devotes only one sentence to the work, and makes no attempts to describe or explain its operations (see Hillier, Arvo Pärt, p. 175). Brauneiss cites Psalom as an example of the scalic ambiguity that Pärt sometimes employs in his works (see Brauneiss, 'Musical Archetypes: The Basic Elements of Tintinnabuli Style', p. 57), while Robinson uses it briefly as an example work to display an approach pitch class multiplicity analysis (see Robinson, "Analyzing Pärt," 88-91.).
} 
ІІалнА 8 ї̈,

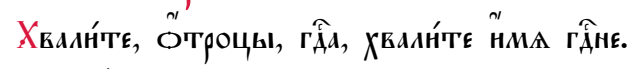

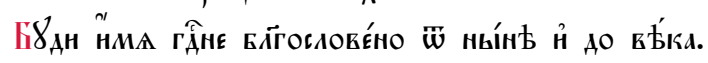

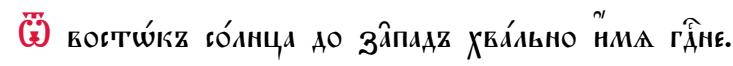

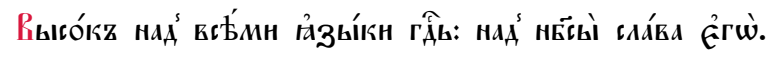

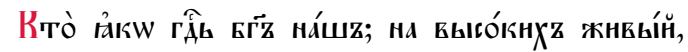

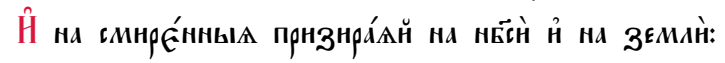

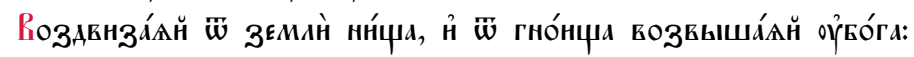

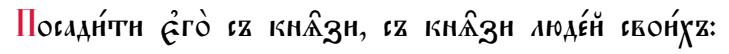

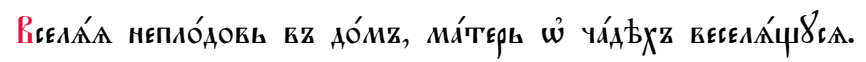

Below is the same text in a less stylised contemporary Cyrillic font (Kliment) that

eschews archaic diacritic marks that have no influence on the pronunciation of

the words in the Russian tradition for pronouncing Church Slavonic words. ${ }^{185}$

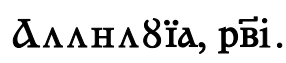

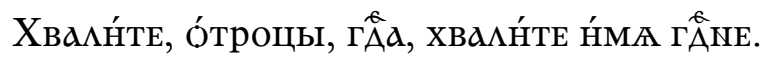

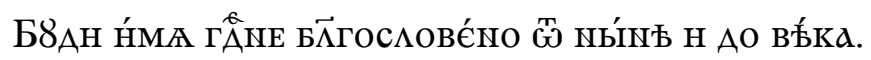

Ḡ востǴкъ сó

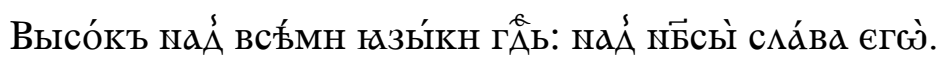

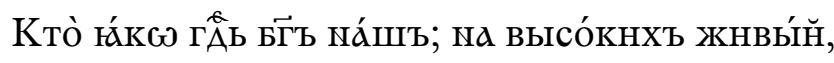

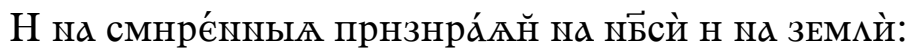

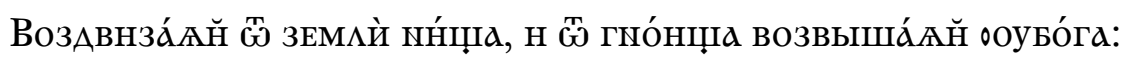

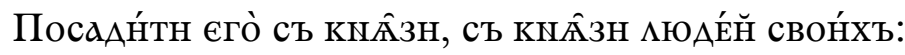

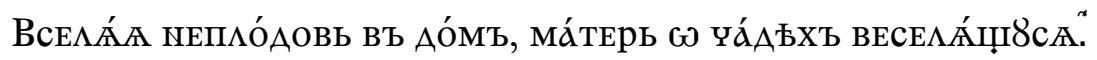

185 Eckhoff, "Email Correspondence Re: Church Slavonic, Its Transliteration into the International Phonetic Alphabet and Pronunciation Traditions."

186 I would like to take this opportunity to acknowledge the input and assistance of Dr. Hanne Eckhoff in the Department of Languages and Linguistics at the University of Tromsø in Norway. As part of a series of email correspondences, Dr. Eckhoff reviewed and corrected my Cyrillic recreations of several Church Slavonic, transliterations into the Latin-based International Phonetics Alphabet (IPA) and subsequent syllabification of the Cyrillic words and identification of which syllables in each word (based on the IPA) were stressed in the texts for Psalom and Orient \& Occident. She also identified which words in the texts functioned as nouns. She also 


\section{Style analysis of Psalom}

The following style analysis of Psalom is supplemented by graphic representation in the form of a MIDI-recreation of the work's musical lines to provide a visual overview of the entire work.

\section{Large dimension}

Comprising 75 bars, Psalom is a single movement work for two sections of violins, a viola section, and a section of violoncellos and contrabasses. The pitch classes used in Psalom (E, F, G\#, A, B, C, and D) constitute the A harmonic minor scale, with E - the fifth degree of the scale - functioning as the M-voice pitch centre.

With the exception of the first violins, the registers of the various instrumental lines of Psalom are quite limited (Figure 5.2 overleaf). The violas and second violin sections are restricted to registral ranges of a fifth (E3 to B3) and a minor seventh (E3 to D4), respectively. While in the figure the first violins would appear to operate across a broad range (E3 to A5), for the majority of the work they are restricted to playing in the range of E3 to D4, a span of a seventh, and only sound A5 towards the end of the work in bars 57 through 66 .

Similarly, the violoncellos and contrabasses are restricted to sounding an open fifth on pitch classes A and E only in bars 36 through 41, and a single sustained E in the penultimate statement of the work. So for the majority of the Psalom, the instrumental lines are quite restricted in range. As evidenced in the MIDIrecreation of the work (Figure 5.3 overleaf), Psalom only 'opens up' to 
encompass a span of greater than five octaves for ten bars (57 through 66), before retreating back to an operational register of a seventh (E3 to D4) for its final eight bars.

Figure 5.2: Psalom - registral ranges of instrumental sections

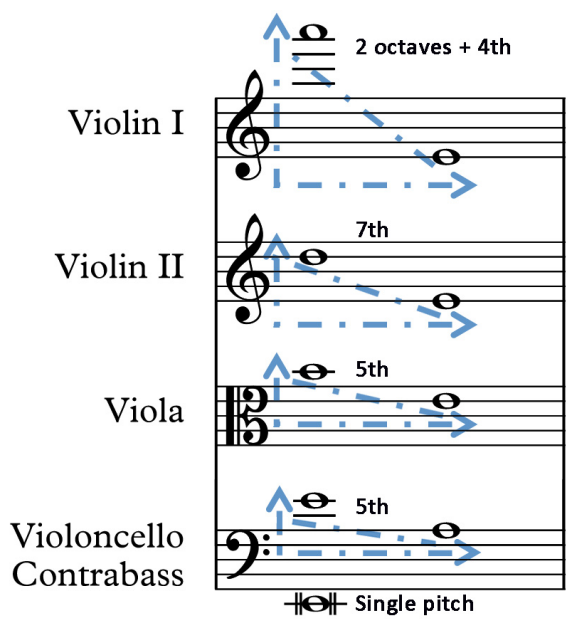

Psalom is unusual among Pärt's tintinnabuli works in that it does not have any true functioning T-voices and, in fact, has very few moments when a full threenote chord occurs. In the place of T-voices, Pärt deploys an interval of an open fifth, using pitch classes A and E intermittently as drones throughout the work, either in the same instrumental line (e.g. the first violins) or assigning each pitch to a different section (e.g. the first violins and the violoncellos/contrabasses). As such, the dominant sonorities of the work, when two or more pitch classes are present, are some permutation of an A minor chord and an open fifth using the pitch classes A and E. Despite this lack of functioning T-voices, the work very much is a member of Pärt's ascetic, tintinnabuli sound world. This is due to Pärt's use of periods of silence, two M-voices operating in unison or parallel thirds, and the implied or actual presence of the A minor triad. While the lack of a proper Tvoice might suggest that Psalom should not be classified as a tintinnabuli work, 
such a determination is dependent upon the lens through which the term is being interpreted.

In her article "Formal algorithms in the music of Arvo Pärt", Elena Tokun notes that there are a number of interpretations of the term tintinnabuli in the literature on Pärt's music. ${ }^{187}$ She writes that at the simplest level, the term tintinnabuli reflects both Pärt's philosophical and religious convictions, as well as defining an approach to composing music, based on a "paradigm [that] springs up from spiritual self-restraint and sonic asceticism, from the profound objectivity of music's spirit and matter"188. At the opposite end of the spectrum, tintinnabuli is defined as the strict contrapuntal application of rules, as initially codified by Hillier, to determine the movements of paired melodic and tintinnabuli musical lines. ${ }^{189}$ Tokun uses a more inclusive interpretation of the term than Hillier, defining tintinnabuli as:

... a compositional system [that] represents a novel unity of counterpoint, harmony, and form in the music at the turn of the 20th and 21st centuries, in which the simplicity of a sound's aural parameters as well as the clarity and strictness of sounding music commingle with the numerical programming of musical material. 190

\footnotetext{
187 Elena Tokun, "Formal Algorithms of Tintinnabuli in Arvo Pärt's Music.," Moscow Conservatory Publishing House, 2011, http://www.arvopart.ee/en/arvo-part-2/selected-texts/formalalgorithms-of-tintinnabuli/. 188 Ibid.

189 Hillier, Arvo Pärt, 86-97.

190 Tokun, "Formal Algorithms of Tintinnabuli in Arvo Pärt's Music."
} 
Figure 5.3: Psalom - MIDI-recreation all strings (with contrabasses shown in their sounding register) ${ }^{191}$

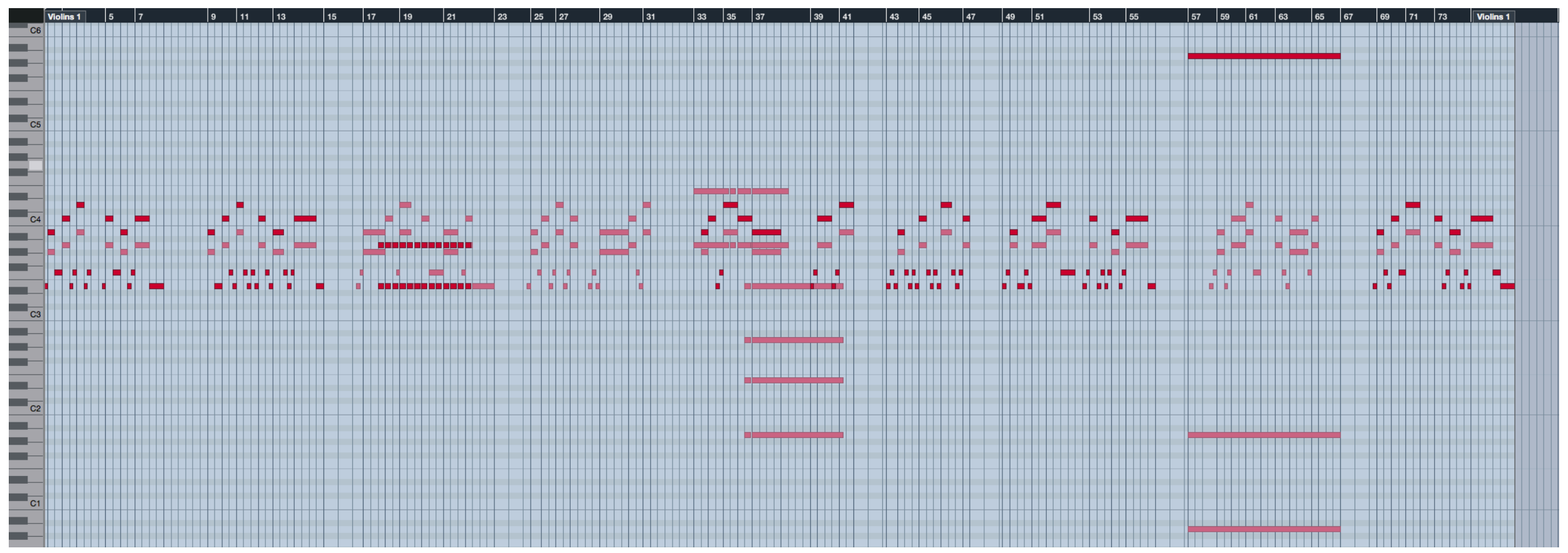

191 Midi-recreation created using Cubase ${ }^{\mathrm{TM}} 7.5$ 
The main sense of motion within Psalom arises from variations of two melodic lines (Figure 5.4) that are played concurrently by paired string sections - either both of the violin sections or one of the violin sections paired with the viola section.

Figure 5.4: Psalom - arch of the melodic material

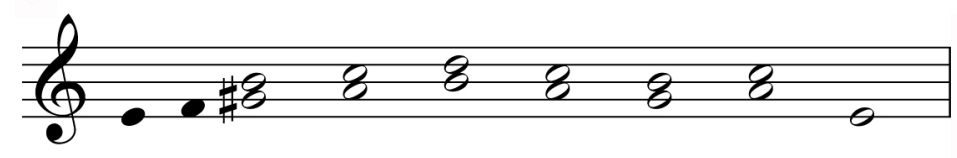

The two instrumental sections always play the pitch classes $\mathrm{E}$ and $\mathrm{F}$ in unison, while respectively taking the pitch classes of either the upper (B, C, D) or lower (G\#, A, B) pitch when playing an interval of a third apart. This is illustrated in the first and second violin lines in the first six bars of the piece (Figure 5.5), wherein the violins alternate between simultaneously playing E4 and F4, or take one pitch each of three intervals $\mathrm{G} \#-\mathrm{B}, \mathrm{A}-\mathrm{C}$, or $\mathrm{B}-\mathrm{D}$, all three of which comprise the interval of a minor third - represented by the interval class vector $<001000>$ or prime form $(0,3)$.

Figure 5.5: Psalom - first six bars violins

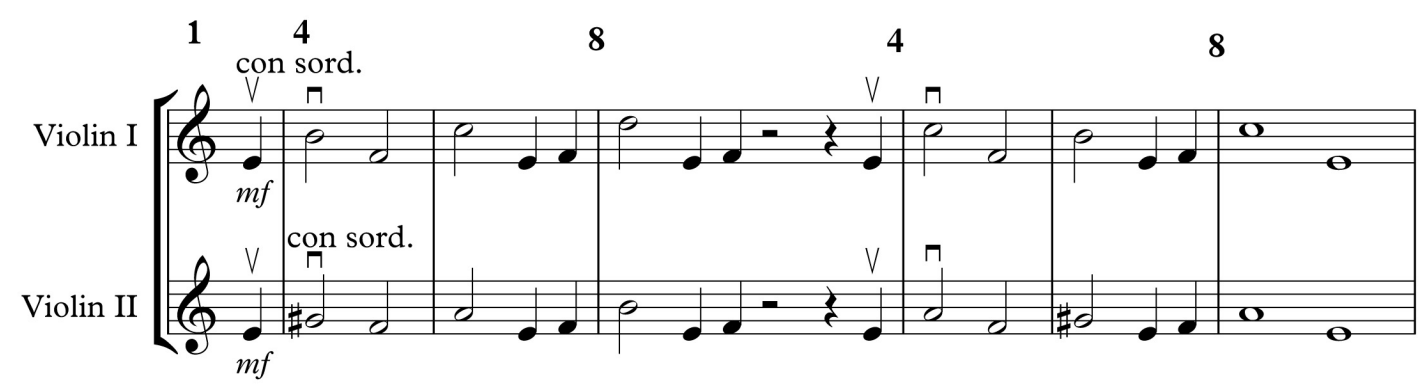

Following the nine-stanza structure of the text, Psalom is broken into nine sections of varying length, as detailed in Table 5.2, with the final bar of all but the last section being silent (indicated by grey-shaded cells in the table). In Section ix 
there is a bar of silence at bar 72 - denoted in the score with a fermata and the instruction Grand Pause (G.P.).

Table 5.2: Psalom metrical structure

\begin{tabular}{|c|c|c|c|c|c|c|c|c|c|c|c|c|c|}
\hline \multirow{2}{*}{$\begin{array}{l}\text { Section } \\
\text { i }\end{array}$} & \multirow{2}{*}{$\begin{array}{c}\begin{array}{c}\text { Number of } \\
\text { bars }\end{array} \\
8 \\
\end{array}$} & \multicolumn{11}{|c|}{ Beats per bar } & \multirow{2}{*}{$\begin{array}{c}\begin{array}{c}\text { Duration } \\
\text { as total } \\
\text { number } \\
\text { of beats }\end{array} \\
45 \\
\end{array}$} \\
\hline & & 1 & 4 & 4 & 8 & 4 & 4 & 8 & 12 & & & & \\
\hline ii & 7 & 4 & 4 & 6 & 4 & 6 & 8 & 9 & & & & & 41 \\
\hline iii & 8 & 2 & 6 & 4 & 6 & 6 & 6 & 8 & 9 & & & & 47 \\
\hline iv & 9 & 1 & 3 & 4 & 4 & 8 & 8 & 4 & 2 & 12 & & & 46 \\
\hline $\mathbf{v}$ & 10 & 4 & 4 & 4 & 4 & 8 & 8 & 2 & 6 & 4 & 9 & & 53 \\
\hline vi & 6 & 3 & 6 & 6 & 6 & 2 & 9 & & & & & & 32 \\
\hline vii & 8 & 2 & 6 & 4 & 12 & 6 & 4 & 8 & 9 & & & & 51 \\
\hline viii & 11 & 6 & 2 & 4 & 4 & 4 & 4 & 4 & 6 & 2 & 6 & 9 & 51 \\
\hline ix & 8 & 1 & 4 & 4 & 4 & 4 & 4 & 6 & 12 & & & & 39 \\
\hline
\end{tabular}

The score for Psalom has no tempo markings, though it does have a number of performance instructions, including dynamic markings, bowing marks (up bow, down bow and slur markings) and an instruction that all of the string sections should play con sordino, i.e. muted.

In their recording of Psalom, the Kronos Quartet executed it at a blisteringly fast pace, ${ }^{192}$ performing it in its entirety in two minutes and six seconds. However, at the end of the Universal Edition score there is an indication that the work should be between four to seven minutes in duration (i.e. durata: ca. 4' - 7'). ${ }^{193}$ Reflecting this indication, the Lithuanian Chamber Orchestra's rendition of the work under the direction of Saulius Sondeckis on the ECM recording Litany is six minutes and 56 seconds long194

192 Kronos, Early Music (Nonesuch, 1997).

193 Arvo Pärt, Psalom, UE 30847 (Wien: Universal Edition, 1991), 4.

194 Various, Arvo Pärt Litany, vol. ECM 1592, ECM New Series (Munich, 1996). 
Middle dimension

The dynamics of Psalom vary across the nine different sections of the work, ranging from $p p p$ to $m f$, with the latter dynamic occurring only in Sections i and vii. Table 5.3 summarises the dynamic schema that applies to both of the M-voice lines in Psalom.

Table 5.3: Psalom melodic line dynamics as indicated in the score

\begin{tabular}{|c|c|c|c|}
\hline Section & $\begin{array}{l}\text { Starting } \\
\text { dynamic }\end{array}$ & Dynamic variation & $\begin{array}{l}\text { Silence \& } \\
\text { duration }\end{array}$ \\
\hline . & $\boldsymbol{m} \boldsymbol{f}$ bar 1 & None & $\begin{array}{l}\text { bar } 8 \\
12 \text { beats }\end{array}$ \\
\hline ii & pp bar 9 & None & $\begin{array}{l}\text { bar } 15 \\
9 \text { beats }\end{array}$ \\
\hline iii & $\boldsymbol{m p}$ bar 16 & $\begin{array}{l}\text { steady crescendo starting at bar } 17 \text { through bar 20, decrescendo } \\
\text { bars } 21 \text { and } 22\end{array}$ & $\begin{array}{l}\text { bar } 23 \\
9 \text { beats }\end{array}$ \\
\hline iv & $\begin{array}{l}\text { ppp bar } \\
24\end{array}$ & $p p p$ through first half of bar $28, p p$ second half of bar 28 & $\begin{array}{l}\text { bar } 32 \\
12 \text { beats }\end{array}$ \\
\hline $\mathbf{v}$ & $\boldsymbol{m} \boldsymbol{p}$ bar 33 & $\begin{array}{l}\text { crescendo for one bar in bar } 34 \text {, short decrescendo at the end of } \\
\text { bar } 37, p \text { at bar } 39 \text { followed by a decrescendo starting in the } \\
\text { second half of bar } 40 \text { through the end of bar } 41\end{array}$ & $\begin{array}{l}\text { bar } 42 \\
9 \text { beats }\end{array}$ \\
\hline vi & $p$ bar 43 & crescendo starting the middle of bar 44 through bar 43 & $\begin{array}{l}\text { bar } 48 \\
9 \text { beats }\end{array}$ \\
\hline vii & $\boldsymbol{m} \boldsymbol{f}$ bar 49 & $\begin{array}{l}\text { crescendo starting at bar } 50 \text { through } 51, \mathrm{mf} \text { starting at the last } \\
\text { two beats of bar } 52 \text {, decrescendo in bar } 55\end{array}$ & $\begin{array}{l}\text { bar } 56 \\
9 \text { beats }\end{array}$ \\
\hline viii & $\boldsymbol{p}$ bar 57 & None & $\begin{array}{l}\text { bar } 67 \\
9 \text { beats }\end{array}$ \\
\hline ix & $\begin{array}{l}\text { ppp bar } \\
68\end{array}$ & $\begin{array}{l}p p p \text { bars } 68 \text { through } 71 \text {, a G.P. of silence in bar } 72 \text { then, } p p p p \\
\text { for the final } 3 \text { bars of the piece. }\end{array}$ & $\begin{array}{l}\text { bar } 72 \\
4 \text { beats with } \\
\text { fermata }\end{array}$ \\
\hline
\end{tabular}

For three sections of the work (i, ii, and viii) there are no internal dynamic variations within the section (i.e. each section has a single, fixed dynamic throughout its duration). The other six sections incorporate a greater degree of dynamic variation, with the central Section v, demonstrating the greatest amount of dynamic variability - mezzo piano at bar 33, crescendo for one bar in bar 34, short decrescendo at the end of bar 37, piano at bar 39 followed by a decrescendo starting in the second half of bar 40 through the end of bar 41 .

In performance, the alternation between two string sections playing in unison and then playing intervals of a minor third can result in a thinning of the volume 
of the individual instrumental lines, particularly where Pärt has not indicated a change of dynamic intensity within the section. This occurs in Sections i, ii, viii, and to some degree, Sections iv and ix. Sections i, ii, and viii each contain only one dynamic marking at the beginning of the section, while the other six sections have a greater degree of dynamic variety. In the case of Sections iv and ix, each has two dynamic markings, but the score includes no crescendi or decrescendi when the two melodic voices shift from playing in unison to playing in parallel thirds in those sections of the piece.

Another middle dimension aspect of Psalom generated out of the nine-stanza structure of the text is the bowing instructions, in relation to whether the Mvoices in each section are to be played legato or détaché. This is illustrated in Figure 5.6, which along with the bowing articulations also includes the dynamic markings for both M-voices (shown together for convenience on a single staff). The odd-numbered M-voice sections (i, iii, v, and vii) are played détaché, while the even numbered sections (ii, iv, vi, and viii) are marked to be played legato. The one exception to this pattern is Section ix, the final section of the work, which is also marked to be played legato. 
Figure 5.6: Psalom - dynamics and articulations of the M-voice lines
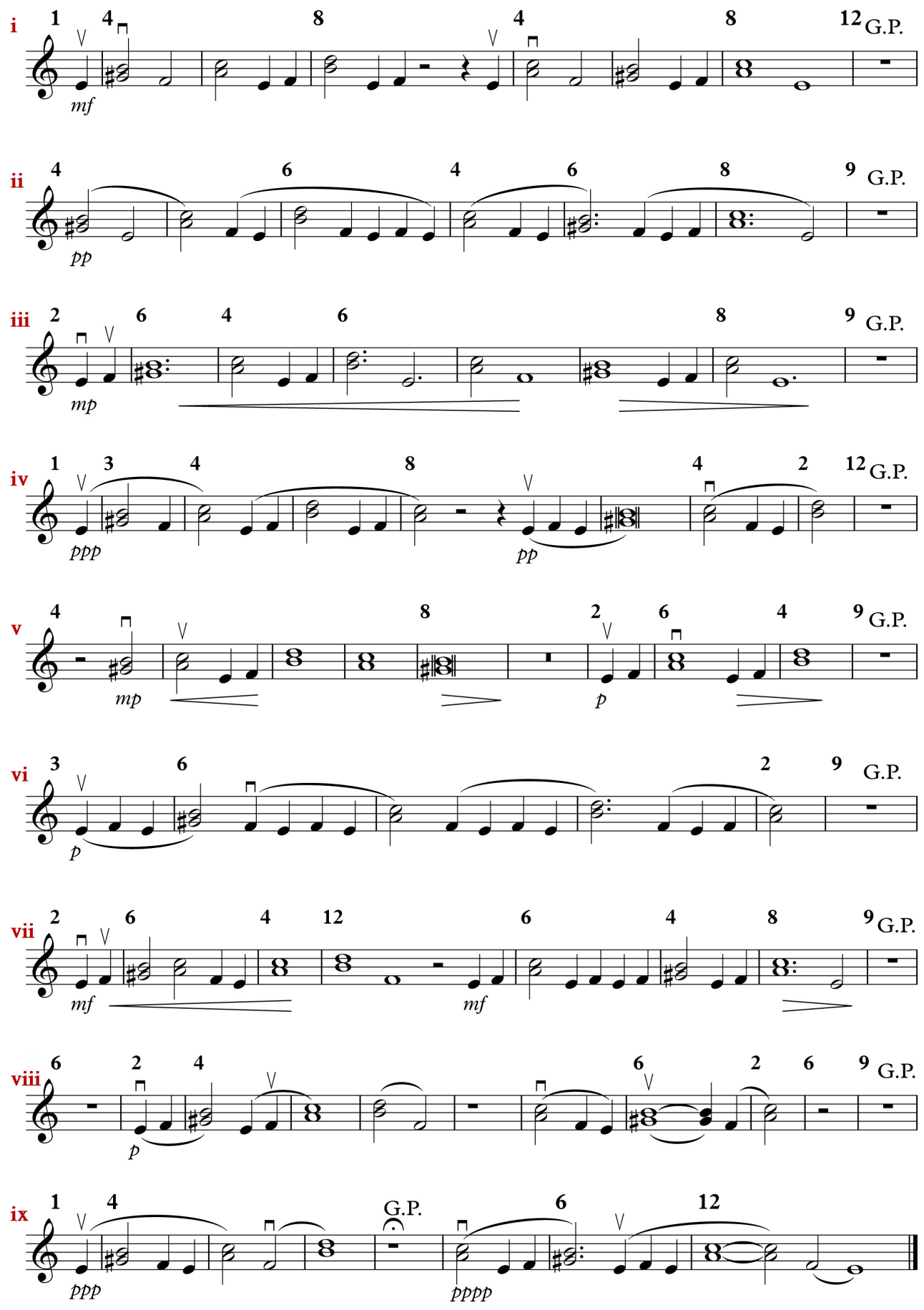

While the general melodic arch, as shown above in Figure 5.4, applies to each of the nine sections of the work, Pärt manipulates the pitches differently in each section, based - according to Kutman of the Arvo Pärt Centre - upon “... [aspects] of the verbal text and prosodic rhythm, accentuations and degrees of quantity, 
intonation and speech melody". 195 Compared to the works examined thus far, Psalom also illustrates a novel approach to voice leading in the way Pärt manipulates its two M-voices, wherein each avoids the use of certain pitch classes. Setting aside rhythmic elements for the moment, the basic patterns of voice leading from pitch to pitch within the two M-voices does not change, regardless of which instrumental line is playing the upper or lower M-voice. The linear pattern of the pitch classes of the upper M-voice is E-B-F-C-E-F-D-E-F, eschewing pitch classes A and G\#, while that of the lower M-voice is E-G\#-F-A-EF-B-E-F, eschewing pitch classes C and D. This is illustrated in the two simple path diagrams in Figure 5.7.

Figure 5.7: Psalom - melodic voice leading
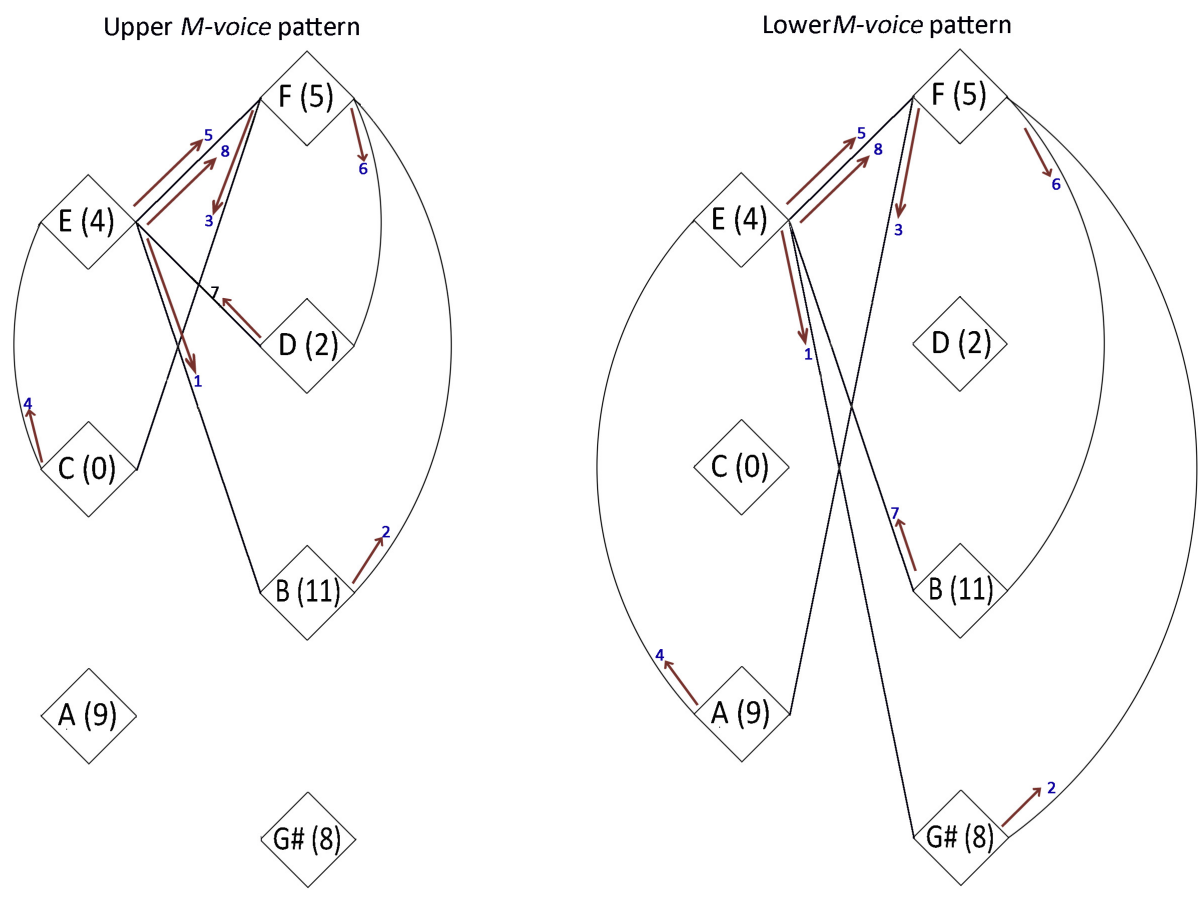

Due to the melodic material being based on characteristics of the text and there being a similar relationship between the rhythmic patterns and textual characteristics of individual words, Psalom is a relatively rhythmically more

195 Kutman, The Arvo Pärt Center, email correspondence with author. 
varied work compared to some of Pärt's earlier 'process' based string orchestral works, such as Cantus in memoriam Benjamin Britten (1976) or Silentium, the second movement of Tabula Rasa (1976). Psalom's nine different rhythmic schemas are illustrated in Figure 5.8. The integers above or below each note duration represent the pitch classes occurring in the two M-voices' lines at the time.

Figure 5.8: Psalom - nine rhythmic schema
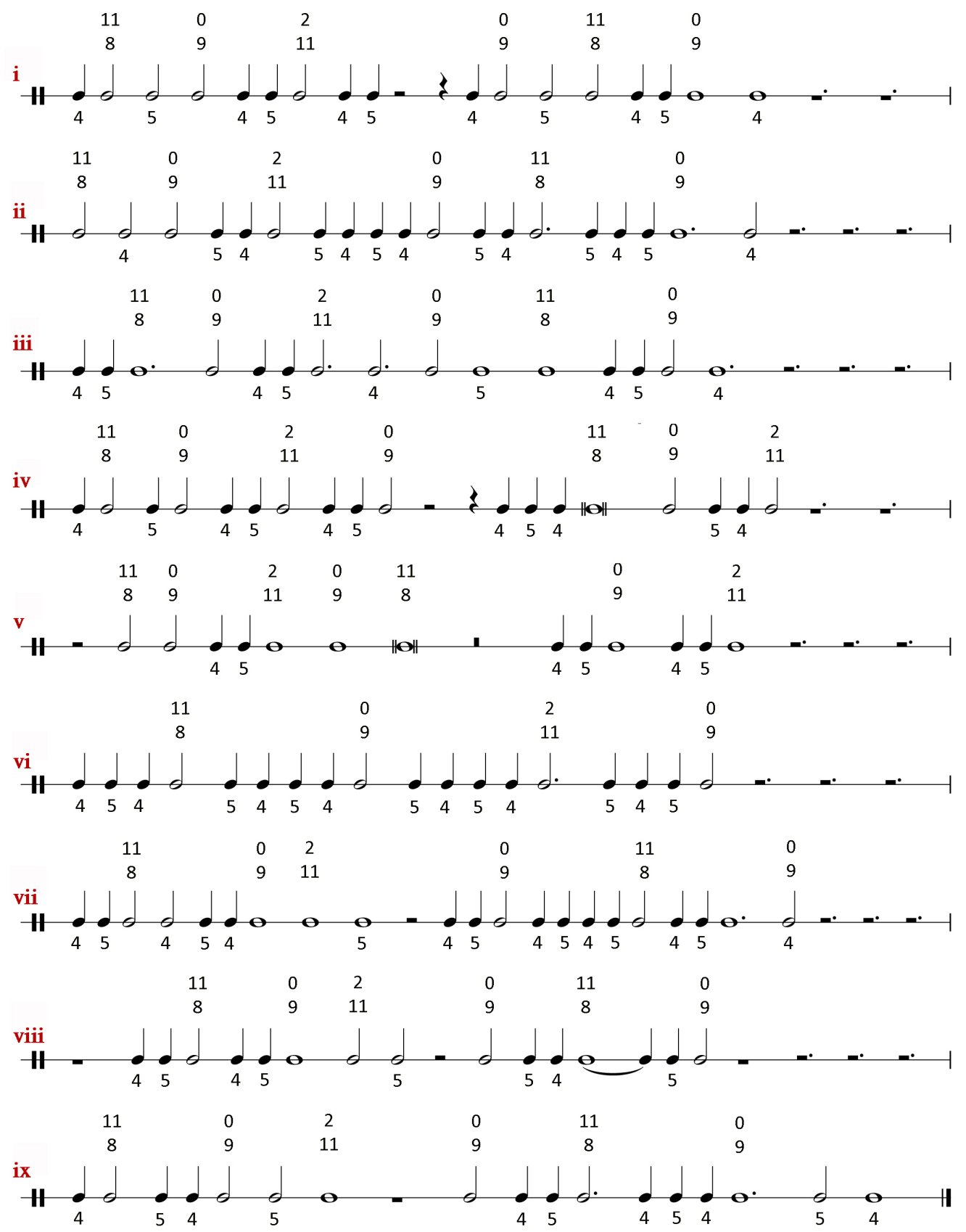


\section{$\underline{\text { Small dimension }}$}

As illustrated in Figure 5.8 above, each of the nine sections of the work has its own unique rhythmic pattern. How these rhythmic patterns and variations of the pitch class material have been generated only becomes apparent, however, when the relevant words of the Church Slavonic text are mapped against the melodic lines of the two M-voices. An example of this can be seen below in Figure 5.9, which illustrates the relationship between the Church Slavonic text and the melodic and rhythmic patterns of the M-voices in the first two sections of Psalom (again shown on a single staff for convenience). ${ }^{196}$ In addition to the non-stylised Cyrillic text, the IPA Latin equivalent transliteration of how each word is pronounced has also been provided below the Cyrillic text.

Figure 5.9: Psalom - M-voice lines of Sections i and ii with the Church Slavonic text

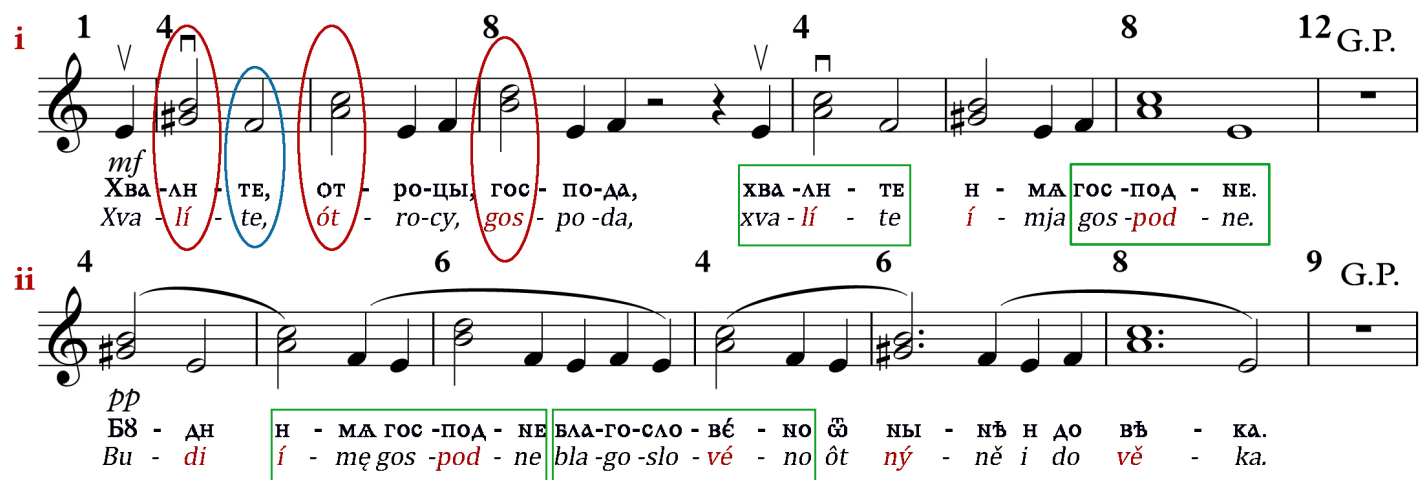

Text-based rules for Psalom

A close examination of the relationship between the text and Psalom's melodic and rhythmic patterns reveals a series of five basic text-based rules (plus two

196 The Church Slavonic text on which Pärt based Psalom has only been recently published by the Arvo Pärt Centre in Hajumaa Estonia in the compendium In Principio the Word in Arvo Pärt's Music - see Rosma, Kõrver, and Kurman, In Principio: The Word In Arvo Pärt's Music. Like many of the texts in the compendium, it has never previously been published in association with the musical score. 
variations to those rules), which dictate the shaping of the majority of the Mvoice material in Psalom.

Rules 1 and 2: One of the first things to note is the alternation between the two M-voices playing in unison on $\mathrm{E}$ or $\mathrm{F}$ and when the two voices play in intervals of a minor third. The minor third intervals only occur in relation to the stressed syllables in multisyllabic words when pronounced (Rule 1), as indicated by the red circles in the first three bars of Figure 5.9 and red shaded text throughout the excerpt. Pitch classes $\mathrm{E}$ and $\mathrm{F}$ occur in alternation to each other on the unstressed syllables (Rule 2).

Rules 3 and 3a: Pitches associated with stressed syllables are usually given a longer duration than non-stressed syllables (Rule 3). The exception is when the stressed syllable is the penultimate syllable of a word. When this occurs, the nonstressed syllable is allotted a longer duration as well (Rule 3a), an example being indicated by the blue circle in the first word in Section i - "Хвалите" (Figure 5.9).

A development in Pärt's use of texts to determine other aspects of musical structure not seen in his early text-based musical works is also shown in Figure 5.9 above. As discussed in Chapter 2, in early choral works, such as missa syllabica (1977, rev. 1996), Summa (1977), de profundus (1977, rev. 1980), Passio (1982) - and in later choral works, such as Te Deum (1984) and the Berliner Mass (1990), each word is usually assigned a single bar and the number of letters or syllables in the word determine the beats for that particular measure. In Psalom, by contrast, Pärt allows multisyllabic words to break across bar lines (as indicated by the green boxes in the figure). 
Rule 4: New bars commence on the first stressed syllable of each multisyllabic word, and the number of beats per measure is determined by how many syllables occur between the first stressed syllable at the beginning of the bar and when the first stressed syllable of the next word occurs.

Figure 5.10: Psalom - melodic lines with the Church Slavonic text
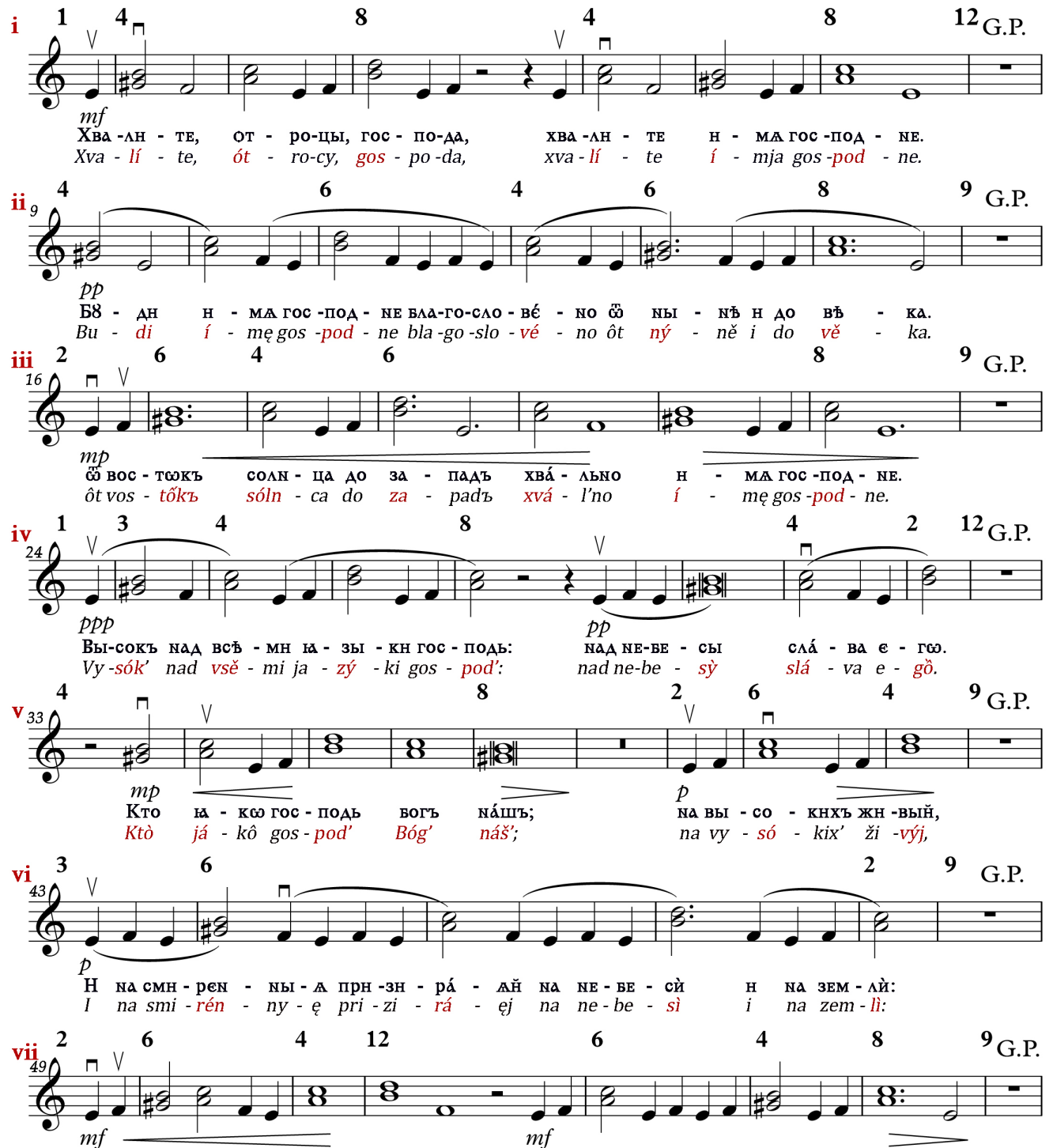

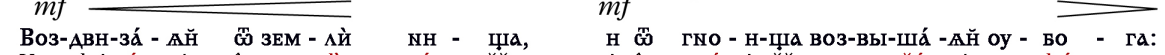

Voz-dvi-zá - ęj ôtzem-lì ní - šča, i ôt gnó-i-šča voz-vy-šá -ejj u - bó - ga:
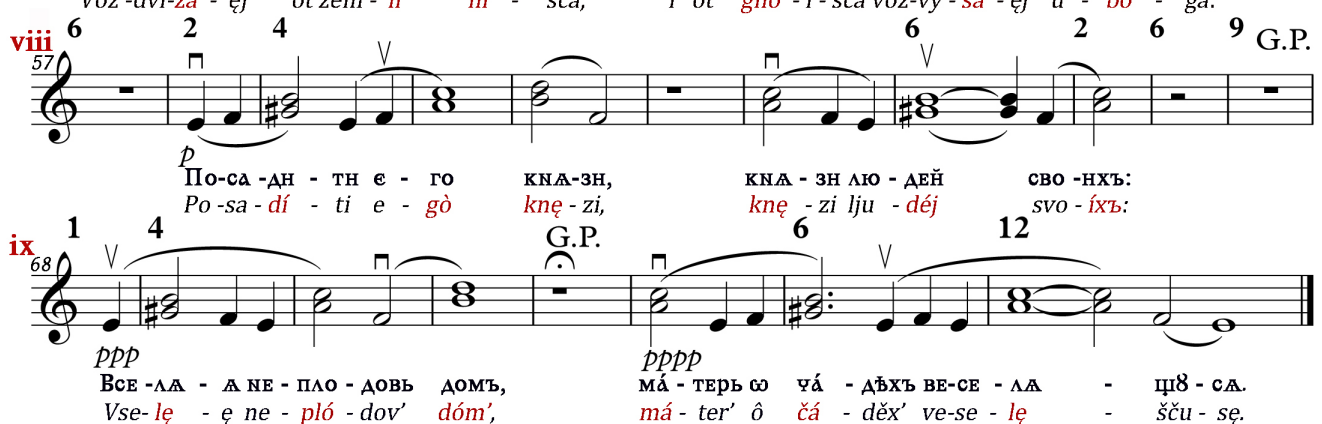
Rule 5 and 5a: Punctuation marks at the end of a stanza of text result in a bar of silence, signalling the end of the section (Rule 5). This is illustrated in Figure 5.10 on the preceding page. All other punctuation marks, such as commas, semicolons, and colons within a stanza result in shorter periods of rest, although the number of beats of rest for the same class of punctuation mark may vary from section to section (Rule 5a). There are two exceptions to the convention of punctuation marks resulting in the insertion of a rest: in Section i, the first two words are followed by a comma and the first rest does not occur until after the third word of the text.

\section{Evidence of minor text painting}

As noted previously, Siitan asserts that Pärt's approach to using texts in his music follows the traditional Eastern and Western liturgical traditions, wherein texts are generally declaimed in a passionless manner that strictly follows the grammatical structure of the text. However, a comparison of the translated text (see overleaf) with the dynamic markings in Sections iii, v, and vii (as shown in Figure 5.10 above) suggests that Pärt has engaged in some minor text painting in relation to his use of crescendos and decrescendos in certain lines of the music. This is not done in a strict 'word-to-music' fashion, however, wherein specific dynamic changes would map perfectly to words of the text.

For example, where the underlined text in the third stanza of Psalom 112 (text overleaf) refers to sunrises and sunsets, this corresponds with the crescendo and decrescendo in Section iii (Figure 5.10 bars 17-22). Pärt uses a crescendo in the same manner in the seventh musical statement (Section vii). The associated line of text in Section vii contains the words "raising the poor up from the earth". 
Section v, which is associated with the text "the Lord God who lives on high", contains a decrescendo - perhaps suggesting a descent towards the lower relative position of his/her supplicants.

\section{Psalm 112 (113) 197198}

i. Praise, servants, the Lord, praise the name of the Lord

ii. May the Lord's name be blessed from now and in eternity.

iii. From sunrise to sunset the Lord's name is praiseworthy.

iv. The Lord is high above all nations, his glory is above the heavens.

v. Who is like our Lord God, who lives on high,

vi. and is watching the humble ones in heaven and on earth:

vii. Raising the poor from earth, raising the miserable from the dunghill:

viii. in order to place him with princes, with the princes of his people:

ix. placing the barren woman in a house, a mother rejoicing over her children.

Pärt appears, however, to have opted not to engage in a similar practice in the fourth musical statement (bars 24-28), which refers to the Lord being "high above all nations". His decision not to do so may relate, in part, to Section iv being one of the alternating legato sections, whereas Sections iii, v, and vii do not have any slur markings, indicating the composer intends them to be played détaché.

\section{Interval class analysis and sonority mappings of Psalom}

The following section of this chapter builds on the preceding style analysis and examines: 1) the intervallic content that arises out of the text-based processes that Pärt used in composing Psalom, and 2) sonority mapping of this content, detailing the shifting musical sonorities throughout the work. This content analysis is supplemented by graphic representation in the form of a Pärtian

197 As translated by Hanne Eckhoff, "Email Correspondence Re: Church Slavonic, Its Transliteration into the International Phonetic Alphabet and Pronunciation Traditions.".

198 Shading, underlining and bolding of text are author's emphasis. 
Tonnetz, to demonstrate the interrelations between the different M-voice and Tvoice pitch classes and the resulting intervallic content when any two pitches occur at the same time.

Sonically, Psalom is the sparest and most austere of Pärt's string orchestral works. While the intervallic potential of the pitch classes E, F, G\#, A, B, C, and D comprises three minor seconds, three major seconds, five minor thirds, four major thirds, four perfect fourths and two tritones - Interval Class Vector <335442> (Forte Code: 7-32) - due to the manner in which Pärt has constructed the piece, Psalom eschews much of the harmonic potentiality that is present in the E Phrygian mode (or A harmonic minor). This is illustrated by mapping the active pitch class relationships in Psalom in a Pärtian Tonnetz (Figure 5.11 overleaf).

By his avoidance of the use of a true T-voice that avails itself of all three pitches of the A minor triad, the pitch class $\mathrm{C}$ is restricted to interacting only with the other two pitches of the triad (A and E). Similarly, pitch class F, when it occurs, only interacts with the pitch classes of $A$ and $E$. This results in a greatly reduced set of potential intervals: two minor seconds, two major seconds, three minor thirds, three major thirds, three perfect fourths and no tritones. If represented as an interval class vector, the set of active interval relationships that occur in the work equates to <223330>; however, no corresponding Forte Code exists for this set of pitches.

This is not to say, however, that through his avoidance of certain pitch class relationships Pärt has stumbled upon a sonority that has not previously been used or identified in Western music. In his preface to the Structure of Atonal Music, Allen Forte notes that in the development of his system for identifying 
pitch class sets and their relations, his study focused primarily on the fundamental pitch class sets used in atonal music, and as such did not "deal with 12-tone music, or with what might be described as paratonal ${ }^{199}$ music, or with more recent music which is rooted in the atonal tradition." 200 This suggests that Forte did not try to identify every possible sonority that might be derived from all possible combinations of the 12 pitch classes of Western music. The absence of certain pitch class relationships in Psalom, however, suggests further evidence of intentional decisions during the composition process, i.e. the purposeful exclusion of certain harmonic relationships at some point during the compositional process to achieve a specific aesthetic end.

Figure 5.11: Pärtian Tonnetz - pitch class relationships of Psalom

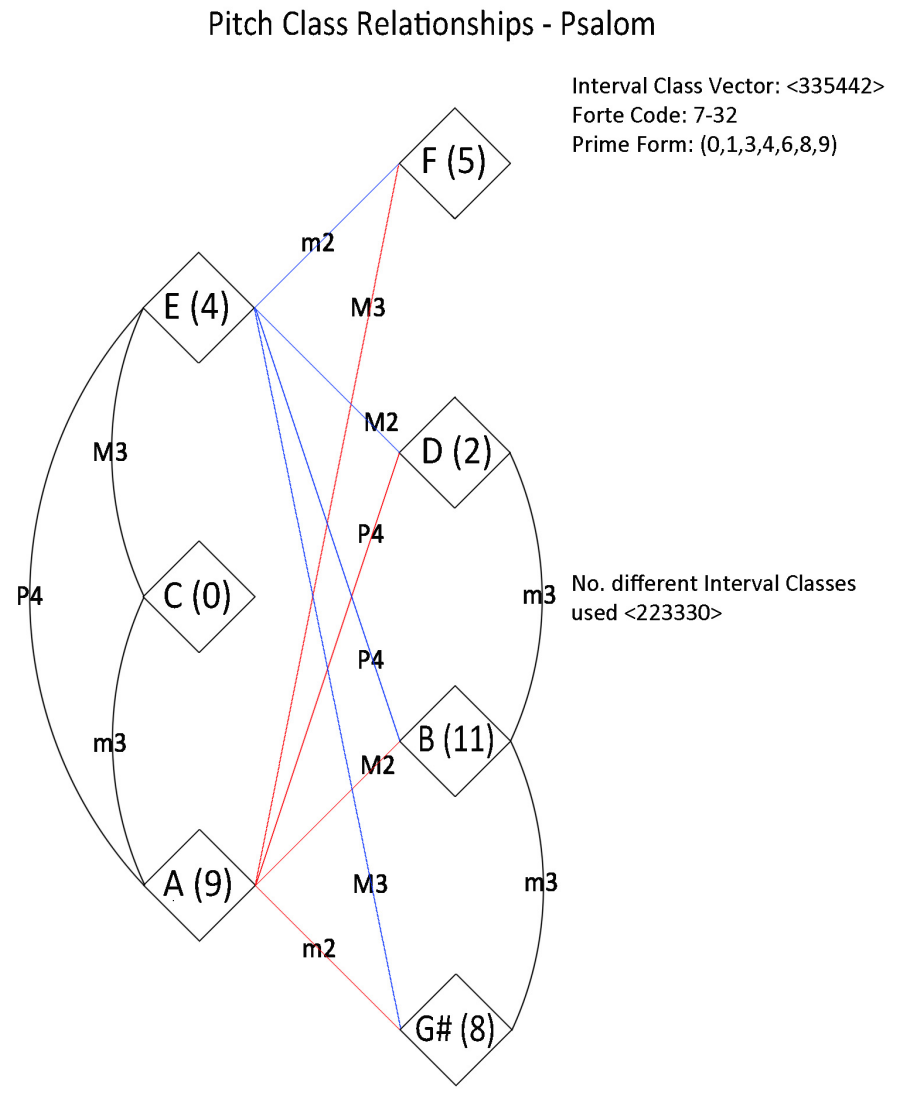

199 The terms paratonal music and paratonality refer to the practice of emphasising certain tone centres in atonal or post-tonal music to suggest tonality and harmonic functions. See Don Michael Randel, Harvard Dictionary of Music (Cambridge: Belknap Press of Harvard University Press, 2003), 381.

200 Forte, The Structure of Atonal Music, ix. 
Psalom comprises only seven interval class vectors (three of which do not have a Forte Code) and eight or ten 'chords' depending upon whether a single pitch is interpreted as implying the root of a chordal sonority (Table 5.4): $<000000>$ (pitch classes E and F or $E^{\text {no } 3 \text { no } 5}$ and $F$ no3 no5); <000010> (A5); <001000> (A min no5, B min no5, and G\# min no5); <001110> (Forte Code: 3-11, A min); <021030> (Forte Code: 4-23, E $7^{\text {th }}$ sus4); <100110> (Forte Code: 3-4, F maj7 no5); and <111120> (Forte Code: 4-14, E add4).

Table 5.4: Interval class vectors and chords generated by the process in Psalom

\begin{tabular}{|l|l|l|l|l|}
\hline $\begin{array}{l}\text { Interval Class } \\
\text { Vector }\end{array}$ & Forte Code & Prime & Chords & $\begin{array}{l}\text { Frequency of } \\
\text { occurrence (as } \\
\text { number of beats) }\end{array}$ \\
\hline$<000000>$ & N/A & Single pitch & $\begin{array}{l}\text { E no3 no5, } \\
\text { F no 3 no5 }\end{array}$ & 56 \\
\hline$<000010>$ & N/A & $(0,5)$ & A5 & 37 \\
\hline$<001000>$ & N/A & $(0,3)$ & $\begin{array}{l}\text { A min no5, } \\
\text { B min no 5, } \\
\text { G\# min no 5 }\end{array}$ & 50 \\
\hline$<001110>$ & $3-11$ & $(0,3,7)$ & A min & 23 \\
\hline$<021030>$ & $4-23$ & $(0,2,5,7)$ & E 7th sus 4 & 24 \\
\hline$<100110>$ & $3-4$ & $(0,1,5)$ & Fmaj7 no 5 & 9 \\
\hline$<111120>$ & $4-14$ & $(0,2,3,7)$ & E add 4 & 15 \\
\hline
\end{tabular}

Table 5.5 overleaf details the interval class vectors and chords that occur across Psalom's nine different sections. Only two interval class vectors comprise the sonic content of Sections i, ii, iv, vi, vii, and ix: <000000> (representing the single pitches $\mathrm{E}$ and $\mathrm{F}$, which have no vertical interactions with other pitches in those sections from which to form an interval) and $<001000>$ (A min ${ }^{n 05}$, B min ${ }^{n 05}$, and G\# min no5). The lack of complex harmonic relationships is clearly evidenced in a sonority mapping of Psalom's intervallic content (Figure 5.12 overleaf). Of note are the relatively long spans when only single pitches (denoted by red) or the interval of a minor third (denoted by turquoise) occur throughout the work. This is in contrast with the three relatively brief periods when multiple sonorities sound concurrently (Sections iii, v, and viii), except for the tritone, which is absent in Psalom. 
Figure 5.12: Psalom - sonority map

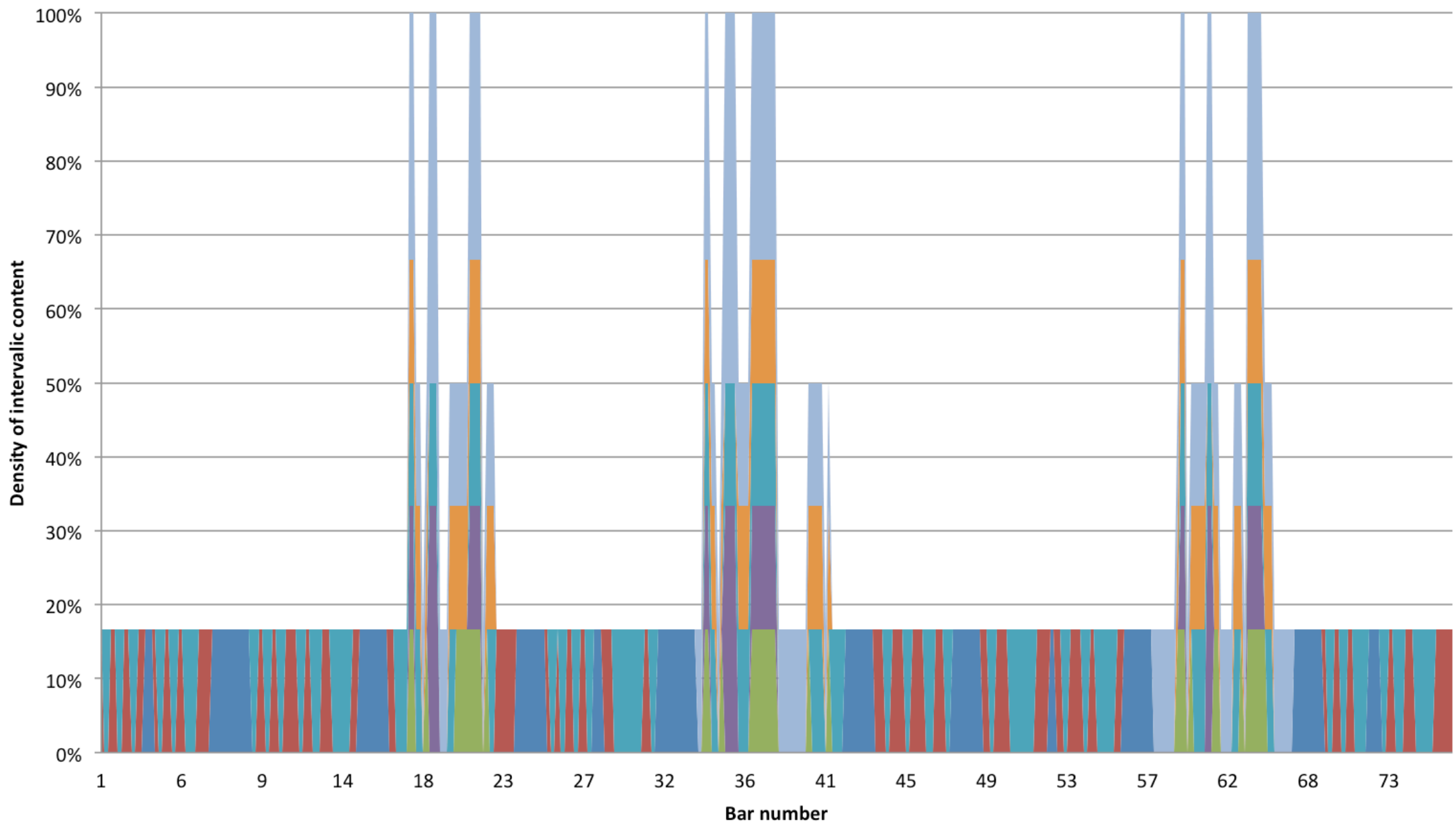

Silence $\square$ Single pitch $=\mathrm{m} 2 \quad \square \mathrm{M} 2 \quad \square \mathrm{m} 3 \quad \square \mathrm{M} 3 \quad \square \mathrm{P} 4 \quad$ Tritone 
Table 5.5: Interval class vectors and chords in the nine different sections of Psalom (frequency of occurrence as number of beats)

\begin{tabular}{|c|c|c|c|c|c|c|c|c|c|c|}
\hline \multirow{2}{*}{$\begin{array}{l}\text { Interval Class } \\
\text { Vector }\end{array}$} & \multirow[b]{2}{*}{ Chords } & \multicolumn{9}{|c|}{ Section } \\
\hline & & i & ii & Iii & iv & $\mathbf{v}$ & vi & vii & viii & ix \\
\hline \multirow{2}{*}{$<000000>$} & E no3 no5 & 9 & 9 & 7 & 6 & & 6 & 10 & & 9 \\
\hline & F no3 no5 & 7 & 6 & 1 & 5 & & 8 & 10 & & 7 \\
\hline$<000010>$ & A5 & & & 5 & & 13 & & & 19 & \\
\hline \multirow{3}{*}{$<001000>$} & A min no5 & 8 & 10 & & 6 & & 4 & 12 & & 10 \\
\hline & B min no5 & 5 & 2 & & 4 & 4 & 3 & 4 & & 4 \\
\hline & G\# min no5 & 4 & 5 & 4 & 9 & & 2 & 4 & & 5 \\
\hline$<001110>$ & A min & & & 6 & & 10 & & & 8 & \\
\hline$<021030>$ & E 7 th sus 4 & & & 3 & & 4 & & & 2 & \\
\hline$<100110>$ & F maj7 no5 & & & 6 & & 3 & & & 6 & \\
\hline$<111120>$ & $\mathrm{E}$ add4 & & & 6 & & 10 & & & 7 & \\
\hline
\end{tabular}

Grey shaded cells indicate sections wherein particular chords or vectors do not occur.

In contrast, Section iii has the greatest variety. This is due to the first violins' droning, pulsing, double stopped dotted crochets at E4 and A4 above the paired M-voices of the second violins and the violas, beginning in the latter part of bar 17 through bar 22 (Figure 5.12 above and Figure 5.13 below). This results in the introduction of a number of additional sonorities <001110> (A min); <021030> (E7th sus 4 ); <100110> (F maj7 no5); and <111120> (E add4). The associated text for these moments of greater harmonic variety in Section iii is "from sunrise to sunset the Lord's name is praiseworthy".

Figure 5.13: Psalom - bars 16-22

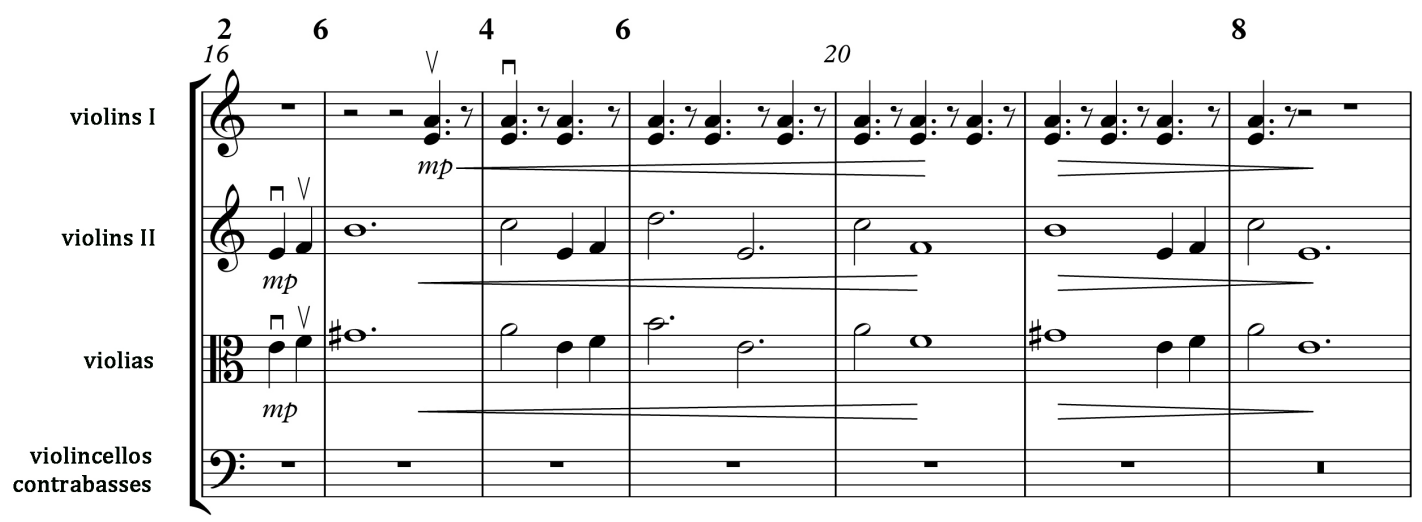


Further sonorities occur in Sections $v$ and viii. In the case of Section $v$, this happens when violins II play sustained double stopped A4 and E5 harmonics, which sound at A5 and E6, during bars 33-38. The musical texture in Section v thickens further in bars 36-38 when the violoncellos and contrabasses, playing divisi, sound the pitches of A2 (sounding as A1 in the contrabasses) and E4 (sounding as E3 in the contrabasses) during bars 36 through the first beat of bar 41 (Figure 5.14). This thickening of texture is associated with the text "who is like our Lord God, who lives on high".

Figure 5.14: Psalom - bars 33-41

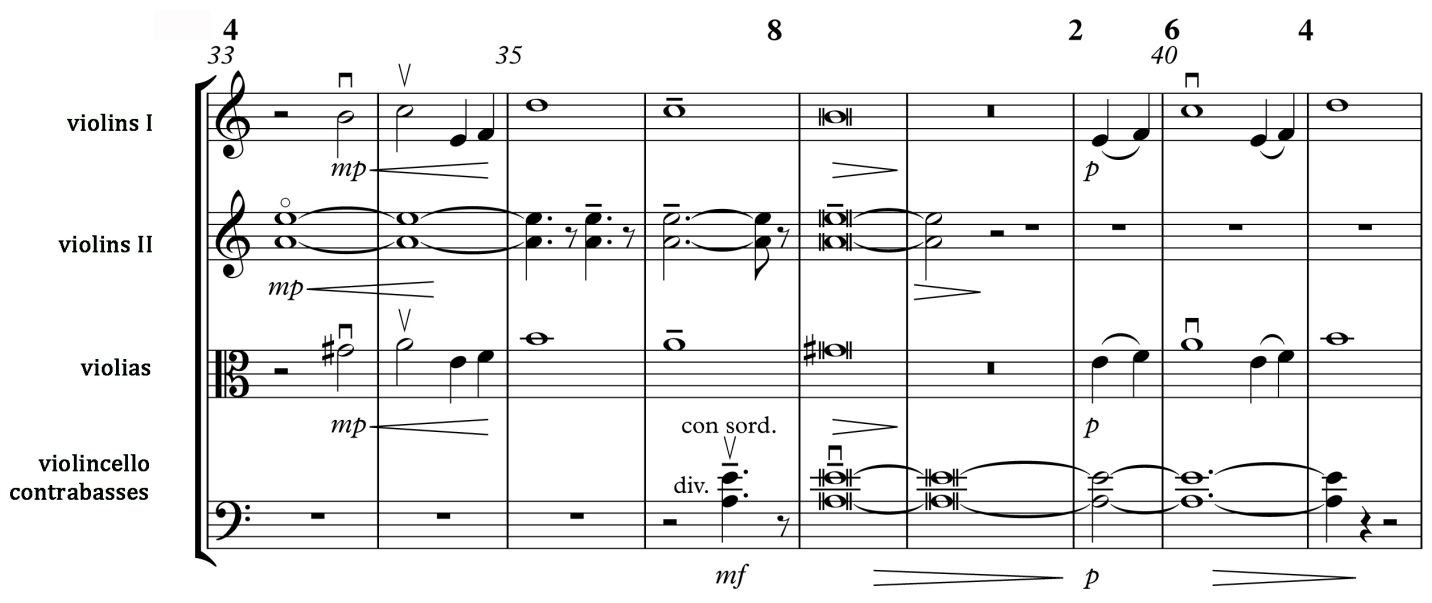

In Section viii, the registral range of Psalom is at its greatest, with violins I playing a sustained A6 during bars 57-66, underpinned by the violoncellos and contrabasses sounding a sustained E (sounding as E2 and E1, respectively) (Figure 5.15). These brief moments of expanded registral range are associated with the text "in order to place him with princes, with the princes of his people". 
Figure 5.15: Psalom - bars 57-66

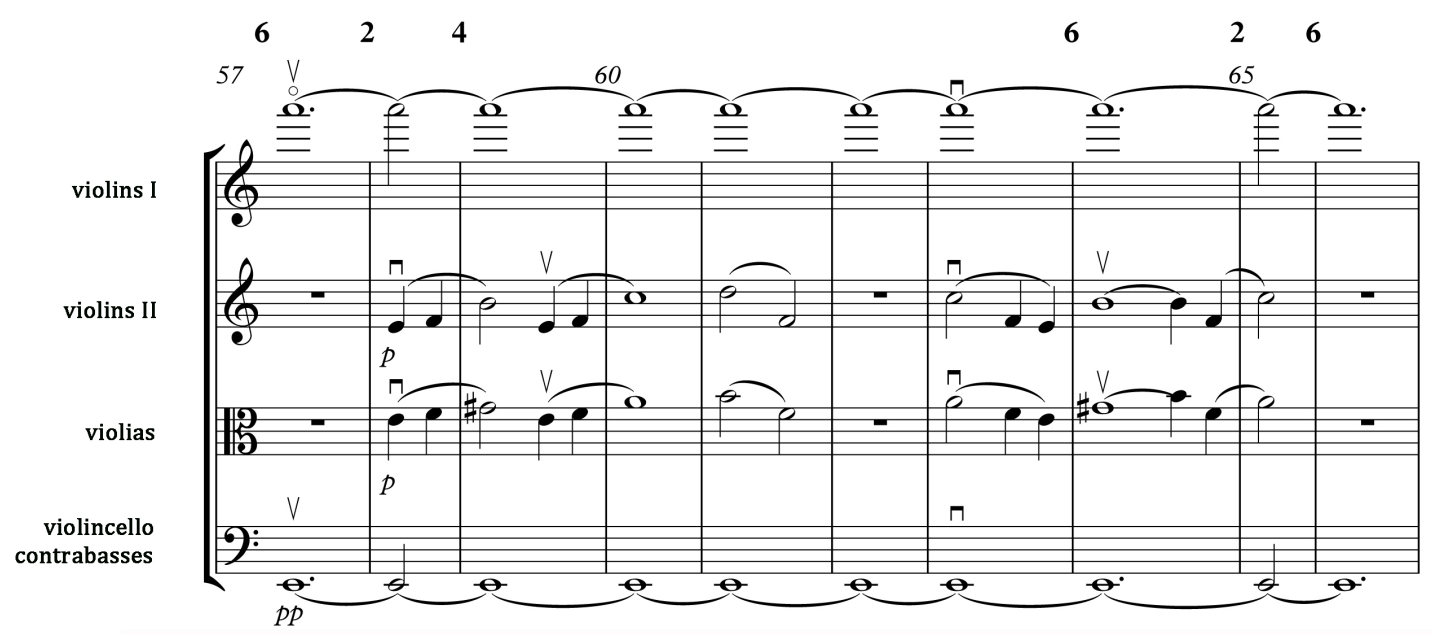

Despite this paucity of complex harmonic content, the listener is not left with the sense that Psalom is lacking in its execution, or that it is an unfinished or incomplete work. As Hillier describes it, Psalom is a "tiny evanescent [work], in which nine varied statements of a single melodic idea are brushed into being, each one vanishing in turn into silence". 201

As a result of the manner in which Pärt has meticulously constructed it, Psalom has a mesmerising 'approach and recede' quality, and an implied sense of purpose in the way that Pärt manages to explore such a limited amount of melodic material, always in a slightly different manner, in each of the work's nine musical statements/sections. There is also a sense of teleology in its design that is enforced by the symmetry within each of its nine sections, as well as the expansion of the working register outwards from the span of a seventh to encompass five octaves and a fourth during the work's penultimate statement, only to then recede back to a span of a seventh in Psalom's final statement.

201 Hillier, Arvo Pärt, 175. 


\section{Silouan's Song}

Silouan's Song (1991), like Psalom, is a text based work, with its M-voice derived from a Russian devotional text by Staretz Silouan the Athonite $\left(1866\right.$ - 1938). ${ }^{202}$ Staretz Silouan was a Russian monk who spent the majority of his adult life in the communal Eastern Orthodox Monastery of Agios Panteleimon on the peninsula of Mount Athos in northeastern Greece. ${ }^{203}$ While almost illiterate, he was an ascetic and spiritual teacher whose hesychastic writings were compiled by his assistant and biographer the Archimandrite Sophrony. Figure 5.16 below is a recreation of the Russian text for Silouan's Song, as it appears in In Principio: The Word in Arvo Pärt's Music ${ }^{204}$, followed by In Principio's rather poetic English translation.

Figure 5.16: Text of Silouan's Song in Russian

Скучает душа моя о Господе, и слезно ищу Его. Как мне Тебя не искать?

Ты прежде взыскал меня, и дал мне насладиться Духом Твоим Святым, Душа моя возлюбила Тебя.

Ты видишь, Господи, печаль мою и слезы... Если бы Ты не привлек меня Своею любовью, то не искал бы я Тебя так, как ищу, но дух Твой дал мне познать Тебя, и радуется душа моя, что Ты мой Бог и Господь, и до слез скучаю я по Тебе.

St. Silouan the Athonite (1866-1938) 205

\footnotetext{
202 Ibid., 177.

203 Anonymous, "St. Panteleimon's Monastery (Athos).”

204 As published by the Arvo Pärt Centre, Rosma, Kõrver, and Kurman, In Principio: The Word In Arvo Pärt's Music, 127.

205 I would like to take this opportunity to acknowledge the input and assistance of Dr. Corinne Seals in the School of Linguistics and Applied Language Studies at Victoria University of Wellington. As part of a series of email correspondences and a personal meeting, Dr. Seals reviewed and corrected my transliteration of the text of Silouan's Song from Russian into the Latin-based International Phonetics Alphabet (IPA) and subsequent syllabification of the Russian words and identification of which syllables in each word (based on the IPA, as well as common modern Russian practice) are stressed. She also reviewed my analysis of the text in relation to which words function as nouns or verbs, and in addition identified the possessive pronouns.
} 
My soul yearns after the Lord and I seek Him in tears. How could I do other than seek Thee, for Thou first didst seek and find me, and gavest me to delight in Thy Holy Spirit, and my soul fell to loving Thee.

Thou seest, 0 Lord, My grief and my tears ... Hadst Thou not drawn me with Thy love, I could not seek Thee as I seek Thee now; but Thy spirit gave me to know Thee, and my Soul rejoices that Thou art my God and my Lord, and I yearn after Thee even to tears. ${ }^{206}$

The text of the poem is an expression of spiritual devotion, longing and the seeking of redemption, which Hillier notes is not dissimilar to the hesychastic aesthetics of Pärt's music. ${ }^{207}$ As noted earlier, hesychasim is a central tenet in the Eastern Orthodox Faith. Anthony Coniaris notes: "the heart of Eastern Orthodox Prayer teaches inner silence" with the aim of achieving an inner "solitude and quietness in order to experience the peace and silence that surround the presence of God". 208 One of the aims of hesychia is to recognise that the voice one hears in prayer does not come from within but is another speaking within. ${ }^{209}$ Hillier and other advocates of Pärt such as Robert Scholl have likened the composer's tintinnabuli music to a musical expression of this tenet. ${ }^{210}$ This is due, in part, to the contemplative nature of works such as Psalom, which emphasise moments of silence at the ends of stanzas and a sense of 'space' between the notes.

\footnotetext{
206 Rosemary Edmonds, trans., "Silouan's Song," in In Principio: The Word In Arvo Pärt's Music (Harjumaa: The Arvo Pärt Centre, 2014), 335.

207 Hillier, Arvo Pärt, 178.

208 Anthony Coniaris, Sacred Symbols That Speak (Edina: Light \& Life Pub Co, 1985), 77.

209 Ibid., 77-78.

210 See also Robert Scholl, "Pärt and Spirituality," in The Cambridge Companion to Arvo Pärt (Boston: Cambridge University Press, 2012), 140-58.
} 


\section{Style analysis of Silouan's Song}

The following style analysis is supplemented by graphic representation in the form of a MIDI-recreation of the work's musical lines to provide a visual overview of the entire work.

\section{Large dimension}

Comprising 66 bars, of varying length, Silouan's Song is a single movement homophonic work for string orchestra (first and second violins, violas, violoncellos, and contrabasses). The work's melodic lines are in C Phrygian mode, and its two M-voices (denoted by the green boxes in Figure 5.17) operate in inverse motion to each other, with $\mathrm{C}$ being the pitch class centre for both.

Unlike Psalom, which technically does not have any 'functional' T-voices, for most of its duration Silouan's Song has two M-voice/T-voice pairings with each of the first position, superior T-voices (denoted by the red boxes) taking pitches from the F minor triad.

Figure 5.17: Silouan's Song - bars 1-5

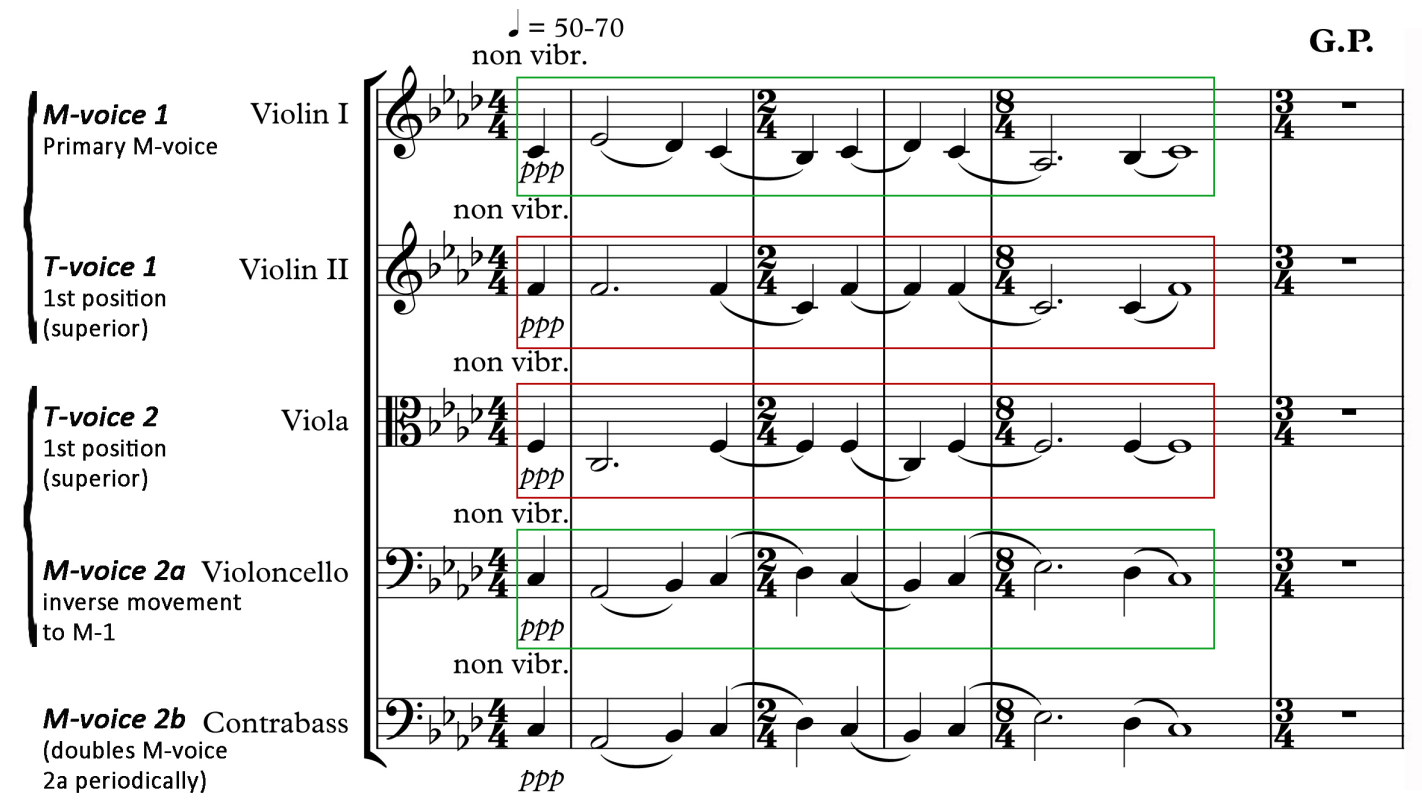


The upper pairing almost always occurs in the violins, with the first and second violins alternating $\mathrm{M}$-voice and T-voice functions. The second pairing occurs in the violoncello and viola sections, with the violoncellos usually taking the M-voice and the violas taking the T-voice. An exception to this arrangement occurs in the 'middle' of the work, which is associated with the eighth and ninth stanzas of the text (bars 35 through 38), when the violoncellos are silent and the violas briefly take over the lower M-voice function.

There are also three points in the work where Pärt expands on the number of functioning M-voice/T-voice pairings by assigning both M-voice and T-voice functions within a divisi string section (bars 35-38, 50-51, and 56-59). Points of heightened emotion in the associated text determine how and why this occurs. These points in the work are discussed in greater detail later in this chapter, when the middle and small dimensions are examined.

As detailed in Figure 5.18, the registral ranges for the string orchestra sections can be divided into primary registers - the registral range in which each section operates for the majority of the piece - and secondary registers that apply to the two violin sections and the violoncellos for a few bars of the work. 


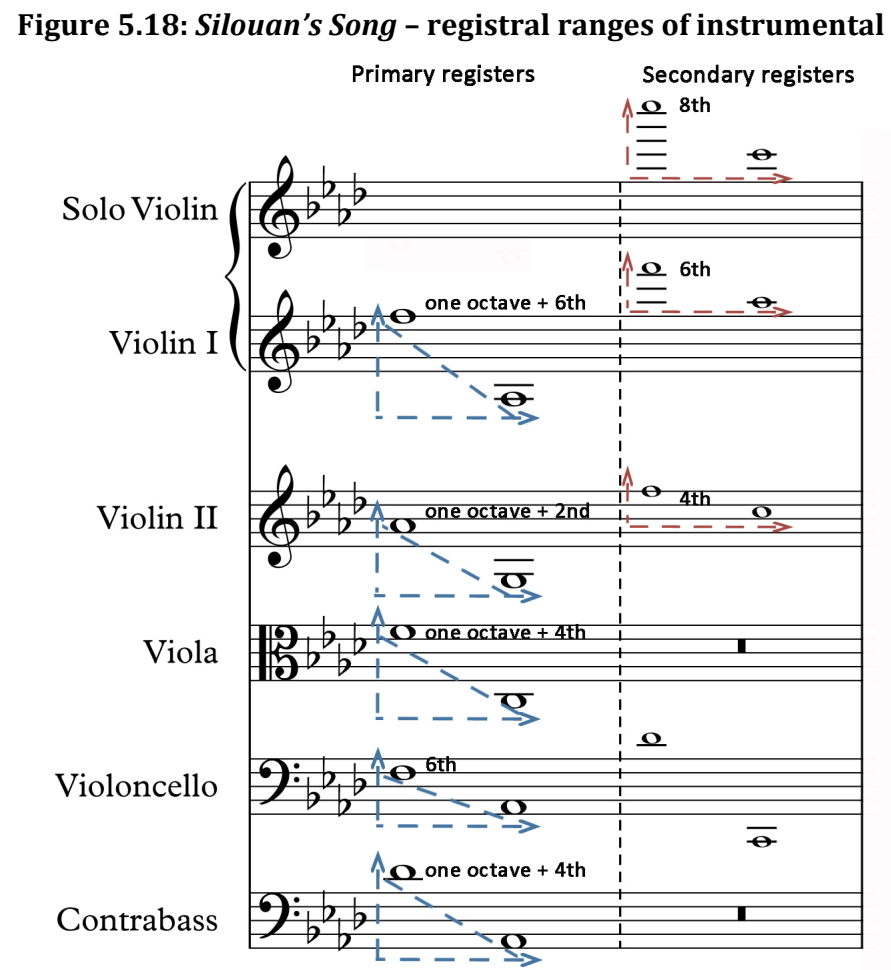

For the majority of the piece the first violins function within the relatively limited range of A3 to F5, or an octave plus an interval of a minor sixth. The exceptions to this are two brief excursions in which they operate in a secondary range of A5 to F6 (bars 32-35 and 56-59). The second violins proceed in a similar fashion, playing primarily between G3 and A4 (a range of one octave plus an interval of a major second), and briefly in a secondary range of C5 to F5 (which again occurs in bars 32-35 and 56-59). Towards the latter part of the work, the principal violin plays in an alternative secondary register, above the rest of the first violins, leaping the span of an octave from C6 to a sustained C7 (bars 57-59).

The sharp contrasts that are introduced by these registral expansions are readily apparent in the MIDI-recreation of Silouan's Song (Figure 5.19 overleaf). Also evident in Figure 5.19 is the clear homophonic structure of the work, as well as the clear delineations of its dynamics within each subsection (as indicated by the MIDI- notes' different colours). 
Figure 5.19: Silouan's Song - MIDI-recreation all strings (with contrabasses shown in their sounding register) ${ }^{211}$

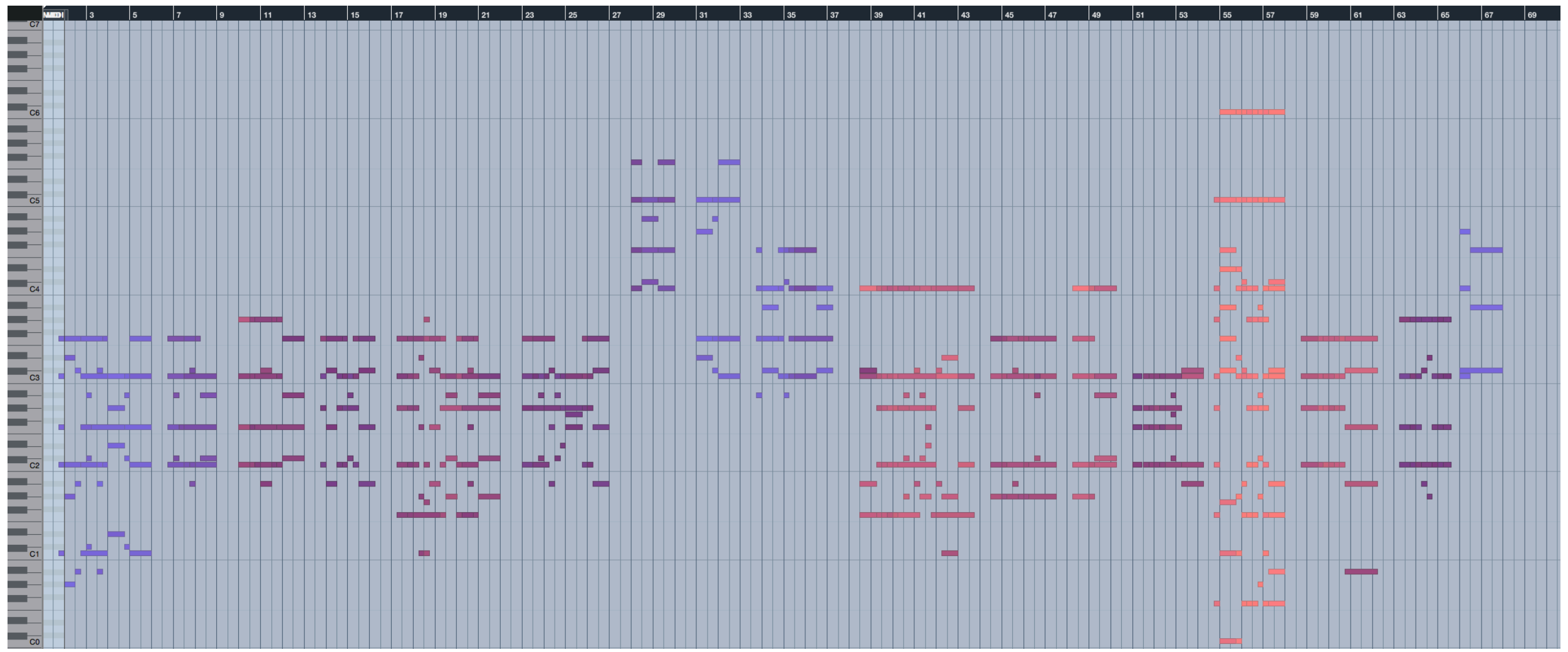

211 Midi-recreation created using Cubase ${ }^{\mathrm{TM}} 7.5$. 
The viola and contrabass sections each have a primary range of only an octave plus a fourth, C3 to F4 and A1 to D2, respectively. For the majority of Silouan's Song, the violoncellos play within a register of A2 to F3 (a registral span of a minor sixth). However, at two different points within the work, they briefly play outside of this range, at one point dropping down to C2 (bar 57), the bottom of the violoncello's playable range, while rising to D4 in inverse to the first violins' descent from A5 to F5 in the final bar of the work.

Silouan's Song is composed of 16 musical statements, with the melodic shape and length of each being determined by the characteristics of the words and punctuation in each phrase of the text (Table 5.6 overleaf). While the direct relationship between the characteristics of each musical statement and the text are discussed in greater detail when the medium and small dimensions are discussed, the statements vary in length from a single bar of eight beats in Statement 8 to 25 beats in Statement 16. Due to parts of the Russian text comprising a number of single syllable words in a row, musically the work alternates between the various instrumental lines sounding reciting tones in alternation with periods when the melody proceeds upwards and downwards, in relation to a central pitch class. 
Table 5.6: Silouan's Song - metrical structure

\begin{tabular}{|l|c|c|c|c|c|c|c|c|}
\hline Statement & $\begin{array}{c}\text { Number of } \\
\text { bars }\end{array}$ & \multicolumn{6}{|c|}{ Beats per bar } & $\begin{array}{c}\text { Duration as total } \\
\text { number of beats }\end{array}$ \\
\hline $\mathbf{1}$ & $\mathbf{5}$ & 4 & 2 & 2 & 8 & 3 & $\mathbf{1 9}$ \\
\hline $\mathbf{2}$ & $\mathbf{5}$ & 1 & 3 & 2 & 3 & 4 & $\mathbf{1 3}$ \\
\hline $\mathbf{3}$ & $\mathbf{4}$ & 4 & 4 & 4 & 3 & & & $\mathbf{1 5}$ \\
\hline $\mathbf{4}$ & $\mathbf{5}$ & 1 & 4 & 2 & 3 & 4 & $\mathbf{1 4}$ \\
\hline $\mathbf{5}$ & $\mathbf{6}$ & 6 & 3 & 4 & 2 & 4 & 4 & $\mathbf{2 3}$ \\
\hline $\mathbf{6}$ & $\mathbf{6}$ & 3 & 2 & 3 & 5 & 3 & 4 & $\mathbf{2 0}$ \\
\hline $\mathbf{7}$ & $\mathbf{3}$ & 2 & 6 & 4 & & & & $\mathbf{1 2}$ \\
\hline $\mathbf{8}$ & $\mathbf{1}$ & 8 & & & & & & $\mathbf{8}$ \\
\hline $\mathbf{9}$ & $\mathbf{4}$ & 4 & 6 & 7 & 5 & & & $\mathbf{2 2}$ \\
\hline $\mathbf{1 0}$ & $\mathbf{6}$ & 8 & 2 & 2 & 3 & 6 & 3 & $\mathbf{2 4}$ \\
\hline $\mathbf{1 1}$ & $\mathbf{4}$ & 4 & 4 & 4 & 3 & & & $\mathbf{1 5}$ \\
\hline $\mathbf{1 2}$ & $\mathbf{3}$ & 4 & 4 & 3 & & & & $\mathbf{1 1}$ \\
\hline $\mathbf{1 3}$ & $\mathbf{3}$ & 7 & 2 & 4 & & & & $\mathbf{1 3}$ \\
\hline $\mathbf{1 4}$ & $\mathbf{4}$ & 3 & 7 & 2 & 6 & & & $\mathbf{1 8}$ \\
\hline $\mathbf{1 5}$ & $\mathbf{3}$ & 8 & 4 & 4 & & & & $\mathbf{1 6}$ \\
\hline $\mathbf{1 6}$ & $\mathbf{4}$ & 5 & 8 & 6 & 6 & & & $\mathbf{2 5}$ \\
\hline
\end{tabular}

The tempo marking for Silouan's Song is $\rfloor=50-70$ (between 50 and 70 beats per minute). Starting with the pickup to bar 57, Pärt indicates that bars 57 through 62 should be played Largo, between 40 and 60 beats per minute, and a further indication in bar 63 that the final bars of the work should be played slightly slower than that, i.e. più lento. In performance Silouan's Song is intended to last between five and six minutes in duration, as indicated at the end of the score. ${ }^{212}$

The melodic and rhythmic motion of Silouan's Song varies from statement to statement, due to aspects of individual words and phrasing within the text (discussed in detail when the small dimensional aspects are examined). However, the general arch of the melodic motion can be distilled down to two M-voices, operating in inverse of each other, moving away from and towards a single central pitch class centre (pitch class C), stepwise or by intervallic leap, with each phrase ending in a bar of silence.

212 Arvo Pärt, Silouan's Song, UE 19889 (Wien: Universal Edition, 1991), 4. 
This is illustrated in the first five bars of the work (Figure 5.20), wherein the first violins move away from and towards the pitch centre, alternatively above and below C3. The violoncellos' motion is inverse to that of the violins moving away from and towards the pitch centre again below and above $\mathrm{C} 2$.

Figure 5.20: Silouan's Song - melodic movement above and below a central pitch.

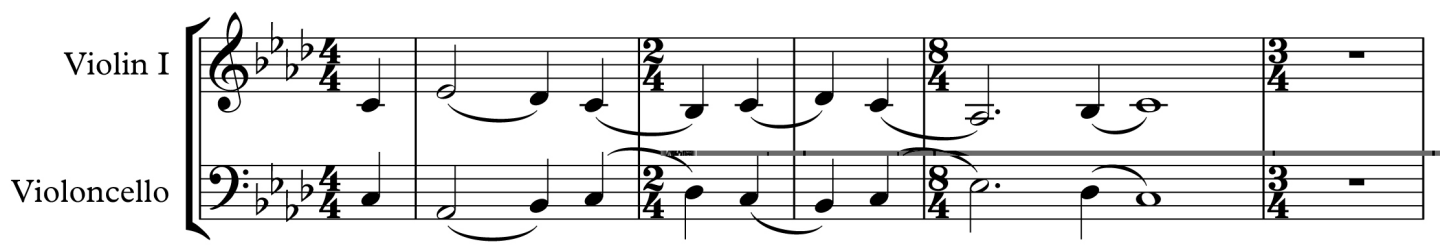

To the listener, this invokes a sense of expansion and contraction from a single pitch centre, with each melodic statement starting with pitch class $C$ and almost always ending on either pitch $\mathrm{C}, \mathrm{Db}$ or $\mathrm{Bb}$, followed by a moment of repose. Due to the inverse nature of the two M-voice operations, when the upper M-voice line ends on $\mathrm{Db}$ the lower M-voice ends on $\mathrm{Bb}$ and vice versa. There are two exceptions to the M-voices commencing a statement from pitch class C: the first is Statement 8, in which the upper M-voice starts on $\mathrm{Ab}$ and ends on $\mathrm{C}$, and the lower M-voice, which has shifted briefly to the violas, moves in inverse from Eb downwards to C; the second occurrence is in Statement 10, which starts on Db in the upper M-voice and $\mathrm{Bb}$ in the lower M-voice. Both statements, however, end at pitch class $\mathrm{C}$, keeping them firmly grounded within the C Phrygian mode.

\section{Middle dimension}

The dynamics of Silouan's Song vary across its 16 statements, with each statement starting at a different dynamic level than the preceding statement (Table 5.7 overleaf). For 11 of the 16 statements $(1-4,6-8,10-12$, and 15) the dynamics do not deviate from the dynamic marking at the beginning of the statement. 
Table 5.7: Silouan's Song - dynamics as indicated in the score

\begin{tabular}{|c|c|c|c|}
\hline Statement & $\begin{array}{l}\text { Starting } \\
\text { dynamic }\end{array}$ & Dynamic variation & $\begin{array}{l}\text { Silence \& } \\
\text { duration }\end{array}$ \\
\hline 1 & $\begin{array}{l}\text { ppp } \\
\text { pickup to bar } 1\end{array}$ & none & $\begin{array}{l}\text { final bar } 5 \\
3 \text { beats }\end{array}$ \\
\hline 2 & $p p$ bar 6 & none & $\begin{array}{l}\text { final bar } 10 \\
4 \text { beats }\end{array}$ \\
\hline 3 & $\boldsymbol{m p}$ bar 11 & none & $\begin{array}{l}\text { final bar } 14 \\
\text { final } 3 \text { beats }\end{array}$ \\
\hline 4 & $\boldsymbol{p}$ bar 15 & None & $\begin{array}{l}\text { final bar } 19 \\
4 \text { beats }\end{array}$ \\
\hline 5 & $\boldsymbol{m p}$ bar 20 & $\begin{array}{l}\text { crescendo last } 3 \text { beats of bar } 20 \text {, decrescendo last } 3 \\
\text { beats of bar } 22\end{array}$ & $\begin{array}{l}\text { final bar } 25 \\
4 \text { beats }\end{array}$ \\
\hline 6 & $p$ bar 26 & None & $\begin{array}{l}\text { final bar } 31 \\
4 \text { beats }\end{array}$ \\
\hline 7 & pp bar 32 & None & $\begin{array}{l}\text { final bar } 34 \\
4 \text { beats }\end{array}$ \\
\hline 8 & ppp bar 35 & None & \\
\hline 9 & $\begin{array}{l}\text { pppp } \\
\text { pickup to bar } 37\end{array}$ & $\begin{array}{l}\text { crescendo last } 3 \text { beats of bar } 37 \text {, decrescendo } \\
\text { throughout bar } 38 \text { ( } 7 \text { beats) }\end{array}$ & $\begin{array}{l}\text { first } 3 \text { beats bar } \\
3 \text { \& final bar } 39 \\
5 \text { beats }\end{array}$ \\
\hline 10 & $f$ bar 40 & None & $\begin{array}{l}\text { final bar } 45 \\
3 \text { beats }\end{array}$ \\
\hline 11 & $\boldsymbol{m f}$ bar 46 & None & $\begin{array}{l}\text { final bar } 49 \\
3 \text { beats }\end{array}$ \\
\hline 12 & $\boldsymbol{f}$ bar 50 & None & $\begin{array}{l}\text { final bar } 52 \\
3 \text { beats }\end{array}$ \\
\hline 13 & $\boldsymbol{m p}$ bar 53 & $\begin{array}{l}\text { crescendo two beats for the duration of bar } 54 \text {, } \\
\text { decrescendo throughout bar } 55\end{array}$ & \\
\hline 14 & $\begin{array}{l}\text { fff } \\
\text { pickup to bar } 56\end{array}$ & None & $\begin{array}{l}\text { first } 3 \text { beats bar } \\
56 \text { \& last } 3 \text { beats } \\
\text { of final bar } 59\end{array}$ \\
\hline 15 & $f$ bar 60 & $\begin{array}{l}\text { decrescendo throughout bar } 61 \text { (four beats with } \\
\text { fermata) }\end{array}$ & $\begin{array}{l}\text { final bar } 62 \\
4 \text { beats }\end{array}$ \\
\hline 16 & $p$ bar 63 & $\begin{array}{l}\text { dynamics change from } p \text { to } p p p \text { last two beats bar } \\
64 \text {, decrescendo throughout out bar } 65 \text { ( } 6 \text { beats) } \\
\text { to silence bar } 66\end{array}$ & $\begin{array}{l}\text { latter half of beat } \\
6 \text { and beat } 7 \text {, bar } \\
64 \text { \& final bar } 66 \\
6 \text { beats }\end{array}$ \\
\hline
\end{tabular}

All but three of the 16 statements end with a full bar of silence, which Pärt indicates should be treated as a Grand Pause. An example of this can be seen in the first and second violin lines in the opening statement of the work (Figure 5.21).

Figure 5.21: Silouan's Song - opening statement

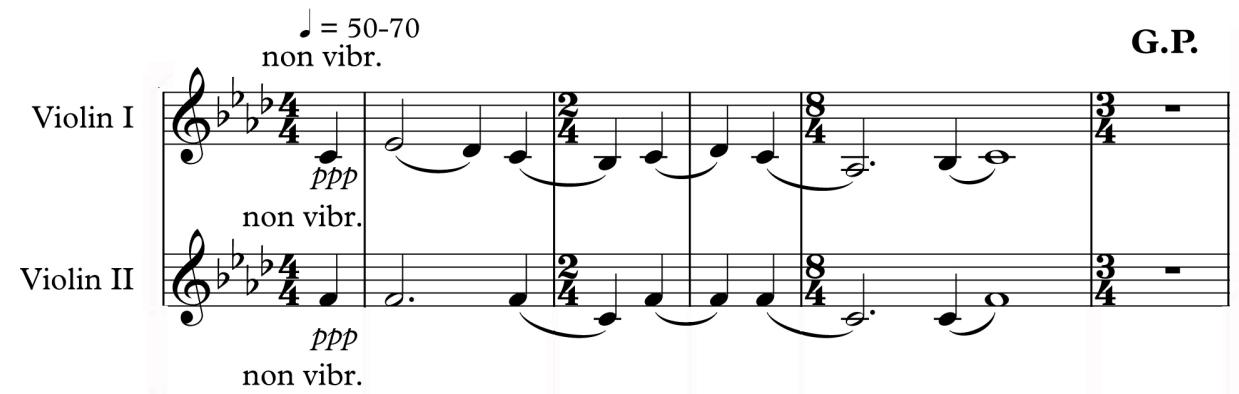


The exceptions are Statements 8 and 13, in which the 'bar' of silence has been displaced into the first three (Statement 8) or two (Statement 13) beats of the first bar of the next statement (Figure 5.22).

Figure 5.22: Silouan's Song - Statements 8, 13 and 14 (first violins)
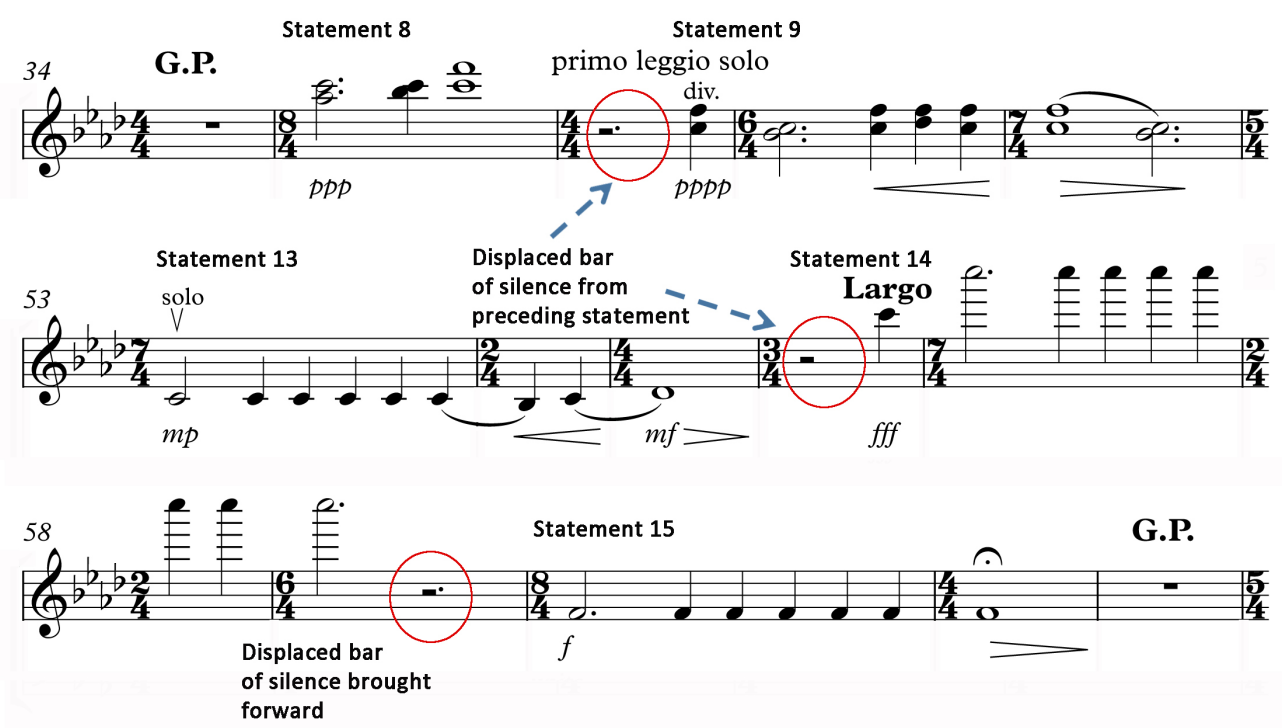

Table 5.8 details the metrical schema of the work, including full bars of silence (denoted by grey cells in the table).

Table 5.8: Silouan's Song - metrical structure with silent bars denoted in grey

\begin{tabular}{|c|c|c|c|c|c|c|c|c|}
\hline Statement & $\begin{array}{c}\text { Number of } \\
\text { bars }\end{array}$ & \multicolumn{6}{|c|}{ Beats per bar } & $\begin{array}{l}\text { Duration as total } \\
\text { number of beats }\end{array}$ \\
\hline 1 & 5 & 4 & 2 & 2 & 8 & 3 & & 19 \\
\hline 2 & 5 & 1 & 3 & 2 & 3 & 4 & & 13 \\
\hline 3 & 4 & 4 & 4 & 4 & 3 & & & 15 \\
\hline 4 & 5 & 1 & 4 & 2 & 3 & 4 & & 14 \\
\hline 5 & 6 & 6 & 3 & 4 & 2 & 4 & 4 & 23 \\
\hline 6 & 6 & 3 & 2 & 3 & 5 & 3 & 4 & 20 \\
\hline 7 & 3 & 2 & 6 & 4 & & & & 12 \\
\hline 8 & 1 & 8 & & & & & & 8 \\
\hline 9 & 4 & 4 & 6 & 7 & 5 & & & 22 \\
\hline 10 & 6 & 8 & 2 & 2 & 3 & 6 & 3 & 24 \\
\hline 11 & 4 & 4 & 4 & 4 & 3 & & & 15 \\
\hline 12 & 3 & 4 & 4 & 3 & & & & 11 \\
\hline 13 & 3 & 7 & 2 & 4 & & & & 13 \\
\hline 14 & 4 & 3 & 7 & 2 & 6 & & & 18 \\
\hline 15 & 3 & 8 & 4 & 4 & & & & 16 \\
\hline 16 & 4 & 5 & 8 & 6 & 6 & & & 25 \\
\hline
\end{tabular}


In all three instances in which the expected bar of silence at the end of a statement has been displaced, this occurs at a point in the text where grammatically the phrase in question is a sub-clause of a larger sentence structure spanning more than one musical statement, and where the respective lines of text are at points of emotional climax within the poem (Statements 7 through 9 and 13 through 15).

This is illustrated in Figure 5.23, in which the various lines of text have been organised to match the 16-statement structure of the musical work, alongside a poetic, rather than literal, English translation of Silouan's Song. The texts associated with musical Statements 7 through 9 and 14 are shaded in grey. Musically, Pärt expresses these points of heightened emotion through extremes in the dynamics. The musical Statements 7,8 , and 9 occur at a point in the text at which the narrator seems to express profound vulnerability, i.e. Thou seest, $O$ Lord, my grief and tears...".

Figure 5.23: Silouan's Song - text as distributed across 16 musical statements ${ }^{213}$

${ }^{1}$ Скучает душа моя о Господе,

${ }^{2}$ и слезно ищу Его.

${ }^{3}$ Как мне Тебя не искать?

${ }^{4}$ Ты прежде взыскал меня,

${ }^{5}$ и дал мне насладиться Духом Твоим вятым,

${ }^{6}$ и душа моя возлюбила Тебя.

${ }^{7}$ Ты видишь,

${ }^{8}$ Господи,

${ }^{9}$ печаль мою и слезы..

${ }^{10}$ Если бы Ты не привлек меня Своею любовью,

${ }^{11}$ то не искал бы я Тебя так,

12 как ищу,

${ }^{13}$ но дух Твой дал мне познать Тебя,

${ }^{14}$ и радуется душа моя,

15 что Ты мой Бог и Господь,

${ }^{16}$ и до слез скучаю я по Тебе.
My soul yearns after the Lord, and I seek him in tears.

How could I do other than to seek thee?

For though didst seek and find me, and gavest me to delight in Thy Holy Spirit, and my soul fell to loving Thee.

Thou seest,

O Lord,

my grief and tears..

Hadst Thou not drawn me with Thy love, I could not seek Thee as I seek Thee now; but my spirit gave me to know thee and my soul rejoices that Thou art my God and my Lord and I yearn after thee even to tears.

213 Edmonds, “Silouan's Song," 335. 
The dynamic markings associated with each of these statements are $p p, p p p$, and pppp, respectively, which gives the listener the impression that, were the text of Silouan's Song sung, Statement 9 would be performed almost as a whisper (Figure 5.24). This is in stark contract with Statement 14 (Figure 5.25) associated with the text “и радуется душа моя", (“and my soul rejoices"). At this point, the texture and dynamics of Silouan's Song come to an 'exultant climax', with a registral range spanning from $\mathrm{C} 0$ in the contrabasses to $\mathrm{C} 7$ in the solo violin line, a dynamic marking of $f f f$ across the entire string orchestra, and a slight slowing of the tempo from $\rfloor=50-70$ to Largo $\rfloor=40-60$.

Figure 5.24: Silouan's Song - Statements 7, 8, and 9

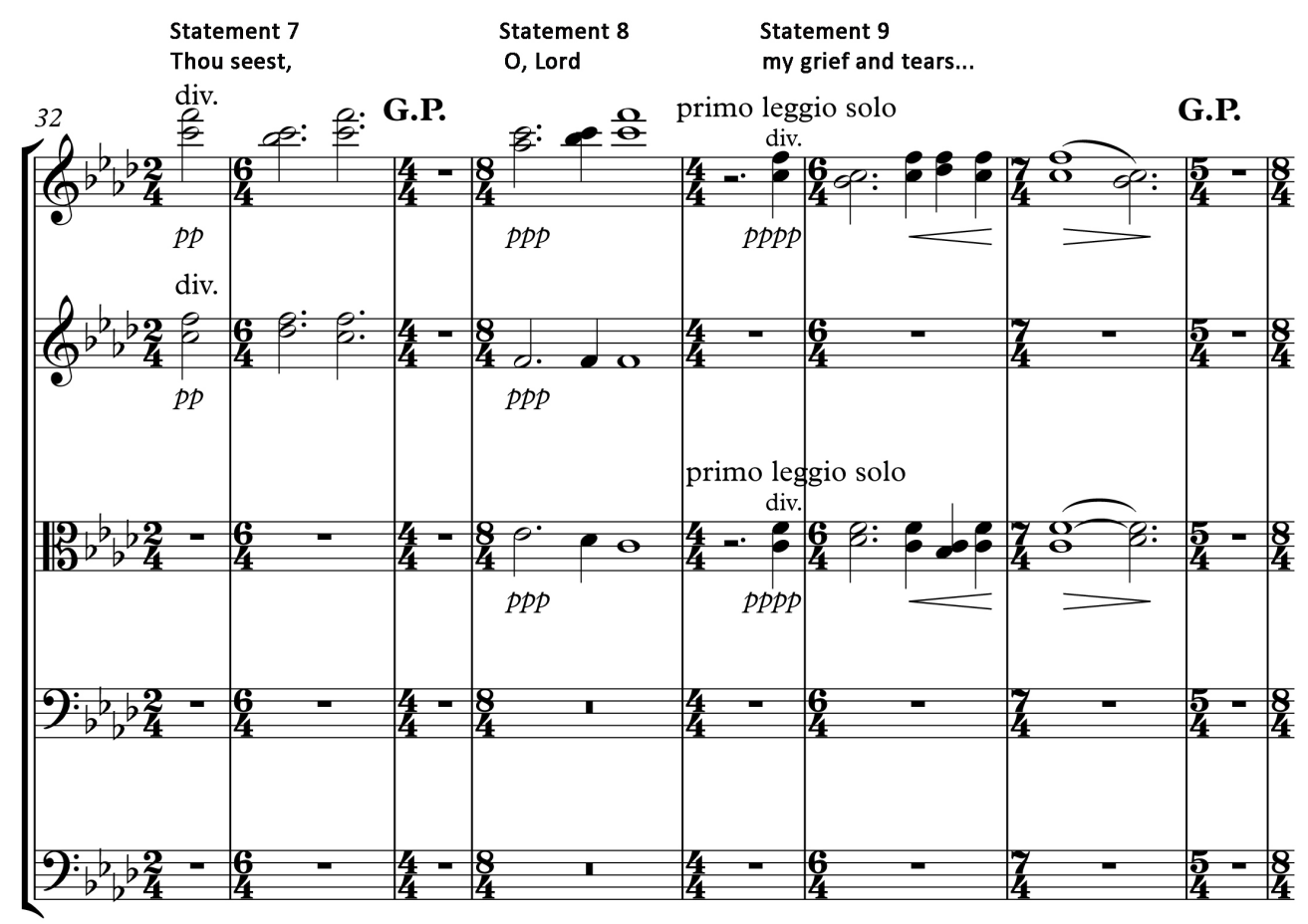


Figure 5.25: Silouan's Song - Statement 14

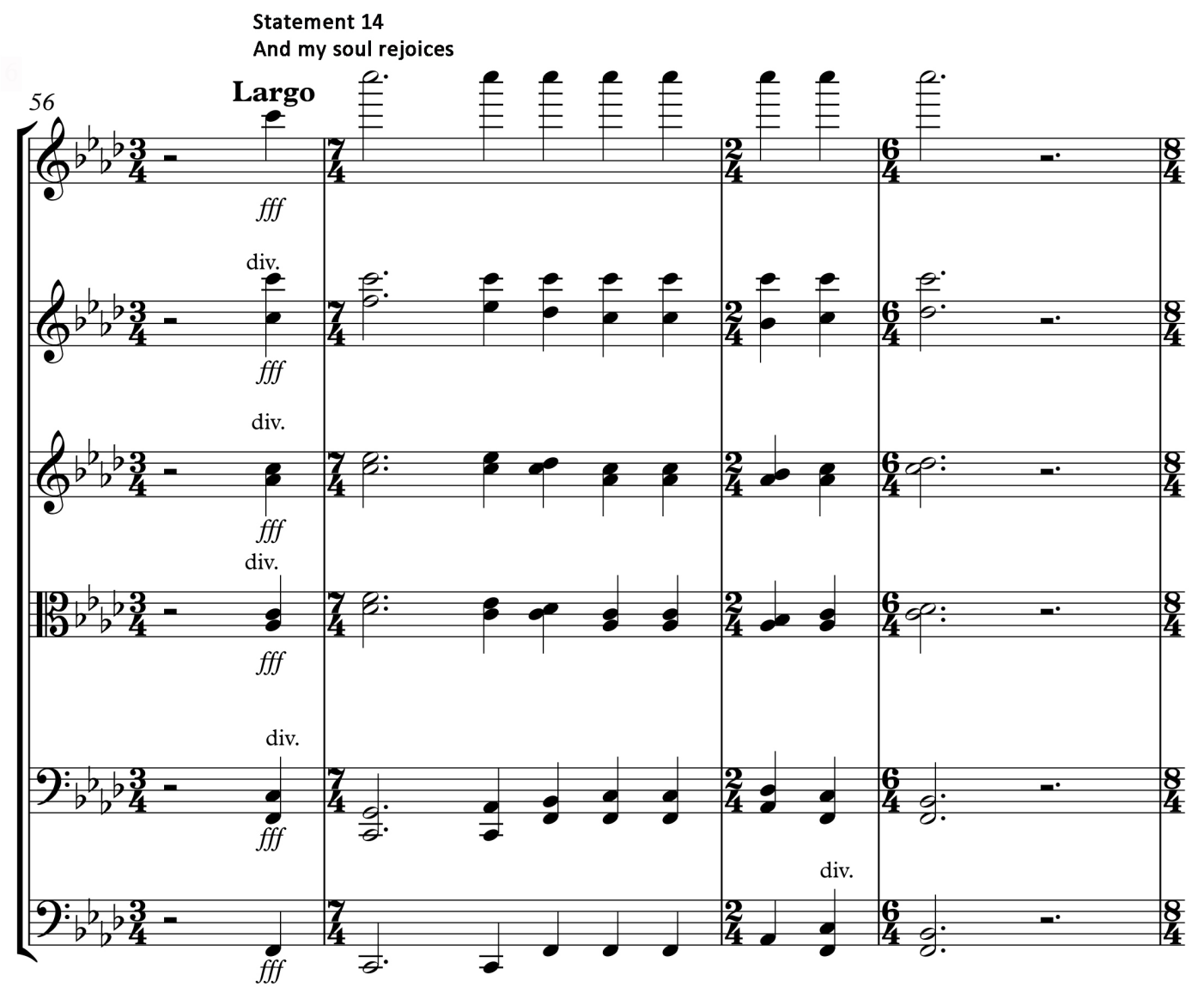




\section{Small dimension}

As in Psalom, characteristics of individual words and syllables of the text determine the melodic and rhythmic shape of Silouan's Song in the small dimension. However, whereas the parameters for Psalom were relatively straightforward, for Silouan's Song Pärt constructed his M-voice material with a significantly more complicated schema of text-derived compositional parameters.

\section{Text-based rules for Silouan's Song}

Below is a summary of the various M-voice rules that apply to the majority of Silouan's Song:

1. The M-voice pitch centre is $\mathrm{C}$.

2. Monosyllabic words always take the pitch class centre.

3. Movement away from the pitch class centre occurs primarily where the associated text comprises multisyllabic words.

4. When movement away from the pitch class centre occurs, this is in alternation above and below the pitch class centre.

5. When a multisyllabic word occurs in the text, additional rules apply as to how melodic movement, phrasing, and durations of pitch are assigned to words and syllables in the text:

a) The stressed syllable falls on the first beat of a measure.

b) When the stressed syllable is not the first syllable, this means that words and the associated melodic movement extend across bar lines.

c) Each measure continues until the next stressed syllable occurs. 
d) For words with three or more syllables, the stressed syllable usually occurs on the pitch that is most distant from the pitch class centre, with the intervallic distance from the pitch class centre being determined by the total number of syllables in the word. For example in a word with three syllables, the most distant pitch is an interval of a third from the pitch class centre, regardless on which syllable the stress occurs.

e) After an intervallic leap away from the pitch class centre, the melody moves stepwise back towards the central pitch of $\mathrm{C}$.

f) The duration of pitches assigned to stressed syllables varies depending upon which syllable of the word they fall on, word length, and the word's location within each musical statement:

i. If the stressed syllable in a two-syllable word is the first syllable, it is assigned a duration of two beats.

ii. If the stressed syllable in a two-syllable word is the second syllable, it is assigned a duration of one beat, with two exceptions: a) if it is the second syllable of the first word of a statement, it is the duration of two beats; b) if it is the last syllable of a statement, it is assigned a duration of three or more beats.

iii. Stressed syllables at the beginning of words with three or more syllables are assigned a duration of three beats.

iv. Where a stressed syllable is in the middle of a three syllable word and its assigned pitch is approached by a skip of an interval of a third, it is assigned a duration of two beats. If its 
assigned pitch is approached in a stepwise manner, it is assigned one beat in duration.

v. Where a stressed syllable occurs on the second or third beat of a four syllable word, it is assigned a duration of two beats with the additional condition that it does not share the bar with any syllables of another word. If it shares the remainder of the bar with one or more syllables of another word, it is assigned a duration of three beats.

Figure 5.26 illustrates an application of some of the more basic parameters described above in the upper M-voice line of Statement 1 of the work.

Figure 5.26: Silouan's Song - upper M-voice line Statement 1

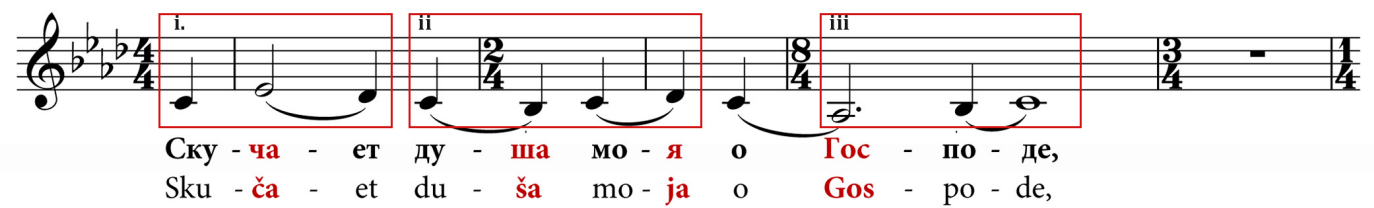

As indicated in example $i$, the statement opens with the three-syllable word “Скучет" (pronounced sku-ča-et). As the second syllable "уч" is stressed, the first syllable "ску" осcurs as a pickup beat to bar one, with "уч" falling on the first beat of measure one. Because it is a three-syllable word, and the movement from the pitch class centre is by a skip of a minor third, "yч" is assigned a duration of two beats. On the third syllable of the word "ет", the M-voice moves back towards the pitch class centre stepwise.

In example ii, the words "душа" and "моя" are both two-syllable words with stress on the second syllable of each. In both cases, the first unstressed syllable falls on C. The stressed syllables of each word mark the commencement of a new 
bar, occur one pitch away from the pitch class centre, and are given the value of only one beat each, as they occur at the end of each word and neither ends the musical statement.

In example iii the Russian word for Lord, "Господе" (pronounced Gos-po-de), is a three-syllable word with the stressed syllable being first. "Гoc" marks the beginning of a new bar, an interval of a third away from the pitch class centre of C. As it is the first syllable of a three-syllable word it is given a value of three beats. The second syllable marks a stepwise progression back towards C. The final syllable "де" ends Statement 1 on the M-voice's pitch class centre and is given the value of four beats.

Statements 2 (bars 6-10), 3 (bars 11-14), and 4 (bars 15-19) follow a similar pattern of rules as those discussed above for Statement 1 (bars 1-5). While not readily apparent when examined individually, when seen as a group Statements 1 through 4 also reveal another text dictated rule in relation to the number of beats that are allocated to the first bar of each statement (Figure 5.27). As noted previously, Statement 1 commences with a multisyllabic word that has a stressed second syllable, with the unstressed syllable being assigned the value of one beat as a pickup beat to bar 1 . Both Statements 2 and 4 start with a single syllable word "И" and "Ты", respectively, but are immediately followed by a multisyllabic word that commences with a stressed syllable. Where this is the case, Pärt assigns these words their own bar with a value of one beat (bars 6 and 15). 


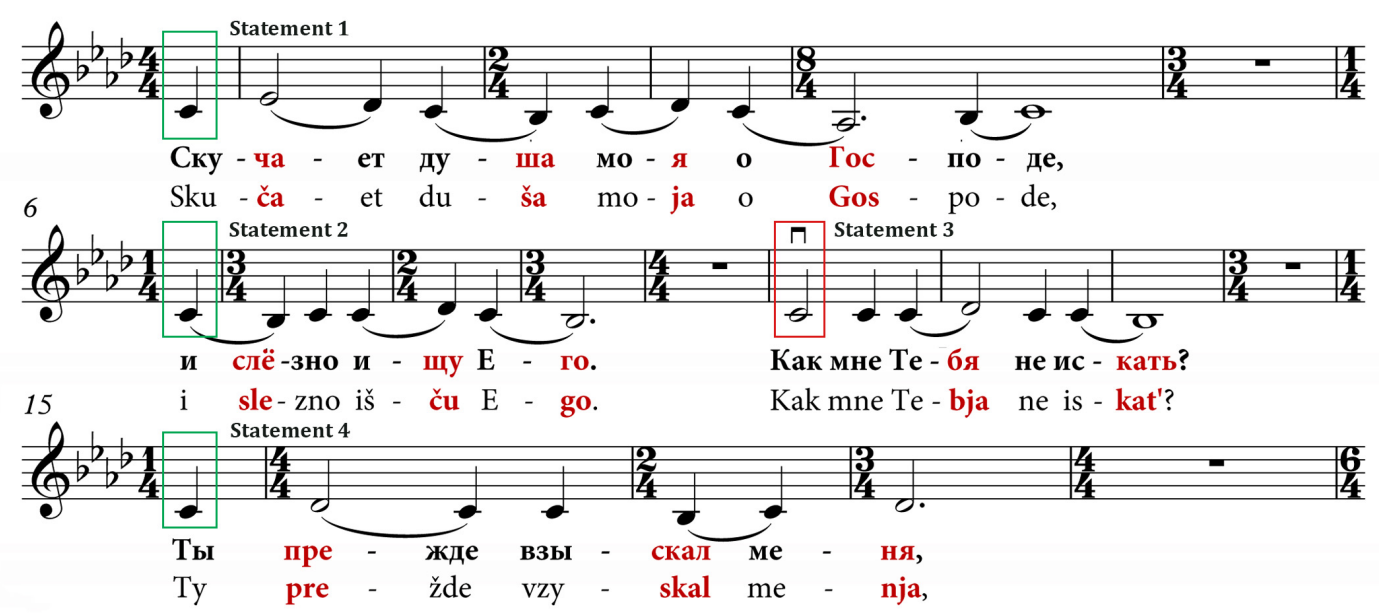

Statement 3 deviates from this pattern; while the statement also commences with a single syllable word "Как", it is not immediately followed by a multisyllabic word with a stressed syllable. When this occurs in the text, Pärt allocates two beats to the first word of the statement (as indicated by the red box in the figure, bar 11), and the bar continues until a stressed syllable of a multisyllabic word next occurs in the text.

For words of three or more syllables in which the stress falls on the penultimate syllable, Pärt introduces an additional rule that takes precedence over the rules of pitch class order as described above. When this occurs, the pitches that would normally comprise an expected progression from the pitch class centre (e.g. 0-13-5 or $0-10-8-7$ ) are still used, but they are reordered, introducing a greater degree of variety to the melodic movement of the M-voices. This is illustrated in Statement 5 (Figure 5.28) in relation to the pitches associated with the word “насладиться", (pronounced as nas-la-dit-'sja) the infinitive form of a Russian verb meaning 'to enjoy'. Pärt still follows the established rules in relation to commencing a new bar with the stressed syllable “ди" and allocates the syllable a metric value of two beats in recognition that it is the second to last syllable. 
Figure 5.28: Silouan's Song - upper M-voice line Statement 5

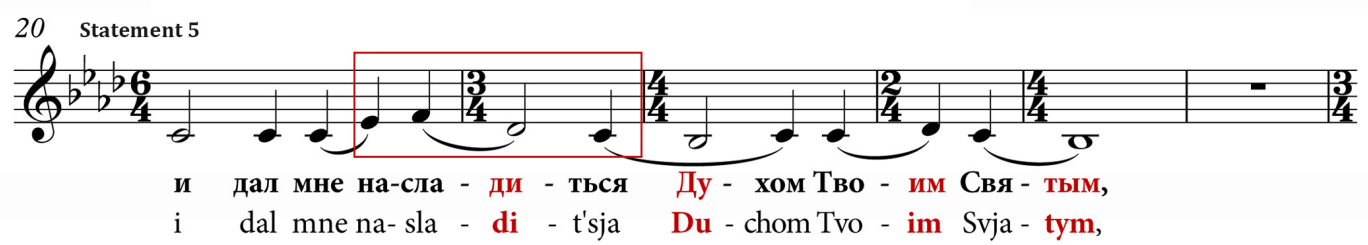

The word also comprises four syllables, and as such it spans the interval of a fourth from its most distant point to the pitch class centre of C. However, Pärt opts to deviate from the pattern he previously used in relation to the melodic movement of the M-voice for multisyllabic words. Based on the precedence of Statements 1, 2, and 4, one would expect that the rules would dictate that both of the syllables “на" and "сла" would take C and Db, respectively, as their sounding pitches, with the intervallic leap by a second to $\mathrm{F}$ (a fourth away from the Mvoice's pitch centre) occurring on the stressed third syllable “ди”. However, were this the case, it would result in the word ending a third away from the pitch class centre on Eb. This would require the M-voice to leap by a third to the pitch class centre $\mathrm{C}$ at the commencement of the next word - a deviation from the established rule in relation to always approaching the pitch class centre of the Mvoice in a stepwise manner. In order to resolve this conflict between two different rules, Pärt choses to reorder the pitch class progression associated with the word “насладиться” from the expected 0-1-5-3 (C-Db-F-Eb) to 3-5-1-0 (Eb-F-Db-C).

Statement 6 (Figure 5.29) - which also contains a four syllable word “возлюбила" (pronounced voz-lju-bi-la and meaning 'loved') with the stress following on the penultimate syllable “би" or $b i$ - deals with the same conflict between the rules regarding: a) always starting on the pitch class centre, unless the first syllable is the stressed syllable; b) the stressed syllable taking a pitch that is the equivalent intervallic distance from the pitch class centre as the 
number of syllables in the word; and c) approaching the return to pitch class centre in a stepwise manner.

Figure 5.29: Silouan's Song - upper M-voice line Statement 6

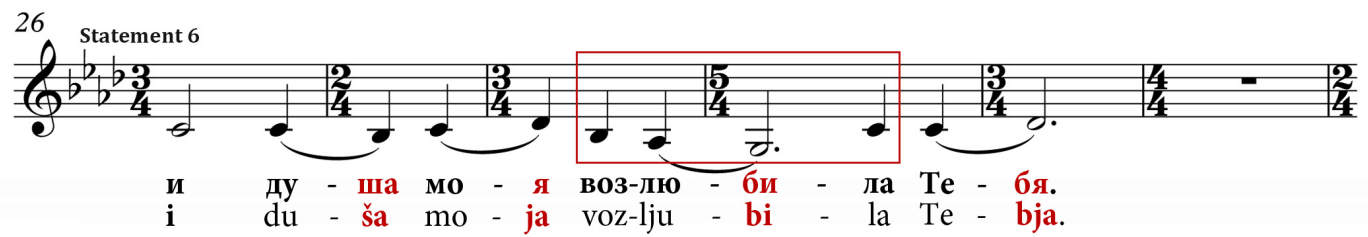

In the case of “озлюбила" in Statement 6, the word also follows a stressed syllable in the preceding word "моя" with the syllable "я" falling on Db. However, the expected downward pitch-class progression of $0-10-7-8(\mathrm{C}-\mathrm{Bb}-\mathrm{G}-\mathrm{Ab})$ would again result in the melody having to leap by a third to $\mathrm{C}$ to commence the next word. In this case Pärt has opted to ignore the rule of starting at the pitch class centre and a stepwise return towards $C$ by reordering the expected pitch class progression to 10-8-7-0. This results in the melody skipping by a fourth from $\mathrm{G}$ to C, to avoid a skip occurring at the beginning of the next word in the text.

Later in the work Pärt undertakes a similar reordering of the pitch progressions for three occurrences of three-syllable words in the texts associated with Statement 10 (the words “своею” and “любовью”) and Statement 16 (the word “скучаю"), where the stressed syllable in each word is also the penultimate syllable (Figure 5.30). Both statements also include examples where Pärt has allocated only one beat to the stressed second syllables in the words "своею" and “скучаю" (see rule 5.f.ii. above), as the stressed syllables are approached in a stepwise manner, rather than by an intervallic skip of a minor third. 
Figure 5.30: Silouan's Song - upper M-voice line Statements 10 and 16
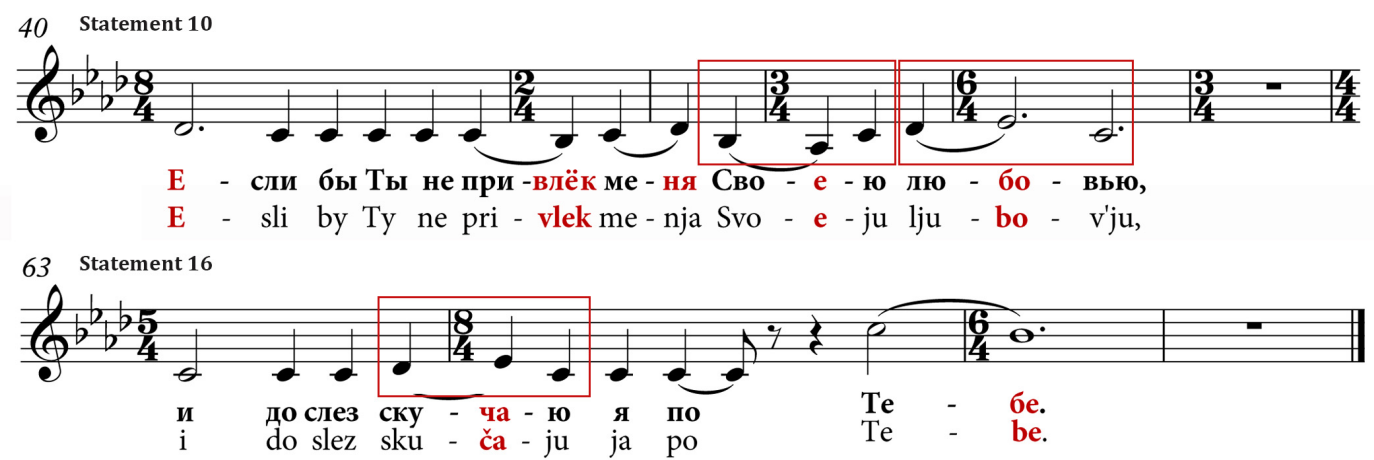

Figure 5.31 shows all 16 melodic statements of the upper M-voice line of Silouan's Song, along with the associated text with stressed syllables identified in red. Also provided in the figure are IPA transliterations of each word, which give a sense of how Pärt has used the pronunciation and rhythmic flavour of the declaimed Russian text in developing the upper melodic line. 
Figure 5.31: Silouan's Song - upper M-voice line all 16 statements

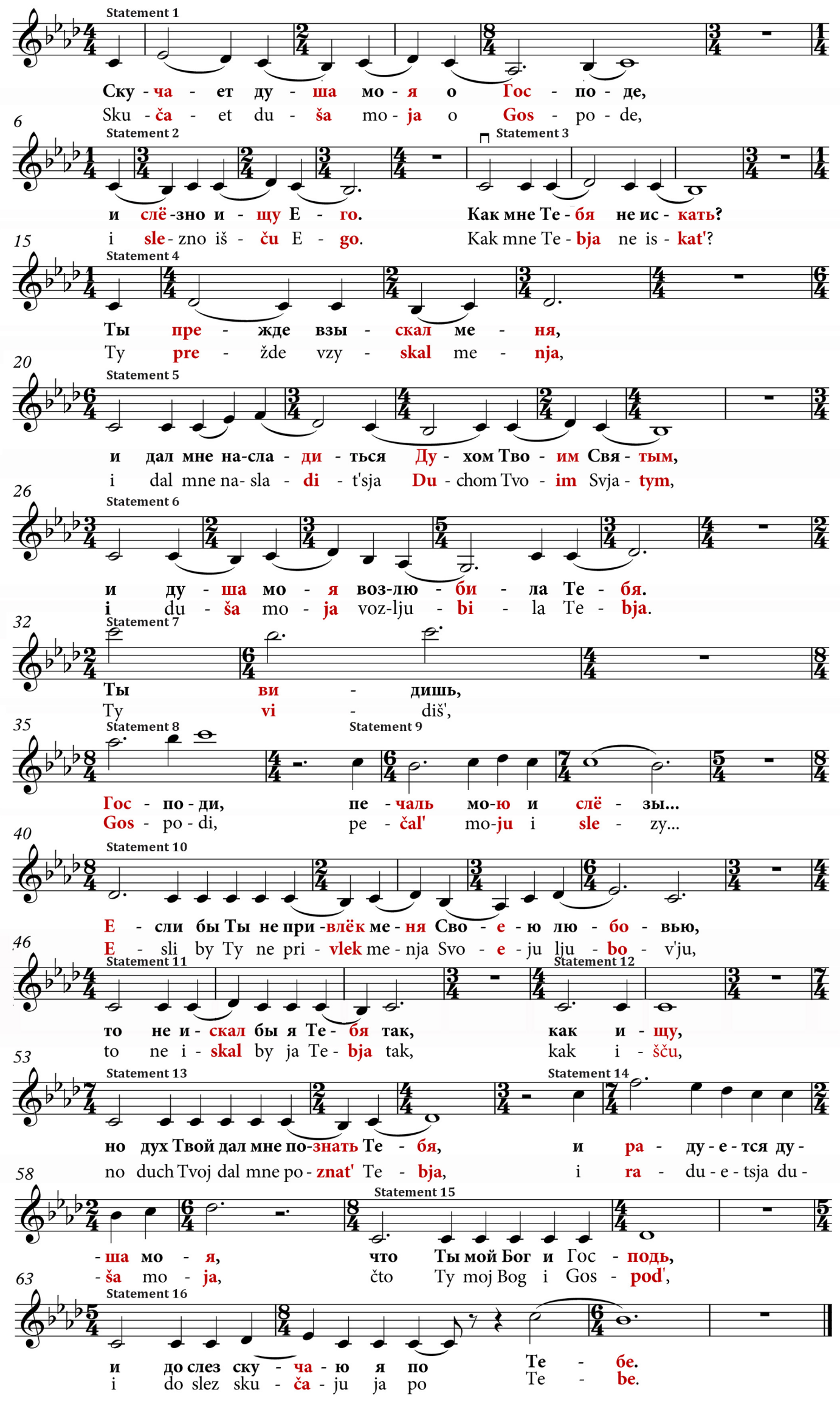




\section{Interval class analysis and sonority mappings of Silouan's Song}

The following section of this chapter builds on the preceding style analysis and examines: 1) the intervallic content that arises out of the text-based processes that Pärt used in composing Silouan's Song and 2) sonority mapping of this content, detailing the shifting musical sonorities throughout the work. This content analysis is supplemented by graphic representation in the form of a Pärtian Tonnetz, to demonstrate the interrelations between the different M-voice and T-voice pitch classes and the resulting intervallic content when any two pitches occur at the same time.

As was seen in Festina Lente many of the processes the composer used in the construction of Silouan's Song are not readily apparent to the listener. Despite Pärt developing a relatively complex text-based schema of rules to dictate the structure and melodic material of Silouan's Song, sonically, this complexity is not evident to the listener. The musical result is perhaps one of the most beautifully solemn works that Pärt has written; as described by Hillier, "in the rapt concentration of its four pages of score is embedded some of Pärt's most heart rending music"214.

The intervallic potential of the pitch classes $\mathrm{C}, \mathrm{Db}, \mathrm{Eb}, \mathrm{F}, \mathrm{G}, \mathrm{Ab}$, and $\mathrm{Bb}$ comprises two minor seconds, five major seconds, four minor thirds, three major thirds, six perfect fourths, and one tritone, i.e. Interval Class Vector $<254361>$ (Forte Code: 7-35). This is illustrated by mapping the potential pitch class relationships of the C Phrygian mode in Figure 5.32 overleaf.

214 Hillier, Arvo Pärt, 117. 
At first glance it would appear that Pärt has constructed the piece so that it makes greater use of the harmonic potentiality that is present in the C Phrygian mode (or F harmonic minor), compared with the paucity of harmonic content found in Psalom. In actuality he does not avail himself of either the harmonic or melodic relationship between pitch classes $\mathrm{Db}$ and $\mathrm{G}$, which create a tritone. This results in Silouan's Song having an effective working Interval Class Vector of $<254360>$ for which, like Psalom, there is no equivalent Forte Code.

Figure 5.32: Pärtian Tonnetz - pitch class relationships of Silouan's Song

Pitch Class Relationships - Silouan's Song

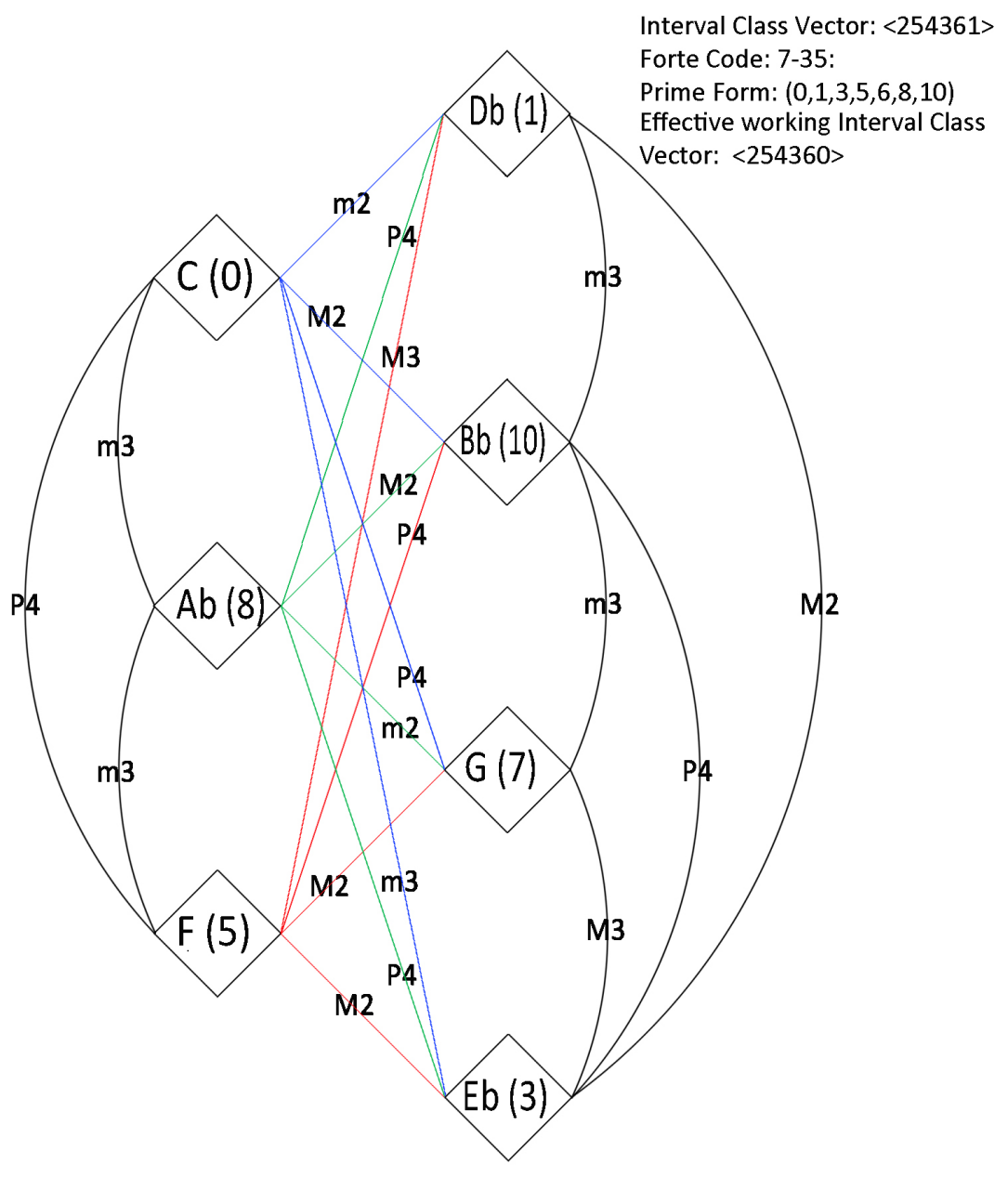

Despite its complex generative rules, Silouan's Song comprises just nine interval class vectors and 13 'chords' (Table 5.9 overleaf), only two more than were used 
in Psalom: <000000> (silence); <000010> (A5); <001000> (A min no 5, B min no5, and G\# min no 5); <001110> (Forte Code: 3-11, A min); <021030> (Forte Code: 423, E $7^{\text {th sus } 4}$ ); $<100110>$ (Forte Code: 3-4, F maj7 no 5); and $<111120>$ (Forte Code: 4-14, E add 4 ).

Table 5.9: Interval class vectors and chords generated by the processes in Silouan's Song

\begin{tabular}{|c|c|c|c|c|}
\hline $\begin{array}{l}\text { Interval Class } \\
\text { Vector }\end{array}$ & Forte Code & Prime & Chords & $\begin{array}{l}\text { Frequency of } \\
\text { occurrence (as } \\
\text { number of beats) }\end{array}$ \\
\hline$<000000>$ & $\mathrm{N} / \mathrm{A}$ & Silence & $\mathrm{N} / \mathrm{A}$ & 60 \\
\hline$<000010>$ & $\mathrm{N} / \mathrm{A}$ & $(0,5)$ & F5 & 27 \\
\hline$<000100>$ & $\mathrm{N} / \mathrm{A}$ & $(0,4)$ & $\mathrm{Ab}$ no 5 & \\
\hline$<001110>$ & $3-11$ & $(0,3,7)$ & $\begin{array}{l}\mathrm{Ab} \\
\mathrm{Bb} \text { min } \\
\mathrm{F} \text { min } \\
\end{array}$ & $\begin{array}{c}3 \\
26 \\
80 \\
\end{array}$ \\
\hline$<0012120>$ & $4-26$ & $(0,3,5,8)$ & $\begin{array}{l}\mathrm{C} \text { min add } 4 \\
\mathrm{Bb} \min 7 \text { th } \\
\mathrm{F} \min 7 \text { th } \\
\end{array}$ & $\begin{array}{c}1 \\
3 \\
10 \\
\end{array}$ \\
\hline$<032140>$ & $5-35$ & $(0,2,4,79)$ & $\mathrm{C} \min 11^{\text {th }}$ & 3 \\
\hline$<111000>$ & $3-2$ & $(0,1,3)$ & $\mathrm{Bb}$ add $9 \mathrm{~m}$ no 5 & 9 \\
\hline$<111120>$ & $4-14$ & $(0,2,3,7)$ & $\begin{array}{l}\mathrm{Bb} \min \text { add } 9 \\
\mathrm{~F} \text { min add } 9\end{array}$ & $\begin{array}{c}29 \\
4 \\
\end{array}$ \\
\hline$<121110>$ & $4-11$ & $(0,1,3,5)$ & $\mathrm{Bb} \min 9$ th no 5 & 14 \\
\hline
\end{tabular}

Table 5.10 maps the interval class vectors and chords that occur across the sixteen different statements of Silouan's Song. Three statements comprise only two sonorities each: Statement 15 has just one interval class vector and two chords $(<001110>, \mathrm{Bb}$ min and F min), while Statement 2 and Statement 12 are each comprised of just two interval class vectors having one chord each: $<000010>$, F5 and <111120>, Bb min add 9 and <001110>, F min and <111120>, Bb min add 9 , respectively. In contrast, Statement 10 and Statement 14 display a greater degree of sonic variety. Statement 10 comprises the interval class vectors $<001110>(\mathrm{Ab}$ and $\mathrm{F} \min ),<0012120>\left(\mathrm{Bb} \min 7^{\mathrm{th}}\right),<111000>\left(\mathrm{Bb}\right.$ add $\left.9 \mathrm{~m}^{\mathrm{no}}\right)$, and $<121110>\left(\mathrm{Bb}\right.$ min $\left.9^{\text {th no }} 5\right)$. Statement 14 comprises the interval class vectors $<001110>(\mathrm{F} \min ),<0012120>(\mathrm{C} \min$ add 4$),<032140>\left(\mathrm{C} \min 11^{\text {th }}\right.$ ), and $<121110>\left(\mathrm{Bb} \min 9^{\text {th no } 5}\right)$. 
Table 5.10: Interval class vectors and chords in the 16 different statements of Silouan's Song (frequency of occurrence as number of beats)

\begin{tabular}{|c|c|c|c|c|c|c|c|c|c|c|c|c|c|c|c|c|c|}
\hline \multirow{2}{*}{$\begin{array}{l}\text { Interval Class } \\
\text { Vector }\end{array}$} & \multirow[b]{2}{*}{ Chords } & \multicolumn{16}{|c|}{ Statement } \\
\hline & & 1 & 2 & 3 & 4 & 5 & 6 & 7 & 8 & 9 & 10 & 11 & 12 & 13 & 14 & 15 & 16 \\
\hline$<000010>$ & F5 & 8 & 4 & & & & & 5 & 4 & 6 & & & & & & & \\
\hline$<000100>$ & $\mathrm{Ab}$ no 5 & & & & & & & & & & & & & & & & 1 \\
\hline \multirow{3}{*}{$<001110>$} & $\mathrm{Ab}$ & & & & & & & & & & 3 & & & & & & \\
\hline & $\mathrm{Bb} \min$ & & & 4 & 5 & 3 & 4 & & & & & & & & & 4 & 6 \\
\hline & F min & & & 6 & 4 & 8 & 7 & & & 1 & 10 & 10 & 4 & 8 & 4 & 8 & 10 \\
\hline \multirow{3}{*}{$<0012120>$} & $\mathrm{C} \min$ add 4 & & & & & & & & & & & & & & 1 & & \\
\hline & $\mathrm{Bb} \min 7$ th & & & & & & & & & & & 1 & & 1 & & & 1 \\
\hline & F min 7th & 5 & & & & 1 & & & 3 & & 1 & & & & & & \\
\hline$<032140>$ & $\mathrm{C} \min 11^{\text {th }}$ & & & & & & & & & & & & & & 3 & & \\
\hline$<111000>$ & $\mathrm{Bb}$ add $9 \mathrm{~m}$ no 5 & & & & & & & & & & & 1 & 4 & 4 & 4 & & \\
\hline \multirow{2}{*}{$<111120>$} & Bb min add 9 & 4 & 5 & & & & & 3 & 1 & 7 & 5 & & & & & & \\
\hline & $\mathrm{F}$ min add 9 & & & & & 1 & 3 & & & & & & & & & & \\
\hline$<121110>$ & Bb min 9 th no 5 & & & 2 & 1 & 6 & 2 & & & & 2 & & & & 1 & & \\
\hline
\end{tabular}

Grey shaded cells indicate statements where particular interval class vectors or chords do not occur. 
As noted previously, Statement 14 is associated with the text "и радуется душа моя" ("and my soul rejoices"), and it is the point in Silouan's Song in which the texture and dynamics, as well as registral range of the work, come to an 'exultant climax' (Figure 5.33). At this point, in addition to the M-voice/T-voice operations, Pärt has opted to include the equivalent of a drone with the upper divisi line of the second violin section pulsing on C5 and the first violins playing an octave higher at $\mathrm{C6}$. The resulting progression of $\mathrm{F}$ minor, $\mathrm{C}$ minor, and $\mathrm{Bb}$ minor chords this creates is shown at the bottom of the figure.

Figure 5.33: Silouan's Song - Statement 14

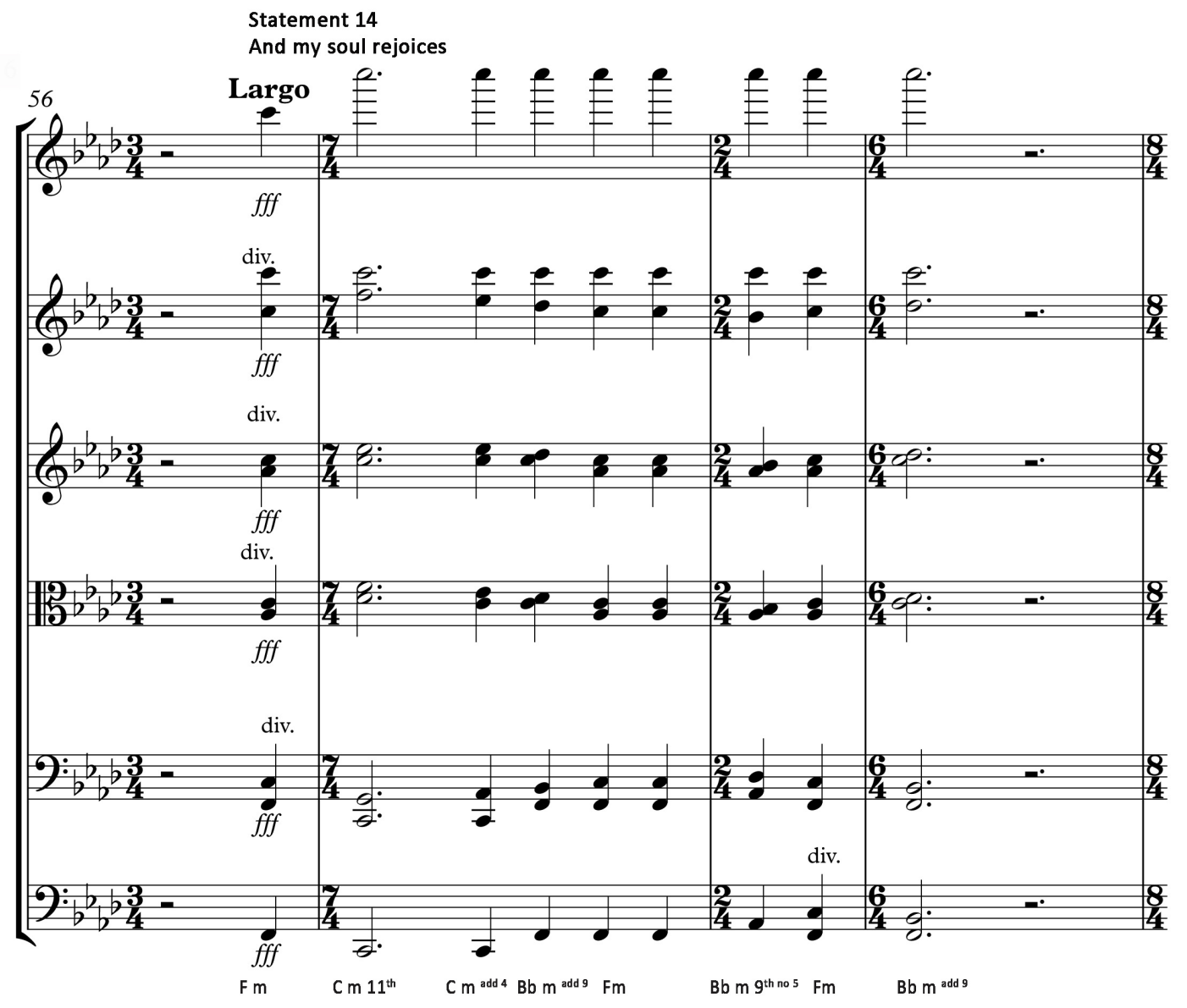


Statement 10 occurs immediately after the other emotional climax in Silouan's Song, Statements 7 through 9 at the point in the text when the narrator exposes their extreme vulnerability, i.e. Thou seest, 0 Lord, my grief and tears...". At this point the violoncellos and contrabasses have fallen silent and the dynamics diminish from $p p$ in Statement 7, $p p p$ in Statement 8 and $p p p p$ in Statement 9.

Statement 10 can be interpreted as the point in the text where the narrator's mood has lightened somewhat with the text “Если бы Ты не привлек меня Своею любовью", poetically translated as "Hadst Thou not drawn me with Thy love". ${ }^{215}$ Musically, Pärt realises this text by starting the M-voices on Db (violins 1) and $\mathrm{Bb}$, rather than the $\mathrm{M}$-voice pitch centre of $\mathrm{C}$ - which can be justified because 1) the first syllable of the word "Если" is stressed, opening the statement with a Bb minor chord with an added $9^{\text {th }} ; 2$ ) progressing to F minor, which is sustained through the single syllable words “бы Ты не” and the first unstressed syllable of the word "привлек"; and 3) before progressing through a number of permutations of $\mathrm{Bb}$ minor and $\mathrm{F}$ minor chords until the final bar, which closes with an Ab major chord that 'resolves' to F minor (Figure 5.34 overleaf).

The musical texture of Statement 10 is also thicker, with the reintroduction of the violoncellos and contrabasses, which had fallen silent during Statements 7 through 9 - the first violins and viola sections now playing uniti rather than divisi and all sections instructed to play with vibrato, for the first time since the end of Statement 5. Dynamically, Statement 10 is marked forte, which also contrasts starkly with the dynamic progressions of $p p$, $p p p$, and $p p p$ of Statements 7, 8, and 9, respectively.

215 Rosma, Kõrver, and Kurman, In Principio: The Word In Arvo Pärt's Music, 335. 


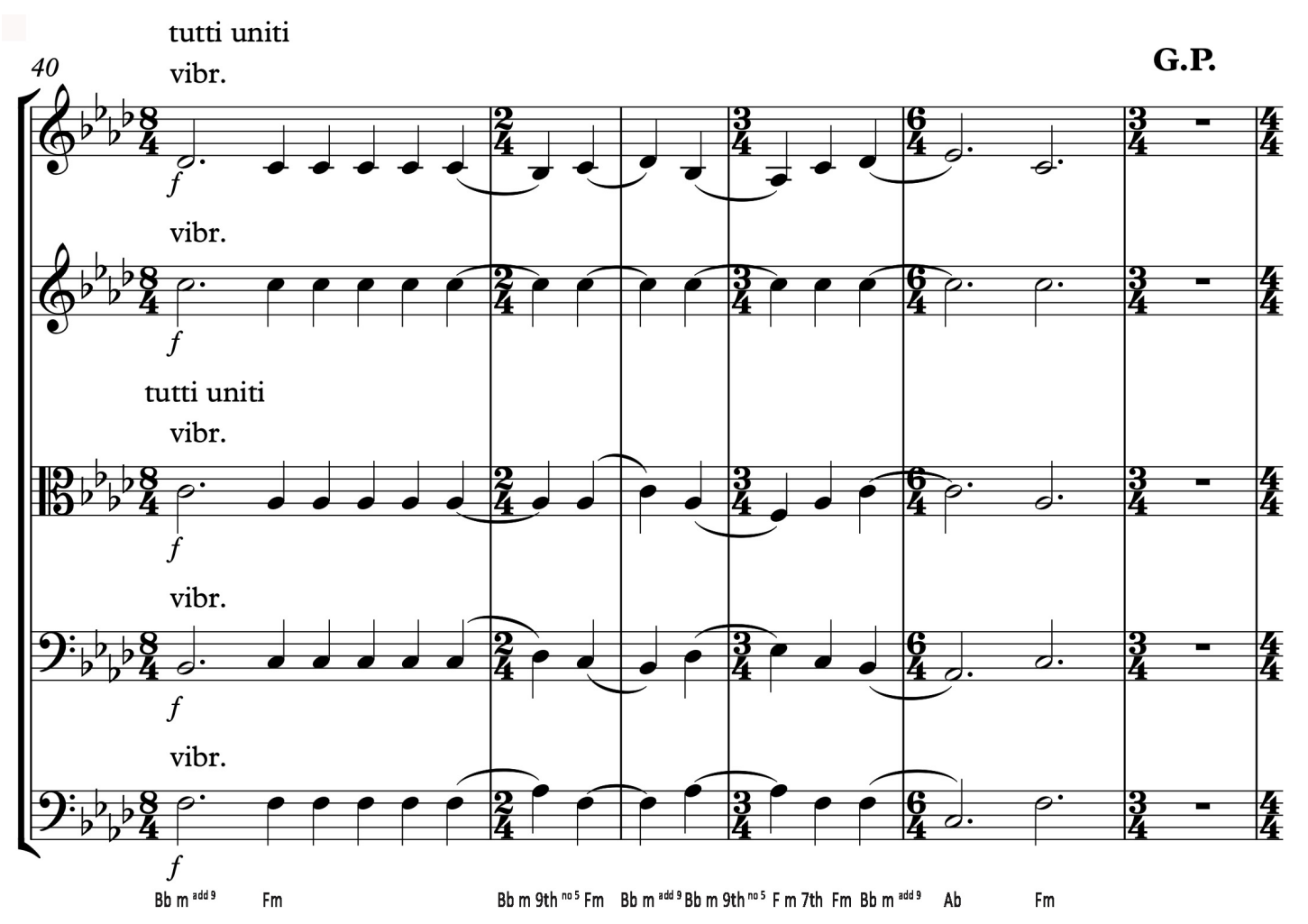

Figure 5.35 overleaf provides a sonority mapping of the harmonic content of Silouan's Song. While it, like Psalom, has several periods where only one interval class occurs (e.g. bars 4 through 6), there are no instances in Silouan's Song when only a single pitch sounds.

Also absent from the work is the interval of a tritone. Notably, the relative density of its intervallic content remains constant throughout the work until bar 57 when there is an increase in the density of minor seconds, minor thirds, and perfect fourths. This spike occurs during the aforementioned Statement 14, when the texture, dynamics, and registral range of Silouan's Song also arrive at its 'exultant climax'. 
Figure 5.35: Silouan's Song - sonority mapping

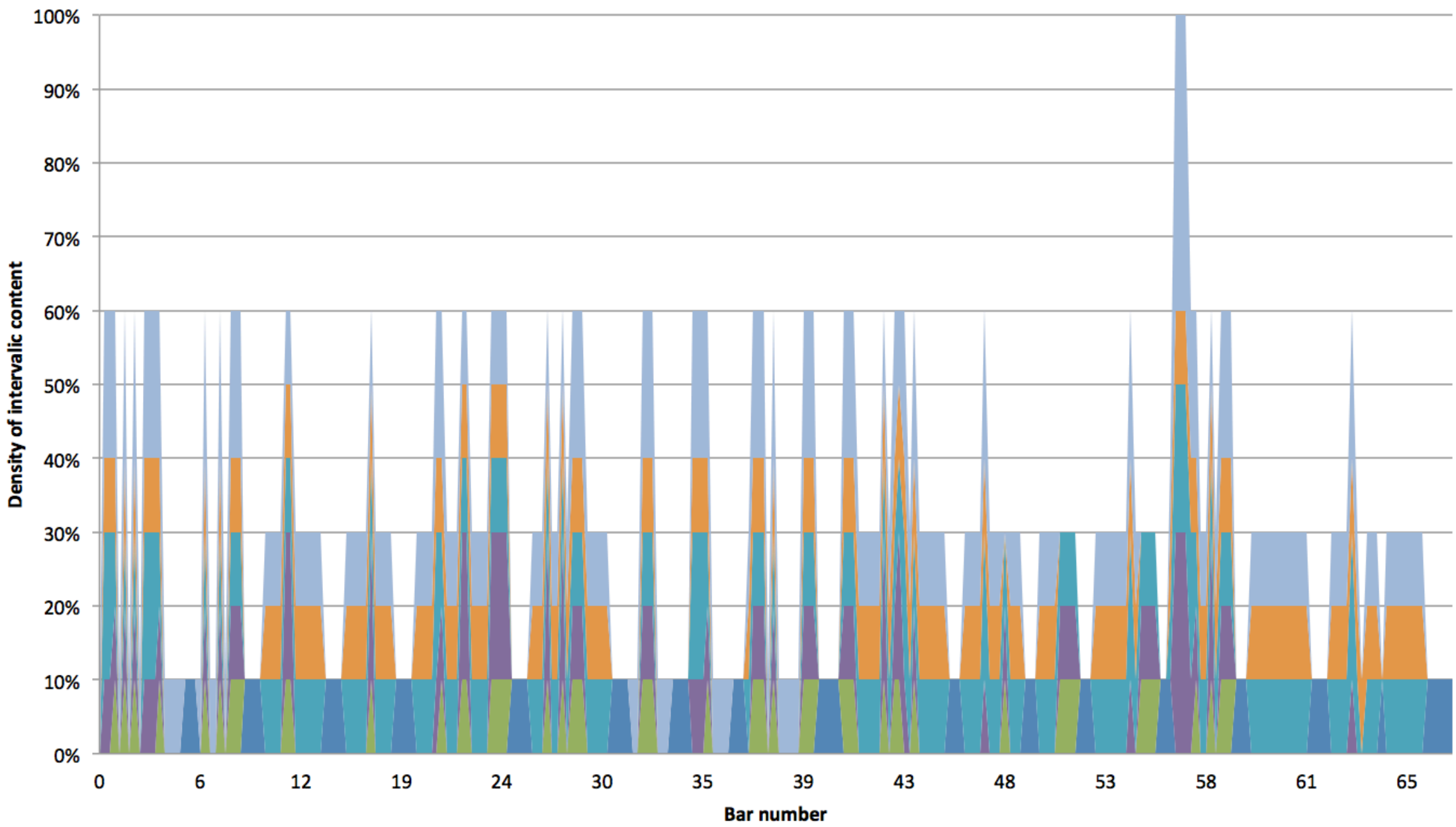

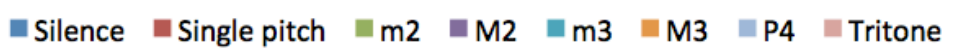




\section{Discussion - Psalom and Silouan's Song}

As a whole, Silouan's Song is an example of Pärt being in full command of the potentialities of his tintinnabuli system, wherein he combines the basic rules dictating M-voice and T-voice operations with an extremely complex set of 14 different text-derived rules to shape the melodic and rhythmic elements of a work, as well as interpreting structural, and to a certain degree hermeneutic, aspects of that text to shape the work's form, dynamics, texture, and instrumental articulations. Despite the relative complexity of text-based processes that the composer used in Silouan's Song and Psalom, as listening experiences both textbased works express a sound world of much greater simplicity than the processbased works, which were discussed in Chapters 3 and 4 . While it is difficult to imagine Psalom being translated into a different instrumental or vocal genre, it is easier to imagine the simple homophonic nature of Silouan's Song being executed by low winds, or choir. Despite being composed for string orchestra, the hymnlike nature of Silouan's Song also seems more closely related to Pärt's choral works than any of the other orchestral works examined in this thesis.

In addition to providing the first detailed analysis of the relationships between the texts associated with Psalom and Silouan's Song and the significant role that each has played in determining a number of aspects across multiple dimensions of their respective works, this chapter clearly demonstrates that Pärt's text-based compositions are carefully crafted works, and have much to reveal to the musical analyst. Throughout both works, strong evidence of the presence of the 'invisible' hand of the composer can be found within the deep underpinning structures of such works, at the more elaborate middle ground level, and even surface aspects, 
such as subtle and not so subtle dynamic and tempo changes, and the use of articulations, register, and tone colour.

Much of the composerly decisions in relation to these various aspects cannot be fathomed without access to, and an understanding of, the text associated with each work. In relation to this Sittan notes:

Arvo Pärt has stated: "The words write my music"; this similarly means that he [Pärt] searches for musical structures, which might be as analogous with his texts as possible. Word and sound, speech and song are among those dialectical pairs of opposites, in the case of which the paradoxical formula $1+1=1$ could ideally be applied. ${ }^{216}$ Pärt has also named this [formula as] the basis of his tintinnabuli technique's musical structure. ${ }^{217}$

This would seem to imply that there is a degree of intertextuality between the content of the texts Pärt selects to serve as structural models for his compositions and the 'musical text' that is the end result, as represented by either the score or a performance of the work; but is there any evidence that the resultant musical work serves to also quote the content of what is said in the original text, or at the least to summarise and express its content and related emotive intention?

Sittan suggests that we can view Pärt's non-vocal works as eschewing the "sound-based, rhythmic and sensuously expressive side" of verbal texts -

\footnotetext{
216 The " $1+1=1$ " formula was first noted by Hillier in his monograph on the composer and attributed to Pärt's wife Nora. It initially served as not only a metaphor for the M-voice/T-voice pairings in Pärt's tintinnabuli music, i.e. that "the two voices are in reality one voice, a twofold single entity", but also Pärt's view that the M-voice signifies the subjectivity and suffering of life while the T-voice signifies "the objective realm of forgiveness", that is, tintinnabuli as representing the "dualism of body and spirit, earth and heaven". See Hillier, Arvo Pärt, 96.

217 Siitan, "Introduction," 2014, 13.
} 
something that would be axiomatic in a vocal work - while still expressing the texts' underlying structures through music. ${ }^{218}$ He notes:

By ignoring the fact that every text possesses both [a content plan and an expression plan] we could conceptualise Pärt's compositions as such, in which the content plan is manifested only in the verbal layer and the expression plan only in the sound layer, while it nevertheless endeavours to achieve complete unity [as metaphorically symbolised by Pärt's $1+1=1]^{219} \ldots$. Apparently striving to draw closer to this idea, Pärt has written a number of instrumental pieces ... the musical material of which is derived from verbal texts, which themselves remain unheard; mute. The notion of dialectics of a word-based content plan and a music-based expression plan could be especially fitting in the case of such pieces. ${ }^{220}$

One might interpret the composer's text-based instrumental works as being instrumental arrangements of vocal works, wherein the texts have been stripped, and thus the composer has 'suppressed' any implied textual meaning. However, based on the preceding analysis of Psalom and Silouan's Song, it is evident that the texts Pärt selects inform his decisions regarding musical structures and processes, and that these serve as determinants of select compositional parameters that he has chosen to deploy during the compositional process. Given their importance in the Eastern Orthodox faith, it is likely that these also have significant personal resonances and meanings for Pärt. However, from the listener's perspective, a knowledge and understanding of the content of the original texts is not requisite to engage with such works and to appreciate them as complete musical experiences.

\footnotetext{
218 Ibid.

219 Parenthetical insertions are mine, not Sittan's.

220 Siitan, “Introduction," 2014, 13.
} 


\section{Chapter 6 - Orient \& Occident (2000)}

The ways of the Occident and the Orient are like two parts of a flowery counterpoint: from one approach to another, a pattern anticipates another, or echoes it, sometimes or synchronously crossing over some notes and in parallel progressing at a consonant distance, yet without ever their voices to merge or to lose their own tone or register

- Jean Durning. ${ }^{221}$

The final analytical chapter of this thesis provides the first detailed analysis of the relationship between the text of the Nicene Constantinopolitan Creed and one of Pärt's most complexly constructed musical works, Orient \& Occident (2000). In this chapter, Orient \& Occident is also examined within the context of its historic reception as an expression of a clash between the musical cultures of the East and West, while proposing an alternative reading of the work as a commentary on the schism between the Eastern and Western traditions of Christianity.

\section{Introduction}

Arvo Pärt composed Orient \& Occident as a commission for Saulus Sondeckis and the Lithuanian Chamber Orchestra in 2000. Lasting just seven minutes in duration, Orient \& Occident was released by ECM New Series in 2002, as part of an album bearing the slightly modified title Orient Occident.

Both the work and the album received positive reviews and a number of commentators noted that Orient \& Occident and the companion pieces on the album - Wallfahrtslied (originally composed in 1984/2001 for men's choir and string orchestra) and Como cierva sedienta (composed in 1998 for women's choir,

\footnotetext{
${ }^{221}$ Jean During, "Question de Gout. L'enjeu de La Modernité Dans Les Arts et Les Musiques de l'Islam. La Modernité En Orient," Cahiers de Musiques Traditionnelles, 1994, 27. Quoted in Elena Ovanescu-Pîrvu, "Perspectives and Musical Analysis Between Occident and Orient," Review of Artistic Education 7 (2014): 73.
} 
soprano soloist and orchestra) - announced a new direction in Pärt's composition style. ${ }^{222}$ Kila Packett noted that the composer had:

reorganized his approach making this change a revelatory turn from past familiar traits. Having rediscovered himself half a dozen times before this year, Pärt introduces a lustrous version of his suffering, and a handsomely classical departure than previously heard.223

In relation to the work Orient \& Occident itself, Packett continues:

It is an arrestingly dramatic piece full of swirling contradictions, climactic rises of pitch and snake-like coiling of monophonic lines. With strings clashing together like ocean waves crashing against rocks it resembles a Russian neo-classic romp blaring its own dissonant vices and questions like that of Stravinsky's muse. 224225

Music reviewer James Manheim described the work as being "positively Ivesian", in the manner Pärt "opposes Indian-sounding Eastern melody to Western chordal textures", which ultimately reach a "tense yet solid coexistence". ${ }^{226}$ Tony Hayward, in his review of the album, noted the 'oriental-tinged' melody of Orient \& Occident as well, but also observed that while still familiarly Pärtian, with hints of earlier works by the composer such as Fratres and Tabula Rasa, the composition reveals threads of a darker undercurrent that is not normally associated with Pärt's version of 'sacred' or 'mystic minimalism':

\footnotetext{
222 Reflecting the many positive reviews it garnered, the string orchestral work Orient \& Occident was subsequently nominated for a Grammy Award in 2003 under the category of 'Best Contemporary Composition', while the album was also nominated as 'Best Classical Album' the same year. Dolp, "Arvo Pärt in the Marketplace," 187.

${ }^{223}$ Kila Packett, 'Arvo Pärt Orient Occident', POPMATTERS, 2003

<http://www.popmatters.com/review/partarvo-orient> [accessed 28 March 2016].

224 Ibid.

225 It is not clear from this statement, however, whether Packet's reference to Stravinsky's muse is an allusion to the exoticism of the East, as reflected in works Firebird and The Nightingale, or the pagan primitivism of The Rite of Spring.

226 James Mainheim, "Arvo Pärt: Orient \& Occident," ALLMusic Review, 2002, http://www.allmusic.com/album/arvo-p\%C3\%A4rt-orient-occident-mw0001850366.
} 
The piece is constructed like links in a chain, with tiny contrasting musical segments - orientally tinted monody and rich chords - converging and juxtaposing in a steady stream of sound. The monophonic line has the feel of a cantus firmus, but the inner eruptions of volume and density give the music a much tougher edge than we are used to with this composer, as if awkward issues are being played out before us. ${ }^{227}$

Tyran Grillo also observed that there are dark currents present not only in Orient \& Occident, but within the other two works on the album as well.

The frame of [the album] Orient Occident captures the dark side of Pärt's compositional moon. Stand too close to it, and its darkness overwhelms; too far and it becomes a mere block of shadow. ${ }^{228}$

Many of these reviewers invoked metaphors and literary imagery to illustrate their interpretation of the composition Orient \& Occident as a dualistic clash of two contrasting sound worlds: an opposition of the dense chordal textures of Western art music against the snake-like coiling of oriental-tinged monophony of an 'exotic East'. Given the work's evocative title and the cultural and historical baggage associated with the terms Orient \& Occident, it is unsurprising that such interpretations might arise.

In relation to the critical reception and hermeneutic interpretations of Pärt's Orient \& Occident, the following section suggests that there is sufficient evidence and cultural baggage in how the Orient has been portrayed in Western music and more particularly in the Russian Art music tradition - to justify the interpretation of Orient \& Occident as Pärt's dualistic portrayal of the clash of Eastern and Western musical cultures, i.e. orientalism and the dualistic 'Other'.

227 Tony Hayward, “Arvo Pärt: Orient Occident," Music Reviews, MusicWeb International, (December 2, 2002), http://www.musicweb-international.com/classrev/2002/Dec02/PartOrientOccident.htm. 228Tyran Grillo, "Arvo Pärt: Orient \& Occident," January 23, 2011, http://ecmreviews.com/2011/01/23/orient-occident/. 
However, in this chapter I will propose an additional layer of interpretation that introduces a further layer of complexity as to what Pärt's Orient \& Occident might be alluding; one which takes into account Pärt's overt religiosity and the significant role that the Eastern Orthodox faith plays in his life.

\section{Orientalism and the dualistic Other}

The term Orientalism and how Oriental cultures have been represented and interpreted by the West have been heatedly debated, and much of this commentary was shaped by the views of Edward Said. ${ }^{229}$ Hodkinson and Walker interpret Said's criticism of the West's historic interpretation and portrayal of the Orient as a means by which Western discourses could "exercise a form of ideological power over the peoples and cultures of the East, reducing them to Europe's consummate other". ${ }^{230}$ Said argued that, historically, this exercise was primarily within the context of the British and French, and later American, political, colonial, and cultural enterprises of the eighteenth and nineteenth centuries. He asserted that, within the context of these enterprises, it was "a project whose dimensions [took] in such disparate realms as the imagination itself, the whole of India and the Levant ... the spice trade, colonial armies and a long tradition of colonial administrators". In addition it encompassed an array of Eastern ideas, philosophies, wisdoms and values that have been recast for the purposes of the Occident's use and importantly to define the dualistic Occidental/Oriental cultural divide. ${ }^{231}$ In relation to this, Said writes:

\footnotetext{
${ }^{229}$ Edward Said, Orientalism (New York: Vintage, 1979). Originally published in 1978.

230 James Hodkinson and John Walker, "Introduction," in Deploying Orientalism in Culture and History: From Germany to Central and Eastern Europe, ed. James Hodkinson et al. (Boydell \& Brewer, 2013), 1.

${ }^{231}$ Said, Orientalism, Introduction.
} 
The Orient is not only adjacent to Europe; it is also the place of Europe's greatest and richest and oldest colonies, the source of its civilisations and languages, its cultural contestant, and one of its deepest and most recurring images of the Other. In addition, the Orient has helped to define Europe (or the West) as its contrasting image, idea, personality, experience..$^{232}$

\section{$\underline{\text { Russia as both Orient and Occident }}$}

Perhaps more pertinent to any hermeneutic musings on Pärt's portrayal of the 'East' in Orient \& Occident, there has been a shift in academic discourse about Orientalism in recent decades to include its eastern European forms - specifically, the cultural impacts of eastern European countries' proximity to, or in some cases containment of, the 'Orient' (e.g. Russia and Austria-Hungary). ${ }^{233}$ German historian Kerstin S. Jobst notes that long before Said fiercely criticised the Orientalist projections of France, Britain, and the United States, Western historians had already begun scrutinising the relationship between the Russian Empire and its Asian colonies, as well as the "mutual interplay between the colonizers and the colonized", resulting in a large number of books on Orientalism and the problematic location of Russia being both, and neither, Asian and/or European. ${ }^{234}$ Jobst observes that in their critical discussion of Orientalism and the Russian/Asian relationship, these authors also commented on "the fact that since the Enlightenment the constructed entity 'eastern Europe' was considered from a Western point of view as a European civilization of lesser quality" - thus making Russia both a 'protagonist' and the ontologically inferior

\footnotetext{
232 Said, Orientalism.

233 Hodkinson and Walker, "Introduction," 1-2.

${ }^{234}$ Kerstin S. Jobst, "Where the Orient Ends? Orientalism and Its Function for Imperial Rule in the Russian Empire," in Deploying Orientalism in Culture and History, From Germany to Central and Eastern Europe (Boydell \& Brewer, 2013), 190.
} 
'inner-European other' of the western European orientalist projects. ${ }^{235}$ On this, Larry Wolf argues that:

It was Western Europe that invented Eastern Europe as its complementary other half in the eighteenth century, the age of Enlightenment. It was also the Enlightenment, with its intellectual centers in Western Europe, that cultivated and appropriated to itself the new notion of "civilization," an eighteenth-century neologism, and civilization discovered its complement, within the same continent, in shadowed lands of backwardness, even barbarism. Such was the invention of Eastern Europe. It has flourished as an idea of extraordinary potency since the eighteenth century, neatly dovetailing in our own times ... surviving in the public culture and its mental maps. ${ }^{236}$

Jobst further posits that Western European views of Imperial Russia as being both Western and an inner European 'other' were in part reinforced by the lengthy historical relationship between Russia and the Muslim world, in terms of both its closer geographic proximity to Islamic Southeast Asian countries and the greater cultural alignment of the populations of many pre-Russian Revolutionary territories with the East than with the West. ${ }^{237}$ The Orient, as seen from the prerevolutionary perspective, was complicated and geographically difficult to define. It included the territories of the Ottoman Empire, China, Japan, central and Southeast Asia, as well as the Russian territories of Siberia, the Crimea (because of its Muslim population, the Tatars), and the Southern Caucasus (comprising

\footnotetext{
235 Ibid.

${ }^{236}$ Larry Wolff, Inventing Eastern Europe: The Map of Civilization on the Mind of the Enlightenment (Stanford Calif.: Stanford University Press, 1994), p. 4, MPublishing, University of Michigan Library <http://hdl.handle.net.helicon.vuw.ac.nz/2027/heb.05073.0001.001> [accessed 13 March 2016].

${ }^{237}$ Jobst, "Where the Orient Ends? Orientalism and Its Function for Imperial Rule in the Russian Empire," 190.
} 
Georgia, Armenia, and present day Azerbaijan), once strongholds of early Christianity, but part of the Ottoman Empire until the nineteenth century. ${ }^{238}$

\section{Music and exoticism}

Shifting the focus to Orientalism and music, the Hungarian musicologist Jánoš Kárpáti notes that the so-called culture of the Occident is, from a historical sense, a relatively recent construction. In the context of music, the European musical tradition can be traced back to the birth and development of Christian liturgical chant in the early Middle Ages. Kárpáti argues that European art music, as based on the Christian liturgy is not a continuation of the Greek and Latin music traditions, but rather those of Hebrew and Syrian musics and that of Asia Minor, noting the significant influences of Byzantine, Coptic Ethiopian, and Mozarabic Christian chants on the development of early Gregorian and Ambrosian chant. 239

Kárpáti also asserts that the influence of the East on Western music was further maintained through the influence of the Arabian Empire until the end of its dominance of the southern Iberian Peninsula in the fifteenth century. ${ }^{240} \mathrm{He}$ further argues that this "cohabitation" of Eastern and Western musical traditions came to an end during the Renaissance when Europe adopted the rediscovered humanistic values of ancient Greek and Latin cultures, - thus "determining for centuries the humanistic character of European culture, its great flowering and, closely associated with the latter, its feeling of superiority over other cultures". ${ }^{241}$

From the 15th to the 17th century, conscious of its value and of its advanced position,

Occidental culture practically closed the door to the Orient and was interested only in

\footnotetext{
238 Ibid., 193.

239 Jáno Kárpáti, “Non-European Influences on Occidental Music (A Historical Survey)," The World of Music 22, no. 2 (1980): 20.

240 Ibid., 20-21.

241 Ibid., 22.
} 
itself. A period of resistance to the Turks succeeded the period of the Crusades and the expulsion of the Arabs, and Christian Europe felt that it was its duty to preserve the humanistic civilization threatened by a barbarous and pagan menace. ${ }^{242}$

Kárpáti suggests that it was only with the flowering of Enlightenment thought, particularly in eighteenth century France, that thinkers such as Montesquieu, Voltaire, and Rousseau began to question the perceived hegemony and superiority of the Occidental white male and European culture when there was a renewed interest in the Orient. Within a few decades European literature became "submerged by Oriental subjects". ${ }^{243}$

Eighteenth-century literary portrayals of the Orient were concerned with cultural differences between the West and the East and in presenting an idealised portrayal of the characteristics and qualities of 'Oriental man'. Kárpáti notes that initially references to the Orient in Western art music occurred most frequently within the context of opera libretti subject matter. However, this did not translate into the content of the music itself, other than through clichéd references to, and poor imitations of, the music of the Janissaries. These musical references to Turkish music - through the use of cymbals, small drums, and nasal sounding double-reed wind instruments - were frequently used in comic operas and primarily intended to provide atmosphere and colour; their primary function being, in the words of Kárpáti, to "present in generic fashion any atmosphere of the Orient". ${ }^{244}$

242 Ibid.

243 Ibid., 23.

${ }^{244}$ Karpati notes that the use of Turkish military music to represent the Orient in this generic fashion was due to the sustained Turkish presence in parts of central and eastern Europe. See Ibid., 24. 
By the second half of the nineteenth century, the sensibilities of Romanticism had shifted the focus of Orientalism away from Turkey to Persia, India, and other parts of the Arab world. As reflected in music, the clichéd use of Turkish military marches fell out of favour, and composers began to adopt sounds of flexible and sensual melodies, which were abundant in ornamentation and, more particularly, a greater use of double harmonic scales. This shift in focus, both in geographic and musical contexts reflected differences between the eighteenth-century and nineteenth-century mindsets. The rationalism of the eighteenth century sought to portray the contrasts between the Occident and the Orient, an exercise informed in part by critical intent to emphasise cultural differences between the West and the East. In contrast, the late Romanticism of the nineteenth century sought to portray the world of the East as being one of mystery and sensuality. While the shift in focus resulted in changes in how the Orient was evoked in Western music, in its own manner it became a type of clichéd poor imitation that rarely used actual music from the East or extra-European musical themes. ${ }^{245} 246$

The association of sensuality with the Orient was not unique to Western Europe's interpretation and portrayal of the Eastern 'Other'. Taruskin observes a similar phenomenon in Russian art music wherein, culturally, the East is not only an "imaginary geography, as historical fiction, as the reduced and totalized other

\footnotetext{
245 Ibid., 24-26.

246 Locke notes that this relationship between fact and truth, and how the East has frequently been portrayed "is rarely simple and direct. ... Rather (or also), they present themselves as fictions, objects intended to provide entertainment or invite aesthetic contemplation." This has been particularly the case in certain historic portrayals, which are clearly fictive presentations of the East that serve "to disguise or make palatable some demonstrably prejudicial portrayals of other peoples and places."Ralph P. Locke, "Cutthroats and Casbah Dancers, Muezzins and Timeless Sands: Musical Images of the Middle East," in The Exotic in Western Music (Boston: Northeastern University Press, 1998), 105-6.
} 
against which we construct our (no less reduced and totalized) sense of ourselves"247 but also a seductive partner that:

... emasculates, enslaves, renders [us] passive. In a word it signifies the promise of the experience of nega, a prime attribute of the orient as imagined by Russians. The word, originally spelled with a "yat" and drawled voluptuously by those who know that fact is usually translated as "sweet bliss," but it really connotes gratified desire, a tender lassitude ... In opera and song, nega often simply denotes S-E-X à la russe..$^{248}$

In Russian art music, and particularly in opera, the presence of the Orient and nega is implied through the use of syncopated undulating chromatic musical lines as an iconically erotic metaphor "evoking languid limbs, writhing torsos, arching necks". ${ }^{249}$ As such, the Orient as portrayed in the Russian art music tradition is one of fantasy, sensuality, and imagination. As noted by Locke, these 'Orients' are mere ideas capable of evoking fantasies - Orients that in the imagination are "mythical, ungraspable, unreal, which is to say more real than any place in history book or atlas". 250

\section{Orient \& Occident and its relationship to the text of the Nicene-} Constantinopolitan Creed

In Orient \& Occident, Pärt draws on structural aspects of the Church Slavonic version of the Nicene-Constantinopolitan Creed. The First and Second Ecumenical Councils established the Nicene-Constantinopolitan Creed during the fourth century, in response to a number of heretical Christian sects that espoused

\footnotetext{
247 Richard Taruskin, "Entoiling the Falconet," in Defining Russia Muscially (Princeton: Princeton University Press, 1997), 153.

248 Ibid., 165.

249 Ibid.

250 Ralph P. Locke, "Cutthroats and Casbah Dancers, Muezzins and Timeless Sands: Musical Images of the Middle East," 133.
} 
alternative doctrines that undermined the Orthodox doctrine of the Holy Trinity. ${ }^{251}$ The text of the Creed, or its Church Latin counterpart Credo, is the core statement of faith or religious belief among many Christians throughout the world, both in the East and in the West.

Orient \& Occident is not the first time that Pärt has turned to the Creed as a source of inspiration. Pärt's seminal work Credo (1968, for mixed choir, piano, and orchestra) signalled the crossroads of his compositional crisis and was the composer's last major pre-tintinnabuli composition. Other musical works by Pärt in which the Creed has played a role, as either inspiration or a source of compositional parameters, include a movement in the mixed choral work Missa Syllabica (1977), Summa (1977, for a capella mixed choir or soloists, as well as various instrumental arrangements) and a movement in the Berliner Mass (1990/2002), for mixed choir or soloists and organ. ${ }^{252}$ Of note, all three musical settings of the Creed are based on the current standard Latin version of the text, whereas Orient \& Occident is based upon the Eastern Orthodox version of the Creed, as translated into Church Slavonic.

Another key point of difference is that the three aforementioned musical settings of the Latin text include the Filioque - an insertion by the Church of Rome in the eleventh century, which refers to the Holy Spirit proceeding from the Father "and the Son", rather than just the Father. The Church Slavonic version of the Creed does not reference the Filioque. ${ }^{253}$ This insertion by the Roman Church was considered

\footnotetext{
${ }^{251}$ The Trinitarian idea of three divine co-eternal persons i.e. the Father, Son and Holy Spirit that constitute one God). The triune concept was particularly challenged by Arianism, which disputed the co-divinity of the Son of God based on the argument that the Son was created by God and that there was a time when the Son did not exist and therefore he could not be co-eternal.

252 Rosma, Kõrver, and Kurman, In Principio: The Word In Arvo Pärt's Music.

253 Siitan, "Introduction," 2014, 11.
} 
by many in the East as heresy and was "one of the major factors leading to the Great Schism between East and West". ${ }^{254}$

It is interesting that despite his own strongly professed religious beliefs, which are grounded in Eastern Orthodoxy, Pärt chose not to delete the reference to the Filioque in his earlier settings of the Latin version of the text. This would seem to suggest a desire by the composer to be true to the text as written, rather than to impose his religious sensibilities upon it. It is also in line with the previously noted assertion by Siitan that the composer "does not highlight a personal aspect [into a text] but rather presumes that the text comprises the entire message perfectly".

The Church Slavonic text of the Nicene Constantinopolitan Creed is shown below, followed by a literal English translation overleaf.

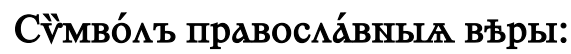

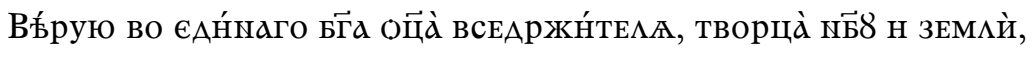

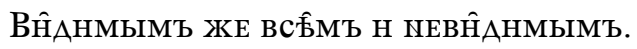

Н во ЄАн́наго ГА̊a i

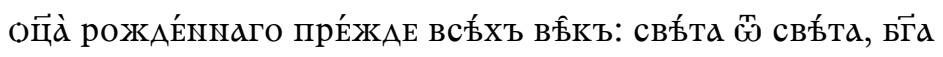

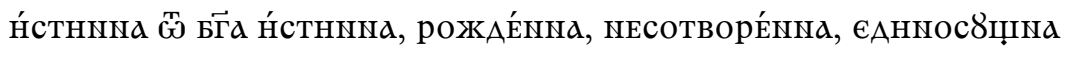
ОЦ8, Н́MжЕ всヘ̂A Бb́ша.

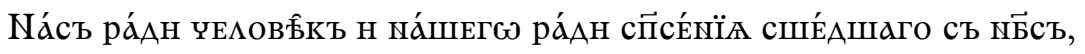

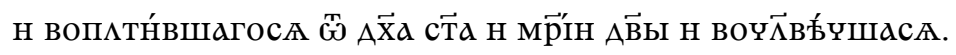

РаспА́таго Же за ны̀ прн понті́нстъмъ пїла́тђ н страда́вша, н

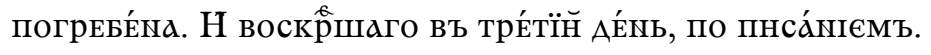

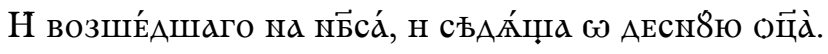

254 Thomas Ross Valentine, "Filioque," Orthodox Wiki, accessed March 28, 2016, http://orthodoxwiki.org/Filioque. 
Н па́кн грААА

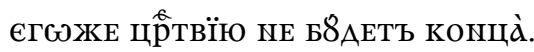

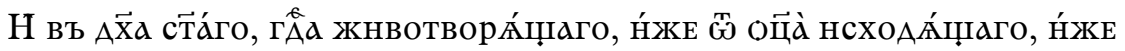

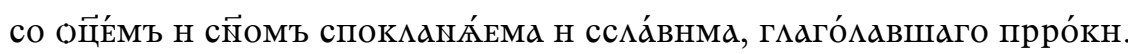

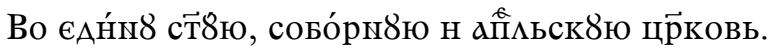

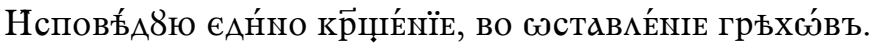

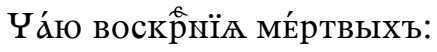

Н жи́знн в8А8џагб въ́ка. Амн́нь.

\section{Nicene Constantinopolitan Creed}

I believe in one God, the Father almighty, the creator of heaven and earth, of all visible and invisible things.

And in one lord Jesus Christ, the son of God, the only-begotten, who was begotten from the Father before all ages, light from light, true God from true God, born, uncreated, one-natured with the Father through whom everything came to be.

Who for the sake of men and for the sake of our salvation came down from heaven and was incarnated through the Holy Spirit and the Virgin Mary and became a man.

And who was crucified for us under Pontius Pilate and suffered and was buried. And who rose on the third day, according to the writings.

And who went up to heaven, and who sits by the Father's right hand.

And who is coming again with glory to judge the living and the dead, whose kingdom will have no end.

And in the Holy spirit, life-creating lord, who went out from the Father, who is to be bowed down to and praised with the Father and the Son, who spoke through the prophets.

In one holy, catholic and apostolic church.

I confess one baptism, for the forgiveness of sins.

I hope for the resurrection of the dead.

And the life of the coming age. Amen. ${ }^{255}$

255 Literal Church Slavonic to English translation by Hanne Eckhoff. Hanne Eckhoff, "Email Correspondence Re: Orient \& Occident," May 7, 2015. 
Having this additional knowledge that the Nicene Constantinopolitan Creed - the statement of faith that, while serving as one of the spiritual foundations of both the Western and Eastern Christian traditions, also represents the schism between those traditions' fundamental interpretation of the concept of the Trinity - is the source material for Orient \& Occident introduces an additional hermeneutic interpretation of the music. As such, it might be possible that while representing the historic clash between the cultures of the East and the West through music, Orient \& Occident could also represent the chasm that separates the two major streams of Christian thought.

\section{Style analysis of Orient \& Occident}

\section{Large dimension}

Comprising 234 bars, Orient \& Occident is a single-movement work for a standard string orchestra (i.e. two violin sections, violas, violoncellos, and contrabasses). The work alternates between monophony and homophony throughout its length. During periods of homophony, in which all sections are instructed to play espressivo, Orient \& Occident has two M-voices that move in parallel motion to each other (Figure 6.1 overleaf). M-voice 1 is generally played by the first violins and Mvoice 2 is usually played by the violoncellos. However, at times the second violins and/or the violas may double M-voice 1 an octave below the first violins. The second violins and/or violas may also periodically double the violoncellos' M-voice 2 , sounding an octave above, thus adding greater depth of colour to the musical lines when this occurs. 
When the M-voices occur during periods of homophonic texture, the violoncellos' pitch classes are always a minor third above those of the first violins - though they are generally displaced by one or more octaves below the register of the first violins. An example of this can be seen in the first violins and violoncellos in Figure 6.1 during bars $1,2,4$, and 5 .

Figure 6.1: Orient \& Occident Section A - opening bars

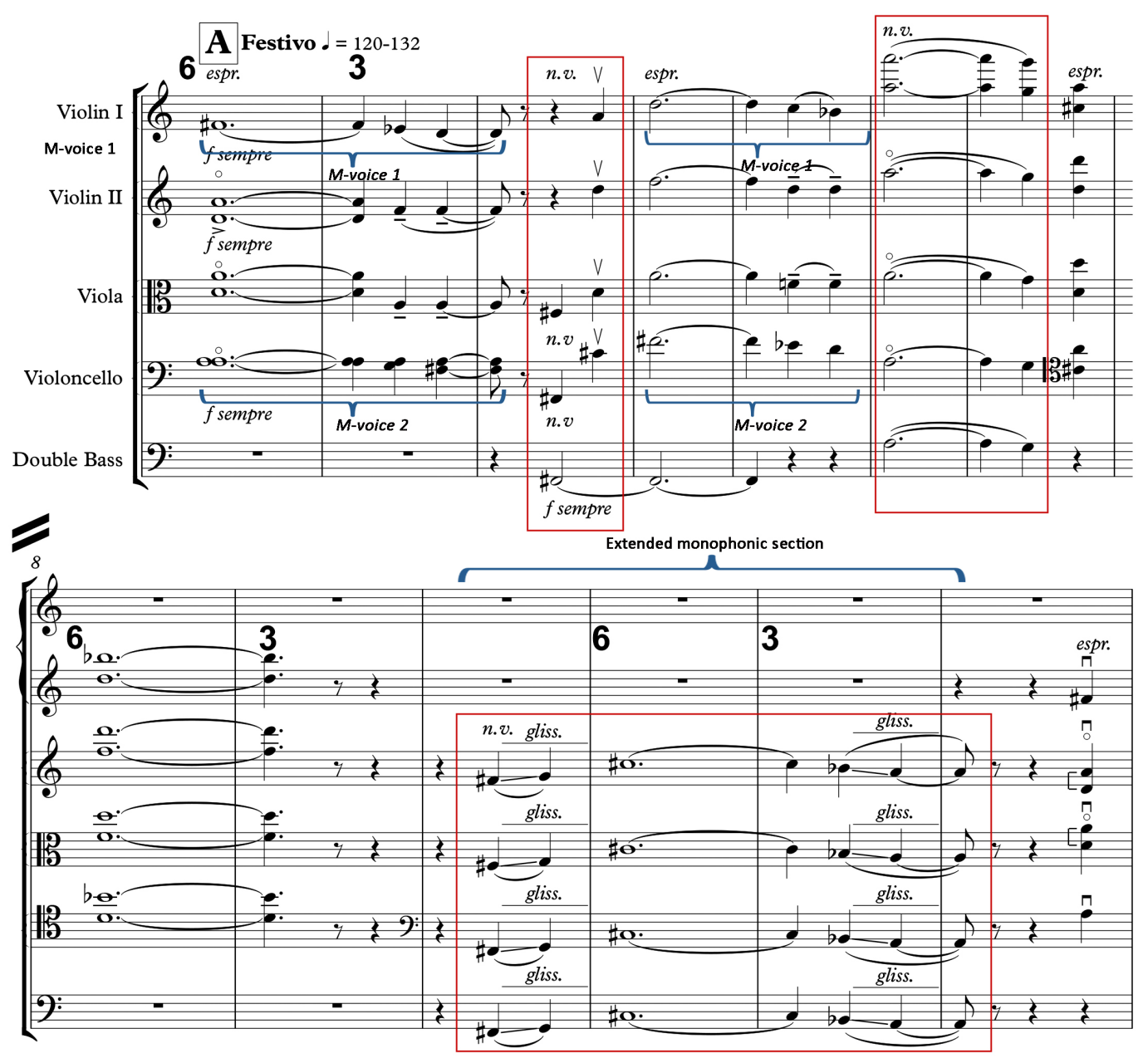

The MIDI-recreation of Orient \& Occident in Figure 6.2 overleaf provides an overview of the scale of the piece and its full use of the registral range. Also illustrated is the work's 12-part architecture (denoted by green lines in the figure) with each of its sections varying in length. Throughout the monophonic sections, during which all instrumental lines play the same musical fragment or 
statement in unison, the performers are instructed to play with no vibrato (shown as n.v. in the score, and denoted above by red boxes in Figure 6.1). In the alternating homophonic sections, the performers are instructed to play with normal vibrato (noted as espr. i.e. espressivo in the score). 
Figure 6.2: Orient \& Occident - MIDI recreation (with contrabasses shown in their sounding register) 256

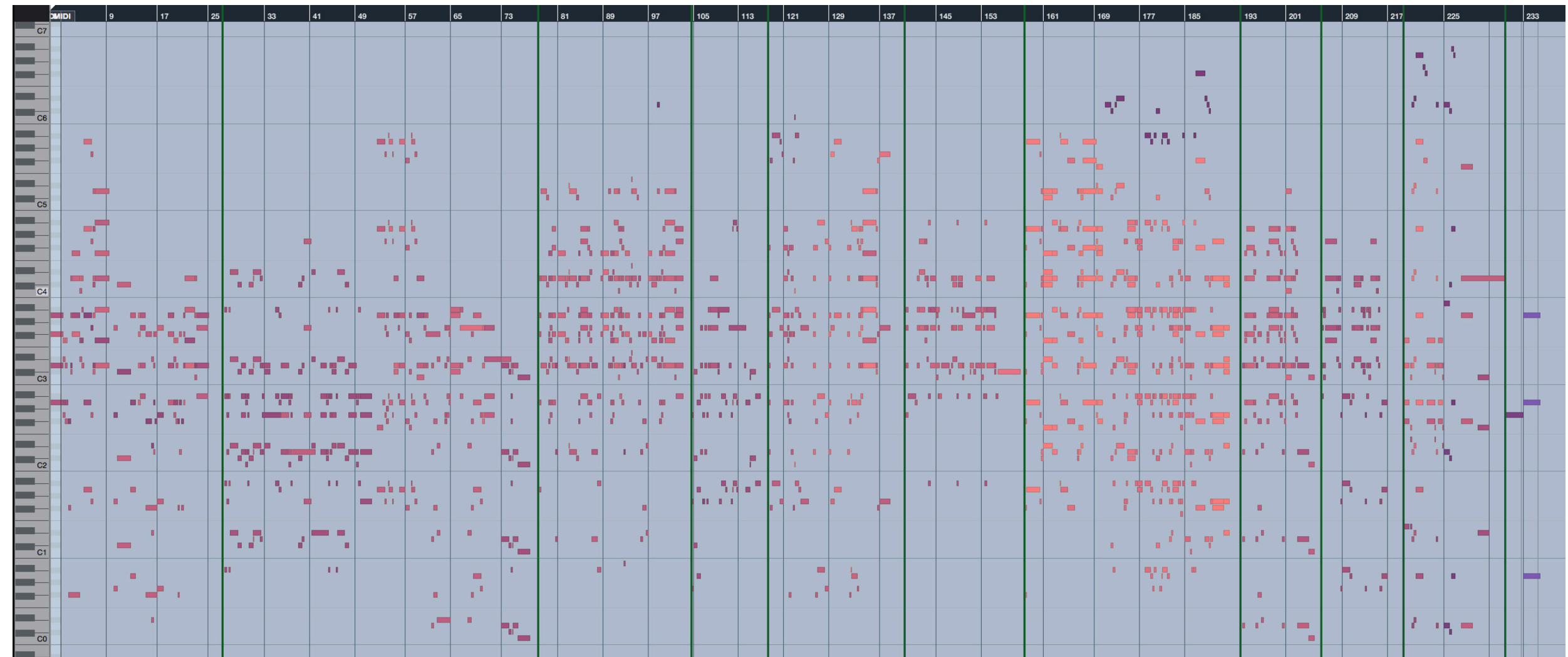

256 Midi-recreation created using Cubase ${ }^{\mathrm{TM}} 7.5$. 
In addition to alternating between homophonic and monophonic sections, the melodic material of Orient \& Occident alternates between different scales. The pitch classes of the first scale comprise a D double harmonic diatonic scale (D, Eb, F\#, G, A Bb, and C\#; also known as a D Byzantine scale) or alternatively a $\mathrm{G}$ Hungarian minor scale (G, A, Bb, C\#, D, Eb, F\#, also known as a G Gypsy minor scale) depending on whether the tonal centre of the melody and/or the triad pitches of the related T-voice is D or G. ${ }^{257} 258$ The second scale uses all of the same pitch classes as those used in the first scale, except C\# which is replaced by $\mathrm{C}$ natural, resulting in a $G$ harmonic minor scale $(G, A, B b, C, D, E b, F \#)$ when the tonal centre of the melodic line is $G$, or a D major Phrygian scale (D, Eb, F\#, G, A $\mathrm{Bb}, \mathrm{C}$,) when the tonal centre is $\mathrm{D}$.

The two scales combined create an asymmetrical eight-pitch pitch class set (D, Eb, F\#, G, A Bb, C, C\#), which is not a true octatonic collection. Specifically, if the pitch classes are arranged starting at $\mathrm{C}$, the intervallic spacing of these pitches (when the scale is ascending) is 1-1-3-1-2-1-2 - whereas a 'true' octatonic collection would have an intervallic spacing of either 1-2-1-2-1-2-1 or 2-1-2-1-2-1-2, depending upon which two out of the three unique diminished 7 th chords are used to construct the collection. ${ }^{259}$ The sonic potentiality of Orient \& Occident is further expanded by the work having two alternating T-voice triads D minor (D,

257 This periodic shifting of the melodic tonal centres throughout Orient \& Occident has also been identified by Thomas Robinson in his diagrammatic illustration of a summary style analysis as one of several approaches that an analyst might draw upon when analysing Pärt's music. See Robinson, "Analyzing Pärt," 80. However, Robinson only notes the shifting of melodic tonal centres between D and G, and does not note that there are periods when neither pitch class D or $\mathrm{G}$ functions as the tonal centre of a melodic statement or fragment. Despite this anomaly, the overall tonal centres of Orient \& Occident can be construed as being D and G, based upon the D minor and G minor triads that comprise the work's two different T-voices.

${ }^{258}$ It is not clear if Pärt's choice of a double harmonic scale is a 'nod' to the practice of using such scales in the nineteenth century to evoke the exotic East.

${ }^{259}$ In the West's 12-tone pitch class system, only three unique diminished seven chords can be constructed, wherein the pitch classes used in each diminished seventh chord are mutually exclusive to the other two diminished seventh chords: $(0,3,6,9),(1,4,7,10)$ and $(2,5,8,11)$.Straus, Introduction to Post-Tonal Theory, 144-45. 
F, A) and G minor (G, Bb D), with the F natural of the D minor triad introducing a ninth pitch class. In the penultimate section of the work, Pärt also briefly alternates between $\mathrm{Eb}$ and $\mathrm{E}$ natural in the violoncello and contrabass melodic lines. The sonic implications of this are discussed later, when the sonorities of Orient \& Occident are examined in detail.

Unlike the instrumental registers of Psalom and Silouan's Song, the registers of the different string sections in Orient \& Occident are quite broad (Figure 6.3). The registers of the first violins and contrabasses both exceed three octaves (G3 to B6 and C1 to D4, respectively). While not as broad as the registers of the outer voices, the registers of the inner voice lines all exceed two octaves and a third violoncellos ( $\mathrm{C} \# 2$ to $\mathrm{Bb} 4$ ), second violins ( $\mathrm{G} 3$ to $\mathrm{D} 6$ ), and violas ( $\mathrm{C} \# 3$ to $\mathrm{F} \# 5$ ).

Figure 6.3: Orient \& Occident - registral ranges of instrumental sections

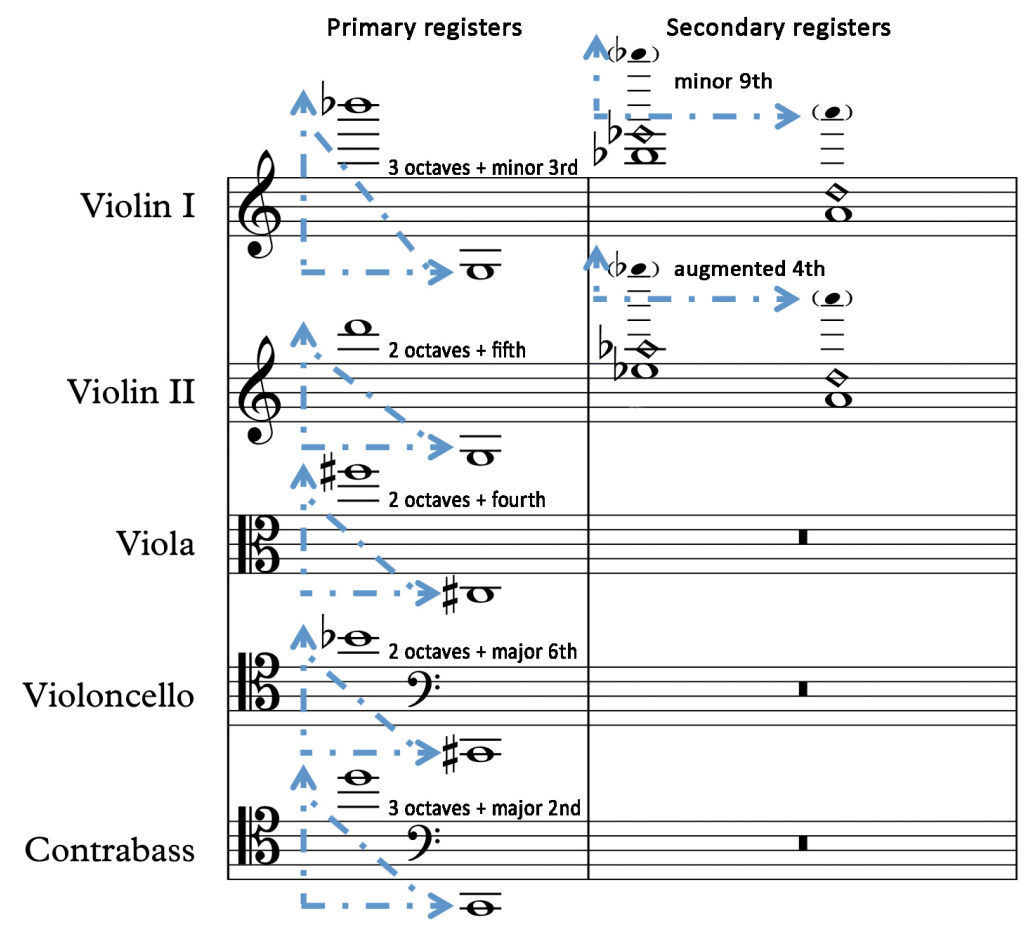

For a few brief moments throughout the work, the first and second violins also play harmonics, sounding in the range of $\mathrm{A} 6$ to $\mathrm{Bb} 7$ (a range of a minor $9^{\text {th }}$ ) and 
A6 to Eb7 (a range of an augmented fourth), respectively. However, this always occurs when the entire orchestra is playing monophonically (i.e. all instruments playing the same instrumental line, but at different octaves) and then only briefly. Thus it could be argued that the expanded range of the violins in such moments merely 'colours' the melodic lines by introducing an additional layer of higher partials.

Like many of Pärt's text-based works, the score has no time signature. The rhythmic and melodic motion of Orient \& Occident varies with each musical statement - as does the direction of the melodic lines, in relation to their respective tonal centres (Figure 6.4). This is due to aspects of individual words and phrases within the text of the Nicene Constantinopolitan Creed determining both the melody and rhythmic structure of each statement (discussed in detail when the middle and small dimensional aspects of the work are examined).

Figure 6.4: Orient \& Occident - first violins bars 26-33

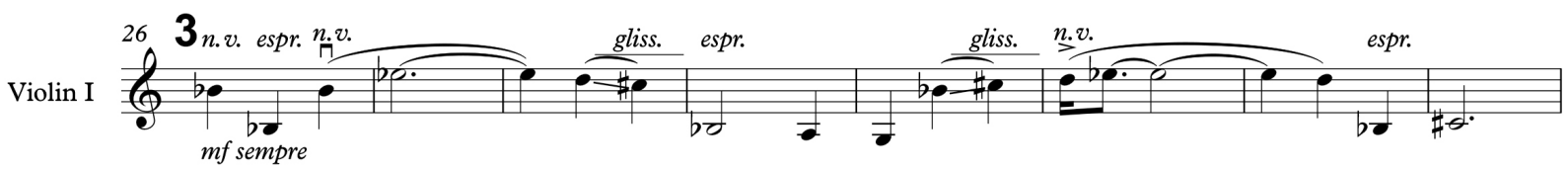

The tempo marking for Orient \& Occident is $\cdot=120-132$ with the annotation Festivo. In the penultimate section of the score, the composer indicates that the tempo should be piu lento and the final bars of the work have the indication "rall. _ _ Lento" - an indication that the tempo should slow to roughly.$=45-60$.

Mirroring the twelve-stanza structure of the Nicene Constantinopolitan Creed, Orient \& Occident has twelve sections, labelled A through L, with each comprising a number of musical statements and fragments that are identifiable in the score by the instructions to the performers to play either espressivo (espr.) or with no 
vibrato (n.v.), as well as the alternation between homophonic and monophonic material. ${ }^{260}$ In addition to the music alternating between homophony and monophony, the various statements and musical fragments are also identifiable to the ear by the alternating changes in direction of the melodic lines away from or towards a pitch centre and large intervallic leaps (see Figure 6.4 above).

It is the combination of these three characteristics, i.e. the orchestra alternating between homophony and monophony, the frequent changes in direction of melodic lines and the frequent alternation between playing espressivo and no vibrato by the performers, that imbues Orient \& Occident with its sense of motion.

\section{Middle dimension}

As already noted, the musical material of Orient \& Occident is organised into twelve sections, each comprising a number of musical statements and fragments. At one extreme, many fragments are a mere one or two crotchets in duration, while others can span multiple bars and, to the attentive listener, sound like cohesive musical statements. As discussed in detail later, the reason for this variance relates to structural aspects of the Nicene Constantinopolitan Creed's Church Slavonic text.

Figure 6.5 shows the organisation of the various lines of text of the Nicene Constantinopolitan Creed as they relate to the 12 sections of Orient \& Occident.

\footnotetext{
260 In his brief article on performing Pärt's music from a musician's perspective, Andreas Kähler notes that the frequent alternation between playing espressivo and no vibrato can be technically particularly challenging for many musicians, Andreas Peer Kähler, 'Radiating from Silence: The Works of Arvo Pärt through a Musician's Eyes', in The Cambridge Companion to Arvo Pärt (Cambridge: Cambridge University Press, 2012), pp. 193-97 (p. 195).
} 


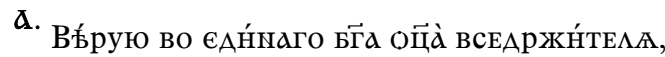
Творца̀ нБ̈8 н ЗЕмАй, ВН̂АНМЫМъ ЖЕ вс६ิмъ н NЕВН̂АНМЫМъ.

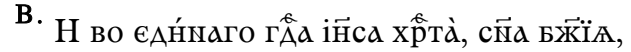

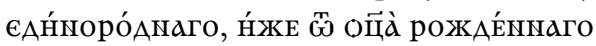

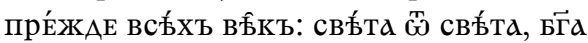

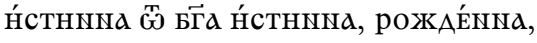

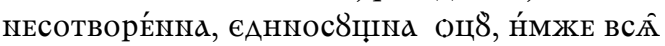
вы́ша.

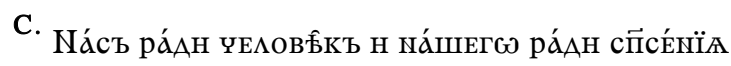

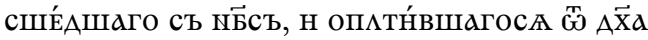

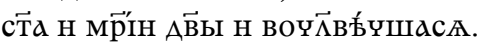

D. РаспА́таго же за ны̀ прн попт́́нстъмъ пї^а́тъ н страАа́вша, н погреье́на.

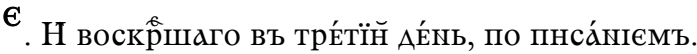

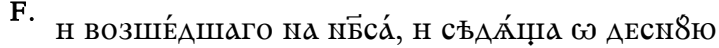
оц̆̀̀.

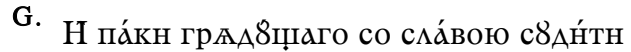

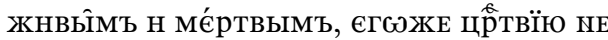
Б8АЕТъ КоNца̇.

H. Н въ А $\overrightarrow{\mathrm{x}} а$ с ста́го, ГА̊

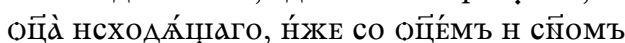

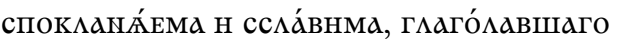
прро́кн.

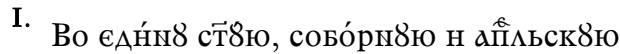
цриковь.

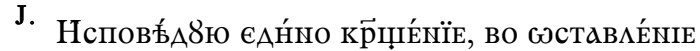
грђхс́въ.

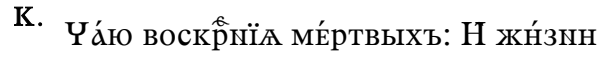
Б8АВџагш вйка.

L. Хми́нь.
A. I believe in one God, the Father almighty, the creator of heaven and earth, of all visible and invisible things.

B. And in one lord Jesus Christ, the son of God, the only-begotten, who was begotten from the Father before all ages, light from light, true God from true God, born, uncreated, one-natured with the Father through whom everything came to be.

C. Who for the sake of men and for the sake of our salvation came down from heaven and was incarnated through the Holy Spirit and the Virgin Mary and became a man.

D. And who was crucified for us under Pontius Pilate and suffered and was buried.

E. And who rose on the third day, according to the writings.

F. And who went up to heaven, and who sits by the Father's right hand.

G. And who is coming again with glory to judge the living and the dead, whose kingdom will have no end.

H. And in the Holy spirit, life-creating lord, who went out from the Father, who is to be bowed down to and praised with the Father and the Son, who spoke through the prophets.

I. In one holy, catholic and apostolic church.

J. I confess one baptism, for the forgiveness of sins.

K. I hope for the resurrection of the dead. And the life of the coming age.

L. Amen. 
As illustrated in Table 6.1, the dynamics vary between major sections of the work (e.g. Section A, Section B, etc.), but within each section the dynamics are relatively static; and for the most part the different string sections are instructed to all play at the same dynamic level. The exceptions to this are a few moments when the first or second violins play drone tones (Section D bars 109-114, Section G bars 150-151, and Section K bars 229-231). However, there are no crescendos indicated in the score, and the only decrescendos occur in the final bars of Section K.

Table 6.1 Orient \& Occident - dynamics as indicated in the score

\begin{tabular}{|c|c|c|c|}
\hline Section & $\begin{array}{l}\text { Starting } \\
\text { dynamic }\end{array}$ & Dynamic variation & Silence \& duration \\
\hline A & $f$ bar 1 & None & final bar $25-8$ and one-half beats \\
\hline B & $\boldsymbol{m f}$ bar 6 & None & $\begin{array}{l}\text { bar } 51-3 \text { beats**; } \\
\text { final bar } 77-5 \text { beats }\end{array}$ \\
\hline C & $\begin{array}{l}f \text { pickup to bar } \\
78\end{array}$ & None & $\begin{array}{l}\text { final bar } 103-2 \text { and one-half } \\
\text { beats }\end{array}$ \\
\hline D & $\boldsymbol{m} \boldsymbol{f}$ bar 104 & $\begin{array}{l}f \text { second violins - bar } 109 \\
\text { through first beat of bar } 114^{*}\end{array}$ & final bar $117-3$ beats \\
\hline $\mathbf{E}$ & $f$ bar 118 & None & final bar $125-1$ and one-half beats \\
\hline $\mathbf{F}$ & $f \boldsymbol{f}$ bar 118 & None & $\begin{array}{l}\text { bar } 131 \text { - last } 2 \text { and one-half } \\
\text { beats through the first beat of } \\
\text { bar } 132 \text {; final bar } 138-6 \text { beats }\end{array}$ \\
\hline G & $f$ pickup bar 140 & $f f$ first violins - bar $150-151^{*}$ & $\begin{array}{l}2 \text { beats of silence at the } \\
\text { beginning of the section - bar } \\
139 \text { as a carryover from the G.P. } \\
\text { at end of Section F }\end{array}$ \\
\hline $\mathbf{H}$ & $f f$ pickup bar 159 & None & final bar $192-6$ beats** \\
\hline I & $f$ bar 193 & None & $\begin{array}{l}1 \text { beat of silence at the beginning } \\
\text { of the section - bar } 193 \text { as a } \\
\text { carryover from the G.P. at end of } \\
\text { Section H; } \\
\text { final bar } 205 \text { - } 5 \text { beats** }\end{array}$ \\
\hline $\mathbf{J}$ & $\boldsymbol{m} \boldsymbol{f}$ bar 206 & None & $\begin{array}{l}1 \text { beat of silence at the beginning } \\
\text { of the section - bar } 193 \text { as a } \\
\text { carryover from the G.P. at end of } \\
\text { Section I; } \\
\text { final bar } 217 \text { - } 9 \text { beats** }\end{array}$ \\
\hline $\mathbf{K}$ & $f f$ bar 218 & $\begin{array}{l}\text { all sections change to } \boldsymbol{f} \text { bar } 228 \text {; } \\
\text { decrescendo second violins bar } \\
229^{*} \text {; all sections change to } \boldsymbol{m \boldsymbol { f }} \\
\text { bar } 230 \text {; decrescendo to } \boldsymbol{p p} \\
\text { second violins bar } 231^{*}\end{array}$ & bar $227-3$ beats** \\
\hline $\mathbf{L}$ & $p$ bar 232; & $\begin{array}{l}\text { all sections change to } \boldsymbol{p p} \\
\text { bar 233; }\end{array}$ & final bar 234 \\
\hline
\end{tabular}

*As drone

** Grande Pause (G.P.) indicated 
Reflecting variations in the length of musical fragments and statements, the metrical schema of Orient \& Occident is relatively complex (Table 6.2) due to the dissimilar lengths of different stanzas of text in the Nicene Constantinopolitan Creed. The number of beats per bar also varies between three and six beats throughout the work, plus two occurrences of a nine beat bar.

Table 6.2 Orient \& Occident - metrical structure

\begin{tabular}{|c|c|c|c|c|c|c|}
\hline $\begin{array}{l}\text { Section \& } \\
\text { bars }\end{array}$ & $\begin{array}{c}\text { Number of } \\
\text { bars }\end{array}$ & $\begin{array}{c}\text { Number of } \\
\text { musical } \\
\text { fragments/ } \\
\text { statements }\end{array}$ & $\begin{array}{l}\text { Number of } \\
\text { time } \\
\text { signature } \\
\text { changes }\end{array}$ & $\begin{array}{l}\text { Number of } \\
3 \text { beat bars }\end{array}$ & $\begin{array}{l}\text { Number of } \\
6 \text { beat bars }\end{array}$ & $\begin{array}{c}\text { Duration } \\
\text { as total } \\
\text { number of } \\
\text { beats }\end{array}$ \\
\hline $\mathbf{A}(1-25)^{*}$ & 25 & 15 & 7 & 20 & 4 & 93 \\
\hline B (26-77) & 52 & 31 & 6 & 48 & 4 & 168 \\
\hline C (78-103) & 26 & 19 & 1 & 27 & 0 & 81 \\
\hline D (104-117) & 14 & 11 & 0 & 14 & 0 & 42 \\
\hline $\mathbf{E}(118-125)$ & 8 & 6 & 0 & 8 & 0 & 24 \\
\hline
\end{tabular}


occurrences of nine-beat bars are moments of silence - the first occurring as the last bar of Section A and the second occurring as the last bar of Section J.

As noted previously, Orient \& Occident has two different T-voices - the D minor triad and the G minor triad - with pitch class D being the common factor in both. ${ }^{261}$ Table 6.3 below shows that Sections A, C, E, F, I, and K have a single Tvoice wherein one or more pitches of the D minor triad are paired with M-voice melodic material. Sections D, G, and J have a single T-voice comprising one or more pitches of the G minor triad. Both T-voices are present in Sections B and H, the two longest sections of Orient \& Occident, though they never occur at the same time.

Table 6.3 Orient \& Occident - T-voice variances

\begin{tabular}{|l|c|c|}
\hline Section \& bars & D minor T-voice (bars) & G minor T-voice (bars)* \\
\hline A $(1-25)$ & $1-25$ & -- \\
\hline B $(26-77)$ & $53-60$ & $26-50,64-74$ \\
\hline C $(78-103)$ & $79-103$ & --- \\
\hline D $(104-117)$ & --- & $106-114$ \\
\hline E $(118-125)$ & $118-122$ & --- \\
\hline F $(126-138)$ & $126-135$ & --- \\
\hline G $(139-157)$ & --- & $139-155$ \\
\hline H $(158-192)$ & $158-172$ & $174-191$ \\
\hline I $(193-205)$ & $193-202$ & --- \\
\hline J $(206-217)$ & --- & $206-215$ \\
\hline K $(218-231)$ & $218-230$ & --- \\
\hline L $(232-234)$ & --- & --- \\
\hline
\end{tabular}

*When a T-voice is present. Bars of extended periods when players are playing in unison are omitted, but short periods where no T-voice is present (e.g. one or two beats, or a single bar) are included in some of the noted bars.

261 The two triads are also closely related on the circle of fifths with pitch class D being a major fifth of both $G$, pitch class A being a major fifth above $D$, and pitch class Bb (the second pitch in the $\mathrm{G}$ minor triad) being a major fifth above $\mathrm{F}$ (the second pitch in the D minor triad). 
As the work alternates between homophony and monophony, in some sections of Orient \& Occident the placement of M-voices and T-voices shifts from one instrumental section to another, particularly when an instrumental section plays divisi. An example of this can be found in Section C bars 89 through 96 (Figure $6.6)$.

Figure 6.6: Orient \& Occident - Section C bars 89-96

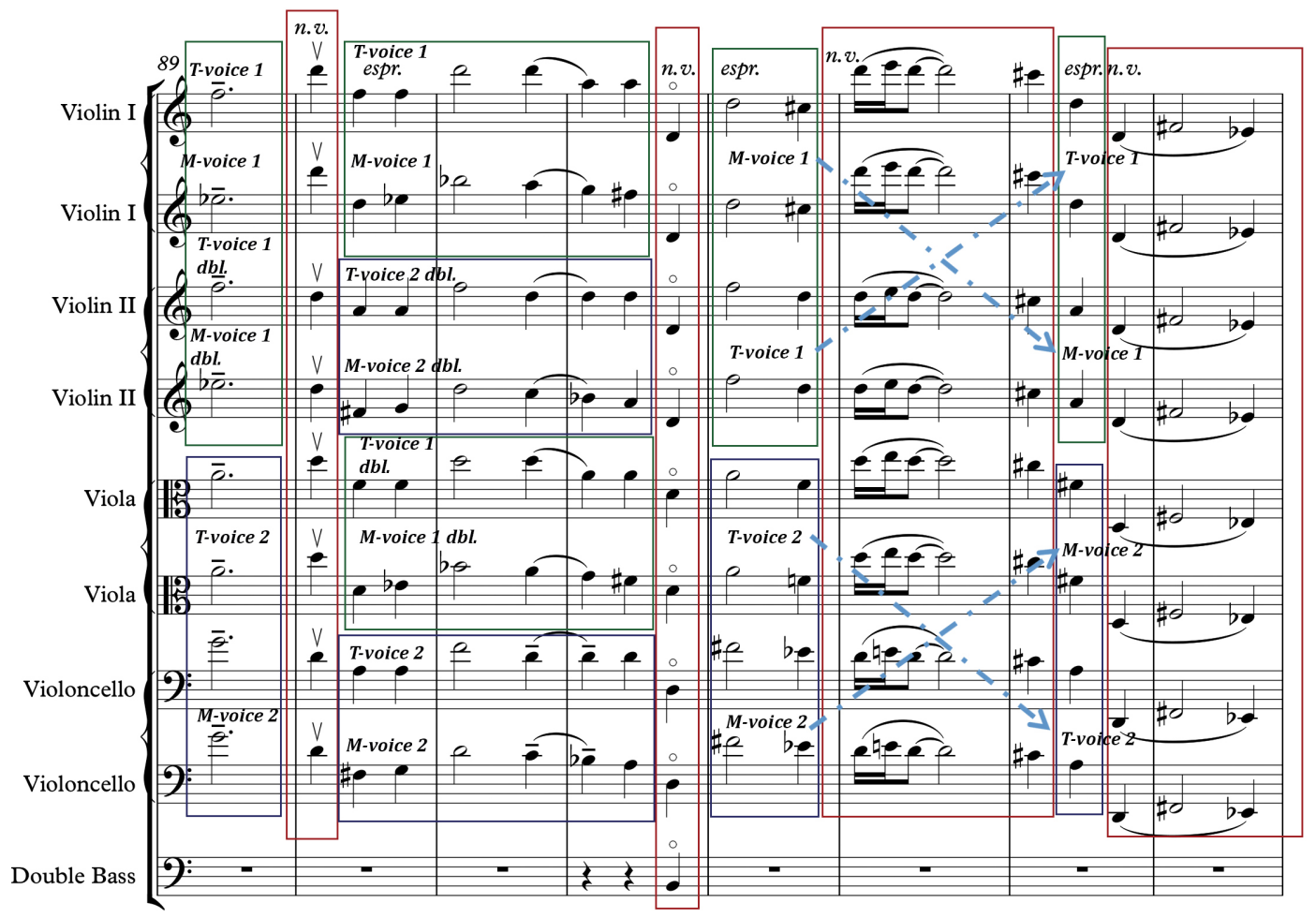

Except for the contrabasses, each of the instrumental lines in bars 89 through 96 is divisi. In bar 89 the writing is homophonic with both the first and second violins playing divisi. The lower divisi lines in each section take the same M-voice 1 pitch of Eb5, while the upper divisi lines take the first position, superior T-voice pitch of F6. In the same bar, both the upper and lower divisi lines play an M-voice 2 pitch in unison a minor sixth below G4; while the violas play the T-voice 2 pitch of A4. Starting on the second beat of bar 90, through the second beat of bar 92, the placement of the M-voices and T-voices in the first violins is the same as that 
in bar 89; however, the upper and lower divisi lines of the second violins now double T-voice 2 and M-voice 2 one octave higher in relation to the M-voice/Tvoice pairing in the divisi violoncello lines. In a similar vein, the divisi viola lines now double M-voice 1 and T-voice 1, one octave below the first violins.

In bar 93 the placement of M-voices 1 and 2 and their respective T-voices changes again, with the first violins playing M-voice 1 in unison; the second violins playing T-voice 1 in unison; the violoncellos playing M-voice 2 in unison and the violas playing T-voice 2, again in unison. The second beat of bar 95 is also a brief moment of homophony, wherein the first and second violins have switched roles. In comparison to bar 93, the second violins now play M-voice 1 while the first violins play T-voice 1 . A similar reversing of roles by the violas and violoncellos, in relation to M-voice 2 and T-voice 2, also occurs in the same bar.

\section{Small dimension}

The above examination of the large and middle dimensional aspects of Orient \& Occident has identified that:

- the time signature changes from three beats per bar to six or nine beats;

- the entire string orchestra alternates between periods of monophony played without vibrato and homophony played with vibrato;

- some melodic gestures are complete musical statements, while others appear to be melodic fragments of one or two notes;

- the work alternates between two different scales - a D double harmonic diatonic scale and a G Hungarian minor scale; 
- reflecting this, Orient \& Occident's T-voices alternate between the pitch classes of the D minor triad and that of the G minor triad; and

- during homophonic episodes, the M-voice and T-voice functions may shift between the different instrumental sections.

An analysis of the large and middle dimensions of Orient \& Occident does not, however, provide a satisfactory explanation for why these changes occur when they do - i.e. whether Pärt is using one or more systematic processes to determine which musical parameters change when, or if the work has for the most part been through composed. Neither does it provide any clarity whether the above aspects of Orient \& Occident indicate any implied meaning on the composer's part. It is only when one examines the relationships between the Church Slavonic text of the Nicene Constantinopolitan Creed and the small dimensional melodic, rhythmic, and harmonic aspects of Orient \& Occident that an explanation for most of these different variances becomes more readily apparent.

As was the case for Psalom and Silouan's Song, the shape of melodic statements, variances of note durations (based upon what syllables in specific words are stressed) and other rhythmic aspects such as rests and Grande Pauses (associated with punctuation marks), instrumental articulations, and the general melodic movement and growth of musical statements can be linked directly back to characteristics of specific words and the structure of different stanzas and phrases in the text of the Nicene Constantinopolitan Creed.

\section{Articulations}

At the most basic level, the articulations of the musical lines, for example arco versus slurred legato, glissandos, and the instructions for the musicians to play 
espressivo (espr.) or without vibrato (n.v), and at times even the bowing instructions, are attributable to individual words in the Church Slavonic text. The linkage between these later performance instructions and the text is clearly illustrated in Figure 6.7.

Figure 6.7: Orient \& Occident - Section B bars 26-41262

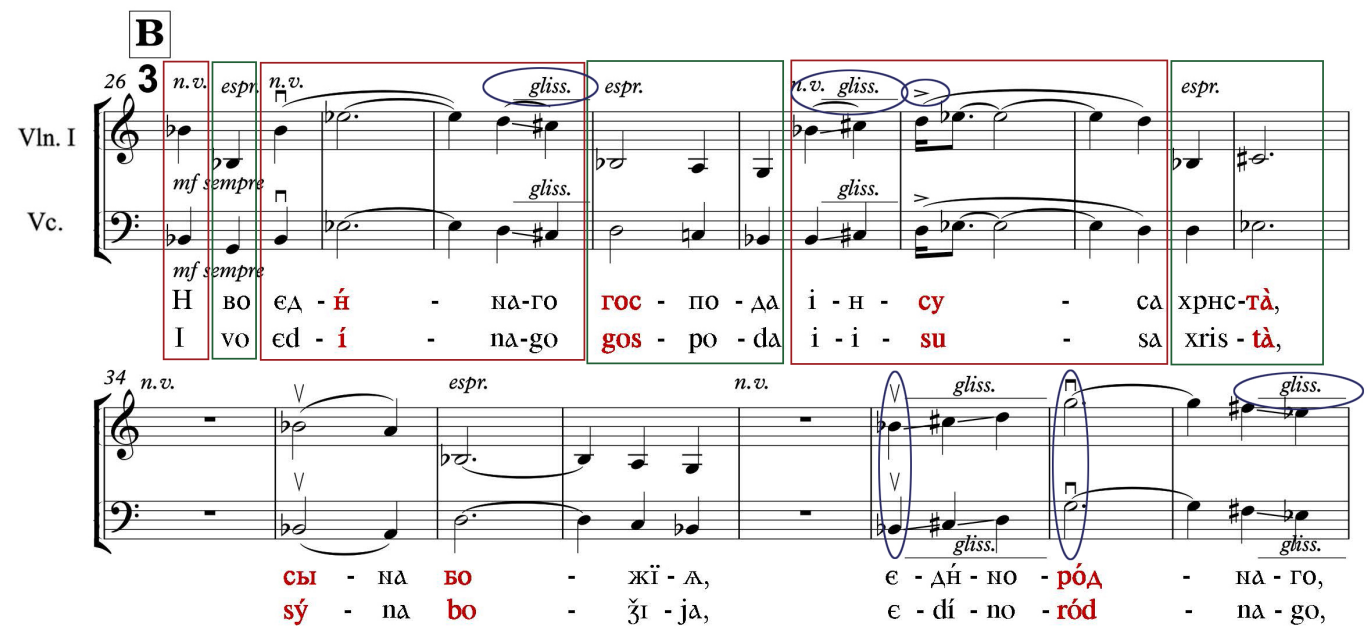

In bars 26 through 33 the demarcations between the individual words of the text are denoted by the alternating red and green boxes: for example, the Church Slavonic words И (pronounced phonetically as i), во (vo), єАн́наго (ed-í-na-go), господа (gos-po-da), which translated to English mean "and in one Lord".

With each new word of the text, the performers are instructed to alternate between playing espressivo (espr.) or with no vibrato (n.v.). This particular textbased rule is adhered to throughout all 12 sections of Orient \& Occident. Another text-determined articulation relates to the performers playing legato versus playing arco. As a general rule, during periods of playing non-vibrato the player

262 Red highlighted and bolded characters in the figure denote stressed syllables in multisyllabic words. 
is also instructed to play legato (i.e. with slurs), whereas when players are instructed to play espressivo, legato slurring is not called for in the score. ${ }^{263}$

Figure 6.7 above also shows that instructions to play glissando only occur during statements marked n.v. A further text-based rule as to when glissandos occur relates to the number of syllables before and after a stressed syllable that occurs in the middle of a word. For example in bars 31 and 32, the syllable "cy" in the word "iнcyca" (the Church Slavonic word for Jesus, pronounced as $i-i-s u-s a$ ) is the stressed syllable of the word and is preceded by two syllables. The relevant rule that Pärt has applied to such situations is that where two or more syllables precede a stressed syllable for a word denoted as n.v., the notes associated with those syllables are to be played glissando.

A similar rule applies when two or more syllables follow a stressed syllable in a multisyllabic word, where the composer has indicated the musician should play without vibrato. An example of this can be seen in bar 41 of Figure 6.7 with the notes associated with the word єАн́моро́днаго (pronounced ed-í-no-ród-na-go). The syllable (póA pronounced ród) is stressed, preceded by three syllables and followed by two syllables. In such situations Pärt indicates that the three notes before the stressed pitches G5 and G3 in the violin and violoncellos lines, as well as the two notes that follow, are to be played glissando.

${ }^{263}$ Section A of Orient \& Occident is an exception to this rule. The first two musical statements marked as to be played espressivo contain legato markings as well. 


\section{Tonal centres - monophonic material}

Pärt has also employed another rule in relation to the pitch class centres of the monophonic melodic statements and fragments associated with each alternate word. The tonal centre for each monophonic melodic statement and fragment is always the pitch class associated with the first syllable of each word. This pitch class remains the tonal centre for all monophonic n.v. melodic statements and fragments within the same section, until a punctuation mark indicates the end of a significant phrase in the text (a single exception to this practice is discussed below).

As shown in Figure 6.8 overleaf (Section B bars 26 through 50), the tonal centre for each monophonic statement or fragment is pitch class Bb. This pitch aligns with the first syllable of the following words in the text: "Н, єАн́наго, $\mathbf{i} \overrightarrow{\mathrm{H}} \mathrm{ca}, \mathrm{c} \overrightarrow{\mathrm{N}}$,

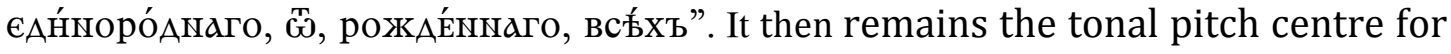
the monophonic material until the occurrence of a colon at the end of the full opening statement of Section B in bar 50. The literal English translation of the full statement of text is "And in one lord Jesus Christ, the son of God, the onlybegotten, who was begotten from the Father before all ages: ...".

Starting in bar 52, the pitch class centre shifts to A. Pitch class A is associated with the first syllables of the words свъ́та, н́стнина, вога. The literal translation of the entire phrase of text is "light from light, true God from true God". Following the comma after the word H́cтнnna, the tonal centre for the remaining monophonic sections in bars 61 through 76 shift to pitch class D - associated with the first syllable of the words poжА́́nna, єАннос8џ̣на, H́мже, вы́ша. The 
literal English translation of the full statement of text at the end of Section B is "uncreated, one-natured with the Father through whom everything came to be".

Figure 6.8: Orient \& Occident - violoncello line Section B bars 26-76
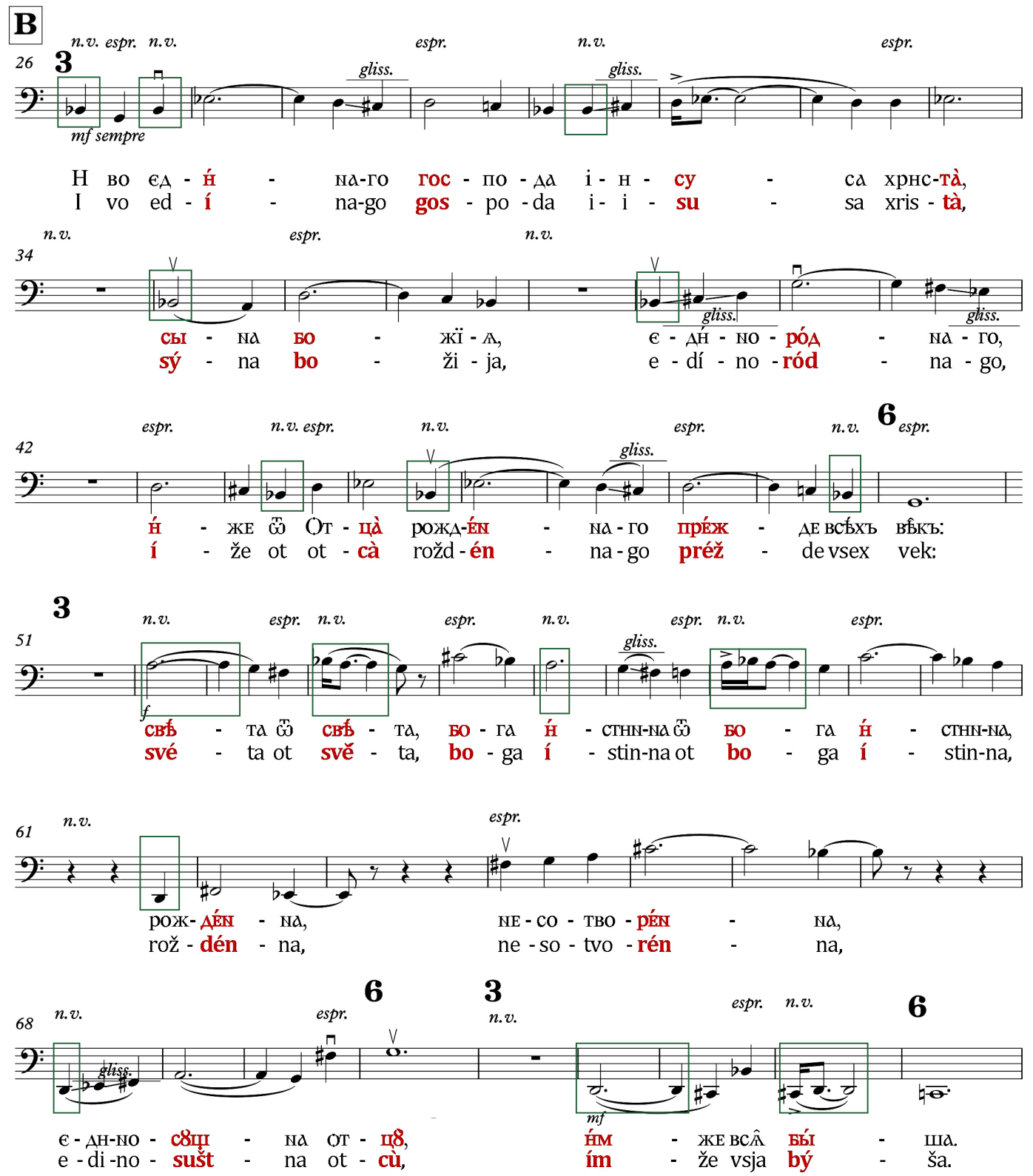

As noted above, there is one exception to Pärt retaining the same pitch class centre for the monophonic material in specific sections of Orient \& Occident (e.g. Section B). This occurs at the beginning of the work in Section A (Figure 6.9). With the exception of bars 6 and 7, the pitch class centre for all monophonic 
material in Section A is F\#. However, in bars 6 and 7 the composer choses pitch class $\mathrm{A}$ as the tonal centre. In this case pitch class $\mathrm{A}$ is associated with the first syllable of the word вога (pronounced as bo-gd), the Church Slavonic word for "God".

Figure 6.9: Orient \& Occident - violoncello line Section A bars 1-25

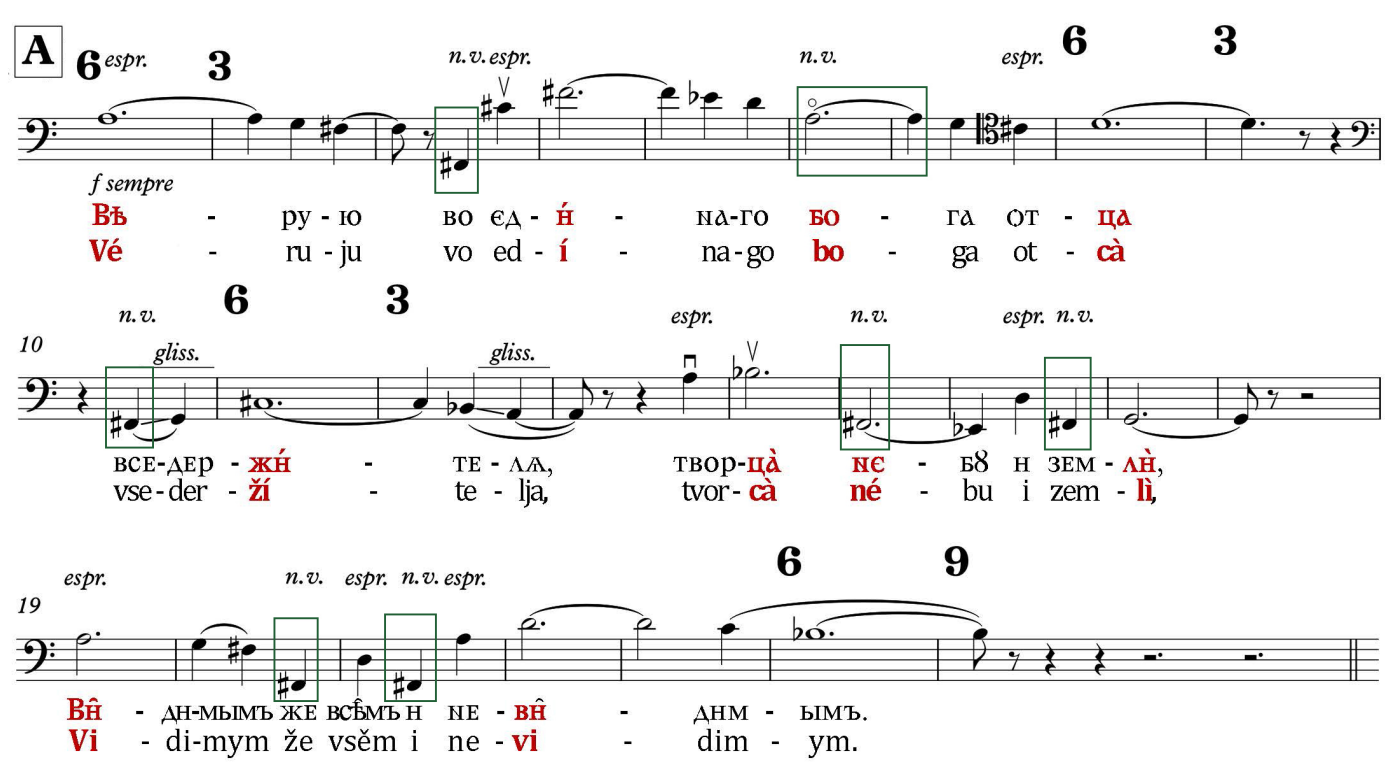

This exception is important, as Pärt only uses pitch class A as the tonal centre for monophonic material four times in Orient \& Occident: in association with Church Slavonic word for God in Section A; the words 'light' and 'true' in Section B in the phrase "light from light, true God from true God"; the words 'spirit' and 'lord' (Ауха and господа, respectively - pronounced as $d u-x d$ and gos-po-da in the Russian transliteration) in Section H bars 159 through 166; and the final pitch of the work, i.e. the last syllable of the word Ами́мь or Amen. Restricting the use of pitch class A as a tonal centre to just these specific moments in Orient \& Occident, as well as the spiritual associations of the related text, suggests that Pärt has chosen to single out pitch class A as representing a specific spiritual sentiment. This is augmented by the fact that the melodic lines during these brief moments 
start at and return to A, further suggesting a certain alpha (d) and omega (C) relationship ${ }^{264}$ within the respective musical lines.

\section{M-voice tonal centres - homophonic material}

Notably, having once identified the relevant tonal centres of the monophonic material in Orient \& Occident, the identification of the primary tonal centres associated with M-voice 1 during alternate periods of homophony is relatively straightforward. As can be seen in Figure 6.10 overleaf, there is a clear relationship between the first violins' starting pitches during homophonic statements and the pitch class centre of the violoncellos at the beginning of each monophonic statement. For example, it has already been identified that the main pitch class centre of the monophonic material in Section A is F\#, except for bars 6 and 7 when the tonal centre shifts to A. Similarly, the first violins' starting pitch for each non-monophonic statement in Section A is also F\#, with the exceptions of the end of bars 3 through 5 and 7 through 9, wherein each melodic statement or fragment commences with pitch class A.

${ }^{264}$ alpha (d) and omega (๗) are the first and last letters of the Greek alphabet, which also have symbolic significance in Christianity as representing Christ and God, respectively. 

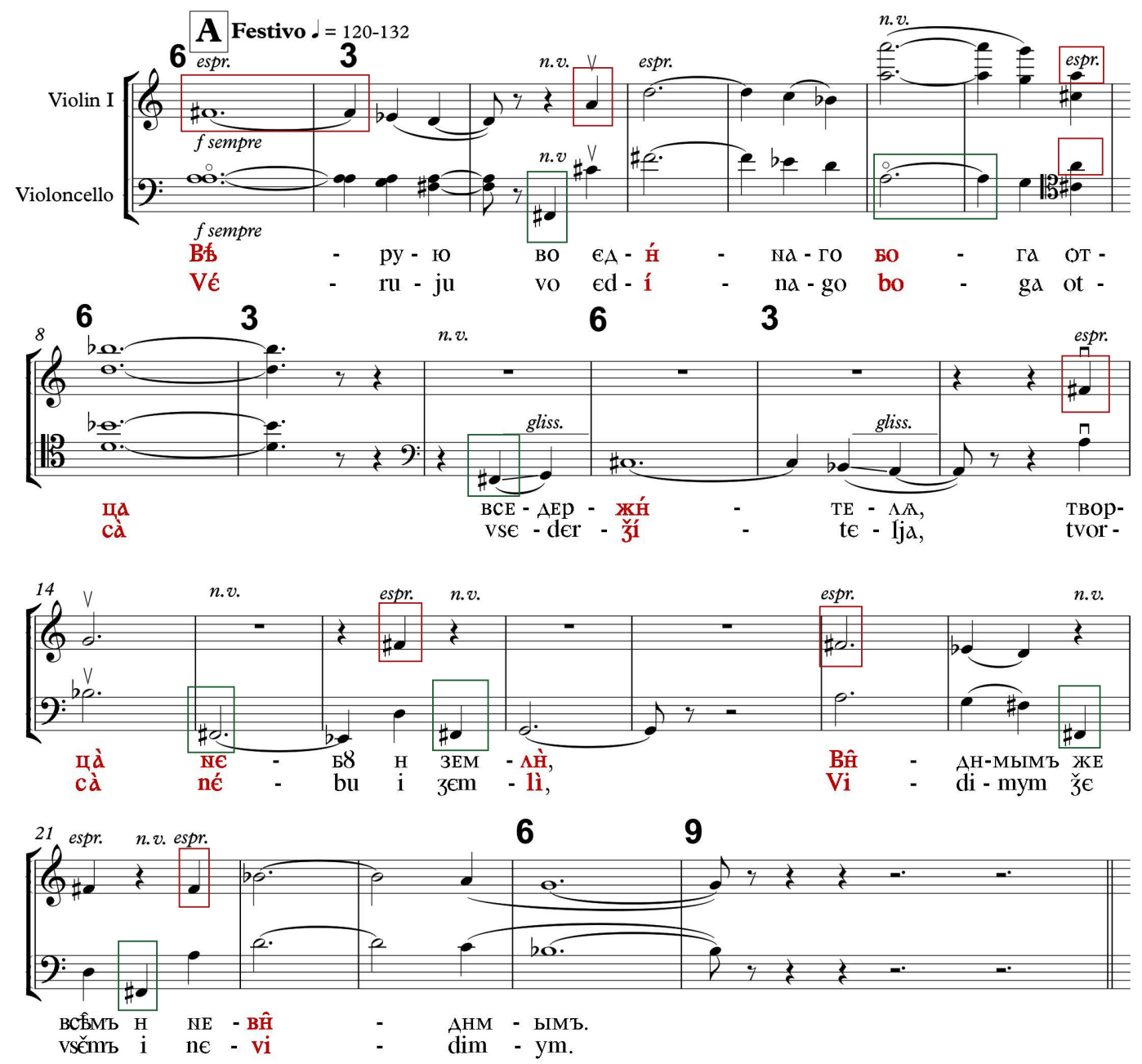

As can be seen in Figures 6.12 through 6.17 in the pages overleaf, this rule holds true for M-voice 1 throughout homophonic sections of the remainder of Orient \& Occident, regardless of which instrumental section plays the M-voice 1 line (periodically the second violins take the role of playing M-voice 1).

Table 6.4 overleaf details the pitch class centres of the monophonic material and M-voice 1 in each of the different sections of Orient \& Occident, and the T-voices that occur during homophonic subsections (light grey shading denotes a G minor triad T-voice) and dark grey shading denotes use of a D minor triad T-voice). Figure 6.11 overleaf provides a visual illustration of these progressions. 
Table 6.4: Pitch class centres of monophonic material and M-voice 1 and associated T-voice during homophonic subsections

\begin{tabular}{|c|c|c|c|c|c|}
\hline \multirow{2}{*}{$\begin{array}{l}\text { Section \& } \\
\text { bars }\end{array}$} & \multicolumn{5}{|c|}{ Pitch class centres and associated bars } \\
\hline & D & F\# & G & A & Bb \\
\hline $\mathbf{A}(1-25)$ & & $1-3^{\wedge}, 10-25$ & & $3-9$ & \\
\hline B $(26-77)$ & $61-76$ & & & $52-60$ & $26-50$ \\
\hline C (78-103) & $78-103$ & & & & \\
\hline D (104-117) & & & $104-117$ & & \\
\hline $\mathbf{E}(118-125)$ & & $118-125$ & & & \\
\hline $\mathbf{F}(126-138)$ & & $126-137$ & & & \\
\hline G (139-157) & & & & & $140-158^{* *}$ \\
\hline $\mathbf{H}(158-192)$ & $171-177$ & & & $159-166$ & $178-191$ \\
\hline I (193-205) & $193-204$ & & & & \\
\hline $\mathbf{J}(206-217)$ & & & $206-216$ & & \\
\hline $\mathbf{K}(218-231)$ & $219-231$ & & & & \\
\hline $\mathbf{L}(232-234)$ & & & $\begin{array}{c}232 \\
\text { (pitch class G) }\end{array}$ & $\begin{array}{c}233 \\
\text { (pitch class A) }\end{array}$ & \\
\hline
\end{tabular}

G minor triad T-voice

D minor triad T-voice

${ }^{\wedge}$ Downbeat of bar

${ }^{* *}$ Use of non-T-voice harmonising pitch class $\mathrm{F} \#$ on last beat of bar 158

Notably, all but one of these pitch class centres corresponds to a pitch in one or both of Orient \& Occident's two T-voice triads D-F-A and G-Bb-D. The exception to this is pitch class F\#, which occurs in both of Orient \& Occident's scales but is not part of either of the work's T-voice triads. ${ }^{265}$ In relation to this, Pärt opts to use a G minor triad T-voice during subsections when the pitch class centre of M-voice 1 during homophonic periods is $\mathrm{G}$ or $\mathrm{Bb}$, and a $\mathrm{D}$ minor triad $\mathrm{T}$-voice for subsections where the pitch class centre of M-voice 1 is F\# or A. As both T-voices share pitch class D, Pärt uses either T-voice when the M-voice 1 pitch class centre is of melodic material D.

\footnotetext{
265 However, Pärt opts to use F\# as the harmonising pitch class in the last beat of bar 158, rather than a pitch class from the D minor or G minor triad.
} 


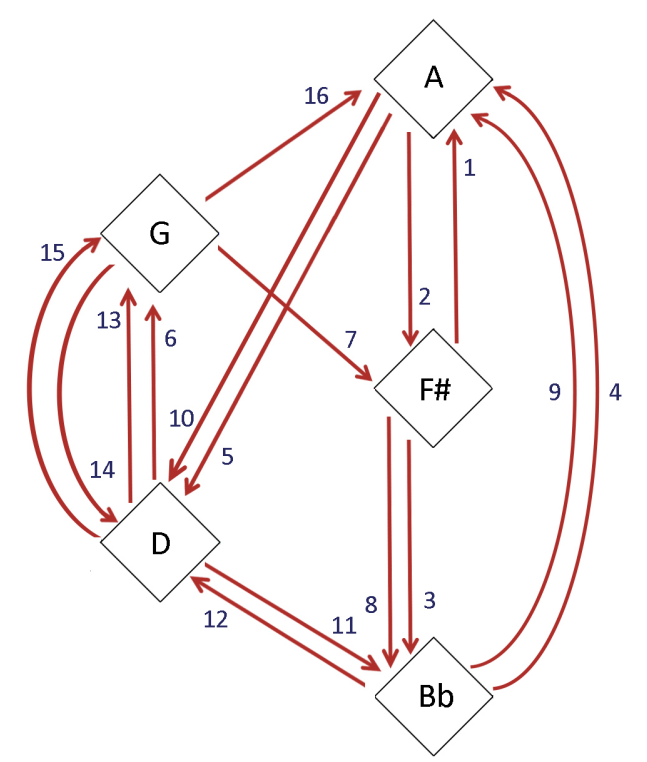

Figures 6.12 through 6.17 overleaf show the violins and violoncellos' M-voice lines for each of the other 11 sections of the work, with the relevant Church Slavonic text for each section. Green boxes in each figure identify the pitch class centres of the monophonic material, while red boxes identify the pitch class centres of M-voice 1 during homophonic statements and fragments.

The relationship between M-voice 1 and M-voice 2 during homophonic segments is also apparent in these figures. When present, the pitches of M-voice 2 are always either enharmonically a minor third above those of M-voice 1 , but displaced downwards by one or more octaves (e.g. the first two beats of bar 29, bar 33 and the last beat of 32, and bars 36 and 37), or a minor third below those of M-voice 1 and again displaced downwards by one or more octaves (e.g. the second beat of bar 26, bar 50 and the last beat of bar 53). 
Figure 6.12: Orient \& Occident - first violin and violoncello lines Sections B bars 26-76

B
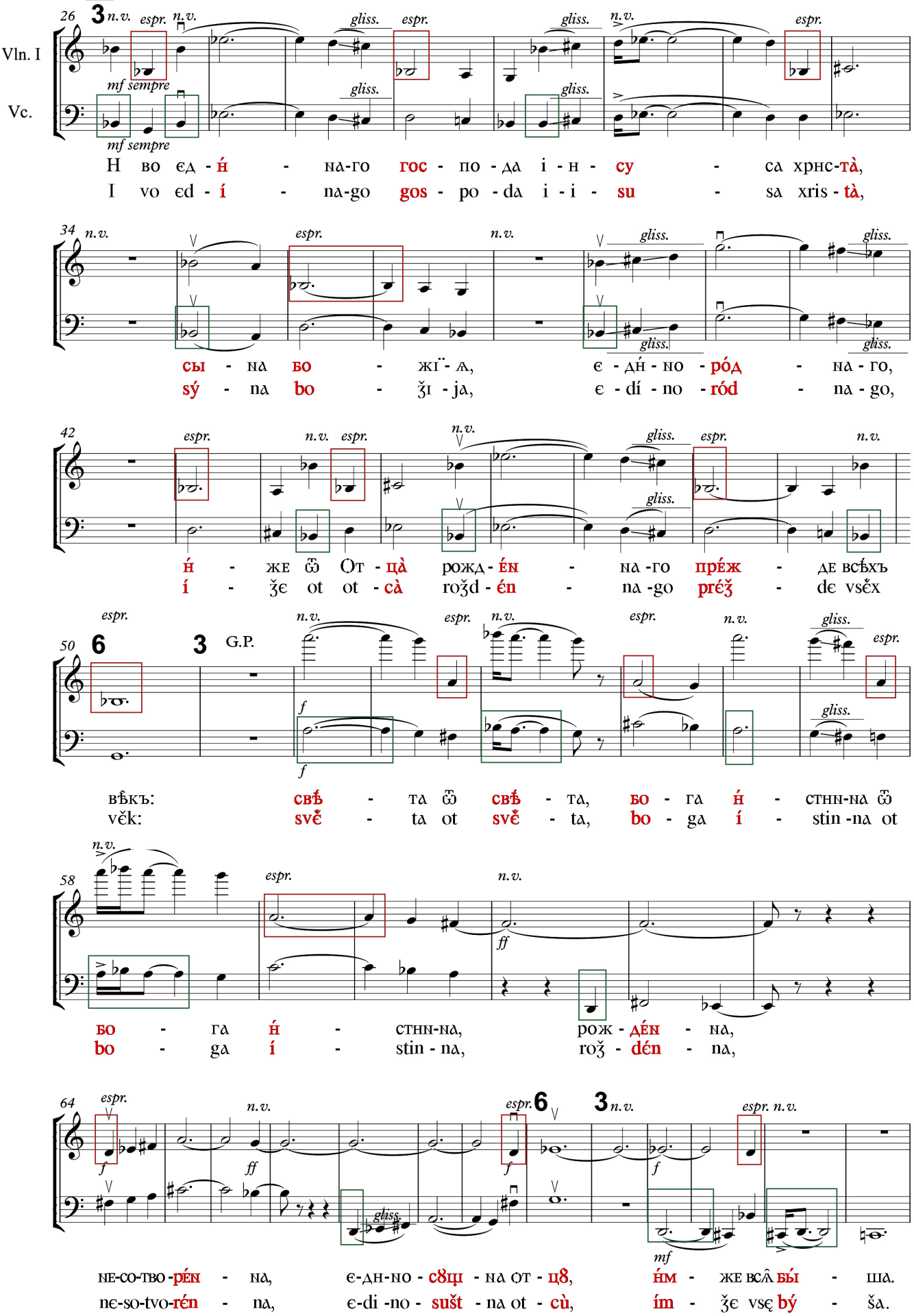
Figure 6.13: Orient \& Occident - first violin and violoncello lines Section C bars 77-103

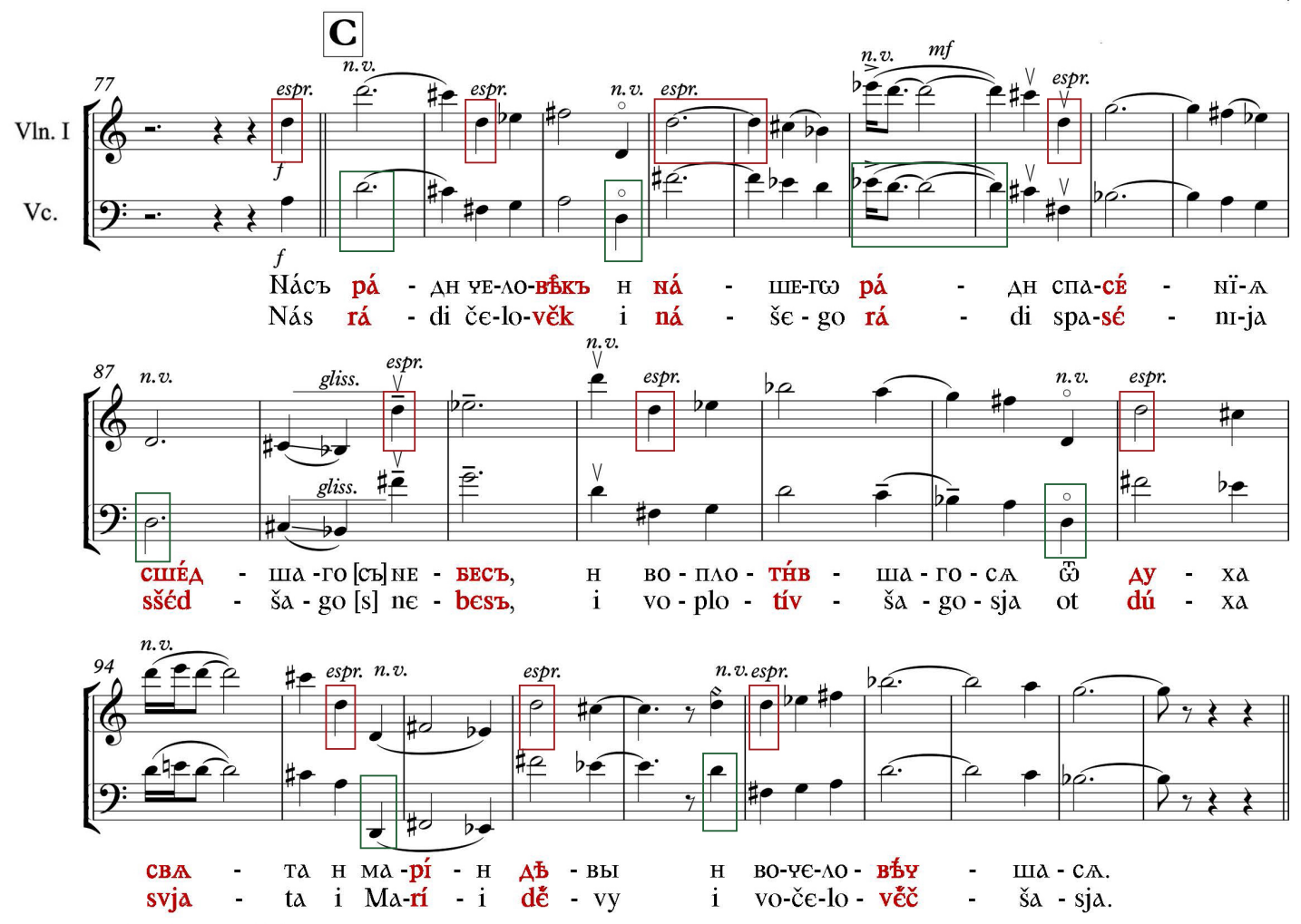

Figure 6.14: Orient \& Occident - first violin, second violin and violoncello lines Sections D and E bars 104-125

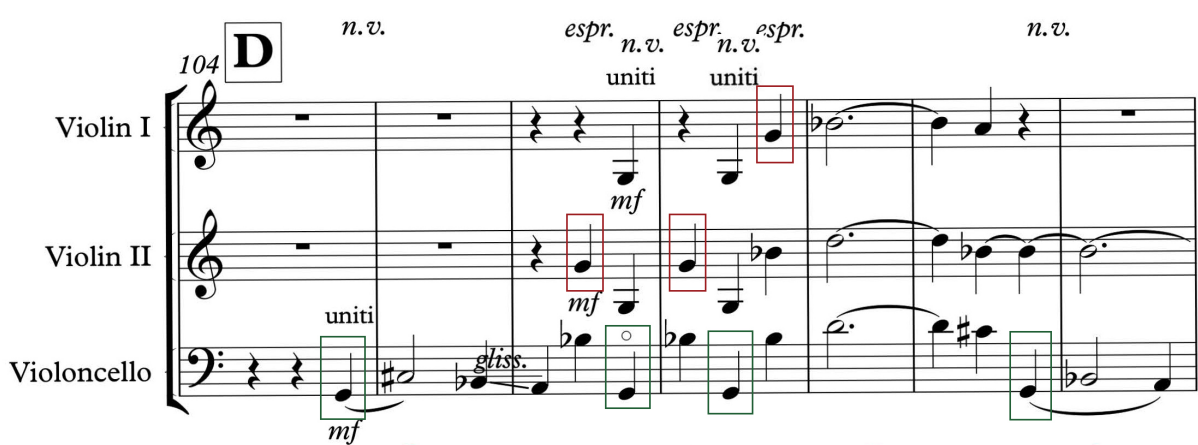

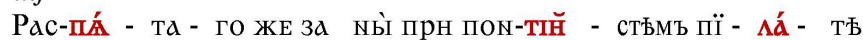

Ras-pjá - ta - go ̌̌c za nỳ pri pon - tíi - stemъ pi - lá - te

espr. n.v.

espr. n.v.

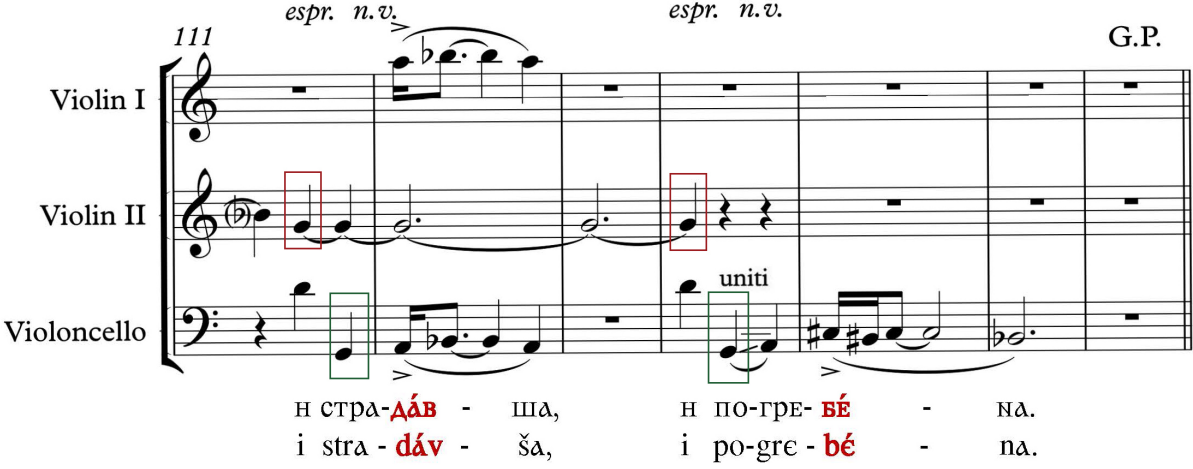


Figure 6.15: Orient \& Occident - first violin and violoncello lines Sections E, F and G bars 118-157
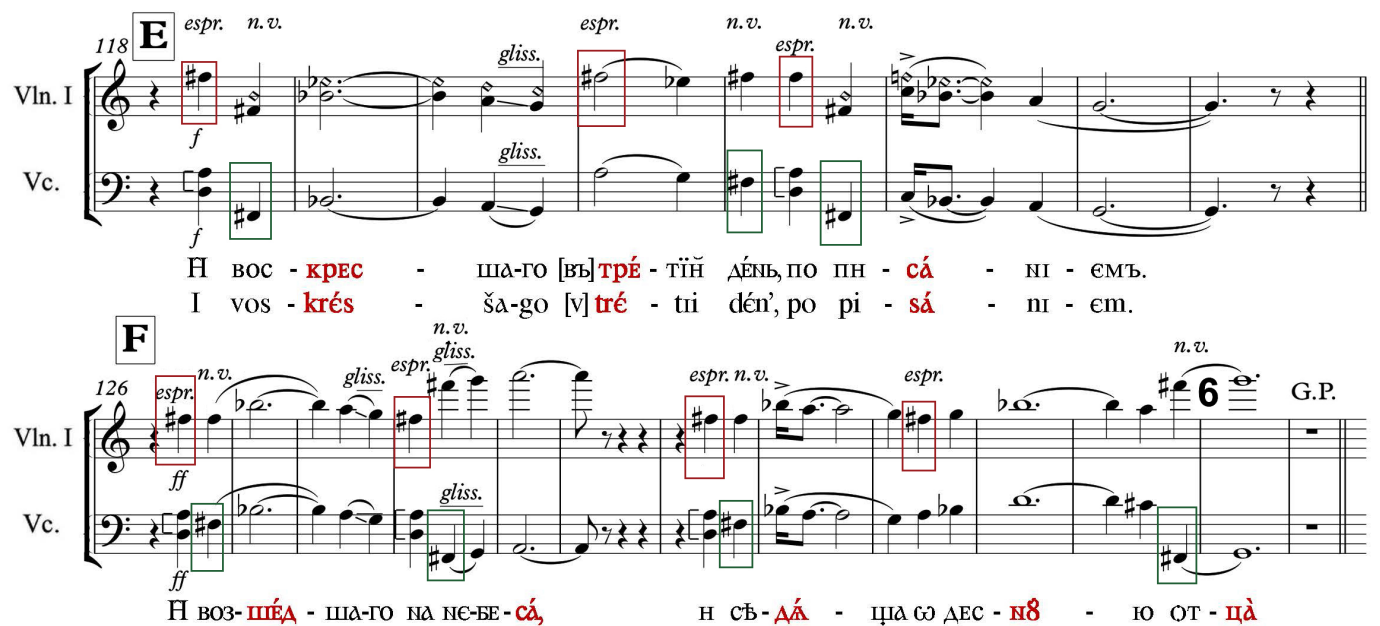

В во3-ШயÉA - Шd-ГO NA NC-BE-CA,

I voz-šéd - ša-go na ne-be-sá, i sě-djá - š́ta o des - nú - ju ot - cà
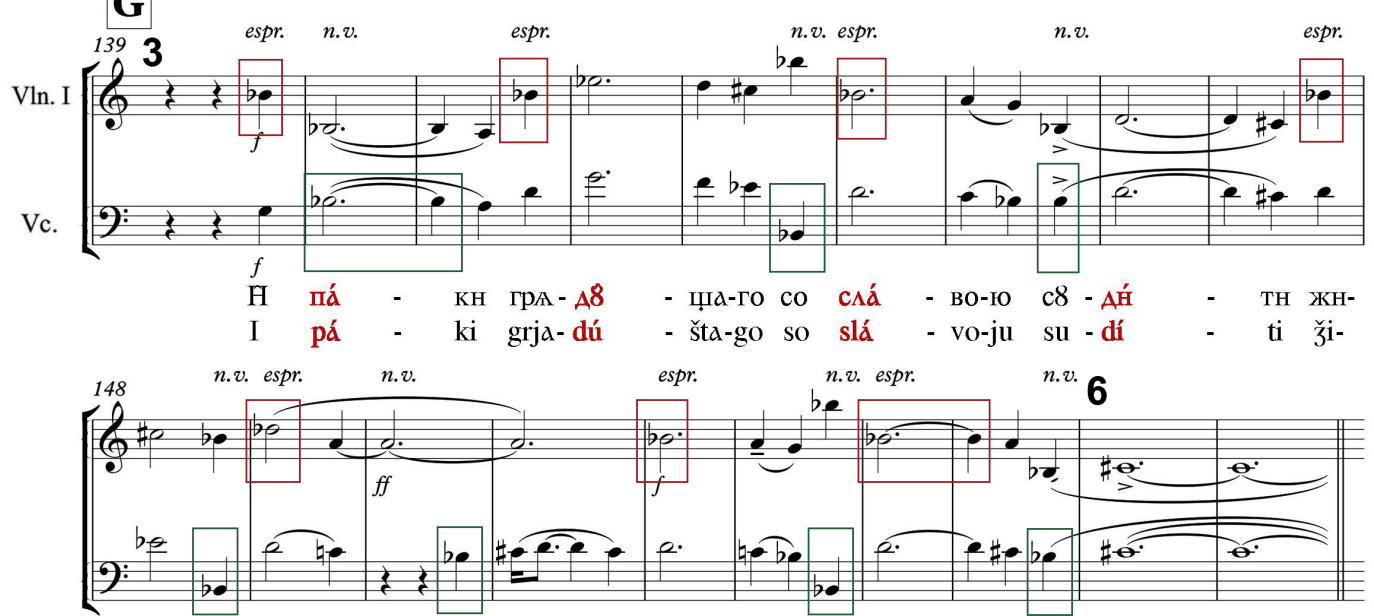

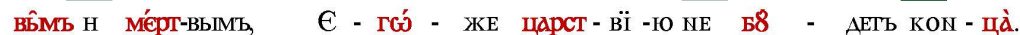

vym i mért-vym, $€$ - gó - క̌€ carst-vi-ju n€ bú - det kon - cà. 
Figure 6.16: Orient \& Occident - violoncello line Section H bars 158-192
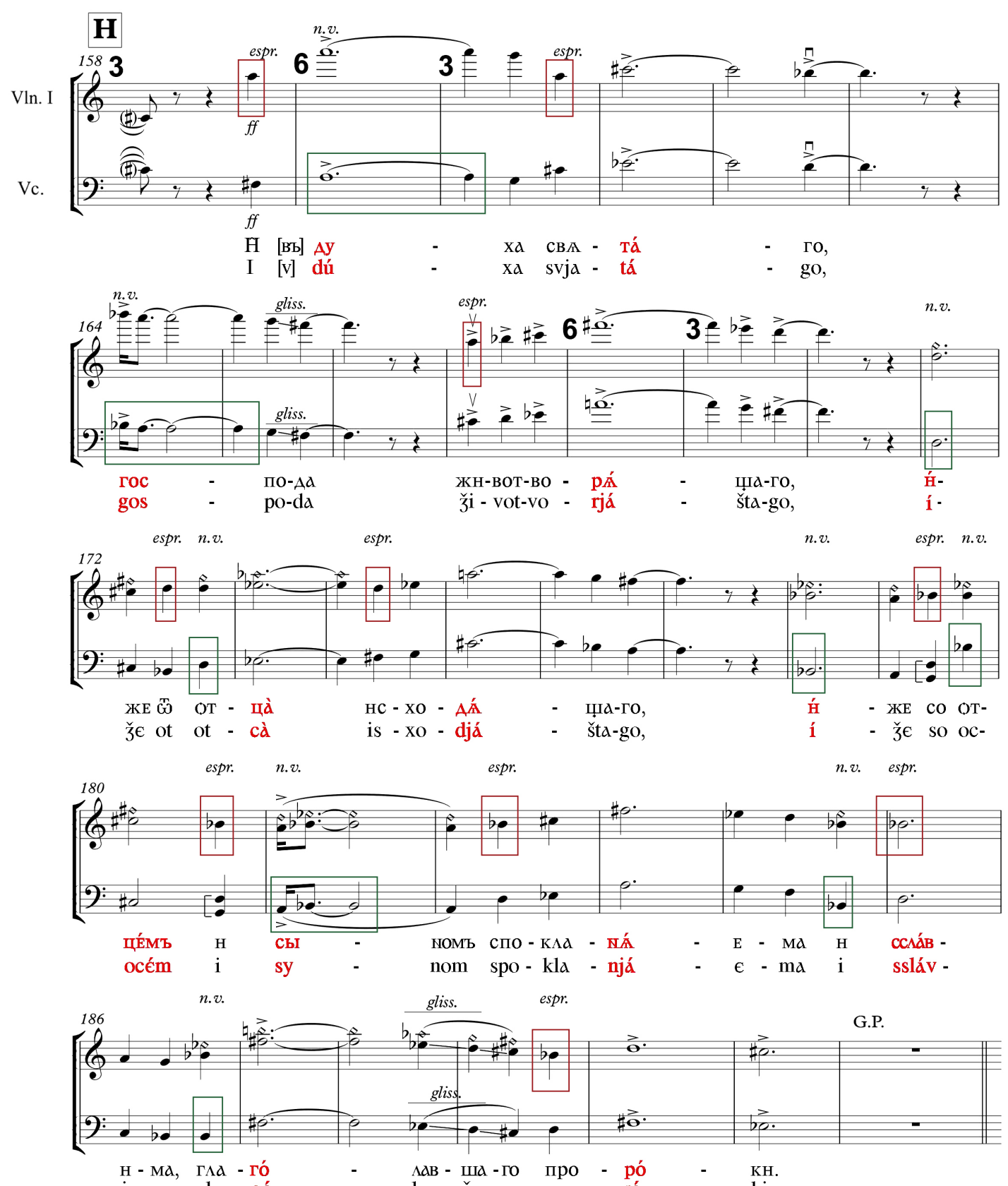

i - ma, gla - gó $\quad$ - $\quad$ lav - ša -go pro - ró $\quad$ - $\quad$ ki. 
Figure 6.17: Orient \& Occident - violoncello line Sections I through L bars 193-234

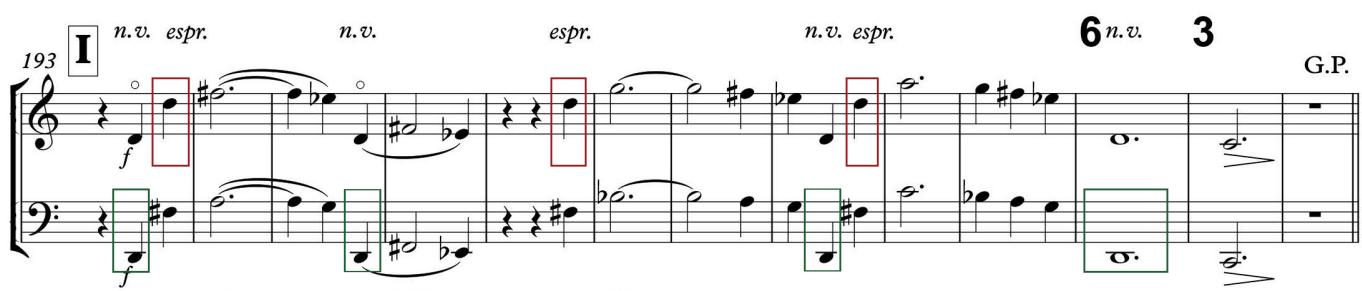

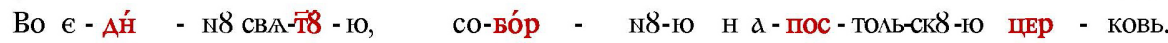

Vo e - dí - nu svja-tú-ju, so-bór - nu-ju i a -pos-tol'-sku-ju cér - kov'.
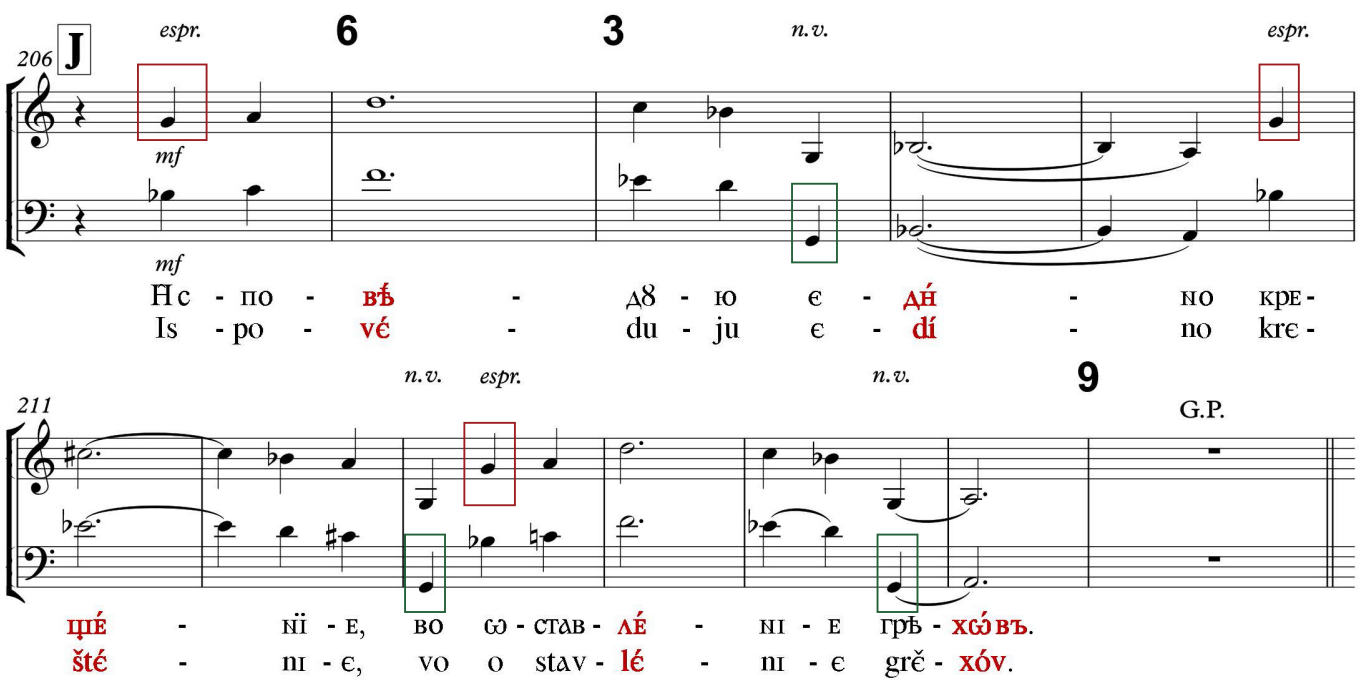

K Piu lento

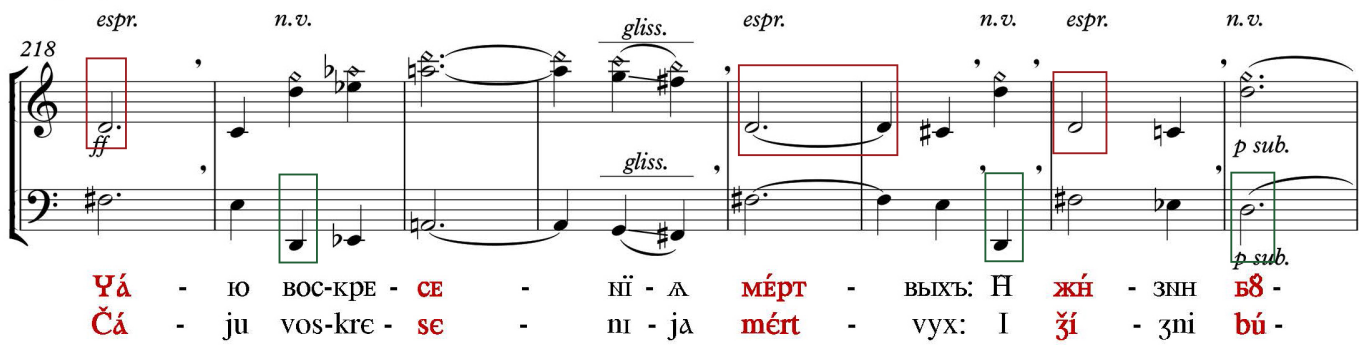

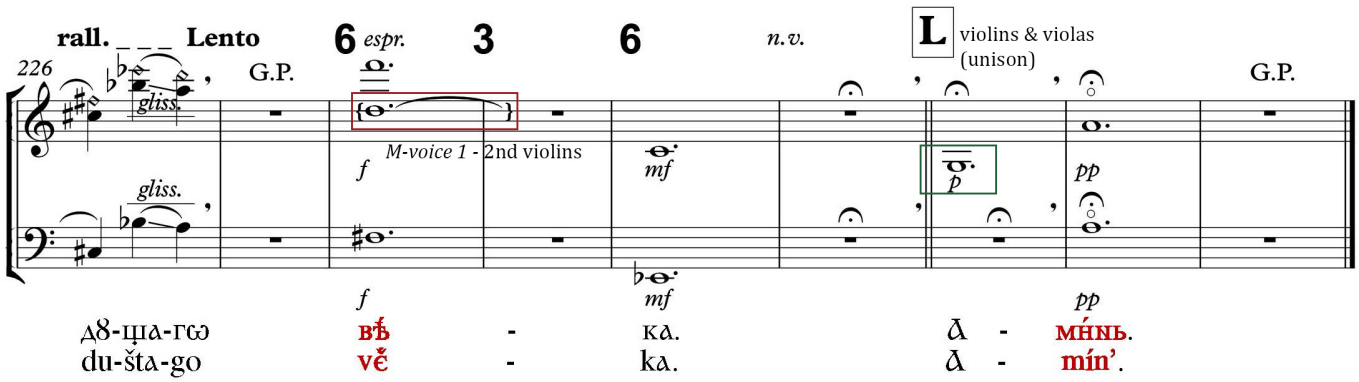




\section{$\underline{\text { Text-based melodic rules in Orient \& Occident }}$}

As in Psalom and Silouan's Song, Pärt also employs a specific set of text-based rules to determine melodic movement away from and towards the various pitch class centres in Orient \& Occident, regardless of which pitch class centre is being used, as well as to determine note durations. Below and overleaf is a summary of the various text-derived melodic and rhythmic rules that apply to the majority of Orient \& Occident. ${ }^{266}$

1. Every word of the text is associated with a musical statement or fragment that alternates between being homophonic and played with vibrato or monophonic and played without vibrato, with the change occurring on the first syllable of each word.

2. Musical phrases associated with multisyllabic words in the text alternate between proceeding downwards or upwards from the relevant M-voice 1 pitch-class centre, except when the stressed syllable of a word containing three or more syllables is both preceded and followed by one or more syllables. Where this is the case, stressed syllables occurring after the first syllable of a multisyllabic word that are followed by:

a) one syllable in the same word are always approached by an upward leap of a third. The melodic line then descends downwards in stepwise fashion.

\footnotetext{
266 As was the case for the "text-derived rules" that apply to Psalom and Silouan's Song (see Chapter 5), the rules described in this section are derived from a detailed analysis of Orient \& Occident and have not been previously codified elsewhere. Therefore the ordering and numbering of these rules are by the author and not meant to imply any hierarchy.
} 
b) two or more syllables in the same word are approached by an upward leap of a fourth. The melodic line then descends downwards in stepwise fashion.

3. A new bar commences every time a stressed syllable occurs in a multisyllabic word. The duration of stressed syllables followed by one or more syllables in multisyllabic words generally extend one or two beats into the following bar though there are exceptions to this, particularly if the stressed syllable is the first syllable of a word.

4. Notes associated with stressed syllables of multisyllabic word are assigned a minimum of two beats. The number of additional beats assigned to a stressed syllable varies, depending upon where within the word the stressed syllable occurs:

a) When a multisyllabic word commences with a stressed syllable, musically it usually is assigned three or four beats, except for the first syllable of the first stanza in Section A, which is assigned six beats plus the downbeat of the next bar.

b) When a stressed syllable of a multisyllabic word is the second syllable, it is usually assigned the duration of four beats - a three beat bar plus the downbeat of the following bar.

c) When a multisyllabic word ends with a stressed syllable it is usually assigned three beats, unless it is also the final syllable of a stanza or sub-clause of text. Where this is the case, the final stressed syllable may be assigned to a six-beat bar and continues into the next bar by one or more beats. 
d) Six-beat bars can also occur when a stressed syllable in the text is the third syllable in a five-syllable word. In some cases they also apply where the stress syllable is the penultimate syllable of a phrase.

5. Notes associated with single syllable words and non-stressed syllables are assigned one beat each, with certain exceptions. Text-derived exceptions to this rule occur when:

a) A single syllable word, or the non-stressed syllable at the end of a multisyllabic word, is followed by a full stop (assigned either three beats, three beats plus the downbeat of the next measure, six beats or six beats plus the downbeat of the next measure) or a colon (assigned six beats).

b) A non-stressed syllable at the end of a multisyllabic word that is followed by a comma can continue through the downbeat of the next bar, if it suits the musical phrasing.

6. Where multiple single syllable words occur in a row, or a single syllable word is followed by a multisyllabic word that commences with an unstressed syllable, alternate occurrences of the same pitch class are displaced upwards or downwards by an octave to avoid the sounding of the same pitch in the same register two or more times in a row.

7. Where a multisyllabic word is repeated later in the same stanza and the second occurrence of the word is also treated monophonically, the pitch associated with the stressed syllable in the word is ornamented with a semiquaver appoggiatura or a mordent either a scale step above or a scale step below the tonal centre of the musical phrase or fragment, depending upon 
whether the direction of the musical melodic line is moving downwards or upwards away from the tonal centre pitch.

8. Where the stressed syllable of a multisyllabic word in the text is being treated monophonically in a melodic line and the stressed syllable is preceded or followed by two or more syllables, the melodic statement or fragment is usually played glissando. In some cases it may also be ornamented with an appoggiatura.

The M-voice lines of Section A illustrate a number of these text-based rules (see Figure 6.18 overleaf), which are presented below in the order in which they occur

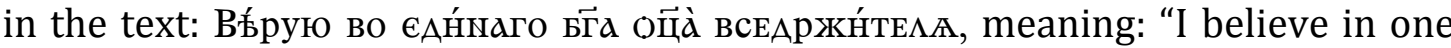
God, the Father Almighty".

Rule 1: For example, bars 1 through 9 exemplify Pärt's practice of associating each melodic statement or fragment in Orient \& Occident with a single word in the text (Rule 1). They also illustrate the role that stressed and non-stressed syllables play in determining note duration (Rules 2 through 4). The first word "Върую" (pronounced as Vé-ru-ju) is a three-syllable word with the stress falling on the first syllable. Looking specifically at the first violins line, Pärt transforms this word into a two bar three pitch melodic segment starting at F\#4 - with the first pitch being allotted six beats in bar 1 plus the first beat of bar 2, before descending stepwise through Eb4 to D4, with each pitch being assigned one beat each, and the last pitch carrying over into the first beat of the next bars. M-voice 2 in the violoncello line follows suit, but commences on pitch class A enharmonically a minor third above pitch class F\# in M-voice 1 - and descends downwards to $\mathrm{F \# 3.}$ 
Rule 5: The second word in the opening line of the text is Bo (pronounced as vo). Musically it is treated as a fragment and assigned a single pitch, also the pitch class centre F\#, and allotted one beat. Of note, had the second word of the text been two or more syllables in length, the notes of each M-voice line would have proceeded upwards in stepwise fashion until a stressed syllable occurred.

Sub-rule 2b: Pärt's treatment of the third word in the first line of the text is an example of Rule 2b. ЄАн́наго is a four-syllable word (pronounced as ed-í-na-go) with the stress falling on the second syllable. As the second syllable of the word "'H" is stressed and is also followed by two further syllables, the melody leaps by a fourth to D5 before proceeding downwards in stepwise fashion.

Rule 4: This example also illustrates Rule 4b. As the stressed syllable is not the third syllable in a five-syllable word, or the penultimate or final syllable of a phrase, it is allotted its own three-beat bar (bar 4) and continues through the downbeat of bar 5 .

Figure 6.18: Orient \& Occident - M-voices Section A bars 1-14

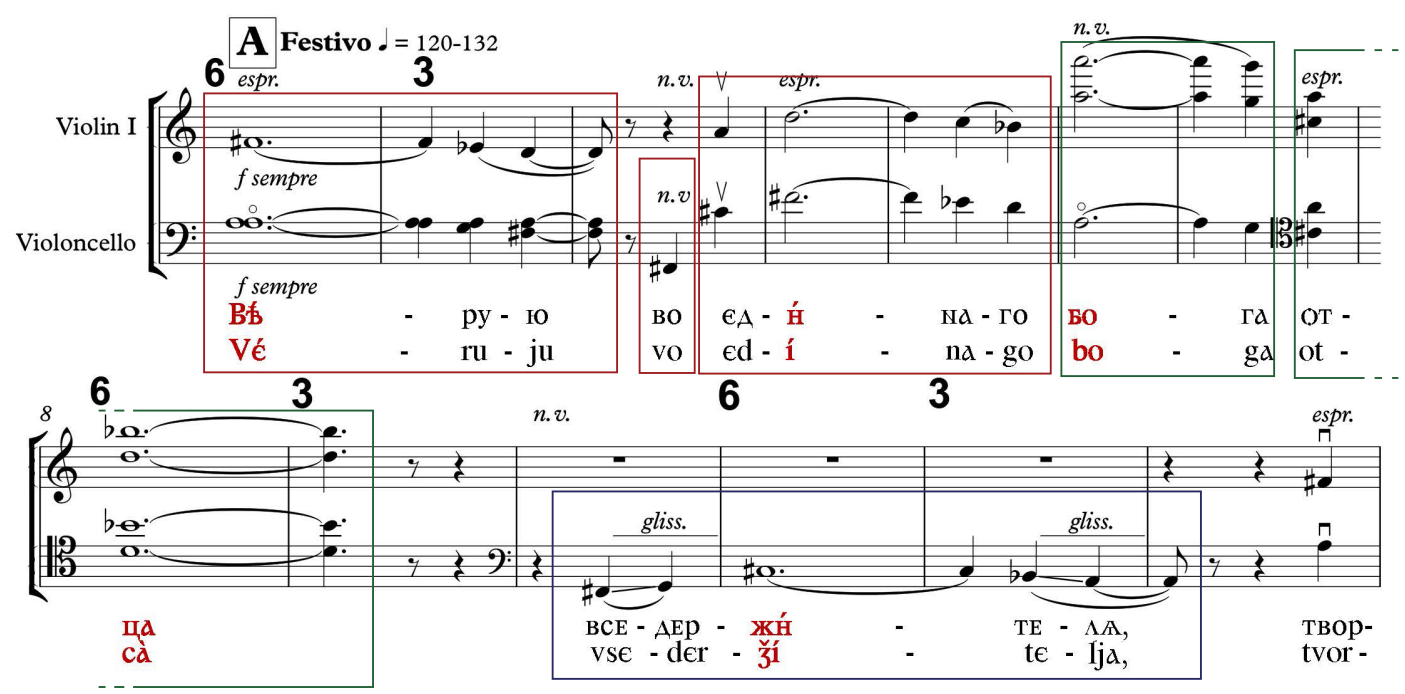

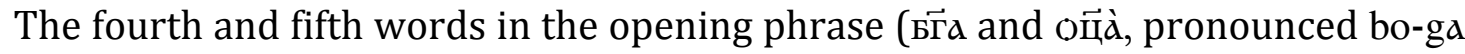
ot-cà) provide examples of Pärt's approach to dealing with two syllable words in 
the Church Slavonic version of the text of the Nicene Constantinopolitan Creed. The fourth word, “Б $\overrightarrow{\text { а } " ~(b a r s ~} 6$ and 7) is an abbreviation of вога with the diacritic

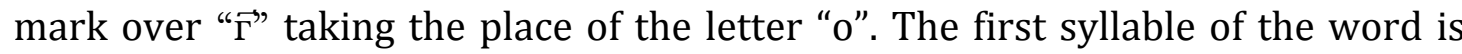
stressed, and thus allotted its own three-beat bar plus the downbeat of bar 7 . In

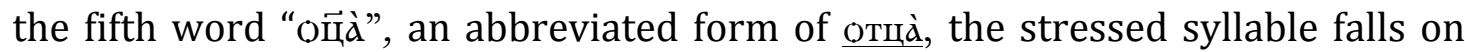
the second syllable. As structurally this word is also the end of the sub-clause "I believe in one God," in the text, it is an example of Rule 4c: Pärt allotting such cases a six-beat bar plus one or more beats of the following bar.

Rule 2: Bars 6 through 8 also illustrate the basic premise of Rule 2, i.e. musical phrases or fragments associated with multisyllabic words in the text alternate between proceeding downwards or upwards from the relevant M-voice 1 pitchclass centre when the music is homophonic and during monophonic sections as well. The monophonic fragment starting in bar 6 - associated with the word $\overrightarrow{5} \overrightarrow{\mathrm{a}} \mathrm{-}$ commences on pitch class A and proceeds stepwise downwards to pitch class $\mathrm{G}$. At the end of bar 7, the word оц̆̀ is treated in a homophonic manner. M-voice 1, which appears in the upper divisi line of both the first violins and the violoncellos, starts at pitch class A, but then moves stepwise upwards to pitch class Bb.

Rules 4 and 8: The final word of the opening phrase всеАржн́тел凡 (pronounced as vse-der-ží-te-lja) comprises five syllables and is associated with bars 10 through 13. It is an illustration of Rule $4 \mathrm{~d}$. The third syllable of the word "жи́" is stressed. The melodic line starts on pitch class F\#, the initial pitch class centre for Section $A$, and proceeds upwards by one step to $G$ for the second syllable, before leaping by a fourth to $\mathrm{C \#}$, and then proceeding stepwise downwards to pitch class A. As the stressed syllable is preceded and followed by two or more syllables, it is 
allotted a six-beat bar (bar 11) plus the downbeat of bar 12. Pärt's treatment of the word всеАржн́телА is also an example of Rule 8. As this particular occurrence is a monophonic musical statement executed without vibrato, based upon a multisyllabic word, it is also an example where the performers are instructed to play the pitches preceding and following the stressed syllable as glissando.

Rule 5: As per Rule 5, generally single syllable words and non-stressed syllables are assigned one beat each, with certain exceptions when the single syllable word or non-stressed syllable is followed by a full stop, a colon, and in certain situations a comma. Section B of Orient \& Occident contains a number of examples of how Rule 5 and its sub-rules $5 \mathrm{a}$ and $5 \mathrm{~b}$ apply when a single word or nonstressed syllable is or is not followed by a punctuation mark (Figure 6.19 overleaf).

The text associated with bars 26 through 75 commences with two single syllable words, "H" and "Bo", each of which is assigned to a single beat in the music. Similarly, the final beats of bars 37 and 41 are associated with the unstressed

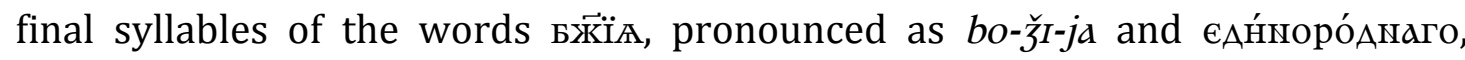
pronounced as ed-í-no-ród-na-go. As each word is followed by a comma in the text, the last note of each associated melodic fragment is allotted a single beat (Rule 5).

In contrast, despite bar 60 being associated with a single syllable word, it is also the end of a phrase in the text and followed by a colon. As such, Pärt assigns six

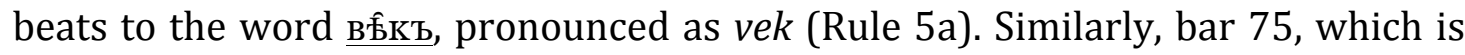
the final bar of Section B, is associated with the final syllable of the two-syllable 
word вы́ша, pronounced as bý-ša, that is followed by a full stop in the text. Hence the composer assigns the final bar six beats.

Bars 62 and 63 are an example of the application of Rule 5b: when a non-stressed syllable at the end of a multisyllabic word is followed by a comma, it can continue through the downbeat of the next bar, if it suits the musical phrasing. In this situation, Pärt treats the word poжAÉnNa (pronounced as rož-dén-na) as its own musical phrase, allowing the final note, which is associated with the non-stressed final syllable of the word, to carry over into the downbeat of bar 63 .

Figure 6.19: Orient \& Occident - M-voices Section B bars 26-75
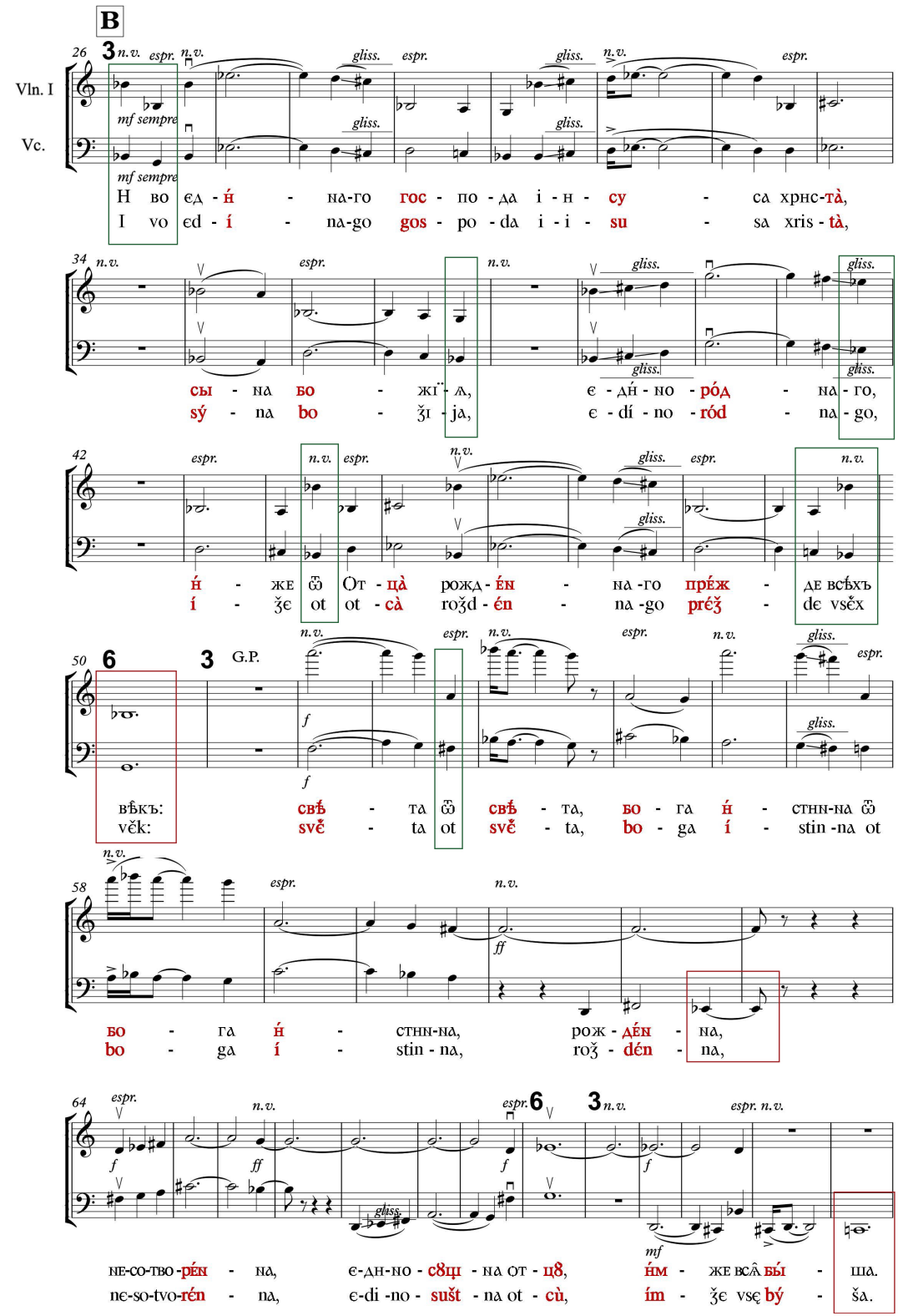
Rule 6: The second violin line in Section D, bars 106 and 107, demonstrates Rule 6 in practice - when the same pitch class is associated with multiple single syllable words in a row, alternate occurrences of that pitch class are displaced upwards or downwards by an octave, in order to avoid sounding the same pitch in the same register two or more times in a row (Figure 6.20). The pitch class centre for monophonic material and M-voice 1 in Section D is G. In bars 106 and 107, the instrumental lines alternate between monophonic and homophonic material each beat for four beats, starting on the second beat of bar 106. The associated text with this musical fragment comprises four single syllable words же, за, мы, and прн. Commencing with the second beat of the bar, M-voice 1 briefly shifts to the second violin line before shifting back to the first violin line on the final beat of bar 107. In order to avoid sounding four instances of G4 in a row, Pärt opts to alternate between G4 and G3, until the multisyllabic word понтійстъмъ осcurs.

Figure 6.20: Orient \& Occident - Section D bars 104-110

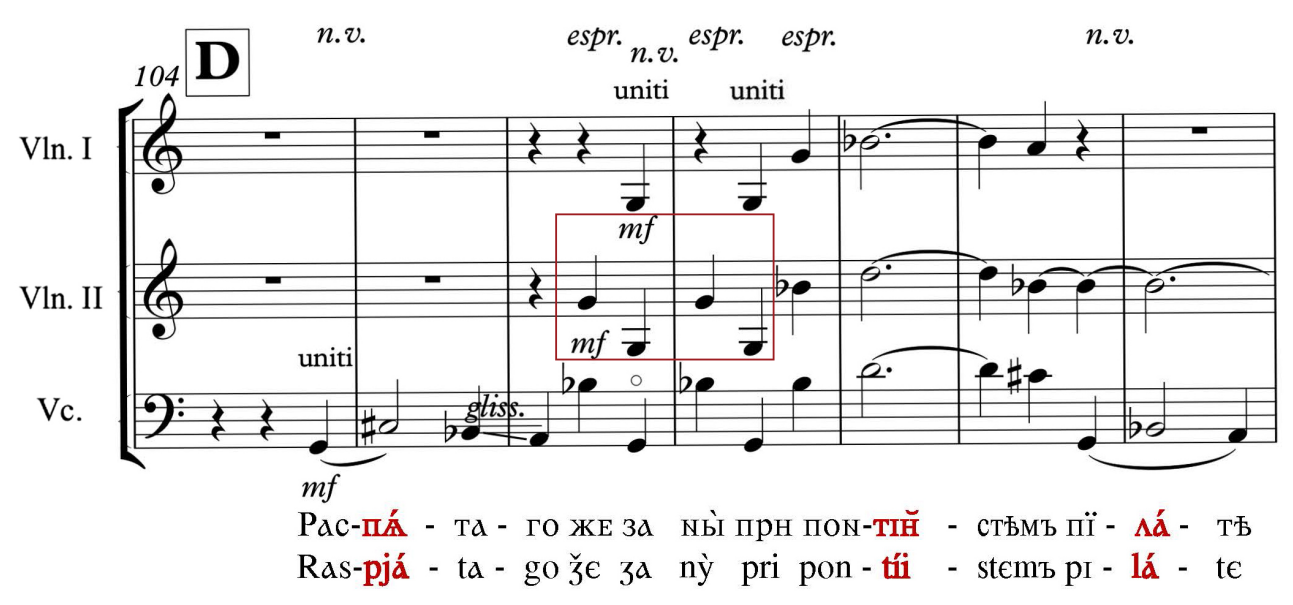


Another example of Rule 6 can be seen in bars 193 and 200 of Section I (Figure 6.21), where there are two occurrences of a single syllable word followed by a multisyllabic word when the first syllable is not stressed. In order to avoid sounding D4 two times in a row, the second occurrence of pitch class D in both bars sounds at D5.

Figure 6.21: Orient \& Occident - Section I bars 193-205

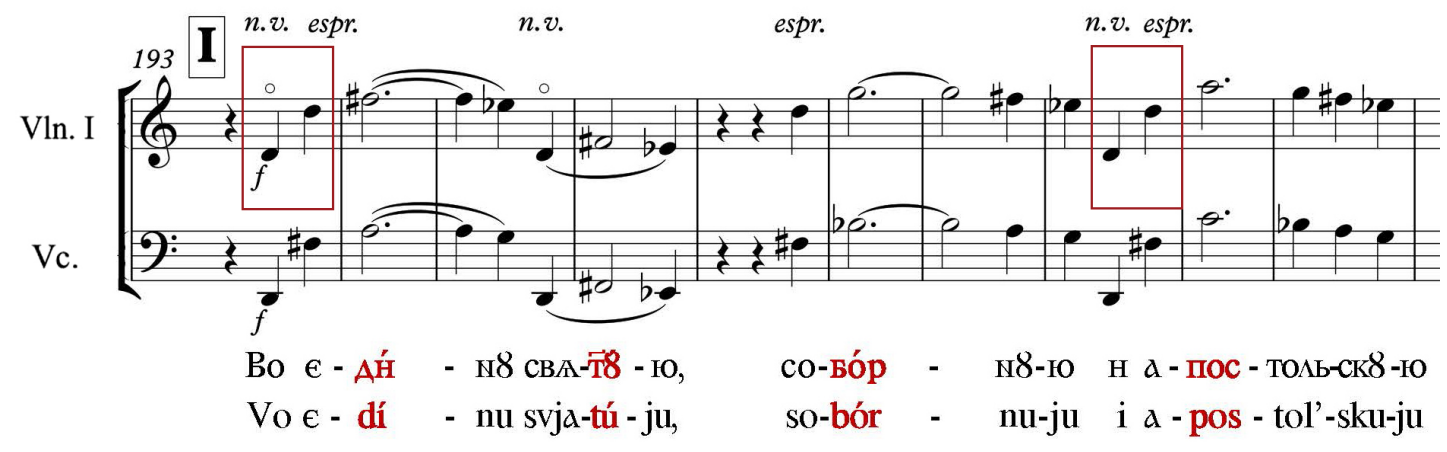

Rule 7: Figure 6.22 overleaf shows two examples of Rule 7 in practice - the musical treatment of repeated words in the same stanza of the text. The melodic

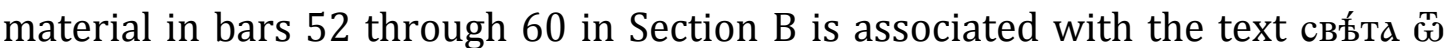

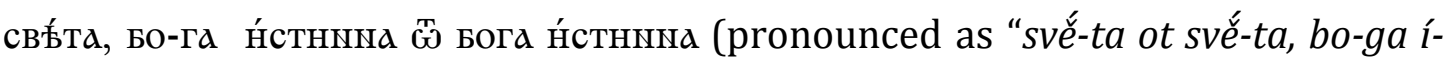
stin-na ot bo-ga í-sti-n-na") This is the previously discussed phrase "light from light, true God from true God", which is also one of the few occurrences in Orient \& Occident where pitch class $\mathrm{A}$ is the tonal centre for monophonic fragments and M-voice 1 homophonic fragments. In the case of the second occurrence of the word свб́ба, Pärt opts to ornament the first syllable of the word, which is stressed, with a semi-quaver appoggiatura ornamenting all occurrences of pitch class A throughout the orchestra in bar 54 from above with $\mathrm{Bb}$. 


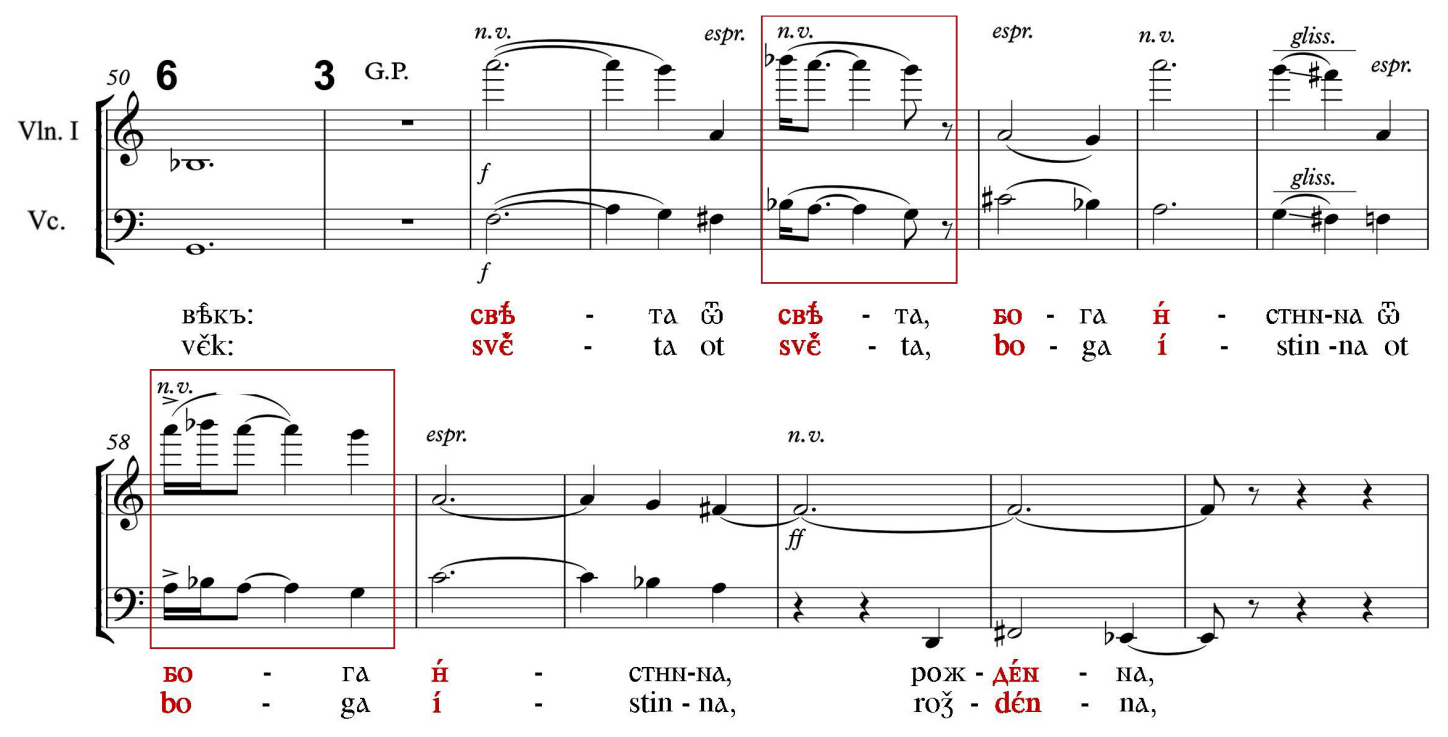

When the word вога is repeated a second time in the same stanza, it occurs during a monophonic melodic statement. In this case, Pärt chooses to ornament the tonal centre A with an upper mordent. The word H́cтнnnd is also repeated twice in the stanza. However, as the second occurrence happens during a homophonic section, the stressed first syllable "H́" is not ornamented.

Rule 8: As noted, where the stressed syllable of a multisyllabic word of four syllables or more is treated monophonically in a melodic line and the stressed syllable is not the first or final syllable of the word, the melodic statement or fragment is usually played glissando. Periodically, Pärt opts to also ornament the stressed syllable in such cases with either an appoggiatura or a mordent. An example of this can be seen in bar 31 of Section B (Figure 6.23) with the musical treatment of the stressed syllable of the word iнcyca (pronounced as i-i-su-sa), the Church Slavonic word for the name Jesus. In this particular case, the composer chooses to bridge the leap of a diminished third from $\mathrm{C \#}$ to Eb with pitch class D acting as a semi-quaver appoggiatura to Eb. 


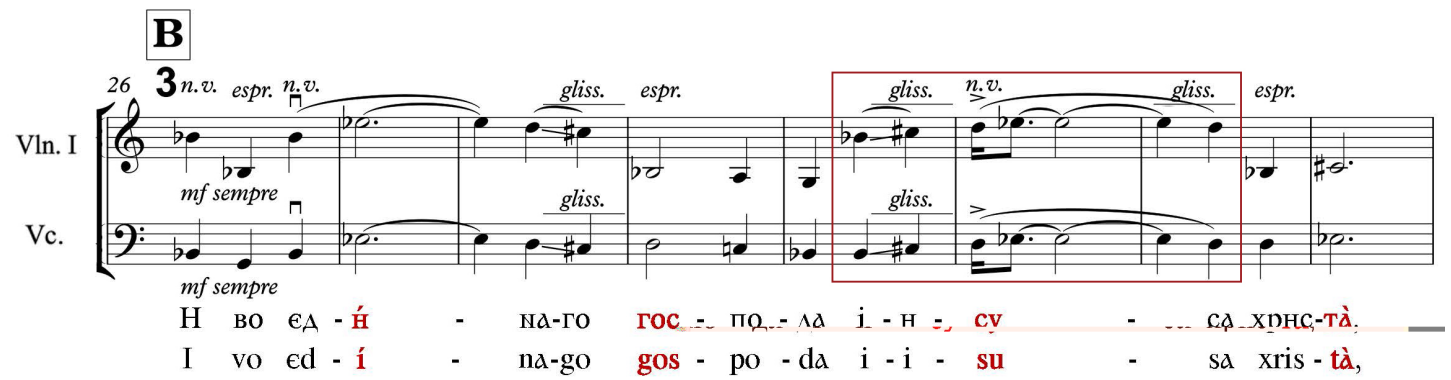

While the rules described above generally apply to the melodic material in Orient \& Occident, there are other instances throughout the work where Pärt chooses not to deploy one or more rules. Where this is the case, it is usually specific to a particular section. For example, in Section F he opts not to apply Rule 6 - the displacement of a specific pitch in a melodic line when it reoccurs two or more times in a row (see violin I, Figure 6.24 bars 126 and 132). The Church Slavonic text for this translates as "And who went up to heaven, and who sits by the Father's right hand". In both cases where F\# is repeated, its first occurrence in bars 126 and 132 is associated with the word " $H$ " the Church Slavonic equivalent for the word "and".

Figure 6.24: Orient \& Occident - Section F bars 126-138

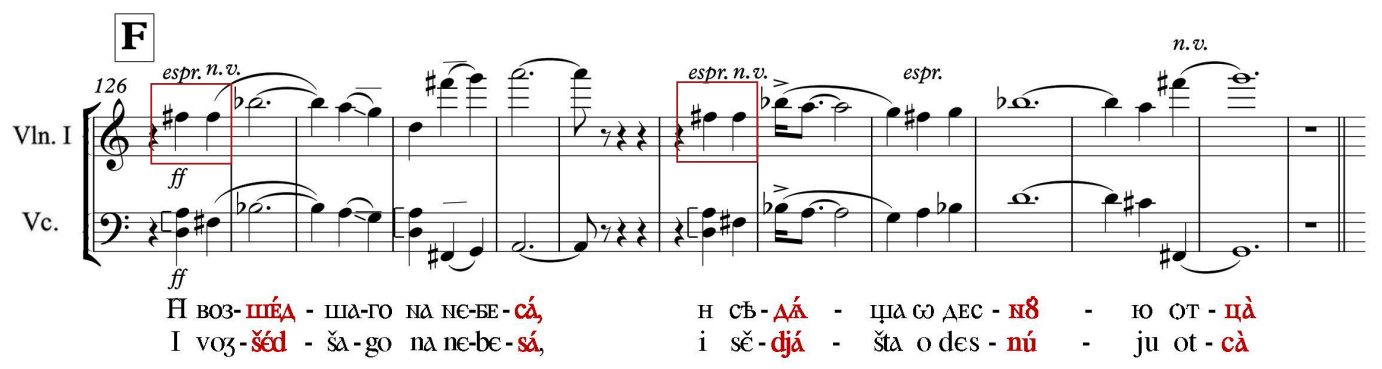

In other instances, Pärt chooses to ornament the stressed syllable of specific three- and four-syllable words, where the stressed syllable falls on the first or second syllable of the word and the text is being treated monophonically. However, there does not appear to be a specific rule or set of rules to dictate 
when this occurs. For example, the second syllable of the word пнса́niємъ (pronounced pi-sá-ni-em) in Section E bar 123, which translates as "scripture" or "writings" receives such treatment. Pärt opts to ornament the Bb from above with a C semi-quaver (Figure 6.25). He does not, however, choose to apply Rule 8, i.e. there is no instruction in the score for the two notes that follow the stressed syllable to be played glissando.

Figure 6.25: Orient \& Occident - Section E bars 118-125

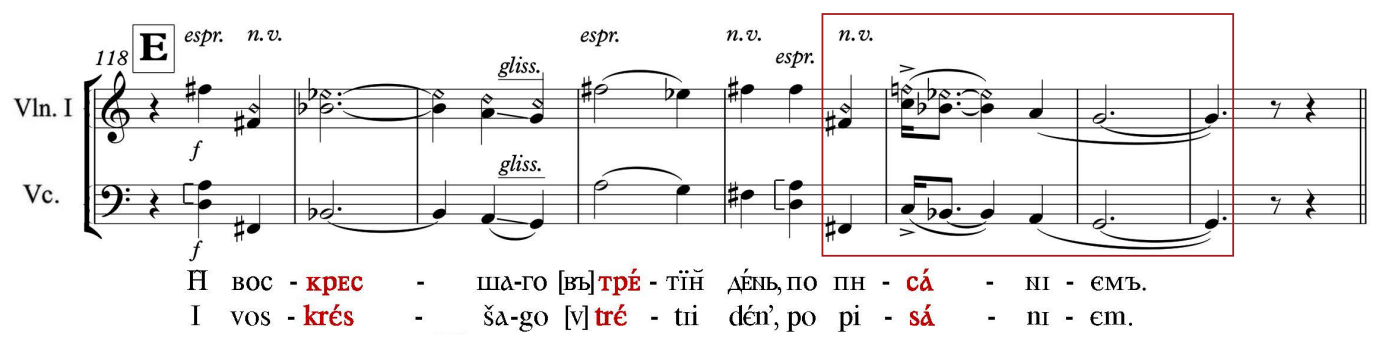

Interval class analysis and sonority mappings of Orient \& Occident

Pärt's use of three different M-voice/T-voice sonorities in Orient \& Occident is unprecedented in his string orchestral works. By combining a G harmonic minor scale (G, A, Bb, C\#, D, Eb, F\#) paired with a G-minor triad T-voice, a D double harmonic scale (D, Eb, F\#, G, A, Bb, C\#) with its periodic alternating D minor triad and G minor triad T-voices, and constant alternation between monophonic and homophonic material, he has created what is perhaps his most sonically complex work since the inception of his tintinnabuli system in 1976. The harmonic potential of these three pitch class sets can be distilled down to three distinct interval class vectors: <545752>, comprising five minor seconds, four major seconds, five minor thirds, seven major thirds, five perfect fourths, and two tritones; <335442>, comprising three minor seconds, three major seconds, five minor thirds, four major thirds, four perfect fourths, and two tritones; and $<424542>$, comprising four minor seconds, two major seconds, four minor thirds, 
five major thirds, four perfect fourths, and two tritones. Figure 6.26 overleaf provides visualisations of these three interval class vectors and the intervallic relationships of their respective pitch class content. Table 6.5 illustrates the various shifts that occur between these three as Orient \& Occident progresses.

In the penultimate section of Orient \& Occident, Section K, the composer also briefly introduces a tenth pitch class to the mix by substituting E natural for $\mathrm{Eb}$ on the first beat of bar 219 and on the second beat of bar 223. These occurrences are associated with the phrase Чáю воскр⿱艹⿻肀̈쇼 ме́ртвыхъ, which translates as "I hope for the resurrection of the dead", with the first substitution occurring on the second syllable of "Yáю”, pronounced "Cha-ju" meaning "I hope", and the second occurrence being associated with the second syllable of the word “ме́ртвыхъ" or "the dead". This results in a chromatic shift from a D sharp9 with3 chord (pitch classes D, F, F\#, and A) to a Dm 9th no5 chord (pitch classes D, E, F, and C) on the first occurrence, and to a Dm add9 maj7 no5 chord (pitch classes D, E, F, and $\mathrm{C \#}$ ) on the second occurrence. Of note, these are the only incidents of either sonority in Orient \& Occident.

Orient \& Occident comprises 24 interval class vectors, 50 distinct chords as well as multiple monophonic occurrences of pitch classes $\mathrm{C}, \mathrm{C \#}, \mathrm{D}, \mathrm{Eb}, \mathrm{F} \#, \mathrm{G}, \mathrm{A}$, and Bb. While it could be correctly contended that works such as Festina Lente and Tabula Rasa's Silentium contain a greater number of interval class vectors (33 and 40, respectively) and individual chords, Orient \& Occident provides listeners with an arguably more complex and varied listening experience, in which it is not possible for the listener to anticipate what sonority will come next. 
T-voice/M-voice Relationships - Orient \& Occident D minor T-voice/D double harmonic scale

Interval Class Vector: <545752>

Forte Code: 8-19

Prime Form: $(0,1,2,4,5,6,8,9)$

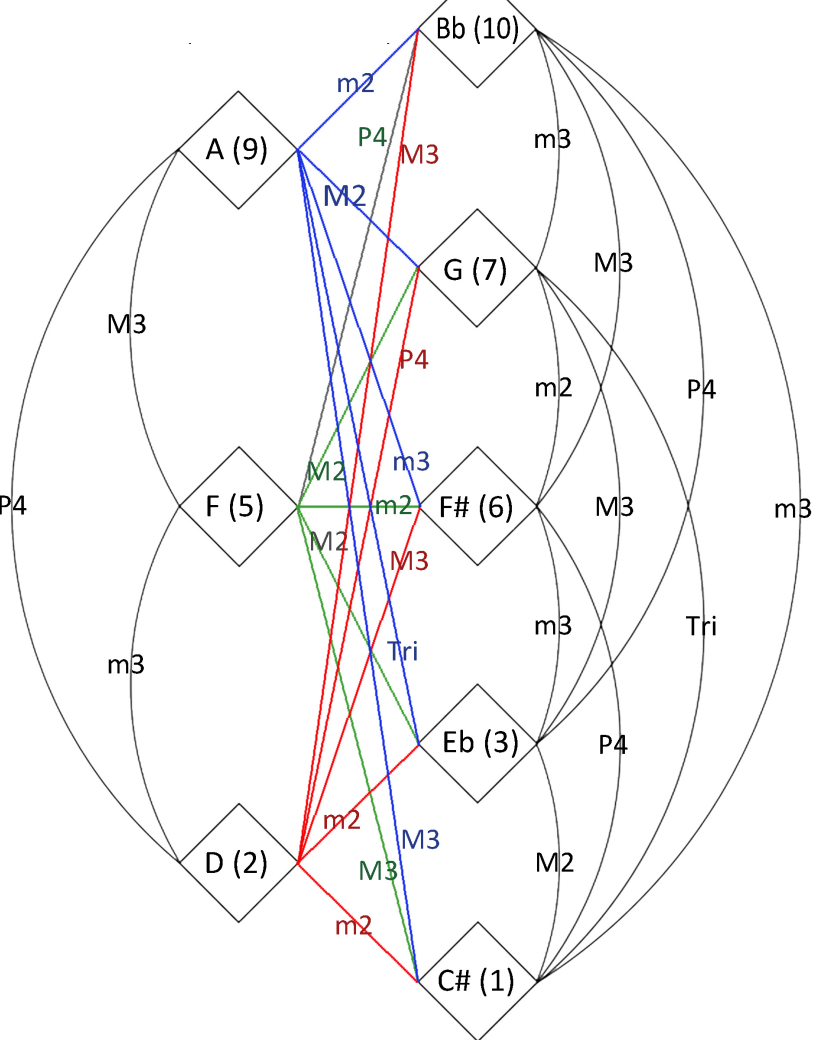

T-voice/M-voice Relationships - Orient \& Occident $\mathrm{G}$ minor T-voice/G harmonic minor scale

Interval Class Vector: <335442>

Forte Code: 7-32

Prime Form: $(0,1,3,4,6,8,9)$

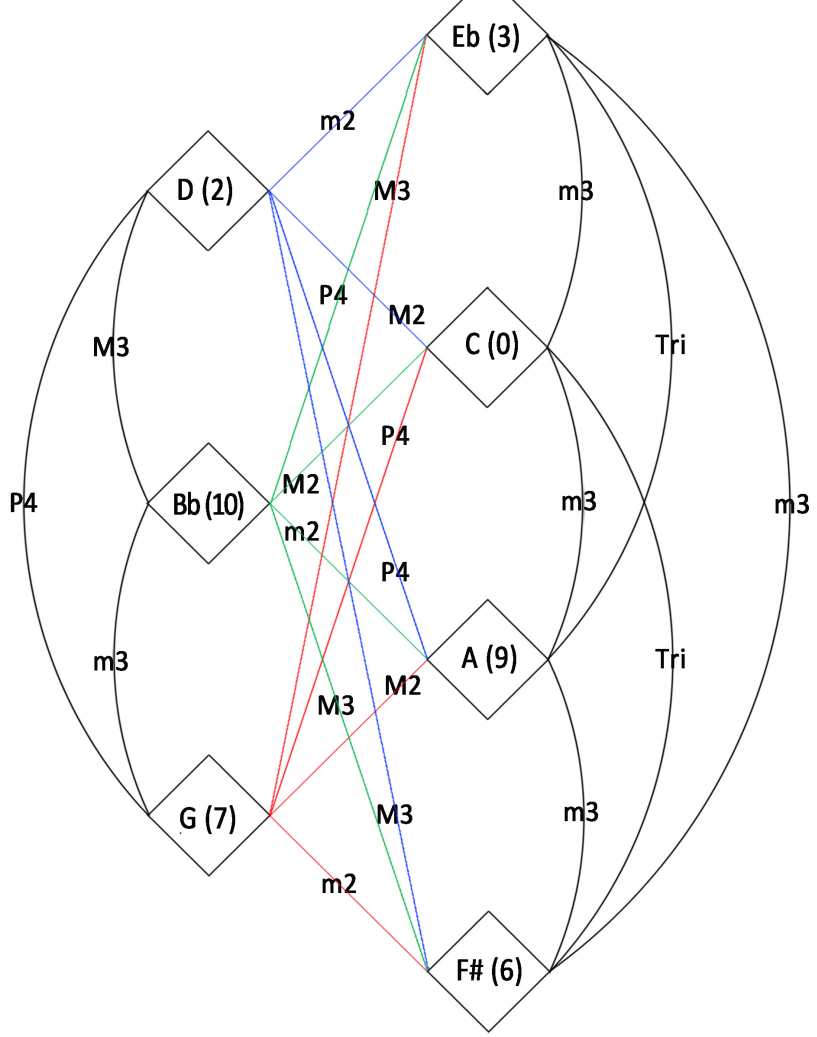

T-voice/M-voice Relationships - Orient \& Occident $\mathrm{G}$ minor T-voice/D double harmonic scale

Interval Class Vector: <424542>

Forte Code: 7-22

Prime Form: $(0,1,2,5,6,8,9)$

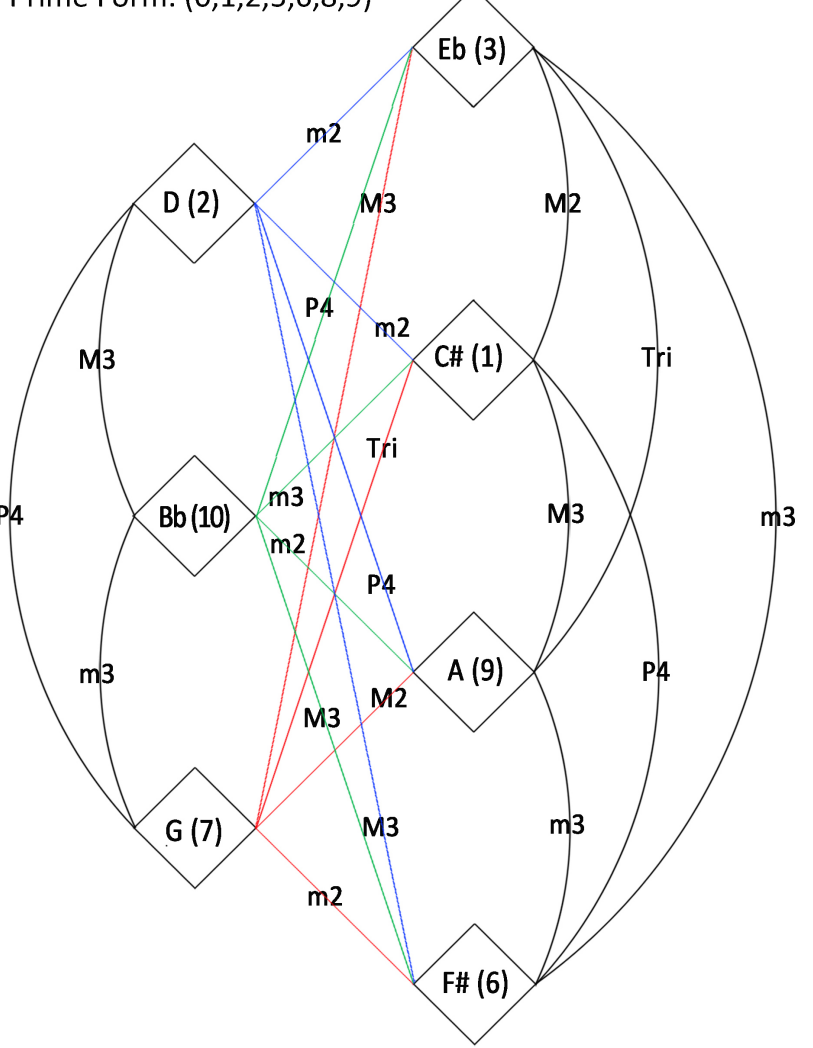


Table 6.5 Illustration of Orient \& Occident's shifting interval class vectors

\begin{tabular}{|c|c|c|c|}
\hline Section \& bars & $\begin{array}{c}<545752> \\
\text { Forte Code: } 8-19\end{array}$ & $\begin{array}{c}<335442> \\
\text { Forte Code: } 7-32\end{array}$ & $\begin{array}{c}\quad<42542> \\
\text { Forte Code: } 7-22\end{array}$ \\
\hline $\mathbf{A}(1-25)$ & $1-25^{*}$ & --- & --- \\
\hline B (26-77) & $52-58$ & 29 and beat 1 bar $30,36-37,48-50,59-60,76$ & $26-28,30-35,38-48,64-74$ \\
\hline C (78-103) & 78-91 (beat 2) 93-101 (beat 2) & 91 (beat 3)-92, 101 (beat 3)-103 & --- \\
\hline D (104-117) & --- & --- & $104-117$ \\
\hline $\mathbf{E}(118-125)$ & $118-121$ & $122-124$ & --- \\
\hline $\mathbf{F}(126-138)$ & $126-135$ & --- & --- \\
\hline G (139-157) & 141 (beat 3)-143 & $144-145,149,152-153$ & $139-141$ (beat 2), 146-148, 150-151 \\
\hline H (158-192) & $158-172$ & 186-187 (beat 2) & 174-185, 187 (beat 3)-191 \\
\hline I (193-205) & $193-200,202$ & $203-204$ & --- \\
\hline$J(206-217)$ & -- & $206,213-216$ & $207,209-212$ \\
\hline $\mathbf{K}(218-231)$ & $218-230^{*}$ & -+- & --- \\
\hline L $(232-234)$ & --- & --- & --- \\
\hline
\end{tabular}

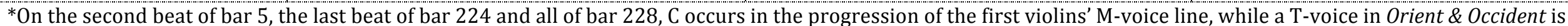

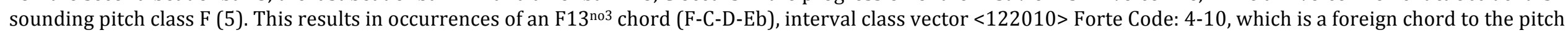

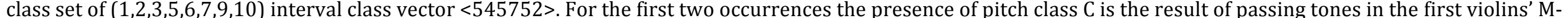

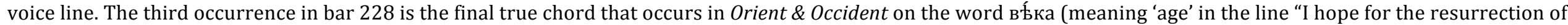
the dead. And the life of the coming age"). 
Table 6.6 overleaf details the various interval class vectors and specific chords that occur in Orient \& Occident's twelve sections. To the listener, Orient \& Occident seems to be primarily a work dominated by dissonant sonorities. Despite this impression, the most frequently occurring sonority is $<000000>$, representing the multiple monophonic occurrences of pitch classes $\mathrm{C}, \mathrm{C \#}, \mathrm{D}, \mathrm{Eb}$, F\#, G, A, and Bb noted above. Monophonic material comprises over forty per cent of Orient \& Occident's seven minutes and twelve seconds - 327 beats of the work's 789 beats. As shown earlier in this chapter, this material generally proceeds in a stepwise manner with periodic leaps of a third or fourth, and is punctuated with sinuous glissandos that imbue the motion of Orient \& Occident's sound world with its sense of "swirling contradictions, climatic rises of pitch and snake like coiling of monophonic lines." 267 The second most frequently occurring sonority in the work is represented by the interval class vector $<001110>$ (Forte Code: 3-11, prime form $(0,3,7)$, comprising all three pitch major and minor triads that occur in Orient \& Occident. In total approximately twenty per cent of the work (152 beats of the works 789 beats) comprises one of the following triads in order of frequency of occurrence: Gm (62 beats), D (42), $\mathrm{Bb}(31), \mathrm{Eb}(12), \mathrm{Dm}(2), \mathrm{F} \# \mathrm{~m}(2)$, and Cm (1).

Figure 6.27 overleaf provides a mapping of the harmonic content of Orient \& Occident, as it frequently shifts between single pitch and single interval sonorities, periods of silence, and more dynamic moments when the intervallic content is relatively dense and periodically punctuated by tritones (denoted by the colour pink).

${ }^{267}$ Packett, "Arvo Pärt Orient Occident." 
Table 6.6: Interval class vectors and chords generated by the processes in Orient \& Occident - frequency of occurrence as number of beats

\begin{tabular}{|c|c|c|c|c|c|c|c|c|c|c|c|c|c|c|c|}
\hline \multirow{2}{*}{$\begin{array}{l}\text { Interval } \\
\text { Class Vector }\end{array}$} & \multirow{2}{*}{$\begin{array}{l}\text { Forte } \\
\text { Code }\end{array}$} & \multirow[b]{2}{*}{ Chords } & \multirow[b]{2}{*}{ Beats } & \multicolumn{12}{|c|}{ Section } \\
\hline & & & & $\mathbf{A}$ & B & C & D & E & $\mathbf{F}$ & G & $\mathbf{H}$ & I & $\mathbf{J}$ & $\mathbf{K}$ & $\mathbf{L}$ \\
\hline \multirow[b]{2}{*}{$<000000>$} & \multirow[b]{2}{*}{$\mathrm{N} / \mathrm{A}$} & Single pitch classes & 327 & 29 & 71 & 27 & 25 & 12 & 25 & 29 & 47 & 15 & 11 & 24 & 12 \\
\hline & & Silence (whole beats) & 78 & 13 & 8 & 2 & 5 & 2 & 10 & 2 & 11 & 6 & 10 & 3 & 6 \\
\hline \multirow[b]{3}{*}{$<000010>$} & \multirow[b]{3}{*}{$\mathrm{N} / \mathrm{A}$} & D sus4 no5 & 1 & & 1 & & & & & & & & & & \\
\hline & & D5 & 1 & & & & & & & 1 & & & & & \\
\hline & & G5 & 7 & & 4 & & & & & & & & 3 & & \\
\hline \multirow[b]{4}{*}{$<000100>$} & \multirow[b]{4}{*}{$\mathrm{N} / \mathrm{A}$} & A no5 & 2 & & & & & & & 2 & & & & & \\
\hline & & Bb no5 & 1 & & 1 & & & & & & & & & & \\
\hline & & Eb no5 & 1 & & 1 & & & & & & & & & & \\
\hline & & D no5 & 2 & & 2 & & & & & & & & & & \\
\hline \multirow[b]{2}{*}{$<000300>$} & \multirow[b]{2}{*}{$3-12$} & D aug5 & 1 & & 1 & & & & & & & & & & \\
\hline & & $\mathrm{F}$ aug5 & 1 & & 1 & & & & & & & & & & \\
\hline \multirow[b]{2}{*}{$<001000>$} & & Ebm no5 & 2 & & 2 & & & & & & & & & & \\
\hline & $\mathrm{N} / \mathrm{A}$ & Gm no5 & 4 & & 2 & & 2 & & & & & & & & \\
\hline & & $\mathrm{Bb}$ & 31 & 12 & & 7 & & & 7 & & 5 & & & & \\
\hline & & $\mathrm{Cm}$ & 1 & & & 6 & & & & & & & 1 & & \\
\hline & & $\mathrm{D}$ & 42 & 13 & 2 & 1 & 1 & 3 & 4 & & 7 & 6 & & & \\
\hline & & $\mathrm{Dm}$ & 2 & 1 & & & & & & & & & & & \\
\hline & & $\mathrm{Eb}$ & 12 & & 7 & & & & & 3 & 2 & & & & \\
\hline & & $\mathrm{F} \# \mathrm{~m}$ & 2 & & 1 & & & & & & 1 & & & & \\
\hline$<001110>$ & $3-11$ & $\mathrm{Gm}$ & 62 & & 21 & & 9 & & & 17 & 9 & & 6 & & \\
\hline & & A 7th no3 no5 & 5 & & 5 & & & & & & & & & & \\
\hline & & Eb 7th no3 no5 & 1 & & 1 & & & & & & & & & & \\
\hline$<010000>$ & $\mathrm{N} / \mathrm{A}$ & G add9 no3 no5 & 3 & & & & 3 & & & & & & & & \\
\hline & & Am sus4 no5 & 4 & & 4 & & & & & & & & & & \\
\hline & & D 7th no3 & 7 & 1 & & 2 & & & & & & 3 & 1 & & \\
\hline$<011010>$ & $3-7$ & G 7th no3 & 7 & & & & & & & 1 & & & 6 & & \\
\hline$<012120>$ & $4-26$ & Gm 7th & 1 & & & & & & & & 1 & & & & \\
\hline$<030201>$ & $4-21$ & F 9th no5 & 14 & 1 & & 7 & & 1 & & & 1 & 3 & & & \\
\hline & & Bb maj7 no3 no5 & 3 & & & & 2 & & & 1 & & & & & \\
\hline & & Bb no5 & 1 & & 1 & & & & & & & & & & \\
\hline & & Eb maj7 no3 no5 & 5 & & 5 & & & & & & & & & & \\
\hline$<100000>$ & $\mathrm{N} / \mathrm{A}$ & G maj7 no3 no5 & 1 & & 1 & & & & & & & & & & \\
\hline & & D maj7 no3 & 6 & 1 & 2 & & & & 1 & & 2 & & & & \\
\hline$<100110>$ & $3-4$ & G maj7 no3 & 8 & & 1 & & & & & & 7 & & & & \\
\hline & & D maj7 & 1 & 1 & & & & & & & & & & & \\
\hline & & Eb flat5 7th w5 no3 & 2 & & 2 & & & & & & & & & & \\
\hline$<101220>$ & $4-20$ & Eb maj7 & 3 & & 3 & & & & & & & & & & \\
\hline$<102111>$ & $4-18$ & Dm aug5 $6^{\text {th }}$ & 2 & 2 & & & & & & & & & & & \\
\hline$<102210>$ & $4-17$ & D sharp9th w3 & 41 & 7 & & 13 & & & & & 3 & 3 & & 15 & \\
\hline & & Bb maj7 & 1 & & & 1 & & & & & & & & & \\
\hline & & $\mathrm{Cm}$ add 9 & 1 & & & & & & & & & & 1 & & \\
\hline$<111120>$ & $4-14$ & Gm add 9 & 27 & 10 & 2 & 8 & & & 1 & & & 6 & & & \\
\hline & & C 13th no3 no5 & 8 & & 3 & & & & & 3 & 1 & & 1 & & \\
\hline$<121110>$ & $4-11$ & D minor 9th no5 & 1 & & & & & & & & & & & 1 & \\
\hline$<122010>$ & $4-10$ & F 13th no3 & 8 & 1 & & & & & & & & & & 7 & \\
\hline & & A flat9 w3 no5 & 7 & & & & 1 & & & 1 & 4 & & 1 & & \\
\hline$<201210>$ & $4-7$ & $\begin{array}{l}\text { Ebm maj7 sharp9th w3 } \\
\text { no5 }\end{array}$ & 1 & & 1 & & & & & & & & & & \\
\hline$<210111>$ & $4-5$ & Eb 7th maj7 no5 & 16 & & 5 & & & & & 3 & 4 & & 4 & & \\
\hline & & Dm add 9 maj7 no5 & 1 & & & & & & & & & & & 1 & \\
\hline$<212100>$ & $4: 3$ & Gm add9 maj7 no5 & 6 & & & & & & & & 6 & & & & \\
\hline$<213211>$ & $5-16$ & Eb flat5 w5 & 1 & & 1 & & & & & & & & & & \\
\hline$<221100>$ & $4-2$ & Dm flat9 maj7 no5 & 10 & & & 4 & & & & & 6 & & & & \\
\hline$<311221>$ & $5-6$ & Eb flat5 7th maj7 w5 no3 & 6 & & 6 & & & & & & & & & & \\
\hline
\end{tabular}




\section{Figure 6.27: Orient \& Occident - sonority mapping}

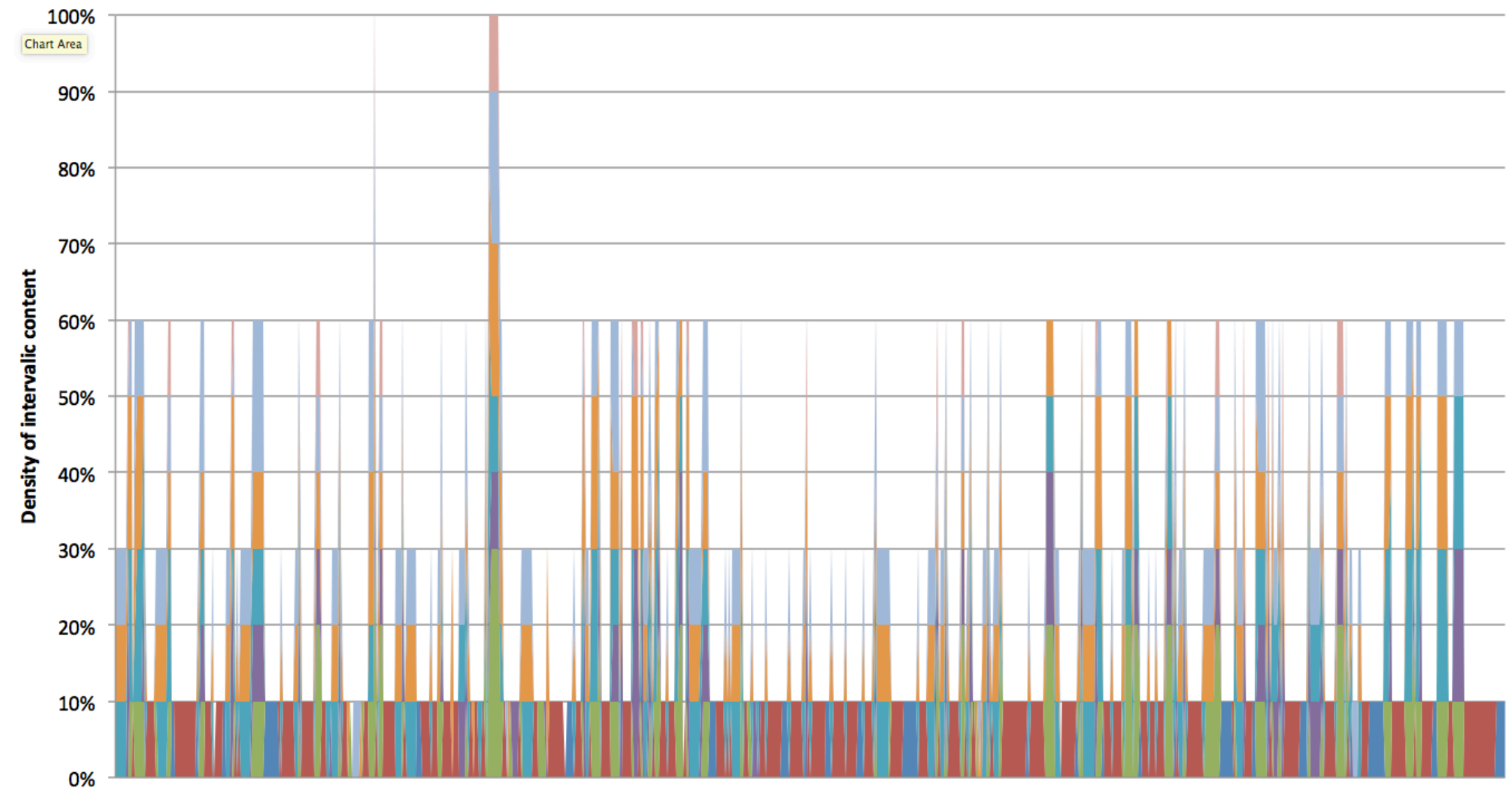

$\begin{array}{llllllllllllllllll}1 & 6 & 12 & 18 & 24 & 28 & 35 & 41 & 48 & 54 & 60 & 67 & 73 & 78 & 84 & 91 & 97 & 104111117124131136141148154159165170177184190195202207213218224230233\end{array}$ Bar number

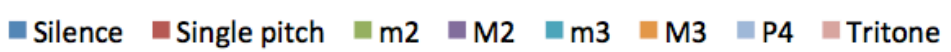


Orient \& Occident can be a relatively 'challenging' work for a listener. This is due to its frequent juxtaposition of monophonic and tintinnabuli-based homophonic content, its periodic changes between a G harmonic minor scale and the relatively more exotic sounding $\mathrm{D}$ double harmonic scale, and the frequent shifting of pitch class centres within those scales. This is compounded by the non-functional harmonic progressions that occur in any of Pärt's tintinnabuli works. The result is a listening experience during which it is relatively impossible to predict what sonority will follow in any given moment. This is illustrated in Table 6.7.

In bars 26 through 29 , the content is all monophonic except for the second beat of bar 26 when a G minor triad occurs, after which the orchestra plays in unison Bb-Eb-D-C\#. From C\# in the final beat of bar 28 , the sonority $G$ minor occurs again, briefly interrupted by a C13th ${ }^{\text {no3 no5 }}$ chord (pitch classes $\mathrm{C}, \mathrm{D}, \mathrm{A}$, and Bb). Bars 35 through 37 comprise only homophonic content, dominated primarily by G minor punctuated by an A7th no3 no5 chord and another C13th no3 no5 chord. One might then expect that $G$ minor will occur again in the next period of homophonic content, but instead, the melodic pitch class centre shifts to D and the homophonic material that does occur is a $\mathrm{Bb}{ }^{\text {no5 }}$ chord and an open G5 chord. 
Table 6.7: Interval vectors and chords, Orient \& Occident - bars 26 through 40

\begin{tabular}{|c|c|c|c|c|c|c|c|c|c|}
\hline Bar and beat & 26.1 & 26.2 & 26.3 & 27.1 & 27.2 & 27.3 & 28.1 & 28.2 & 28.3 \\
\hline Interval Class Vector & $<000000>$ & $<001110>$ & $<000000>$ & $<000000>$ & $<000000>$ & $<000000>$ & $<000000>$ & $<000000>$ & $<000000>$ \\
\hline Forte Code & $\mathrm{N} / \mathrm{A}$ & $3-11$ & $\mathrm{~N} / \mathrm{A}$ & $\mathrm{N} / \mathrm{A}$ & $\mathrm{N} / \mathrm{A}$ & $\mathrm{N} / \mathrm{A}$ & $\mathrm{N} / \mathrm{A}$ & $\mathrm{N} / \mathrm{A}$ & $\mathrm{N} / \mathrm{A}$ \\
\hline Monophonic/Homophonic & Monophonic & Homophonic & Monophonic & Monophonic & Monophonic & Monophonic & Monophonic & Monophonic & Monophonic \\
\hline Chord/Pitch & $\mathrm{Bb}$ & $\mathrm{Gm}$ & $\mathrm{Bb}$ & $\mathrm{Eb}$ & $\mathrm{Eb}$ & $\mathrm{Eb}$ & $\mathrm{Eb}$ & $\mathrm{D}$ & C\# \\
\hline Bar and beat & 29.1 & 29.2 & 29.3 & 30.1 & 30.2 & 30.3 & 31.1 & 31.2 & 31.3 \\
\hline Interval Class Vector & $<001110>$ & $<001110>$ & $<121110>$ & $<001110>$ & $<000000>$ & $<000000>$ & $<000000>$ & $<000000>$ & $<000000>$ \\
\hline Forte Code & $3-11$ & $3-11$ & $4-11$ & $3-11$ & $\mathrm{~N} / \mathrm{A}$ & $\mathrm{N} / \mathrm{A}$ & $\mathrm{N} / \mathrm{A}$ & $\mathrm{N} / \mathrm{A}$ & $\mathrm{N} / \mathrm{A}$ \\
\hline Monophonic/Homophonic & Homophonic & Homophonic & Homophonic & Homophonic & Monophonic & Monophonic & Monophonic & Monophonic & Monophonic \\
\hline Chord/Pitch & $\mathrm{Gm}$ & $\mathrm{Gm}$ & C13thno3 no5 & $\mathrm{Gm}$ & $\mathrm{Bb}$ & $\mathrm{C \#}$ & $\mathrm{Eb}$ & $\mathrm{Eb}$ & $\mathrm{Eb}$ \\
\hline Bar and beat & 32.1 & 32.2 & 32.3 & 33.1 & 33.2 & 33.3 & 34.1 & 34.2 & 34.3 \\
\hline Interval Class Vector & $<000000>$ & $<000000>$ & $<001110>$ & $<210111>$ & $<210111>$ & $<210111>$ & $<000000>$ & $<000000>$ & $<000000>$ \\
\hline Forte Code & $\mathrm{N} / \mathrm{A}$ & $\mathrm{N} / \mathrm{A}$ & $3-11$ & $4-5$ & $4-5$ & $4-5$ & $\mathrm{~N} / \mathrm{A}$ & N/A & $\mathrm{N} / \mathrm{A}$ \\
\hline Monophonic/Homophonic & Monophonic & Monophonic & Homophonic & Homophonic & Homophonic & Homophonic & Monophonic & Monophonic & Monophonic \\
\hline Chord/Pitch & $\mathrm{Eb}$ & $\mathrm{D}$ & $\mathrm{Gm}$ & Eb 7th maj7 no5 & Eb 7th maj7 no5 & Eb 7th maj7 no5 & G & G & G \\
\hline Bar and beat & 35.1 & 35.2 & 35.3 & 36.1 & 36.2 & 36.3 & 37.1 & 37.2 & 37.3 \\
\hline Interval Class Vector & $<001000>$ & $<001000>$ & $<010000>$ & $<001110>$ & $<001110>$ & $<001110>$ & $<001110>$ & $<121110>$ & $<001110>$ \\
\hline Forte Code & $\mathrm{N} / \mathrm{A}$ & $\mathrm{N} / \mathrm{A}$ & $\mathrm{N} / \mathrm{A}$ & $3-11$ & $3-11$ & $3-11$ & $3-11$ & $4-11$ & $3-11$ \\
\hline Monophonic/Homophonic & Homophonic & Homophonic & Homophonic & Homophonic & Homophonic & Homophonic & Homophonic & Homophonic & Homophonic \\
\hline Chord/Pitch & Gm no5 & Gm no5 & A 7 th no3 no5 & $\mathrm{Gm}$ & $\mathrm{Gm}$ & $\mathrm{Gm}$ & $\mathrm{Gm}$ & C 13th no3 no5 & $\mathrm{Gm}$ \\
\hline Bar and beat & 38.1 & 38.2 & 38.3 & 39.1 & 39.2 & 39.3 & 40.1 & 40.2 & 40.3 \\
\hline Interval Class Vector & $<000000>$ & $<000000>$ & $<000000>$ & $<000100>$ & $<100000>$ & $<000000>$ & $<000010>$ & $<000010>$ & $<000010>$ \\
\hline Forte Code & $\mathrm{N} / \mathrm{A}$ & $\mathrm{N} / \mathrm{A}$ & $\mathrm{N} / \mathrm{A}$ & $\mathrm{N} / \mathrm{A}$ & $\mathrm{N} / \mathrm{A}$ & $\mathrm{N} / \mathrm{A}$ & $\mathrm{N} / \mathrm{A}$ & $\mathrm{N} / \mathrm{A}$ & $N / A$ \\
\hline Monophonic/Homophonic & Monophonic & Monophonic & Monophonic & Homophonic & Homophonic & Monophonic & Homophonic & Homophonic & Homophonic \\
\hline Chord/Pitch & $\mathrm{D}$ & $\mathrm{D}$ & $\mathrm{D}$ & $\mathrm{Bb}$ no5 & $\mathrm{Bb}$ no5 & $\mathrm{D}$ & G5 & G5 & G5 \\
\hline
\end{tabular}


The periodic use of glissandi during episodes of monophony also adds to the listener's disorientation, with the music sounding as if the orchestra is lurching drunkenly as it tries to find its way from one moment of monophony to the next moment of homophony. In the final bars of Orient \& Occident (the end of Section $\mathrm{K}$ and Section $\mathrm{L}$ ), however, this sonic clash of two conflicting sound worlds finds a common ground and comes to a single monophonic point of repose (Table 6.8). After sounding its final homophonic moment in bar 230, an F 13 th no 3 chord (pitch classes F, C, D, and Eb), the orchestra then briefly revisits the root notes of its two scales, D and G, before coming to rest on A, and then falling silent.

Table 6.8: Interval vectors and chords, Orient \& Occident - bars 230 through 234

\begin{tabular}{|c|c|c|c|c|c|c|}
\hline Bar and beat & 230.1 & 230.2 & 230.3 & 230.4 & 230.5 & 230.6 \\
\hline $\begin{array}{l}\text { Interval Class } \\
\text { Vector }\end{array}$ & $<122010>$ & $<122010>$ & $<122010>$ & $<122010>$ & $<122010>$ & $<122010>$ \\
\hline Forte Code & $4-10$ & $4-10$ & $4-10$ & $4-10$ & $4-10$ & $4-10$ \\
\hline $\begin{array}{l}\text { Monophonic/ } \\
\text { Homophonic }\end{array}$ & Homophonic & Homophonic & Homophonic & Homophonic & Homophonic & Homophonic \\
\hline Chord/Pitch & $\mathrm{F} 13^{\text {th no } 3}$ & $\mathrm{~F} 13^{\text {th no } 3}$ & $\mathrm{~F} 13^{\text {th n no } 3}$ & F $13^{\text {th no } 3}$ & $\mathrm{~F} 13^{\text {th no } 3}$ & F $13^{\text {th no } 3}$ \\
\hline Bar and beat & 231.1 & 231.2 & 231.3 & 231.4 & 231.5 & 231.6 \\
\hline $\begin{array}{l}\text { Interval Class } \\
\text { Vector }\end{array}$ & $<000000>$ & $<000000>$ & $<000000>$ & $<000000>$ & $<000000>$ & $<000000>$ \\
\hline Forte Code & $\mathrm{N} / \mathrm{A}$ & $\mathrm{N} / \mathrm{A}$ & $\mathrm{N} / \mathrm{A}$ & $\mathrm{N} / \mathrm{A}$ & $\mathrm{N} / \mathrm{A}$ & $\mathrm{N} / \mathrm{A}$ \\
\hline $\begin{array}{l}\text { Monophonic/ } \\
\text { Homophonic }\end{array}$ & Monophonic & Monophonic & Monophonic & Monophonic & Monophonic & Monophonic \\
\hline Chord/Pitch & D & $\mathrm{D}$ & D & $\mathrm{D}$ & $\mathrm{D}$ & $\mathrm{D}$ \\
\hline Bar and beat & 232.1 & 232.2 & 232.3 & 232.4 & 232.5 & 232.6 \\
\hline $\begin{array}{l}\text { Interval Class } \\
\text { Vector }\end{array}$ & $<000000>$ & $<000000>$ & $<000000>$ & $<000000>$ & $<000000>$ & $<000000>$ \\
\hline $\begin{array}{l}\text { Monophonic/ } \\
\text { Homophonic }\end{array}$ & Monophonic & Monophonic & Monophonic & Monophonic & Monophonic & Monophonic \\
\hline Chord/Pitch & $\mathrm{G}$ & $\mathrm{G}$ & $G$ & $\mathrm{G}$ & $\mathrm{G}$ & $\mathrm{G}$ \\
\hline Bar and beat & 233.1 & 233.2 & 233.3 & 233.4 & 233.5 & 233.6 \\
\hline $\begin{array}{l}\text { Interval Class } \\
\text { Vector }\end{array}$ & $<000000>$ & $<000000>$ & $<000000>$ & $<000000>$ & $<000000>$ & $<000000>$ \\
\hline $\begin{array}{l}\text { Monophonic/ } \\
\text { Homophonic }\end{array}$ & Monophonic & Monophonic & Monophonic & Monophonic & Monophonic & Monophonic \\
\hline Chord/Pitch & A & A & A & A & A & A \\
\hline Bar and beat & 234.1 & 234.2 & 234.3 & 234.4 & 234.5 & 234.6 \\
\hline $\begin{array}{l}\text { Interval Class } \\
\text { Vector }\end{array}$ & $<000000>$ & $<000000>$ & $<000000>$ & $<000100>$ & $<100000>$ & $<000000>$ \\
\hline $\begin{array}{l}\text { Monophonic/ } \\
\text { Homophonic }\end{array}$ & Silence & Silence & Silence & Silence & Silence & Silence \\
\hline Chord/Pitch & & & & & & \\
\hline
\end{tabular}




\section{Discussion - Orient \& Occident}

Whether Orient \& Occident is interpreted as a clash between the musical cultures of the East and West or as a commentary on the schism between the Eastern and Western traditions of Christianity will ultimately come down to the imagination of each listener. On this the music itself does not readily reveal a decisive answer. For example, Pärt does not restrict the use of either the D double harmonic or G harmonic minor scales to only one or the other of the work's homophonic or monophonic moments. Nor are the work's shifting melodic pitch class centres mutually exclusive to any one domain, monophonic or homophonic.

The sinuous nature of the monophonic material, with its stepwise glissandos and subtle leaps of a third or a fourth and periodic use of drone tones certainly evokes musical references of the 'exotic', whereas the many rich harmonies of the homophonic material do not. However, there is no apparent answer to be found in the music as to whether it was truly the composer's intention to invite the former to represent the Orient and the latter to represent the Occident. But it would not be a stretch to imagine that this intention was there.

In developing Orient \& Occident's musical parameters, Pärt opted to use the Church Slavonic version of Creed for this particular work, rather than the more familiar Latin version, which he had deployed quite successfully in the past. In relation to this, Pärt's use of three different M-voice/T-voice schemes might well be interpreted as reflecting some allusion to the triune nature of the Trinity in both the Eastern and Western Christian traditions. The knowledge that the composer developed Orient \& Occident out of the text of the Nicene 
Constantinopolitan Creed does lead one to wonder whether the composer might be making an affirmative reference to not only the historic tensions between the Orient and the Occident, as played out culturally over time, but also to the divide that continues to separate the Western and Eastern Christian traditions. Perhaps the work's final moments when the orchestra ultimately finds repose in unison on A (the same pitch class that many of his early tintinnabuli works centre upon), hint at some hope on the composer's part for a rapprochement of both historic dilemmas.

In the end, it is not possible to resolve these issues conclusively, as the interpretation of any work of art is dependent not only upon the intentions of its creator, but also its reception and interpretation by the audience. To quote Jonathan Bellman, "For all the unmistakable musical codes, therefore, much depends on who is doing the composing and who the listening." ${ }^{268}$ Regardless of one's interpretation of the work, as noted by Packett, with Orient \& Occident Pärt has introduced us to "a lustrous version of his suffering, and a handsomely classical departure than previously heard" in his music. ${ }^{269}$

\footnotetext{
${ }^{268}$ Jonathan Bellman, "Introduction," in The Exotic in Western Music (Boston: Northeastern University Press, 1998), $\mathrm{x}$.

${ }^{269}$ Packett, “Arvo Pärt Orient Occident.”
} 


\section{Chapter 7 - Conclusion and reflections}

This thesis demonstrates that a multimodal application of post-tonal analytical approaches can yield valuable and productive insights into Pärt's tintinnabuli compositional system. It evidences that hidden beneath the seemingly 'minimal' surface layers of his music are carefully crafted musical constructions that result from intersecting processes and multifaceted rules, as well as what appear to be intentional exceptions to those rules, that indicate the presence of the composer's hand throughout. Importantly, it calls into question, at least in the case of Pärt's music, some theorists' and analysts' perceptions that there is little to be gained from analyses of minimalist and process-based music.

\section{New knowledge}

This thesis has demonstrated that when multiple M-voice/T-voice pairings interact with each other, a wide array of sonorities and unexpected chord progressions is generated. These sonorities, in turn, result in the creation of cohesive musical structures of consonances and dissonances that provide each work its own unique identity. This is due to the composer's seemingly meticulous approach to constructing his music.

In Chapter 2, it was shown that the pandiatonic manner in which Pärt constructed most of the M-voice/T-voice pairings for his early tintinnabuli works creates a phenomenon in which the general sonority of the interval-class content of specific pairings is not affected when the M-voice is shifted to a different scalic mode. Only the order in which intervals are presented to the listener, as the M-voice proceeds towards or away from its pitch centre, is affected by such shifts. 
Chapter 2 also illustrated that:

1) a 'fixed' T-voice in its different positions results in only three possible sets of interval class content, i.e. $<121210>$ and $<122110>$ and $<001150>$, regardless of which modally-related M-voice scale is paired with it;

2) superior and inferior, second position M-voice/T-voice pairings result in relatively consonant interval class content (i.e. $<001150>$ ), when compared with both the superior and inferior, first position M-voice/T-voice pairings $<121210>$ and $<122110>$ respectively; and

3) in contrast to what occurs when a fixed T-voice is paired with different modally related M-voice scales, a fixed diatonic scale paired with its different 'possible' related triads results in nine distinct interval class vectors, i.e. $<001141\rangle, \quad<001150\rangle, \quad<002041\rangle, \quad<031210\rangle, \quad<032110\rangle, \quad<121210\rangle$, $<122101>,<122110>$, and $<212110>$.

Chapter 2 also presents an original new model (Pärtian Tonnetz) for visualising the interrelationships between the three pitch classes that comprise a tintinnabuli work's T-voice and the remaining pitch classes of the M-voice. The model allows the user to readily identify what intervallic content is occurring at any one moment in the music. In addition, Chapter 2 and Appendix A include a taxonomy of the ordering of intervallic content and sonorities that results from different diatonic M-voice/T-voice pairings, when different modal scales and triads are combined together. Prior to this thesis, this cataloguing of the ordering of this content had not been done. 
Chapter 3 provides insights into how Pärt used the same simple melodic generative procedure, yet achieved significantly different musical effects, in Tabula Rasa's two movements Ludus and Silentium. It demonstrates how, with only a small number of M-voice/T-voice pairings and a basic melodic generative process combined with two other common musical processes (melodic and mensural variation), Pärt is able to deploy his seemingly simple tintinnabuli principles to construct multiple cyclical patterns that move from lesser to greater complexity on numerous levels, creating myriad arrays of different sonorities.

Chapter 4 illustrates how Pärt's tintinnabuli system evolved from a relatively stringent system of rules derived from the combination of stepwise processes and vertical and horizontal relationships (as exemplified by both Tabula Rasa and Cantus in memorium Benjamin Britten) to a more fluid interpretation of what comprises a 'process' piece of music (as exemplified by Festina Lente). Festina Lente, while expanding on the process-based techniques introduced earlier in Tabula Rasa and Cantus, breaks from these antecedents in a number of ways. Rather than having a clearly identifiable modal home, as was the case for the two earlier works, the mode of Festina Lente shifts periodically from its initial Aeolian/Phrygian-centred home to F Lydian and even implying briefly D Dorian. Like Ludus and Cantus, the T-voices in Festina Lente are grounded in an A minor triad, but the relationships between the T-voices' pitches and those of their respective M-voices in Festina Lente become much more fluid as the work progresses, with some T-voices shifting between first and second, superior positions, as well as first position, inferior. In addition, the contrapuntal writing 
of some T-voices is no longer operating in a strict note-on-note rhythmic manner in relation to their respective $M$-voices in Festina Lente.

The theme and variation approach taken by Pärt in Festina Lente demonstrates a greater mutability in the composer's approach to melody than was seen in his earlier process-based works. A number of the composer's melodic interventions in Festina Lente also imply a desire on his part to exercise greater discretion in shaping the harmonic relationships of his process-based works. This is in opposition to some common perceptions about process-based music, i.e. that the composer merely sets up a series of rules and processes and then, abrogating composerly ownership, allows those processes to run their course unimpeded.

Chapter 5 provides the first detailed analyses of the relationships between the texts associated with Psalom and Silouan's Song and the significant role that text has played in determining the deep underpinning structures of both works, at the more elaborate middle ground level, and even surface aspects such as subtle and not so subtle dynamic and tempo changes, the use of articulations, register, and tone colour. The analyses of text-based works in Chapter 5 (and Chapter 6) demonstrate that much of the composer's decisions in relation to form, melodic line, articulations, and tempo dynamic changes cannot be fathomed without having access to, and an understanding of, the text associated with each work.

While this might suggest to some that Pärt's text-based instrumental works are merely instrumental arrangements of vocal works, wherein the texts have been removed and the composer has suppressed any implied textual meaning, in reality this is not the case. In fact, other than some minimal suggestions of 
periodic tone painting in relation to dynamic markings and tempos, there is little evidence that the resultant musical works serve to quote the content of what is said in the original texts, or to summarise and reflect their expressive intentions. Rather it is apparent that the texts that Pärt selects inform his decisions regarding musical structures and processes and serve, primarily, as determinants of select compositional parameters that he has chosen to deploy during the compositional process. It seems clear that the composer did not feel that knowledge of the specific content of these texts was requisite for these musical works to be appreciated by potential listeners. Despite this, having a greater knowledge of these texts and the role they have played in Psalom and Silouan's Song's construction can inform performers' decisions as to how to execute those works, while enriching the listener's appreciation of both pieces' aesthetic merits.

Finally, Chapter 6 provides the first detailed analysis of the integration of tintinnabuli processes, mathematical rules, and text-derived rules that underpin Orient \& Occident's sinuous and disorienting sound world. Pärt's use of three different M-voice/T-voice sonorities in Orient \& Occident is unprecedented in his string orchestral works. By combining a G harmonic minor scale paired with a Gminor triad T-voice, a D double harmonic scale with its periodic alternating D minor triad and G minor triad T-voices, and constant alternation between monophonic and homophonic material, he has created what is perhaps his most sonically complex work since the inception of his tintinnabuli system in 1976.

In consideration of the above discoveries, an alternative hermeneutic interpretation has been proposed, arising from knowledge that the work is based on the Nicene Constantinopolitan Creed. While the sinuous nature of the 
monophonic material, with its stepwise glissandos and subtle leaps of a third or a fourth and periodic use of drone tones, certainly evokes musical references of the Orient (for a Western listener), the many rich harmonies of the alternating homophonic material do not - and can be interpreted as representing the Occident. The knowledge that the composer developed Orient \& Occident out of the text of the Nicene Constantinopolitan Creed, as well as the implied 'triune nature' of the three different M-voice/T-voice sonorities, does lead one to postulate that Pärt might be making an affirmative reference to not only the historic cultural tensions between the Orient and the Occident, but also the divide that continues to separate the Western and Eastern Christian traditions.

\section{Constraints}

One of the constraints of this investigation involves lack of access to the composer to discuss his music. Even though Arvo Pärt is still living at the time of this writing, several years ago he ceased giving interviews to students and scholars wishing to discuss technical aspects of his music. In 2007, PhD candidate Kimberly Cargile attempted to contact Pärt for such an interview through her connections with Paul Hillier, as well as through the composer's representatives at Universal Edition. In relation to this, she received the following response from Eric Marinitsch, Pärt's publishing agent:

... meeting Mr. Pärt is quite difficult ... and would - by the way - not really help you in your work. Mr. Pärt leaves it to scholars and musicologists like you to analyse all aspects of his work. He prefers not getting involved into the discussion of these 
analyses. He usually replies to th[ese] kinds of requests that the words are not his means of expression. He is writing the music, but does not want to talk about it. ${ }^{270}$

A second constraint was the investigation's scope being limited to a detailed examination of the composer's string orchestral compositions, due to the sheer number of compositions in Pärt's oeuvre. This will be mitigated later by other scholars, in part through future studies of the composers' musical outputs that rely on other instrumental forces.

\section{Future work}

This investigation lays an important foundation for establishing new avenues of study for future scholars. For example, no investigations have been undertaken to date that examine how Pärt's practice of deriving compositional parameters from specific texts translates into his writing for brass, woodwinds or percussion. As noted previously, Pärt has composed more than 80 text-based works from texts spanning nine different languages (Estonian, Latin, English, German, Russian, Church Slavonic, Italian, Spanish, and French). ${ }^{271}$ Given this, other future avenues of study might include a comparative analysis of the stylistic similarities and differences between different works derived from texts in different languages. For example, how do Pärt's instrumental works that are based on Latin liturgical texts differ from those based on Russian or Church Slavonic liturgical texts? What are the similarities and differences between his compositions for voice and choir, versus instrumental works that have compositional parameters that are derived from texts?

\footnotetext{
270 Kimberly Cargile, “An Analytical Conductor's Guide to the SATB A Cappella Works of Arvo Pärt" (Doctor of Musical Arts Dissertation, University of Southern Mississipi, 2008), 12, ProQuest Dissertations \& Theses Global. Email message from Eric Marinitsch to Kimberly Cargile (Referenced as footnote 32 in her dissertation).

271 See also Rosma, Kõrver, and Kurman, In Principio: The Word In Arvo Pärt's Music, 18.
} 


\section{Conclusion}

Process-based music relies on the composer establishing a set of prescribed rules for a particular work. While certain basic rules of Arvo Pärt's tintinnabuli system are evident throughout each of the six string orchestral works that are examined in this thesis, the preceding analyses also elucidate the unique workspecific rules that the composer established for each composition.

Importantly, it has been shown that Pärt also deliberately deviates and makes exceptions to the rules that apply to specific works. In doing so, the composer's hand becomes even more clearly evident. Understanding when and why Pärt breaks one or more of his own rules - and how he does so in ways that actually reinforce and enhance the aesthetic outcomes for a particular composition - is the key to understanding how his tintinnabuli works move away from being purely process-driven.

Many of the details about how the six works examined in this thesis were constructed and operate would not have been revealed had a more traditional approach to analyses been taken. Similarly, relying on only one or two post-tonal analytical approaches would likely have proven insufficient in revealing the hidden constructions and the careful craftsmanship that went into each work's creation. An awareness of these hidden constructions and the careful craftsmanship that went into their creation can provide the informed listener with the critical foundation from which the aesthetic value of Pärt's music can be assessed and appreciated. 
Importantly, the discoveries made through the non-traditional application of blended post-tonal analytical approaches in this thesis suggest that this methodology might serve as a template for other analysts and theorists to explore genres such as minimalism and process-based music that may not be receiving the amount of scholarly attention that they merit. 


\section{Bibliography}

Alfred Mann, J. Kenneth Wilson, and Peter Urquhart. "Canon (I).” Grove Music Online. Accessed May 10, 2014.

http://www.oxfordmusiconline.com/subscriber/article/grove/music/04 741.

Anonymous. “St. Panteleimon's Monastery (Athos).” Orthodox Wiki. Accessed March 5, 2015. http://orthodoxwiki.org/St._Panteleimon\%27s_Monastery_\%28Athos\%2 9.

Bellman, Jonathan. "Introduction." In The Exotic in Western Music, ix-xiii. Boston: Northeastern University Press, 1998.

Brauneiss, Leopold. "Arvo Pärt's Tintinnabuli Style: Contemporary Music Toward a New Middle Ages?" In Postmodern Medievalisms, XIII:27-34. Studies in Medievalism. Cambridge: D. S. Brewer, 2005.

- - . "Musical Archetypes: The Basic Elements of Tintinnabuli Style." In The Cambridge Companion to Arvo Pärt, 49-75. Cambridge: Cambridge University Press, 2012.

Brown, Galen H. "Process as Means and End in Minimalist and Postminimalist Music." Perspectives of New Music 48, no. 2 (2010): 180-92.

Burkholder, J. Peter. "Museum Pieces: The Historicist Mainstream in Music in the Last Hundred Years." The Journal of Musicology 2, no. 2 (1983): 115-34.

- - - "Musical Time and Continuity as a Reflection of the Historical Situation of Modern Composers." The Journal of Musicology 9, no. No. 4 (1991): 41129.

Cargile, Kimberly. “An Analytical Conductor's Guide to the SATB A Cappella Works of Arvo Pärt." Doctor of Musical Arts Dissertation, University of Southern Mississipi, 2008. ProQuest Dissertations \& Theses Global.

Cizmic, Maria. "Transcending the Icon: Spirituality and Post Modernism in Arvo Pärt's Tabula Rasa and Spiegel Im Spiegel." Twentieth-Century Music 5, no. 1 (2008): 45-78.

Clarke, David. "Parting Glances: David Clarke Reappraises the Music and the Aesthetics of Arvo Pärt." The Musical Times 134, no. 1810 (December 1, 1993): 680-84.

_-_. "Summa for String Quartet; Festina Lente, for String Orchestra and Harp Ad Libitum; Fratres for String Quartet; Freatres for String Orchestra and Percussion; Fratres for Violonello and Piano; Fratres for Violin and Piano by Arvo Pärt. Review by David Clarke." Music \& Letters 75, no. 4 (November 1994): 652-58.

Clendinning, Jane Piper. "Postmodern Architecture/Postmodern Music.” In Postmodern Music/Postmodern Thought, 4:119-40. Studies in Contemporary Music and Culture. New York and London: Routledge, 2002.

Coniaris, Anthony. Sacred Symbols That Speak. Edina: Light \& Life Pub Co, 1985.

"Cyrillic Alphabet." Britannica Academic. Accessed August 9, 2015. http://academic.eb.com.helicon.vuw.ac.nz/EBchecked/topic/148713/Cyr illic-alphabet. 
Dolp, Laura. "Arvo Pärt in the Marketplace." In The Cambridge Companion to Arvo Pärt, 2012th ed., 177-92. Cambridge: Cambridge University Press, n.d.

During, Jean. "Question de Gout. L'enjeu de La Modernité Dans Les Arts et Les Musiques de l'Islam. La Modernité En Orient." Cahiers de Musiques Traditionnelles, 1994.

Eckhoff, Hanne. "Email Correspondence Re: Church Slavonic, Its Transliteration into the International Phonetic Alphabet and Pronunciation Traditions," April 14, 2015.

-_—. "Email Correspondence Re: Orient \& Occident," May 7, 2015.

ECM Records / Universal Edition AG, ed. Arvo Pärt - Tabula Rasa. ECM New Series 1275. Wien: Universal Edition, 2010.

ECM Records/ Universal Edition AG, ed. Arvo Pärt - Tabula Rasa. CD, Issue, Special edition. Munich: ECM in collaboration with Universal Edition, 2010.

Edmonds, Rosemary, trans. "Silouan's Song." In In Principio: The Word In Arvo Pärt's Music, 335. Harjumaa: The Arvo Pärt Centre, 2014.

Elste, Martin. "An Interview with Arvo Pärt.” Fanfare, November 1988.

Fisk, Josiah. "The New Simplicity: The Music of Górecki, Tavener and Pärt.” The Hudson Review 47, no. 3 (Autumn 1994): 394-412.

Forte, Allen. The Structure of Atonal Music. New Haven: Yale University Press, 1973.

Goehr, Lydia. The Imaginary Museum of Musical Works. New York: Oxford University Press, 1992.

Griffiths, Paul. Modern Music and After - Directions since 1945. New York: Oxford University Press, 1995.

-_- "Now, and Then." In Arvo Pärt - Tabula Rasa, 5-7. ECM New Series 1275. Wien: Universal Edition, 2010.

Grillo, Tyran. "Arvo Pärt: Orient \& Occident," January 23, 2011. http://ecmreviews.com/2011/01/23/orient-occident/.

Hayward, Tony. "Arvo Pärt: Orient Occident.” Music Reviews. MusicWeb International, December 2, 2002. http://www.musicwebinternational.com/classrev/2002/Dec02/PartOrientOccident.htm.

Hillier, Paul. Arvo Pärt. New York: Oxford University Press, 1997.

——_. "Arvo Pärt: Magister Ludi." The Musical Times 130, no. 1753 (March 1, 1989): 134-37. doi:10.2307/1193820.

Hodkinson, James, and John Walker. "Introduction." In Deploying Orientalism in Culture and History: From Germany to Central and Eastern Europe, edited by James Hodkinson, John Walker, Shaswati Mazumdar, and Johannes Feichtinger, 1-14. Boydell \& Brewer, 2013.

Jimenez, Ivan. “Textural Depth, Structural Depth, Expressive Depth: Ladders from Line to Sonority in Arvo Pärt and Henryk Mikolaj Gorecki, And, Burning the Deep Red Sea (an Original Composition for Chamber Ensemble)." Doctor of Musical Arts Dissertation, University of Pittsburgh, 2005. ProQuest Dissertations \& Theses Global.

Jobst, Kerstin S. "Where the Orient Ends? Orientalism and Its Function for Imperial Rule in the Russian Empire." In Deploying Orientalism in Culture and History, 190-208. From Germany to Central and Eastern Europe. Boydell \& Brewer, 2013. http://www.jstor.org.helicon.vuw.ac.nz/stable/10.7722/j.ctt3fgn1p.4. 
Johnson, Timothy A. "Minimalism: Aesthetic, Style or Technique?" The Musical Quarterly 78, no. 4 (Winter 1994): 742-73.

Kähler, Andreas Peer. "Radiating from Silence: The Works of Arvo Pärt through a Musican's Eyes." In The Cambridge Companion to Arvo Pärt, 193-97. Cambridge: Cambridge University Press, 2012.

Kárpáti, Jáno. "Non-European Influences on Occidental Music (A Historical Survey)." The World of Music 22, no. 2 (1980): 20-37.

Kramer, Jonathan D. "The Nature and Origins of Musical Postmodernism." In Postmodern Music/Postmodern Thought, 4:13-26. Studies in Contemporary Music and Culture. New York and London: Routledge, 2002.

Kronos. Early Music. Nonesuch, 1997.

Kutman, The Arvo Pärt Center, Kai. "Email Correspondence Re: Psalom," March 24, 2015.

LaRue, Jan. Guidelines for Style Analysis. Edited by Marian Green LaRue. Second Edtion. Detroit Monographs in Musical Studies/Studies in Music, No. 57. Detroit: Harmony Park Press, 2011.

Lubow, Arthur. "The Sound of Spirit." The New York Times. October 15, 2010. http://www.nytimes.com/2010/10/17/magazine/17partt.html?pagewanted=all\&_r=0.

Mainheim, James. “Arvo Pärt: Orient \& Occident.” ALLMusic Review, 2002. http://www.allmusic.com/album/arvo-p\%C3\%A4rt-orient-occidentmw0001850366.

McCarthy, Jamie. "An Interview with Arvo Pärt." Contemporary Music Review 12:22 (1995): 55-64. http://dx.doi.org/10.1080/07494469500640171.

McClary, Susan. "Terminal Prestige: The Case of Avant-Garde Music Composition." Cultural Critique, no. 12 (1989): 57-81.

Mellers, Willifrid. "Arvo Pärt, God and Gospel: Passio Domini Nostri Jesu Christi Secudum Johannem." Contemporary Music Review 12 Part 2 (1995): 3548.

Nyman, Michael. Experimental Music: Cage and Beyond. Second Edition. Music in the 20th Century. New York: Cambridge University Press, 2009.

Ovanescu-Pîrvu, Elena. "Perspectives and Musical Analysis Between Occident and Orient." Review of Artistic Education 7 (2014): 67-73. http://search.proquest.com.helicon.vuw.ac.nz/docview/1556448967?acc ountid=14782.

Owens, Lewis. "Arvo Pärt : Miserere : Miserere and Minimalism." Spike Magazine. Accessed September 4, 2011. http://www.spikemagazine.com/0600arvopart.php.

Packett, Kila. "Arvo Pärt Orient Occident." Cultural commentary and reviews. POPMATTERS, February 25, 2003. http://www.popmatters.com/review/partarvo-orient.

Pärt, Arvo. Psalom. UE 30 847. Wien: Universal Edition, 1991.

_- - Silouan's Song. UE 19 889. Wien: Universal Edition, 1991.

Pinkerton, David. "David Pinkerton's Arvo Pärt Information Archive," n.d. http://www.arvopart.org/.

Pinto, Vivian. "Church Slavonic." In The Slavic Literary Languages: Formation and Development, Yale Russian and East European Publications:1-33. New Haven: Yale Concilium on International and Area Studies, 1980. 
Quinn, Ian. "Minimal Challenges: Process Music and the Uses of Formalist Analysis." Contemporary Music Review 25, no. 3 (June 2006): 283-94.

Ralph P. Locke. "Cutthroats and Casbah Dancers, Muezzins and Timeless Sands: Musical Images of the Middle East." In The Exotic in Western Music, 10436. Boston: Northeastern University Press, 1998.

Randel, Don Michael. Harvard Dictionary of Music. Cambridge: Belknap Press of Harvard University Press, 2003.

Reich, Steve. "Music as a Gradual Process." In Writings on Music 1965-2000, edited by Paul Hillier, 34-36. New York: Oxford University Press, 2002.

Restagno, Enzo, Leopold Brauneiss, Saale Kareda, and Arvo Pärt. Arvo Pärt in Conversation. Translated by Robert Crow. Champaign, Illinois: Dalkey Archive Press, 2011.

Robinson, Thomas. "Analyzing Pärt." In The Cambridge Companion to Arvo Pärt, 76-110. Cambridge: Cambridge University Press, 2012. . "Pitch-Class Multisets." Doctoral of Philosophy, City University of New York, 2009.

Rosma, Hedi, Kristina Kõrver, and Kai Kurman, eds. In Principio: The Word In Arvo Pärt's Music. Harjumaa: The Arvo Pärt Centre, 2014.

Said, Edward. Orientalism. New York: Vintage, 1979.

Schenker, Alexander M., and Edward Stankiewicz, eds. The Slavic Literary Languages: Formation and Development. Vol. Yale Russian and East European Publications. 1 of 3 vols. New Haven: Yale Concilium on International and Area Studies, 1980.

Scholl, Robert. "Pärt and Spirituality." In The Cambridge Companion to Arvo Pärt, 140-58. Boston: Cambridge University Press, 2012.

Shenton, Andrew. "Introduction: The Essential and Phenomenal Arvo Pärt." In The Cambridge Companion to Arvo Pärt. Cambridge: Cambridge University Press, 2012.

Sholl, Robert. "Arvo Pärt and Spirituality." In The Cambridge Companion to Arvo Pärt, 140-58. Cambridge: Cambridge University Press, 2012.

Siitan, Toomas. "Introduction." In In Principio: The Word in Arvo Pärt's Music, 915. Harjumaa: The Arvo Pärt Centre, 2014.

-_- "Introduction." In In Principio: The Word In Arvo Pärt's Music, 9-15. Harjumaa: The Arvo Pärt Centre, 2014.

Smith, Geoff. "An Interview with Arvo Pärt: Sources of Invention." The Musical Times 140, no. 1868 (October 1, 1999): 19-25. doi:10.2307/1004490.

Sööt, Andreas. "Arvo Pärt in November 1978." Translated by Andreas Didrik. Teater, Muusika, Kino, 1988.

Straus, Joseph Nathan. Introduction to Post-Tonal Theory. Third Edition. Pearson Prentice Hall, 2005.

Taruskin, Richard. "Entoiling the Falconet." In Defining Russia Muscially, 152-85. Princeton: Princeton University Press, 1997.

- - - Music in the Late Twentieth. Vol. 5.5 vols. The Oxford History of Western Music. Oxford: Oxford University Press, 2010.

Taylor, Timothy D. "Music and Musical Practices in Postmodernity." In Postmodern Music/Postmodern Thought, 4:90-118. Studies in Contemporary Music and Culture. New York and London: Routledge, 2002. 
Tillman, Joakim. "Postmodernism and Art Music in the German Debate." In Postmodern Music/Postmodern Thought, 4:75-91. Studies in Contemporary Music and Culture. New York and London: Routledge, 2002.

Tokun, Elena. "Formal Algorithms of Tintinnabuli in Arvo Pärt's Music." Moscow Conservatory Publishing House, 2011. http://www.arvopart.ee/en/arvopart-2/selected-texts/formal-algorithms-of-tintinnabuli/.

Universal Edition. "Paert Catalogue," 1991. http://www.universaledition.com/Arvo-Paert/composers-andworks/composer/534/worklist\#page $=0$.

Valentine, Thomas Ross. "Filioque.” Orthodox Wiki. Accessed March 28, 2016. http://orthodoxwiki.org/Filioque.

Various. Arvo Pärt Litany. Vol. ECM 1592. ECM New Series. Munich, 1996.

Vuorinen, Mark. "Arvo Pärt's Serial and Tintinnabuli Works: A Continuum of Process." Doctor of Musical Arts, Faculty of Music, University of Toronto, 2014. ProQuest Dissertations \& Theses Global.

Wade, Terence. Comprehensive Russian Grammar (Blackwell Reference Grammars). Second. Oxford: Wiley-Blackwell, 2000.

Wolff, Larry. Inventing Eastern Europe: The Map of Civilization on the Mind of the Enlightenment. Stanford Calif.: Stanford University Press, 1994. http://hdl.handle.net.helicon.vuw.ac.nz/2027/heb.05073.0001.001.

Yudkin, Jeremy. Music in Medieval Europe. Prentice Hall History of Music Series. Upper Saddle River, New Jersey: Prentice Hall, 1989. 


\section{Appendix A: Interval class ordering in Pärt's tintinnabuli system - diatonic modal scales}

Table A.0.1: Interval class sets arising from a C Ionian scale paired with different triads and T-voice positions

\begin{tabular}{|l|l|l|l|l|}
\hline $\begin{array}{l}\text { Interval } \\
\text { class set }\end{array}$ & $\begin{array}{l}\mathbf{1}^{\text {st }} \text { position, } \\
\text { superior }\end{array}$ & $\mathbf{1}^{\text {st position, inferior }}$ & $\begin{array}{l}\mathbf{2}^{\text {nd }} \text { position, } \\
\text { superior }\end{array}$ & $\begin{array}{l}\mathbf{2}^{\text {nd }} \text { position, } \\
\text { inferior }\end{array}$ \\
\hline 001141 & & $\begin{array}{l}\text { D minor, E minor, } \\
\text { F major, G major }\end{array}$ & $\begin{array}{l}\text { D minor, E minor, } \\
\text { F major, G major }\end{array}$ \\
\hline 001150 & & & A minor, C major & A minor, C major \\
\hline 002041 & & B diminished & B diminished \\
\hline 031210 & E minor & F major & & \\
\hline 032110 & G major & D minor & & \\
\hline 121210 & A minor & C major & & \\
\hline 122101 & B diminished & B diminished & & \\
\hline 122110 & C major, D minor & G major, A minor & & \\
\hline 212110 & F major & E minor & & \\
\hline
\end{tabular}


Figure A.1: Interval ordering and class content of a C Ionian scale paired with different triads in 1st position, superior

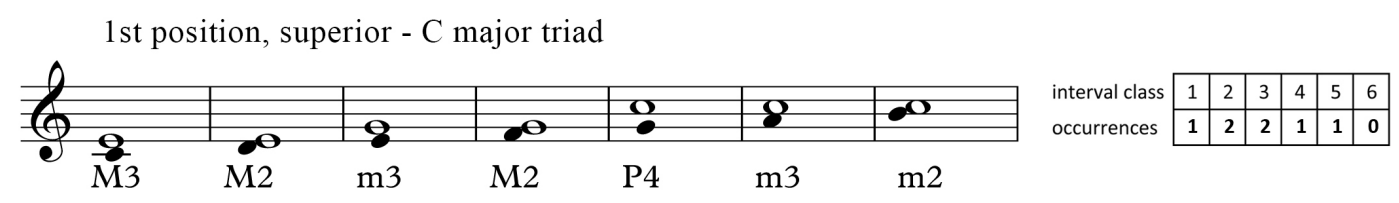

1st position, superior - D minor triad

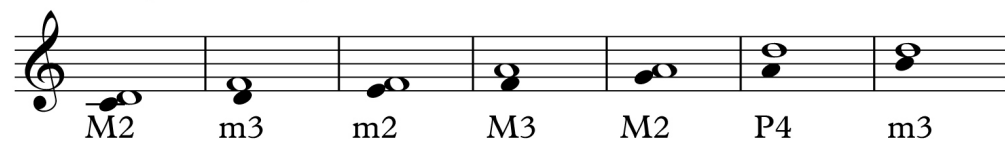

\begin{tabular}{l|l|l|l|l|l|l|}
\cline { 2 - 6 } interval class & $\mathbf{1}$ & $\mathbf{2}$ & $\mathbf{3}$ & 4 & 5 & 6 \\
\cline { 2 - 7 } occurrences & $\mathbf{1}$ & $\mathbf{2}$ & $\mathbf{2}$ & $\mathbf{1}$ & $\mathbf{1}$ & $\mathbf{0}$ \\
\cline { 2 - 6 } & & & & &
\end{tabular}

1st position, superior - E minor triad

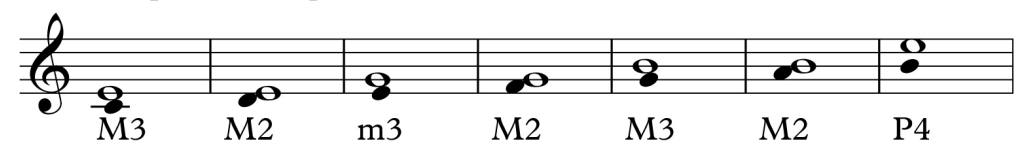

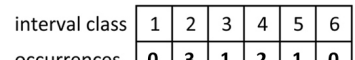

\begin{tabular}{ll|l|l|l|l|l|}
\multirow{2}{*}{ occurrences } & 0 & 3 & 1 & 2 & 1 & 0 \\
\cline { 2 - 6 } \\
\cline { 2 - 5 } & & & &
\end{tabular}

1st position, superior - F major triad

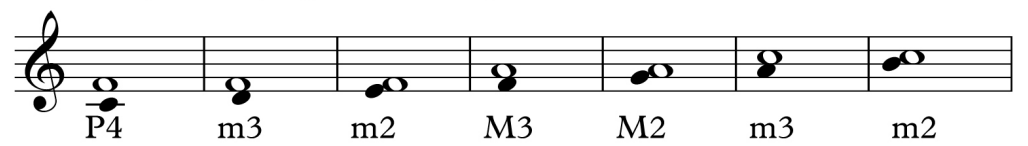

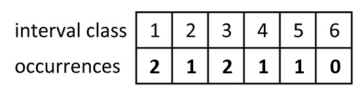

1st position, superior - G major triad

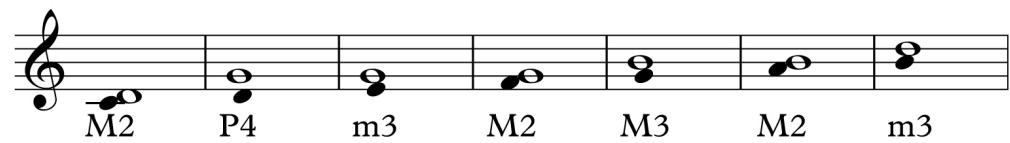

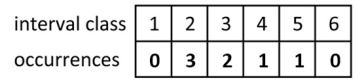

1st position, superior - A minor triad

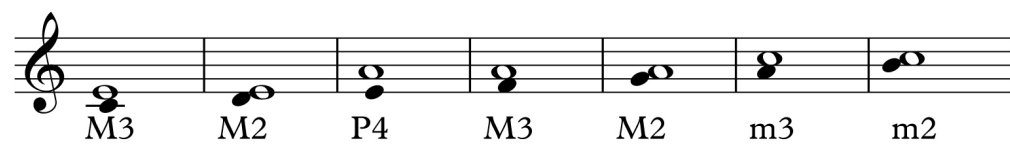

\begin{tabular}{l|l|l|l|l|l|l|}
\cline { 2 - 6 } interval class & 1 & 2 & 3 & 4 & 5 & 6 \\
\cline { 2 - 7 } occurrences & $\mathbf{1}$ & $\mathbf{2}$ & $\mathbf{1}$ & $\mathbf{2}$ & $\mathbf{1}$ & $\mathbf{0}$ \\
\cline { 2 - 6 } & & & &
\end{tabular}

1st position, superior - B diminished triad

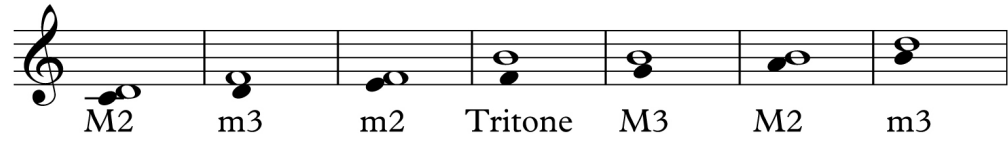

\begin{tabular}{l|l|l|l|l|l|l|}
\cline { 2 - 6 } interval class & 1 & 2 & 3 & 4 & 5 & 6 \\
\cline { 2 - 6 } occurrences & $\mathbf{1}$ & $\mathbf{2}$ & $\mathbf{2}$ & $\mathbf{1}$ & $\mathbf{0}$ & $\mathbf{1}$ \\
\cline { 2 - 6 } & &
\end{tabular} 
Figure A.2: Interval ordering and class content of a C Ionian scale paired with different triads in 1st position, inferior

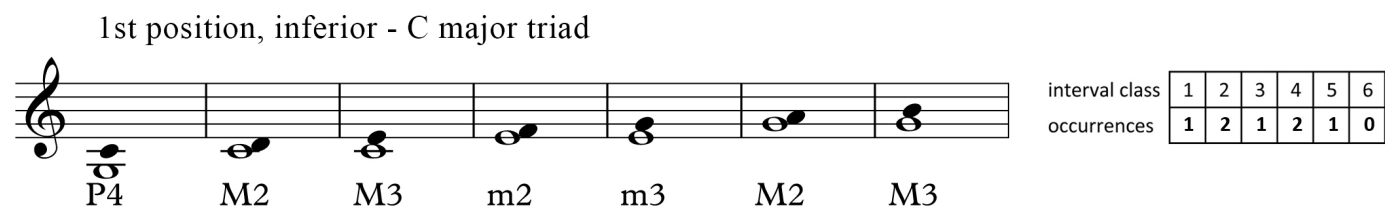

1st position, inferior - D minor triad

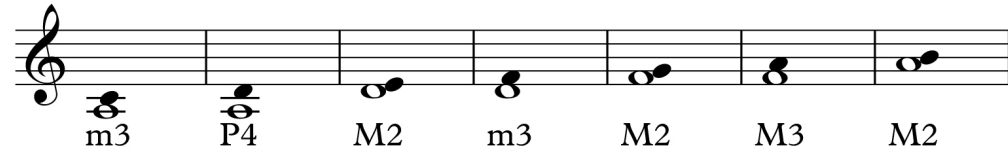

\begin{tabular}{l|l|l|l|l|l|l|}
\cline { 2 - 5 } interval class & 1 & 2 & 3 & 4 & 5 & 6 \\
\cline { 2 - 6 } occurrences & $\mathbf{0}$ & $\mathbf{3}$ & $\mathbf{2}$ & $\mathbf{1}$ & $\mathbf{1}$ & $\mathbf{0}$ \\
\cline { 2 - 5 }
\end{tabular}

1st position, inferior - E minor triad

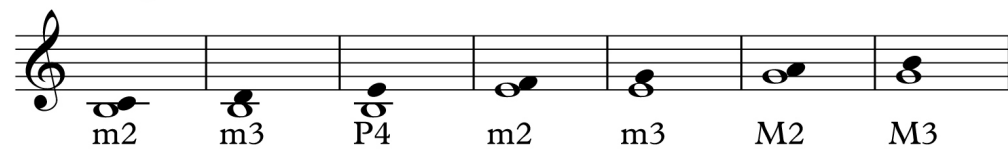

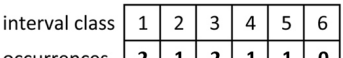

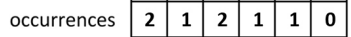

1st position, inferior $\mathrm{F}$ major triad

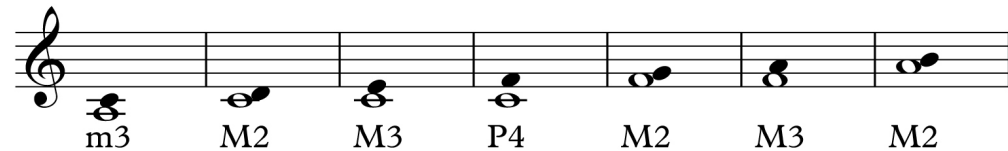

\begin{tabular}{l|l|l|l|l|l|l|} 
& & \\
interval class & 1 & 2 & 3 & 4 & 5 & 6 \\
\cline { 2 - 7 } occurrences & $\mathbf{0}$ & $\mathbf{3}$ & $\mathbf{1}$ & $\mathbf{2}$ & $\mathbf{1}$ & $\mathbf{0}$ \\
\cline { 2 - 6 } & & & & &
\end{tabular}

1 st position, inferior - $\mathrm{G}$ major triad

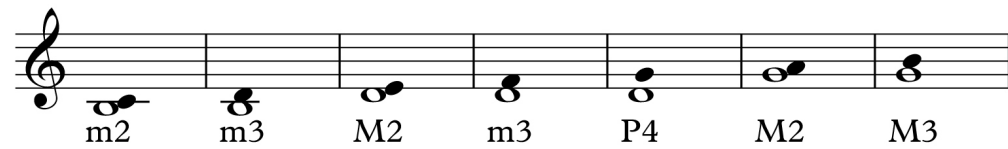

\begin{tabular}{l|l|l|l|l|l|l|}
\cline { 2 - 5 } interval class & 1 & 2 & 3 & 4 & 5 & 6 \\
\cline { 2 - 6 } occurrences & $\mathbf{1}$ & $\mathbf{2}$ & $\mathbf{2}$ & $\mathbf{1}$ & $\mathbf{1}$ & $\mathbf{0}$ \\
\cline { 2 - 5 }
\end{tabular}

1st position, inferior - A minor triad

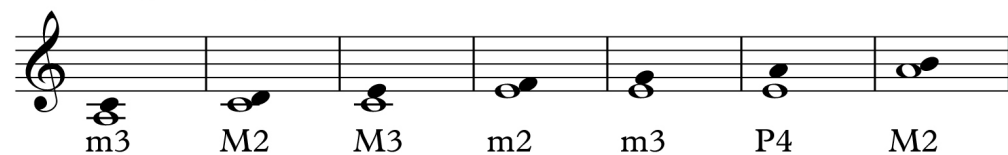

interval class \begin{tabular}{l|l|l|l|l|l|l|}
\cline { 2 - 6 } & 1 & 2 & 3 & 4 & 5 & 6 \\
\cline { 2 - 7 } & 1 & 2 & 2 & 1 & 1 & 0 \\
\hline
\end{tabular}

m3 M2 M3

$\mathrm{m} 2$

triad

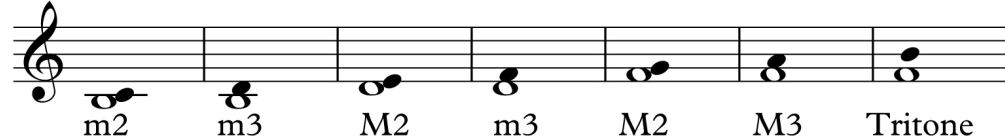

\begin{tabular}{l|l|l|l|l|l|l|}
\cline { 2 - 6 } interval class & 1 & 2 & 3 & 4 & 5 & 6 \\
\cline { 2 - 7 } occurrences & $\mathbf{1}$ & $\mathbf{2}$ & $\mathbf{2}$ & $\mathbf{1}$ & $\mathbf{0}$ & $\mathbf{1}$ \\
\cline { 2 - 7 } & & & &
\end{tabular} 
Figure A.3: Interval ordering and class content of a C Ionian scale paired with different triads in 2 nd position, superior

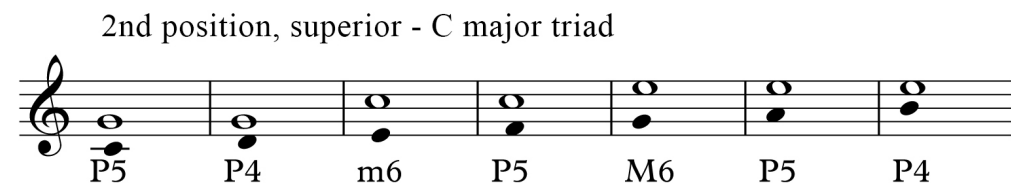

\begin{tabular}{l|l|l|l|l|l|l|} 
interval class & 1 & 2 & 3 & 4 & 5 & 6 \\
\cline { 2 - 7 } occurrences & $\mathbf{0}$ & $\mathbf{0}$ & $\mathbf{1}$ & $\mathbf{1}$ & $\mathbf{5}$ & $\mathbf{0}$ \\
\cline { 2 - 6 } & & & &
\end{tabular}

2nd position, superior - D minor triad

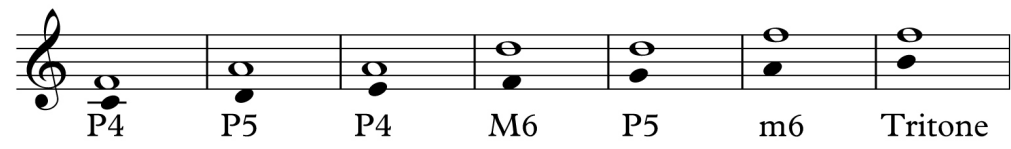

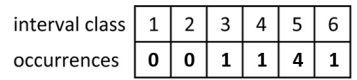

2nd position, superior - E minor triad

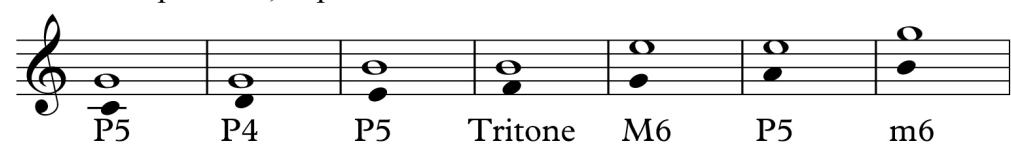

\begin{tabular}{l|l|l|l|l|l|l|} 
interval class & 1 & 2 & 3 & 4 & 5 & 6 \\
\cline { 2 - 7 } occurrences & $\mathbf{0}$ & $\mathbf{0}$ & $\mathbf{1}$ & $\mathbf{1}$ & $\mathbf{4}$ & $\mathbf{1}$ \\
\cline { 2 - 6 } & & & &
\end{tabular}

2nd position, superior - F major triad

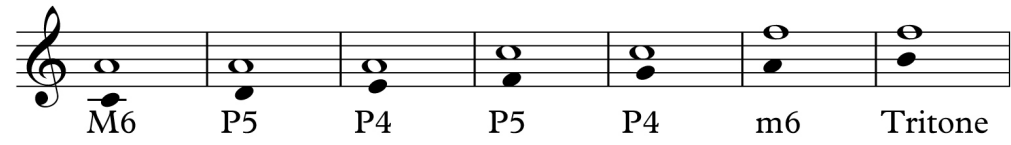

\begin{tabular}{l|l|l|l|l|l|l|} 
& & \\
interval class & 1 & 2 & 3 & 4 & 5 & 6 \\
\cline { 2 - 7 } occurrences & $\mathbf{0}$ & $\mathbf{0}$ & $\mathbf{1}$ & $\mathbf{1}$ & $\mathbf{4}$ & $\mathbf{1}$ \\
\cline { 2 - 6 } & & & & &
\end{tabular}

2nd position, superior - G major triad

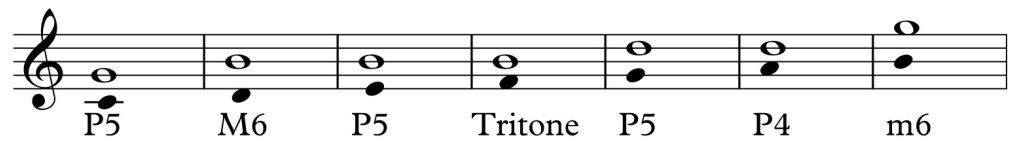

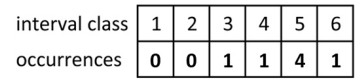

2nd position, superior - A minor triad

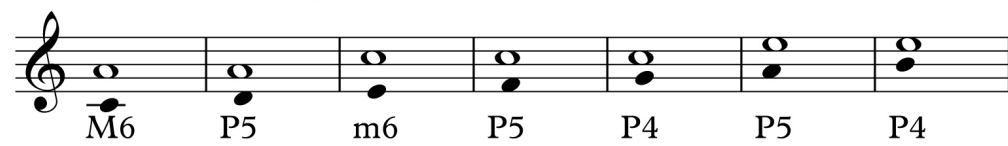

\begin{tabular}{l|l|l|l|l|l|l|} 
interval class & 1 & 2 & 3 & 4 & 5 & 6 \\
\cline { 2 - 7 } occurrences & $\mathbf{0}$ & $\mathbf{0}$ & $\mathbf{1}$ & $\mathbf{1}$ & $\mathbf{5}$ & $\mathbf{0}$ \\
\cline { 2 - 6 } & & & & &
\end{tabular}

2nd position, superior - B diminished triad

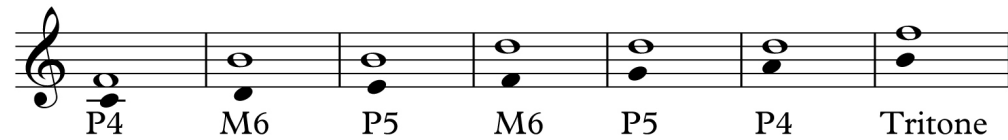

\begin{tabular}{l|l|l|l|l|l|l|} 
interval class & 1 & 2 & 3 & 4 & 5 & 6 \\
\cline { 2 - 7 } occurrences & $\mathbf{0}$ & $\mathbf{0}$ & $\mathbf{2}$ & $\mathbf{0}$ & $\mathbf{4}$ & $\mathbf{1}$ \\
\cline { 2 - 7 } & & & &
\end{tabular} 
Figure A.4: Interval ordering and class content of a C Ionian scale paired with different triads in 2 nd position, inferior

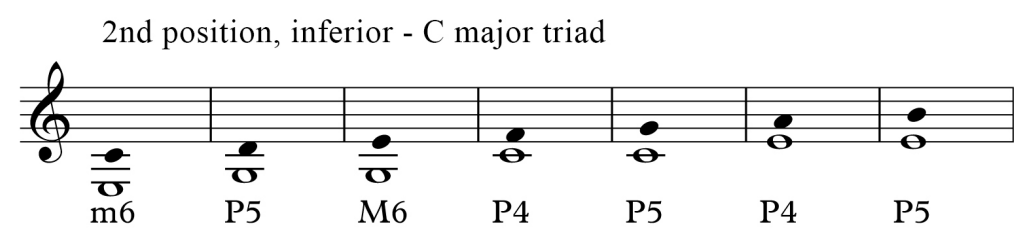

\begin{tabular}{l|l|l|l|l|l|l|} 
interval class & 1 & 2 & 3 & 4 & 5 & 6 \\
\cline { 2 - 7 } occurrences & $\mathbf{0}$ & $\mathbf{0}$ & $\mathbf{1}$ & $\mathbf{1}$ & $\mathbf{5}$ & $\mathbf{0}$ \\
\cline { 2 - 6 } & & & &
\end{tabular}

2nd position, inferior - D minor triad

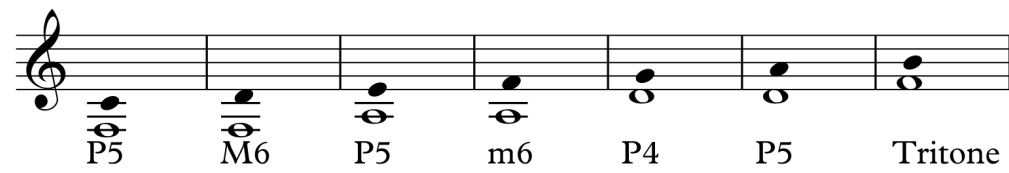

\begin{tabular}{l|l|l|l|l|l|l|} 
interval class & 1 & 2 & 3 & 4 & 5 & 6 \\
\cline { 2 - 7 } occurrences & $\mathbf{0}$ & $\mathbf{0}$ & $\mathbf{1}$ & $\mathbf{1}$ & $\mathbf{4}$ & $\mathbf{1}$ \\
\cline { 2 - 6 } & \multicolumn{3}{|c|}{} & \multicolumn{3}{|c}{}
\end{tabular}

2nd position, inferior - E minor triad

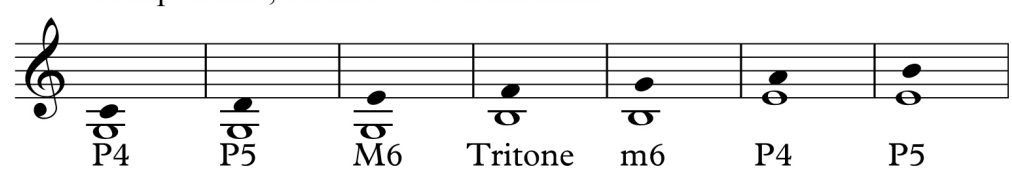

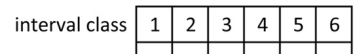
\begin{tabular}{lllllll|}
\multirow{2}{*}{ occurrences } & 0 & 0 & 1 & 1 & 4 & 1 \\
\cline { 2 - 6 } \\
\cline { 2 - 5 }
\end{tabular}

2nd position, inferior - F major triad

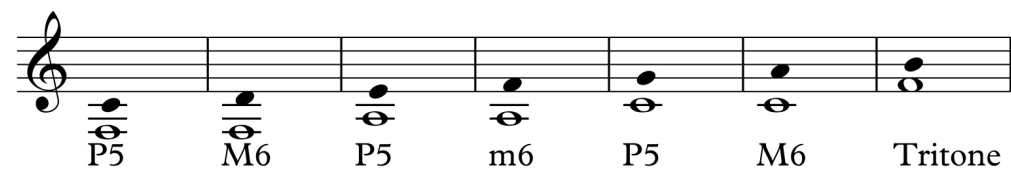

\begin{tabular}{l|l|l|l|l|l|l|}
\multirow{3}{*}{ interval class } & 1 & 2 & 3 & 4 & 5 & 6 \\
\cline { 2 - 6 } occurrences & $\mathbf{0}$ & $\mathbf{0}$ & $\mathbf{1}$ & $\mathbf{1}$ & $\mathbf{4}$ & $\mathbf{1}$ \\
\cline { 2 - 6 } & & & & &
\end{tabular}

2nd position, inferior - G major triad

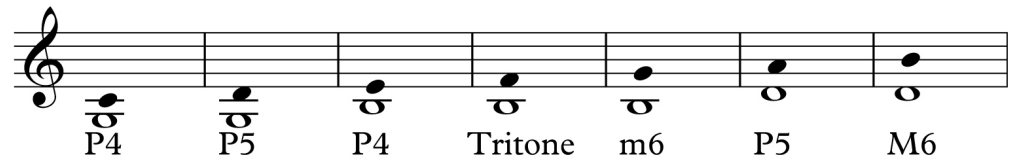

2nd position, inferior - A minor triad

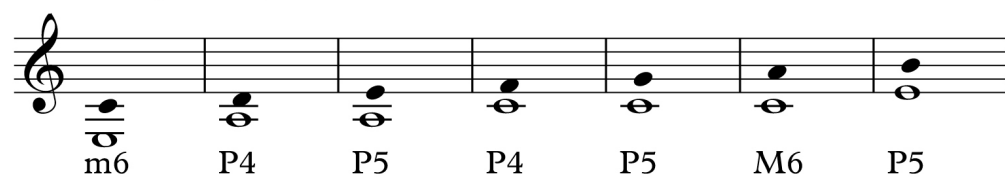

\begin{tabular}{l|l|l|l|l|l|l|}
\cline { 2 - 6 } interval class & 1 & 2 & 3 & 4 & 5 & 6 \\
\cline { 2 - 7 } & 0 & 0 & 1 & 1 & 5 & 0 \\
\cline { 2 - 6 }
\end{tabular}

2nd position, inferior - $\mathrm{B}$ diminished triad

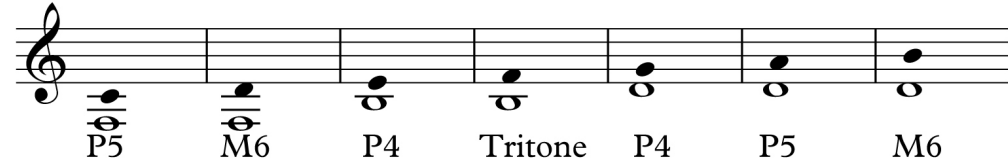

\begin{tabular}{l|l|l|l|l|l|l|}
\cline { 2 - 6 } interval class & 1 & 2 & 3 & 4 & 5 & 6 \\
\cline { 2 - 6 } occurrences & $\mathbf{0}$ & $\mathbf{0}$ & $\mathbf{2}$ & $\mathbf{0}$ & $\mathbf{4}$ & $\mathbf{1}$ \\
\cline { 2 - 6 } & & & &
\end{tabular} 
Table A.0.2: Interval class sets arising from a D Dorian scale paired with different triads and T-voice positions

\begin{tabular}{|c|c|c|c|c|}
\hline $\begin{array}{l}\text { Interval } \\
\text { class set }\end{array}$ & $\begin{array}{l}1^{\text {st }} \text { position, } \\
\text { superior }\end{array}$ & $1^{\text {st }}$ position, inferior & $\begin{array}{l}2^{\text {nd }} \text { position, } \\
\text { superior }\end{array}$ & $\begin{array}{l}2^{\text {nd }} \text { position, } \\
\text { inferior }\end{array}$ \\
\hline 001141 & & & $\begin{array}{l}\text { D minor, E minor, } \\
\text { F major, G major }\end{array}$ & $\begin{array}{l}\text { D minor, E minor, } \\
\text { F major, G major }\end{array}$ \\
\hline 001150 & & & A minor, $\mathrm{C}$ major & A minor, $\mathrm{C}$ major \\
\hline 002041 & & & B diminished & B diminished \\
\hline 031210 & E minor & F major & & \\
\hline 032110 & G major & D minor & & \\
\hline 121210 & A minor & C major & & \\
\hline 122101 & B diminished & B diminished & & \\
\hline 122110 & C major, D minor & G major, A minor & & \\
\hline 212110 & F major & E minor & & \\
\hline
\end{tabular}


Figure A.5: Interval ordering and class content of a D Dorian scale paired with different triads in 1st position, superior

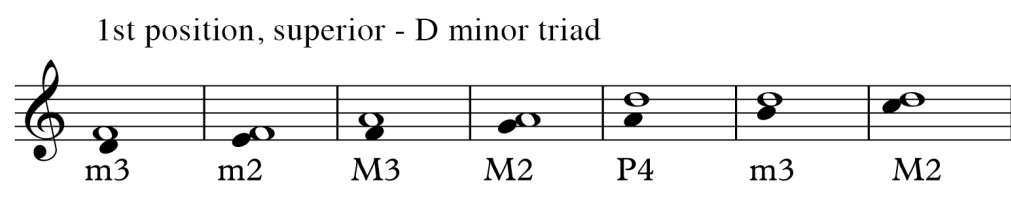

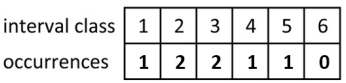

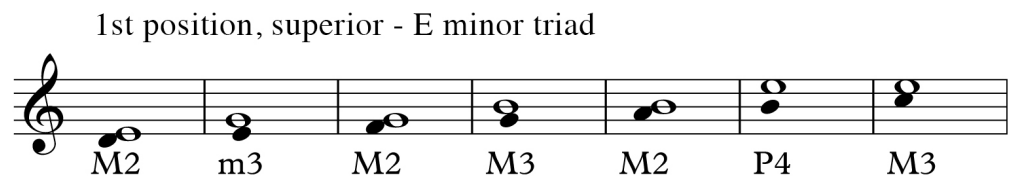

\begin{tabular}{l|l|l|l|l|l|l|}
$\begin{array}{l}\text { interval class } \\
\text { occurrences }\end{array}$ & $\mathbf{1}$ & $\mathbf{2}$ & $\mathbf{3}$ & $\mathbf{4}$ & $\mathbf{5}$ & $\mathbf{6}$ \\
\cline { 2 - 7 } & $\mathbf{0}$ & $\mathbf{3}$ & $\mathbf{1}$ & $\mathbf{2}$ & $\mathbf{1}$ & $\mathbf{0}$ \\
\cline { 2 - 6 } & & & & &
\end{tabular}

1st position, superior F major triad

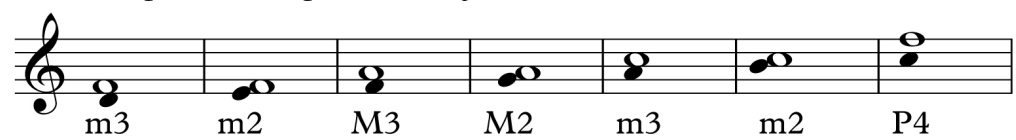

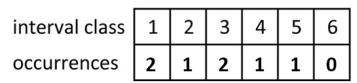

1st position, superior - G major triad

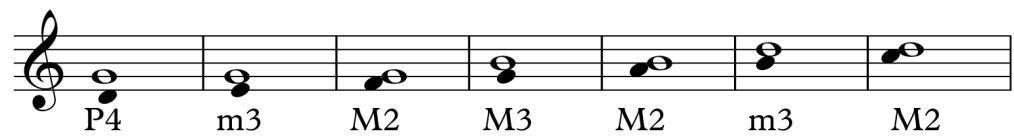

\begin{tabular}{l|l|l|l|l|l|l|} 
interval class & 1 & 2 & 3 & 4 & 5 & 6 \\
\cline { 2 - 7 } occurrences & $\mathbf{1}$ & $\mathbf{3}$ & $\mathbf{2}$ & $\mathbf{1}$ & $\mathbf{1}$ & $\mathbf{0}$ \\
\cline { 2 - 6 } & & & & &
\end{tabular}

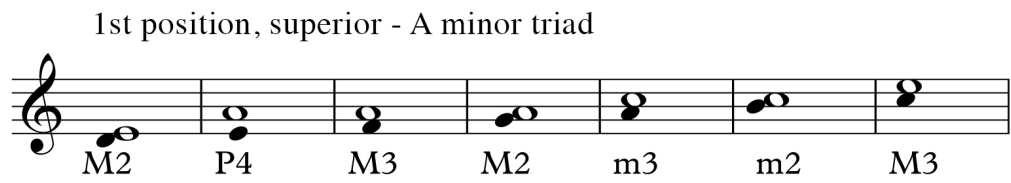

\begin{tabular}{l|l|l|l|l|l|l|} 
interval class & 1 & 2 & 3 & 4 & 5 & 6 \\
\cline { 2 - 7 } occurrences & $\mathbf{1}$ & $\mathbf{2}$ & $\mathbf{1}$ & $\mathbf{2}$ & $\mathbf{1}$ & $\mathbf{0}$ \\
\cline { 2 - 6 } & & & & &
\end{tabular}

1st position, superior - B diminished triad

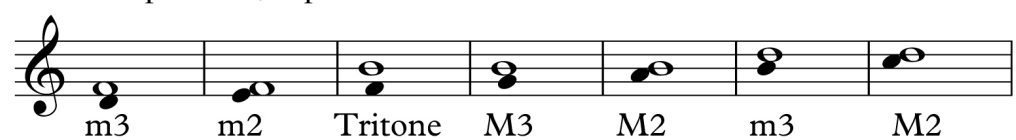

\begin{tabular}{l|l|l|l|l|l|l|} 
interval class & $\mathbf{1}$ & 2 & $\mathbf{3}$ & 4 & 5 & 6 \\
\cline { 2 - 7 } occurrences & $\mathbf{1}$ & $\mathbf{2}$ & $\mathbf{2}$ & $\mathbf{1}$ & $\mathbf{0}$ & $\mathbf{1}$ \\
\cline { 2 - 6 } & & & & &
\end{tabular}

1st position, superior - C major triad

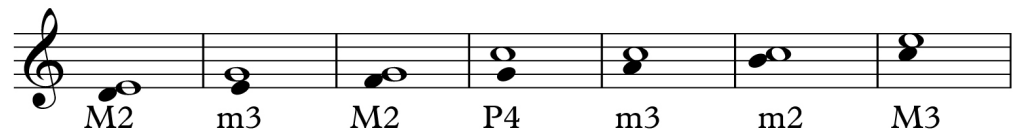

interval class \begin{tabular}{l|l|l|l|l|l|l|}
\cline { 2 - 6 } & 1 & 2 & 3 & 4 & 5 & 6 \\
\cline { 2 - 6 } & 1 & 2 & 2 & 1 & 1 & 0 \\
\hline
\end{tabular}

\begin{tabular}{l|l|l|l|l|l|l|}
\multirow{3}{*}{ occurrences } & $\mathbf{1}$ & $\mathbf{2}$ & $\mathbf{2}$ & $\mathbf{1}$ & $\mathbf{1}$ & $\mathbf{0}$ \\
\cline { 2 - 7 } & & & &
\end{tabular} 
Figure A.6: Interval ordering and class content of a D Dorian scale paired with different triads in 1st position, inferior
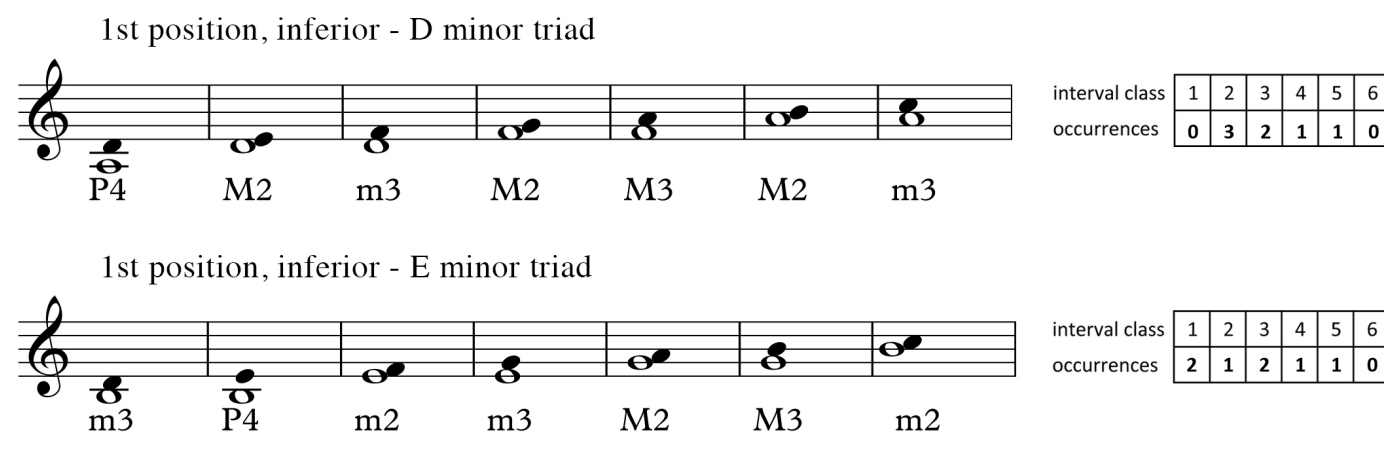

\begin{tabular}{l|l|l|l|l|l|l|} 
interval class & 1 & 2 & 3 & 4 & 5 & 6 \\
\cline { 2 - 7 } occurrences & $\mathbf{2}$ & $\mathbf{1}$ & $\mathbf{2}$ & $\mathbf{1}$ & $\mathbf{1}$ & $\mathbf{0}$ \\
\cline { 2 - 6 } & & & &
\end{tabular}

1st position, inferior - F major triad

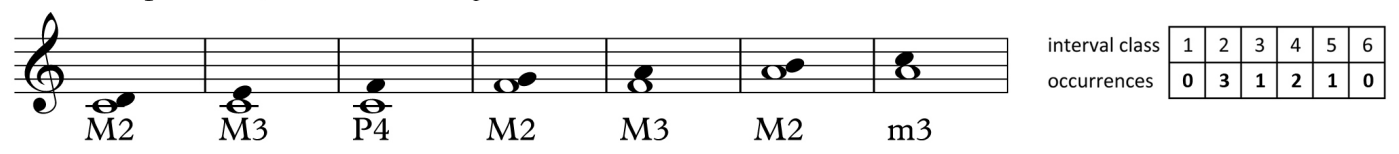

1st postion, inferior - G major triad

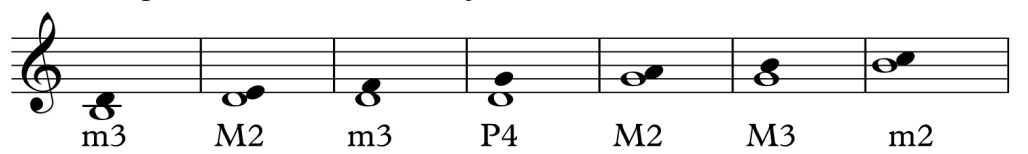

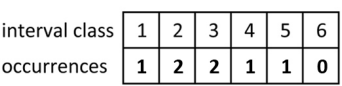

1st position, inferior - A minor triad

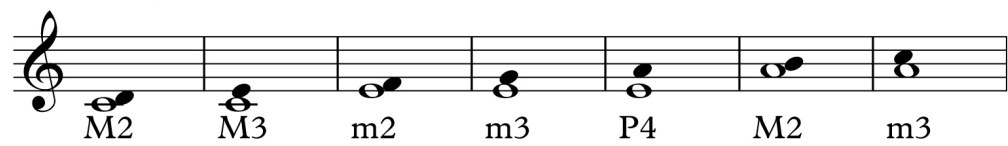

\begin{tabular}{l|l|l|l|l|l|l|}
\cline { 2 - 6 } interval class & 1 & 2 & 3 & 4 & 5 & 6 \\
\cline { 2 - 7 } occurrences & $\mathbf{1}$ & $\mathbf{2}$ & $\mathbf{2}$ & $\mathbf{1}$ & $\mathbf{1}$ & $\mathbf{0}$ \\
\cline { 2 - 6 } & \multicolumn{3}{|c|}{} & \multicolumn{3}{|c}{}
\end{tabular}

1st position, inferior - B diminished triad

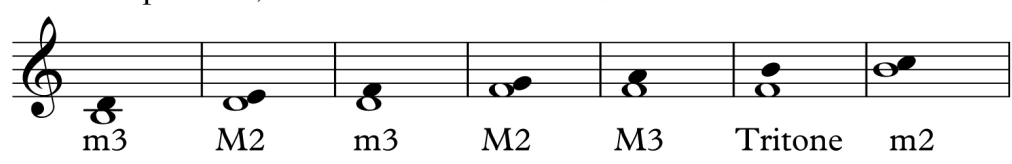

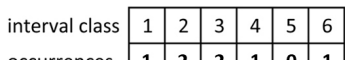

$\mathrm{m} 3 \quad \mathrm{M} 2 \quad \mathrm{~m} 3 \quad \mathrm{M} 2 \quad \mathrm{M} 3 \quad$ Tritone $\mathrm{m} 2$

1st position, inferior $\mathrm{C}$ major triad

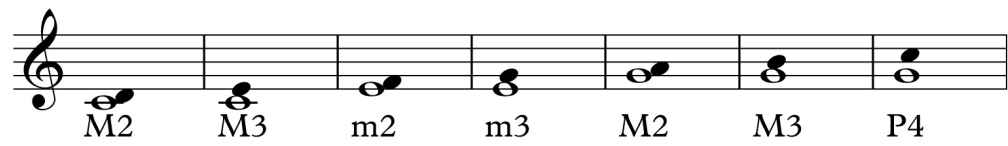

\begin{tabular}{l|l|l|l|l|l|l|}
\cline { 2 - 6 } interval class & 1 & 2 & 3 & 4 & 5 & 6 \\
\hline
\end{tabular}

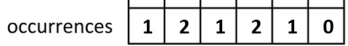


Figure A.7: Interval ordering and class content of a D Dorian scale paired with different triads in 2nd position, superior

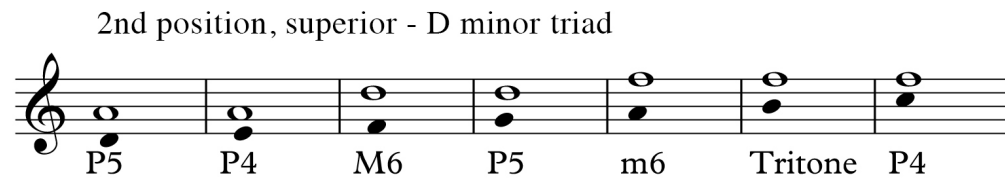

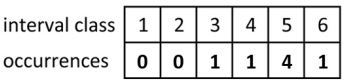

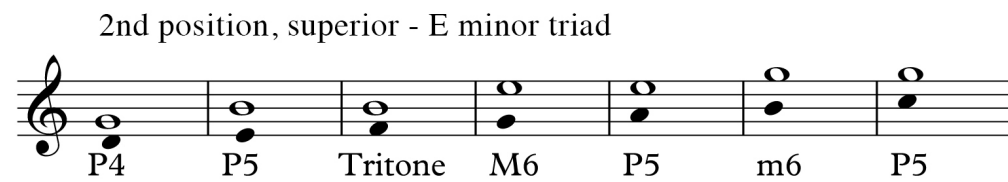

\begin{tabular}{l|l|l|l|l|l|l|}
\cline { 2 - 5 } interval class & 1 & 2 & 3 & 4 & 5 & 6 \\
\cline { 2 - 5 } occurrences & $\mathbf{0}$ & $\mathbf{0}$ & $\mathbf{1}$ & $\mathbf{1}$ & $\mathbf{4}$ & $\mathbf{1}$ \\
\cline { 2 - 5 } & & &
\end{tabular}

2nd position, superior - F major triad

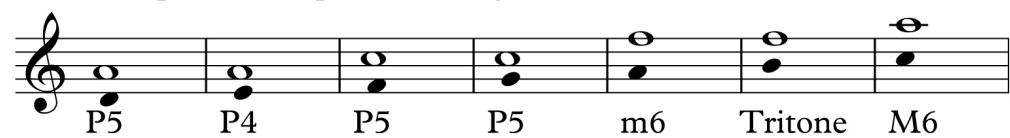

\begin{tabular}{l|l|l|l|l|l|l|} 
interval class & 1 & 2 & 3 & 4 & 5 & 6 \\
\cline { 2 - 7 } occurrences & $\mathbf{0}$ & $\mathbf{0}$ & $\mathbf{1}$ & $\mathbf{1}$ & $\mathbf{4}$ & $\mathbf{1}$ \\
\cline { 2 - 6 } & & & &
\end{tabular}

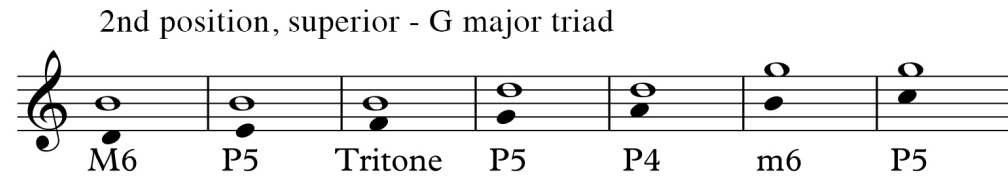

\begin{tabular}{l|l|l|l|l|l|l|} 
& & \\
interval class & 1 & 2 & 3 & 4 & 5 & 6 \\
\cline { 2 - 7 } occurrences & $\mathbf{0}$ & $\mathbf{0}$ & $\mathbf{1}$ & $\mathbf{1}$ & $\mathbf{4}$ & $\mathbf{1}$ \\
\cline { 2 - 6 } & & & & &
\end{tabular}

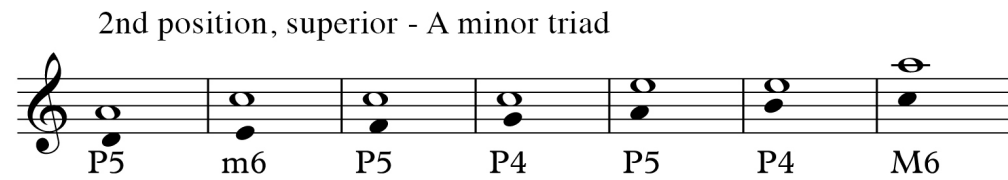

\begin{tabular}{l|l|l|l|l|l|l|}
\cline { 2 - 5 } interval class & 1 & 2 & 3 & 4 & 5 & 6 \\
\cline { 2 - 5 } occurrences & $\mathbf{0}$ & $\mathbf{0}$ & $\mathbf{1}$ & $\mathbf{1}$ & $\mathbf{5}$ & $\mathbf{0}$ \\
\cline { 2 - 5 }
\end{tabular}

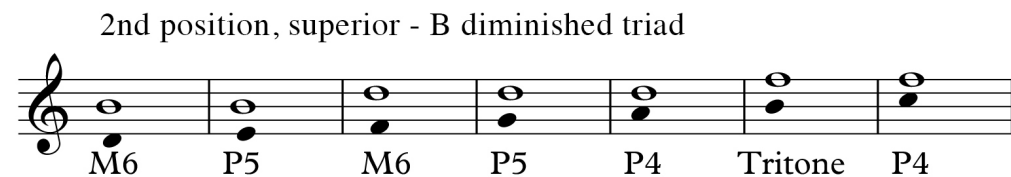

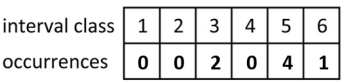

1st position, superior - C major triad

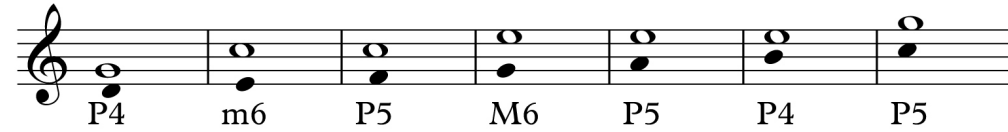

\begin{tabular}{l|l|l|l|l|l|l|}
\cline { 2 - 5 } interval class & 1 & 2 & 3 & 4 & 5 & 6 \\
\cline { 2 - 6 } occurrences & $\mathbf{0}$ & $\mathbf{0}$ & $\mathbf{1}$ & $\mathbf{1}$ & $\mathbf{5}$ & $\mathbf{0}$ \\
\cline { 2 - 5 } & &
\end{tabular} 
Figure A.8: Interval ordering and class content of a D Dorian scale paired with different triads in 2 nd position, inferior

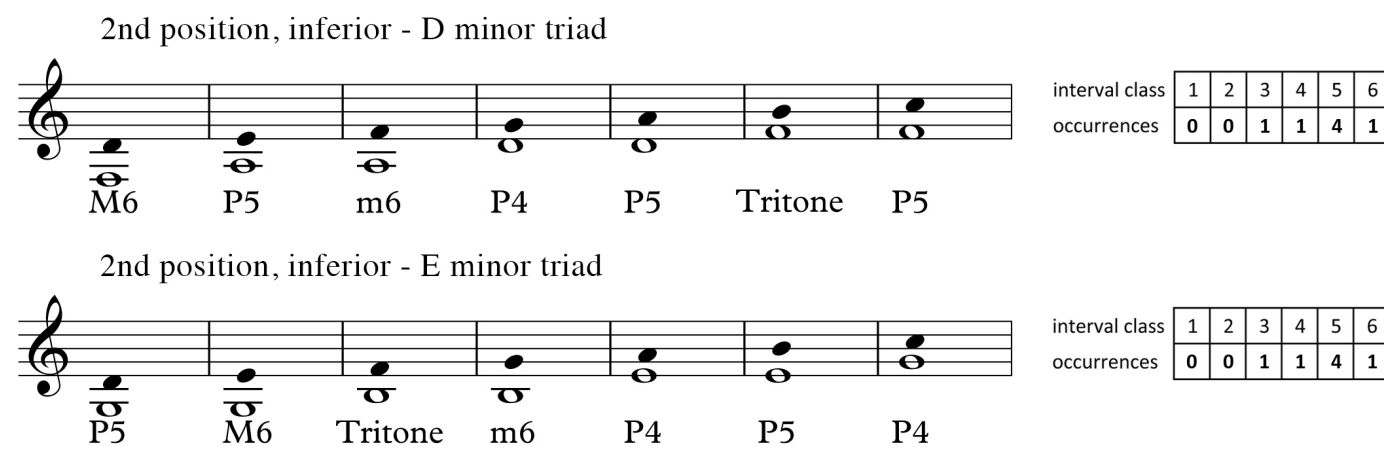

2nd position, inferior - F major triad

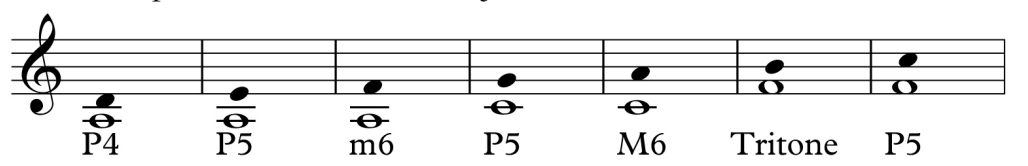

\begin{tabular}{l|l|l|l|l|l|l|}
\cline { 2 - 6 } interval class & 1 & 2 & 3 & 4 & 5 & 6 \\
\cline { 2 - 6 } occurrences & 0 & 0 & 1 & 1 & 4 & 1 \\
\hline
\end{tabular}

P5

2nd position, inferior - G major triad

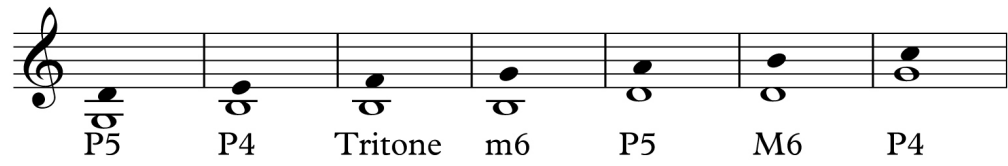

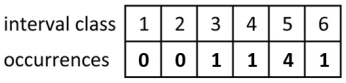

2nd position, inferior - A minor triad

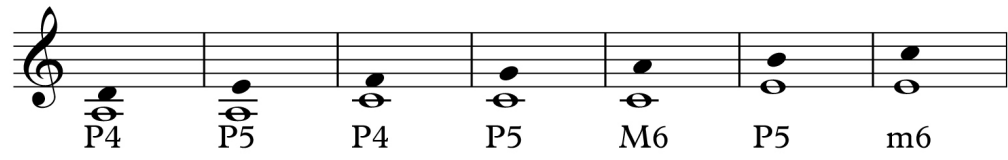

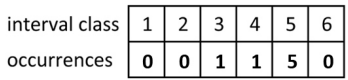

2nd position, inferior - B diminished triad

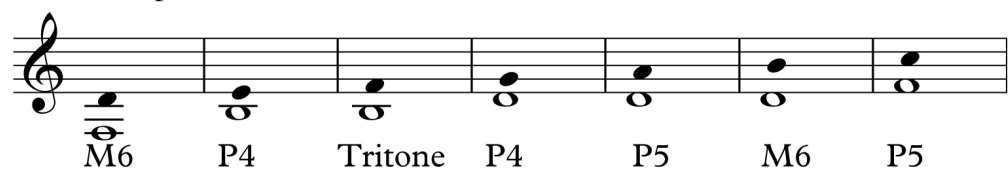

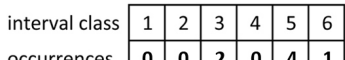

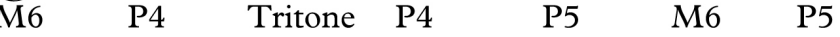

2nd position, inferior - $\mathrm{C}$ major triad

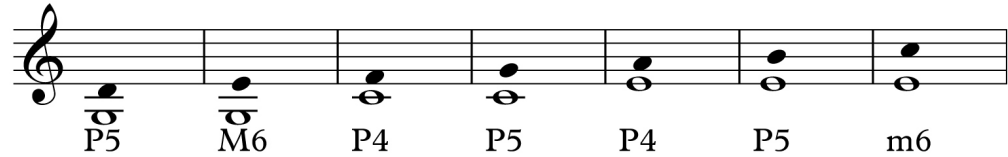

\begin{tabular}{l|l|l|l|l|l|l|} 
interval class & 1 & 2 & 3 & 4 & 5 & 6 \\
\cline { 2 - 7 } occurrences & $\mathbf{0}$ & $\mathbf{0}$ & $\mathbf{1}$ & $\mathbf{1}$ & $\mathbf{5}$ & $\mathbf{0}$ \\
\cline { 2 - 6 } & & & & &
\end{tabular} 
Table A.0.3: Interval class sets arising from an E Phrygian scale paired with different triads and Tvoice positions

\begin{tabular}{|l|l|l|l|l|}
\hline $\begin{array}{l}\text { Interval } \\
\text { class set }\end{array}$ & $\begin{array}{l}\mathbf{1}^{\text {st }} \text { position, } \\
\text { superior }\end{array}$ & $\mathbf{1}^{\text {st position, inferior }}$ & $\begin{array}{l}\mathbf{2}^{\text {nd }} \text { position, } \\
\text { superior }\end{array}$ & $\mathbf{2}^{\text {nd }}$ position, inferior \\
\hline 001141 & & & $\begin{array}{l}\text { D minor E minor, } \\
\text { F major, G major }\end{array}$ & $\begin{array}{l}\text { D minor E minor, } \\
\text { F major, G major }\end{array}$ \\
\hline 001150 & & & A minor, C major & A minor, C major \\
\hline 002041 & & B diminished & B diminished \\
\hline 031210 & E minor & F major & & \\
\hline 032110 & G major & D minor & & \\
\hline 121210 & A minor & C major & & \\
\hline 122101 & B diminished & B diminished & & \\
\hline 122110 & C major, D minor & G major, A minor & & \\
\hline 212110 & F major & E minor & & \\
\hline
\end{tabular}


Figure A.9: Interval ordering and class content of an E Phrygian paired scale paired with different triads in 1st position, superior

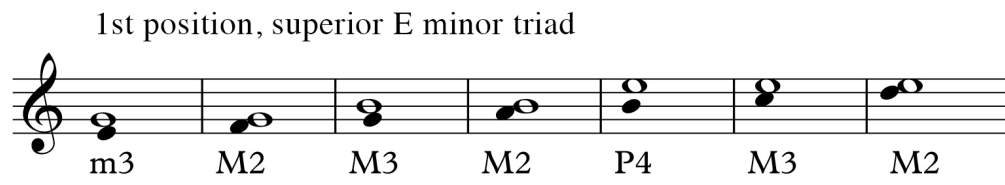

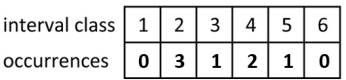

1st position, superior - F major triad

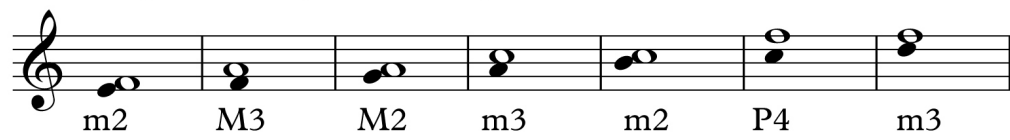

\begin{tabular}{l|l|l|l|l|l|l|}
\cline { 2 - 6 } interval class & 1 & 2 & 3 & 4 & 5 & 6 \\
\cline { 2 - 7 } occurrences & $\mathbf{2}$ & $\mathbf{1}$ & $\mathbf{2}$ & $\mathbf{1}$ & $\mathbf{1}$ & $\mathbf{0}$ \\
\cline { 2 - 6 } & & & &
\end{tabular}

st position, superior - G major triad

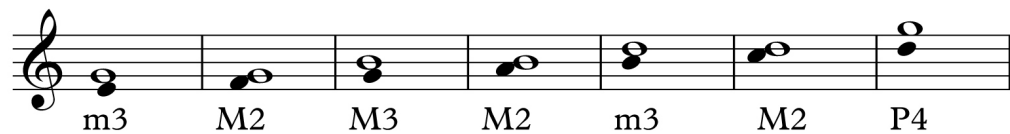

\begin{tabular}{l|l|l|l|l|l|l|} 
interval class & 1 & 2 & 3 & 4 & 5 & 6 \\
\cline { 2 - 7 } occurrences & $\mathbf{0}$ & $\mathbf{3}$ & $\mathbf{2}$ & $\mathbf{1}$ & $\mathbf{1}$ & $\mathbf{0}$ \\
\cline { 2 - 6 } & & & & &
\end{tabular}

$\begin{array}{llllll}\mathrm{m} 3 & \mathrm{M} 2 & \mathrm{M} 3 & \mathrm{M} 2 & \mathrm{~m} 3 & \mathrm{M} 2\end{array}$

1st position, superior - A minor triad

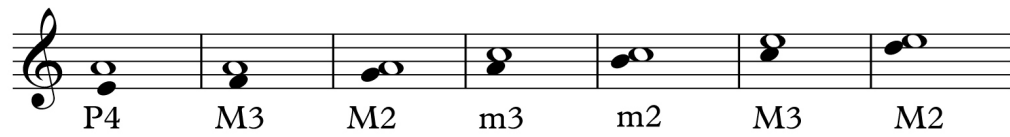

\begin{tabular}{l|l|l|l|l|l|l|}
\cline { 2 - 6 } interval class & 1 & 2 & 3 & 4 & 5 & 6 \\
\cline { 2 - 7 } occurrences & $\mathbf{1}$ & $\mathbf{2}$ & $\mathbf{1}$ & $\mathbf{2}$ & $\mathbf{1}$ & $\mathbf{0}$ \\
\cline { 2 - 7 } & & & &
\end{tabular}

1st position, superior B, diminished triad

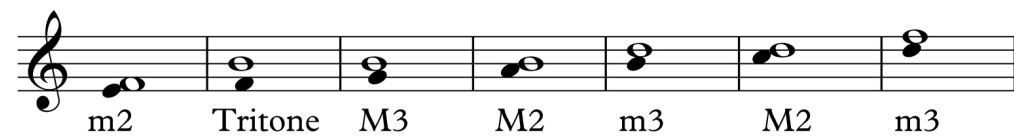

\begin{tabular}{l|l|l|l|l|l|l|}
\cline { 2 - 5 } interval class & 1 & 2 & 3 & 4 & 5 & 6 \\
\cline { 2 - 6 } occurrences & $\mathbf{1}$ & $\mathbf{2}$ & $\mathbf{2}$ & $\mathbf{1}$ & $\mathbf{0}$ & $\mathbf{1}$ \\
\cline { 2 - 6 } & & & &
\end{tabular}

1st position, superior - C major triad

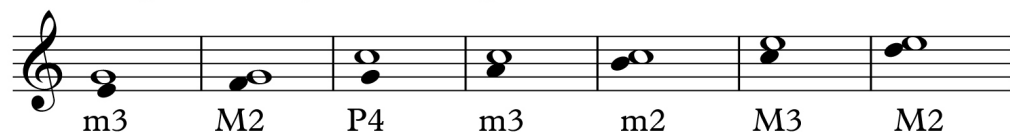

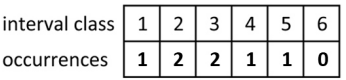

1st position, superior - D minor triad

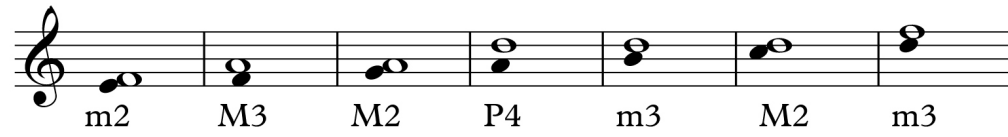

\begin{tabular}{l|l|l|l|l|l|l|}
\cline { 2 - 6 } interval class & 1 & 2 & 3 & 4 & 5 & 6 \\
\cline { 2 - 7 } occurrences & $\mathbf{1}$ & $\mathbf{2}$ & $\mathbf{2}$ & $\mathbf{1}$ & $\mathbf{1}$ & $\mathbf{0}$ \\
\cline { 2 - 6 } & & &
\end{tabular} 
Figure A.10: Interval ordering and class content of a E Phrygian scale paired with different triads in 1st position, inferior

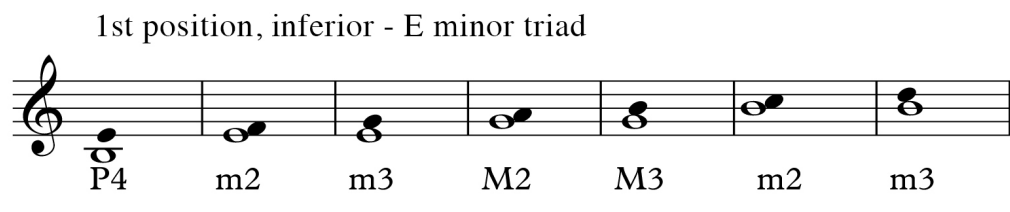

\begin{tabular}{l|l|l|l|l|l|l|}
\cline { 2 - 6 } interval class & 1 & 2 & 3 & 4 & 5 & 6 \\
\cline { 2 - 7 } occurrences & $\mathbf{2}$ & $\mathbf{1}$ & $\mathbf{2}$ & $\mathbf{1}$ & $\mathbf{1}$ & $\mathbf{0}$ \\
\cline { 2 - 7 } & & & &
\end{tabular}

1st position, inferior - $\mathrm{F}$ major triad

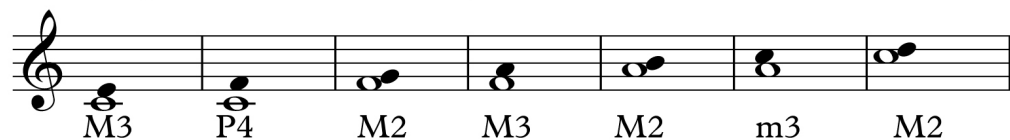

\begin{tabular}{l|l|l|l|l|l|l|}
\cline { 2 - 5 } interval class & 1 & 2 & 3 & 4 & 5 & 6 \\
\cline { 2 - 5 } occurrences & $\mathbf{0}$ & $\mathbf{3}$ & $\mathbf{1}$ & $\mathbf{2}$ & $\mathbf{1}$ & $\mathbf{0}$ \\
\cline { 2 - 5 }
\end{tabular}

1st position, inferior - $\mathrm{G}$ major triad

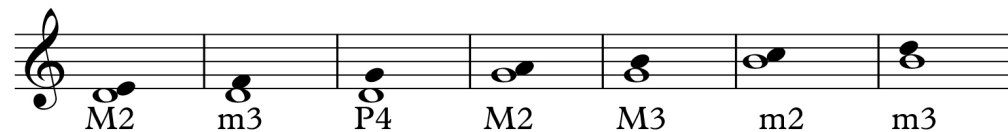

interval class \begin{tabular}{l|l|l|l|l|l|l|}
\cline { 2 - 5 } & 1 & 2 & 3 & 4 & 5 & 6 \\
\cline { 2 - 6 } & 1 & 2 & 2 & 1 & 1 & 0 \\
\hline
\end{tabular}

M2

M2

M3

$\mathrm{m} 2$

\begin{tabular}{ll|l|l|l|l|l|} 
occurrences & 1 & 2 & 2 & 1 & 1 & 0 \\
\cline { 2 - 7 } & & & &
\end{tabular}

1st position, inferior - A minor triad

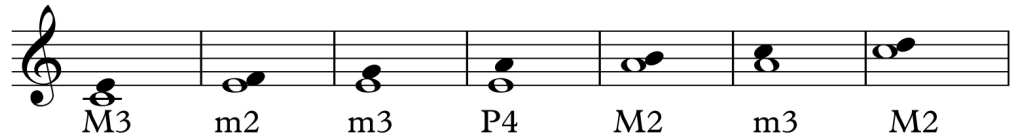

\begin{tabular}{l|l|l|l|l|l|l|}
\cline { 2 - 5 } interval class & 1 & 2 & 3 & 4 & 5 & 6 \\
\cline { 2 - 6 } occurrences & $\mathbf{1}$ & $\mathbf{2}$ & $\mathbf{2}$ & $\mathbf{1}$ & $\mathbf{1}$ & $\mathbf{0}$ \\
\cline { 2 - 5 } & & &
\end{tabular}

1st position, inferior - B diminished triad

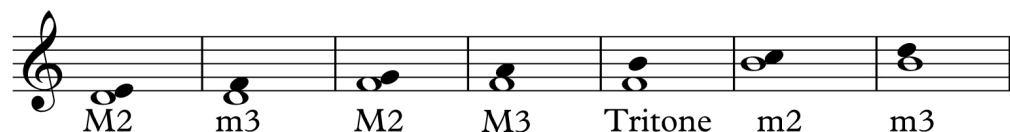

\begin{tabular}{l|l|l|l|l|l|l|} 
interval class & 1 & 2 & 3 & 4 & 5 & 6 \\
\cline { 2 - 6 } occurrences & $\mathbf{1}$ & $\mathbf{2}$ & $\mathbf{2}$ & $\mathbf{1}$ & $\mathbf{0}$ & $\mathbf{1}$ \\
\cline { 2 - 5 } & &
\end{tabular}

1st position, inferior - C major triad

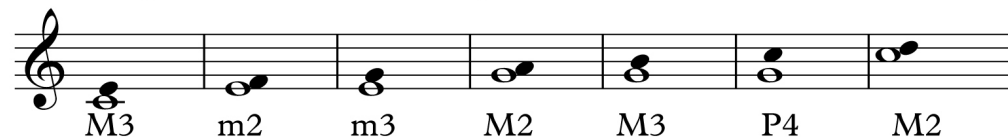

interval class \begin{tabular}{l|l|l|l|l|l|l|}
\cline { 2 - 6 } & 1 & 2 & 3 & 4 & 5 & 6 \\
\cline { 2 - 7 } & 1 & 2 & 1 & 2 & 1 & 0 \\
\hline
\end{tabular}

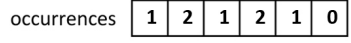

1st position, inferior - D minor triad

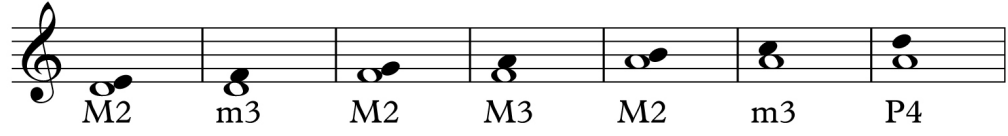

\begin{tabular}{l|l|l|l|l|l|l|}
\cline { 2 - 6 } interval class & 1 & 2 & 3 & 4 & 5 & 6 \\
\cline { 2 - 7 } occurrences & $\mathbf{0}$ & $\mathbf{3}$ & $\mathbf{2}$ & $\mathbf{1}$ & $\mathbf{1}$ & $\mathbf{0}$ \\
\hline
\end{tabular} 
Figure A.11: Interval ordering and class content of an E Phrygian scale paired with different triads in 2nd position, superior
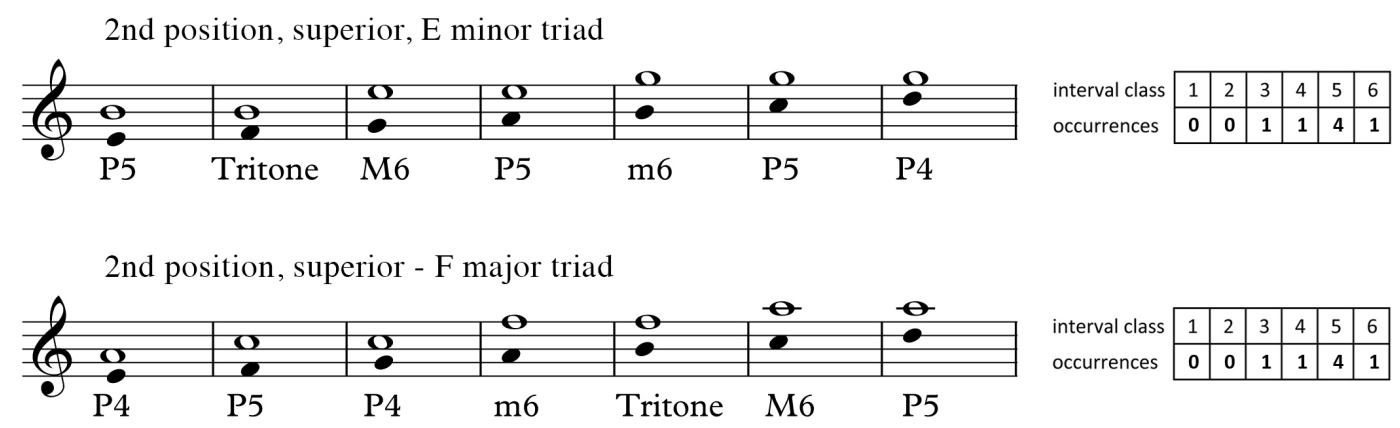

\begin{tabular}{l|l|l|l|l|l|l|} 
interval class & 1 & 2 & 3 & 4 & 5 & 6 \\
\cline { 2 - 7 } occurrences & $\mathbf{0}$ & $\mathbf{0}$ & $\mathbf{1}$ & $\mathbf{1}$ & $\mathbf{4}$ & $\mathbf{1}$ \\
\cline { 2 - 6 } & & & &
\end{tabular}

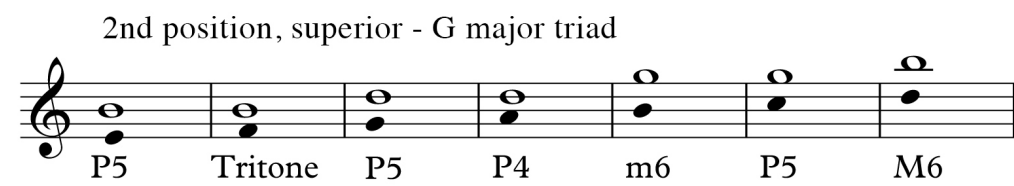

\begin{tabular}{l|l|l|l|l|l|l|} 
interval class & 1 & 2 & 3 & 4 & 5 & 6 \\
\cline { 2 - 7 } occurrences & $\mathbf{0}$ & $\mathbf{0}$ & $\mathbf{1}$ & $\mathbf{1}$ & $\mathbf{4}$ & $\mathbf{1}$ \\
\cline { 2 - 6 } & & & & &
\end{tabular}

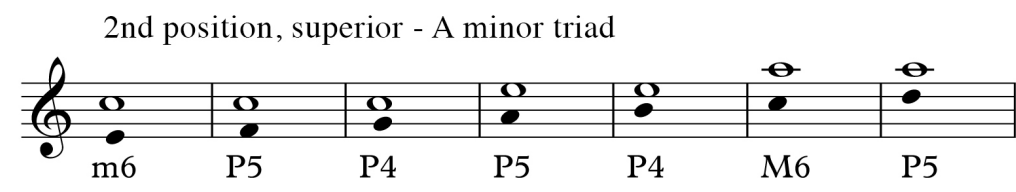

\begin{tabular}{l|l|l|l|l|l|l|} 
interval class & $\mathbf{1}$ & $\mathbf{2}$ & 3 & 4 & 5 & 6 \\
\cline { 2 - 7 } occurrences & $\mathbf{0}$ & $\mathbf{0}$ & $\mathbf{1}$ & $\mathbf{1}$ & $\mathbf{5}$ & $\mathbf{0}$ \\
\cline { 2 - 6 } & & & & &
\end{tabular}

2nd position, superior - B diminished triad

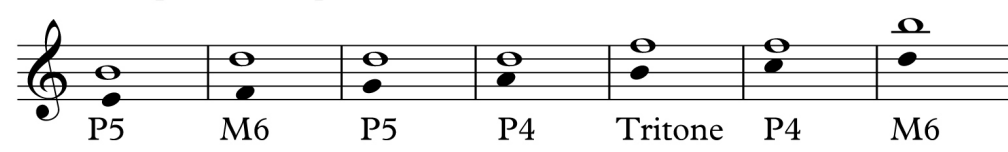

\begin{tabular}{l|l|l|l|l|l|l|}
\multirow{4}{*}{ interval class } & $\mathbf{1}$ & $\mathbf{2}$ & $\mathbf{3}$ & 4 & 5 & 6 \\
\cline { 2 - 7 } occurrences & $\mathbf{0}$ & $\mathbf{0}$ & $\mathbf{2}$ & $\mathbf{0}$ & $\mathbf{4}$ & $\mathbf{1}$ \\
\cline { 2 - 6 } & & & &
\end{tabular}

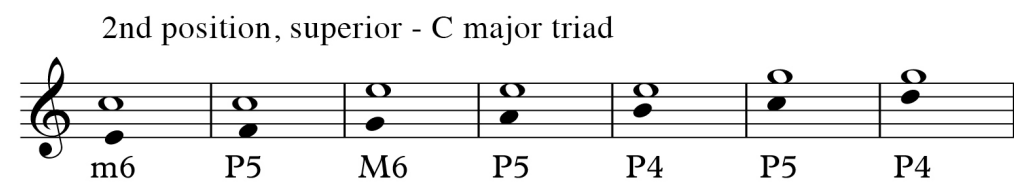

\begin{tabular}{l|l|l|l|l|l|l|} 
interval class & 1 & 2 & 3 & 4 & 5 & 6 \\
\cline { 2 - 7 } occurrences & $\mathbf{0}$ & $\mathbf{0}$ & $\mathbf{1}$ & $\mathbf{1}$ & $\mathbf{5}$ & $\mathbf{0}$ \\
\cline { 2 - 6 } & & & &
\end{tabular}

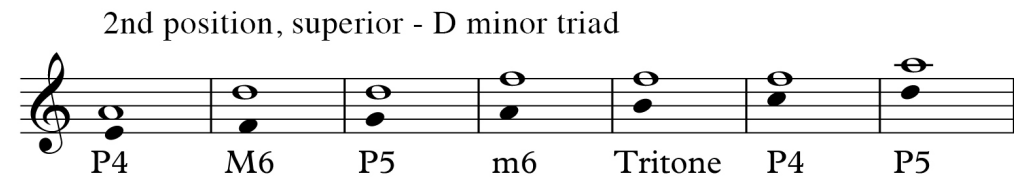

\begin{tabular}{l|l|l|l|l|l|l|}
\cline { 2 - 6 } interval class & 1 & 2 & 3 & 4 & 5 & 6 \\
\cline { 2 - 7 } occurrences & $\mathbf{0}$ & $\mathbf{0}$ & $\mathbf{1}$ & $\mathbf{1}$ & $\mathbf{4}$ & $\mathbf{1}$ \\
\hline
\end{tabular} 
Figure A.12: Interval ordering and class content of a E Phrygian scale paired with different triads in 2nd position, inferior

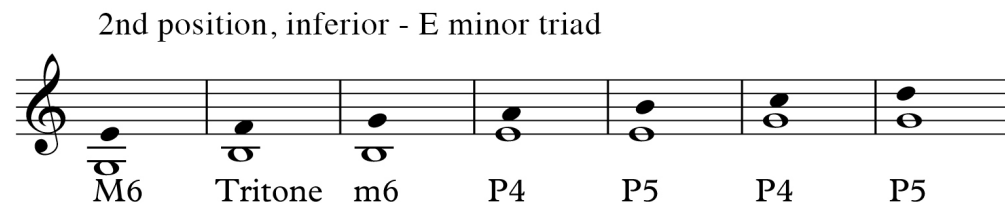

\begin{tabular}{l|l|l|l|l|l|l|} 
interval class & 1 & 2 & 3 & 4 & 5 & 6 \\
\cline { 2 - 7 } occurrences & $\mathbf{0}$ & $\mathbf{0}$ & $\mathbf{1}$ & $\mathbf{1}$ & $\mathbf{4}$ & $\mathbf{1}$ \\
\cline { 2 - 6 } & & & &
\end{tabular}

2nd position, inferior - F major triad

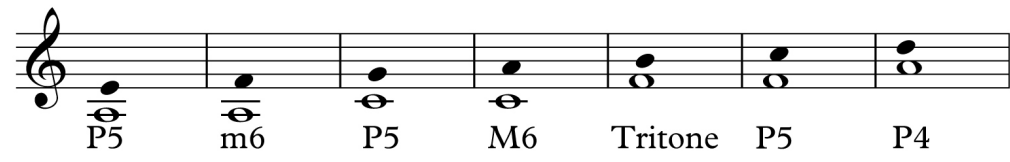

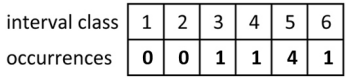

2nd position, inferior - G major triad

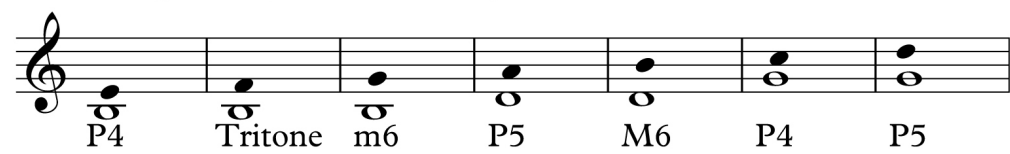

\begin{tabular}{l|l|l|l|l|l|l|} 
interval class & 1 & 2 & 3 & 4 & 5 & 6 \\
\cline { 2 - 7 } occurrences & $\mathbf{0}$ & $\mathbf{0}$ & $\mathbf{1}$ & $\mathbf{1}$ & $\mathbf{4}$ & $\mathbf{1}$ \\
\cline { 2 - 6 } & & & &
\end{tabular}

2nd position, inferior - A minor triad

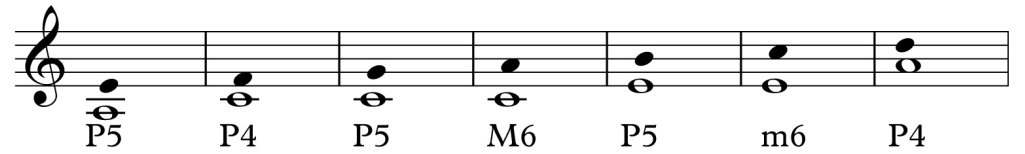

\begin{tabular}{l|l|l|l|l|l|l|}
\cline { 2 - 6 } interval class & 1 & 2 & 3 & 4 & 5 & 6 \\
\cline { 2 - 7 } occurrences & $\mathbf{0}$ & $\mathbf{0}$ & $\mathbf{1}$ & $\mathbf{1}$ & $\mathbf{5}$ & $\mathbf{0}$ \\
\cline { 2 - 6 } & & \multicolumn{3}{|c}{} & \multicolumn{3}{|c}{}
\end{tabular}

2nd position, inferior - B diminished triad

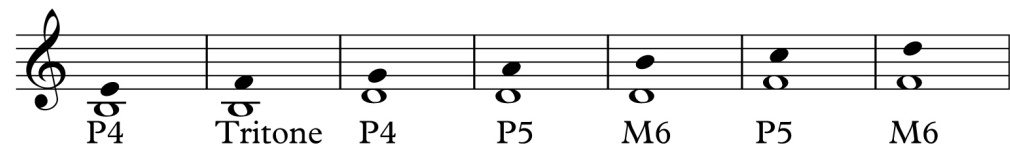

\begin{tabular}{l|l|l|l|l|l|l|}
\cline { 2 - 6 } interval class & 1 & 2 & 3 & 4 & 5 & 6 \\
\cline { 2 - 7 } occurrences & $\mathbf{0}$ & $\mathbf{0}$ & $\mathbf{2}$ & $\mathbf{0}$ & $\mathbf{4}$ & $\mathbf{1}$ \\
\cline { 2 - 6 } & & & &
\end{tabular}

2nd position, inferior - C major triad

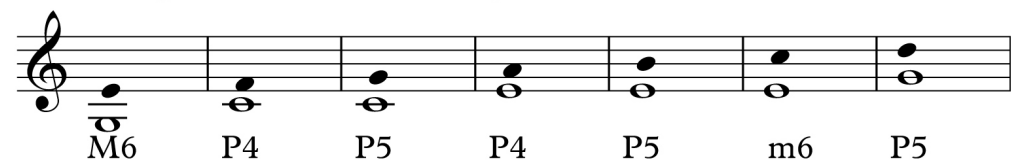

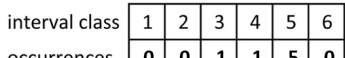

$\begin{array}{lllllll}\mathbf{M} 6 & \text { P4 } & \text { P5 } & \text { P4 } & \text { P5 } & \text { m6 } & \text { P5 }\end{array}$

2nd position, inferior - D minor triad

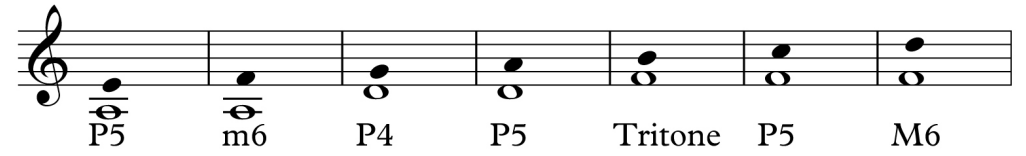

\begin{tabular}{l|l|l|l|l|l|l|} 
interval class & 1 & 2 & 3 & 4 & 5 & 6 \\
\cline { 2 - 7 } occurrences & $\mathbf{0}$ & $\mathbf{0}$ & $\mathbf{1}$ & $\mathbf{1}$ & $\mathbf{4}$ & $\mathbf{1}$ \\
\cline { 2 - 7 } & & & & &
\end{tabular} 
Table A.0.4: Interval class sets arising from an F Lydian scale paired with different triads and T-voice positions

\begin{tabular}{|l|l|l|l|l|}
\hline $\begin{array}{l}\text { Interval } \\
\text { class set }\end{array}$ & $\begin{array}{l}\mathbf{1}^{\text {st }} \text { position, } \\
\text { superior }\end{array}$ & $\mathbf{1}^{\text {st position, inferior }}$ & $\begin{array}{l}\mathbf{2}^{\text {nd }} \text { position, } \\
\text { superior }\end{array}$ & $\begin{array}{l}\text { 2 }^{\text {nd }} \text { position, } \\
\text { inferior }\end{array}$ \\
\hline 001141 & & & $\begin{array}{l}\text { D minor, E minor, } \\
\text { F major, G major }\end{array}$ & $\begin{array}{l}\text { D minor, E minor, } \\
\text { F major, G major }\end{array}$ \\
\hline 001150 & & & A minor, C major & A minor, C major \\
\hline 002041 & & & B diminished & B diminished \\
\hline 031210 & E minor & F major & & \\
\hline 032110 & G major & D minor & & \\
\hline 121210 & A minor & C major & & \\
\hline 122101 & B diminished & B diminished & & \\
\hline 122110 & C major, D minor & G major, A minor & & \\
\hline 212110 & F major & E minor & & \\
\hline
\end{tabular}


Figure A.13: Interval ordering and class content of a F Lydian scale paired with different triads in 1st position, superior

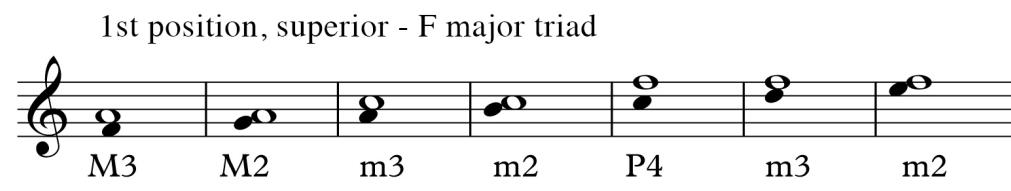

\begin{tabular}{l|l|l|l|l|l|l|} 
interval class & 1 & 2 & 3 & 4 & 5 & 6 \\
\cline { 2 - 7 } occurrences & $\mathbf{2}$ & $\mathbf{1}$ & $\mathbf{2}$ & $\mathbf{1}$ & $\mathbf{1}$ & $\mathbf{0}$ \\
\cline { 2 - 6 } & & & & &
\end{tabular}

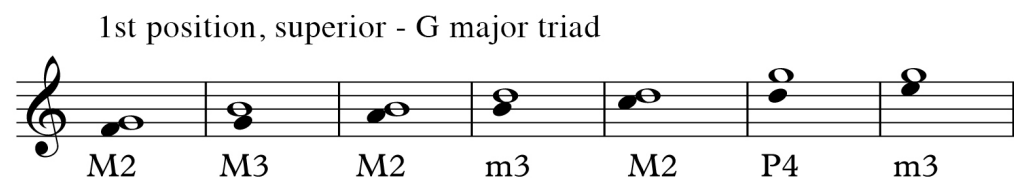

\begin{tabular}{l|l|l|l|l|l|l|} 
interval class & $\mathbf{1}$ & 2 & 3 & 4 & 5 & 6 \\
\cline { 2 - 7 } occurrences & $\mathbf{0}$ & $\mathbf{3}$ & $\mathbf{2}$ & $\mathbf{1}$ & $\mathbf{1}$ & $\mathbf{0}$ \\
\cline { 2 - 6 } & & &
\end{tabular}

1st position, superior - A minor triad

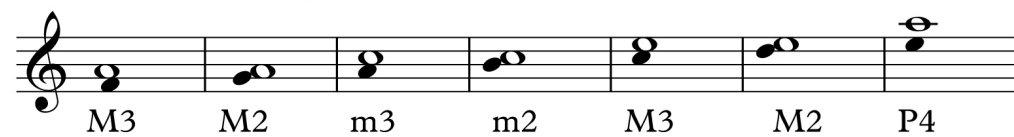

\begin{tabular}{l|l|l|l|l|l|l|} 
interval class & 1 & 2 & 3 & 4 & 5 & 6 \\
\cline { 2 - 7 } occurrences & $\mathbf{1}$ & $\mathbf{2}$ & $\mathbf{1}$ & $\mathbf{2}$ & $\mathbf{1}$ & $\mathbf{0}$ \\
\cline { 2 - 6 } & & & &
\end{tabular}

M3

$\mathrm{m} 3$

$\mathrm{m} 2$

M3 M2

P4

1st position, superior - B diminished triad

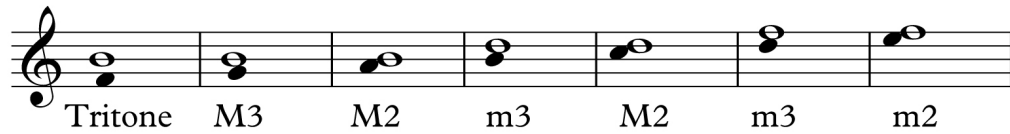

\begin{tabular}{l|l|l|l|l|l|l|}
\cline { 2 - 6 } interval class & 1 & 2 & 3 & 4 & 5 & 6 \\
\cline { 2 - 7 } occurrences & $\mathbf{1}$ & $\mathbf{2}$ & $\mathbf{2}$ & $\mathbf{1}$ & $\mathbf{0}$ & $\mathbf{1}$ \\
\cline { 2 - 6 } & & & &
\end{tabular}

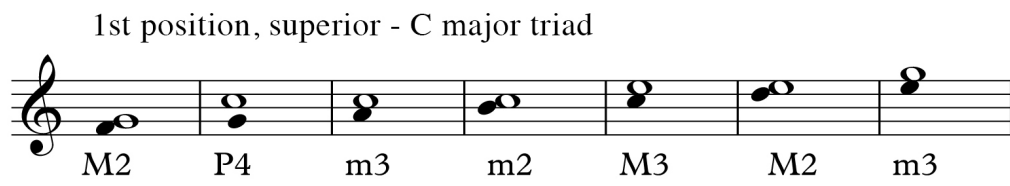

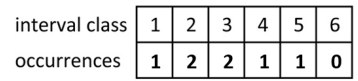

1st position, superior, D minor triad

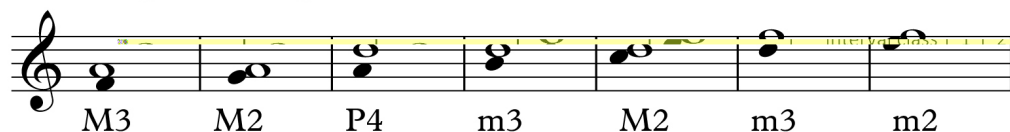

\begin{tabular}{l|l|l|l|l|l|l|}
\cline { 2 - 5 } & 1 & 2 & 2 & 1 & 5 & 6 \\
\cline { 2 - 6 } & $\mathbf{1}$ & $\mathbf{2}$ & $\mathbf{2}$ & $\mathbf{1}$ & $\mathbf{1}$ & $\mathbf{0}$ \\
\hline
\end{tabular}

M3

M2

P4 m3

M2

$\mathrm{m} 3$

$\mathrm{m} 2$

1st position, superior - E minor triad

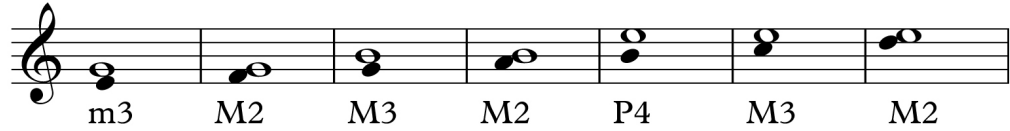

\begin{tabular}{l|l|l|l|l|l|l|} 
interval class & 1 & 2 & 3 & 4 & 5 & 6 \\
\cline { 2 - 7 } occurrences & $\mathbf{0}$ & $\mathbf{3}$ & $\mathbf{1}$ & $\mathbf{2}$ & $\mathbf{1}$ & $\mathbf{0}$ \\
\cline { 2 - 7 } & & & &
\end{tabular} 
Figure A.14: Interval ordering and class content of a F Lydian scale paired with different triads in 1st position, inferior

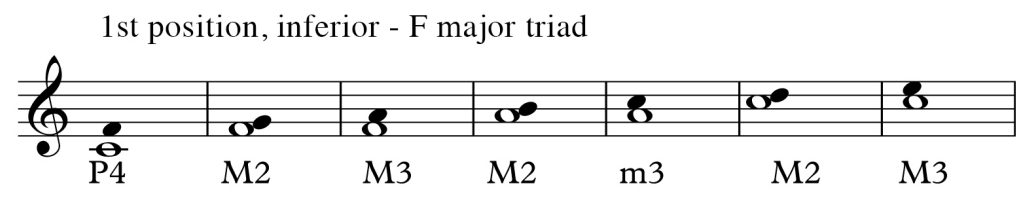

\begin{tabular}{l|l|l|l|l|l|l|} 
interval class & 1 & 2 & 3 & 4 & 5 & 6 \\
\cline { 2 - 7 } occurrences & $\mathbf{0}$ & $\mathbf{3}$ & $\mathbf{1}$ & $\mathbf{2}$ & $\mathbf{1}$ & $\mathbf{0}$ \\
\cline { 2 - 6 } & & & & &
\end{tabular}

1st position, inferior - G major triad

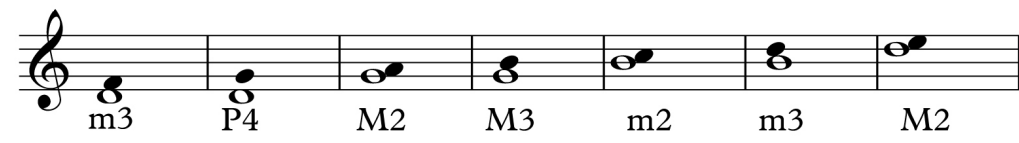

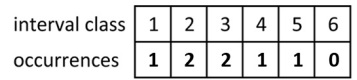

1st position, inferior - A minor triad

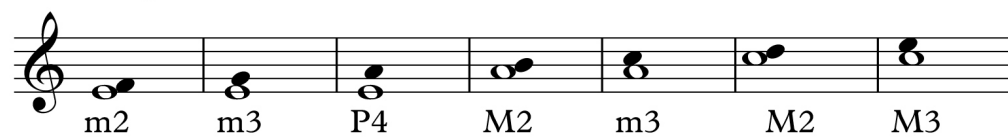

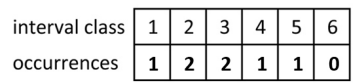

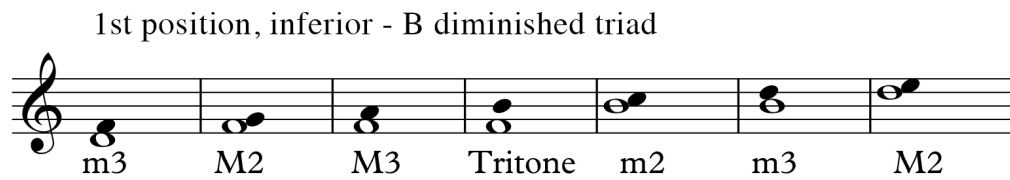

\begin{tabular}{l|l|l|l|l|l|l|} 
interval class & 1 & 2 & 3 & 4 & 5 & 6 \\
\cline { 2 - 7 } occurrences & $\mathbf{1}$ & $\mathbf{2}$ & $\mathbf{2}$ & $\mathbf{1}$ & $\mathbf{0}$ & $\mathbf{1}$ \\
\cline { 2 - 6 } & & & & &
\end{tabular}

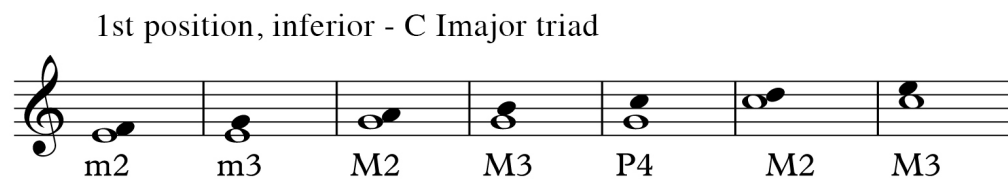

\begin{tabular}{l|l|l|l|l|l|l|}
\cline { 2 - 6 } interval class & 1 & 2 & 3 & 4 & 5 & 6 \\
\cline { 2 - 7 } occurrences & $\mathbf{1}$ & $\mathbf{2}$ & $\mathbf{1}$ & $\mathbf{2}$ & $\mathbf{1}$ & $\mathbf{0}$ \\
\cline { 2 - 6 } & \multicolumn{3}{|c}{} & \multicolumn{3}{|c}{}
\end{tabular}

1st position, inferior - D minor triad

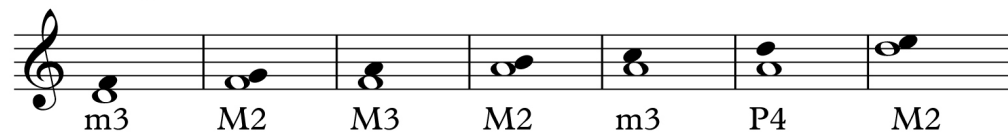

\begin{tabular}{l|l|l|l|l|l|l|} 
interval class & 1 & 2 & 3 & 4 & 5 & 6 \\
\cline { 2 - 7 } occurrences & $\mathbf{0}$ & $\mathbf{3}$ & $\mathbf{2}$ & $\mathbf{1}$ & $\mathbf{1}$ & $\mathbf{0}$ \\
\cline { 2 - 6 } & & & & &
\end{tabular}

1st position, inferior - E minor triad

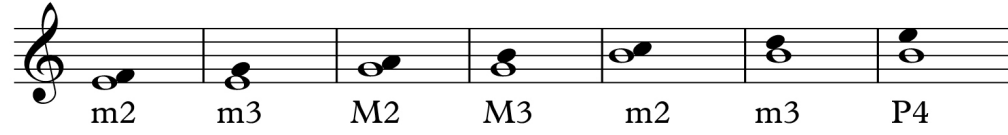

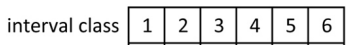

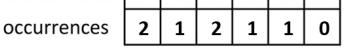


Figure A.15: Interval ordering and class content of a F Lydian scale paired with different triads in 2nd position, superior

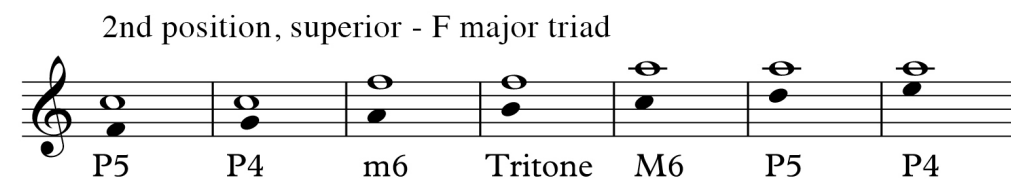

\begin{tabular}{l|l|l|l|l|l|l|} 
interval class & 1 & 2 & 3 & 4 & 5 & 6 \\
\cline { 2 - 7 } occurrences & $\mathbf{0}$ & $\mathbf{0}$ & $\mathbf{1}$ & $\mathbf{1}$ & $\mathbf{4}$ & $\mathbf{1}$ \\
\cline { 2 - 6 } & & & & &
\end{tabular}

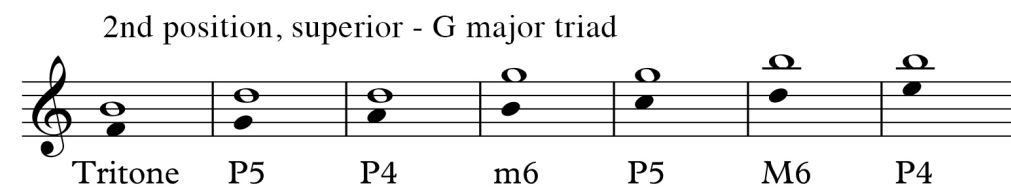

\begin{tabular}{l|l|l|l|l|l|l|} 
interval class & 1 & 2 & 3 & 4 & 5 & 6 \\
\cline { 2 - 7 } occurrences & $\mathbf{0}$ & $\mathbf{0}$ & $\mathbf{1}$ & $\mathbf{1}$ & $\mathbf{4}$ & $\mathbf{1}$ \\
\cline { 2 - 6 } & & & &
\end{tabular}

Tritone

P4 m6

P5 M6

$\mathrm{P} 4$

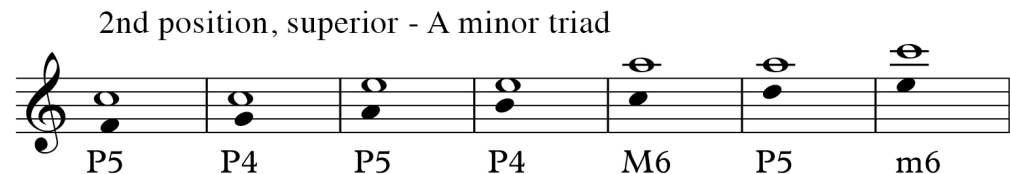

\begin{tabular}{l|l|l|l|l|l|l|} 
interval class & 1 & 2 & 3 & 4 & 5 & 6 \\
\cline { 2 - 6 } occurrences & $\mathbf{0}$ & $\mathbf{0}$ & $\mathbf{1}$ & $\mathbf{1}$ & $\mathbf{5}$ & $\mathbf{0}$ \\
\cline { 2 - 5 } \\
\cline { 2 - 4 }
\end{tabular}

P5

P4

P5

P4

M6

P5 m6

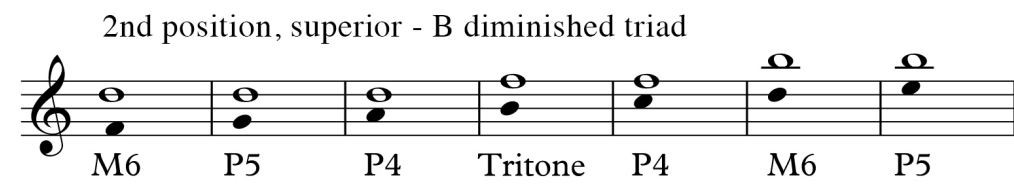

\begin{tabular}{l|l|l|l|l|l|l|}
$\begin{array}{l}\text { interval class } \\
\text { occurrences }\end{array}$ & 1 & 2 & 3 & 4 & 5 & 6 \\
\cline { 2 - 6 } & $\mathbf{0}$ & $\mathbf{0}$ & $\mathbf{2}$ & $\mathbf{0}$ & $\mathbf{4}$ & $\mathbf{1}$ \\
\cline { 2 - 5 } & & &
\end{tabular}

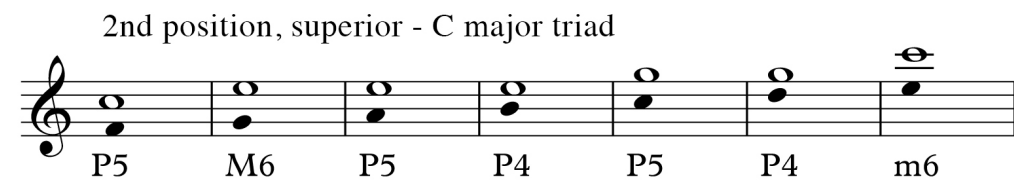

\begin{tabular}{l|l|l|l|l|l|l|}
\cline { 2 - 5 } interval class & 1 & 2 & 3 & 4 & 5 & 6 \\
\cline { 2 - 6 } occurrences & 0 & $\mathbf{0}$ & $\mathbf{1}$ & $\mathbf{1}$ & $\mathbf{5}$ & $\mathbf{0}$ \\
\cline { 2 - 5 } & & \multicolumn{3}{|c|}{} & &
\end{tabular}

2nd position, superior - D minor triad

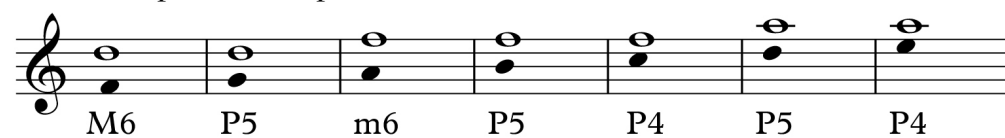

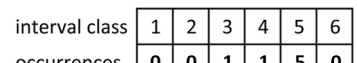

M6

P5

m6

P5

P4

P5

P4

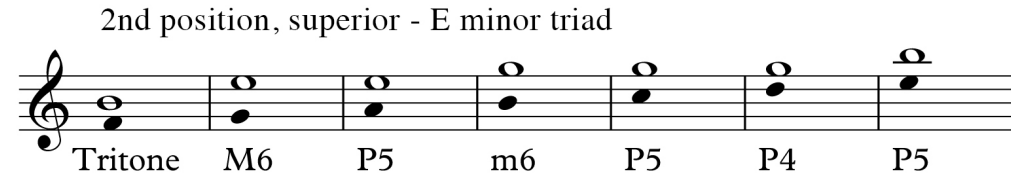

\begin{tabular}{l|l|l|l|l|l|l|}
\cline { 2 - 6 } interval class & $\mathbf{1}$ & $\mathbf{2}$ & $\mathbf{3}$ & $\mathbf{4}$ & $\mathbf{5}$ & $\mathbf{6}$ \\
\cline { 2 - 6 } occurrences & $\mathbf{0}$ & $\mathbf{0}$ & $\mathbf{1}$ & $\mathbf{1}$ & $\mathbf{4}$ & $\mathbf{1}$ \\
\cline { 2 - 6 } & \multicolumn{3}{|c|}{} & \multicolumn{1}{|c|}{}
\end{tabular} 
Figure A.16: Interval ordering and class content of a F Lydian scale paired with different triads in 2nd position, inferior

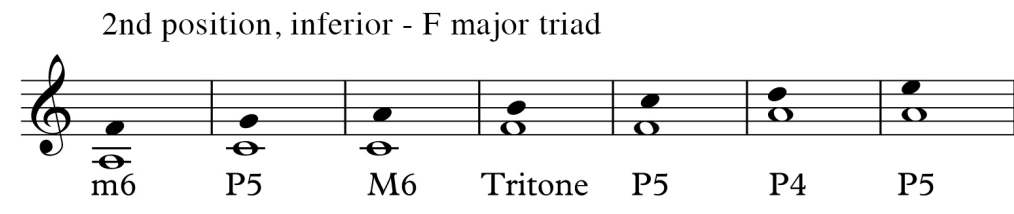

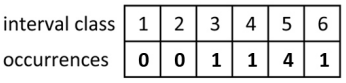

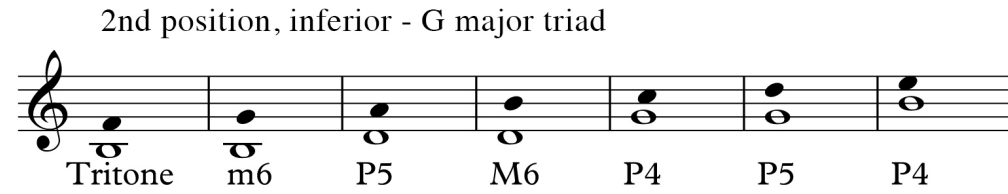

\begin{tabular}{l|l|l|l|l|l|l|} 
interval class & 1 & 2 & 3 & 4 & 5 & 6 \\
\cline { 2 - 7 } occurrences & $\mathbf{0}$ & $\mathbf{0}$ & $\mathbf{1}$ & $\mathbf{1}$ & $\mathbf{4}$ & $\mathbf{1}$ \\
\cline { 2 - 6 } & \multicolumn{3}{|c|}{} & \multicolumn{3}{|c}{}
\end{tabular}

2nd position, inferior - A minor triad

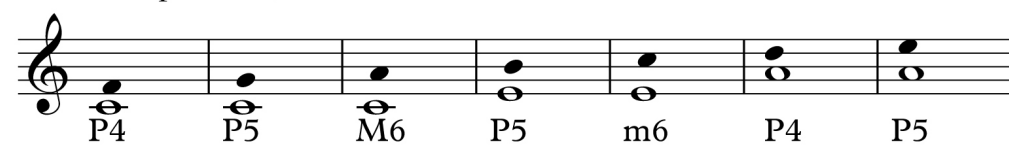

interval class \begin{tabular}{l|l|l|l|l|l|l|}
\cline { 2 - 6 } & 1 & 2 & 3 & 4 & 5 & 6 \\
\cline { 2 - 6 } & 0 & 0 & 1 & 1 & 5 & 0 \\
\hline
\end{tabular} \begin{tabular}{l|l|l|l|l|l|l|}
\multirow{2}{*}{ occurrences } & 0 & 0 & 1 & 1 & 5 & 0 \\
\cline { 2 - 6 }
\end{tabular}

2nd position, inferior - B diminished triad

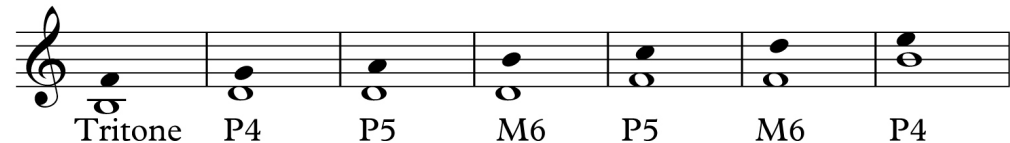

\begin{tabular}{l|l|l|l|l|l|l|} 
& & \\
interval class & 1 & 2 & 3 & 4 & 5 & 6 \\
\cline { 2 - 7 } occurrences & $\mathbf{0}$ & $\mathbf{0}$ & $\mathbf{2}$ & $\mathbf{0}$ & $\mathbf{4}$ & $\mathbf{1}$ \\
\cline { 2 - 6 } & & & & &
\end{tabular}

Tritone

P5

M6

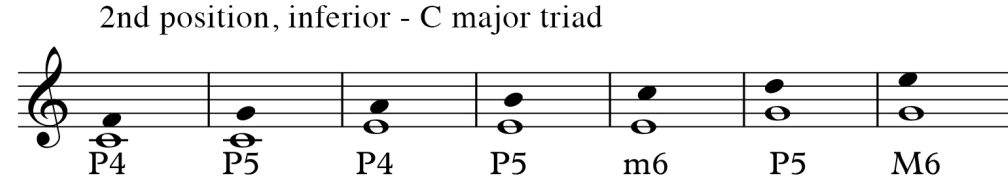

\begin{tabular}{l|l|l|l|l|l|l|}
\cline { 2 - 6 } interval class & 1 & 2 & 3 & 4 & 5 & 6 \\
\cline { 2 - 7 } occurrences & $\mathbf{0}$ & $\mathbf{0}$ & $\mathbf{1}$ & $\mathbf{1}$ & $\mathbf{5}$ & $\mathbf{0}$ \\
\cline { 2 - 6 } & & & &
\end{tabular}

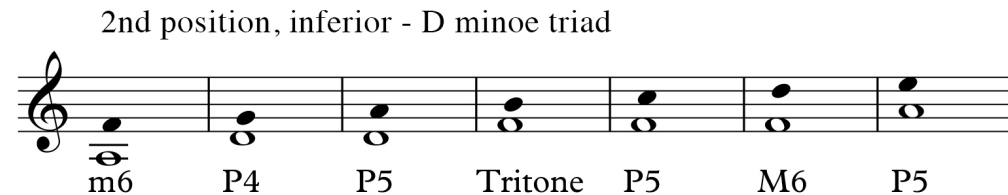

\begin{tabular}{l|l|l|l|l|l|l|}
\cline { 2 - 5 } interval class & 1 & 2 & 3 & 4 & 5 & 6 \\
\cline { 2 - 6 } occurrences & $\mathbf{0}$ & $\mathbf{0}$ & $\mathbf{1}$ & $\mathbf{1}$ & $\mathbf{5}$ & $\mathbf{0}$ \\
\cline { 2 - 5 } & & &
\end{tabular}

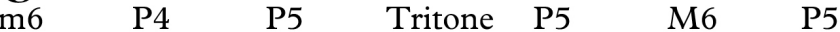

2nd position, inferior - E minor triad

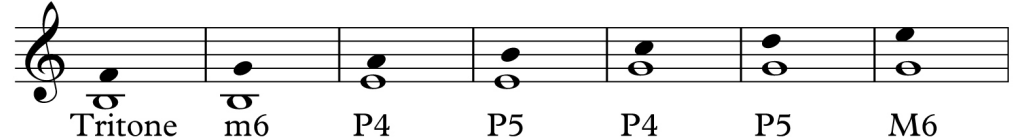

\begin{tabular}{l|l|l|l|l|l|l|}
\cline { 2 - 6 } interval class & 1 & 2 & 3 & 4 & 5 & 6 \\
\cline { 2 - 7 } occurrences & $\mathbf{0}$ & $\mathbf{0}$ & $\mathbf{1}$ & $\mathbf{1}$ & $\mathbf{4}$ & $\mathbf{1}$ \\
\cline { 2 - 6 } & & & \multicolumn{3}{|c}{}
\end{tabular} 
Table A.0.5: Interval class sets arising from a G Mixolydian scale paired with different triads and Tvoice positions

\begin{tabular}{|c|c|c|c|c|}
\hline $\begin{array}{l}\text { Interval } \\
\text { class set }\end{array}$ & $\begin{array}{l}1^{\text {st }} \text { position, } \\
\text { superior }\end{array}$ & $\begin{array}{l}\text { 1st position, } \\
\text { inferior }\end{array}$ & $\begin{array}{l}2^{\text {nd }} \text { position, } \\
\text { superior }\end{array}$ & $\begin{array}{l}2^{\text {nd }} \text { position, } \\
\text { inferior }\end{array}$ \\
\hline 001141 & & & $\begin{array}{l}\text { D minor, E minor, } \\
\text { F major, G major }\end{array}$ & $\begin{array}{l}\text { D minor, E minor, } \\
\text { F major, G major }\end{array}$ \\
\hline 001150 & & & A minor, $\mathrm{C}$ major & A minor, $\mathrm{C}$ major \\
\hline 002041 & & & B diminished & B diminished \\
\hline 031210 & E minor & F major & & \\
\hline 032110 & G major & D minor & & \\
\hline 121210 & A minor & C major & & \\
\hline 122101 & B diminished & B diminished & & \\
\hline 122110 & $\mathrm{C}$ major, $\mathrm{D}$ minor & G major, A minor & & \\
\hline 212110 & F major & E minor & & \\
\hline
\end{tabular}


Figure A.17: Interval ordering and class content of a G Mixolydian scale paired with different triads in 1st position, superior

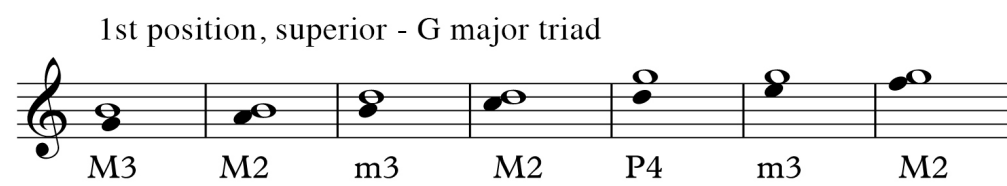

\begin{tabular}{l|l|l|l|l|l|l|} 
interval class & $\mathbf{1}$ & $\mathbf{2}$ & 3 & 4 & 5 & 6 \\
\cline { 2 - 7 } occurrences & $\mathbf{0}$ & $\mathbf{3}$ & $\mathbf{2}$ & $\mathbf{1}$ & $\mathbf{1}$ & $\mathbf{0}$ \\
\cline { 2 - 6 } & & & & &
\end{tabular}

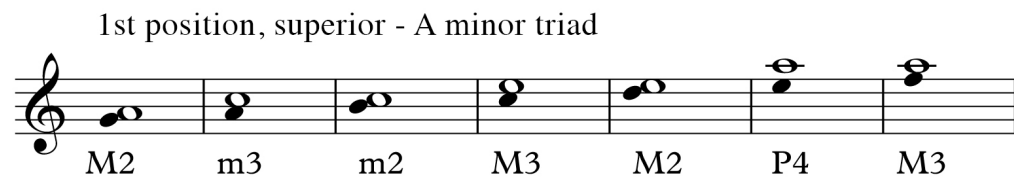

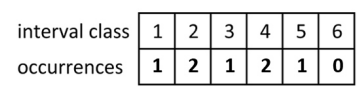

st position, superior - B diminished triad

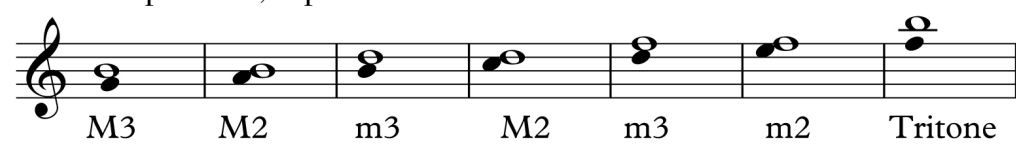

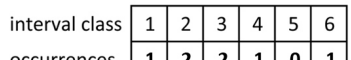

\begin{tabular}{lllllll|}
\multirow{2}{*}{ occurrences } & 1 & 2 & 2 & 1 & 0 & 1 \\
\cline { 2 - 6 } \\
\cline { 2 - 5 } & & &
\end{tabular}

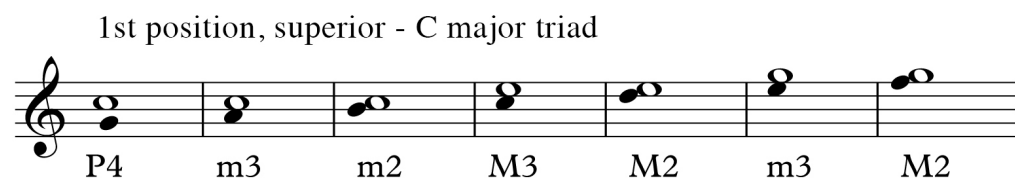

\begin{tabular}{l|l|l|l|l|l|l|} 
interval class & $\mathbf{1}$ & 2 & 3 & 4 & 5 & 6 \\
\cline { 2 - 7 } occurrences & $\mathbf{1}$ & $\mathbf{2}$ & $\mathbf{2}$ & $\mathbf{1}$ & $\mathbf{1}$ & $\mathbf{0}$ \\
\cline { 2 - 6 } & & & & &
\end{tabular}

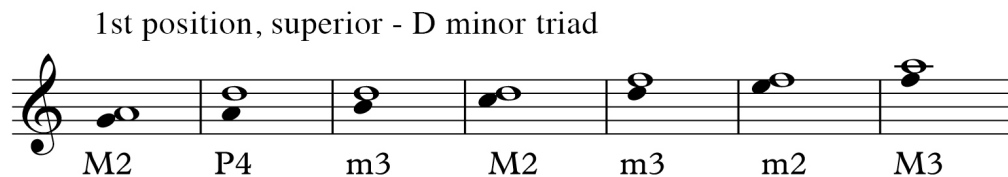

\begin{tabular}{l|l|l|l|l|l|l|} 
interval class & 1 & 2 & 3 & 4 & 5 & 6 \\
\cline { 2 - 7 } occurrences & $\mathbf{1}$ & $\mathbf{2}$ & $\mathbf{2}$ & $\mathbf{1}$ & $\mathbf{1}$ & $\mathbf{0}$ \\
\cline { 2 - 6 } & & & & &
\end{tabular}

1st position, superior - E minor triad

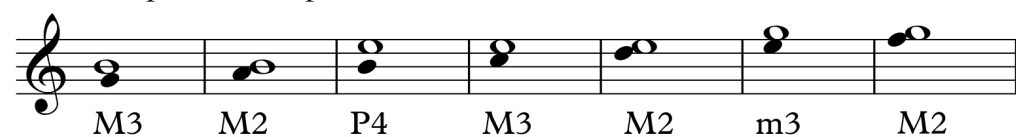

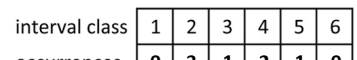

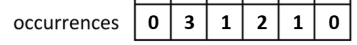

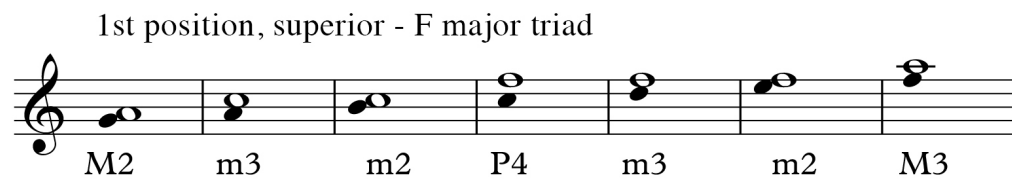

\begin{tabular}{l|l|l|l|l|l|l|}
\cline { 2 - 7 } interval class & 1 & 2 & 3 & 4 & 5 & 6 \\
\cline { 2 - 7 } & 2 & 1 & 2 & 1 & 1 & 0 \\
\hline
\end{tabular}

\begin{tabular}{ll|l|l|l|l|l|}
\multirow{3}{*}{ occurrences } & 2 & 1 & 2 & 1 & 1 & 0 \\
\cline { 2 - 7 } \\
\cline { 2 - 6 } & & &
\end{tabular} 
Figure A.18: Interval ordering and class content of a G Mixolydian scale paired with different triads in 1st position, inferior

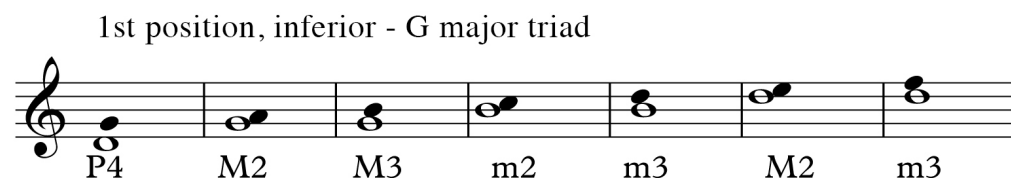

\begin{tabular}{l|l|l|l|l|l|l|}
\cline { 2 - 6 } interval class & 1 & 2 & 3 & 4 & 5 & 6 \\
\cline { 2 - 7 } occurrences & $\mathbf{1}$ & $\mathbf{2}$ & $\mathbf{2}$ & $\mathbf{1}$ & $\mathbf{1}$ & $\mathbf{0}$ \\
\cline { 2 - 7 } & & & &
\end{tabular}

1st position, inferior - A minor triad

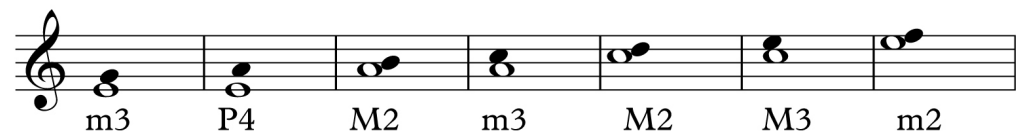

\begin{tabular}{l|l|l|l|l|l|l|}
\cline { 2 - 6 } interval class & 1 & 2 & 3 & 4 & 5 & 6 \\
\cline { 2 - 7 } occurrences & $\mathbf{1}$ & $\mathbf{2}$ & $\mathbf{2}$ & $\mathbf{1}$ & $\mathbf{1}$ & $\mathbf{0}$ \\
\cline { 2 - 6 } & \multicolumn{3}{|c|}{} & \multicolumn{3}{|c}{}
\end{tabular}

1 st position, inferior - B diminished triad

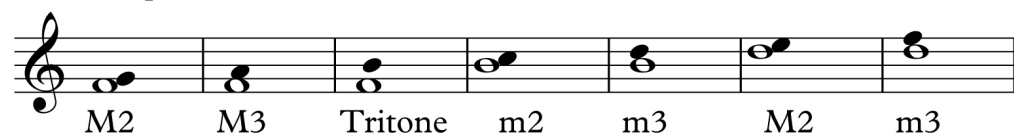

\begin{tabular}{l|l|l|l|l|l|l|} 
interval class & 1 & 2 & 3 & 4 & 5 & 6 \\
\cline { 2 - 7 } occurrences & $\mathbf{1}$ & $\mathbf{2}$ & $\mathbf{2}$ & $\mathbf{1}$ & $\mathbf{0}$ & $\mathbf{1}$ \\
\cline { 2 - 6 } & & & & &
\end{tabular}

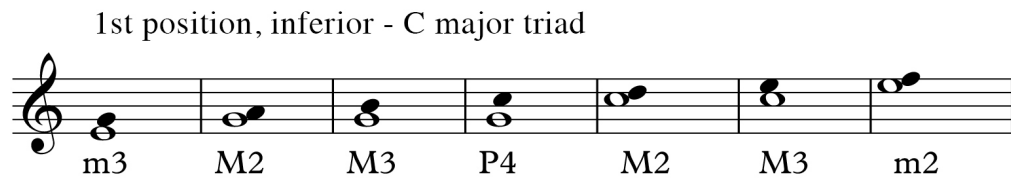

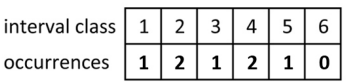

1st position, inferior D minor triad

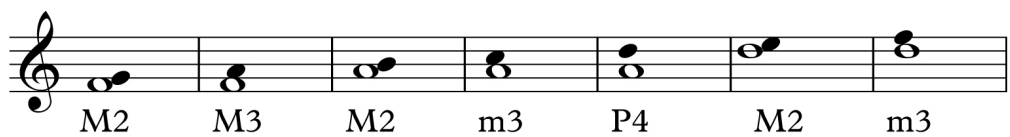

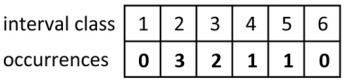

1st position, inferior - E minor triad

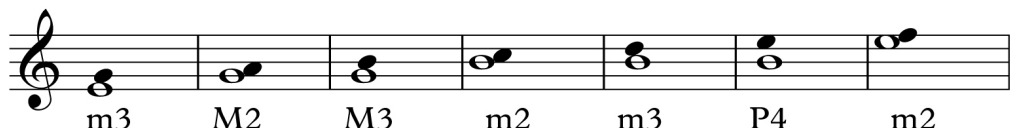

\begin{tabular}{l|l|l|l|l|l|l|} 
interval class & 1 & 2 & 3 & 4 & 5 & 6 \\
\cline { 2 - 7 } occurrences & $\mathbf{2}$ & $\mathbf{1}$ & $\mathbf{2}$ & $\mathbf{1}$ & $\mathbf{1}$ & $\mathbf{0}$ \\
\cline { 2 - 6 } & & & &
\end{tabular}

1st position, inferior - F major triad

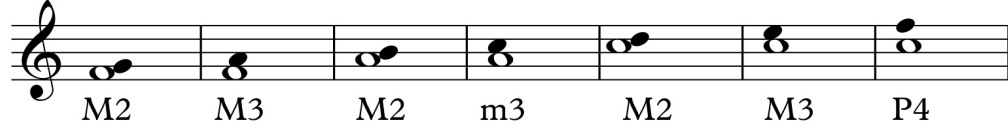

\begin{tabular}{l|l|l|l|l|l|l|}
\cline { 2 - 5 } interval class & 1 & 2 & 3 & 4 & 5 & 6 \\
\cline { 2 - 6 } occurrences & $\mathbf{0}$ & $\mathbf{3}$ & $\mathbf{1}$ & $\mathbf{2}$ & $\mathbf{1}$ & $\mathbf{0}$ \\
\cline { 2 - 5 }
\end{tabular} 
Figure A.19: Interval ordering and class content of a G Mixolydian scale paired with different triads in 2 nd position, superior

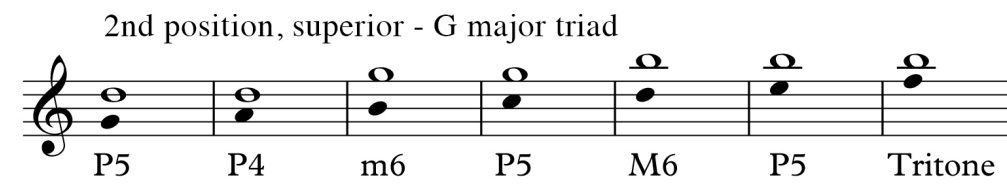

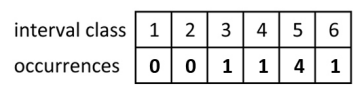

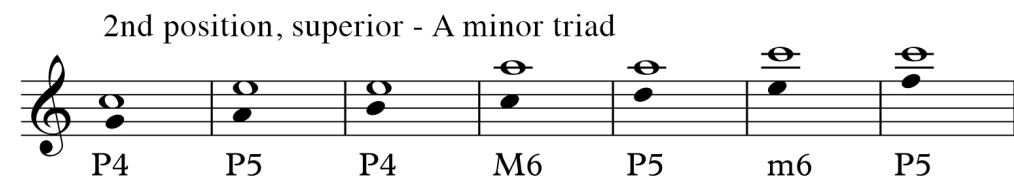

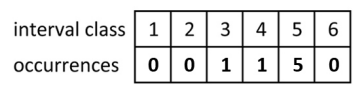

2nd position, superior - B diminished triad

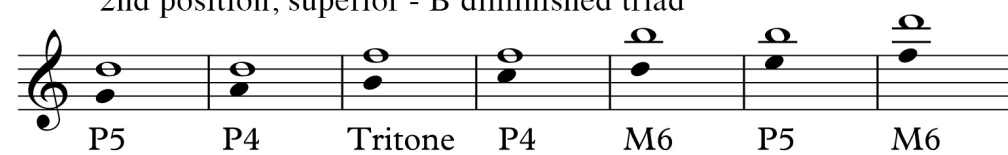

\begin{tabular}{l|l|l|l|l|l|l|} 
interval class & $\mathbf{1}$ & 2 & 3 & 4 & 5 & 6 \\
\cline { 2 - 7 } occurrences & $\mathbf{0}$ & $\mathbf{0}$ & $\mathbf{2}$ & $\mathbf{0}$ & $\mathbf{4}$ & $\mathbf{1}$ \\
\cline { 2 - 6 } & & & & &
\end{tabular}

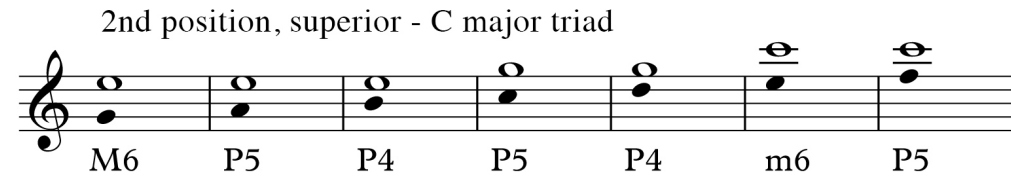

\begin{tabular}{l|l|l|l|l|l|l|}
\multirow{3}{*}{ interval class } & $\mathbf{1}$ & $\mathbf{2}$ & 3 & 4 & 5 & 6 \\
\cline { 2 - 7 } occurrences & $\mathbf{0}$ & $\mathbf{0}$ & $\mathbf{1}$ & $\mathbf{1}$ & $\mathbf{5}$ & $\mathbf{0}$ \\
\cline { 2 - 6 } & & & & &
\end{tabular}

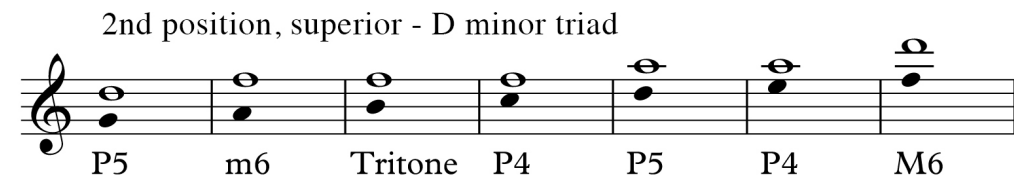

\begin{tabular}{l|l|l|l|l|l|l|} 
interval class & 1 & 2 & 3 & 4 & 5 & 6 \\
\cline { 2 - 7 } occurrences & $\mathbf{0}$ & $\mathbf{0}$ & $\mathbf{1}$ & $\mathbf{1}$ & $\mathbf{4}$ & $\mathbf{1}$ \\
\cline { 2 - 6 } & & & & &
\end{tabular}

2nd position, superior - E minor triad

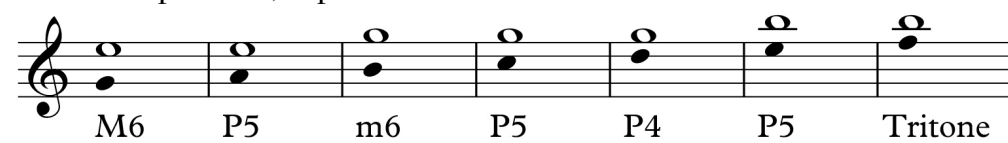

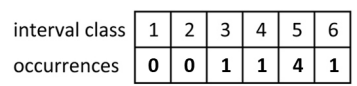

M6

m6 P5

P4

P5 Tritone

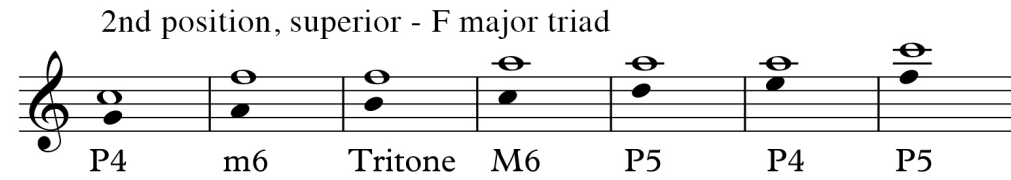

\begin{tabular}{l|l|l|l|l|l|l|}
\cline { 2 - 6 } interval class & 1 & 2 & 3 & 4 & 5 & 6 \\
\cline { 2 - 7 } occurrences & $\mathbf{0}$ & $\mathbf{0}$ & $\mathbf{1}$ & $\mathbf{1}$ & $\mathbf{4}$ & $\mathbf{1}$ \\
\cline { 2 - 6 } & & & & &
\end{tabular} 
Figure A.20: Interval ordering and class content of a G Mixolydian scale paired with different triads in 2 nd position, inferior

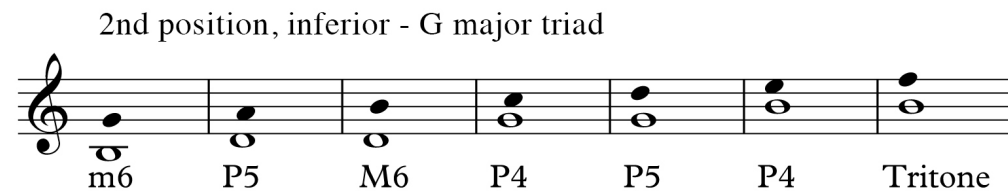

\begin{tabular}{l|l|l|l|l|l|l|} 
interval class & 1 & 2 & 3 & 4 & 5 & 6 \\
\cline { 2 - 7 } occurrences & $\mathbf{0}$ & $\mathbf{0}$ & $\mathbf{1}$ & $\mathbf{1}$ & $\mathbf{4}$ & $\mathbf{1}$ \\
\cline { 2 - 6 } & & & &
\end{tabular}

2nd position, inferior - A minor triad

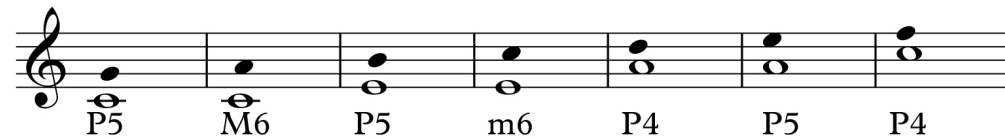

\begin{tabular}{l|l|l|l|l|l|l|} 
interval class & 1 & 2 & 3 & 4 & 5 & 6 \\
\cline { 2 - 7 } occurrences & $\mathbf{0}$ & $\mathbf{0}$ & $\mathbf{1}$ & $\mathbf{1}$ & $\mathbf{5}$ & $\mathbf{0}$ \\
\cline { 2 - 6 } & & &
\end{tabular}

2nd position, inferior - B diminished triad

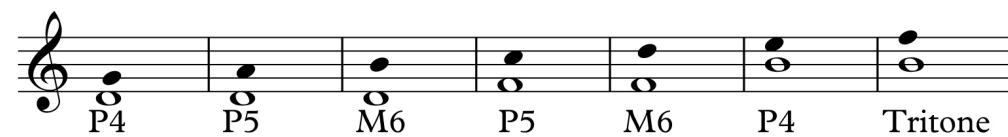

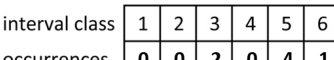

\begin{tabular}{lllllll|}
\multirow{2}{*}{ occurrences } & 0 & 0 & 2 & 0 & 4 & 1 \\
\cline { 2 - 6 }
\end{tabular}

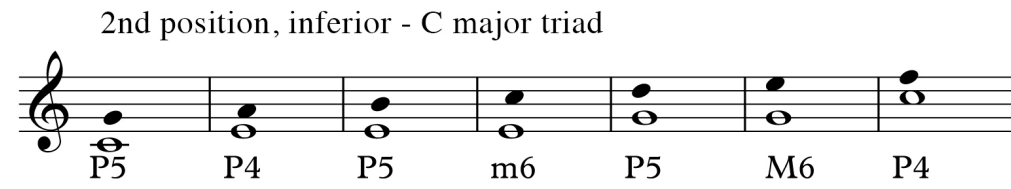

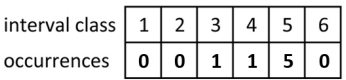

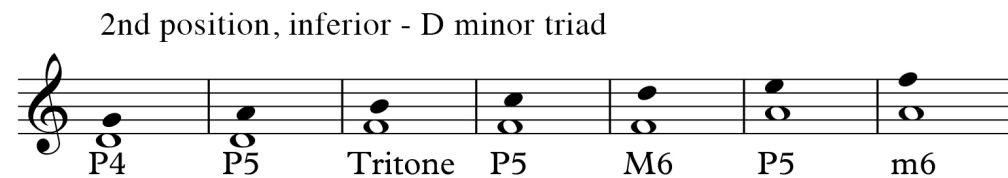

\begin{tabular}{l|l|l|l|l|l|l|}
\cline { 2 - 5 } interval class & 1 & 2 & 3 & 4 & 5 & 6 \\
\cline { 2 - 5 } occurrences & $\mathbf{0}$ & $\mathbf{0}$ & $\mathbf{1}$ & $\mathbf{1}$ & $\mathbf{4}$ & $\mathbf{1}$ \\
\hline
\end{tabular}

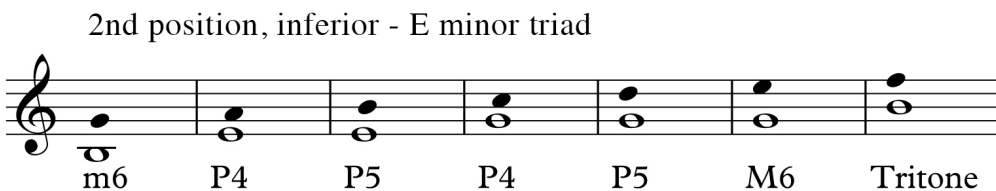

interval class \begin{tabular}{l|l|l|l|l|l|l|}
\cline { 2 - 6 } & 1 & 2 & 3 & 4 & 5 & 6 \\
\cline { 2 - 6 } & 0 & 0 & 1 & 1 & 4 & 1 \\
\hline
\end{tabular}

\begin{tabular}{|l|l|l|l|l|l|l|}
\multirow{3}{*}{ occurrences } & 0 & 0 & 1 & 1 & 4 & 1 \\
\cline { 2 - 6 } & & & &
\end{tabular}

2nd position, inferior - $F$ major triad

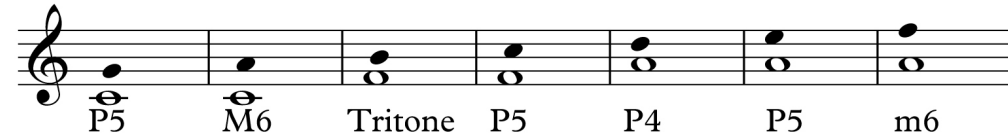

\begin{tabular}{l|l|l|l|l|l|l|}
\cline { 2 - 6 } interval class & 1 & 2 & 3 & 4 & 5 & 6 \\
\cline { 2 - 7 } occurrences & $\mathbf{0}$ & $\mathbf{0}$ & $\mathbf{1}$ & $\mathbf{1}$ & $\mathbf{4}$ & $\mathbf{1}$ \\
\cline { 2 - 6 } & & & &
\end{tabular} 
Table A.0.6: Interval class sets arising from an A Aeolian scale paired with different triads and Tvoice positions

\begin{tabular}{|l|l|l|l|l|}
\hline $\begin{array}{l}\text { Interval } \\
\text { class set }\end{array}$ & $\begin{array}{l}\mathbf{1}^{\text {st }} \text { position, } \\
\text { superior }\end{array}$ & $\mathbf{1}^{\text {st }}$ position, inferior & $\begin{array}{l}\mathbf{2}^{\text {nd }} \text { position, } \\
\text { superior }\end{array}$ & $\mathbf{2}^{\text {nd }}$ position, inferior \\
\hline 001141 & & & $\begin{array}{l}\text { D minor, E minor, } \\
\text { F major, G major }\end{array}$ & $\begin{array}{l}\text { D minor, E minor, } \\
\text { F major, G major }\end{array}$ \\
\hline 001150 & & & C major, A minor & C major, A minor \\
\hline 002041 & & & B diminished & B diminished \\
\hline 031210 & E minor & F major & & \\
\hline 032110 & G major & D minor & & \\
\hline 121210 & A minor & C major & & \\
\hline 122101 & B diminished & B diminished & & \\
\hline 122110 & C major, D minor & G major, A minor & & \\
\hline 212110 & F major & E minor & & \\
\hline
\end{tabular}


Figure A.21: Interval ordering and class content of an A Aeolian scale paired with different triads in 1st position, superior
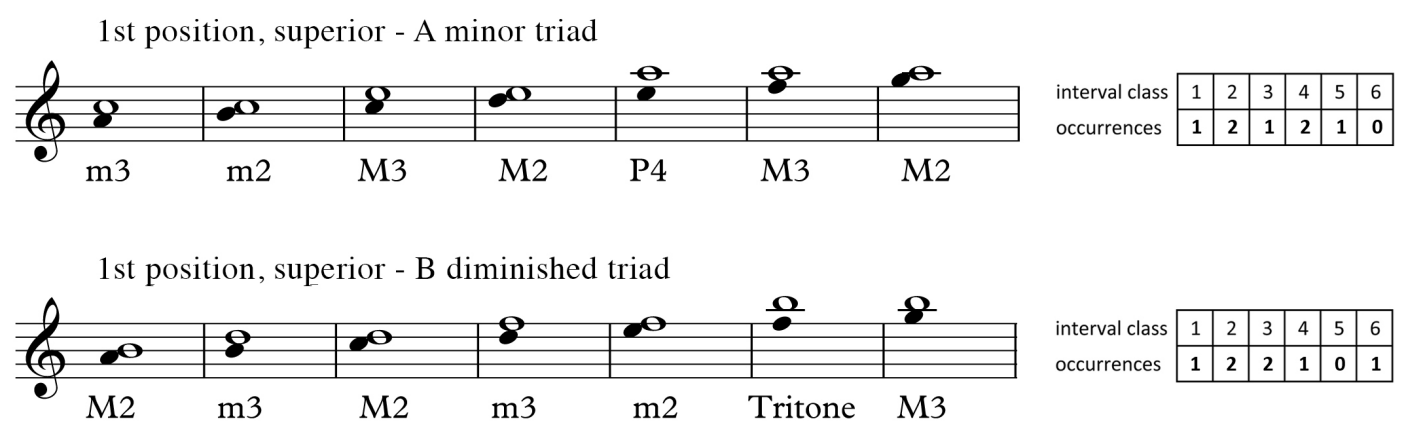

\begin{tabular}{l|l|l|l|l|l|l|} 
interval class & $\mathbf{1}$ & $\mathbf{2}$ & $\mathbf{3}$ & 4 & $\mathbf{5}$ & 6 \\
\cline { 2 - 7 } occurrences & $\mathbf{1}$ & $\mathbf{2}$ & $\mathbf{2}$ & $\mathbf{1}$ & $\mathbf{0}$ & $\mathbf{1}$ \\
\cline { 2 - 7 } & & & & &
\end{tabular}

1st position, superior - C major triad

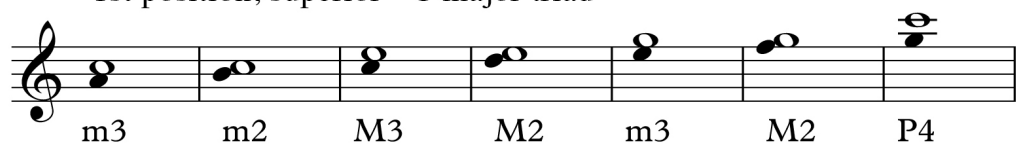

\begin{tabular}{l|l|l|l|l|l|l|} 
interval class & 1 & 2 & 3 & 4 & 5 & 6 \\
\cline { 2 - 7 } occurrences & $\mathbf{1}$ & $\mathbf{2}$ & $\mathbf{2}$ & $\mathbf{1}$ & $\mathbf{1}$ & $\mathbf{0}$ \\
\cline { 2 - 6 } & & & &
\end{tabular}

1st position, superior - D minor triad

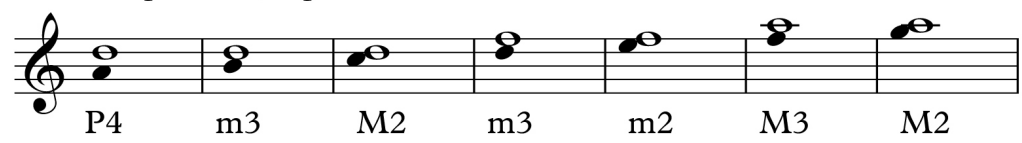

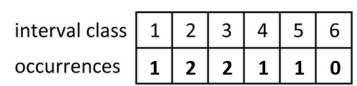

1st position, superior - E minor triad

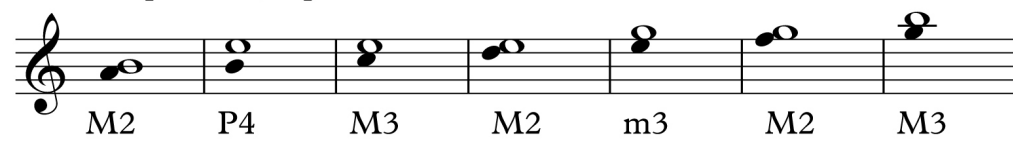

\begin{tabular}{l|l|l|l|l|l|l|}
\cline { 2 - 5 } interval class & 1 & 2 & 3 & 4 & 5 & 6 \\
\cline { 2 - 6 } occurrences & $\mathbf{0}$ & $\mathbf{3}$ & $\mathbf{1}$ & $\mathbf{2}$ & $\mathbf{1}$ & $\mathbf{0}$ \\
\cline { 2 - 5 } & & & &
\end{tabular}

1st position, superior - F major triad

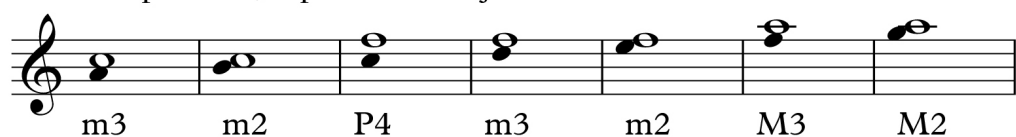

\begin{tabular}{l|l|l|l|l|l|l|}
\cline { 2 - 5 } interval class & 1 & 2 & 3 & 4 & 5 & 6 \\
\cline { 2 - 7 } occurrences & $\mathbf{2}$ & $\mathbf{1}$ & $\mathbf{2}$ & $\mathbf{1}$ & $\mathbf{1}$ & $\mathbf{0}$ \\
\cline { 2 - 6 } \\
\cline { 2 - 5 } & & \multicolumn{3}{|c}{} &
\end{tabular}

$\mathrm{m} 3$

$\mathrm{m} 2$

$\mathrm{P} 4 \mathrm{~m} 3 \mathrm{~m} 2$

1st position, superior - G major triad

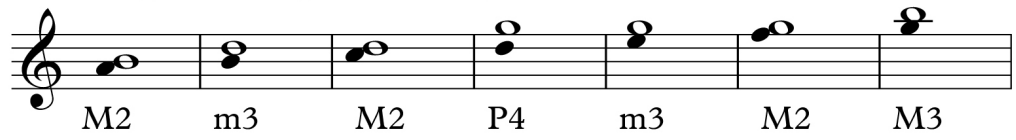

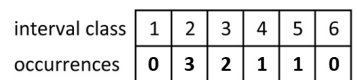


Figure A.22: Interval ordering and class content of an A Aeolian scale paired with different triads in 1st position, inferior

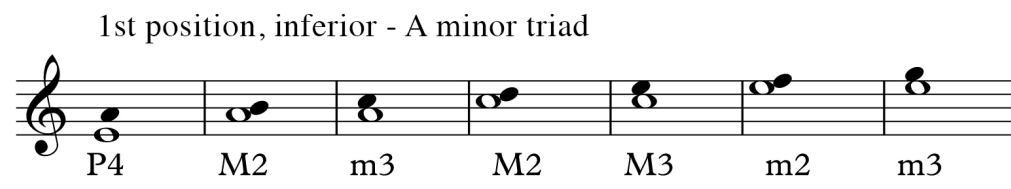

\begin{tabular}{l|l|l|l|l|l|l|} 
interval class & $\mathbf{1}$ & $\mathbf{2}$ & $\mathbf{3}$ & $\mathbf{4}$ & $\mathbf{5}$ & $\mathbf{6}$ \\
\cline { 2 - 7 } occurrences & $\mathbf{1}$ & $\mathbf{2}$ & $\mathbf{2}$ & $\mathbf{1}$ & $\mathbf{1}$ & $\mathbf{0}$ \\
\cline { 2 - 6 } & & & & &
\end{tabular}

1st position, inferior - B diminished triad

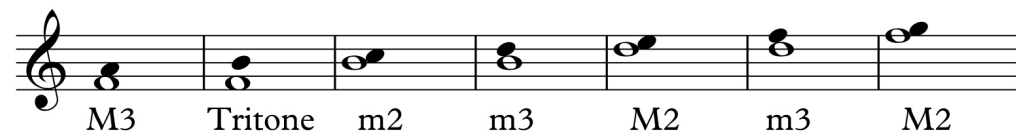

\begin{tabular}{l|l|l|l|l|l|l|}
\cline { 2 - 6 } interval class & 1 & 2 & 3 & 4 & 5 & 6 \\
\cline { 2 - 7 } occurrences & $\mathbf{1}$ & $\mathbf{2}$ & $\mathbf{2}$ & $\mathbf{1}$ & $\mathbf{0}$ & $\mathbf{1}$ \\
\cline { 2 - 6 } & & & & &
\end{tabular}

1st position, inferior - C major triad

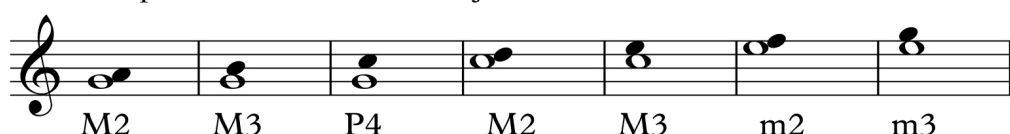

\begin{tabular}{l|l|l|l|l|l|l|}
\cline { 2 - 5 } interval class & 1 & 2 & 3 & 4 & 5 & 6 \\
\cline { 2 - 6 } occurrences & $\mathbf{1}$ & $\mathbf{2}$ & $\mathbf{1}$ & $\mathbf{2}$ & $\mathbf{1}$ & $\mathbf{0}$ \\
\cline { 2 - 5 }
\end{tabular}

M2

M3

P4 M2

M3

m3

1st position, inferior - D minor triad

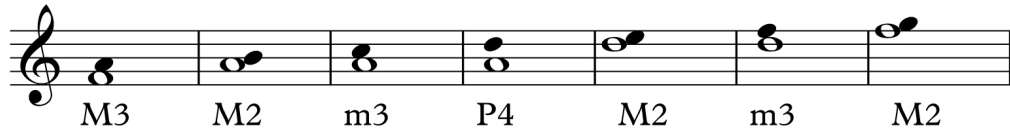

\begin{tabular}{l|l|l|l|l|l|l|}
\cline { 2 - 5 } interval class & 1 & 2 & 3 & 4 & 5 & 6 \\
\cline { 2 - 6 } occurrences & $\mathbf{0}$ & $\mathbf{3}$ & $\mathbf{2}$ & $\mathbf{1}$ & $\mathbf{1}$ & $\mathbf{0}$ \\
\cline { 2 - 6 } & & &
\end{tabular}

1st position, inferior - E minor triad

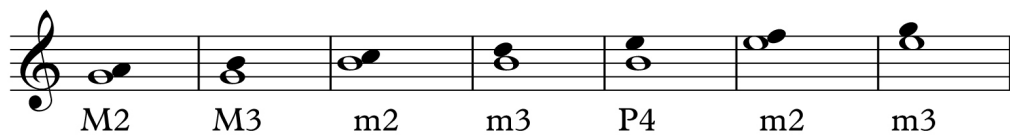

\begin{tabular}{l|l|l|l|l|l|l|}
\cline { 2 - 5 } interval class & 1 & 2 & 3 & 4 & 5 & 6 \\
\cline { 2 - 6 } occurrences & $\mathbf{2}$ & $\mathbf{1}$ & $\mathbf{2}$ & $\mathbf{1}$ & $\mathbf{1}$ & $\mathbf{0}$ \\
\cline { 2 - 6 }
\end{tabular}

1st position, inferior - F major triad

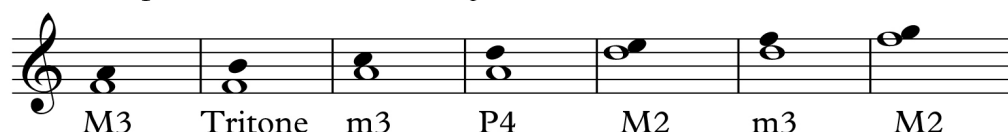

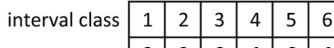

M3 Tritone $\mathrm{m3} \quad \mathrm{P} 4 \quad \mathrm{M} 2 \quad \mathrm{~m} 3 \quad$ M2

\begin{tabular}{ll|l|l|l|l|l|}
\multirow{3}{*}{ occurrences } & 0 & 2 & 2 & 1 & 0 & 1 \\
\cline { 2 - 6 } \\
\cline { 2 - 5 }
\end{tabular}

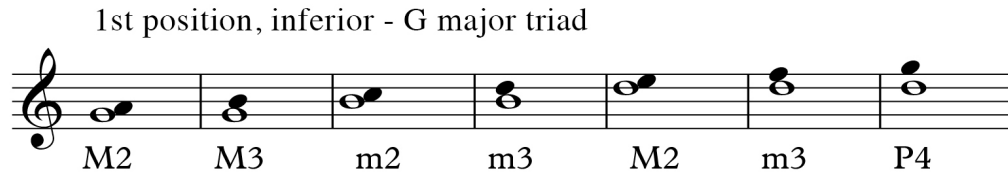

\begin{tabular}{l|l|l|l|l|l|l|}
\cline { 2 - 6 } interval class & 1 & 2 & 3 & 4 & 5 & 6 \\
\cline { 2 - 6 } occurrences & $\mathbf{1}$ & $\mathbf{2}$ & $\mathbf{2}$ & $\mathbf{1}$ & $\mathbf{1}$ & $\mathbf{0}$ \\
\hline
\end{tabular} 
Figure A.23: Interval ordering and class content of an A Aeolian scale paired with different triads in 2nd position, superior
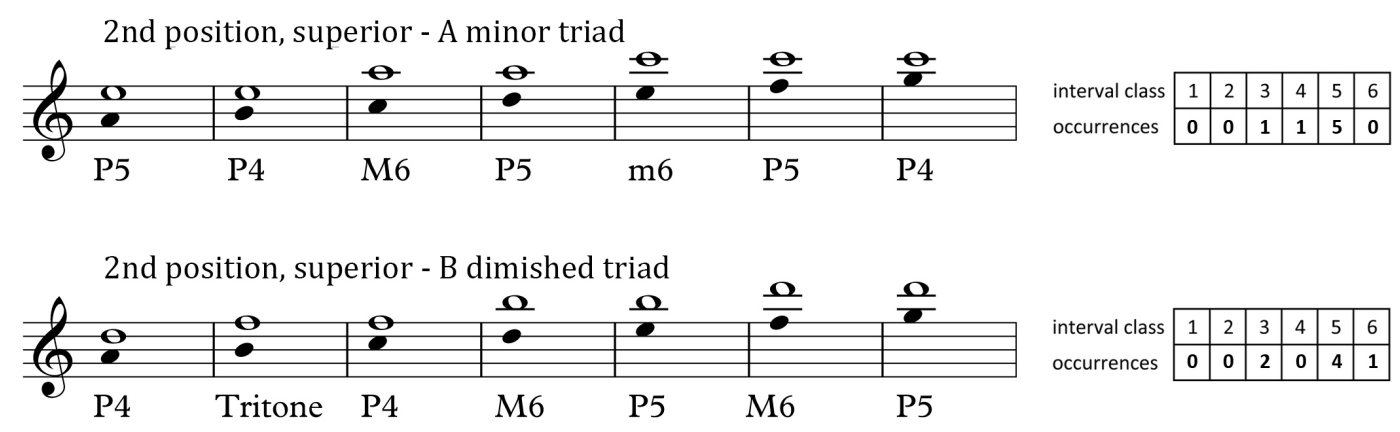

\begin{tabular}{l|l|l|l|l|l|l|}
\multirow{2}{*}{$\begin{array}{l}\text { interval class } \\
\text { occurrences }\end{array}$} & $\mathbf{1}$ & $\mathbf{2}$ & $\mathbf{3}$ & $\mathbf{4}$ & $\mathbf{5}$ & $\mathbf{6}$ \\
\cline { 2 - 7 } & $\mathbf{0}$ & $\mathbf{0}$ & $\mathbf{2}$ & $\mathbf{0}$ & $\mathbf{4}$ & $\mathbf{1}$ \\
\cline { 2 - 6 } & & & & &
\end{tabular}

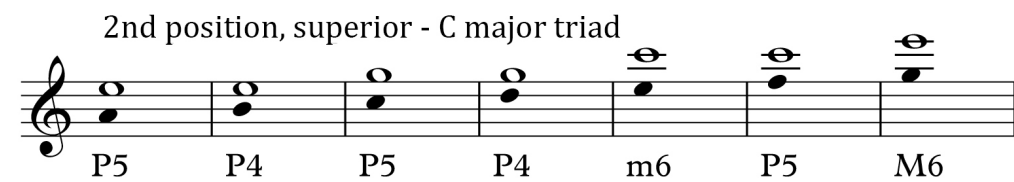

\begin{tabular}{l|l|l|l|l|l|l|} 
interval class & 1 & 2 & 3 & 4 & 5 & 6 \\
\cline { 2 - 7 } occurrences & $\mathbf{0}$ & $\mathbf{0}$ & $\mathbf{1}$ & $\mathbf{1}$ & $\mathbf{5}$ & $\mathbf{0}$ \\
\cline { 2 - 6 } & & & &
\end{tabular}

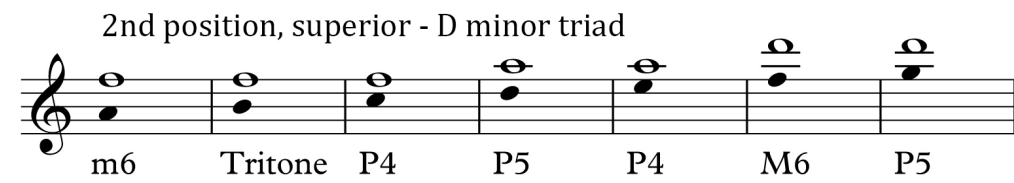

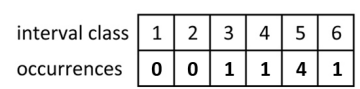

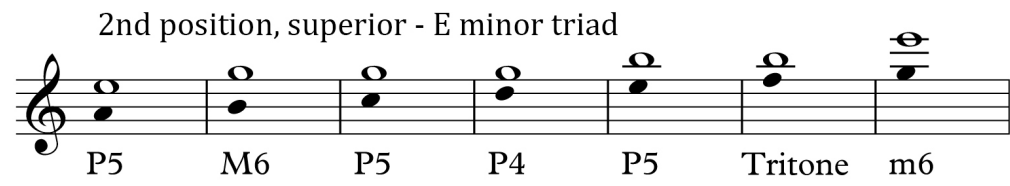

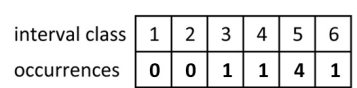

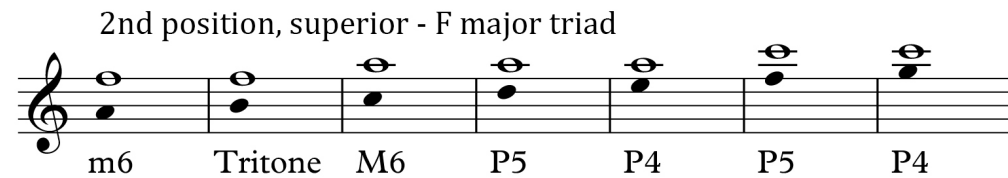

\begin{tabular}{l|l|l|l|l|l|l|} 
interval class & $\mathbf{1}$ & $\mathbf{2}$ & $\mathbf{3}$ & $\mathbf{4}$ & 5 & 6 \\
\cline { 2 - 7 } occurrences & $\mathbf{0}$ & $\mathbf{0}$ & $\mathbf{1}$ & $\mathbf{1}$ & $\mathbf{4}$ & $\mathbf{1}$ \\
\cline { 2 - 6 } & & & &
\end{tabular}

2nd position, superior - G major triad

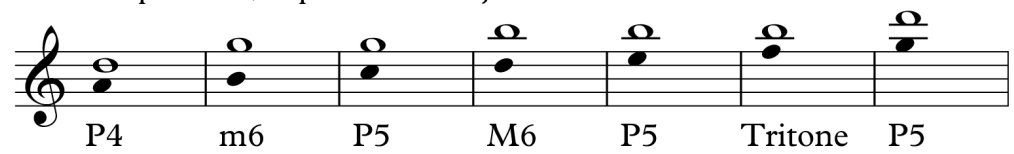

\begin{tabular}{l|l|l|l|l|l|l|} 
interval class & 1 & 2 & 3 & 4 & 5 & 6 \\
\cline { 2 - 7 } occurrences & $\mathbf{0}$ & $\mathbf{0}$ & $\mathbf{1}$ & $\mathbf{1}$ & $\mathbf{4}$ & $\mathbf{1}$ \\
\cline { 2 - 6 } & & & &
\end{tabular} 
Figure A.24: Interval ordering and class content of an A Aeolian scale paired with different triads in 2nd position, inferior

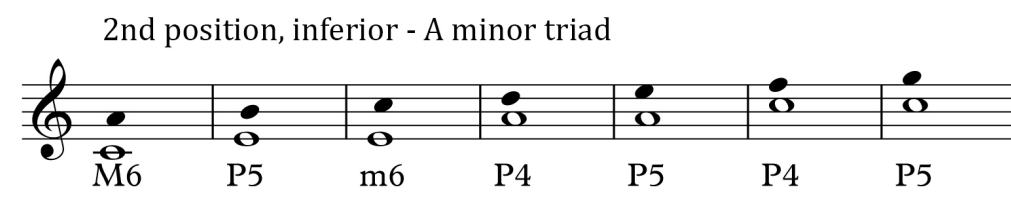

\begin{tabular}{l|l|l|l|l|l|l|} 
interval class & 1 & 2 & 3 & 4 & 5 & 6 \\
\cline { 2 - 7 } occurrences & $\mathbf{0}$ & $\mathbf{0}$ & $\mathbf{1}$ & $\mathbf{1}$ & $\mathbf{5}$ & $\mathbf{0}$ \\
\cline { 2 - 6 } & & & & &
\end{tabular}

2nd position, inferior - B diminished triad

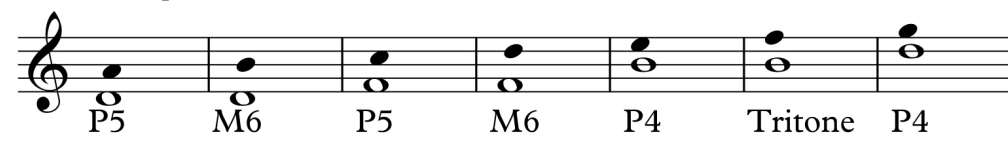

\begin{tabular}{l|l|l|l|l|l|l|}
\cline { 2 - 6 } interval class & 1 & 2 & 3 & 4 & 5 & 6 \\
\cline { 2 - 6 } occurrences & $\mathbf{0}$ & $\mathbf{0}$ & $\mathbf{2}$ & $\mathbf{0}$ & $\mathbf{4}$ & $\mathbf{1}$ \\
\cline { 2 - 5 }
\end{tabular}

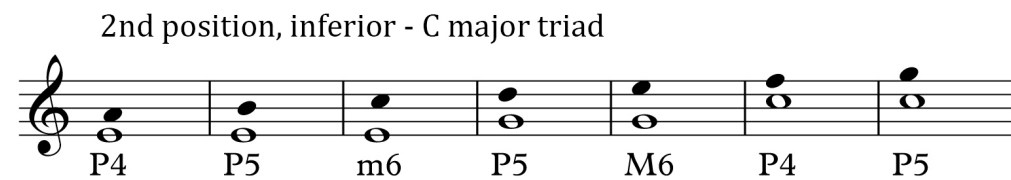

\begin{tabular}{l|l|l|l|l|l|l|} 
interval class & 1 & 2 & 3 & 4 & 5 & 6 \\
\cline { 2 - 7 } occurrences & $\mathbf{0}$ & $\mathbf{0}$ & $\mathbf{1}$ & $\mathbf{1}$ & $\mathbf{5}$ & $\mathbf{0}$ \\
\cline { 2 - 6 } & & & & &
\end{tabular}

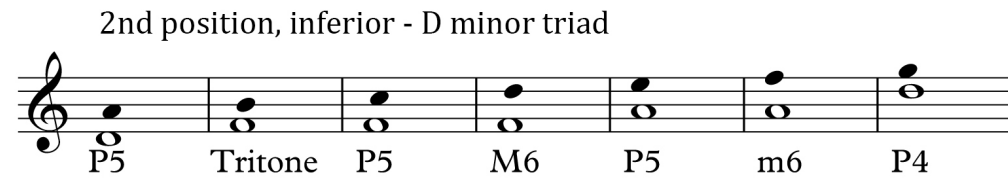

\begin{tabular}{l|l|l|l|l|l|l|}
\cline { 2 - 6 } interval class & 1 & 2 & 3 & 4 & 5 & 6 \\
\cline { 2 - 7 } occurrences & $\mathbf{0}$ & $\mathbf{0}$ & $\mathbf{1}$ & $\mathbf{1}$ & $\mathbf{4}$ & $\mathbf{1}$ \\
\cline { 2 - 6 } & & & &
\end{tabular}

2nd position, inferior - E minor triad

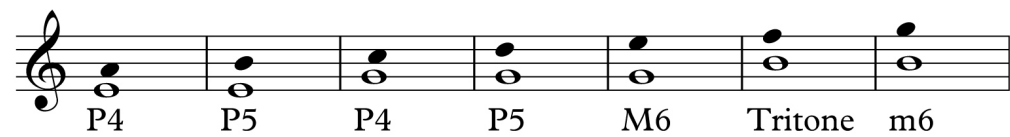

\begin{tabular}{l|l|l|l|l|l|l|}
\cline { 2 - 5 } interval class & 1 & 2 & 3 & 4 & 5 & 6 \\
\cline { 2 - 6 } occurrences & $\mathbf{0}$ & $\mathbf{0}$ & $\mathbf{1}$ & $\mathbf{1}$ & $\mathbf{4}$ & $\mathbf{1}$ \\
\cline { 2 - 5 }
\end{tabular}

2nd position, inferior - F major triad

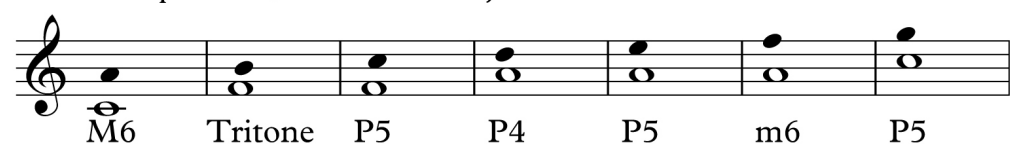

\begin{tabular}{|l|l|l|l|l|l|l|} 
interval class & 1 & 2 & 3 & 4 & 5 & 6 \\
\cline { 2 - 6 } & 0 & 0 & 1 & 1 & 4 & 1 \\
\hline
\end{tabular} \begin{tabular}{|l|l|l|l|l|l|l|}
\multirow{3}{*}{ occurrences } & 0 & 0 & 1 & 1 & 4 & 1 \\
\cline { 2 - 6 } & & & &
\end{tabular}

2nd position, inferior - G major triad

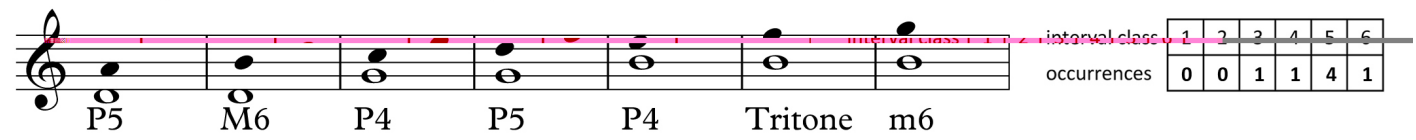


Table A.0.7: Interval class sets arising from a B Locrian scale paired with different triads and T-voice positions

\begin{tabular}{|l|l|l|l|l|}
\hline $\begin{array}{l}\text { Interval } \\
\text { class set }\end{array}$ & $\begin{array}{l}\mathbf{1}^{\text {st }} \text { position, } \\
\text { superior }\end{array}$ & $\mathbf{1}^{\text {st } \text { position, inferior }}$ & $\begin{array}{l}\mathbf{2}^{\text {nd }} \text { position, } \\
\text { superior }\end{array}$ & $\mathbf{2}^{\text {nd }}$ position, inferior \\
\hline 001141 & & & $\begin{array}{l}\text { D minor, E minor, } \\
\text { F major, G major }\end{array}$ & $\begin{array}{l}\text { D minor, E minor, } \\
\text { F major, G major }\end{array}$ \\
\hline 001150 & & & C major, A minor & C major, A minor \\
\hline 002041 & & B diminished & B diminished \\
\hline 031210 & E minor & F major & & \\
\hline 032110 & G major & D minor & & \\
\hline 121210 & A minor & C major & & \\
\hline 122101 & B diminished & B diminished & & \\
\hline 122110 & C major, D minor & G major, A minor & & \\
\hline 212110 & F major & E minor & & \\
\hline
\end{tabular}


Figure A.25: Interval ordering and class content of a B Locrian scale paired with different triads in 1st position, superior

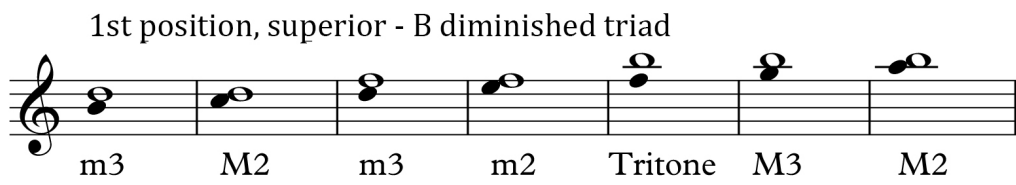

\begin{tabular}{l|l|l|l|l|l|l|} 
& & & \\
interval class & 1 & 2 & 3 & 4 & 5 & 6 \\
\cline { 2 - 7 } occurrences & $\mathbf{1}$ & $\mathbf{2}$ & $\mathbf{2}$ & $\mathbf{1}$ & $\mathbf{0}$ & $\mathbf{1}$ \\
\cline { 2 - 6 } & & & &
\end{tabular}

1st position, superior - C major triad

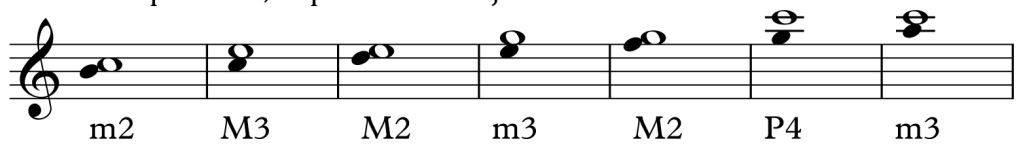

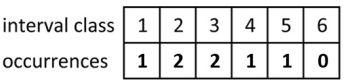

1st position, superior - D minor triad

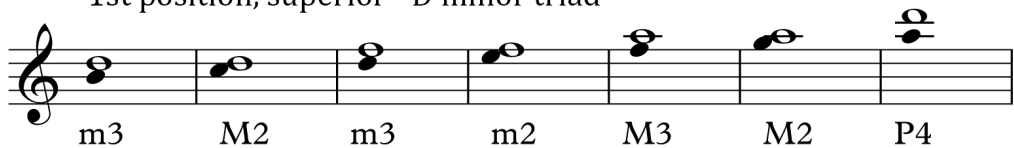

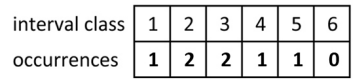

$\begin{array}{lllllll}\mathrm{m} 3 & \mathrm{M} 2 & \mathrm{~m} 3 & \mathrm{~m} 2 & \mathrm{M} 3 & \mathrm{M} 2 & \mathrm{P} 4\end{array}$

1st position, superior - E minor triad

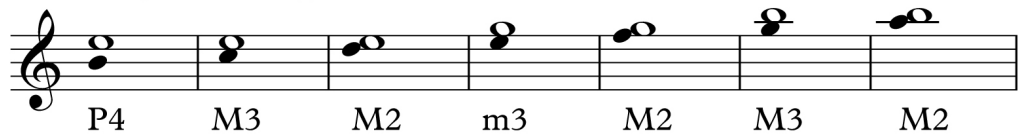

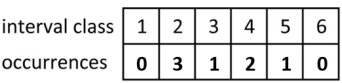

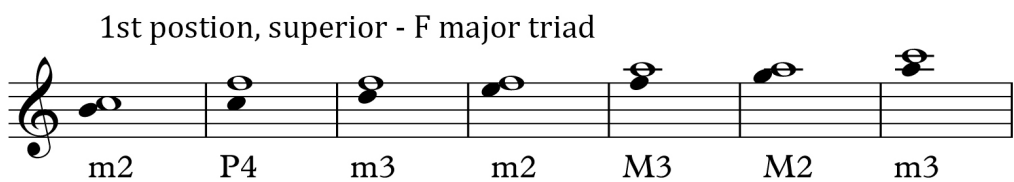

\begin{tabular}{l|l|l|l|l|l|l|} 
interval class & 1 & 2 & 3 & 4 & 5 & 6 \\
\cline { 2 - 7 } occurrences & $\mathbf{2}$ & $\mathbf{1}$ & $\mathbf{2}$ & $\mathbf{1}$ & $\mathbf{1}$ & $\mathbf{0}$ \\
\cline { 2 - 6 } & & & & &
\end{tabular}

1st position, superior - G major triad

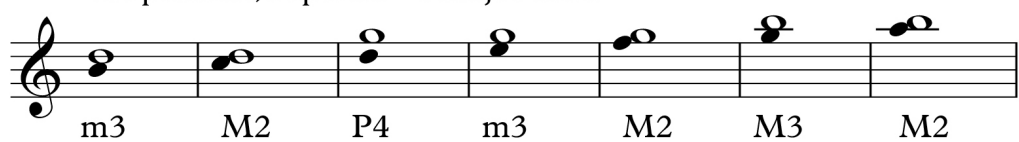

\begin{tabular}{l|l|l|l|l|l|l|} 
interval class & $\mathbf{1}$ & $\mathbf{2}$ & $\mathbf{3}$ & 4 & $\mathbf{5}$ & $\mathbf{6}$ \\
\cline { 2 - 7 } occurrences & $\mathbf{0}$ & $\mathbf{3}$ & $\mathbf{2}$ & $\mathbf{1}$ & $\mathbf{1}$ & $\mathbf{0}$ \\
\cline { 2 - 6 } & & & &
\end{tabular}

$\mathrm{m} 3$

$\mathrm{P}$

$$
\text { M3 M2 }
$$

1st position, superior - A minor triad

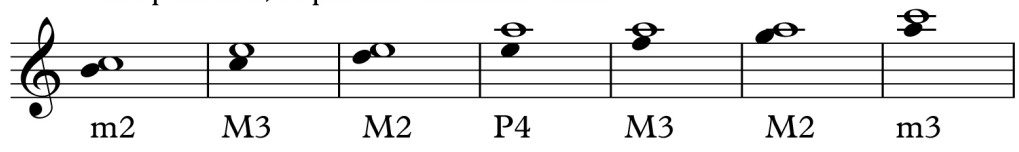

\begin{tabular}{l|l|l|l|l|l|l|}
\cline { 2 - 6 } interval class & 1 & 2 & 3 & 4 & 5 & 6 \\
\cline { 2 - 7 } occurrences & $\mathbf{1}$ & $\mathbf{2}$ & $\mathbf{1}$ & $\mathbf{2}$ & $\mathbf{1}$ & $\mathbf{0}$ \\
\cline { 2 - 6 } & & & & &
\end{tabular} 
Figure A.26: Interval ordering and class content of a B Locrian scale paired with different triads in 1st position, inferior

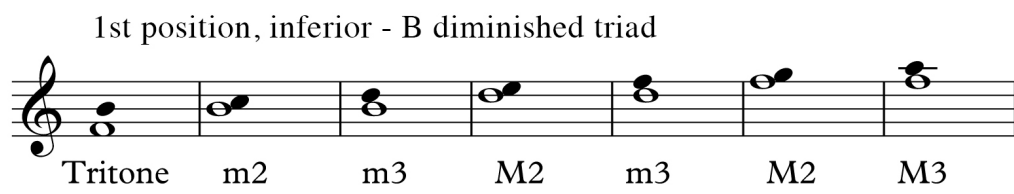

\begin{tabular}{l|l|l|l|l|l|l|} 
interval class & 1 & 2 & 3 & 4 & 5 & 6 \\
\cline { 2 - 7 } occurrences & $\mathbf{1}$ & $\mathbf{2}$ & $\mathbf{2}$ & $\mathbf{1}$ & $\mathbf{0}$ & $\mathbf{1}$ \\
\cline { 2 - 6 } & & & & &
\end{tabular}

1st position, inferior - Cmajor triad

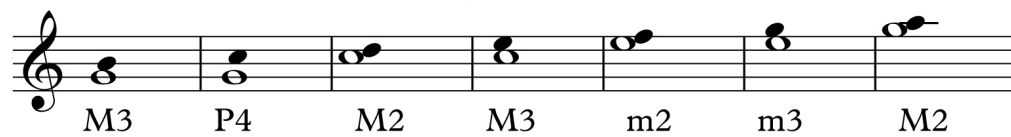

\begin{tabular}{l|l|l|l|l|l|l|}
\cline { 2 - 5 } interval class & 1 & 2 & 3 & 4 & 5 & 6 \\
\cline { 2 - 6 } occurrences & $\mathbf{1}$ & $\mathbf{2}$ & $\mathbf{1}$ & $\mathbf{2}$ & $\mathbf{1}$ & $\mathbf{0}$ \\
\cline { 2 - 5 }
\end{tabular}

1st position, inferior - D minor triad

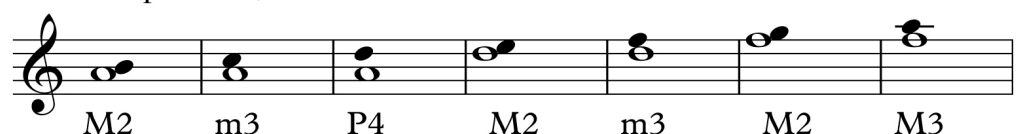

\begin{tabular}{l|l|l|l|l|l|l|} 
interval class & 1 & 2 & 3 & 4 & 5 & 6 \\
\cline { 2 - 7 } occurrences & $\mathbf{0}$ & $\mathbf{3}$ & $\mathbf{2}$ & $\mathbf{1}$ & $\mathbf{1}$ & $\mathbf{0}$ \\
\cline { 2 - 6 } & & & & &
\end{tabular}

1st position, inferior - E minor triad

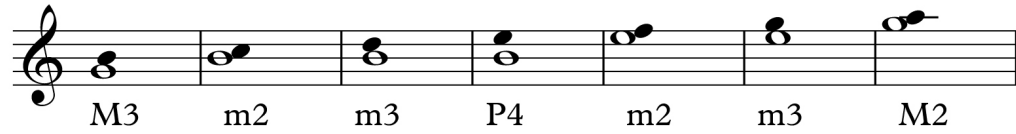

\begin{tabular}{l|l|l|l|l|l|l|}
\cline { 2 - 6 } interval class & 1 & 2 & 3 & 4 & 5 & 6 \\
\cline { 2 - 7 } occurrences & $\mathbf{2}$ & $\mathbf{1}$ & $\mathbf{2}$ & $\mathbf{1}$ & $\mathbf{1}$ & $\mathbf{0}$ \\
\cline { 2 - 7 } & & & &
\end{tabular}

1st position, inferior - F major triad

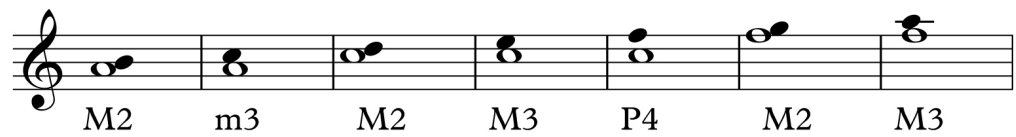

\begin{tabular}{l|l|l|l|l|l|l|}
\cline { 2 - 5 } interval class & 1 & 2 & 3 & 4 & 5 & 6 \\
\cline { 2 - 5 } occurrences & $\mathbf{0}$ & $\mathbf{3}$ & $\mathbf{1}$ & $\mathbf{2}$ & $\mathbf{1}$ & $\mathbf{0}$ \\
\cline { 2 - 5 } & &
\end{tabular}

st position, inferior - $\mathrm{G}$ major triad

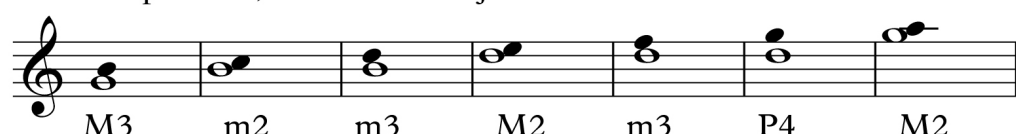

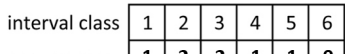

$\begin{array}{llllll}M 3 & \mathrm{~m} 2 & \mathrm{~m} 3 & \mathrm{M} 2 & \mathrm{~m} 3 & \mathrm{P}\end{array}$

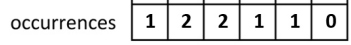

1st position, inferior - A minor triad

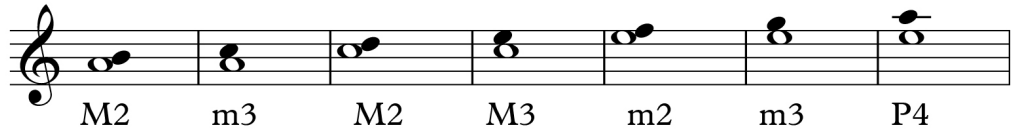

\begin{tabular}{l|l|l|l|l|l|l|}
\cline { 2 - 6 } interval class & 1 & 2 & 3 & 4 & 5 & 6 \\
\cline { 2 - 6 } occurrences & $\mathbf{1}$ & $\mathbf{2}$ & $\mathbf{2}$ & $\mathbf{1}$ & $\mathbf{1}$ & $\mathbf{0}$ \\
\cline { 2 - 5 }
\end{tabular} 
Figure A.27: Interval ordering and class content of a B Locrian scale paired with different triads in 2nd position, superior

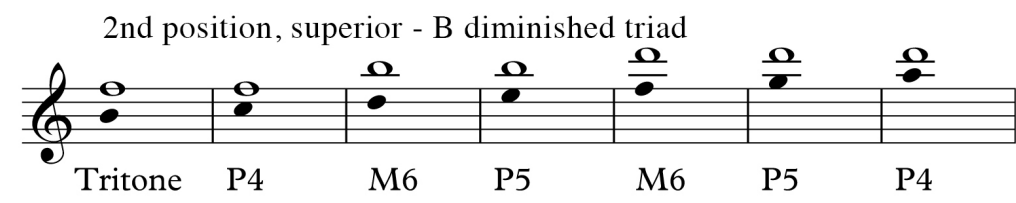

\begin{tabular}{l|l|l|l|l|l|l|} 
interval class & $\mathbf{1}$ & $\mathbf{2}$ & $\mathbf{3}$ & $\mathbf{4}$ & 5 & 6 \\
\cline { 2 - 7 } occurrences & $\mathbf{0}$ & $\mathbf{0}$ & $\mathbf{2}$ & $\mathbf{0}$ & $\mathbf{4}$ & $\mathbf{1}$ \\
\cline { 2 - 6 } & & & & &
\end{tabular}

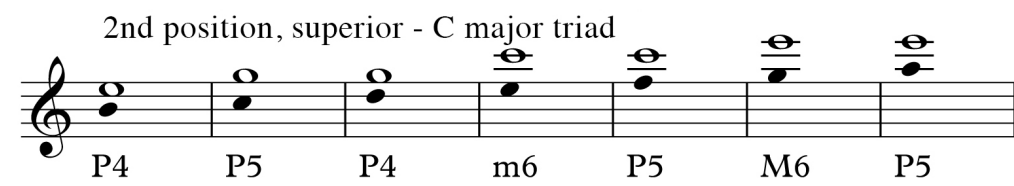

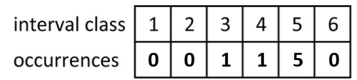

2nd position, superior - D minor triad

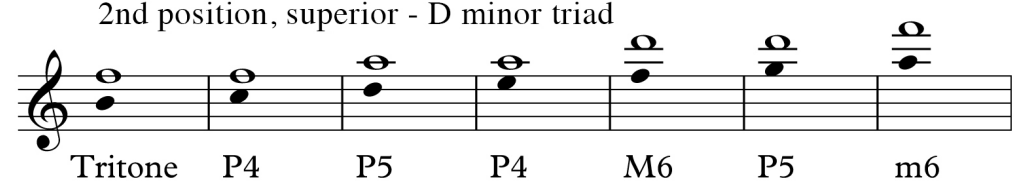

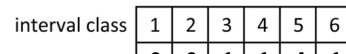

Tritone $\mathrm{P}$

P5 10

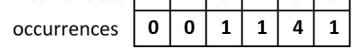

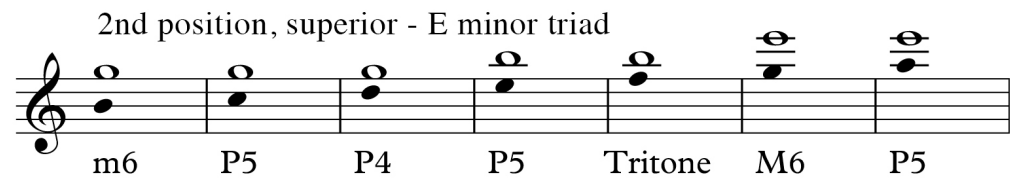

\begin{tabular}{l|l|l|l|l|l|l|} 
& & & \\
interval class & 1 & 2 & 3 & 4 & 5 & 6 \\
\cline { 2 - 7 } occurrences & $\mathbf{0}$ & $\mathbf{0}$ & $\mathbf{1}$ & $\mathbf{1}$ & $\mathbf{4}$ & $\mathbf{1}$ \\
\cline { 2 - 6 } & & & &
\end{tabular}

2nd position, superior - F major triad

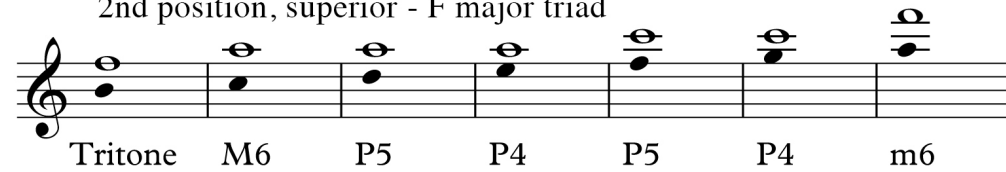

\begin{tabular}{l|l|l|l|l|l|l|} 
interval class & 1 & 2 & 3 & 4 & 5 & 6 \\
\cline { 2 - 7 } occurrences & $\mathbf{0}$ & $\mathbf{0}$ & $\mathbf{1}$ & $\mathbf{1}$ & $\mathbf{4}$ & $\mathbf{1}$ \\
\cline { 2 - 6 } & & & &
\end{tabular}

Tritone M6

P5

P4

P5

P4 m6

2nd position, superior - G major triad

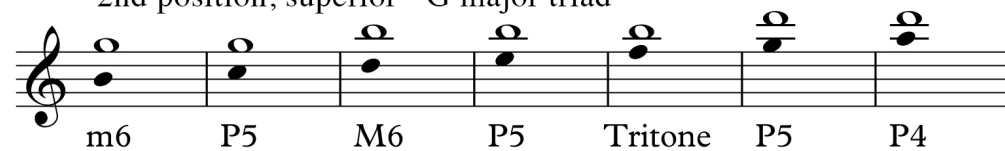

interval class \begin{tabular}{c|c|c|c|c|c|c|}
\cline { 2 - 6 } & 1 & 2 & 3 & 4 & 5 & 6 \\
\cline { 2 - 6 } & 0 & 0 & 1 & 1 & 4 & 1 \\
\hline
\end{tabular}

\begin{tabular}{l|l|l|l|l|l|l|}
\multirow{3}{*}{ occurrences } & 0 & 0 & 1 & 1 & 4 & 1 \\
\cline { 2 - 7 } & & &
\end{tabular}

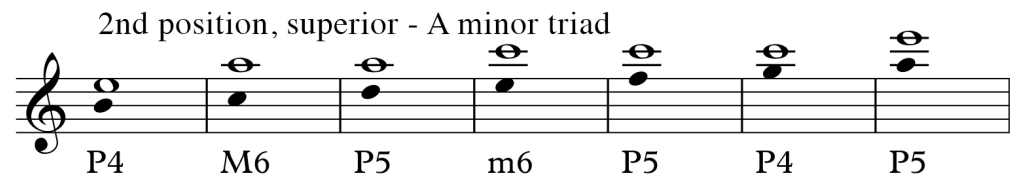

\begin{tabular}{c|c|c|c|c|c|c|}
\cline { 2 - 7 } interval class & 1 & 2 & 3 & 4 & 5 & 6 \\
\cline { 2 - 7 } occurrences & $\mathbf{0}$ & $\mathbf{0}$ & $\mathbf{1}$ & $\mathbf{1}$ & $\mathbf{5}$ & $\mathbf{0}$ \\
\hline
\end{tabular} 
Figure A.28: Interval ordering and class content of a B Locrian scale paired with different triads in 2nd position, inferior

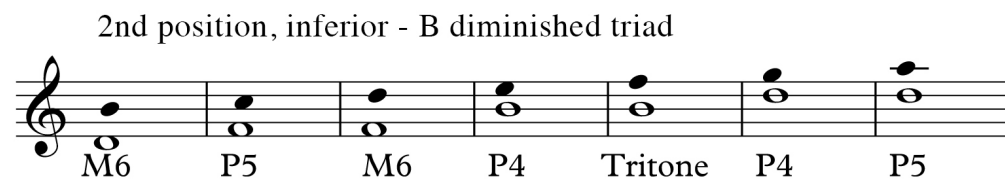

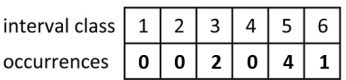

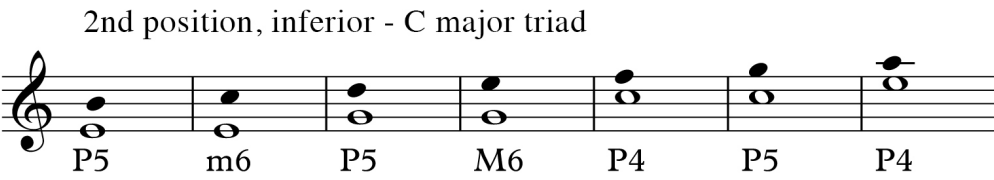

\begin{tabular}{l|l|l|l|l|l|l|}
\cline { 2 - 5 } interval class & 1 & 2 & 3 & 4 & 5 & 6 \\
\cline { 2 - 5 } occurrences & $\mathbf{0}$ & $\mathbf{0}$ & $\mathbf{1}$ & $\mathbf{1}$ & $\mathbf{5}$ & $\mathbf{0}$ \\
\cline { 2 - 5 }
\end{tabular}

2nd position, inferior - D minor triad

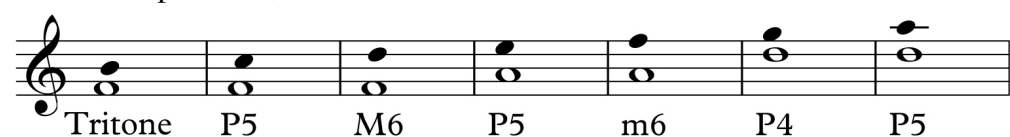

interval class \begin{tabular}{l|l|l|l|l|l|l|}
\cline { 2 - 5 } & 1 & 2 & 3 & 4 & 5 & 6 \\
\cline { 2 - 6 } & 0 & 0 & 1 & 1 & 4 & 1 \\
\hline
\end{tabular}

Tritone

P5

M6

P5

m6

\begin{tabular}{llllll|l|l|}
\multirow{2}{*}{ occurrences } & 0 & 0 & 1 & 1 & 4 & 1 \\
\cline { 2 - 7 } \\
\cline { 2 - 6 } & & &
\end{tabular}

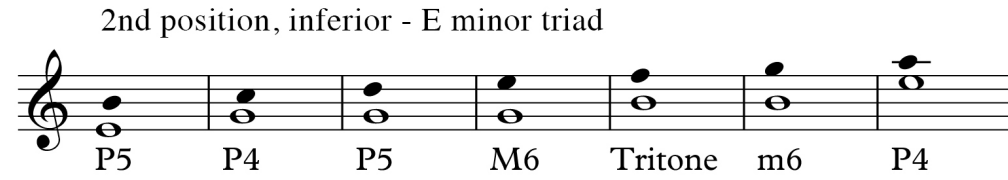

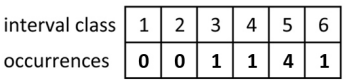

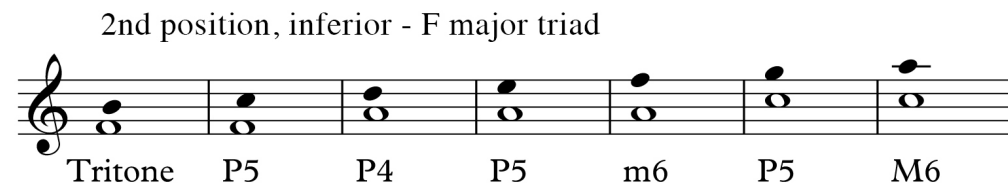

\begin{tabular}{l|l|l|l|l|l|l|}
\cline { 2 - 6 } interval class & 1 & 2 & 3 & 4 & 5 & 6 \\
\cline { 2 - 7 } occurrences & $\mathbf{0}$ & $\mathbf{0}$ & $\mathbf{1}$ & $\mathbf{1}$ & $\mathbf{4}$ & $\mathbf{1}$ \\
\cline { 2 - 6 } & & & &
\end{tabular}

Tritone

P5

$\mathrm{m} 6$

P5 M6

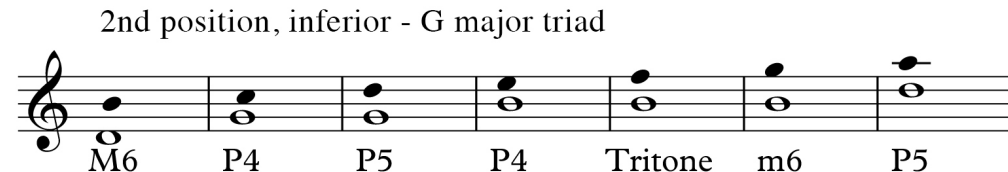

\begin{tabular}{l|l|l|l|l|l|l|} 
interval class & 1 & 2 & 3 & 4 & 5 & 6 \\
\cline { 2 - 7 } occurrences & $\mathbf{0}$ & $\mathbf{0}$ & $\mathbf{1}$ & $\mathbf{1}$ & $\mathbf{4}$ & $\mathbf{1}$ \\
\cline { 2 - 6 } & & & &
\end{tabular}

2nd position, inferior - A minor triad

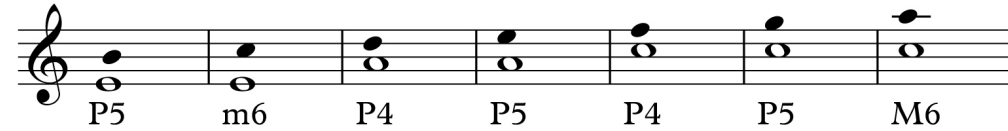

\begin{tabular}{l|l|l|l|l|l|l|} 
interval class & 1 & 2 & 3 & 4 & 5 & 6 \\
\cline { 2 - 6 } occurrences & $\mathbf{0}$ & $\mathbf{0}$ & $\mathbf{1}$ & $\mathbf{1}$ & $\mathbf{5}$ & $\mathbf{0}$ \\
\cline { 2 - 6 } & & & &
\end{tabular} 